

\section{DISCLAIMER}

This report was prepared as an account of work sponsored by an agency of the United States Government. Neither the United States Government nor any agency Thereof, nor any of their employees, makes any warranty, express or implied, or assumes any legal liability or responsibility for the accuracy, completeness, or usefulness of any information, apparatus, product, or process disclosed, or represents that its use would not infringe privately owned rights. Reference herein to any specific commercial product, process, or service by trade name, trademark, manufacturer, or otherwise does not necessarily constitute or imply its endorsement, recommendation, or favoring by the United States Government or any agency thereof. The views and opinions of authors expressed herein do not necessarily state or reflect those of the United States Government or any agency thereof. 


\section{DISCLAIMER}

Portions of this document may be illegible in electronic image products. Images are produced from the best available original document. 


\section{LEGAL NOTICE}

This book was prepared as an account of work sponsored by an agency of the United States Government. Neither the United States Giovernment nor any agency thereof, nor any of their employees, makes any warranty, express or implied, or assumes any legal liability or responsibility for the accuracy, completeness, or usefulness of any information, apparatus, product, or process disclosed, or represents that its use would not infringe privately owned rights. Reference herein to any specific commercial product, process, or service by trade name, trademark, manufacturer, or otherwise, does not necessarily constitute or imply its endorsement, recommendation, or favoring by the United States Government or any agency thereof. The views and opinions of authors expressed herein do not necessarily state or reflect those of the United States Government or any agency thercof.

Printed in the United States of America Available from

National Technical Information Service

U.S. Department of Commerce

5285 Purt Ruyal Road

Springfield, VA 22161

Price Code: A10 


\title{
BIOLOGY AND MEDICINE DIVISION ANNUAL REPORT 1982-1983
}

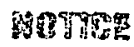

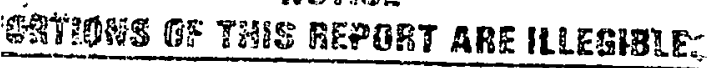

has been reprodisced from the best
vailable copy to permit the broades
osslble availability.

\author{
Lawrence Berkeley Laboratory \\ University of California \\ Berkeley, California 94720
}

\author{
DISCLAIMER
}

\begin{abstract}
This report was prepared as an account of work sponsored by an agency of the United States Government. Neither the United States Government nor any agency thereof, nor any of their employees, makes any warranty, express or implied, or assumes any legal liability or responsi- bility for the accuracy, completeness, or usefulness of any information, apparatus, product, or proccss disclosed, or represents that its use would not infringe privately owned rights. Reference herein to any specific commercial product, process, or service by trade name, trademark, manufacturer, or otherwise does not necessarily constitute or imply its endorsement, recommendation, or favoring by the United States Government or any agency thereof. The views and opinions of authors expressed herein do not necessarily state or reflect those of the United States Government or any agency thereof.
\end{abstract}

This work was supported by the Office of Health and Environmental Research of the United States Department of Energy under Contract DE-AC0376SF00098. Portions of this work were also supported by the National Institutes of Health, Department of Health and Human Services; the Environmental Protection Agency; the National Aeronautics and Space Administration; the Nuclear Regulatory Commission; the United States Army; the Veterans Administration; the Electric Power Research Institute; the American Heart Association, and the American Lung Association. Contracts and grants are listed in Appendix A. 


\section{THIS PAGE \\ WAS INTENTIONALLY \\ LEFT BLANK}




\section{CONTENTS}

\section{INTRODUCTION}

Edward L. Alpen

\section{RESEARCH MEDICINE}

INTRODUCTION

THE USE OF POSITRON TOMOGRAPHY IN THE DIFFERENTIAL

DIAGNOSIS OF DEMENTIA

Robert P. Friedland, Thomas F. Budinger, William J. Jagust,

Yukio Yano, Ronald $H$. Huesman, Chester A. Mathis,

Brian R. Moyer, Betty Koss, and Beth A. Ober

BRAIN METABOLISM IN MENTAL DISORDERS

Thornton W. Sargent, III, Natalia Kusubov, Alexander T. Shulgin,

Chester A. Mathis, and Reese M, Jones

NUCLEAR MAGNETIC RESONANCE IMAGING AND SPECTROSCOPY

Todd Richards, Thomas F. Budinger, Rudi Nunlist,

Reese Jones, Andy Hasenfeld, and Mark Roos

RADIONUCLIDE AND RADIOPHARMACEUTICAL DEVELOPMENT

FOR POSITRON EMISSION TOMOGRAPHY

Yukio Yano, Thomas F. Budinger, Mohindar Singh,

Reese Jones, Jim Hunter, and David Moore

NEW INSTRUMENTATION FOR HIGH-RESOLUTION DYNAMIC

THREE-DIMENSIONAL IMAGING OF POSITRON-LABELED

COMPOUNDS IN THE HUMAN BODY

Stephen E. Derenzo, John L. Cahoon, Ronald H. Huesman,

Tony Vuletich, and Thomas F. Budinger

MURINE MEGAKARYOCYTOPOIESIS AND HUMAN ERYTHROPOIESIS

Shirley Ebbe, Clara Adrados, Cathryne Allan,

Violet Barghe-Sharghi, Dorothy Carpenter, Ruth Cohen,

Patricia Garbutt, Carol Lum, and Elizabeth Phalen.

Attending Physicians: Hunter Cutting,

Lester Hollander, and Henry Stauffer

MARROW TRANSFUSION INTO NORMAL AND SUBLETHALLY

IRRADIATED ANIMALS

George Brecher

\section{DONNER PAVILION}

INTRODUCTION 
STEREOTACTIC HEAVY-ION BRAGG PEAK RADIOSURGERY

Jacob I. Fabrikant, John T. Lyman, Yoshio Hosobuchi,

Kenneth A. Frankel, Edward L. Alpen, Leal L. Kanstein,

Frederick W. Yeater, Neela Manley, Britta Heise,

Myrtle L. Foster, Cornelius T. Gaffey, Thomas S. Tenforde,

Bent Kjos, David Norman, Catherine M. Miller,

David Feinberg, Carla Fulton, Ronald Harris,

Kay H. Woodruff, and Maureen H. Morford

\section{ENVIRONMENTAL PHYSIOLOGY}

INTRODUCTION

FETAL AND NEONATAL ERYTHROPOIETIN STUDIES IN RATS

Gisela $K$. Clemuris and Joseph F. Garcia

HEMATOPOIETIC CELL PROLIFERATION

Juhin C. Schooley

ESTRADIOL RECEPTOR IN THE MALE MOUSE LUNG

Gerald M. Connell and Betsy Carr

STIMULATION OF BONE MARROW PROGENITORS BY INTERLEUKINS

Joan W. Goodman, Elizabeth A. Hall, and Sarah G. Shinpock

BIOLOGICAL EFFECTS OF MAGNETIC FIELDS

Thomas S. Tenforde, Cornelius T. Gaffey, Michael S. Raybourn,

and Lynette Levy

DISTRIBUTION AND RETENTION OF ${ }^{238} \mathrm{PU}$ IN MACAQUE MONKEYS

Patricia W. Durbin, Nylan Jeung, and Charles T. Schmidt

PLUTONIUM REMOVAL FROM MICE BY POLY(CATECHOYLAMIDE)

LIGANDS, Ca-DTPA, DESFERRIOXAMINE B, AND TIRON:

EFFECT OF LIGAND DOSAGE

Patricia W. Durbin, Nylan M. Jeung, E. Sarah Jones,

Kenneth N. Raymond, and Frederick L. Weitl

\section{RADIATION BIOPHYSICS}

INTRODUCTION

\section{Radiation Therapy}

RADIOTHERAPY PHYSICS

George T.Y. Chen, J. Michael Collier, Sandra R. Zink,

Samuel Pitluck, and Todd Richards

TREATMENT OF CANCER WITH CHARGED PARTICLES HEAVIER

THAN HELIUM

Joseph R. Castro, William M. Saunder's, Mary Austin-Seymour,

George T.Y. Chen, J. Michael Collier, Sandra R. Zink,

Samuel Pitluck, Kay A. Woodruff, Denise Capra-Young,

Aude Cartigny, Todd Richards, Jacquelyn St. John, and Robert Ė. Walton 
PRECISION HIGH-DOSE RADIOTHERAPY WITH HELIUM-ION BEAMS:

TREATMENT OF MALIGNANT TUMORS IN HUMANS

William M. Saunders, Joseph R. Castro, Mary Austin-Seymour,

George T.Y. Chen, J. Michael Collier, Sandra R. Zink,

Denise Capra-Young, Samuel Pitluck, Robert E. Walton,

Charles R. Pascale, Leal L. Kanstein, and Frederick W. Yeater

Tissue Radiobiology

LATE EFFECTS OF RADIATION ON MOUSE LUNG

Edward L. Alpen, Linda D. Harrison, and Patricia Powers-Risius ............................. 60

LATE EFFECTS OF RADIATION ON THE HEMATOPOIETIC SYSTEM

E. John Ainsworth, Lynn J. Mahlmann, and John C. Prioleau

RADIOSENSITIVITY OF MOUSE COLONY FORMING UNITS-SPLEEN

(CFU-S) TO HEAVY CHARGED PARTICLES

E. John Ainsworth, Lynn J. Mahlmann, and John C. Prioleau

LIFE SPAN STUDIES ON MICE EXPOSED TO HEAVY CHARGED

PARTICLES: A STATUS REPORT

E. John Ainsworth, John C. Prioleau, and Lynn J. Mahlmann

THE RELATIVE BIOLOGICAL EFFECTIVENESS OF HEAVY-ION

RADIATION FOR NORMAL TISSUE AND 9L MULTICELLULAR

TUMOR SPHEROIDS

Adrian Rodriguez, Edward L. Alpen, Patricia Powers-Risius,

Linda D. Harrison, and Randy J. DeGuzman

POTENTIALLY LETHAL DAMAGE REPAIR IN 9L MULTICELL

TUMOR SPHEROIDS

Adrian Rodriguez, Edward L. Alpen, and Randy J. DeGuzman

\section{Radiological Physics}

PHYSICAL CHARACTERIZATION OF HEAVY-ION BEAMS

Walter Schimmerling, Marwin Rapkin, Mervyn Wong, Jerry Howard,

Selig N. Kaplan, Helmuth G. Spieler, Blair V. Jarrett,

and John T. Walton

MEASUREMENTS OF W FOR HIGH-ENERGY HEAVY IONS

Walter Schimmerling, Selig N. Kaplan, T.S. Subramanian,

W. John McDonald, George Gabor, and Ahren J. Sadoff

ENERGY DEPOSITION NEAR HEAVY-ION TRACKS

Les A. Braby, Noel F. Metting, Harold H. Rossi, Paul J. Kliauga,

Jerry Howard, Marwin Rapkin, Mervyn Wong, and Walter Schimmerling

TRANSPORT OF HIGH-ENERGY HEAVY IONS THROUGH EXTENDED MATTER Mervyn Wong, Walter Schimmerling, Joe Civello, Jerry Howard, John W. Wilson, Lawrence W. Townsend, and Hari B. Bidasaria 
A COMPARISON OF WATER EQUIVALENT THICKNESS MEASUREMENTS:

CT METHOD VERSUS HEAVY-ION BEAM TECHNIQUE

Edward L. Alpen, William M. Saunders, Aloke Chatterjee,

Jorge Llacer, George T.Y. Chen, and Janis S. Scherer

RADIOLOGICAL PHYSICS AND CHEMISTRY

Aloke Chatterjee and John L. Magee

Cellular and Molecular Radiobiology

ATAXIA TELANGIECTASIA: MODELING EXTREME RADIOSENSITIVITY

Eleanor A. Blakely, Cornelius A. Tobias, Polly Y. Chang, and Leora Lommel

VERY HEAVY IONS: CHROMOSOMAL ABERRATIONS AND INACTIVATION

OF MAMMALIAN CELLS

Gerhard Kraft, Wilma Kraft-Weyrather, and Eleanor A. Blakely

ATTEMPTS TO REDUCE THE RADIOBIOLOGICAL OXYGEN EFFECT WITH

NEW HYPOXIC RADIOSENSITIZERS

Mary Austin-Seymour, Eleanor A. Blakely, Polly Y. Chang,

and Leora Lommel

CHARACTERIZATION OF CELLULAR AND MOLECULAR DAMAGE AFTER

IRRADIATION WITH DENSELY IONIZING PARTICLE BEAMS

Ruth J. Roots, Gerhard Kraft, Aloke Chatterjee, Polly Y. Chang,

Leora Lommel, and Eleanor A. Blakely

CELL PROGRESSION CELL EFFECTS

Eleanor A. Blakely, Ruth J. Roots, Polly Y. Chang,

Leora Lommel, and Michael J. Yezzi

HEAVY-ION FRAGMENTATION: PHYSICS AND BIOLOGY

Eleanor A. Blakely, Jorge Llacer, and Cornelius A. Tobias

HEAVY-ION MICROSCOPY

Mark H. Phillips, Joseph M. Jaklevic, James B. Schmidt,

Ann C. Birge, and Cornelius A. Tobias

$\beta$-araA ENHANCED CELL TRANSFORMATION BY RADIATION

Tracy C. Yang, Cornelius A. Tobias, and Laurie M. Craise

104

IONIZING RADIATION ENHANCES DNA TRANSFECTION

Carl F. Perez, Cornelius A. Tobias, and Tracy C. Yang

PROTECTION EFFECT OF DIMETHYL SULFOXIDE ON THE

INITIATION AND EXPRESSION OF RADIOGENIC NEOPLASTIC

CELL TRANSFORMATION

Tracy Chui-hsu Yang, Laurie M. Craise, and C.A. Tobias

106

EFFECTS OF SEQUENTIAL EXPOSURE OF MIXED RADIATION

MODALITIES ON NEOPLASTIC CELL TRANSFORMATION

Tracy C. Yang, Laurie M. Craise, Jerry Howard, and Cornelius A. Tobias 
NEW DEVELOPMENTS IN THE LETHAL, POTENTIALLY LETHAL MODEL

Stanley B. Curtis

\section{Biophysical Studies}

BIOPHYSICAL STUDIES ON WHOLE RED BLOOD CELL AND

MEMBRANE SYSTEMS

Howard C. Mel, Gary V. Richieri, Frank Kooi,

Steven P. Akeson, and James P. Yee

NEW THERMODYNAMICS RESEARCH: GLOBAL THERMODYNAMIC

POTENTIAL FUNCTIONS FOR NONEQUILIBRIUM, OPEN SYSTEMS

Howard C. Mel and Peter S. Geissler

\section{STRUCTURAL BIOPHYSICS}

INTRODUCTION

\section{Ultrastructural Research}

TEMPERATURE DEPENDENCE OF RADIATION DAMAGE IN

ELECTRON MICROSCOPY

Kenneth $\mathrm{H}$. Downing and Robert $\mathrm{M}$. Glaeser

STRUCTURAL ANALYSIS OF BACTERIOPHAGE LAMBDA RECEPTOR PROTEIN

Bing K. Jap

STRUCTURAL STUDIES OF THE SURFACE LAYER PROTEIN OF AQUASPIRILLUM SERPENS

Wennie $\mathrm{H}$. Wu, Melvyn Dickson, Kenneth $\mathrm{H}$. Downing,

and Robert M. Glaeser

QUANTITATION OF HUMAN LUNG TISSUE SHRINKAGE DURING

PREPARATION FOR ELECTRON MICROSCOPY

Jacob Bastacky, Thomas L. Hayes, Richard P. Gelinas,

L. Michael Sprague, May F. McKoon, Gregory L. Finch, Susan B. Klein,

Barbara von Schmidt, Lee W. Paris, and Mark E. Williams

INTERACTIONS BETWEEN PARTICLES AND RESPIRATORY

EPITHELIUM IN CULTURED TRACHEAL EXPLANTS AS

REVEALED BY SCANNING ELECTRON MICROSCOPY

Gregory L. Finch, Thomas L. Hayes, Ming J.W. Chang,

Gerald L. Fisher, and Brooke T. Mossman

X-RAY MICROANALYSIS OF DIFFERENTIATING PRIMARY MESENCHYME CELLS WITHIN THE SEA URCHIN EMBRYO, LYTECHINUS PICTUS

Susan B. Klein, Thomas L. Hayes, and Fred H. Wilt 


\section{Studies of Lipoproteins and Other Macromolecules}

CIRCULAR DIFFERENTIAL SCATTERING CAN BE AN

IMPORTANT PART OF THE CIRCULAR DICHROISM OF

MACROMOLECULES

Marcos F. Maestre, Carlos Bustamante, and Ignacio Tinoco, Jr.

BIOPHYSICAL STUDIES OF IMMUNE RECOGNITION

John C. Owicki

INHIBITION OF PROTON TRANSPORT IN PURPLE MEMBRANE

BY DICYCLOHEXYLCARBODIIMIDE

Bing K. Jap and Robert M. Glaeser

HIGH DENSITY LIPOPROTEIN (HDL) ORIGINS: A MAJOR

CONVERSION PATHWAY

Alex V. Nichols, Elaine L. Gong, Patricia J. Blanche,

Trudy M. Forte, and Virgie G. Shore

PARTIAL SPECIFIC VOLUME AND PREFERENTIAL HYDRATION

OF LDL SUBFRACTIONS

Talwinder S. Kahlon, Gerald L. Adamson, Laura A. Glines,

Joseph R. Orr, and Frank T. Lindgren

EXTRAMURAL COLLABORATIONS BY THE ANALYTIC ULTRACENTRIFUGE

CORE OF THE LIPOPROTEIN PROGRAM PROJECT

Frank T. Lindgren

UNUSUAL COMPOSITION AND APOLIPOPROTEIN DISTRIBUTION OF

CORD BLOOD LOW DENSITY LIPOPROTEIN SUBFRACTIONS

Trudy Forte, Paul Davis, Ronald Krauss, John Kane,

and Conrad Blum

WHAT HAPPENS TO LIPOPROTEINS IN THE INTERSTITIAL SPACE?

A LOOK AT LUNG LYMPH

Trudy Forte, Carroll Cross, Rob Gunther, and George Kramer

\section{DNA and Genetic Studies}

CHARACTERIZATION OF ISOLATED YEAST DNA REPAIR GENES

Robert K. Mortimer, Isabel L. Calderon, Rebecca Contopoulou, Herschell S. Emery, Susan T. Lovett, David Schild,

Karen C. Sitney, and John N. Takakuwa

CLONING AND MAPPING OF THE YEAST PHOTOREACTIVATION GENE

PHR1

David Schild, John Johnston, Caren Chang and Robert K. Mortimer

THE USE OF A COLD-SENSITIVE DNA REPAIR MUTANT TO STUDY

MEIOTIC RECOMBINATION IN YEAST

John C. Game and Robert K. Mortimer 
AN EMPIRICAL EQUATION THAT CAN BE USED TO DETERMINE GENETIC MAP DISTANCES FROM TETRAD DATA

Charles $M a$ and Robert K. Mortimer

MITOTIC AND MEIOTIC RECOMBINATION IN SACCHAROMYCES

CEREVISIAE: PROPERTIES AND GENETIC CONTROL

Michael S. Esposito, Carlo V. Bruschi, Kathleen Bjornstad,

and Dimitrios T. Maleas

QUANTITATIVE gP32 AFFINITY CHROMATOGRAPHY OF THE INTACT AND

MODIFIED gp32 MOLECULES TO EXAMINE gp32 SELF INTERACTIONS

Junko Hosoda and Herbert W. Moise

\section{Cell Culture Studies}

GROWTH OF HUMAN MAMMARY EPITHELIAL CELLS IN CULTURE

Martha R. Stampfer and Jack C. Bartley

IN VITRO TRANSFORMATION OF HUMAN MAMMARY

EPITHELIAL CELLS

Martha R. Stampfer and Jack C. Bartley

A POSSIBLE ROLE FOR BASAL LAMINA GLYCOSAMINOGLYCANS

IN THE REGULATION OF MAMMARY EPITHELIAL CELL

DIFFERENTIATION

Gordon Parry, Eva Lee, Debbie Farson, Mike Koval,

and Mina Bissell

CULTURED HUMAN HEP G2 CELLS AS A MODEL FOR

INVESTIGATING LIPOPROTEIN SYNTHESIS AND

METABOLISM

Richard Thrift and Trudy Forte

PLASMA MEMBRANE REORGANIZATION INDUCED BY CHEMICAL

TRANSFORMATION IN CULTURE

Beverly S. Packard, Mina J. Bissell, and Melvin P. Klein

REGULATION OF EXTRACELLULAR MATRIX FORMATION BY

AVIAN TENDON CELLS IN CULTURE

Julie A. Robinson and Mina J. Bissell

RSV ASSOCIATED MALIGNANCIES MAY REQUIRE ADDITIONAL

FACTORS FOR TUMOR FORMATION

David Dolberg, Missie-Joe Gates, and Mina J. Bissell

\section{Carcinogenesis}

EFFECTS OF ALKYLATING CARCINOGENS ON MAMMALIAN

CELLS IN CULTURE

Regine Goth-Goldstein and Mildred Hughes

INDUCIBLE REPAIR OF DNA DAMAGE BY CHEMICAL CARCINOGENS

Priscilla K. Cooper, Mark F. Henteleff, Peter Origenes,

and Vincent Ling 
HUMAN MAMMARY EPITHELIAL CELLS IN CULTURE:

METABOLISM OF CHEMICAL CARCINOGENS

Jack C. Bartley and Martha R. Stampfer

COMPARATIVE ANALYSIS OF DATA FROM SHORT-TERM

TESTS FOR CARCINOGENS AND MUTAGENS

Joyce McCann, Laura Horn, John Kaldor; and Bob Siegel

CARCINOGENIC POTENCY

Lois Swirsky Gold, Georganne Beckman, Margarita de Veciana,

Robert H. Levinson, Renae I. Magaw, Mark Smith, and Bruce N. Ames

\section{APPENDICES}

Appendix A. List of Contacts and Cirants Supporting

Portions of Work Presented in this Annual Report

Appendix B. 1983 Publications

Appendix C. Biology and Medicine Division Staff 


\title{
INTRODUCTION
}

\author{
Edward L. Alpen
}

As stated by Dr. Hayes in last year's annual report, I spent the academic year 1982-83 at the Gray Laboratory in London. I remark on this personal activity only because it gives me an opportunity to note the vigor and health of our organization and the sustained growth and development in my absence. I wish to personally thank Dr. Thomas L. Hayes, who so superbly acted for me in my absence, and to thank Dr. Thomas Tenforde and Mr. Baird Whaley for their outstanding assistance to Tom as Deputy Division Head and Division Administrator, respectively.

There has been no significant change in the level of Federal support for science during this last year, and this continuing austerity has required an all-out effort by all of our investigators to maintain our historic level of outstanding quality research. We remain a strong, viable, and still changing. organization in spite of outside funding constraints.

A Division goal established some five years ago to develop a laboratory program on the fundamental science of mutagenesis and carcinogenesis is now at a level of full development. From an almost nonexisting base we have grown to the point that we now have a program both nationally and internationally recognized.

As an unexpected but welcome dividend we see that this new program area is rapidly converging on long existing programs in more classical genetlcs. A central emerging theme is DNA replication control and DNA repair. The radiobiologically derived cellular studies on DNA repair in the Radiation Biophysics Group are leading to further interactions on this same general subject.

The Research Medicine Group is receiving international attention for their successes in developing well validated diagnostic procedures for Alzheimer's disease and other senile dementias. They are now attempting to test simpler diagnostic procedures against the "gold-standard" of fluorodeoxyglucose. Early prototype subassemblies of the multi-ring positron camera have been successful, and I believe we can look forward to an operating prototype of the multi-ring system within the year. Simultaneously, we have made great strides in implementing our nuclear magnetic resonance program.

Dr. Fabrikant's program on the treatment of arteriovenous malformations in the brain, which was reported in a preliminary fashion last year, has continued as a resounding success, and we expect further growth in this program.

Dr. Tenforde's group examining the effects of magnetic field continues its progress, with reports on visual and neurological effects. They are acquiring a new high-field cryogenic magnet during the coming year that will allow them to extend the field strength regions they have examined.

This year has seen continuing successful efforts in our charged-particle radiotherapy program, with continuing good progress in the treatment of tumors of the eye and tumors near sensitive central nervous system structures. The efforts to demonstrate improved control of disease with helium-ion beams for carcinoma of the pancreas and of the esophagus have not been successful. We hope that as we move to therapy with heavier charged particles with their improved biological effectiveness (neon and silicon), that more success might be demonstrable.

The project for design of a medical-based radiotherapy accelerator is drawing to a successful close, on schedule and within budget. We will now mount our efforts to obtain funding for this machine.

I take this opportunity to welcome all the many new people who have joined the Donner staff during my absence and since my return. I hope they can share fully with me the sense of excitement and enthusiasm that motivates our staff. 


\section{THIS PAGE}

\section{WAS INTENTIONALLY LEFT BLANK}




\section{SECTION 1. RESEARCH MEDICINE}

\section{INTRODUCTION}

The Research Medicine Group consists of research physicians, chemists, biologists, mathematicians, and physicists devoted to the study of normal and diseased processes in man. The group is the outgrowth of research programs initiated by Dr. John Lawrence, who was first to use radioactive isotopes for the treatment of blood and thyroid diseases. Major advances in the use of heavy ions for the treatment of pituitary tumors and, more recently, advances in noninvasive imaging techniques have been a part of our activity, along with the application of these techniques to the problems of disease.

A major emphasis of our program continues to be the study of the blood system in man with a special emphasis on examination of platelet abnormalities in human disease. New programs of major importance to the group include the study of early aging or dementia of the Alzheimer's type. During the past year this research has evolved to the perfection of a differential diagnosis technique using positron emission tomography. We have discovered new methods, using noninvasive radioisotope techniques, for investigating this fourth most common cause of death in the United States. We are also studying the biochemical basis of schizophrenia. In our study of both of these brain disorders, the patients are brought to the Lawrence Berkeley Laboratory for evaluation and, if appropriate, are given an injection of a tracer isotope that gives a very low radiation dose. The distribution of the tracer is imaged by a device similar in appearance to an x-ray CT scanner, but the physiological and biochemical processes of the body are measured rather than the anatomical form as with $\mathrm{x}$-ray systems.

Another program of major interest to our group is the investigation of atherosclerosis, which is presently the most common cause of death in this country. The approaches are to develop techniques for the noninvasive measurement of blood perfusion of the heart muscle and thereby to investigate the cause of atherosclerosis. These techniques include methods for labeling platelets and lipoproteins so that their behavior in the body and at the arterial wall can be examined.

A new program, increasing in momentum over the past two years, is the use of nuclear magnetic resonance (NMR) for both imaging and spectroscopic studies in humans. This program was a natural off-shoot of early developments made by this group in algorithms for reconstruction tomography on the one hand, and the investigation of the possible hazards of NMR for very high field studies on the other. Through a series of investigations by the $L B L$ researchers, as well as an analysis of experiments done elsewhere, we have been able to ascertain that there are no important health hazards in the NMR experiment up to the level of the present field strength and gradients associated with the imaging technique. In this respect the group completed this year an epidemiological survey of the magnetic field effects on workers at national laboratories where bubble-chamber and cyclotron workers have been working at moderate to high fields for the past two decades. In an analysis of 21 disease categories, we found no significant increase in the prevalence of disease for those workers exposed to high fields relative to other matched controls. The NMR program is now focused on investigation of the characteristics of the atherosclerotic plaque in the arterial wall, the effect of radiation on the central nervous system (particularly for heavy-ion treatment planning purposes), and the use of NMR as an investigative and diagnostic tool for Alzheimer's disease and other mental disorders. 


\title{
THE USE OF POSITRON TOMOGRAPHY IN THE DIFFERENTIAL DIAGNOSIS OF DEMENTIA
}

\author{
Robert P. Friedland, Thomas F. Budinger, William J. Jagust, Yukio Yano, \\ Ronald H. Huesman, Chester A. Mathis, Brian R. Moyer, Betty Koss, ${ }^{*}$ and \\ Beth A. Ober*
}

Dementia is a symptomatic classification applied to a generalized impairment of intellectual function that results from brain disease. The impact of dementia on our society in terms of personal suffering and economic burden is enormous. The most common known cause of dementia is Alzheimer's disease, a condition that is responsible for as much as $60 \%$ of all dementia in the United States Another common cause is multi-infarct dementia, resulting from multiple strokes and usually associated with hypertension. At least 10 to $20 \%$ of all dementia is caused by treatable conditions, including brain tumors, infections, blood clots, nutritional deficiencies, endocrine disorders, poisonings, communicating hydrocephalus and masked depression.

Management of the demented subject is made difficult by limitations in available diagnostic tests. $\mathrm{X}$-ray computed tomography is valuable in the elimination of space occupying lesions as causes of dementia (such as brain tumor or blood clot), but unfortunately, the $\mathrm{x}$-ray $\mathrm{CT}$ image in Alzheimer's disease is not diagnostic. Cortical atrophy and ventricular dilatation is often seen on $\mathrm{x}$-ray $\mathrm{CT}$ in Alzheimer's disease, but is also seen in healthy aged subjects. This is not surprising in view of the considerable overlap between the gross cerebral atrophy of Alzheimer's disease and that of normal aging detected on post-mortem brain examination.

With positron emission tomography (PET) we are able to noninvasively quantitate aspects of brain metabolism. Demented subjects are being studied with PET using the Donner Laboratory 280-crystal tomograph with a glucose analog labeled with fluorine-18 (2-fluoro-2-deoxy-D-glucose) synthesized at the Lawrence Berkeley Laboratory 88-Inch Cyclotron and the University of California Davis Crocker Cyclotron. This procedure provides for assessment of glucose metabolism and quantitation of regional alterations in crucial aspects of brain work.

We have found diminished rates of glucose use in the temporal-parietal cortex in all 17 Alzheimer subjects studied. This is illustrated in Fig. 1, where this regional alteration is represented as the frontal-temporal percentage difference. In all seven

*University of California Davis, VA Medical Center, Martinez, CA. control subjects, metabolic rates for frontal and temporal parietal cortex are equal. These findings are also evident from study of experimentally determined kinetic rate constants for glucose uptake and phosphorylation. Also, a significant increase in the

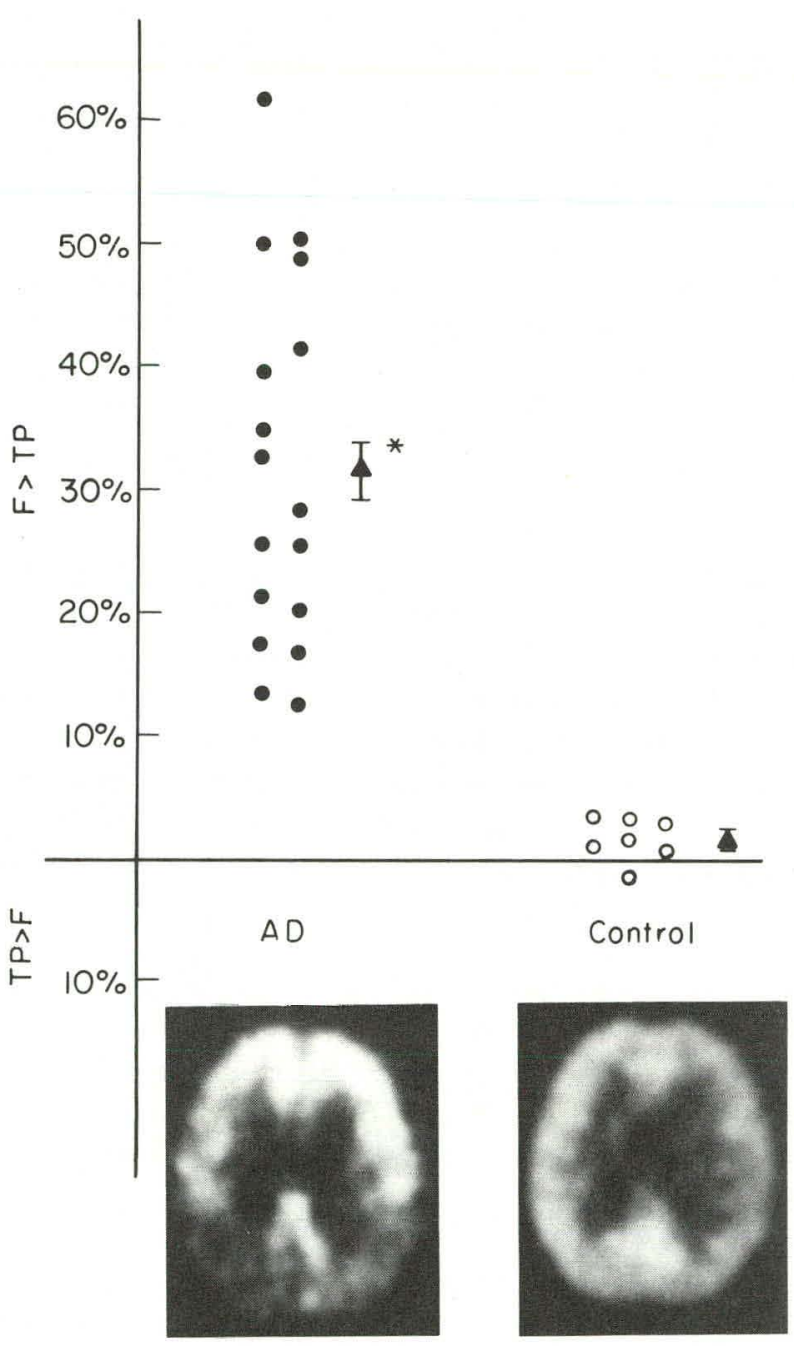

Fig. 1. Top: Individual values for F-TP percentage difference of activity densities (mean of right and left). Mean and standard error of the mean for each group presented to right of individual values. $N=17$ for Alzheimer's disease (AD) subjects (filled circles); $N=7$ for controls (open circles). ${ }^{*}=$ mean different from control group $(P<0.0005$, one-tailed). Bottom: PET images for FDG accumulation, midventricular level. The subject's left is on the right side of the image. Bilateral temporal-parietal hypometabolism, right greater than left, is noted in the $A D$ subject.

(XBB 830-9804A) 
egree of lateral hemispheric asymmetry was found .. the Alzheimer group.

The temporal-parietal focality of the disease has not been observed in other varieties of dementia studied with this technique, with one interesting exception (Creutzfeldt-Jakob Disease). We have studied subjects with several other causes of dementia: multi-infarct dementia, communicating hydrocephalus, "alcoholic" dementia, olivopontocerebellar atrophy with dementia, and Pick's disease. Temporal-parietal hypometabolism is not observed in these individuals. The subject with histologically confirmed Creutzfeldt-Jakob disease, on the other hand, had a pattern remarkably similar to that of the Alzheimer subjects. This subject demonstrated hypometabolism in both temporal lobes with marked asymmetry (left side hypometabolic in comparison to the right).

The temporal-parietal predilection for the Alzheimer process has been established from neurochemical and neuropathological studies. The present work extends these findings to noninvasive studies in living human subjects, and serves to further emphasize the point that Alzheimer's is not a diffuse brain disease. This regional focality is remarkably consistent with the PET-FDG approach, and may be used to develop a diagnostic test for Alzheimer's disease. With single photon emission computed tomography using isotopes for regional cerebral blood flow determination, it is likely that similar regional alterations could be demonstrated in Alzheimer subjects. This could be done without the use of isotopes that must be produced in a local cyclotron. The findings of lateral hemispheric asymmetries in Alzheimer subjects as well as the temporal focality of metabolic changes in the Creutzfeldt-Jakob disease patient, add further evidence to known similarities between these two conditions. This further supports the possibility that Alzheimer's disease may originate in a transmissible agent, an hypothesis which requires further investigation.

\section{BRAIN METABOLISM IN MENTAL DISORDERS}

\section{Thornton W. Sargent, III, Natalia Kusubov, Alexander T. Shulgin, Chester A. Mathis, and Reese M. Jones}

In this program we are presently investigating three major modalities for studying brain metabolism in mental illness: 1) blood flow, 2) amino acid metabolism, and 3) glucose metabolic rate.

\section{BLOOD FLOW}

To measure brain blood flow we are developing a new radiopharmaceutical based on our earlier studies of methoxylated amphetamines. The details of this study were described in the previous annual report. Briefly, the chemistry of labeling by which radioiodine is attached to the precursor to form the final product, 4-iodo-2,5-dimethoxy-N,N-dimethyl amphetamine (IDNNA), is rapid enough that 3.6$\min { }^{122}$ I may be used in the synthesis. This positron-emitting radioisotope is the daughter of $20-\mathrm{hr}{ }^{122} \mathrm{Xe}$ and can thus be withdrawn repeatedly from the parent isotope.

We have investigated a series of 15 chemical analogs using ${ }^{131} \mathrm{I}$ in rats, with varied nitrogen substituents, and found that the N,N-dimethyl provides the greatest total brain uptake $(3.6 \%)$ and the highest brain/blood ratio (9 at $6 \mathrm{~min}$ ). We have chieved a radiochemical yield of $50 \%$ in 10 seconds, producing 1 microgram of the product.
Based on these reaction conditions, which produce good yield, speed, and high specific activity, we are now designing a generator, reaction vessel and purification system that can be used to produce the desired ${ }^{122}$ IDNNA. Because IDNNA is extracted from the blood by the brain on its first pass and then remains there, it will form a static image of brain blood flow when ${ }^{122}$ IDNNA is used in a positron emission tomograph (PET), and accurate numerical values of flow can be determined for all areas of the brain. We will use this means to examine the question of whether brain blood flow is altered in various forms of mental illness such as schizophrenia and Alzheimer's dementia.

\section{AMINO ACID METABOLISM}

Our studies of amino acid metabolism are concentrated principally on methionine. Experimental evidence of abnormal metabolism of the S-methyl carbon of methionine and the fact that feeding methionine worsens schizophrenic illness have led to a hypothesis by Levi and Waxman that schizophrenia results from a deficiency of methionine-adenosyl transferase. We are preparing experiments in which patients will be injected with 
$\left[\mathrm{S}^{11} \mathrm{CH}_{3}\right]$-methionine, have their brains dynamically imaged in the PET system, their breath analyzed for expired ${ }^{11} \mathrm{CO}_{2}$, and their serial plasma samples analyzed for ${ }^{11} \mathrm{C}$ metabolites of methionine. High performance liquid chromatography (HPLC) is the only method with the potential of sufficient speed to separate metabolites, and our efforts have been concentrated on developing this technique during the past year. We have developed what appears to be the maximally efficient and rapid separation method for the metabolites of interest, and are ready to test the method on patients.

\section{GLUCOS[ M[TABOLIC RATE}

Glucose metabolic rate can be measured in specific areas of the brain by injecting the glucose analog fluoro-deoxyglucose (FDG) labeled with ${ }^{18} \mathrm{~F}$ into a patient and imaging the brain with positron emission tomography. Other workers have reported a relative decrease of FDG uptake in the frontal lobes of the brain of patients with schizo phrenia.

We have studied four normal subjects and four patients both before and after medication, performing dynamic imaging and blood input function by sampling at intervals of 2 to 7 seconds immediately after injection, and longer sample times out to 40 minutes. Examination of the final values of FDG concentration has shown a small but significant decrease in FDG in the right frontal lobes of our patients. In agreement with the previous findings we observed a decrease of about $8 \%$. The importance and meaning of such a finding in this disease remains to be demonstrated.

The rapid dynamic image acquisition, which is a capability unique to the Donner PET system, permits calculation of the rate constants for glucose transport in the brain in individual brain regions for each patient. The analysis of these rate constants and of the glucose metabolic rate for brain regions in these patients is presently in progress.

\section{NUCLEAR MAGNETIC RESONANCE IMAGING AND SPECTROSCOPY}

\section{Todd Richards, Thomas F. Budinger, Rudi Nunlist, Reese Jones, Andy Hasenfeld, and Mark Roos}

Nuclear magnetic resonance (NMR) imaging has already proven to be valuable in diagnostic medicine. The proton NMR image is mainly influenced by the concentration and molecular environment of water in tissue, which has been shown to be useful in distinguishing white from gray matter in the brain. However, the state of the water in the tissue can provide only limited pathological information, and this type of imaging can lead to ambiguous tissue characterization (e.g, edematous and cancerous tissue both give the same appearance). In vivo hydrogen-1, phosphorus-31, and carbon-13 spectroscopy can add a wealth of chemical information which, unlike the proton image, could be very specific to disease processes. We are currently developing NMR imaging and spectroscopic techniques which can be applied to the evaluation of radiation brain damage, atherosclerosis, dementia, and schizophrenia.

\section{IMAGING OF RADIATION BRAIN DAMAGE}

For two years we have studied the potentials of NMR for the investigation of heavy-ion radiation effects in the brain. We posed the following questions:
1. What are the changes in proton NMR parameters due to heavy-ion radiation of the brain?

2. Can NMR be used to evaluate the effects of radiation on the CNS and spinal cord tissues?

3. Can NMR relaxation and spectroscopic changes be used to evaluate the progress of heavy-ion radiotherapy?

In collaboration with Doctors John Lyman of LBL, and George Wesbey and Larry Crooks of UCSF, we performed the following experiment.

The left hemisphere of the brain of 16 rats was irradiated (1000-3000 rads), using the helium beam produced at the LBL 184-Inch Cyclotron, and the rats were imaged 14 days post-irradiation. The spin echo image of the rat brains (3000 rads) showed a decrease in intensity on the irradiated side cerebral cortex (Fig. 1). T1 relaxation time, which is a measure of the time it takes the nuclei (protons) to realign in the magnetic field after a radio-frequency pulse, was calculated form the intensity images of the rat brain. T1 increased significantly with dose on the control and decreased slightly with dose or the irradiated side. From our measurements, we 


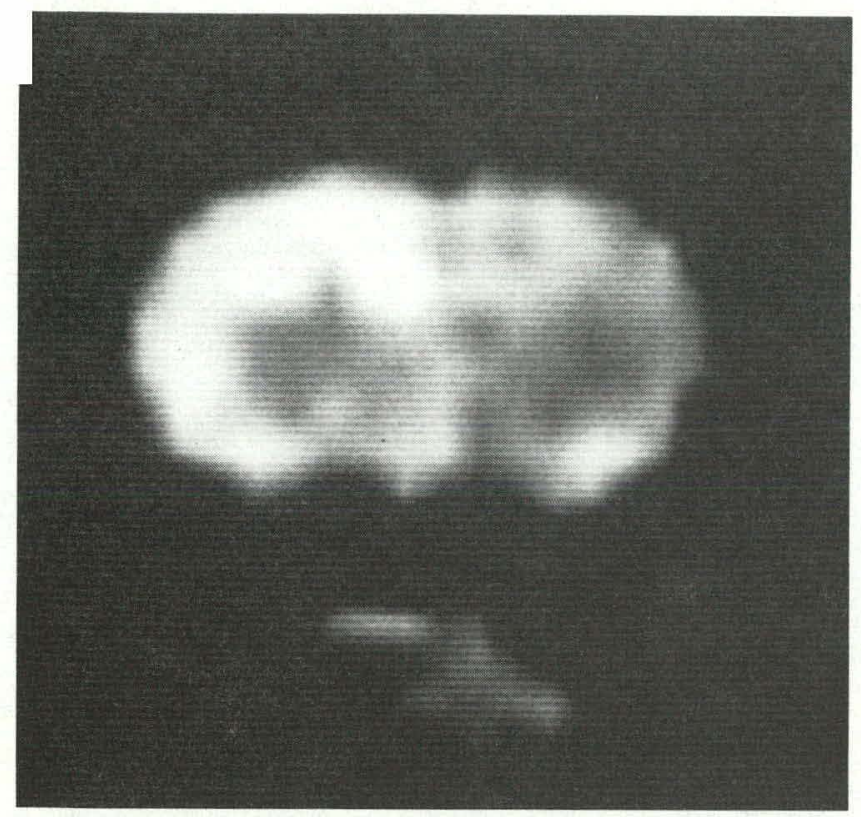

Fig. 1. Spin echo image 14 days post-irradiation of a rat that received 3000 rads to the left side of the brain. Contrast between gray and white matter on the irradiated side is not as great as that on the control side.

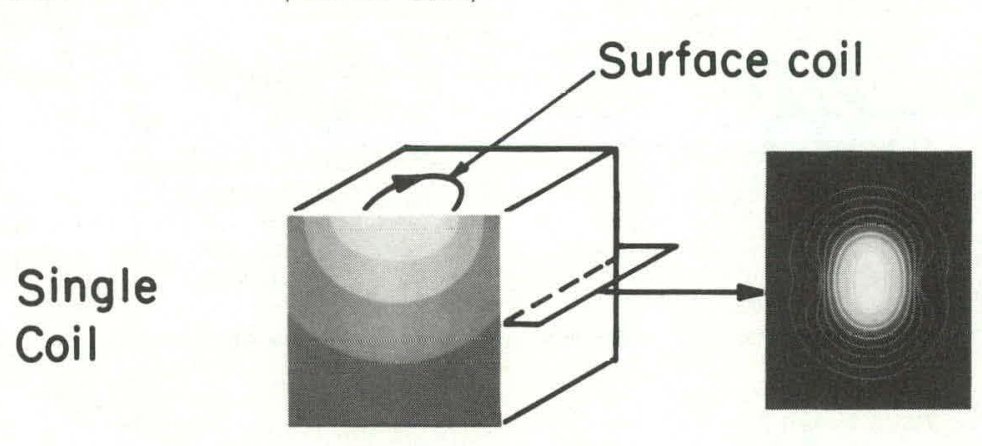

\section{Single Coil}
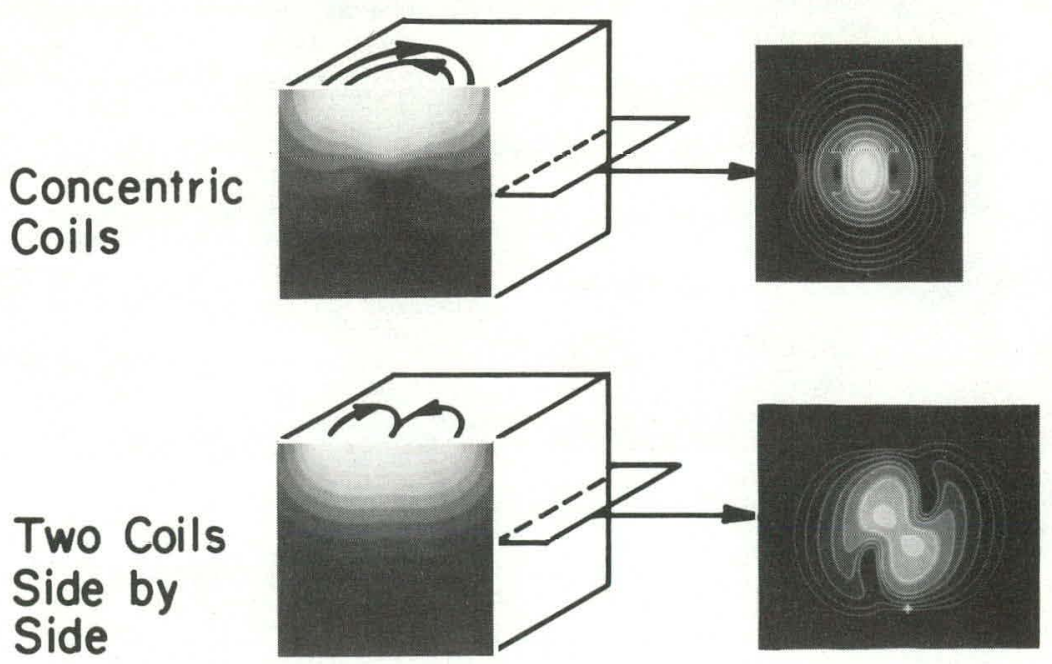

\section{Radio Frequency Field Shaping}

Fig. 2. Computer simulation of radio-frequency coil configurations. With each of the three coil configurations are shown two views of the if magnetic field component perpendicular to the main field. These 3-dimensional field calculations can be used to simulate the NMR experiment with various phantoms placed in front of the coils. 
to apply NMR spectroscopy to in vivo situations, principally in isolating and detecting the desired nuclei from a specific region in the body. We have begun both computer simulations and theoretical/experimental studies to perfect strategies for selective region spectroscopy. Figure 2 shows some rf coil configurations that have been used in computer calculations of the $\mathrm{rf}$ magnetic field distribution in three dimensions. By using these computer simulations, we can try many different coil configurations until we find one that may be useful in selective region spectroscopy.

We built a NMR probe which could be used to measure proton, phosphorus, and carbon spectra of the rat brain in vivo (Fig. 3). Figure 4 is an exdIIIple of a phosphorus-31 spectrum we obtained from

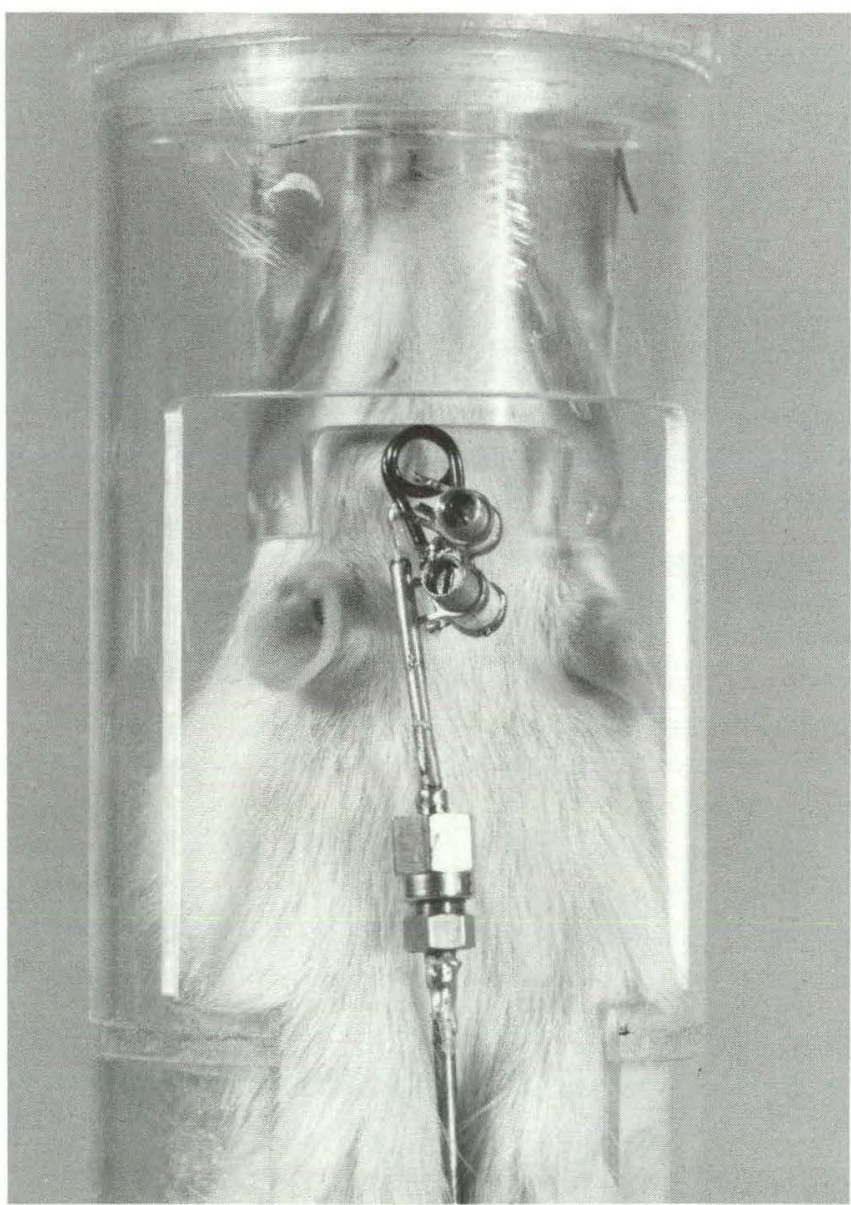

Fig. 3. Rat in the NMR probe used to obtain in vivo proton and phosphorus spectra. The surface coil is a two-turn enamel coated copper wire. The capacitors are tuned in this case to the proton resonant frequency $(180 \mathrm{MHz})$. The NMR signal comes from the region of tissue directly in front of the coil.

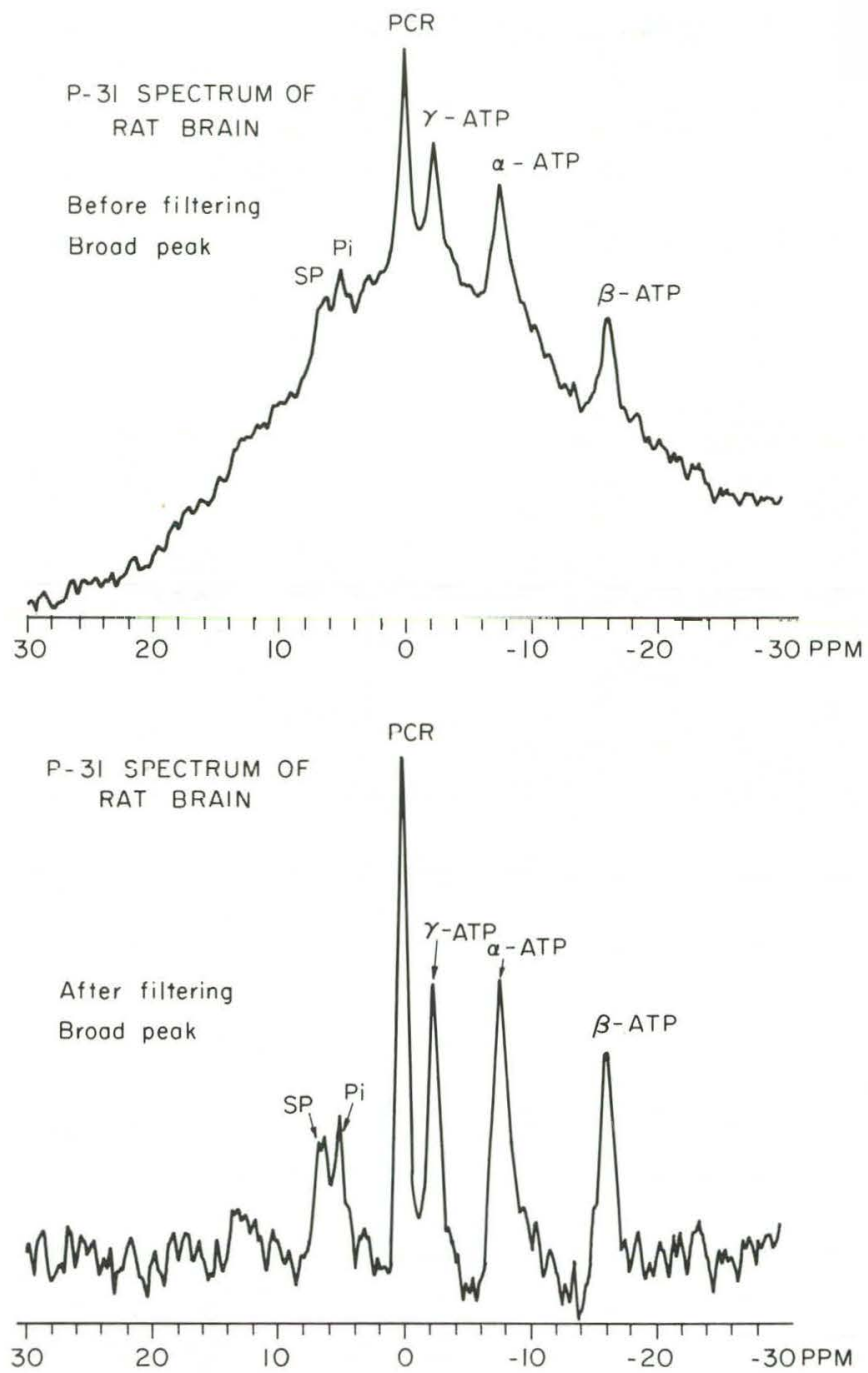

Fig. 4. Phosphorus spectra of anesthetized rat brain. Phosphorus-31 spectra were recorded at $72.9 \mathrm{MHz}$ using a spectrometer built by the UC Berkeley Chemistry Department with a Bruker 4.3-T wide bore magnet and Nicolet 1180 data system. The signal was averaged 1000 times (total acquisition time of $35 \mathrm{~min}$ ) and an exponential filter with $20 \mathrm{~Hz}$ line broadening was applied before Fourier transformation (top spectrum). The bottom spectrum is the result after an additional high-pass filter was applied to the signal to suppress the broad phosphate component of skull bone.

(XBL 834-3694)

the live rate having seven major resonances. These are 1) sugar phosphate (SP), 2) inorganic phosphate $(\mathrm{Pi})$, 3) phosphodiester (PD), 4) phosphocreatine (PCR), 5) ATP1, 6) ATP2, and 7) ATP3. The proton spectrum (Fig. 5) has great potential in measuring the metabolism of lactic acid and creatine as well as some amino acids. 
Proton Spectrum of /n-vivo Rat Brain (normal)

Peak assignments from Behor et al., 1983

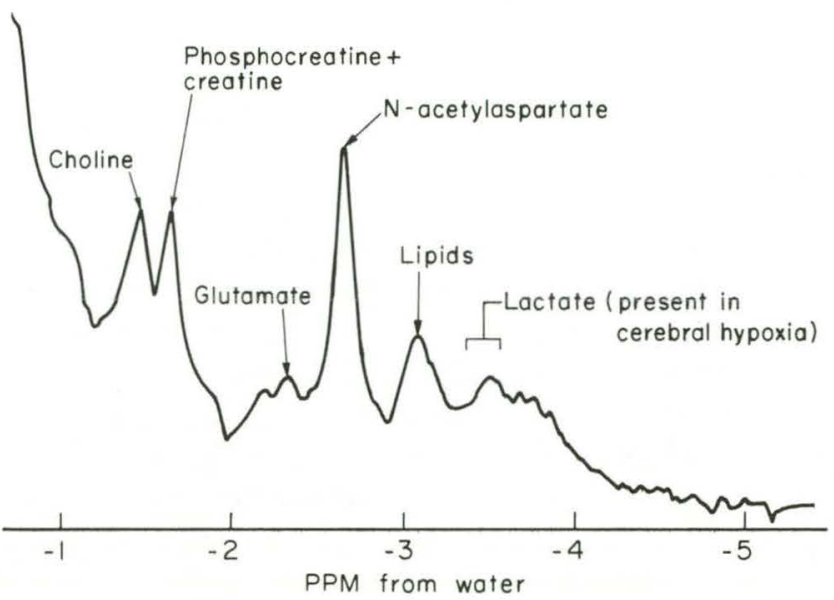

Fig. 5. Proton spectrum of in vivo rat brain (normal). A spin echo pulse sequence was used with a delay time of $110 \mathrm{msec}$. As suggested by Brown and Campbell, ${ }^{1}$ this spin echo sequence removes the broad lipid and protein resonances from the spectra. The peak assignments made so far are choline, creatine/phosphocreatine, n-acetyl aspartate, lipids, and lactic acid. Note: Peak assignments are from Behar et al. ${ }^{2}$

(XBL 839-4010)

\section{REFERENCES}

1. Brown, F.F., Campbell, I.D., Kuchel, P.W., and Rabenstein, D.C. Human erythrocyte metabolism studies by ${ }^{1} \mathrm{H}$ spin echo NMR. FEBS Letters 82, 12-16 (1977).

2. Behar, K.L., den Hollander, J.A., Stromski, M.E., Ogino, T., Shulman, R.G., Petroff, O.A.C., and Prichard, J.W. High-resolution ${ }^{1} \mathrm{H}$ nuclear magnetic resonance study of cerebral hypoxia in vivo. Proc. Natl. Acad. Sci 80, 4945-4948 (1983).

\section{RADIONUCLIDE AND RADIOPHARMACEUTICAL DEVELOPMENT FOR POSITRON EMISSION TOMOGRAPHY}

\section{Yukio Yano, Thomas F. Budinger, Mohindar Singh, Reese Jones, Jim Hunter, and David Moore}

This program developed and improved methods for the cyclotron or generator production of positron emitting radionuclides and for the synthesis of radiolabeled biochemical substrates to investigate human physiology and metabolism by noninvasive procedures with the Donner Positron Emission Tomograph. The LBL 88-Inch Cyclotron was used to produce the short-lived positron emitters of carbon, nitrogen, oxygen, and fluorine that were synthesized into biochemical compounds. Radioisotope generators were used to provide a readily available supply of gallium-68 and rubidium-82. Both preparative and analytical high performance liquid chromatography (HPLC) are under development to provide high specific activity and high radio and chemical purity of the labeled compound. In addi${ }^{+}$On, isocratic and gradient elution HPLC were used , investigate the radiolabeled metabolites in body ..uids.

\section{CYCLOTRON PRODUCED RADIONUCLIDES}

Oxygen-15 labeled $\mathrm{H}_{2} \mathrm{O}$ is a freely diffusible blood-flow tracer for brain and heart studies. Progress has been made on the production of 2 minute ${ }^{15} \mathrm{O}$ by the irradiation of a mixed gas target consisting of $95 \%$ nitrogen and $5 \%$ hydrogen with deuterons. The various parameters of targetry and irradiation were investigated to optimize the target window thickness and cooling, deuteron beam energy and current, and the continuous flow-rate of the target gas through a saline bubbler for maximum ${ }^{15} \mathrm{O}$ yield without ${ }^{13} \mathrm{~N}$ contamination from a competing nuclear reaction. At the end of a 10minute irradiation, $300 \mathrm{mCi}\left(\mathrm{H}_{2}{ }^{15} \mathrm{O}\right)$ of ${ }^{15} \mathrm{O}$ are produced with a radiopurity $>99.999 \%$ and a radiochemical purity $>99.9 \%$ as determined by half-life measurements and gas chromatography, respectively. Three separate production batches of 
$150 \mathrm{mCi}$ each of $\mathrm{H}_{2}{ }^{15} \mathrm{O}$ can be delivered per hour to the PET imaging site.

Carbon-11 as $\mathrm{CO}_{2}$ was used for the Grignard reaction to label fatty acids and acetate or as ${ }^{11} \mathrm{CH}_{3} \mathrm{I}$ for the methylation reaction to label methionine or choline. Preparative and analytical HPLC were used to increase the radio and chemical purity of the product as shown in Fig. 1.

${ }^{18} \mathrm{~F}$-fluorodeoxyglucose (FDG) was produced at the U.C. Davis Crocker Cyclotron. About 40 production runs were made to supply ${ }^{18} \mathrm{FDG}$ for 1 to 2 patient studies per run. Studies were done on Alzheimer's senile dementia patients (Dr. R. Friedland) and patients with schizophrenia (Dr. T. Sargent and Palo Alto V.A.).

\section{RADIONUCLIDE GENERATORS}

The germanium-68/gallium-68 generator was used to obtain ionic gallium-68 for platelet and lipoprotein labeling studies.

Endothelial injury and thrombosis are involved in the development of both the early and advanced lesions of atherosclerosis and in the thromboembolic complications of atherosclerosis.

Endothelial injury may be brought about by blood-borne factors and by effects of blood flow that affect the vessel wall and the endothelium. Blood-borne factors are serum lipids (particularly LDL), high concentrations of abnormal metabolites such as homocysteine, antigen-antibody complexes, catecholamines, bacteria, and viruses. It is wellknown that platelet deposition occurs at these injury sites on the arterial wall. For this reason the radiolabeling of platelets and the imaging of platelet accumulation with positron emission tomography may permit evaluation of individual vascular lesions.

Gallium-68 platelet labeling studies were conducted in collaboration with Dr. D. C. Price of UCSF and Dr. Shirley Ebbe of LBL. Various complexes of

"C - CHOLINE SYNTHESIS SYSTEM

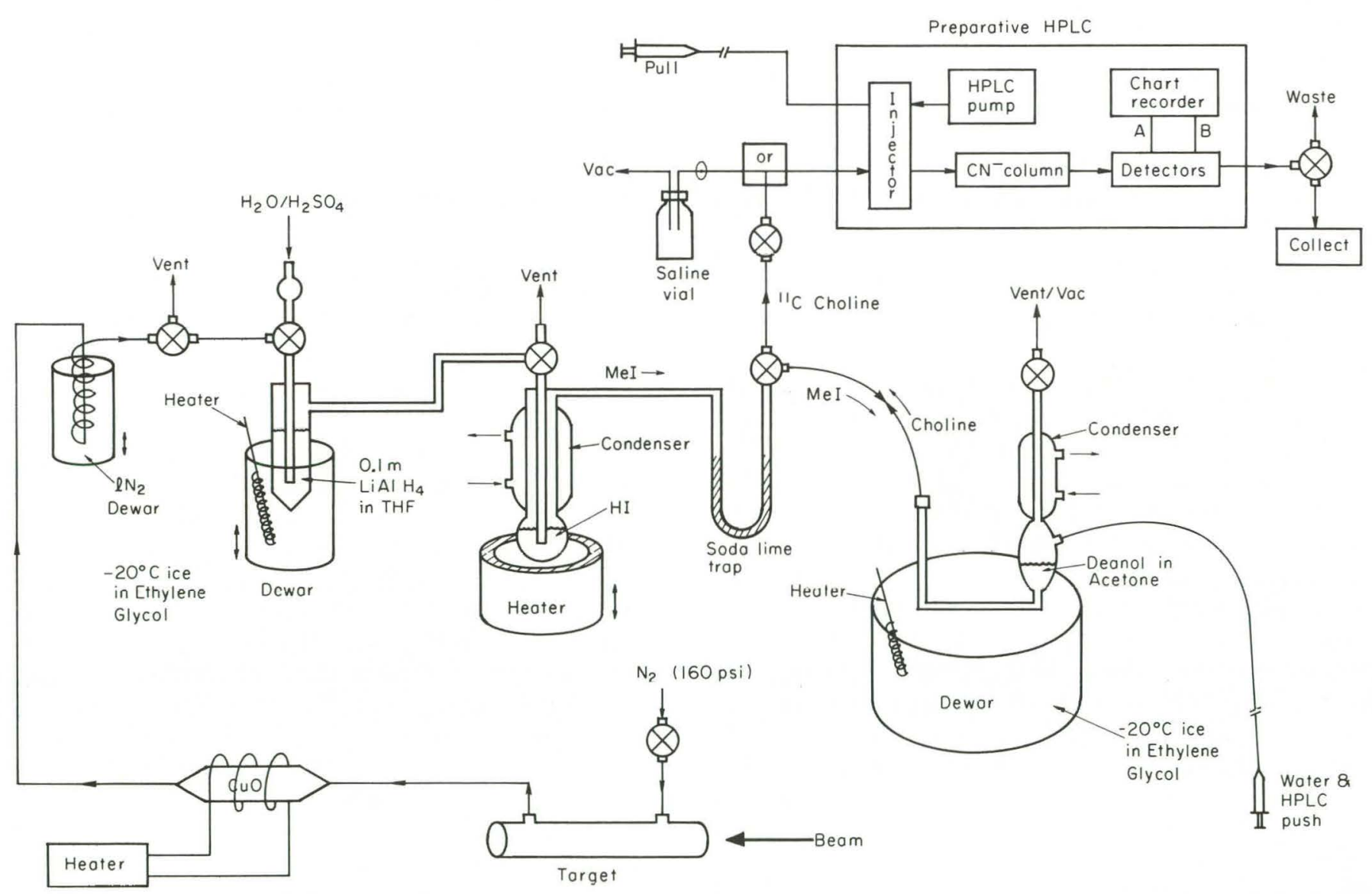

Fig. 1. ${ }^{11} \mathrm{C}$-choline or methionine synthesis system coupled to HPLC. Remotely controlled organic synthesis system for the labeling of methionine and choline with carbon-11 and the chemical separation of the labeled product using preparative HPLC.

(XBL 837-3845) 
${ }^{8} \mathrm{Ga}$ such as oxine, mercaptopyridine oxide, and tropolone, were investigated as carrier molecules for transporting ${ }^{68} \mathrm{Ga}$ across the platelet membrane. Numerous problems related to contaminating metal ions, concentration of complexing ligand, $\mathrm{pH}$, buffers, and isolation of viable platelets from human, dog, and rabbit blood were investigated. Of importance to progress in ${ }^{68} \mathrm{Ga}$ platelet labeling was the development of a thin layer chromatography (TLC) system for analyzing the formation of ${ }^{68} \mathrm{Ga}$-oxine under various conditions and to determine the available ${ }^{68} \mathrm{Ga}$-oxine at the time of addition to the separated platelet button. We have now succeeded in labeling human platelets with about $40 \%$ labeling yield. Comparable success was found in labeling rabbit platelets, but the labeling of dog platelets was not as successful.

Another aspect of ${ }^{68} \mathrm{Ga}$ chemistry has been the labeling of lipoprotein fractions with the bifunctional chelate of the cyclic anhydride of DTPA conjugated to low density lipoprotein (LDL) in research conducted by Doctors David Moore and Jim Hunter in collaboration with Doctors Alex Nichols and Trudy Forte (LBL). The cyclic anhydride of DTPA was formed and evaluated first as a conjugate of human serum albumin and labeled with ionic ${ }^{68} \mathrm{Ga}$. Separations were done on a sephadex gel column first to obtain the conjugated protein and second to isolate the ${ }^{68} \mathrm{Ga}$-labeled protein from the ${ }^{68} \mathrm{Ga}-\mathrm{DTPA}$ formed by hydrolysis of the cyclic anhydride. Preliminary studies with the ${ }^{68} \mathrm{Ga}$ labeling of separated LDL from human plasma has indicated highly suc- cessful labeling yields as well as high radiochemical purity of the labeled protein. Further studies will be done to utilize gel-column chromatography and HPLC to determine the subfractions of LDL labeled with ${ }^{68} \mathrm{Ga}$. Other animal distribution studies and assay methods will be used to determine the usefulness of the ${ }^{68} \mathrm{Ga}$-labeled lipoprotein for PET imaging studies in animal models to determine the biological activity of the radiolabeled protein fraction.

The LBL rubidium-82 generator was kept in operation throughout the year with four separate loadings of ${ }^{82} \mathrm{Sr}$ that was produced at Los Alamos Scientific Laboratory by H. A. O'Brien's group. Two hundred millicuries of ${ }^{82} \mathrm{Sr}$ were received for each loading. The ${ }^{82} \mathrm{Rb}$ generator was used in PET studies of patients with brain tumors and Alzheimer's type senile dementia. Animal studies were done to evaluate measurement of myocardial blood flow with ${ }^{82} \mathrm{Rb}, \mathrm{H}_{2}{ }^{15} \mathrm{O}$, and radiolabeled microspheres.

Preliminary discussions with Doctors P. Richards and L. Mausner of the Brookhaven Linac Isotope Produce (BLIP) have led to substantial progress in planning for the production and delivery of 100 to $200 \mathrm{mCi}$ of ${ }^{122} \mathrm{Xe}$ on a weekly basis. The design and fabrication of the shipping shield for the ${ }^{122} \mathrm{Xe}$ activity and the generator system for the isolation of the $3.5-\mathrm{min}$ positron emitter ${ }^{122} \mathrm{I}$ is being carried out, in collaboration with Doctors T. Sargent and A. Shulgin, and the synthesis and radiolabeling reactions for the rapid iodination of an amphetamine analog with ${ }^{122}$ l. This compound will be useful in determining brain blood flow by PET.

\section{NEW INSTRUMENTATION FOR HIGH-RESOLUTION DYNAMIC THREE- DIMENSIONAL IMAGING OF POSITRON-LABELED COMPOUNDS IN THE HUMAN BODY}

\section{Stephen E. Derenzo, John L. Cahoon, Ronald H. Huesman, Tony Vuletich, and Thomas F. Budinger}

\section{ULTRAHIGH RESOLUTION SINGLE-LAYER POSITRON TOMOGRAPH}

A new 600-crystal positron tomograph is under construction and will be completed mid-1984. It will have a spatial resolution ("image sharpness") of $2.5 \mathrm{~mm}$ FWHM (full-width at half maximum), which is better than any existing instrument by a factor of three, and it will be able to acquire 100,000 coincident events per second, permitting sequences of mages as rapidly as one image per second. The 3 $\mathrm{nm}$ wide bismuth germanate crystals and photoubes are mounted in aluminum holders (Fig. 1) and the 600-crystal detector ring consists of 30 holders (Fig. 2).

This unique instrument will be used for the study of abnormal metabolism in brain disorders, brain tumor metabolism before and after therapy, and the development of the arterial plaques that cause stroke and heart disease. For these studies, selected biological compounds are labeled with a positron emitting isotope such as 2 -min ${ }^{15} \mathrm{O}, 20$ min ${ }^{11} \mathrm{C}$, or $108-\min { }^{18} \mathrm{~F}$ and then administered by inhalation or simple injection. Information on the biochemical processes of an organ is obtained from 


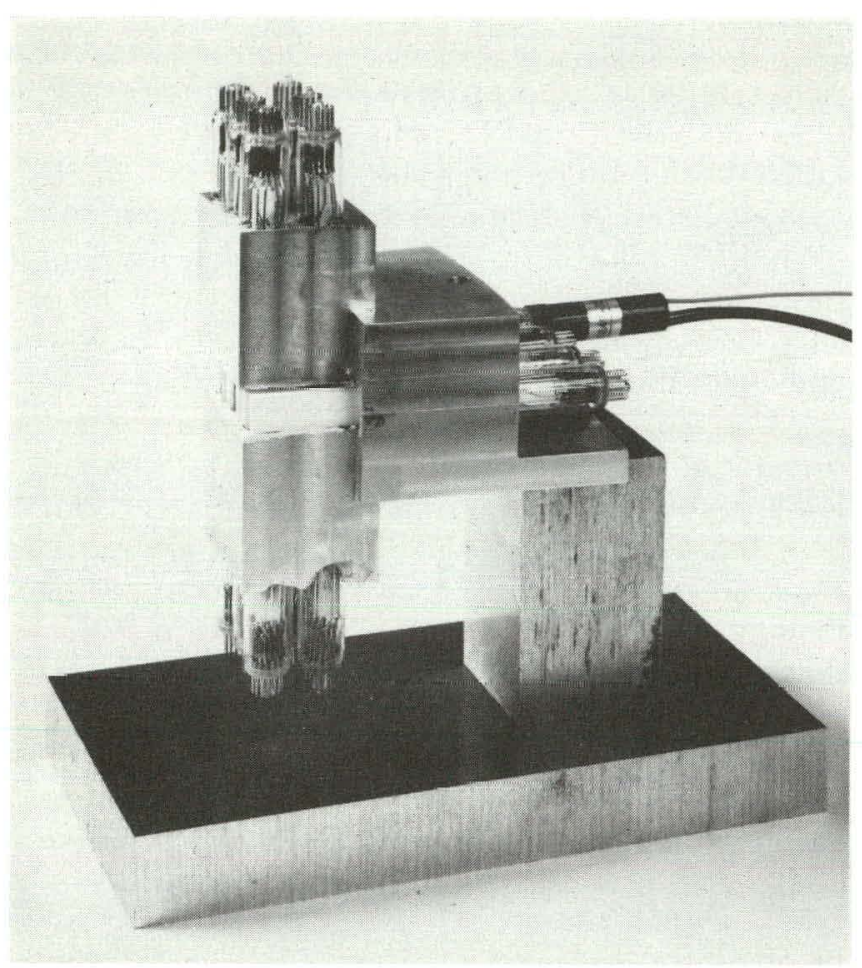

Fig. 1. One of the 30 detector holders for the 600 crystal ultrahigh resolution positron tomograph. Each holds an average of 20 bismuth germanate crystals and phototubes.

(XBB 830-8658)

measurements of the rate at which the tracer is delivered to that organ, and the accumulation and clearance of the tracer in the organ as a function of time.

The tomograph is especially designed to image tracers that decay by producing positrons. These positrons travel a short distance in tissue (less than $1 \mathrm{~mm}$ for isotopes such as ${ }^{18} \mathrm{~F}$ and ${ }^{11} \mathrm{C}$ ), and annihilate with a nearby electron to produce two 511-keV photons that fly off in nearly opposite directions. Because the electron and positron have some motion at the instant of annihilation there is an angular spread of about $0.32^{\circ} \mathrm{FWHM}$. For our detector ring with a diameter of $60 \mathrm{~cm}$, this corresponds to a spatial broadening of $0.9 \mathrm{~mm}$ FWHM.

Each crystal is coupled to a phototube, and electronic circuits determine when any crystal has detected an annihilation photon in time coincidence (within 15 billionths of a second) with any of the opposing crystals. Events are accumulated in high-speed semiconductor memory, and reconstructed by a high-speed special processing unit to produce an image of the distribution of the tracer on a TV screen.

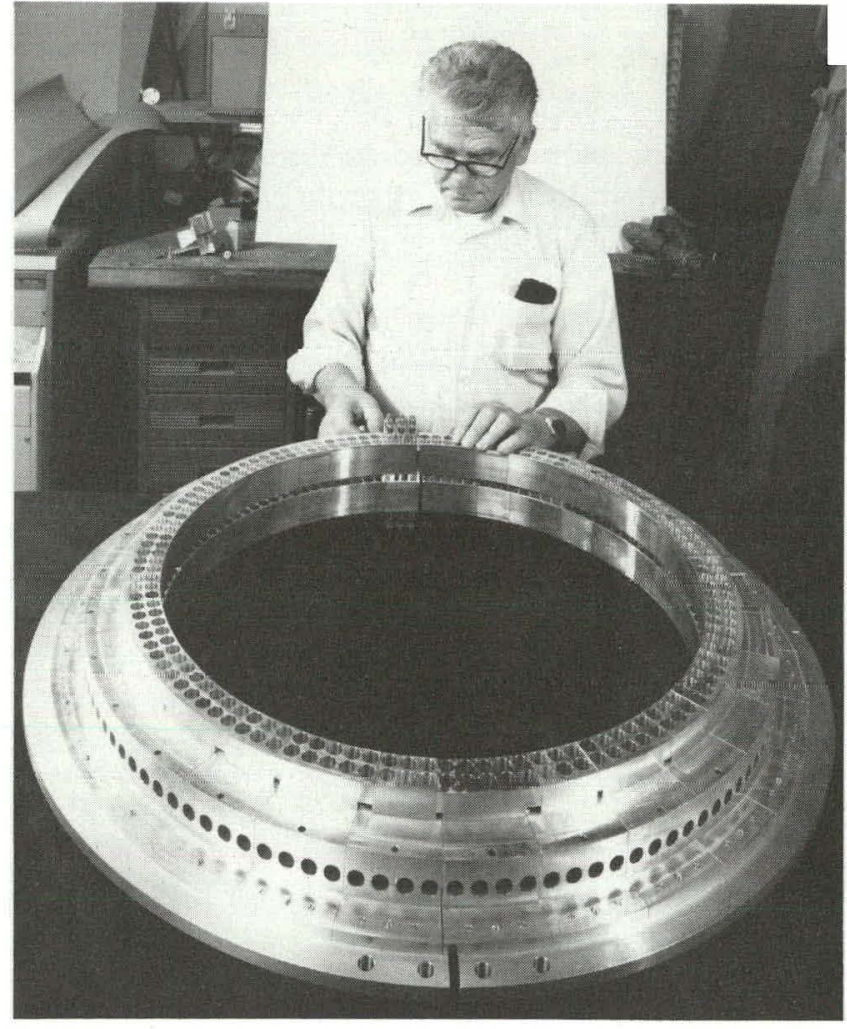

Fig. 2. Assembly of 30 detector holders for the complete detector ring.

(CBB 8310-8660)

This new work is an evolution of the Donner 280-Crystal Positron Tomograph which is now in its sixth year of successful operation.

\section{ULTRAHIGH RESOLUTION SEVEN-LAYER POSITRON TOMOGRAPH}

The most serious limitation of the 280-crystal tomograph and the new 600-crystal ultrahigh resolution tomograph is that they can only image one section at a time. The size of available phototubes prohibits the close packing of small crystals in multiple layers. We realized that if a design could be developed for small crystals close-packed in many rings, then many layers could be imaged simultaneously. This would permit a great increase in speed and sensitivity without sacrificing spatial resolution. Thus one of our major research activities is to develop advanced detector technologies such as those following.

\section{Multiple-Anode Phototube}

We have established specifications for a new photomultiplier tube, to be built by industry, con taining eight very fine electron multiplier structure in a single glass vacuum envelope. 


\section{iolid-State Photosensors}

A second promising approach uses a recently developed rectangular photomultiplier tube and new solid-state photosensors individually coupled to each crystal. The phototube provides accurate timing information for a group of crystals and the silicon photodiodes determine which crystal is producing the scintillation light. The amount of light from the BGO crystals is small, however, and the charge signal from the photodiode consists of only a few thousand electrons. Prior to our work, individual $511-\mathrm{keV}$ gamma ray pulses had never been observed from a BCO-photodiode detector combination.

\section{CRYSTAL IDENTIFICATION USING SILICON PHOTODIODES}

In an important technical advance, we have achieved an energy resolution of $7.2 \%$ FWHM for $662-\mathrm{keV}$ gamma rays using small BGO crystals, commercially available silicon photodiodes, and low-noise charge amplifiers developed at LBL (Fig. 3). This energy resolution is better than any resolution reported for $\mathrm{BGO}$ using phototubes (10\% FWHM) and far better than any resolution reported for solid-state photodetectors (20\% FWHM for $\mathrm{HgI}_{2}$ or silicon avalanche photodiodes). A pulse height spectrum for a ${ }^{22} \mathrm{Na}$ source is shown in Fig. 4.

In a preliminary experiment, two small BCO crystals were cemented to a common phototube, and individually coupled to silicon photodiodes. The spatial resolution of the phototube only (Fig. 5) is relatively broad. When information from the two silicon photodiodes is used (photodiode A and B curves) the phototube peak is clearly resolved into

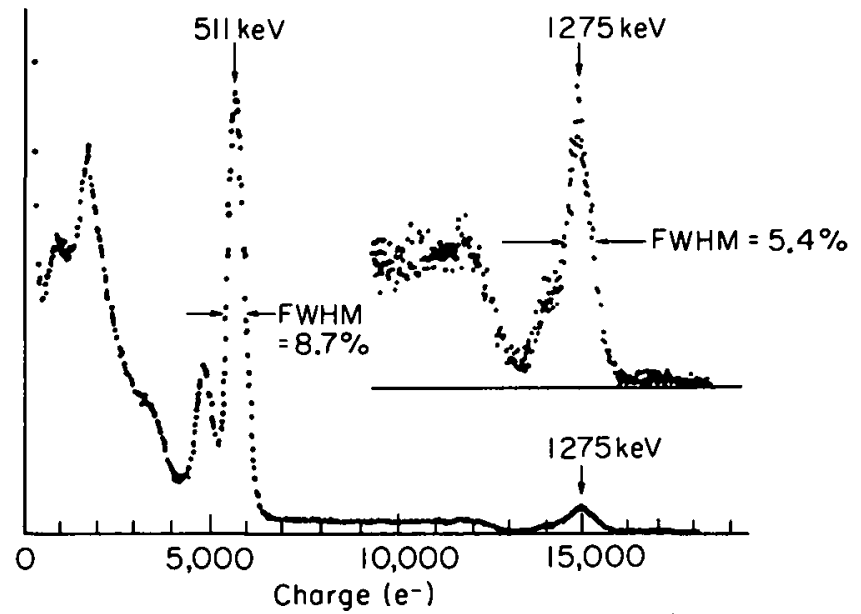

Fig. 4. Pulse height spectrum from ${ }^{22} \mathrm{Na}$ taken with the set-up of Fig. 3 at a temperature of $-150^{\circ} \mathrm{C}$.

(XBL 8311-4086)

two narrow peaks with FWHM $=2 \mathrm{~mm}$. This demonstrates the potential for a new class of multilayer ultrahigh resolution positron tomographs. The proposed 2400-crystal tomograph will have a total of 300 phototubes with 8 crystals coupled to each phototube. Specially designed photodiodes will be coupled individually to each crystal.

Table 1. Development of positron emission tomographs at Donner Laboratory.

\begin{tabular}{lccc}
\hline \hline Completion date & June 1978 & 1984 & 1987 (Est) \\
Total number of BGO crystals & 280 & 600 & 2,400 \\
Number of image planes & 1 & 1 & 7 \\
In-plane resolution (FWHM) (mm) & 9 & 2.5 & 2.5 \\
\hline \hline
\end{tabular}
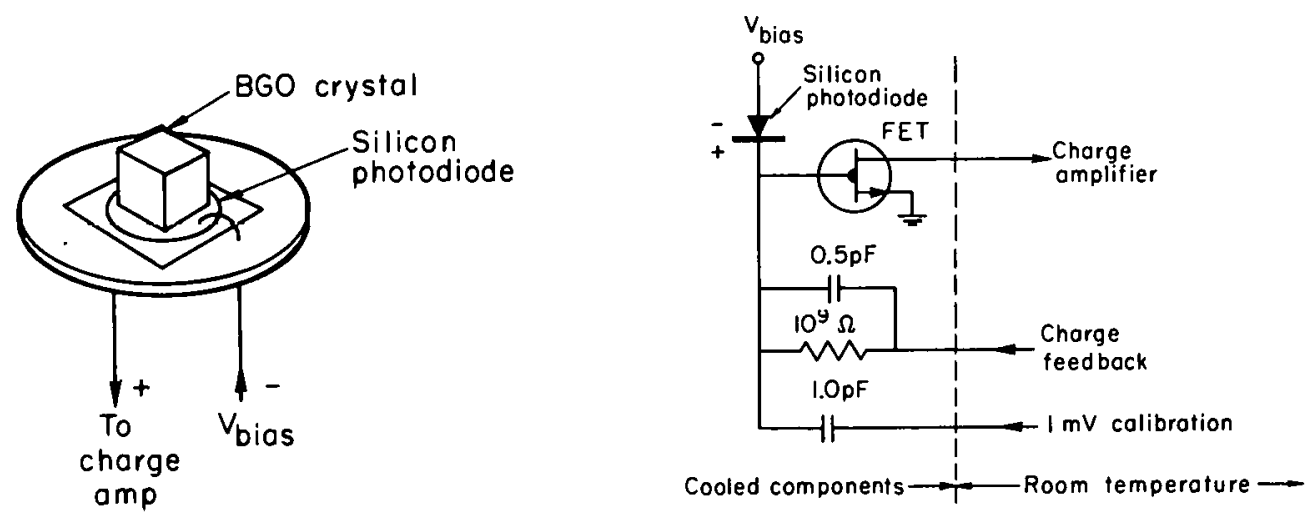

Fig. 3. (a) Schematic of $3 \times 3 \times 3 \mathrm{~mm} \mathrm{BGO} \mathrm{crystal} \mathrm{cemented} \mathrm{to} \mathrm{a} 4 \mathrm{~mm}$ diameter silicon photodiode. (b) Circuit diagram of low-noise charge amplifier, showing cooled components.

(a: XBL 833-3678, b: XBL 833-3646) 


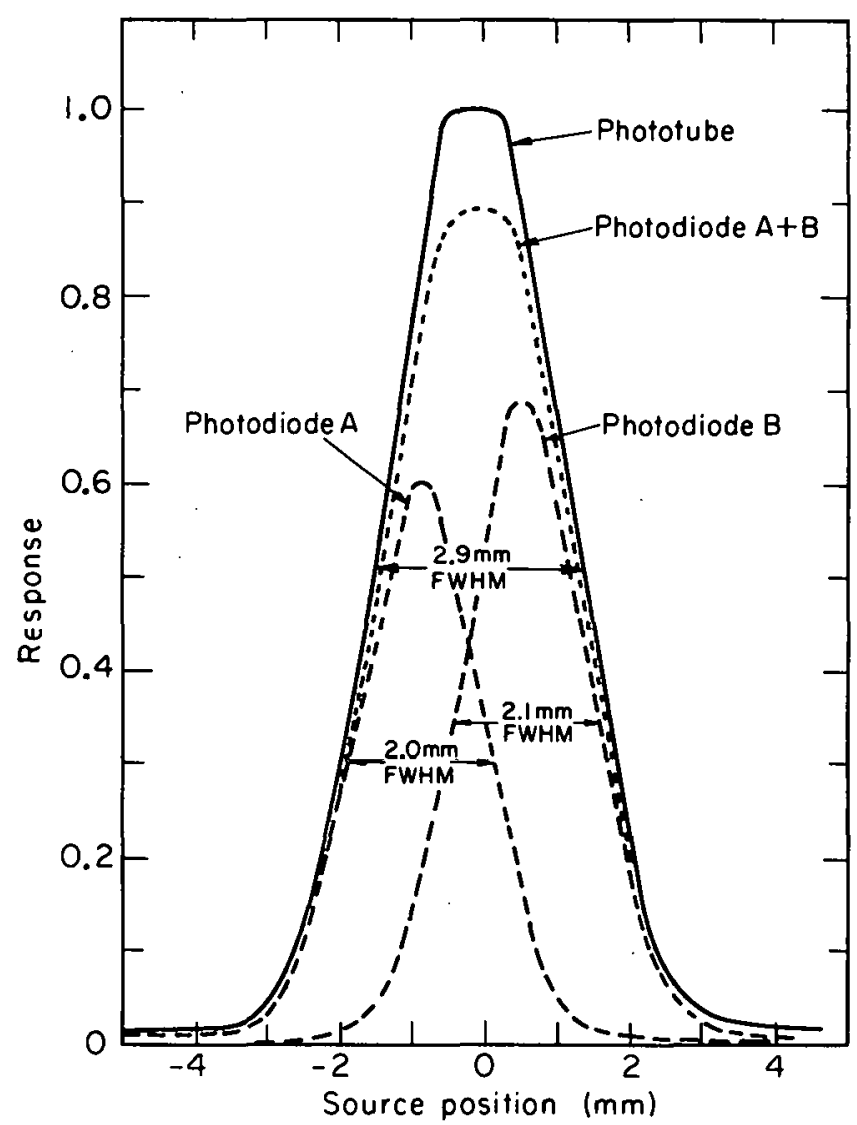

Fig. 5. Coincident response function as a very narrow line source of ${ }^{22} \mathrm{Na}$ is moved between opposing phototubes. One phototube is cemented to a single $3 \mathrm{~mm}$ wide $B G O$ crystal and the other is cemented to two $3 \mathrm{~mm}$ wide $B C O$ crystals. The curve marked phototube is the coincident response between the two phototubes and is relatively broad because the second phototube cannot distinguish between the two crystals cemented to it. Photodiode $A$ and $B$ curves include photopeak pulses from the respective photodiodes and demonstrate their ability to determine the crystal of interaction on an event-by-event basis.

(XBL 839-4016)

\section{MURINE MEGAKARYOCYTOPOIESIS AND HUMAN ERYTHROPOIESIS}

Shirley Ebbe, Clara Adrados, Cathryne Allan, Violet Barghe-Sharghi, Dorothy Carpenter, Ruth Cohen, Patricia Garbutt, Carol Lum, and Elizabeth Phalen. Attending Physicians: Hunter Cutting, Lester Hollander, and Henry Stauffer.

\section{MEGAKARYOCYTES}

Platelets are the smallest of the formed elements of the circulating blood. They function to prevent hemorrhage by sealing off defects in blood vessels that may occur spontaneously or as a result of trauma, and by initiating blood clotting. Platelets are fragments of cytoplasm from megakaryocytes, which are the largest of the blood-forming cells of the bone marrow. The growth of megakaryocytes is regulated in part by the demand for platelets. One of the important determinants of platelet production appears to be the sizes of individual megakaryocytes, which may vary considerably in different experimental situations. Thus, if platelets are experimentally depleted from the blood, megakaryocytopoiesis is stimulated and, amongst other changes individual megakaryocytes grow to a larger than nor mal size. Each macrocytic megakaryocyte then pro- 
Juces a greater mass of platelets than normal to compensate for the deficiency of platelets in the blood. This change appears to be induced by a hormone called thrombopoietin that appears in the blood when the platelet count is low, but the cellular mechanisms within the bone marrow that are responsible for regulating megakaryocyte size have not been identified. We have recently found that megakaryocytic macrocytosis that is characteristic of $\mathrm{S} 1 / \mathrm{S}^{\mathrm{d}}$ mice can be reproduced in bone marrow cell cultures, a finding that opens a new avenue of approach to the identification of cell to cell interactions that may influence megakaryocyte growth.

$S 1 / S 1^{d}$ mice have genetically determined abnormalities of hemopoiesis, pigmentation, reproductive ability, and radiosensitivity. Their hemopoietic abnormality is due to an abnormality of the microenvironment of hemopoietic organs (bone marrow and spleen) rather than to deficiencies or dysfunction of the hemopoietic cells themselves. However, the cellular or chemical nature of the critical microenvironmental defect has not been described. The only obvious abnormality of the blood of these mice is a severe macrocytic anemia. In addition, however, $\mathrm{S} 1 / \mathrm{S} 1^{\mathrm{d}}$ mice have only about half the normal number of megakaryocytes in their bone marrow, but individual megakaryocytes are substantially larger than normal. The end result is that platelet production and platelet number and mass in the blood are normal. Because of normality of the platelet count, the recognized thrombopoietin mechanism can not explain the prominent macrocytosis of megakaryocytes. It was, therefore, proposed that the hemopoietic microenvironmental abnormality of $\mathrm{S} 1 / \mathrm{S} 1^{\mathrm{d}}$ mice might be directly responsible for abnormal growth of megakaryocytes and, if so, that the defect might be reproducible in cell culture.

Dexter described a technique for producing bone marrow cell cultures in which hemopoietic cell growth is maintained for prolonged periods of time. This technique appeared to be especially applicable to the study of $\mathrm{S} 1 / \mathrm{S}^{\mathrm{d}}$ mice because continuance of the cultures depends on the initial growth of a layer of bone marrow stromal cells (fat cells, endothelial cells, macrophages, reticular cells) on the bottoms of the culture flasks. After initial growth of this layer for three weeks, the cultures are recharged with a second inoculum of bone marrow to provide an adequate source of hemopoietic stem cells. Megakaryocytes and leukocytes can then be periodically harvested from the superratant culture medium. Cultures of $\mathrm{S} 1 / \mathrm{S}^{\mathrm{d}}$ bone narrow were compared to cultures of marrow from normal $(+/+)$ littermate mice to determine if abnormalities of megakaryocytopoiesis would be reproduced. Megakaryocytes were identified by histochemical staining for acetylcholinesterase, an enzyme that is specific for megakaryocytes and platelets in murine marrow, then were sized with an image analysis system attached to a microscope. Analyses were done weekly for seven weeks after recharging the cultures 10 weeks after cultures were initiated).

Cultures composed entirely of $\mathrm{S} 1 / \mathrm{S}^{\mathrm{d}}$ marrow cells showed persistent macrocytosis of megakaryocytes when compared to cultures of normal cells (Fig. 1). At various times of culture, there were also reduced numbers of megakaryocytes, total cells, and granulocytes in the supernatants of $\mathrm{S} 1 / \mathrm{S} 1^{\mathrm{d}}$ cultures, but these findings lacked the consistency of the megakaryocytic macrocytosis. These

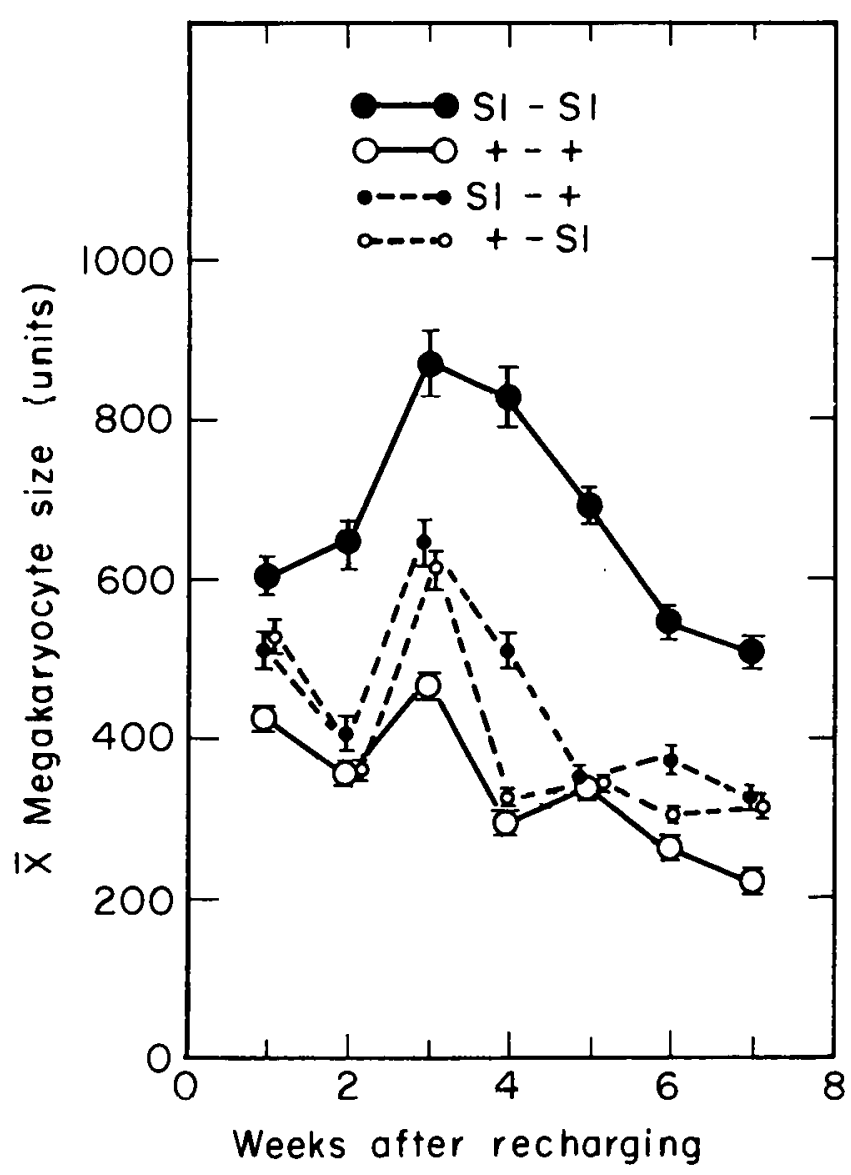

Fig. 1. Mean megakaryocyte sizes ( $\pm S E M)$ in cultures of bone marrow cells from $S 1 / S 1^{d}$ and $+/+$ mice. In cultures composed purely of $S 1 / S 1^{d}$ cells (S1-S1), megakaryocytes were consistently larger than in cultures composed purely of normal cells (+-+). The significance of the results in mixed cultures of the two cells types (designated by dashed lines) can not be determined with available data. 
findings suggest that determinants of megakaryocyte size in vivo were reproduced in the cultures and that one or more of the types of stromal cells that grew in the cultures may be responsible for the megakaryocytic macrocytosis (and, possibly, other hemopoietic abnormalities) of $\mathrm{S} 1 / \mathrm{S}^{\mathrm{d}}$ mice.

Further studies are underway to evaluate cellular interactions in marrow cell cultures that might regulate the size of megakaryocytes.

\section{ERYTHROPOIETIN}

Serum and urine levels of erythropoietin (EP) have been measured before and after therapeutic phlebotomies with and without mild perturbations of acid and base balance. Subjects were normal or had polycythemia or hemochromatosis. In many of the samples, EP was measured both by bioassay and by radioimmunoassay (RIA) (the latter by Dr.
Gisela Clemons). The results tend to show agree ment in the levels of EP determined by the two methods, which is of interest because the subjects had EP levels that were only modestly elevated above normal values. Agreement between the two assays had previously been shown for sera from severely anemic patients in whom EP levels were very high. These findings extend the range of concordance between biologically active EP and that which is detected immunologically.

In patients with severe anemia, levels of EP are increased in both their serum and their urine. However, the quantitative relationship between the concentration of EP in the blood and the amount excreted in the urine is not known. Our preliminary results in individuals subjected to phlebotomies suggest that the relationship may not be constant. Additional studies are underway to test this finding.

\section{MARROW TRANSFUSION INTO NORMAL AND SUBLETHALLY IRRADIATED ANIMALS}

\section{George Brecher}

During the past two years, we have used a strain of mice developed by H.S. Micklem of the University of Edinburgh to trace transfused marrow cells in isogeneic hosts. The new strain (CBA/PGK/A,B) carries two alloenzymes, A and B, of the $x$-linked enzyme phosphoglycerate kinase. Both male and female offspring can be bred with only one or the other of the enzymes. After transfusion of marrow from an $A$ into a $B$ animal (or vice versa), the percentage of donor enzyme in the recipient's blood or marrow can be determined electrophoretically and reflects the percentage of donor cells and their progeny proliferating in the host. The technique has two major advantages over the cytogenetic cell identification used earlier. The new methodology is much less time consuming and changes in the mature cells derived from the transplanted stem cells can be followed by repeated examination of the peripheral blood of the same animal. This is in contrast to the cytogenetic technique which identifies only the immature, still dividing cells. The procurement of the new strain and the establishment of a local colony was made possible by a Director's Grant in 1980 and the generosity of Dr. Micklem in providing the breeding stock.

We have shown earlier that bone marrow readily seeds and proliferates in normal mice, pro- vided large enough numbers of cells are transfused. Following transfusion of 50 million cells on each of 4 or 5 consecutive days, 20 to $40 \%$ of the host marrow are of donor origin. We had previously reported that lethally irradiated animals that recovered if given an initial bone marrow transfusion accepted a second transfusion more readily.

In an extension of this earlier work, we exposed mice to 300,600 , and $900 \mathrm{R}$, none of which caused any mortality. Two months later, when the peripheral blood counts had returned to normal, the irradiated mice and controls were given 100 million marrow cells. The percentage of donor cells in the mice that had been exposed to 600 or $900 \mathrm{R}$ reached $55-100 \%$, while controls averaged $24 \%$ and never exceeded $40 \%$ (Fig. 1). The 100 million cells transfused represent approximately $40 \%$ of the total number of marrow cells in the normal mouse. Thus, the donor cells could not have replaced $100 \%$ of the host's cells unless they proliferated more rapidly than the host cells. The implied competitive advantage of the donor cells is ascribed to a reduced capacity for self-renewal of the host's irradiated cells.

In recipients exposed to $300 R$ and in nonirradiated controls, female cells failed to grow in male recipients, while male cells grew as well as femal $\epsilon$ as in male hosts. The inhibition of growth of 


\section{PAGES 17 to 19 WERE INTENTIONALLY LEFT BLANK}




\section{SECTION 2. DONNER PAVILION}

\section{INTRODUCTION}

The Donner Pavilion has continued to develop a strong experimental program of stereotactic heavy-ion Bragg peak radiosurgery in the central nervous system combined with the application of heavy-ion beams to fundamental and applied brain research. Certain of the research activities are being carried out in collaboration with members of the Departments of Radiology and Neurological Surgery of the University of California San Francisco. The growth of the clinical research program has been considerable; over 50 radiosurgical patients from the United States and abroad have been studied and treated with charged particle beams at the 184-Inch Synchrocyclotron. Research activities have expanded into areas of interactive charged particle treatment planning for narrow beams and applications of nuclear magnetic resonance imaging of intracranial vascular disorders. The fundamental brain research program examines the effects of narrow heavy-ion beams on neural conduction, on cellular control mechanisms in the central nervous system, and on focal cell and tissue injury and repair of the mammalian brain. New programs include studies of nucleic acid metabolism, cell proliferation, and NMR imaging of temporal and morphological patterns of brain injury in the irradiated mammalian brain. The quantitative radiation epidemiology program continues to examine biophysical, mathematical, and health parameters of risk estimation of potential late radiation effects in the human brain.

\section{STEREOTACTIC HEAVY-ION BRAGG PEAK RADIOSURGERY}

Jacob I. Fabrikant, John T. Lyman, Yoshio Hosobuchi, Kenneth A. Frankel, Edward L. Alpen, Leal L. Kanstein, ${ }^{*}$ Frederick W. Yeater, ${ }^{*}$ Neela Manley, Britta Heise, Myrtle L. Foster, Cornelius T. Gaffey, Thomas S. Tenforde, Bent Kjos, ${ }^{\dagger}$ David Norman, ${ }^{\dagger}$ Catherine M. Miller, ${ }^{\dagger}$ David Feinberg, $^{\dagger}$ Carla Fulton, Ronald Harris, Kay H. Woodruff, and Maureen H. Morford

\section{CLINICAL RESEARCH STUDIES}

Fabrikant, Lyman, and Hosobuchi and the staffs of the Donner Pavilion and the 184-Inch Synchrocyclotron have worked together to develop a strong clinically-based experimental program of stereotactic helium-ion Bragg peak radiosurgery for inoperable and inaccessible intracranial arteriovenous malformations (AVMs) of the brain. Whenever possible, conventional surgical excision of the entire lesion remains the treatment of choice for AVMs of the brain and, in certain situations, intravascular embolization in conjunction with surgical excision may prove advantageous. When AVMs are inaccessible and conditions preclude surgery and/or embolization, stereotactic charged particle Bragg peak radiosurgery (alone, or in combination with partial surgical ligation and/or excision, and/or

*Accelerator and Fusion Research Division, Accelerator Operations Group, LBL.

${ }^{\dagger}$ Department of Radiology, University of California San Francisco. embolization of larger feeder vessels) appears to be a safe, reliable, and potentially effective alternative. It is presently used at the Donner Pavilion as the definitive form of treatment, either alone, or in combination with vascular ligation or embolization of accessible arterial feeders. It appears that early experience compels the conclusion that virtually all AVMs of the brain can be treated with stereotactic charged particle Bragg peak radiosurgery. Cerebral irradiation using stereotactically-directed heavy-ion Bragg peak radiosurgery is more advantageous than gamma beams or proton beams because of improved spatial definition and dose-distribution within the AVM target volume in the brain. Experience demonstrates that therapeutic failure results from irradiating some but not all of the multiple arterial feeder shunts of the AVM, or where only a part of the pathological cluster of vessels is irradiated. This has not occurred with our use of helium-ion Bragg peak beams and improved doselocalization and dose-distribution. Initial therapeu- 
tic results demonstrate that heavy-ion focal irradiation can induce hemodynamic changes and neurovascular obliteration of the AVM associated with reduction in size and in flow often leading to complete obliteration of the vascular abnormality (Fig. 1). Neurological changes with improvement have been observed within periods as short as three months; cerebral angiographic changes with decreased AVM size and flow have been observed within six months following irradiation. However, most changes require more than a year to develop and may extend over a one to two year period.

The stereotactic heavy-ion radiosurgical method can prove to be a highly selective one for treatment of surgically-inaccessible structures within the brain. Its advantages are that 1 ) it is a safe, noninvasive procedure without any blood loss, 2) patients under threat of hemorrhage from inoperable or inaccessible AVMs can be treated in cases where neurosurgery is unable to help, and 3) prc longed hospitalization is not required and all ou patients are treated on an ambulatory basis. The disadvantages of the method are that 1) radiographic evidence of change within AVM usually does not begin until after some six months and, frequently, obliteration requires 12 to 18 months or more, so that 2) patients are not protected and are under threat of hemorrhage for a long time, and 3) time-dose-volume-fractionation relationships for heavy-ion focal irradiation of brain and other CNS tissues are not fully understood. Experience with gamma beams and proton beams indicate that for large AVMs in functionally important brain regions, when large doses of radiation or large radiation fields have to be applied, there exists the danger of serious brain damage and neurological deficits. This has not occurred in our experience using stereotactically-directed narrow beams of helium-
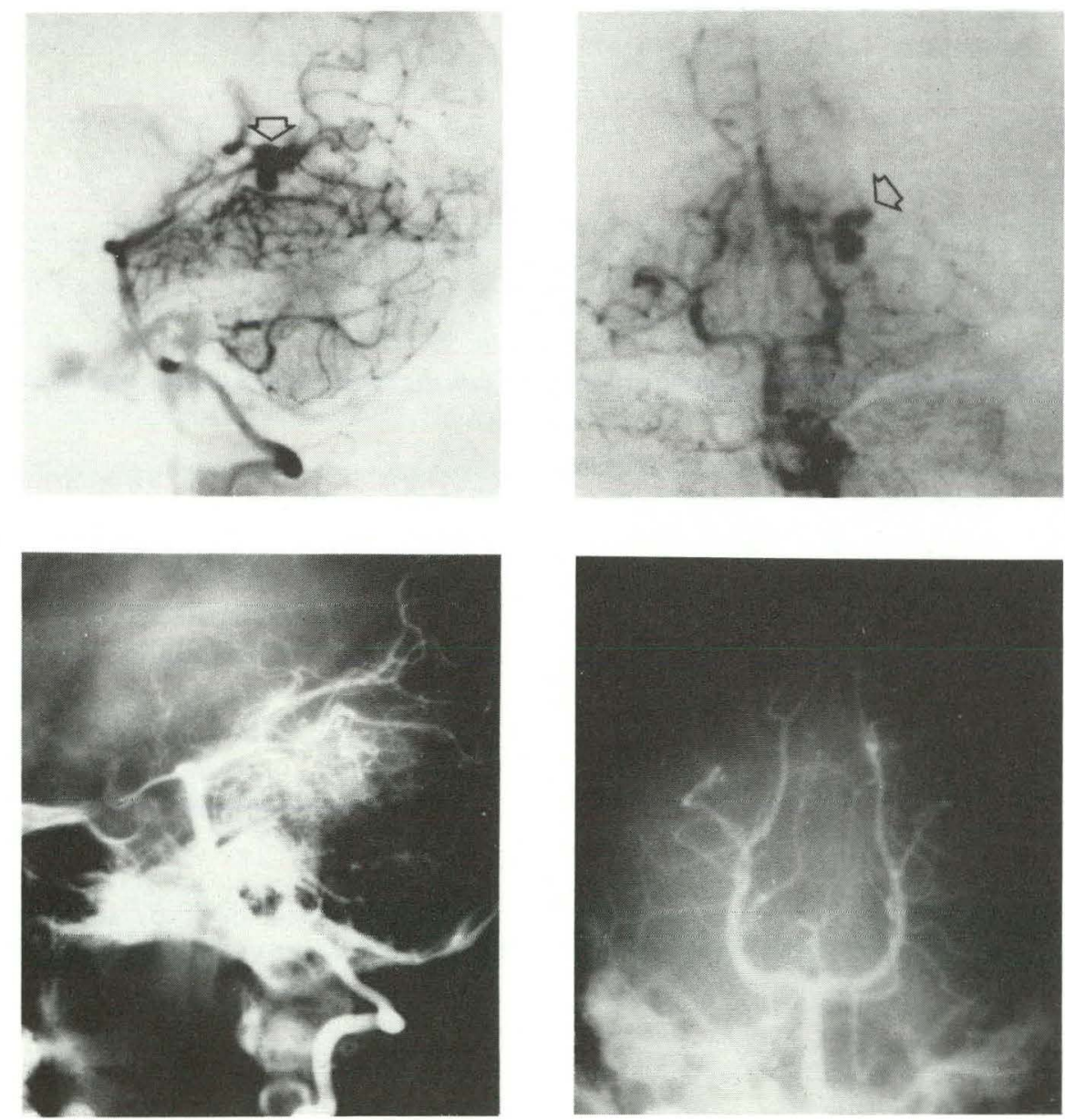

Fig. 1. Upper: Cerebral angiograms of inaccessible and inoperable brain AVM (arrow) in a 12-year old boy suffering from subarachnoid hemorrhage. The AVM was treated with a narrow 18-mm helium-ion beam (dose, 45 Gy equivalent) using stereotactic Bragg peak radiosurgery. Lower: Cerebral angiograms 9 months later demonstrating complete obliteration of the original AVM; the boy is in excellent health.

(XBB 830-10609A) 
ms. However, much research must be done - at ..ne tissue and animal levels and on heavy-ion beam quality and dosimetry establishing a firm scientific basis for LET/RBE relationships in the cells and tissues of the central nervous system - for this method of stereotactic heavy-ion Bragg peak radiosurgery to offer the possibility of complete recovery with no late sequelae in patients with deep-seated AVMs. The clinically applied research program is designed to introduce technical modifications and improvements of the stereotactic radiosurgical technique, including stereotactic neuroradiological studies for quantitating radiation changes in the brain, computer-based interactive treatment planning, heavy-ion beam-delivery, dose localization, and dose-distribution, to achieve a safe and reliable therapeutic procedure, to evaluate the long-term results in patients treated with helium-ion cerebral irradiation for AVMs of the brain and spinal cord, and to develop the method using carbon ions or possibly heavier ions at the Bevalac.

\section{CLINICAI DATA BASE}

Lyman, Fulton, Harris, Frankel, and Fabrikant are developing an expanded clinical data base for assessing treatment strategies and for improving follow-up records in all intracranial AVM patients treated with stereotactic helium-ion Bragg peak radiosurgery. The distribution of initial and subsequent neurologic symptoms in the first 49 of the 54 patients treated thus far, have been characterized (Table 1). The most frequent initial symptom is subarachnoid hemorrhage (SAH); almost all SAH patients experience moderate to severe headaches, which are frequently of intractable migraine type. These SAH patients frequently rebleed and may be at a high risk of death. rixed neurologic deficit is a common symptom associated with SAH. Progressive neurological deficit frequently accompanies severe headache. Patients initially presenting with seizure and/or progressive neurological deficit comprise the smallest group of those who have received cerebral irradiation.

All patients are treated with stereotactic radiosurgery, sometimes with pre-irradiation intraluminal embolization and/or surgical ligation, to prepare the AVM (Table 2). Half the patients are treated with radiosurgery only; in one-third, neurosurgical ligation of accessible feeder vessels was carried out prior to radiosurgery to reduce the size of the AVM. In only $10 \%$ of patients, intraluminal -mbolization was attempted to decrease the size nd flow in the AVM prior to radiosurgery. The - olume of the AVM lesions treated with radiosur-
Table 1. Initial and subsequent neurologic symptoms of 49 patients with intracranial arteriovenous malformations treated with stereotactic radiosurgery.

\begin{tabular}{|c|c|}
\hline Initial Symptoms & Number of Patients \\
\hline Hemorrhage & 23 \\
\hline No neurologic deficit & 4 \\
\hline Fixed neurologic deficit & 11 \\
\hline Hemorrhage only & 0 \\
\hline \multicolumn{2}{|l|}{ Followed by: } \\
\hline Seizure & 7 \\
\hline Progressive neurologic deficit & 8 \\
\hline Headache & 20 \\
\hline Other & 0 \\
\hline Headache & 17 \\
\hline No migraine & 8 \\
\hline Migraine & 9 \\
\hline Headache only & 3 \\
\hline \multicolumn{2}{|l|}{ Followed by: } \\
\hline Hemorrhage & 1 \\
\hline Seizure & 3 \\
\hline Progressive neurologic deficit & 8 \\
\hline Other & 0 \\
\hline Seizure & 3 \\
\hline Seizure only & 1 \\
\hline \multicolumn{2}{|l|}{ Followed by: } \\
\hline Hemorrhage & 0 \\
\hline Progressive neurologic deficit & 1 \\
\hline Headache & 1 \\
\hline Other & 0 \\
\hline Progressive Neurologic Deficit & 6 \\
\hline Progressive neurologic deficit only & 1 \\
\hline \multicolumn{2}{|l|}{ Followed by: } \\
\hline Hemorrhage & 0 \\
\hline Seizure & 4 \\
\hline Headache & 4 \\
\hline Other & 1 \\
\hline
\end{tabular}

gery varies widely among patients, but the majority of surgically inaccessible lesions irradiated are less than $2500 \mathrm{~mm}^{3}$.

\section{PHYSICS RESEARCH}

\section{Beam Quality}

Lyman, Kanstein, Yeater, Frankel, and Fabrikant have developed a new radiation beamline configuration for stereotactic helium-ion Bragg peak radiosurgery for cerebral irradiation with intracranial deep arteriovenous malformations using the 230$\mathrm{MeV} / \mathrm{u}$ helium-ion beam at the 184-Inch Synchrocyclotron. The narrow beam has been designed to have a variable depth of penetration between 4 and $14 \mathrm{~cm}$ (Fig. 2). This is obtained by first reducing the beam energy from $230 \mathrm{MeV} / \mathrm{u}$ to about $145 \mathrm{MeV} / \mathrm{u}$ by a combination of polyethylene and copper absorbers; this beam 
Table 2. Treatment strategies for stereotactic heavy-ion Bragg peak radiosurgery for intracranial arteriovenous malformations.

\begin{tabular}{|c|c|c|c|c|c|}
\hline AVM location & Total & $\begin{array}{l}\text { Stereotactic } \\
\text { radiosurgery }\end{array}$ & $\begin{array}{c}\text { SRS + } \\
\text { surgery }\end{array}$ & $\begin{array}{c}\text { SRS + } \\
\text { embolization }\end{array}$ & $\begin{array}{l}\text { SRS + surgery } \\
+ \text { embolization }\end{array}$ \\
\hline Basal ganglia & 5 & 3 & 2 & 0 & 0 \\
\hline Brain stem & 1 & 0 & 1 & 0 & 0 \\
\hline Carotid-cavernous fistula & 3 & 3 & 0 & 0 & 0 \\
\hline Cerebellum & 9 & 5 & 2 & 2 & 0 \\
\hline Cervical spinal cord & 1 & 0 & 1 & 0 & 0 \\
\hline Frontal & 5 & 2 & 2 & 1 & 0 \\
\hline Hypothalamus & 1 & 0 & 1 & 0 & 0 \\
\hline Occipital & 2 & 2 & 0 & 0 & 0 \\
\hline Paraventricular & 14 & 7 & 4 & 1 & 2 \\
\hline Parietal & 5 & 0 & 3 & 1 & 1 \\
\hline Temporal & 1 & 0 & 0 . & 0 & 1 \\
\hline Thalamus & 4 & 4 & 0 & 0 & 0 \\
\hline
\end{tabular}

energy and the appropriate absorber configuration permits penetration of any intracranial target. The modulation of the stopping region of the beam is controlled by a rotating variable thickness acrylic

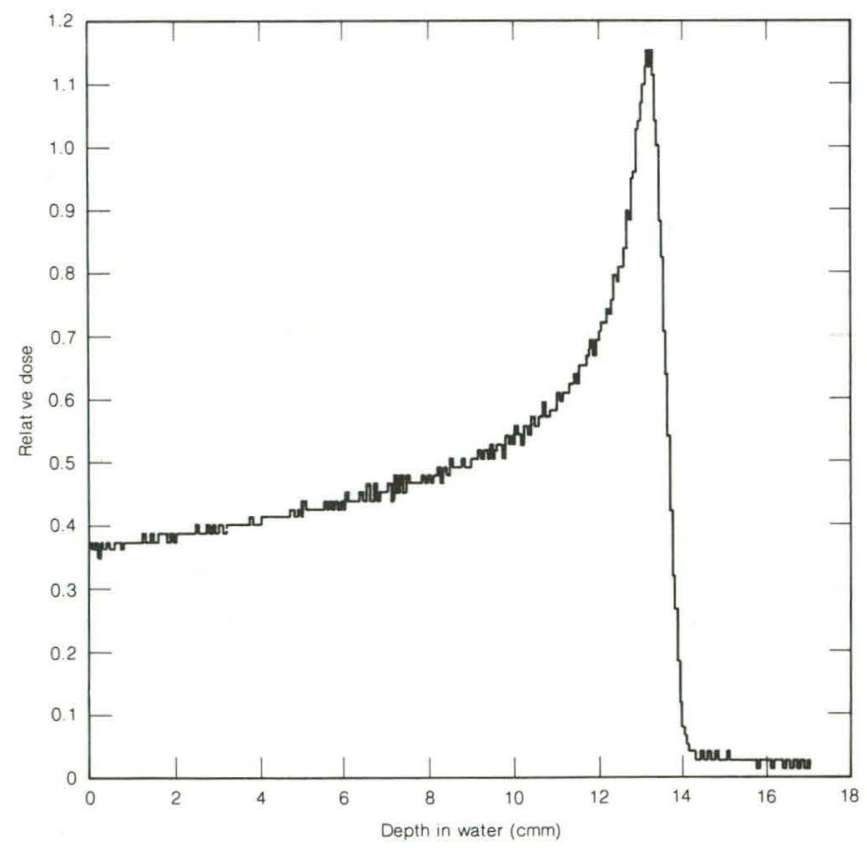

Fig. 2. Depth-dose measurements of the $230-\mathrm{MeV} / \mathrm{u}$ heliumion beam at the 184-Inch Synchrocyclotron using a parallel plate ionization chamber. The maximum range to the Bragg peak is $14.7 \mathrm{~cm}$ in water. absorber located upstream of the beam degraders. The penumbra of the narrow beam is kept extremely small to maintain a sharp lateral edge; this is done by placing all the beam energy degrading material about $3.6 \mathrm{~m}$ upstream from the final beam collimator. The beam striking the degrader is about $3 \mathrm{~cm}$ by $4 \mathrm{~cm}$ (FWHM); after the degrading material the beam is collimated by a $2.2 \mathrm{~cm}$ diameter collimator. With this configuration, a dose rate of approximately $8 \mathrm{~Gy} / \mathrm{min}$ is achieved. The beam current is monitored by ionization chambers upstream of the beam modulator and degrader and behind an intermediate collimator, and measurements of the depth-dose relations at the center of the ISAH patient positioner have been completed.

\section{Radiosurgical Treatment Planning}

Lyman, Frankel, and Fabrikant are developing techniques for improving radiosurgical methods of patients with CNS vascular disorders based on optimal dose-delivery and dose-distribution. The stereotactic head-immobilization system permits precise transfer of three-dimensional localization data from the stereotactic computerized tomographic and cerebral angiographic images to the treatment planning codes for determining bear delivery of the helium-ion Bragg-peak radiosurger strategies. The patient's head is immobilized in a 
stereotactic apparatus designed for stereotactic iadiodiagnostic and radiosurgical procedures that transfer stereotactic imaging for defining the size, shape, and position of the AVM, to the CT image, for determining heavy-ion beam range and direction (Fig. 3). The system is designed to minimize the introduction of computerized tomographic artifacts diIl restrictions on possible beam entry portals. Treatment-volume target-shaping techniques are being improved hy development of the system of data transfer for the spatial distribution of the vascular abnuminalıty, and treatment-planning dose calculations provide accurate isodensity information of the dose-distribution within the brain in relation to the target contour and adjacent critical brain structures. Many patients have irregularly-shaped AVM lesions, which require the construction of complex collimators and compensators that conform the beam and its range to the shape of the abnormality. A radiosurgical treatment plan for the dosedistribution of the helium-ion beam derived from stereotactic neurodiagnostic imaging data is illustrated in Fig. 4. A radiation dose of $45 \mathrm{~Gy}$ equivalent is delivered through multiple ports in 1-3 daily fractions; the $90 \%$ isodensity contour closely follows the treatment volume, and the amount of irradiated brain receiving less than 10\% of the dose is small. In the future, heavier-ion beams (carbon, neon, and/or silicon) at the Bevalac will be used for stereotactic radiosurgery. These beams provide improved dose distributions, due to the sharper Bragg peak and decreased straggling, that more than offset effects of fragmentation.

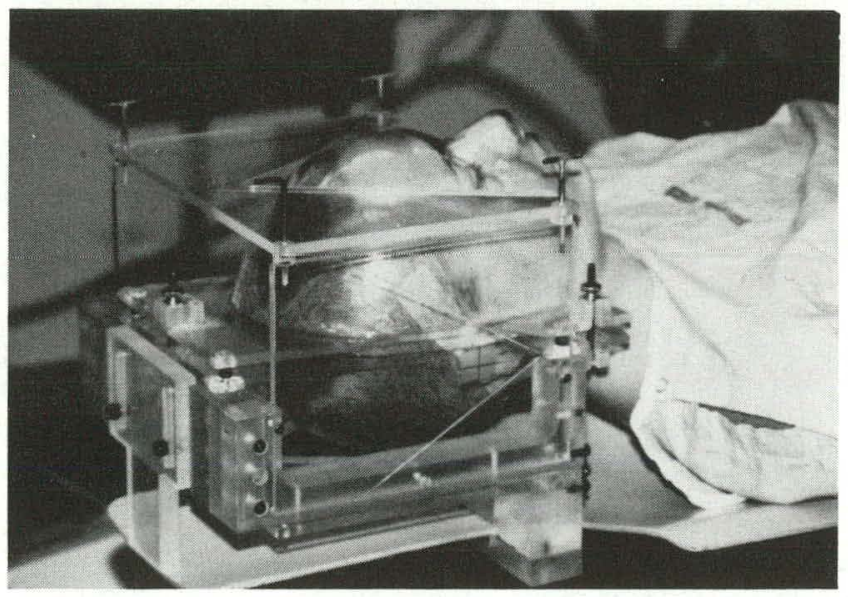

Fig. 3. Stereotactic radiosurgical frame and immobilizing mask ystem designed for stereotactic neurodiagnostic imaging and adiosurgical treatment with narrow heavy-ion Bragg peak veams.

(CBB 836-5261)

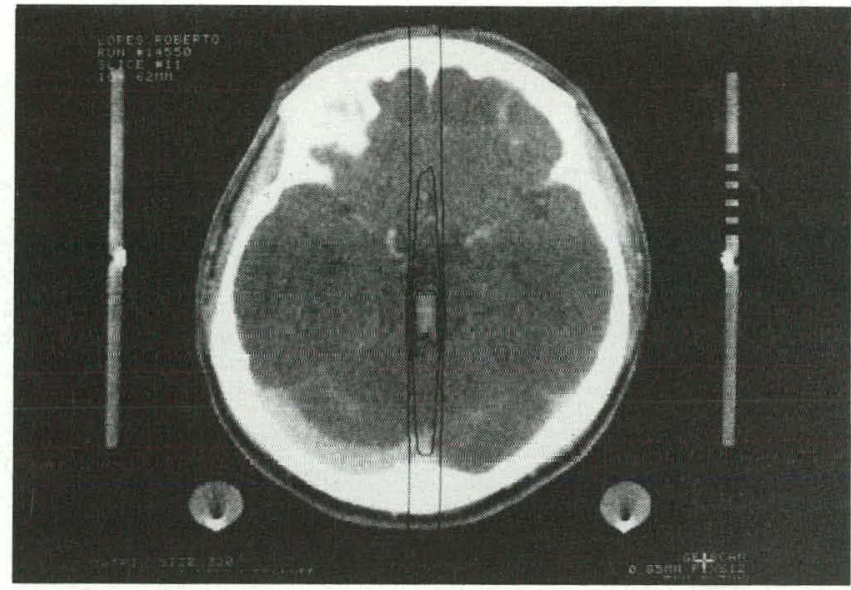

Fig. 4. Isoeffect radiosurgical helium-ion treatment plan for an intracranial brain stem arteriovenous malformation.

(CBB 835-4438)

\section{NMR IMAGING}

\section{Human Studies}

Frankel, Lyman, Mills, Feinberg, Fabrikant, and Norman have begun to utilize nuclear magnetic resonance brain imaging of radiosurgical patients with AVMs for neurodiagnosis, treatment planning, and long-term post-irradiation follow-up. NMR imaging is proving to be a useful method for stereotactic localization of AVMs; blood flowing rapidly through abnormal vessels can be imaged rapidly and identified (Fig. 5). Stereotactic NMR imaging has the potential of replacing certain $x$-ray procedures for stereotactic radiosurgical treatment planning. The region of arterial blood shunting through the AVM is of critical importance and is the target for the charged particle beams; presently, these arterial feeders are defined by digital subtraction cerebral arteriography, which delineates the flow of iodinated contrast material into the AVM. NMR imaging is sensitive to both arterial and venous flow and comparisons are presently being made to assess size and location of treatment volumes derived from NMR imaging and from cerebral angiography. Development of gated subtraction NMR imaging, in which the imaging sequence is gated by the heartbeat and timed at intervals of maximum and minimum arterial flow, is also in progress. NMR imaging of AVM changes provides a potentially useful technique for the follow-up of stereotactic radiosurgical patients, both to monitor the change in size and the rate of blood flow through the AVM and, also, to demonstrate radiation effects in brain tissue, if any do occur, such as perturbation of myelination processes. 


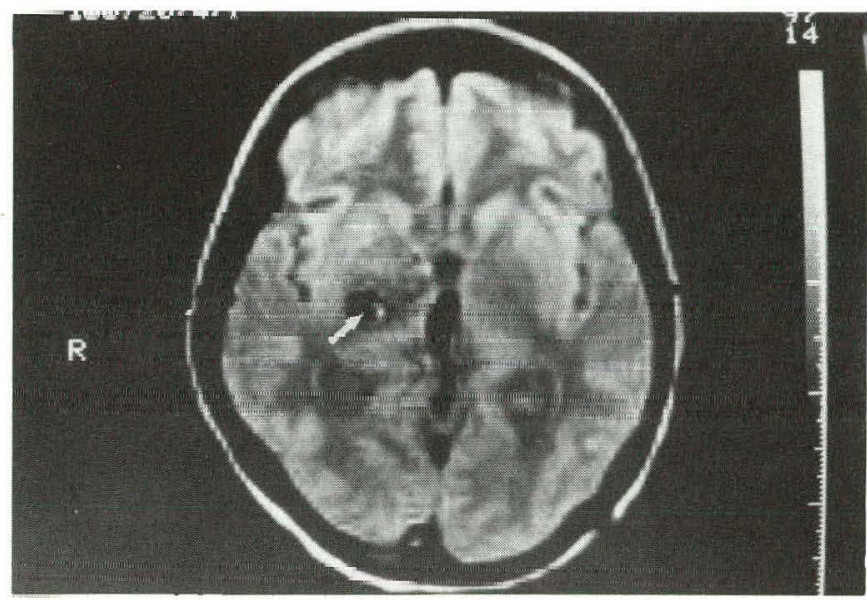

Fig. 5. Axial NMR image of AVM (arrow) in brain of a patient treated with stereotactic helium-ion Bragg peak radiosurgery at the 184-Inch Synchrocyclotron. The patient was imaged at the University of California San Francisco Radiologic Imaging Laboratory (Professor A.R. Margulis and Professor L. Kaufman) by a spin echo technique. The bright regions in the AVM indicate "slow blood flow," i.e., the blood does not flow out of this section of the brain during the imaging interval; these observations are presently being quantified. There is no evidence of radiation injury to the surrounding brain, e.g., edema, demyelination, or necrosis, as a result of radiosurgical treatment to a dose of 45 Gy equivalent.

(XBB 8310-9299)

\section{Animal Studies}

Frankel, Lyman, Kjos, Fabrikant, and Norman are currently developing methods of NMR imaging of the mammalian brain irradiated by stereotactically-directed narrow beams of heavy charged particles in order to gain a better understanding of the temporal patterns of CNS tissue responses and associated radiation effects, and to develop more effective methods for stereotactic heavy-ion Bragg peak radiosurgery of human brain disorders. NMR imaging is utilized as a quantitative method to examine pathophysiological alterations following charged particle cerebral irradiation in the rat in relation to correlation of dose-, volume-, and time-dependency for the induction of central nervous system (CNR) damage, with known differences in RBE, correlation of CNS effects of damage and repair as a function of fractionation of dose and use of different charged particles, correlation of sites and nature of tissue injury with functional neuropathophysiological alterations, and assessment of anatomical changes to estimate tolerance for normal CNS tissues for protection during stereotactic radiosurgery of intracranial disorders. Initial studies demonstrate that sufficient resolution can be achieved to examine differential response in a number of critical CNS structures, including the cerebral cortex, thalamus, midbrain, brain stem, and cerebelluniı, dind llıal il will be jüssible to correla changes in NMR images with observed pathophysiological alterations. The brain of the living rat irradiated with narrow beams of helium ions demonstrates early changes that are dose- and time-dependent (Fig. 6). With optimal pulse sequences and resnlution, it may be possible to identify vascular effects, edemá, reversible and irreversible brain damage, and demyelination and remylination proncesars.

\section{DNA METABOLISM AND CELL PROLIFERATION}

Fabrikant, Manley, Heise, and Foster are examining cellular response and cell population kinetics in the mammalian brain and the response to heavy-ion irradiation with narrow beams. Studies are in progress in which a radioactively-labeled specific precursor of DNA and RNA is administered to animals to tag newly forming brain cells, which are rendered visible and their fate traced in situ with high resolution autoradiography. Emphasis is placed on DNA metabolism and cell proliferation in the young mature rodent brain under normal and irradiated conditions.

Initial studies with thymidine- ${ }^{3} \mathrm{H}$ autoradiography confirmed earlier observations that the subependymal layer of the lateral ventricle is a site of active oligodendrocyte cell proliferation in the brains of young adult mammals (Fig. 7, upper). There is limited regional cell proliferation in the cerebral cortex in the young mouse, and the migration of labeled granule cells from the subependymal matrix of the lateral ventricle, by way of the

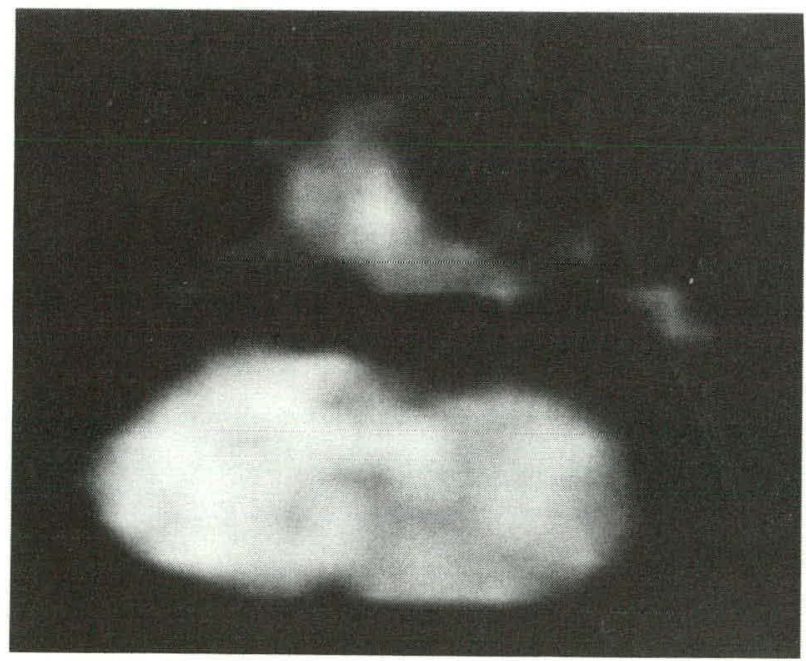

Fig. 6. Axial NMR image of rat brain; one hemisphere wac irradiated with a narrow helium-ion beam $(230 \mathrm{MeV} / \mathrm{u})$ to dose of $45 \mathrm{~Gy}$ equivalent. A difference in relaxation time noted between the two halves of the brain. (XBB 830-9813) 

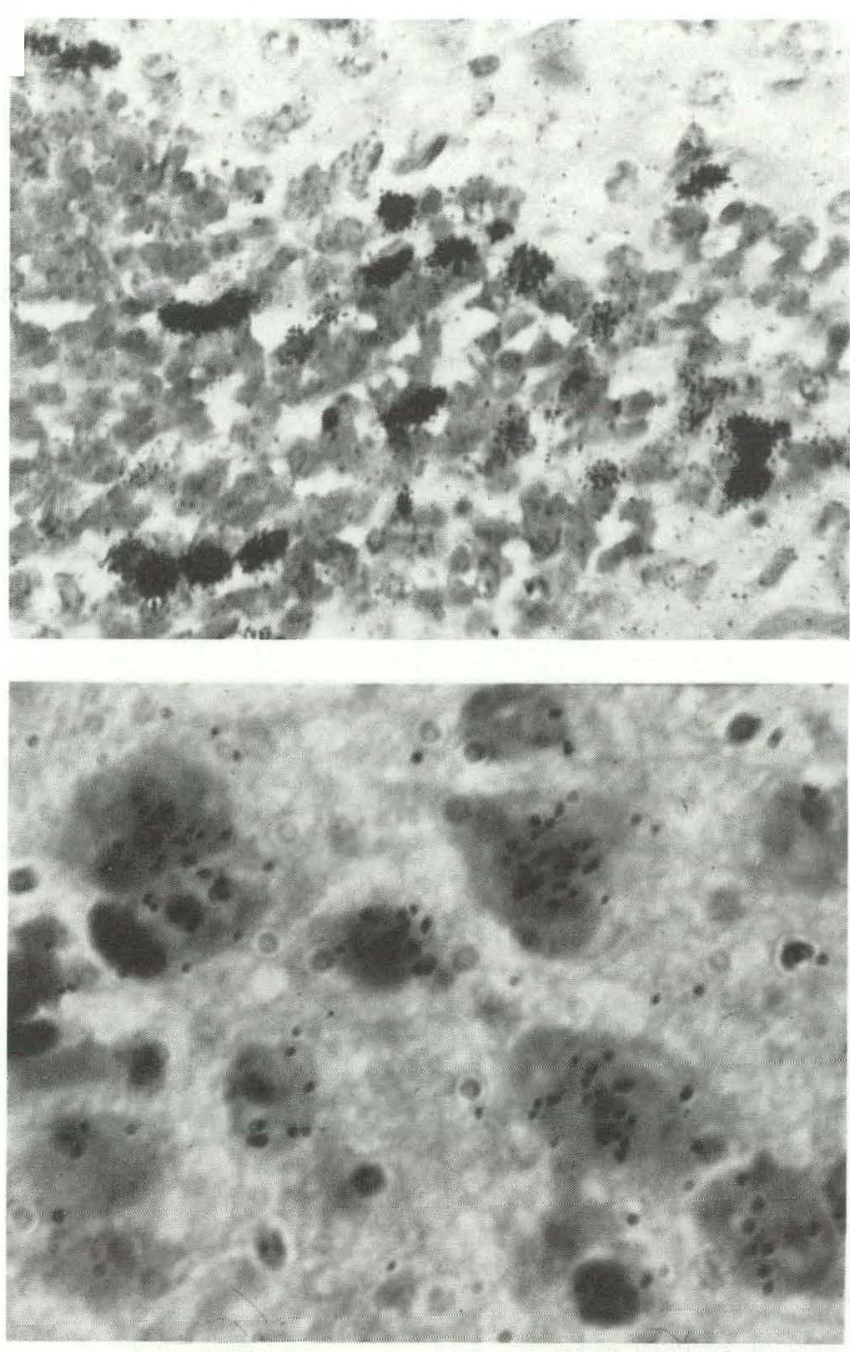

Fig. 7. Upper: High-resolution autoradiograph of the subependymal layer of the lateral ventricle of the brain in four week old mice injected with thymidine- ${ }^{3} \mathrm{H}$. Numerous labeled nuclei are readily identified. Lower: Synthesis of nuclear RNA demonstrated by high-resolution autoradiography taking place in mature nerve cells (Purkinje cclls of the cerebellum in the young adult mouse brain; the animal was killed 3 hours following injection of uridine ${ }^{3} \mathrm{H}$ ).

(XBB 831-9661A)

cerebral white matter, to the cortex has now been demonstrated. Of particular interest is the fact that granule cell proliferation is maintained for the longest period in the young adult mouse in the anterior part of the lateral ventricle, where a mitntir subependymal layer is present that is characterized by a high rate of cell production. Numerous labeled pyknotic subepidymal cells indicate that proliferation of these cells is accompanied by cell loss. Thymidine labeling indices reach 19\%, 1 hour after injection, and as high as 30\%, 24 hours following pulse labeling, consistent with a cell cycle time of approximately 20 hours and a DNA synthesis time of approximately 10 hours.
Evidence exists that some neuroglia, endothelial cells, and cells of the subependymal layer continue to proliferate throughout adult life. For these quite different cell types, the cell cycle parameters and mode of proliferation (i.e., proliferation with cell loss and permanent exchange of cells between growth fraction and nongrowth fraction) appear to be similar. This suggests that there may be common pathways of regulatory mechanisms of cell proliferation in the brain of the adult animal. Furthermore, the cell cycle parameters are consistent and surprisingly short.

In initial irradiation studies, narrow 2-mm helium-ion beams were used; doses of 10 to $30 \mathrm{~Gy}$ equivalent depressed the 1 -hour thymidine- ${ }^{3} \mathrm{H}$ labeling indices to $7.5-14 \%$, and the decrease was dose-dependent 48 hours after exposure. This suggests that the charged particle beams at dose levels used clinically for stereotactic radiosurgery affects proliferative sites in the mammalian brain, such as the subependymal layer of the cerebral ventricles, by depressing DNA metabolism and cell proliferation in rapidly renewing brain cell populations.

The synthesis, transport, and fate of RNA is being examined by autoradiography in nerve and glial cells. After administration of the labeled precursor of RNA (uridine- ${ }^{3} \mathrm{H}$ ) Purkinje cells in the cerebellum show rapid incorporation of the label into RNA of the chromatin and nucleolus at early intervals (30 minutes), and became intensely limited to the nucleus by 2 hours (Fig. 7, lower).

These autoradiographic studies provide reliable nuclear tracer methods that allow the detection and the location of radioactive atoms in biological structures of the mammalian brain. Autoradiographs obtained at various intervals after administration of labeled DNA and RNA precursors make it possible to trace the incorporation and migration of the metabolic label through the various regions of the brain, and thereby permits study of the cellular response and cell population kinetics in the mammalian brain, to narrow beams of heavy charged particles, and the metabolic events of the cell cycle under normal and irradiated conditions.

\section{NEUROPHYSIOLOGY RESEARCH}

Nerve impulses are transmitted with very little variation in either amplitude or shape; this high fidelity impulse is a code element, like the "YES" $(+)$ of a computer. In a peripheral nerve trunk a large multiplicity of parallel fibers transmits detailed information in a brief interval of time. It is of radiobiological interest, and of practical concern for radiosurgery and radiological protection, to deter- 
mine the minimum dose of radiation necessary to inhibit neural transmission. Gaffey and Tenforde are carrying out electroneurophysiological studies in the isolated frog nerve and have found that the neural signal could be made nonconducting after absorbing $280 \mathrm{krad}$ of $200-\mathrm{kV} \times$ rays. When 250 krad of $x$ rays were absorbed, impulse conduction failed 2.2 hours post irradiation; at doses of 200, 150 , and $100 \mathrm{krad}$, neural activity stopped at 6.5, 12.25 , and 20.50 hours, respectively (Fig. 8 ). These findings suggest that the damaging action of radiation is stored in the neural membrane. Experiments are planned to determine the relationship between the post-irradiation time for the loss if impulse conduction and the radiation duses of less than 100 krad. In acute studies, $280 \mathrm{krad}$ of $200-\mathrm{kV}$ x ra immediately inhibited neural signals in frog nerves; for this same biological effect, a different dose of cobalt-60 gamma rays was required. Thus, equal doses of different types of ionizing radiation do not produce equal physiological effects, indicating different LET/RBE relationships. Gaffey and Tenforde have now demonstrated that neural impulses can be recorded as potential differences during the time the isolated nerve preparation is being irradiated with a beam of $670-\mathrm{MeV}$ neon ions. Therefore, the relative biological effectiveness will be determined for the neural response of frog nerve exposed to narrow beams of heavy ions at the Bevalac.

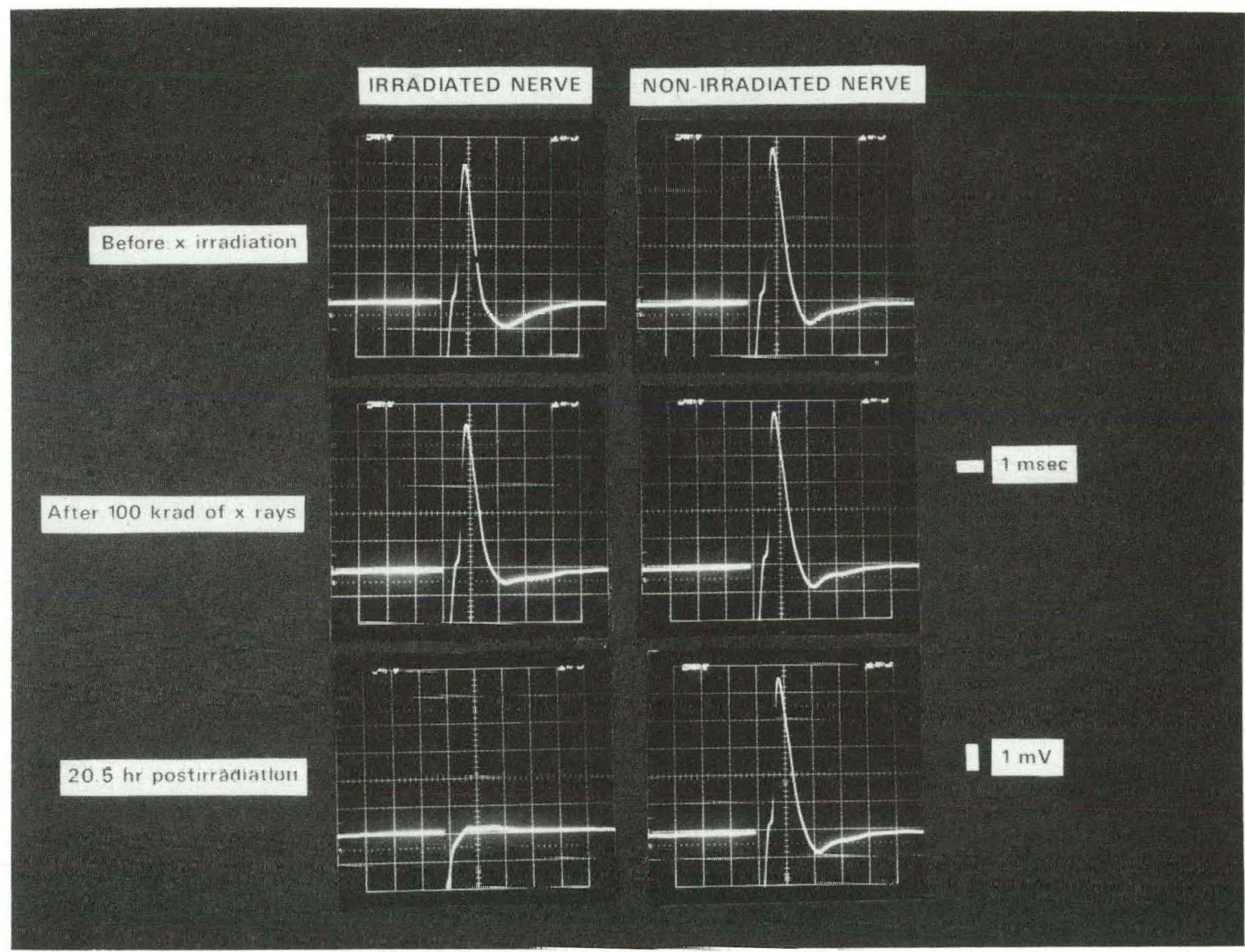

Fig. 8. Pre-irradiation and post-irradiation transmission of neural impulses exposed to high doses of low-LET radiation; oscillograms of action potentials of x-irradiated isolated sciatic nerve of the frog. One sciatic nerve was exposed to x-irradiation (left column); the other sciatic nerve served as an unirradiated control (right column). An electric shock delivered to each nerve initiated a maximal action potential, whose amplitudes, prior to irradiation, were $25.0 \mathrm{mV}$ (treated) and $28.0 \mathrm{mV}$ (control). When the treated nerve absorbed $100 \mathrm{krad}$ of $\times$ rays, the action potential amplitude was enhanced to $26.5 \mathrm{mV}$ and its duration was broadened slightly; the control nerve remained stable. The irradiated nerve failed to generate a neural impulse at 20.5 hours post irradiation, while a full action potential could be obtained from the control nerve.

XBB 830-9812) 


\section{SECTION 3. ENVIRONMENTAL PHYSIOLOGY}

\section{INTRODUCTION}

During the past decade research programs in the Environmental Physiology Group have been focused on the study of the interactions of nuclear and nonnuclear pollutants with living systems. The initial research in this area was necessarily of a survey nature in order to identify the tissue and organ systems that were potentially responsive to various pollutants at concentrations encountered in the environment. More recent studies have been directed toward determining the specific loci of pollutant interactions with target tissues in an effort to provide a mechanistic understanding of the damage caused by these agents. These investigations, in turn, are now leading toward an increased emphasis on studies of the basic mechanisms underlying normal cellular and tissue development, differentiation, and regulation. The progressive transition that is being made from an applied to a fundamental research orientation is evident in many of the annual progress reports presented here for programs of the Group.

An area of major programmatic emphasis is the study of erythropoietin biogenesis and the regulation of hematopoiesis. Although it has been accepted for many years that the kidney plays a major role in the production of erythropoietin in adult animals, the source of this hormone in prenatal and neonatal animals has not been carefully analyzed. The recent purification of erythropoietin has now permitted the development of a highly sensitive radioimmunoassay procedure llial is capable of delecling the small quantities of this hormone that are present in the blood and organs of developing fetuses and newborn animals. By using this technique, it has been demonstrated that the liver is the sole source of fetal erythropoietin beginning on approximately the fifteenth day of gestation, and that detectable levels of this hormone do not appear in the kidney until the nineteenth day of gestation. By the sixth day of postnatal life, the erythropoietin content of liver and kidney tissues are comparable. Beyond this stage of neonatal development, the kidney becomes the organ primarily responsible for an increased production of erythropoietin in response to hypoxic stress. These results offer promise for the use of erythropoietin radioimmunoassays to liagnose the possible presence of hypoxemia in ceraain types of high risk pregnancies.
In other research on erythropoietin, the in vitro production of significant quantities of this hormone by cloned lines of erythroleukemic cells has been verified by several independent biochemical and biological assay procedures. The production of erythropoietin in serum-free medium by one of these cell lines offers new possibilities for the rapid purification and sequencing of this glycoprotein hormone, and for its in vitro translation using purified messenger RNA isolated from the erythroleukemic cells.

Endocrine interactions with lung tissue, and hormonal changes in response to ozone exposure, are also being investigated. Previous research in this area demonstrated the existence of androgen receptors in the adult mouse lung, and a decrease in the content of these receptors was observed in response to chronic ozone inhalation. Recent investigations have also shown the existence of estrogen receptors in the lungs of male mice, and the tissue content and binding affinities of the receptors have been quantitated by Scatchard analysis. Competitive inhibitor studies have been used to demonstrate the specificity of estradiol receptors in the mouse lung.

An in vitro cell culture technique is being refined for the detection and enumeration of thymic lymphocyte progenitors produced in the bone marrow of experimental animals. Evidence has previously been obtained that the development of pre-T lymphocytes is promoted in culture medium that has been "conditioned" by the prior growth of spleen cells in the presence of pokeweed mitogen, a plant lectin. Several stimulatory proteins known as interleukins are present in conditioned medium, and tests have now been made to assess the influence of these factors in the development of various classes of marrow stem cells. Of the three purified interleukins examined to date, the glycoprotein designated II-3 has been found to be highly effective in promoting the growth of BFU-E (burst forming unit erythroid), CFU-S (colony forming unit - spleen) and CFU-C (colony forming unit - culture, a precursor of the granulocyte/monocyte/macrophage line). The other two interleukins tested for stimulatory activity were either less effective than $11-3$, or were completely ineffective in promoting the growth of various marrow stem cell lines. These results suggest that II-3, which previously has been reported to 
promote the growth of thymic lymphocyte progenitors, may act either on an earlier uncommitted precursor or, alternatively, on many different precursors within the bone marrow.

The study of nonionizing and ionizing radiation interactions with living systems is a research area that is receiving increased emphasis within the Environmental Physiology Group. One large program involves the study of magnetic field bioeffects, which has become an important issue in recent years as a consequence of the development of several new energy-related and medical technologies that use intense magnetic fields. Although research with experimental animals exposed to extremely high fields has revealed no irreversible perturbations of critical physiological functions, the electrical properties of the retina and the central circulatory system are altered in the presence of magnetic fields. Current research is focused on elucidating the mechanisms underlying these magneticallyinduced changes in tissue electrical properties.

Another area of radiation research involves the study of actinide element distribution and retention in primates. Recent investigations on the body distribution of ${ }^{238} \mathrm{Pu}$ over periods from 7 to 1100 days post-injection have yielded new data on the eat deposition of this isotope in various tissues, ariu have shown that its localization on the surfaces of cancellous bone is approximately six times greater than on compact bone. The results of this study indicate that plutonium metabolic and dosimetric parameters recently adopted by the International Commission on Radiological Protection may be overly conservative. In other plutonium research using mice as experimental subjects, a comparison has been made of the efficiencies of various chelating agents in facilitating the removal of ${ }^{238} \mathrm{Pu}$ from the skeleton, liver and whole body. The relatively new polycatechoylamine ligands were shown to have a significantly higher efficiency for ${ }^{238} \mathrm{Pu}$ removal than the chelating agents DPTA and desferrioxamine, which are currently in use. This finding supports the view that metal-chelate stability is a major determinant of the in vivo efficiency of a given ligand for plutonium removal. The several ligands tested were also found to have differing efficiencies for removing plutonium from the liver and skeleton, and experiments were conducted to determine the efficiency of various combinations of ligands for facilitating overall plutonium removal from the body.

\section{FETAL AND NEONATAL ERYTHROPOIETIN STUDIES IN RATS}

\section{Gisela K. Clemons and Joseph F. Garcia*}

The production of red blood cells in the normal animal is subject to a control which responds positively when confronted by a reduction in circulating red-blood-cell concentration, or, more fundamentally, by a deficiency in the delivery of oxygen to the tissue. Also, red-blood-cell production is negatively affected in the face of excessive numbers of circulating red blood cells or an overabundant delivery of oxygen, relative to the oxygen requirements of the tissues. The result of these controls is to maintain a degree of constancy in the total mass of circulating red cells.

It is now generally accepted that the hormone erythropoietin (Ep) exerts its controlling influence on erythropoiesis primarily by directing the differentiation of a multipotential stem cell into erythroid precursors. The most convincing evidence supports the kidney as the source for this hormone. The ability to accurately measure the concentration of this

*Joseph Garcia died September 20, 1982. important hormone in circulating blood will add significantly to our understanding of the nature of its control over the production of red blood cells.

The purification of human Ep has allowed us to develop a specific, highly sensitive and reliable radioimmunoassay (RIA) for Ep that not only measures human Ep, but is also capable of measuring Ep concentrations in a variety of animal species, both in fluids and tissues. This suggests that portions of the Ep molecule in all these species may be similar. However, there must also be molecular differences because the affinity of this particular antiserum differs for rat, mouse and sheep $\mathrm{Ep}$ from that for human Ep and among these species. Because of this phenomenon the absolute quantification of nonhuman Ep's required well-titered animal $\mathrm{Ep}^{\prime} \mathrm{s}$ for use in the development of the standard curves. We have prepared such standards for rat and mouse Ep using serum from male animals exposed to hypoxi equivalent to $22,000 \mathrm{ft}$ of high altitude. The shee standard is the commercially available Connaughı 
tep III fraction. These preparations were bioassayed and standardized against the 2 nd International Reference Preparation (IRP) using the in vivo polycythemic mouse assay.

Our measurements of immunoreactive Ep concentrations in tissues derived from hypoxic rats and mice have confirmed that the kidney is the primary Ep-producing tissue in adult animals. The liver has been implicated as a source of extrarenal Ep in the adult and in weanling rats. It appears from our studies that in the presence of normally functioning renal tissue the Ep synthesis in the liver cannot be documented in the unmanipulated hypoxic rat or mouse. Erythropoiesis in the fetus is also under control of Ep. It has been postulated that the source for this Ep is the liver, in both the fetus and the neonatal animal.

We have utilized the sensitivity of the RIA to measure fetal- and neonatal-rat plasma and tissue Ep concentrations and their possible alteration by maternal and neonatal exposure to hypoxia. Timed pregnant rats were exposed to hypoxia $(18,000 \mathrm{ft}$ for 18 hours) as early as day 14 of pregnancy. Eight rats were used for each remaining day of pregnancy, four for hypoxia and four for control. Fetal plasma, liver, and kidney tissues were collected as early as possible and pooled for each mother. The tissues were homogenized in an equal volume of buffer $(w / v)$, and the Ep determinations were carried out in duplicate. Liver tissue was collected from day 15, plasma from day 17 and kidney tissue from day 19 of gestation. Neonatal animals were exposed to the same hypoxic conditions and killed on day 2, 4, 6, 8 and 10 days, with an additional control group at 14 days of life. The Ep con- centration was determined in whole pups on day 15 and in pups minus tissue through day 19 of gestation when all three tissues, plasma, liver and kidney had been removed. In addition, the plasma of the pregnant mothers was analyzed. The plasma and tissue concentrations are presented in Table 1. All fetal plasma, liver and kidney concentrations of immunoreactive $\mathrm{Ep}$ measured were below 50 $\mathrm{mU} / \mathrm{ml}$ or $50 \mathrm{mU} / \mathrm{g}$ of tissue, as were the values for the three parameters in the control neonatal animals. Fetal liver tissue did not seem to respond to maternal hypoxia on day 15 of gestation. This observation is also supported by the Ep concentration in the whole pups on day 14 and the pups minus liver on day 15 . In neither case was there any difference measured, and the observed decrease in Ep concentration in the pups is thereafter largely accounted for by the removal of blood, kidney, and liver tissue. The significant difference on day 19 is most likely due to residual blood in the pups of mothers exposed to hypoxia. From day 16 to term, the fetal liver Ep concentrations were generally twice that of control fetal liver tissue. Fetal kidney tissue did not respond to maternal hypoxia on day 19 of gestation, while on day 20 and 21 the fetal kidney responded with a significant threefold increase in Ep concentration, which was also reflected in elevated plasma levels on day 21.

Maternal-plasma Ep levels increased approximately tenfold during hypoxic exposure, which is the same order of magnitude observed in normal female rats, but significantly less than measured in adult male rats. The levels of immuno-reactive Ep in the amniotic fluid (AF) are relatively high on day

Table 1. Erythropoietin concentrations in fetal and neonatal rats and the effects of maternal and neonatal exposure to hypoxia (HA).

\begin{tabular}{|c|c|c|c|c|c|c|c|c|c|c|c|c|c|c|}
\hline \multirow{2}{*}{$\begin{array}{c}\text { Fetal Age } \\
\text { (days) }\end{array}$} & \multirow[b]{2}{*}{$n$} & \multirow{2}{*}{$\begin{array}{l}\text { pups/ } \\
\text { pool }\end{array}$} & \multicolumn{2}{|c|}{$\begin{array}{l}\text { PLASMA } \\
\text { (mU/m) }\end{array}$} & \multicolumn{2}{|c|}{$\begin{array}{l}\text { LIVER } \\
(\mathrm{mU} / \mathrm{g})\end{array}$} & \multicolumn{2}{|c|}{$\begin{array}{l}\text { KIDNEY } \\
(\mathrm{mU} / \mathrm{g})\end{array}$} & \multicolumn{2}{|c|}{$\begin{array}{l}\text { PUPS } \\
\text { (mU/g) }\end{array}$} & \multicolumn{2}{|c|}{$\begin{array}{c}\text { AMNIOTIC FLUID } \\
(\mathrm{mU} / \mathrm{ml})\end{array}$} & \multicolumn{2}{|c|}{$\begin{array}{l}\text { MATERNAL PLASMA } \\
(\mathrm{mU} / \mathrm{ml})\end{array}$} \\
\hline & & & Control & HA & Control & HA & Controd & HA & Control & HA & Control & HA & Control & HA \\
\hline 14 & 4 & $8-11$ & - & - & - & - & - & - & $80.2=65$ & $784 \pm$ b & $992 \pm 30$ & $874=95$ & $203=16$ & $322 \pm 54$ \\
\hline 15 & 4 & $9-12$ & - & - & $14.4 \pm 1.5$ & $135 \pm 08$ & - & - & $617 \pm 2.1$ & $682 \pm 64^{c)}$ & $1010=32$ & $1091 \div 55$ & $201 \pm 18$ & $476 \pm 71$ \\
\hline 16 & 4 & $8-12$ & - & - & $13.4 \pm 0.9$ & $20.3 \pm 37$ & - & - & $45.9 \pm 1.6$ & $538=32^{c)}$ & $908 \pm 106$ & $921=57$ & $317=35$ & $446 \pm 59$ \\
\hline 17 & 4 & $8-13$ & $32.6 \pm 4.0^{8)}$ & $72.5 \quad$ (1) & $16.5 \pm 1.7$ & $30.6 \pm 3.3$ & - & - & $27.9=1.1$ & $376 \pm 2$, d) & $709 \pm 24$ & $840 \pm 34$ & $25.2 \pm 53$ & $336 \pm 13$ \\
\hline 18 & 4 & $8-11$ & $28.0 \pm 2.1$ & $56.1 \pm 4.5$ & $11.8 \pm 1.3$ & $37.8 \pm 8.3$ & - & - & $28.1 \pm 29$ & $190 \pm 07^{\circ}$ & $683 \pm 88$ & $523 \pm 18$ & $312=60$ & $308 \pm 50$ \\
\hline 19 & 4 & $8-12$ & $6.6 \pm 1.6$ & $26.2 \pm 2.2$ & $10.1 \pm 0.9$ & $17.5 \pm 2.7$ & $6.8 \pm 1.3$ & $8.2 \pm 0.7$ & $8.5 \pm 10$ & $157 \pm 23^{0)}$ & $40.5 \pm 75$ & $489 \pm 11$ & $291=70$ & $288 \pm 45$ \\
\hline 20 & 4 & $7-11$ & $4.2 \pm 0.2$ & $10.2 \pm 1.7$ & $7.9 \pm 0.7$ & $15.0 \pm 1.8$ & $7.8 \pm 01$ & $219 \pm 46$ & - & - & $205 \pm 16$ & $224 \pm 13$ & $256 \pm 33$ & $495 \pm 100$ \\
\hline 21 & 4 & $8-12$ & $8.6 \pm 0.7$ & $38.6 \pm 4.8$ & $7.7 \pm 0.4$ & $208 \pm 1.3$ & $9.3 \pm 0.7$ & $347 \pm 7.6$ & - & - & $151 \pm 51$ & $266 \pm 19$ & $208 \pm 32$ & $197=24$ \\
\hline \multicolumn{15}{|l|}{$\begin{array}{l}\text { Neonatal Age } \\
\text { (days) }\end{array}$} \\
\hline 1 & 5 & 3 & $22.8 \pm 3.9$ & - & $32.6 \pm 8.5$ & - & $135 \pm 1.9$ & - & & & & & & \\
\hline 2 & 5 & 3 & $18.3 \pm 0.7$ & $441 \pm 50$ & $51.2 \pm 5.4$ & $106 \pm 12$ & $13.2 \pm 1.0$ & $374 \pm 53$ & & & & & & \\
\hline 4 & 5 & 3 & $39.7 \pm 5.7$ & $591 \pm 32$ & $33.8 \pm 4.9$ & $126 \pm 13$ & $22.4 \pm 4.3$ & $362 \pm 54$ & \multicolumn{2}{|c|}{ a) mean \pm SEM } & & & & \\
\hline 6 & 5 & 2 & $49.2 \pm 2.9$ & $1061 \pm 56$ & $10.9 \pm 0.6$ & $221 \pm 10$ & $34.6 \pm 3.0$ & $834 \pm 38$ & \multicolumn{2}{|c|}{ whote pup } & & & & \\
\hline 8 & 5 & 2 & $35.2 \pm 2.3$ & $975 \pm 72$ & $10.2 \pm 1.3$ & $147 \pm 6$ & $16.7 \pm 0.8$ & $1009 \pm 79$ & \multicolumn{2}{|c|}{ pup minus liver } & & & & \\
\hline 10 & 5 & 2 & $53.5 \pm 7.3$ & $1165 \pm 95$ & $15.4 \pm 1.5$ & $160 \pm 9$ & $21.6 \pm 1.3$ & $1991 \pm 211$ & \multirow{2}{*}{\multicolumn{2}{|c|}{ pup minus liver and kıdney }} & & & & \\
\hline- & - & - & - & - & - & - & - & - & & & & & & \\
\hline 14 & 12 & 1 & $21.1 \pm 1.2$ & - & $10.5 \pm 0.7$ & - & $18.0 \pm 0.9$ & - & & & & & & \\
\hline
\end{tabular}


14 and decline with progressing pregnancy from approximately $100 \mathrm{mU} / \mathrm{ml}$ to $15 \mathrm{mU} / \mathrm{ml}$. There is no significant difference between the control and hypoxic groups except on day 21 of gestation, and it is likely that this increase reflects the renal response to maternal hypoxia on day 20 and 21 in the fetus. The nature of the material in the AF and possible differences between biological and immunological activity will be further investigated in the polycythemic mouse assay. In addition, the highly significant difference in Ep levels measured in the hypoxic mothers as compared to controls is neither reflected in the amniotic fluid and pups nor in the fetal plasma, liver and kidney tissues. This observation supports the evidence that Ep does not cross the placental barrier in either direction and that the fetus responds to the hypoxic stimulus independently.

Exposure of neonatal rats to hypoxia resulted in highly significant increases in plasma, renal and liver Ep concentrations. However, the levels measured in the liver declined after day 2 (controls) and $\mathrm{d}$ 6 (hypoxic), while the renal concentration in the unstimulated neonate increased from birth to day 6 and reached adult levels between day 10 and 14 ; it increased steadily from day 2 to day 10 during 18 hours of hypoxia. Calculations of the actual amount of Ep available to each pup on the basis of tissue weight allow the following conclusions: 1) the fetal rat liver is the major Ep producing tissue and responds to maternal hypoxia during the last 6 days of gestation, 2) maternal hypoxia stimulates the fetal kidney tissue to increase endogenous Ep production shortly before birth, and 3 ) in the neonatal normal and hypoxic rat the liver appears to be the major Ep producing tissue during the first 4 days of life. Thereafter, in response to hypoxia, the kidney tissue is the main source of Ep while in the normal neonatal rat up to 14 days of age, both tissues appear to contribute equally to erythropoietin homeostasis (Fig. 1).

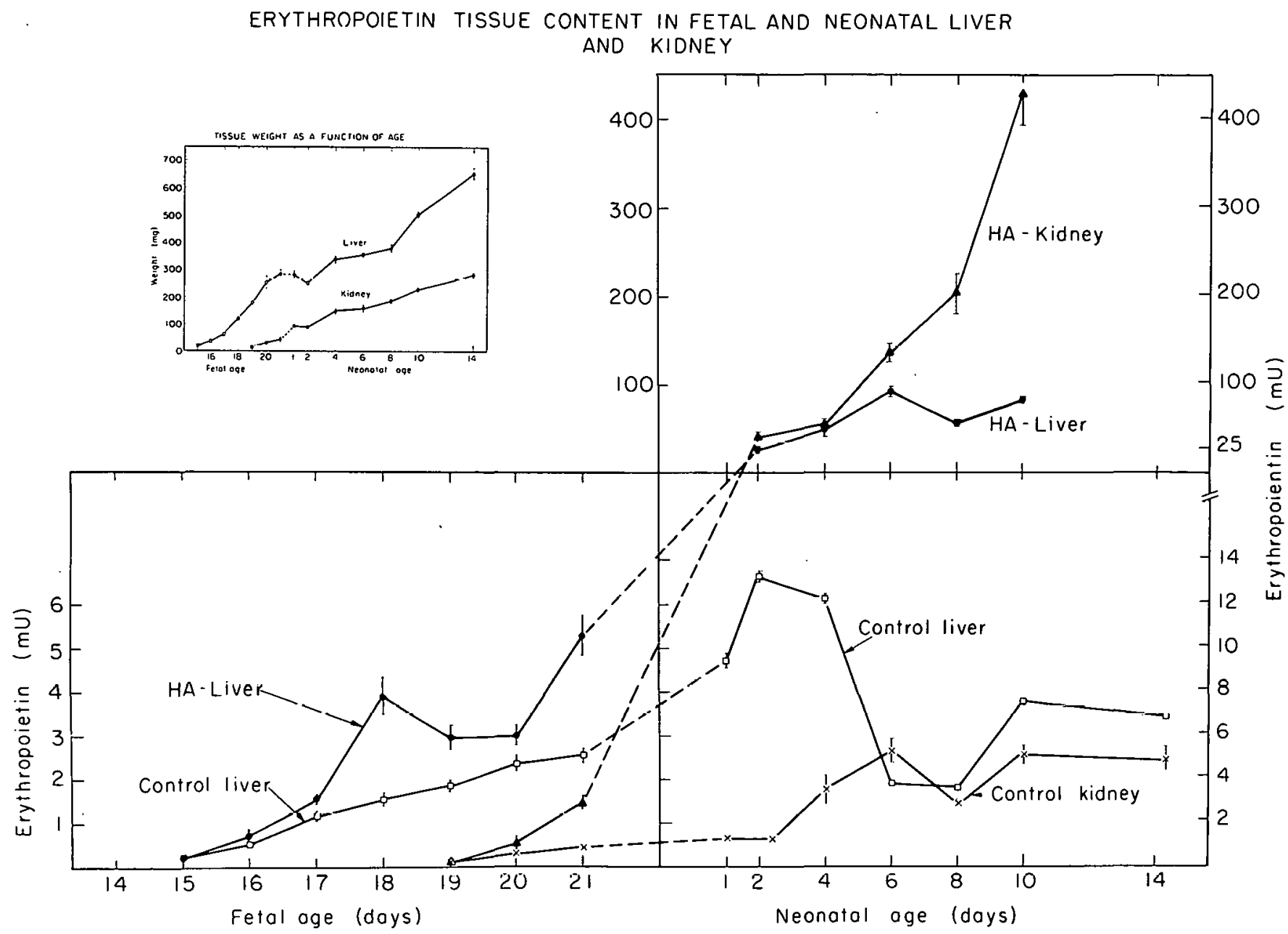

Fig. 1. Erythropoietin tissue content in fetal and neonatal liver and kidney. 
In addition to our own erythropoietin studies in aboratory animals, and realizing the limited availability of the radioimmunoassay for measuring human erythropoietin levels, we have been accepting carefully collected serum samples from outside investigators in order to maximize the use of the assay. The assay may be of value as a general monitor of hypoxemia, whatever its cause. Fetal hypoxemia is one of the possible explanations for the increased erythropoietin levels seen in cord blood of infants of diabetic mothers. Fetal hypox-

\section{HEMATOPOIETIC CELL PROLIFERATION}

\section{John C. Schooley}

This laboratory, for over 30 years, has had an ongoing concern with factors regulating the proliferation of blood cells, especially red blood cells. There is now little doubt that erythropoiesis is normally regulated by the hormone erythropoietin (Ep). This hormone is a glycoprotein with a mol wt of about 40,000 that appears to be made, particularly when increases in red blood cell production occur, by the kidney. The identity of the cells in the kidney producing the hormone is unknown, but certain evidence suggests to me that the mesangial cell of the glomerulus is involved. It is also known that extra-renal sources of the hormone exist.

Data from a number of laboratories have documented the actions of $\mathrm{Ep}$ both in vivo and in vitro. In general, the hormone stimulates hemoglobin synthesis and a variety of enzymatic, nucleic acid, and metabolic changes associated with terminal erythroid cell maturation. The identity of the precursor cell is unknown but a variety of in vitro techniques are available that permit kinetic studies of Ep's action on its precursor cell(s). Due primarily to a scarcity of pure Ep, neither Ep receptors nor the developmental range of potential target cells has been satisfactorily defined. Purification of Ep has been hindered by poor starting materials, poor yields, and instability; however, Goldwasser has purified small amounts of human urinary Ep to homogeneity.

Recently, in collaboration with Dr. W. David Hankins of the National Cancer Institute of the National Institutes of Health, three independently derived erythroid cell lines have been isolated that secrete large quantities of $\mathrm{Ep}$ as measured by a variety of biological, biochemical and immunologizal criteria. Supernatants were screened from several mouse, rat and human erythroleukemia cell emia in high risk pregnancies can be diagnosed by measuring the hormone concentration in the amniotic fluid and, where possible, in fetal blood. Erythropoietin responses to controlled stimuli may ultimately also be of value in diagnosing increased or decreased erythropoietin secretory ability in a wide variety of clinical situations. Examples would be anemias of malignancy and infection, and erythrocytosis, due either to hypoxic pathology or to autonomous erythropoietin production.

lines for their ability to induce hemoglobin synthesis or erythroid proliferation in cultures of fetal liver cells. Although most of the lines tested were negative, the media from three lines (HFTC-5, IW32 and TP-3) reproducibly stimulated ${ }^{59} \mathrm{Fe}$ uptake in cultures. Since this in vitro assay has been shown to be influenced by factors other than Ep and changes in the specific activity of the added ${ }^{59} \mathrm{Fe}$ could possibly explain the results, we tested the media in five additional in vitro and three different in vivo assays. We conclude that while each of the individual assays may have deficiencies, the collective data from these nine separate assays represent overwhelming evidence that the biological activity in media from HFTC-5, IW-32 and TP-3 is the protein hormone, erythropoietin.

Table 1 presents evidence that the erythropoietic activities in media from HFTC-5 and IW-32

Table 1 . Effect of rabbit anti-Ep, trypsin and neuraminidase on the enthropoietic activity of the culture media.

\begin{tabular}{lc}
\hline \hline & $\begin{array}{c}72-\mathrm{hr}^{59} \mathrm{Fe} \\
\text { uptake }\end{array}$ \\
\hline Media 493 + Normal rabbit serum + GARGG & $12.8 \pm 1.5^{\mathrm{a}}$ \\
Media 493 + Rabbit anti-Ep + GARGG & $0.16 \pm 0.02$ \\
(Rabbit anti-Ep + GARGG) + Media 493 & $9.63 \pm 1.0$ \\
Media 493 + trypsin ${ }^{\mathrm{b}}$ & $2.90 \pm 0.71$ \\
Media 493 + neuraminidase & $2.10 \pm 0.39$ \\
Uninjected & $0.08 \pm 0.01$ \\
\hline \hline
\end{tabular}

a Standard error of the mean, 6 mice/assay.

b Tripsin-affin-gel beads overnight with shaking.

c Neuraminidase 10 units for $3 \mathrm{hr}$ at $22^{\circ} \mathrm{C}$, overnight at $4^{\circ} \mathrm{C}$, then heated $65^{\circ} \mathrm{C}$ for $20 \mathrm{~min}$. 
corresponds immunologically to Ep. Anti-serum from rabbits which have been immunized with human urinary erythropoietin has been shown, in a number of studies from this laboratory, to neutralize the biological activity of mouse Ep as well as Ep obtained from a number of other mammals. The media from the cultures were mixed with this antiserum for a $30-\mathrm{min}$ incubation at $37^{\circ} \mathrm{C}$ after which sufficient goat anti-rabbit gamma globulin (GARGG) was added to precipitate all of added rabbit antibody (even the antibody complexed with Ep). The immune precipitate was then removed by centrifugation. This approach was taken to ensure that anti-Ep was not injected into the plethoric mouse used for Ep assay. This procedure minimizes the possibility that the medium does not contain something capable of stimulating Ep production in the plethoric mouse. If this did occur and anti-Ep was injected into the mouse, the biological activity of the endogenous Ep would be neutralized. To ensure that an adequate amount of GARGG was added, the pattern of additions of GARGG, anti-Ep and media was reversed, i.e., the anti-Ep was removed by GARGG before the addition of media containing Ep. The results clearly indicate that the erythropoietic-stimulating activity of the media is because of the presence of Ep. Further, experiments indicated that the activity in the media was virtually abolished by digestion with trypsin and the enzyme neuraminidase. This indicates that the stimulation activity resides in a protein; and this protein depends upon its terminal sialic acid residues for its biological activity in vivo, which is true of Ep. Suitable control experiments were also performed to eliminate the possibility that the stimulation was due to the Freund virus.

The molecular size of the erythropoietic activity was estimated after fractionation of concentrated HFTC-5 media on a Sephacryl S200 gel column. The column was calibrated prior to this separation with proteins of known molecular weights. Each fraction was pooled, for certain mol wt ranges and assayed for the presence of Ep using the plethoric mouse bioassay. As can be seen in Table 2, some biological activity was observed in the 130,000 dalton range, but most of the activity was in the 40-60,000 dalton range. We do not know the significance of the activity in the higher mol wt range but believe it may represent aggregates of Ep. Similar results, however, were observed from serum from rats exposed to simulated altitude and eluted on the same column.

Lastly, as shown in Table 3, we have found that significant amounts of Ep are generated by at least
Table 2. Erythropoietic stimulating activity of fractions of culture media separated using Sephacryl S200.

\begin{tabular}{|c|c|c|}
\hline & $\begin{array}{l}72-\mathrm{hr}{ }^{59} \mathrm{Fe} \\
\text { uptake }\end{array}$ & \\
\hline $\begin{array}{l}\text { Fraction I } \\
\text { void volume, tubes } 46-49\end{array}$ & $0.08 \pm 0.01^{a}$ & \\
\hline $\begin{array}{l}\text { Fraction II } \\
\text { (130 kilodalton area) }\end{array}$ & $2.70 \pm 0.48$ & \\
\hline $\begin{array}{l}\text { Fraction III, tubes } 68-114 \\
\text { ( } 40-60 \text { kilodalton area) }+ \\
\text { normal rabbit serum }\end{array}$ & $23.7 \pm 0.78$ & \\
\hline $\begin{array}{l}\text { Fraction III, same as above } \\
\text { + rabbil anili-Ep selull }\end{array}$ & $6.95 \pm 1.2$ & $\begin{array}{l}71 \% \text { reduction in } \\
\text { Ep activity }\end{array}$ \\
\hline $\begin{array}{l}\text { Fraction IV, tubes } 85-114 \\
\text { low mol wt area }\end{array}$ & $0.12 \pm 0.03$ & \\
\hline $\begin{array}{l}\text { Fraction } V \text {, tubes } 124-126 \\
\text { (salt area) }\end{array}$ & $0.20 \pm 0.12$ & \\
\hline Uninjected & $0.07 \pm 0.01$ & \\
\hline 0.1 IRP Unit & $7.84 \pm 0.56$ & \\
\hline
\end{tabular}

a Standard error of the mean, 6-8 mice/assay

one clone in serum-free culture conditions. These experiments clearly indicate that at least three independently derived erythroid cell lines produce and secrete copious amounts of erythropoietin in culture conditions.

The availability of these Ep-synthesizing clones is an important breakthrough in studies of this hormone. It should allow rapid purification of Ep, especially since the hormone is generated in serum-free media. The production of antibodies against Ep and fragments of the hormone should be possible. It should be possible to sequence the purified mouse Ep and compare it to human Ep and thus obtain some insight into the nature of the sites necessary for biological activity. The isolation of poly $\mathrm{A}^{+}$mRNA from the clones is already in progress and translations have been made using the in vitro reticulocyte lysate system and the in vivo amphibian egg. Such studies should provide insight into the secretion of the hormone and whether it exists as a pre and pro form. In addition, the role of glycosylation in biological activity can be ascertained. In the intact kidney over 20,000 specific mRNA's exist so that purification and enrichment of the specific Ep mRNA is extremely difficult: nevertheless, my colleague, Brian Fletcher, and have achieved successful translation of immunologi 
Table 3. Biogenesis of erythropoietin in vitro by two clones cultured in media with different serum concentrations.

\begin{tabular}{lcccccc}
\hline \hline & \multicolumn{2}{c}{ Serum free } & \multicolumn{2}{c}{$2 \%$ serum } & \multicolumn{2}{c}{$10 \%$ serum } \\
\cline { 2 - 7 } & $\begin{array}{c}72-\mathrm{hr}^{59} \mathrm{Fe} \\
\text { uptake }\end{array}$ & $\begin{array}{c}\text { IRP } \\
\text { units }\end{array}$ & $\begin{array}{c}72-\mathrm{hr}{ }^{59} \mathrm{Fe} \\
\text { uptake }\end{array}$ & $\begin{array}{c}\text { IRP } \\
\text { units }\end{array}$ & $\begin{array}{c}72-\mathrm{hr}^{59} \mathrm{Fe} \\
\text { uptake }\end{array}$ & $\begin{array}{c}\text { IRP } \\
\text { units }\end{array}$ \\
\hline $\begin{array}{l}\text { HENA } \\
2 \text { days of culture }\end{array}$ & $4.85 \pm 0.81^{\mathrm{a}}$ & 0.12 & $7.19 \pm 0.83$ & 0.22 & $9.19 \pm 1.6$ & 0.75 \\
$\begin{array}{l}\text { HENA } \\
4 \text { days of culture }\end{array}$ & $9.41 \pm 1.6$ & 0.25 & $7.63 \pm 0.84$ & 0.22 & $11.4 \pm 1.3$ & 0.84 \\
$\begin{array}{l}\text { HENA } \\
7 \text { days of culture }\end{array}$ & $8.52 \pm 1.3$ & 0.24 & $14.2 \pm 1.9$ & 0.90 & $12.4 \pm 1.1$ & 0.85 \\
\hline \hline
\end{tabular}

a Standard error of the mean.

Hypertransfused female LAF, mice, 9-10 mice/assay $1 \mathrm{ml}$ media injected sc.

cally detectable Ep from hypoxic rat kidney mRNA, although at this time biological activity is lacking. In contrast, these isolated clones should not contain large numbers of non-Ep synthesizing cells, and purification of the specific Ep mRNA's from other mRNA's should be more readily accomplished.

In addition to the collaborative experiments cited above, Brian Fletcher, Birgitta Kullgren and I have continued our studies of the effects of the heavy element, lead, on the hematopoietic system. We have found that lead is quite toxic to the megakaryocytic system in addition to its well known actions on erythroid cells. Some early progenitor of megakaryocytic cells is especially sensitive to lead. Paradoxically, however, lead stimulates the proliferative activity of early progenitors of the granulocytic cell line and of the pluripotential stem cell population. These findings have provided a new probe for studying the regulation of the proliferation of these various cell lines. In addition, we have found that lead stimulates these systems in vitro as well as in vivo. In the case of granulocyte precursors, lead stimulates the production of CSF (colony-stimulating factor), a protein analogous to $\mathrm{Ep}$, that is absolutely necessary for the growth of granulocytic progenitors in vitro. The role of CSF in the living animal is not, however, resolved. Not only does lead stimulate some of these hematopoietic progenitors to proliferate, but it also stimulates the proliferation of various nonhematopoietic stromal cells that reside within the bone marrow. The function of these cells is unknown, but more id more evidence is accumulating to implicate such cells in the modulation of the growth of true hematopoietic cells. The development of bone marrow cells is believed to depend in vitro on the development of adipocytes or fat cells from preadipocyte precursors. Bone marrow preadipocytes differ from the preadipocytes of other tissues in that they require hydrocortisone rather than insulin for differentiation into fat cells. We have recently found that this hydrocortisone requirement, as shown in Table 4, can be almost completely eliminated if bone marrow cultures are grown in 5\% $\mathrm{CO}_{2}, 5 \% \mathrm{O}_{2}, 90 \% \mathrm{~N}_{2}$ rather than the usually used $5 \% \mathrm{CO}_{2}$ plus air. These findings have exciting implications with regard to the differentiation of blood-forming cells, and the heretofore not realized role of the microenvironment in regulating the activities of stromal cells.

Table 4. Number of adherent adipocyte colonies in cultures of bone marrow cells with and without added hydrocortisone in $5 \% \mathrm{CO}_{2}$ and air and $5 \% \mathrm{CO}_{2}, 5 \% \mathrm{O}_{2}, 90 \% \mathrm{~N}_{2}$.

\begin{tabular}{lcc}
\hline \hline & \multicolumn{2}{c}{ Bone Marrow } \\
\cline { 2 - 3 } & $\begin{array}{c}\text { with } \\
\text { hydrocortisone }\end{array}$ & $\begin{array}{c}\text { without } \\
\text { hydrocortisone }\end{array}$ \\
\hline $5 \% \mathrm{CO}_{2}$ air & $19 \pm 1.3^{\mathrm{a}}$ & $2.8 \pm 0.73$ \\
$5 \% \mathrm{CO}_{2}, 5 \% \mathrm{O}_{2}, 90 \% \mathrm{~N}_{2}$ & $78 \pm 4.3$ & $30 \pm 1.3$ \\
\hline \hline
\end{tabular}

a Standard error of the mean, $1.5 \times 10^{6}$ bone marrow cells cultured/flask, colonies counted after 2 weeks growth. 
ESTRADIOL RECEPTOR IN THE MALE MOUSE LUNG

\section{Gerald M. Connell and Betsy Carr}

Morphological and biochemical changes occur within lung tissue after inhalation of an oxidant pollutant gas, such as ozone. Previously we demonstrated that sex hormones, androgens and estrogens, modify the toxicity of ozone in male mice, and subsequently showed that the lung content of androgen receptors declined after chronic ozone exposure. In this report, properties of the estrogen binding receptor of the male mouse lung are described.

A cytosol fraction $(189,000 \times \mathrm{g}$ supernatant $)$ was prepared from homogenates of lung tissue of adult male mice. Estradiol receptors were quantitated in the cytosol by saturation analysis. Briefly, this analysis involves the incubation of lung cytosol $(0.25 \mathrm{ml})$, containing $1-2 \mathrm{mg}$ protein, with increasing quantities of radioactive estradiol dissolved in $0.05-\mathrm{ml}$ buffer. Multiple samples of cytosol were incubated with $\left[{ }^{3} \mathrm{H}\right]$-estradiol concentrations which ranged from $20 \mathrm{pM}$ to $1.5 \mathrm{nM}$. A parallel series of incubation tubes, identical except for the addition of $100 \mathrm{nM}$ non-radioactive estradiol were assayed simultaneously to quantitate nonspecific binding. After the cytosol samples incubated 4 hours at $4^{\circ} \mathrm{C}$, the bound and free steroid fractions were separated and the estradiol binding was quantitated by Scatchard analysis.

An example of estradiol receptor analysis by this method is shown in Fig. 1. In this experiment, the male mouse lung cytosol had a receptor content of 4.88 femtomole (fmol) estradiol $/ \mathrm{mg}$ cytosol protein.

Steroid receptors also can be examined by sucrose density gradient centrifugation. In this technique, lung cytosol samples are incubated with $\left[{ }^{3} \mathrm{H}\right]$-estradiol for 4 hours at $4^{\circ} \mathrm{C}$. Bound and free steroid are separated and an aliquot of the bound fraction is carefully layered on the top of a linear $10-30 \%$ buffered sucrose solution. After the samples are centrifuged at $189,000 \times \mathrm{g}$ for 16 hours at $2-4^{\circ} \mathrm{C}$, they are fractionated by collecting drops from the bottom of each tube. The radioactive $\left[{ }^{3} \mathrm{H}\right]$-estradiol is then determined. A representation of this type of analysis is shown in Fig. 2. In this experiment, some cytosol samples contained increasing amounts of nonradioactive estradiol and this is reflected by a decreased binding of the $\left[{ }^{3} \mathrm{H}\right.$ estradiol in the receptor peak region. When the receptor is either heat treated or exposed to the enzyme, pronase, for short times, estradiol binding

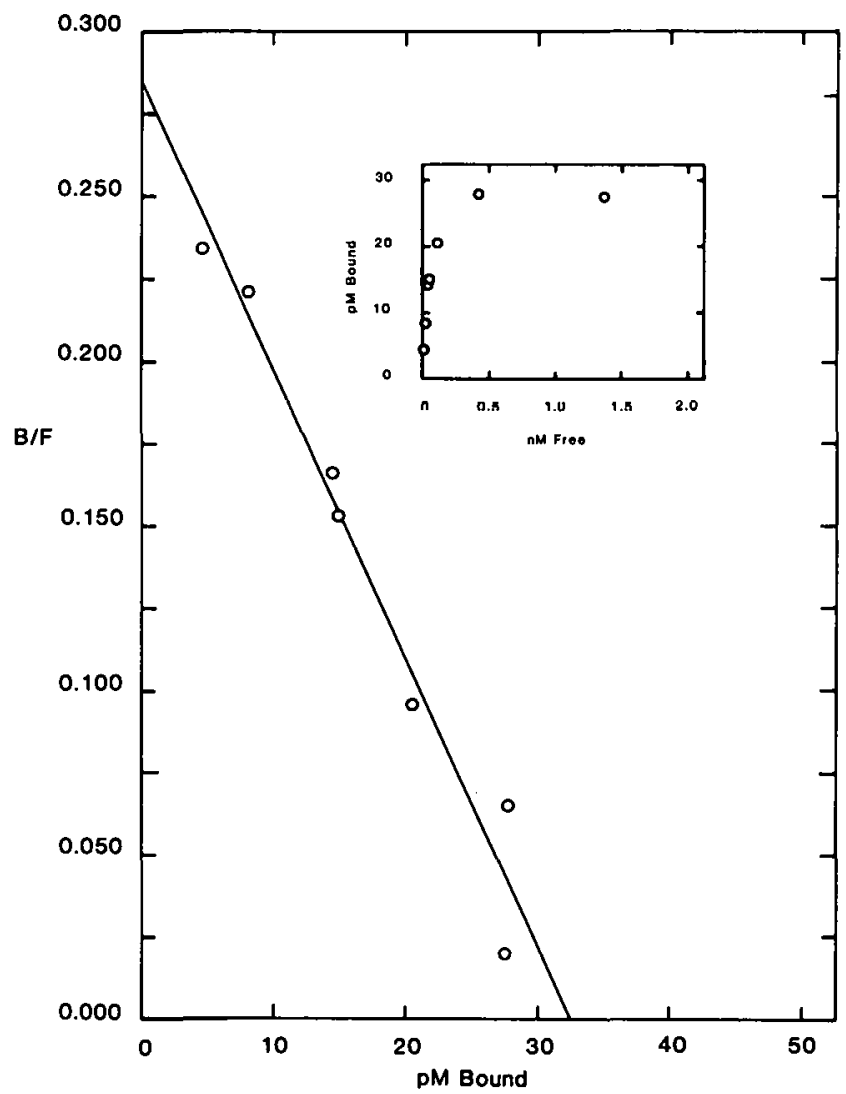

Fig. 1. $\left[{ }^{3} \mathrm{H}\right]$-estradiol binding to male mouse lung cytosol analyzed by the method of Scatchard. Mice were castrated 18 hours before cytosol preparation. Lung cytosol $(250 \mathrm{\mu l}$ containing $2.0 \mathrm{mg}$ protein) were incubated for 4 hours at $4^{\circ} \mathrm{C}$ with increasing quantities of $\left[{ }^{3} \mathrm{H}\right]$-estradiol. The incubation volume was $0.3 \mathrm{ml}$. Bound and free steroid was separated by charcoal/dextran and radioactivity in an aliquot of the supernatant was determined. Values are corrected for nonspecific binding. Saturation data are represented in the inset. This experiment represents $4.88 \mathrm{fmol}$ estradiol bound $/ \mathrm{mg}$ cytosol protein and the apparent $K d$ is $0.11 \mathrm{nM}$. (XBL 833-8613)

in the receptor region is eliminated (data not shown).

Estradiol binding to this lung receptor also is specific as is shown in Table 1 . Only nonradioactive estradiol and diethylstilbestrol competed with $\left[{ }^{3} \mathrm{H}\right]$-estradiol for binding sites. Other steroids which included the androgen, dihydrotestosterone, and the adrenal corticoid, corticosterone, were much less effective.

Estradiol receptors were quantitated in lung tissue from normal male mice and mice that we castrated for various periods of time. These resul 


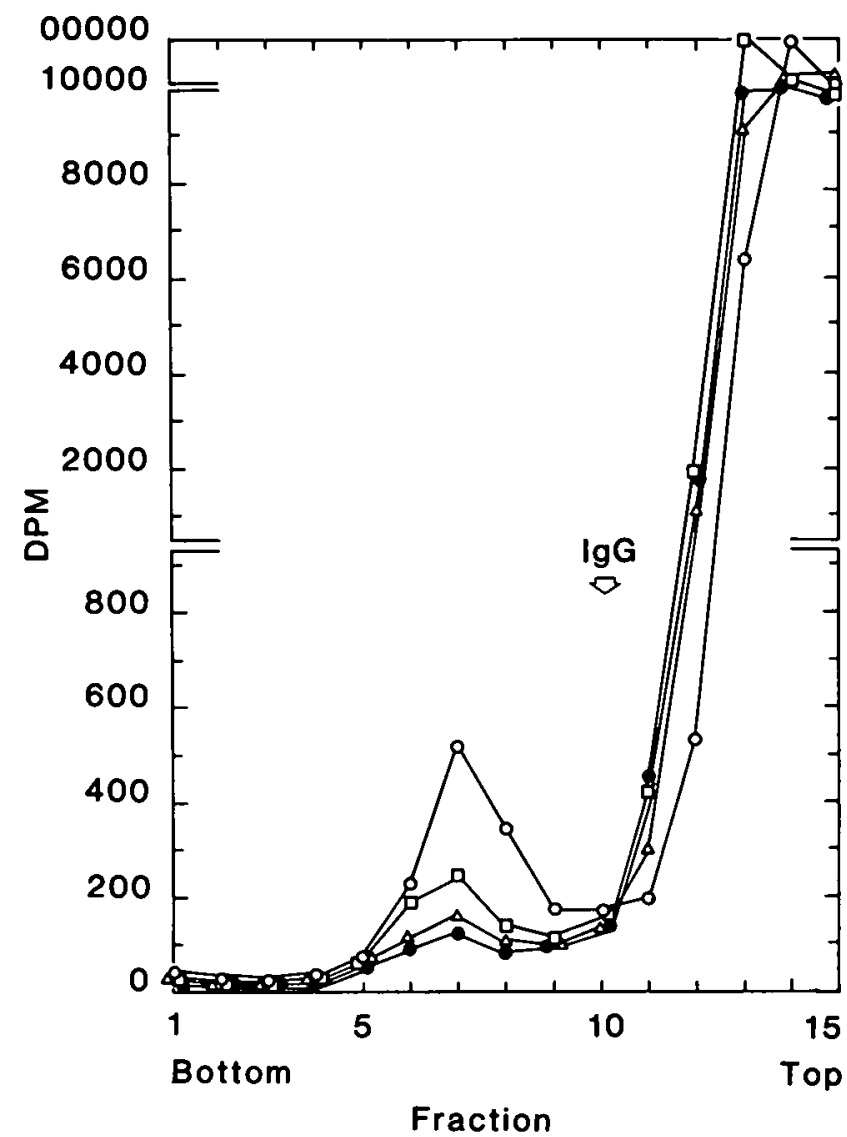

Fig. 2. Sucrose density gradient analysis of estradiol binding by lung cytosol that was prepared from ten male mice castrated 18 hours previously. Cytosol $(250 \mu l)$ was incubated with $5 \mathrm{nM}$ $\left.{ }^{3} \mathrm{H}\right]$-estradiol in the absence $(\mathrm{O})$ or presence of nonradioactive estradiol ( $\square=10 \mathrm{~nm}$ estradiol, $\Delta=50 \mathrm{nM}$ estradiol and $\square=$ $100 \mathrm{nM}$ estradiol). After a 4-hour incubation, the samples were

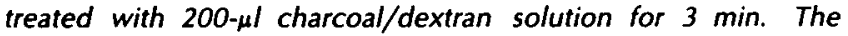
samples were centrifuged and $200 \mu /$ of the supernatant was layered on a 10-30\% continuous sucrose gradient in TEM and centrifuged for 18 hours at $189,000 \times \mathrm{g}$.

(XBL 834-9118)

(Table 2) show that the quantity of estradiol bound by lung tissue gradually increases as the time after castration increases.

These combined data illustrate that lung tissue from adult male mice contain an estradiol receptor. This receptor is a macromolecular protein located in the cytosol and has a sedimentation coefficient of approximately $8 \mathrm{~S}$. This binding component has a very high affinity, a very low capacity, and a high specificity for estradiol.

Our previous observations with the ozoneexposed mouse model show that estrogens and androgens modify ozone toxicity, that androgen receptors are present in mouse lung tissue, and that hronic ozone exposure promotes a reduction of ndrogen receptor content in lung tissue. These results, when combined with our current data that
Table 1. Specificity of ${ }^{3} \mathrm{H}$-estradiol binding to mouse lung cytoplasmic estrogen receptor. ${ }^{a}$

\begin{tabular}{lcc}
\hline \hline & \multicolumn{2}{c}{ Percent competition } \\
\cline { 2 - 3 } & $\begin{array}{c}10 \mathrm{nM} \\
\text { Competitor }\end{array}$ & $\begin{array}{c}100 \mathrm{nM} \\
\text { Competitor }\end{array}$ \\
\hline Estradiol & 47 & 100 \\
Diethylstilbestrol & - & 80 \\
Dihydrotestosterone & 18 & 40 \\
Corticosterone & 22 & 39 \\
Estrone & 13 & 37 \\
Progesterone & 5 & 11 \\
\hline \hline
\end{tabular}

a Specificity of the estrogen binding component of male mouse lung cytosol was determined by sucrose gradient centrifugation studies. $\left[{ }^{3} \mathrm{H}\right]$-estradiol was the radioactive ligand in these studies. Nonradioactive steroid concentrations were $10 \mathrm{nM}$ and $100 \mathrm{nM}$. Specific binding in the 8-9 S region of $10-30 \%$ linear sucrose gradients in TEM was quantitated. Competition by $100 \mathrm{nM}$ nonradioactive estradiol, which was included with each centrifugation study, was arbitrarily established at $100 \%$, and competition generated by other competitor steroids was based on this value. Results from several experiments are summarized in this table.

establishes the presence of estradiol receptors in mouse lung tissue, strongly support the thesis that sex hormones are involved in important, perhaps adaptive, biochemical mechanisms within lung tissue.

The mechanism whereby steroid hormones promote responses within tissues involves the binding

Table 2. Estrogen receptor content in adult male mouse lung cytosol. ${ }^{a}$

\begin{tabular}{lc}
\hline \hline & $\begin{array}{c}\mathrm{fmol} / \mathrm{mg} \text { cytosol protein } \\
\text { (mean } \pm \mathrm{SE} \text { ) }\end{array}$ \\
\hline Intact (3) & $3.43 \pm 0.35^{\mathrm{b}}$ \\
18-hr castrate (7) & $3.43 \pm 0.27$ \\
24-hr castrate (3) & $4.65 \pm 0.68$ \\
$57-$ hr castrate (4) & $5.32 \pm 0.72$ \\
245-day castrate (3) & $11.69 \pm 0.12^{\mathrm{b}}$ \\
\hline \hline
\end{tabular}

a Statistical differences were determined by one-way analysis of variance. Numbers within parentheses indicate number of determinations within each group.

b $\mathrm{P}<0.005$. 
of the steroid to a cytoplasmic protein receptor. A conformational change occurs to this complex (an activation process) that enables it to bind to the nuclear chromatin where transcription of specific DNA regions is initiated and the production of specific mRNA occurs. Translation of this mRNA within the cytoplasm results in the production of a specific protein that would be the biochemic response to the steroid hormone. Future work wiu, this system will need to identify specific proteins synthesized by lung tissue after estrogen and/or androgen treatment and establish their metabolic links between these proteins and biochemical changes that occur within the lungs.

\section{STIMULATION OF BONE MARROW PROGENITORS BY INTERLEUKINS}

\section{Joan W. Goodman, Elizabeth A. Hall, and Sarah G. Shinpock}

Interested in the study of stem cells in the bone marrow (BM), we have been developing a method that would allow us to enumerate T lymphocyte progenitors in experimental animals. This method is based on a short-term in vitro culture system that promotes cluster formation by BM in the presence of horse serum (HS) and pokeweed mitogen conditioned medium (PWM-CM). These clusters or colonies seen after 3-4 days of culture are putatively pre-T lymphocytes.

In addition to pursuing the proper identification of cells in colonies, we are attempting to refine the culture method. Because one of the required ingredients, PWM-CM (i.e., the supernatant from spleen cells cultured for 7 days in the presence of the plant lectin), contains several factors, including the interleukins $\|-1\|-$,2 and $\|-3$, we have carried out preliminary experiments in which a single interleukin is substituted for PWM-CM. The II-1 and II2 , both derived from mouse cells, were prepared and partially purified by Prof. R. I. Mishell and his collaborators at UC Berkeley. II-3 was purified to homogeneity from Wehi-3 supernatant and kindly supplied to us by ). N. Ihle of the Frederick Cancer Research Facility. Figure 1 a shows that $\|-1$ and II-3 were just as effective as PWM-CM in promoting large clusters (each containing more than 100 cells) at 3 days. II-2, on the other hand, was ineffective: only a few more colonies were counted in cultures to which it had been added than were seen in control (CBM) cultures containing no added $C M$ or purified factor.

Cells from each of the cultures depicted in Fig. 1a were harvested (clusters and single cells together) and analyzed for their content of BFU-E (burst forming unit-erythroid), an early erythroid precursor, CFU-S (colony forming unit-spleen) which is equated with a relatively early uncommitted myeloid stem cell, and CFU-C (colony forming unit-culture) representing a precursor of the granulocyte/monocyte/macrophage line. The results, shown in Fig. 1b, $c$, and d demonstrate that II-3 supported growth of all three stem cell types and was about 2 times as effective at the dose recommended by Dr. Ihle as the crude supernatant, PWM-CM. II-1 and II-2 were less effective than PWM-CM at maintaining CFU-S and slightly less effective at maintaining CFU-C; none of the three factors was effective in promoting BFU-E. Cells from II-2 stimulated primary cultures maintained or promoted growth of CFU-S, but because of the paucity of cells harvested initially, BFU-E and CFU$C$ assays could not always be carried out as they were in this particular experiment.

The results with II-3 stimulated cells come as something of a surprise, as this glycoprotein, thought to be produced by activated $T$ lymphocytes, has been reported to maintain indefinitely in culture progenitors of T lymphocytes (pre-t's) and mast-like cells. ${ }^{1}$ The preliminary data presented here suggest II-3 acts either on an even earlier, less committed progenitor or alternatively on many different precursors. We are currently investigating effects on primary cultures grown for different durations.

\section{REFERENCE}

1. Ihle, James N. In Cont. Top. in Mol. Immunology, in press, 1983. 
ABILITY OF FACTORS TO STIMULATE COLONIES IN CULTURE

3-day BM CULTURES

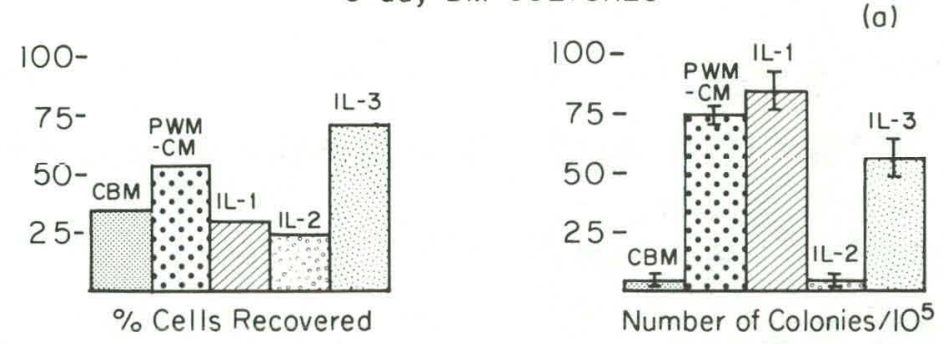

(a)

HEMOPOIETIC PROGENITOR CONTENT OF ABOVE CULTURES

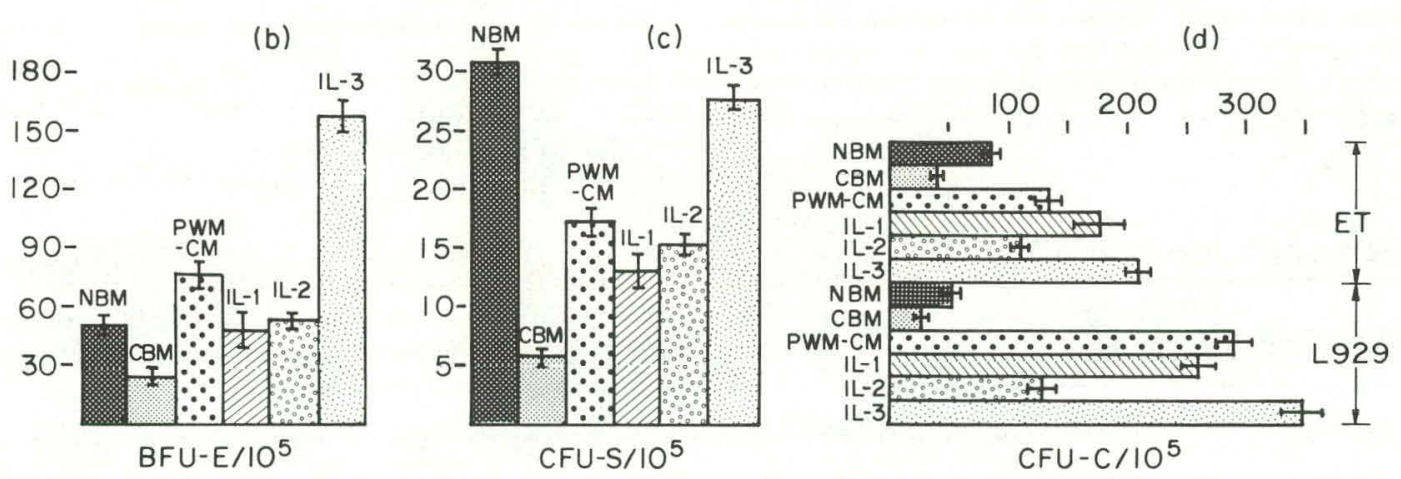

Fig. 1. (a) Ability of factors to stimulate colonies in culture. Anti-Thy 1 treated BM grown for 3 days in the presence of $10 \%$ horse serum plus crude supernatant (PWM-CM) or purified interleukins. CBM represents control cells of the same origin grown without any factor. (b), (c), and (d) depict stem cell contents of primary cultures presented above in (a). CFU-S (c) are grown for 8 days in lethally irradiated isogenic mice, and BFU-E (b) and CFU-C (d) are grown in vitro for 7 days. ET in segment (d) stands for endotoxin serum and 1929 for conditioned medium from a cell line, each of which was used as a source of colony stimulating factor (CSF) in the assay.

(XBL 8311-4139)

\section{BIOLOGICAL EFFECTS OF MAGNETIC FIELDS}

\section{Thomas S. Tenforde, Cornelius T. Gaffey, Michael S. Raybourn, and Lynette Levy}

A large number of newly developing medical and energy-related technologies use high dc magnetic fields, including nuclear magnetic resonance systems for imaging human tissues, thermonuclear fusıon reactors, magnetohydrodynamic systems, and superconducting energy storage and transmission systems. Because of the associated increase in the frequency of human exposures to large magnetic fields, programs were undertaken at LBL in the late 1970 s to develop quantitative personnel dosimetry techniques and to evaluate the potential health fects of magnetic field exposures in human subcts and in experimental animal systems.
In the dosimetry program (F.S. Goulding and T.S. Tenforde, principal investigators), a portable microprocessor-controlled dosimeter has been developed with sufficient battery life and memory capacity to provide a record of personnel magnetic field exposure levels during an 8-hour work shift. ${ }^{1}$ The final prototype of this personnel dosimeter, shown on the right in Fig. 1, is approximately the size of a cigarette package. The portable magnetic field dosimeter has been used in field tests at several industrial and research facilities, which are listed in Table 1 along with the highest field levels and time rates of change that were recorded at locations accessible to occupational personnel. 


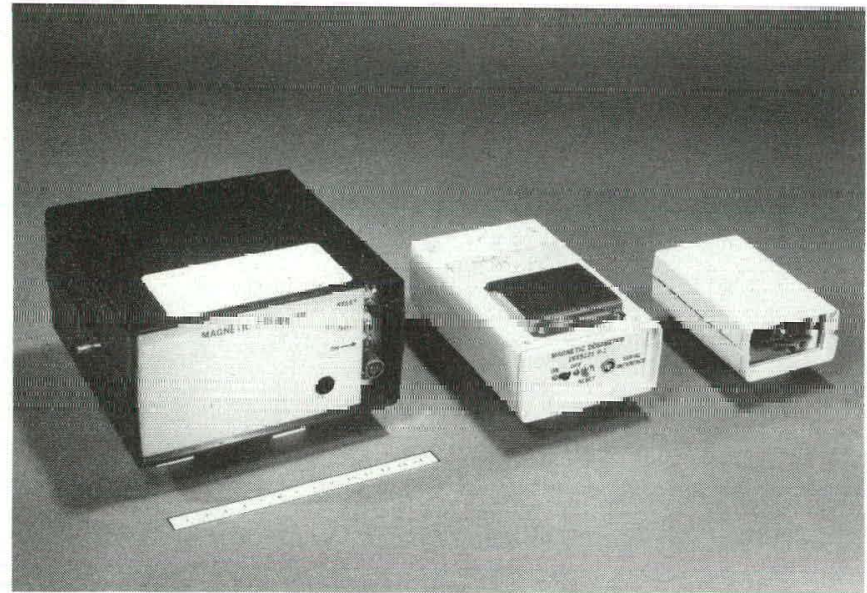

Fig. 1. Three prototype magnetic field dosimeters developed during the period 1980-1983. The first prototype, shown at the left, weighs $1.1 \mathrm{~kg}$ and is too bulky to be used as a personnel dosimeter. The second prototype, shown in the middle of the figure, weighs $420 \mathrm{~g}$ and can be worn by personnel as a beltmounted unit. The third and final prototype, shown at the right, weighs $230 \mathrm{~g}$ and is sufficiently compact to be worn in a shirt pocket. The front cover of this dosimeter has been removed to show the three internal circuit boards that house the analog, logic and memory components.

(CBB 831-540)

In a magnetic field epidemiology program (T.F. Budinger, principal investigator), the health records of 813 occupationally exposed individuals have been encoded and analyzed in parallel with the records of a matched control group of equal size. The subjects in this study are employees at the
Argonnc, Brookhaven, and Oilk Ridge Nulium Laboratories, Fermilab, the National Magnet Labolatory at MIT, the Stanford Linear Acceleralor, and LBL. The data analysis is still in the final stages, but it appears that there are $\mathrm{n} n$ significant differences in the incidence of 19 major disease classes among the exposed and control populations. Calibration of the data is currently being carried out to evaluate the extent of any potential biases associaled with age anul ilurlinu uf rmpluyment in the exposed and control groups.

A third magnetic field research program has been centered on the analysis of magnetic field interactions with experimental animals and selected organ and tissue systems (T.S. Tenforde, principal investigator). A major focus of this program has been the use of electrophysiological techniques to detect functional alterations in systems that involve ionic conduction processes, and are thereby potentially sensitive to electrodynamic interactions with an applied magnetic field.

Electrophysiological research. Electrical recordings have been used to detect perturbations in ionically-mediated processes in the cardiac, neural and visual systems. A major finding in this research area has been the observation of large, magnetically-induced potentials associated with pulsatile blood flow in the presence of dc magnetic fields. ${ }^{2,3}$ Induced flow potentials have been recorded for mammals ranging in size from rodents

Table 1. Portable magnetic field dosimeter applications.

\begin{tabular}{lcc}
\hline & Maximum B & Maximum dB/dt \\
\cline { 2 - 3 } Field test location & Gauss & Gauss/sec \\
\hline $\begin{array}{l}\text { Large Aperture Solenoid Spectrometer } \\
\text { Stanford Linear Accelerator }\end{array}$ & 5735 & 2710 \\
$\begin{array}{l}\text { Kaiser Aluminum Production Test Facility } \\
\quad \text { Permanente, California }\end{array}$ & 570 & 290 \\
$\begin{array}{l}\text { Tandem Mirror Fusion Reactor } \\
\text { Lawrence Livermore National Laboratory }\end{array}$ & 375 & 230 \\
$\begin{array}{l}\text { 184-Inch Cyclotron } \\
\text { Lawrence Berkeley Laboratory }\end{array}$ & 190 & 145 \\
$\begin{array}{l}\text { 76-Inch Cyclotron } \\
\text { University of California, Davis }\end{array}$ & 100 & 40 \\
$\begin{array}{l}\text { Bevatron } \\
\text { Lawrence Berkeley Laboratory }\end{array}$ & 40 & 30 \\
$\begin{array}{l}\text { 88-Inch Cyclotron } \\
\text { Lawrence Berkeley Laboratory }\end{array}$ & 30 & \\
\hline \hline
\end{tabular}


o nonhuman primates (baboons and monkeys), and rave been found in a 15 kilogauss field to reach levels of several millivolts in the central circulatory system of the larger animal species. However, the occurrence of large induced potentials has also been shown to have no detectable influence on various indices of cardiovascular performance, including heart rate, intraarterial blood pressure, and heart muscle bioelectric activity. Electrical recordings from isolated sciatic nerve preparations have similarly failed to reveal functional alterations in high dc magnetic fields, as determined from measurements of action potential amplitudes, conduction velocities, and relative and absolute refractory periods. ${ }^{4}$

Recordings of the electrical activity elicited by photon absorption in retinal photoreceptor cells have demonstrated an acute, suppressive effect of dc magnetic fields with intensities less than one kilogauss. ${ }^{5}$ This magnetically-induced change in retinal electrical activity has been found in turlle retinal preparations to occur only during the lightto-dark transition phase, when the photoreceptor cells are undergoing rapid shifts in physiological and metabolic activities. The apparent dependence of this effect on the circadian rhythm in photoreceptor activity has been further substantiated by recent studies in which the light/dark cycle was phaseshifted by 6 hours. Preliminary visual studies with cats have not revealed an effect of dc magnetic fields on photically-evoked retinal electrical activity. However, further experiments are needed in order to assess whether there is a circadian dependence of magnetic field sensitivity in the mammalian retina comparable to that observed for turtles.

Animal physiology studies. Noninvasive transducer techniques have becn used to continuously monilur general physiological parameters and their circadian oscillations in rodents chronically exposed to dc magnetic fields with intensities up to 15 kilogauss. Implantable radio-frequency telemetry units have been developed for measurements of circadian variations in core body temperature and heart rate, and an exposure system has been devised that permits the parallel measurement of circadian rhythms in respiration, body mass, locomotor activity, food intake and excreta. The circadian waveforms of these physiological and behavioral indices are known from earlier investigations to be responsive to a variety of chemical and physical stressors.

Studies during the past year have reinforced our revious observation that the circadian waveform of rodents is not perturbed during protracted exposures to a 15 kilogauss magnetic field. No significant effects of magnetic field exposure on circadian rhythms have been observed under conditions of light/dark entrainment or under free-running (i.e., nonentrained) conditions.

Organ and tissue studies. An extensive series of measurements have been completed on the blood cell counts, serum chemistry, organ weights and tissue histology of rodents subjected to prolonged exposures to a 15 kilogauss magnetic field. No statistically significant differences have been observed in any of these parameters for exposed mice relative to matched controls. Similar results have been obtained in a series of collaborative immunology experiments with $M$. Shifrine of the Laboratory for Energy-Related Health Research at the University of California at Davis, in which the cellular immune competence of exposed and control groups of mice was evaluated from the lymphocyte response to mitogen stimulation (concanavalin A, phytohemagglutinin, and lipopolysaccharide) and to challenge with a foreign antigen (sheep red blood cells). Studies completed during the past year have shown no statistically significant differences in the primary antibody response or the sensitivity to mitogen stimulation of spleen lymphocytes from mice chronically exposed to a 15 kilogauss field in comparison with control mice.

\section{REFERENCES}

1. Fujita, T.Y., and Tenforde, T.S. Portable magnetic field dosimeter with data acquisition capabilities. Rev. Sci. Instrum. 53, 326-331 (1982).

2. Gaffey, C.T., and Tenforde, T.S. Alterations in the rat electrocardiogram induced by stationary magnetic fields. Bioelectromagnetics 2, 357-370 (1981).

3. Tenforde, T.S., Gaffey, C.T., Moyer, B.R., and Budinger, T.F. Cardiovascular alterations in Macaca monkeys exposed to stationary magnetic fields: Experimental observations and theoretical analysis. Bioelectromagnetics 4, 1-9 (1983).

4. Gaffey, C.T., and Tenforde, T.S. Bioelectric properties of frog sciatic nerves during exposure to stationary magnetic fields. Radiat. Environ. Biophys. 22, 61-73 (1983).

5. Raybourn, M.S. The effects of direct-current magnetic fields on turtle retinas in vitro. Science 220, 715-717 (1983). 


\title{
DISTRIBUTION AND RETENTION OF ${ }^{238}$ Pu IN MACAQUE MONKEYS
}

\author{
Patricia W. Durbin, Nylan Jeung, and Charles T. Schmidt*
}

Plutonium production began about 40 years ago, but human metabolic data are still scarce and incomplete. The inadequacy of these data lead the International Commission on Radiological Protection (ICRP) to adopt parameters for their metabolic and dosimetric models that are probably overly conservative. $^{1}$ The resulting new occupational limits may involve at least an eightfold reduction of allowable $\mathrm{Pu}$ concentration in workplace air, and, by implication, equally severe new limits on release of $\mathrm{Pu}$ to the environment. The new ICRP limits are beiry considered for adoption by regulatory bodies in many countries including the United States, and their implementation will be costly, so it is important that all relevant data be made available.

A biokinetic study of ${ }^{238} \mathrm{Pu}$ was conducted using three Macaque species $(\mathcal{M}$. fascicularis, $M$. mulatta, $M$. arctoides). Old World monkeys are closer in all respects to human beings than any other animal that can be readily studied in the laboratory. ${ }^{238} \mathrm{Pu}$ was selected because the abundant ${ }^{234} U \mathrm{~L} x$ rays accompanying its decay permit most biological samples to be analyzed simply and accurately. At the injected dosage of $1.1 \times 10^{4}$ $\mathrm{Bq} / \mathrm{kg}$, the radioactivity was great enough to permit accurate detection of the $x$ rays in excreta and most bone and tissue specimens, but the radiation damage accumulated in three years in bone and liver was not expected to be great enough to alter the physiology of those tissues significantly.

Monkeys of both sexes [20 adult ( 14 female, 6 male) and 4 late adolescent ( 3 female, 1 male)] were given one intravenous (i.v.) or intramuscular (i.m.) injection of $1.1 \times 10^{4} \mathrm{~Bq} / \mathrm{kg}$ of monomeric ${ }^{238} \mathrm{Pu}(\mathrm{IV})$ in $0.08 \mathrm{M}$ citrate buffer, $\mathrm{pH} 3.5$, that had been passed through a $0.22 \mu \mathrm{m}$ Millipore filter. Blood was drawn periodically, beginning a few minutes after injection. Separated excreta were collected continuously. Animals were killed 1 to 1100 days after injection, autopsied and completely analyzed for ${ }^{238} \mathrm{Pu}$. All soft tissue, 35 individual organs and tissue specimens, and all bones were dry ashed and dissolved in dilute acid. The $x$ rays were detected in whole large samples with two thin, coaxially-mounted Nal crystals. Aliquots of small samples were spread and dried on glass plates, and alphas were detected with a winduwless proportional counter. Self-absorption corrections, based on ash weight, were applied to all measurements. Material recovery, in these complete balance studies, was $102 \pm 8 \%$ of the injected actively.

The monomeric state of the injected ${ }^{238} \mathrm{Pu}$ was confirmed by the biological evidence - slow plasma clearance, consistently low ${ }^{238} \mathrm{Pu}$ concentrations in spleen and lympls nudes, rapid absorption from an i.m. site, and absence of alpha track stars in autoradiographs of livers from 1- or 7-day animals. Absorption of ${ }^{238} \mathrm{Pu}$ citrate from an i.m. injection was nearly complete in 10 days. Biokinetic data obtained for this ${ }^{238} \mathrm{Pu}$ preparation by the two modes of administration (i.v. and i.m.) were indistinguishable and have been combined.

The initial distribution of ${ }^{238} \mathrm{Pu}$ was defined by six monkeys killed at one week. Excretion and redistribution of ${ }^{238} \mathrm{Pu}$ were defined by two groups of five monkeys, one group killed at 107 to 173 and, the other at 552 to 1100 days. The mean ${ }^{238} \mathrm{Pu}$ contents of major tissues, endocrine glands and excreta of those three groups of monkeys are shown in Table 1 . Table 2 shows the variability (mean and standard deviation) of the ${ }^{238} \mathrm{Pu}$ activity in the major tissues and excreta of the early and longest-studied groups: all differences are statistically significant $(p<0.01)^{2}$

This is the first presentation, to our knowledge, of a body of $\mathrm{Pu}$ biokinetic data from an animal whose physiologic attributes include both bone remodeling in adult life, as in man, and a significant hepato-biliary excretory outlet for actinides, and their important influence on the retention and redistribution of $\mathrm{Pu}$ in monkey tissues is apparent from the data that follow. The average retention of ${ }^{238} \mathrm{Pu}$ in whole body (Fig. 1), liver, and skeleton (Fig. 2) were described from 7 to 1100 days by Eqs. 1, 2, and 3 below; and initial deposition in and subsequent loss of ${ }^{238} \mathrm{Pu}$ from gonads were defined in 17 females ( 1 to 1100 days p.i.) and 7 males (7 to 552 days p.i.) by Eqs. 4 and 5 ( $t$ is in days). 
Table 1. Distribution and retention of ${ }^{238} \mathrm{Pu}$ in macaques.

\begin{tabular}{llll}
\hline & \multicolumn{3}{c}{ Percent Pu at days after injection } \\
\cline { 2 - 4 } & 7 to $8(6)^{\mathrm{b}}$ & 103 to $173(5)^{\mathrm{b}}$ & 552 to $1100(5)^{\mathrm{b}}$ \\
\hline Skeleton & 29. & 23. & 13. \\
Teeth & 0.12 & 0.18 & 0.19 \\
Liver & 60. & 34. & 12. \\
Kidneys & 0.62 & 0.16 & 0.05 \\
Spleen & 0.20 & 0.23 & 0.10 \\
Muscle and Pelt & 3.1 & 1.4 & 0.33 \\
Other Organs & 1.9 & 0.85 & 0.36 \\
Testes & $0.046(2)^{\mathrm{b}}$ & $0.061(3)^{\mathrm{b}}$ & $0.019(1)^{\mathrm{b}}$ \\
Ovaries & $0.005(4)^{\mathrm{b}}$ & $0.002(2)^{\mathrm{b}}$ & $0.001(4)^{\mathrm{b}}$ \\
Pancreas & 0.012 & 0.014 & 0.005 \\
Adrenals & 0.009 & 0.018 & 0.006 \\
Thyroid & 0.002 & 0.001 & 0.0007 \\
Pituitary & 0.0005 & 0.0004 & 0.0002 \\
Cumulative urine & 2.4 & 4.1 & 13. \\
Cumulative feces & 2.0 & 36. & 61. \\
\hline \hline
\end{tabular}

a Intravenous, \% injected Pu; Intramuscular, \% Absorbed Pu.

b (Number of monkeys).

Body (t) $\%$ dose $=$

$19 \exp (-0.693 t / 42)+50 \exp (-0.693 t / 980)$

Liver(t) $\%$ dose $=$

$15 \exp (-0.693 t / 25)+46 \exp (-0.693 t / 170)$

Skeleton(t) $\%$ dose $=$

$7 \exp (-0.693 t / 43)+22 \exp (-0.693 t / 1030)$

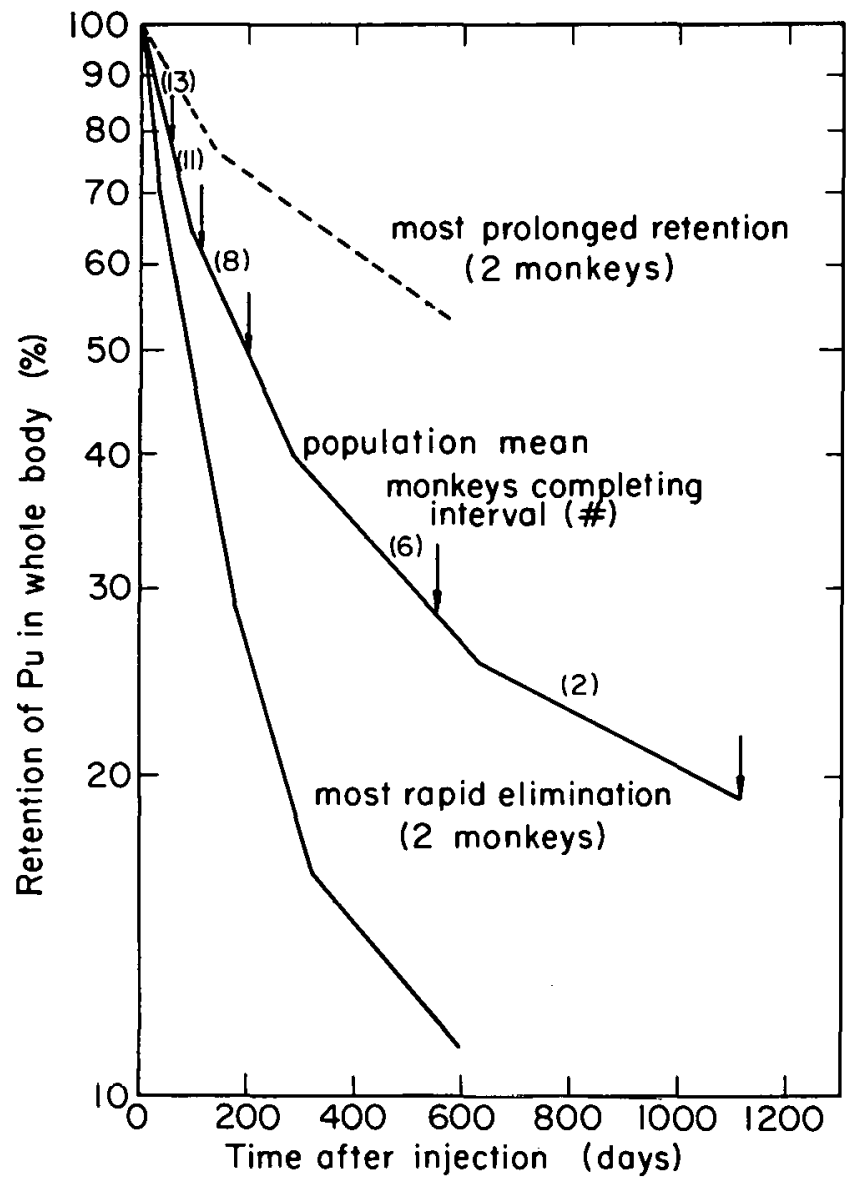

Fig. 1. Retention of ${ }^{238} \mathrm{Pu}$ in the whole body. (XBL 835-3759)

Ovary(t) \% dose $=$

$$
0.026 \exp (-0.693 t / 7)
$$

$+0.0038 \exp (-0.693 t / 390)$

Testes(t) \% dose $=$

$$
0.053 \exp (-0.693 t / 370)
$$

Table 2. Distribution of ${ }^{238} \mathrm{Pu}$ (percent injected activity).

\begin{tabular}{cccccc}
\hline \hline Days p.i. & Skeleton & Liver & Soft tissue & Urine & Feces \\
\hline 7 & $29 \pm 8$ & $60 \pm 10$ & $5.8 \pm 3.5$ & $2.4 \pm 0.5$ & $2.1 \pm 1.4$ \\
$712 \pm 310$ & $13 \pm 4$ & $12 \pm 18$ & $0.9 \pm 0.3$ & 8.0 & 66 \\
\hline \hline
\end{tabular}




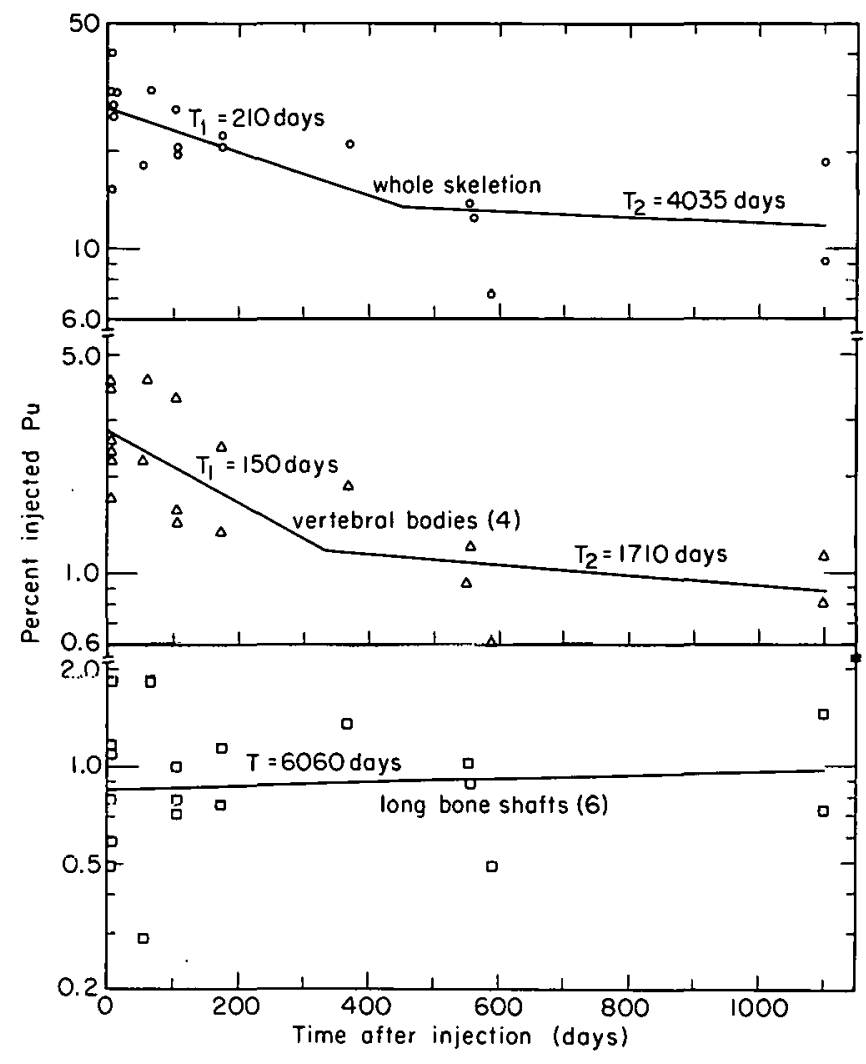

Fig. 2. Retention of ${ }^{238} \mathrm{Pu}$ in the skeleton and skeleton components.

(XBL 835-3761)

Initial relative ${ }^{238} \mathrm{Pu}$ concentrations (see Table 3 ) in cancellous bone (lumbar vertebral bodies and sternum) and compact bone (long bone shafts) imply a deposition of ${ }^{238} \mathrm{Pu}$ about six times more intense on cancellous than on compact surfaces. Different rates of loss of ${ }^{238} \mathrm{Pu}$ from cancellous and compact bone structures were demonstrated by the significant $(P \leqslant 0.01)^{2}$ decreases in the relative ${ }^{238} \mathrm{Pu}$ concentrations in lumbar vertebral bodies and sternum and increases in long bone shafts and paw bones between 7 days and 3 years.

Extraskeletal Pu distribution in monkeys is qualitatively similar to other species studied. ${ }^{3-6}$ Ini- tially, Pu was prominent in hepatic cells, nonske tal mineralized structures, arteries and arterioles, renal tubular structures, and occasionally, in involuting ovarian follicles and corpora lutea: Pu was consistently present at low concentrations in the reticulum of all tissues. Within 3 years, $\mathrm{Pu}$ in the soft tissues was $10 \%$ to $50 \%$ of the initial values. Clearance of liver $\mathrm{Pu}$, as inferred from plasma and excretion data occurred variably and idiosyncratically by both biliary excretion and by recirculation. In many animals clearance of liver Pu was nearly complete at 1 year (see Fig. 1, monkeys with most rapid elimination). However, in a few, clearance was only about $50 \%$ complete at 1.5 years (see Fig. 1, monkeys with most prolonged retention), and autoradiographs showed that much of the retained $\mathrm{Pu}$ was large aggregates associated with hemosiderin in RE cells.

Skeletal $\mathrm{Pu}$ deposition in adult monkeys is skewed to cancellous bone in red marrow sites. In 3 years about $65 \%$ of the $\mathrm{Pu}$ initially deposited in those bones was lost; most of the lost $\mathrm{Pu}$ was recovered in excreta (mainly feces); but some $\mathrm{Pu}$, recirculated from either liver or skeleton, was redeposited as is suggested by the small increase in $\mathrm{Pu}$ content of teeth and long bone shafts.

With respect to current ICRP recommendations, these results indicate that: 1) The initial deposited fraction used for $\mathrm{Pu}$ in tests is reasonable, but that for liver is low, and those for bone and ovary are high. 2) The net rates of $\mathrm{Pu}$ loss as recommended by ICRP are conservatively low for all tissues. 3) The bone surface dosimetry scheme needs adjustment to account for the skewed deposition of $\mathrm{Pu}$ to cancellous bone in the adult skeleton and the different rates of Pu loss from cancellous and compact bone.

\section{REFERENCES}

1. International Commission on Radiological Protection. Limits for Intakes of Radionuclides by Workers, ICRP Pub. 30. Pergamon Press, Oxford (1979).

Table 3. Relative ${ }^{238} \mathrm{Pu}$ concentration, ${ }^{\mathrm{a}}$

\begin{tabular}{lcccc}
\hline \hline Days p.i. & LV bodies & Sternum & Paw bones & Long bone shafts \\
\hline 7 & $6.7 \pm 1.1$ & $6.2 \pm 1.8$ & $0.30 \pm 0.08$ & $0.17 \pm 0.054$ \\
$712 \pm 310$ & $4.5 \pm 1.1$ & $3.7 \pm 1.2$ & $0.59 \pm 0.18$ & $0.35 \pm 0.085$ \\
\hline \hline
\end{tabular}


2. Fisher, R.A. Statistical Methods for Research Workers. Hafner Publishing Co. (1954).

3. International Commission on Radiological Protection. The Metabolism of Compounds of Plutonium and Other Actinides, ICRP Pub. 19. Pergamon Press, Oxford (1972).

4. Vaughan, J., Bleaney, B., and Taylor, D.M. Distribution, excretion and effects of plutonium and a bone-seeker. In Uranium, Plutonium, Transplutonic Elements, Handbook of Experimental Pharmacology, vol. 36 (H.C. Hodge, J.N. Stannard, J.B. Hursh, Eds.), pp.
349-503. Springer-Verlag, Berlin (1973).

5. Durbin, P.W. Plutonium in mammals: Influence of plutonium chemistry, route of administration, and physiological status of the animal on internal distribution and long-term metabolism. Health Phys. 29, 493-510 (1975).

6. Lloyd, R.D., Atherton, D.R., McFarland, S.S., Mays, C.W., Stevens, W., Williams, J.L., and Taylor, G.N. Studies of injected ${ }^{237} \mathrm{Pu}(\mathrm{IV})$ citrate in beagles. Health Phys. 30, 47-52 (1976).

\section{PLUTONIUM REMOVAL FROM MICE BY POLY(CATECHOYLAMIDE) LIGANDS, Ca-DTPA, DESFERRIOXAMINE B, AND TIRON: EFFECT OF LIGAND DOSAGE}

\section{Patricia W. Durbin, Nylan M. Jeung, E. Sarah Jones, ${ }^{\star}$ Kenneth N. Raymond," and Frederick L. Weitl*}

The effectiveness of a ligand for in vivo chelation of plutonium is determined by the properties, number, and configuration of its electron-donor groups and those of the biological ligands that complex it in the body. The efficiency of a ligand for in vivo $\mathrm{Pu}$ chelation, i.e., the amount of $\mathrm{Pu}$ excreted per unit of ligand administered, is the combined result of the stability of the Pu-ligand chelate, the tendency of the ligand to react with competing metals, and the achievement of an effective concentration of ligand in body fluids in spite of continuous ligand excretion. Linearly configured macromolecules containing catechoylamide (o-dihydroxybenzamide, CAM) functional groups joined by $\mathrm{n}$-alkyl chains form very stable $\mathrm{Pu}(\mathrm{IV})$ chelates, and their effectiveness for promoting $\mathrm{Pu}$ excretion has been demonstrated in mice and dogs. $^{1-4}$ The CAM ligands appear to be biologically stable (that point remains to be verified), and they are selective for small, highly charged cations like Fe(III) and Pu(IV), so there is little or no loss of ligand to degradation or to divalent metal complexation. $^{5}$ Maintenance of an effective concentration of ligand for sufficient time to intercept a significant amount of circulating $\mathrm{Pu}$ depends on the biolugical half-time of the ligand, which is the net result of ligand chemistry (structure, hydrophilicity, and molecular weight) and biochemistry (rates and routes of ligand excretion). One way to study the in vivo efficiency of a Pu-removal agent is to measure $\mathrm{Pu}$ excretion as a function of ligand dosage.
Evaluation of ligand dosage effectiveness also provides information about the rates of ligand reaction with circulating $\mathrm{Pu}$ and with $\mathrm{Pu}$ newly deposited on bone and liver cell surfaces, and a comparison of the efficiencies of new ligands with those in clinical use.

The ability of the ligands synthesized at LBL to chelate $\mathrm{Pu}$ in vivo is routinely tested at a dosage of $30 \mu \mathrm{mole} / \mathrm{kg}$ body weight. This dosage was chosen because it allows comparison of ligand potency with that of $\mathrm{CaNa}_{3}$-DTPA (DTPA, Fig. 1) at the dosage level used clinically. ${ }^{6}$ At that level, the tetrameric CAM ligands, 3,4,3-LICAM(C) and 3,4,3LICAM(S) (see Fig. 2 for structures and formulae), are as effective for removing $\mathrm{Pu}$ from mice and more effective for removing $\mathrm{Pu}$ from dogs than an equimolar amount of DTPA. ${ }^{2-4}$ The great stabilities of $\mathrm{Fe}(\mathrm{III})$ chelates with the CAM ligands, compared to ferric iron chelates with transferrin and with the ligands in clinical use, DTPA and desferrioxamine $B$ (DFOM, Fig. 1), suggested that the CAM ligands should be able to remove $\mathrm{Pu}$ from mice at dosages much lower than $30 \mu$ mole $/ \mathrm{kg}$.

Dosage-effectiveness (D-E) curves were prepared for three CAM ligands, 3,4,3-LICAM(C), 3,4,3-LICAM(S) and 4,4,4-LICAM(S) and the baseline ligands, DTPA and DFOM. The monomer Tiron (Fig. 1), was included because it complexes $\mathrm{Fe}$ (III) and is structurally similar to the sulfonated CAM ligands. Groups of five mice were given an intravenous injection of ${ }^{238} \mathrm{Pu}$ (IV) citrate followed 1

*Materials and Molecular Research Division, LBL. 


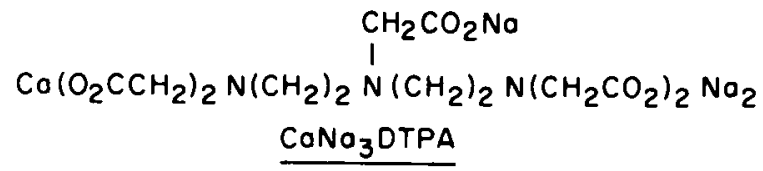<smiles>O=S(=O)(O)c1cc(O)c(O)c(S(=O)(=O)O[Na])c1</smiles>

"TIRON"

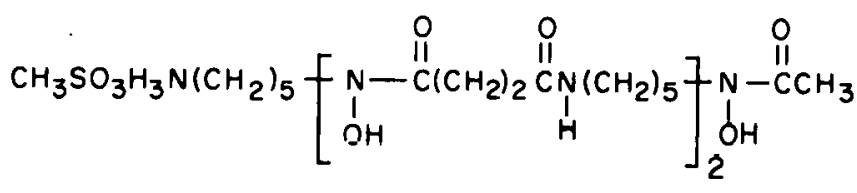

DFOM

\begin{tabular}{|c|c|c|}
\hline Abbreviotion & $\begin{array}{l}\text { Molccular formula } \\
\text { (weight) }\end{array}$ & Common nome \\
\hline $\mathrm{CoNo}_{3}$ DTPA & $\mathrm{C}_{14} \mathrm{H}_{18} \mathrm{~N}_{3} \mathrm{O}_{10} \mathrm{CoNo}_{3}$ (497.4) & $\begin{array}{l}\text { Diethylenetriominepentaocetate, } \\
\text { colcium irisodium solf }\end{array}$ \\
\hline "TIRON" & $\mathrm{C}_{6} \mathrm{H}_{4} \mathrm{O}_{8} \mathrm{~S}_{2} \mathrm{No}_{2}(3 / 4.2)$ & $\begin{array}{l}2,3 \text {-dihydroxy-1,5-benzenedisulfote, } \\
\text { disodium solf }\end{array}$ \\
\hline DFOM & $\mathrm{C}_{26} \mathrm{H}_{52} \mathrm{~N}_{6} \mathrm{O}_{11} \mathrm{~S}(656.8)$ & Desferrioxomine mesylate \\
\hline
\end{tabular}

Fig. 1.

(XBL 8312-4146)<smiles>[Y]c1cc(C(=O)N[Tl])c(O)c([Y])c1O</smiles>

\begin{tabular}{|c|c|c|c|c|c|}
\hline Abbreviation & $m n$ & $x$ & $Y$ & $\begin{array}{l}\text { Molecular formulo } \\
\text { ond (we ight) }\end{array}$ & IUPAC nome \\
\hline $3,4,3-L I C A M(S)$ & 34 & & & $\begin{array}{l}\mathrm{C}_{38} \mathrm{H}_{38} \mathrm{~N}_{4} \mathrm{O}_{24} \mathrm{~S}_{4} \mathrm{No}_{4} \\
(1155)\end{array}$ & $\begin{array}{l}N^{1}, N^{5}, N^{10}, N^{14} \text { - - Tetrakis }(2,3-d i- \\
\text { hydroxy-5-sulfobenzoyl) - tetra- } \\
\text { azafetradecone, fetrosodium salt }\end{array}$ \\
\hline 4,4,4-LICAM(S) & 44 & $\begin{array}{l}H \\
H\end{array}$ & $\begin{array}{l}-\mathrm{SO}_{3} \mathrm{No} \\
-\mathrm{SO}_{3} \mathrm{No}\end{array}$ & $\begin{array}{l}\mathrm{C}_{40} \mathrm{H}_{42} \mathrm{~N}_{4} \mathrm{O}_{24} \mathrm{~S}_{4} \mathrm{No}_{4} \cdot \\
4 \mathrm{H}_{2} \mathrm{O} \cdot \frac{1}{2} \mathrm{NO}_{2} \mathrm{SO}_{4} \\
(1183)\end{array}$ & $\begin{array}{l}N^{1}, N^{6}, N^{11}, N^{16} \text { - fetro(2.3-dihydroxy- } \\
5 \text {-sulfo-benzoyl)-tetroazohexadecane }\end{array}$ \\
\hline
\end{tabular}
$\begin{array}{rlll}\text { 3,4,3-LICAM(C) 3 4-CO2No H } & \mathrm{C}_{42} \mathrm{H}_{38} \mathrm{~N}_{4} \mathrm{O}_{20} \mathrm{NO}_{4} \\ & (1010)\end{array}$
$N^{1}, N^{5}, N^{10}, N^{14}-$ Tefrokis $(2,3-d i-$ hydroxy - 4-corboxybenzoyl) tetroazatetrodecone, tetrosodium solt

Fig. 2. 
sur later by an intraperitoneal injection of $0.5 \mathrm{ml}$ $\checkmark$ is isotonic saline containing the appropriate amount of a test ligand. Ligand dosage was reduced below $30 \mu \mathrm{mole} / \mathrm{kg}$ in threefold steps until $\mathrm{Pu}$ excretion was not different from the 24-hour controls, and it was increased in threefold steps until there was litthe additional $\mathrm{Pu}$ excretion above the preceding dosage level tested or until a toxic reaction was anticipated. ${ }^{2-4}$ Intermediate dosage points were added to verify trends or improve the definition of inflection points. Thirteen Pu-injected control mice were killed 1 hour after the $\mathrm{Pu}$ injection to define $\mathrm{Pu}$ distribution at the time ligands were administered and at 24-hours (19 groups of 5 mice) to define the distribution and excretion of $\mathrm{Pu}$ in untreated mice at the time treated mice were killed. Details of animal care, preparation of $\mathrm{Pu}$ and ligand solutions, injection and autopsy procedures, $\mathrm{Pu}$ assay methods, and data reduction have been reported. 2,3

Plutonium retention, mean \pm standard deviation, ${ }^{7}$ in control mice killed at 1 hour and 24 hours, respectively, was as follows: whole body, $93 \pm$ $2.7 \%$ and $91 \pm 6.7 \%$; skeleton, $24 \pm 4.2 \%$ and 32 $\pm 7.9 \%$; liver, $31 \pm 4.6 \%$ and $49 \pm 8.3 \%$; and soft tissue remainder (including kidneys), $37.6 \pm$ $4.9 \%$ and $9.7 \pm 2.0 \%{ }^{3}$ The mean Pu content of the body, skeleton and liver of the ligand-treated mice, plotted as a function of log ligand dosage, is shown in Figs. 3 to 5 . The D-E curves shown are the linear regression lines (or pairs of broken lines) fitted by least squares to the greatest number of data points that could be included without substantially reducing the correlation coefficient. Data for dosages less than the highest one that did not elicit $\mathrm{Pu}$ excretion in excess of the 24-hour controls were omitted from the fitting procedure. The S.D.s for the experimental groups, which ranged from 5 to $25 \%$ of the means, have been omitted from the plots for clarity. The results obtained for the two sulfonated CAM ligands were indistinguishable and were combined for the regression analysis. Their structures differ only slightly, in the lengths of the intergroup alkyl chains, and similar D-E behavior was expected.

Four ligand dosage benchmarks were selected for comparing ligand efficiency. An effectiveness threshold dosage was estimated by extrapolating the D-E curve for each tissue to the 24-hour $\mathrm{Pu}$ control content (mean \pm S.D. shown in the figures). The significantly effective ligand dosage was obtained by comparing the means of ligand-treated and 24-hour control groups with the t-test $(p<0.01) .^{7} \quad$ Efficiency for preventing additional $\mathrm{Pu}$ deposition after ligand administration, which approximates the ability of a ligand to clear circulating $\mathrm{Pu}$ from the body, was read from the $D-E$ curves, assuming that $20 \%$ of the $\mathrm{Pu}$ in liver and skeleton at 1 hour is in contained plasma, ${ }^{2}$ as follows: the ligand dosage required to reduce skeletal or liver $\mathrm{Pu}$ in treated mice to 19 and $25 \%$ of the injected activity respectively; or to reduce

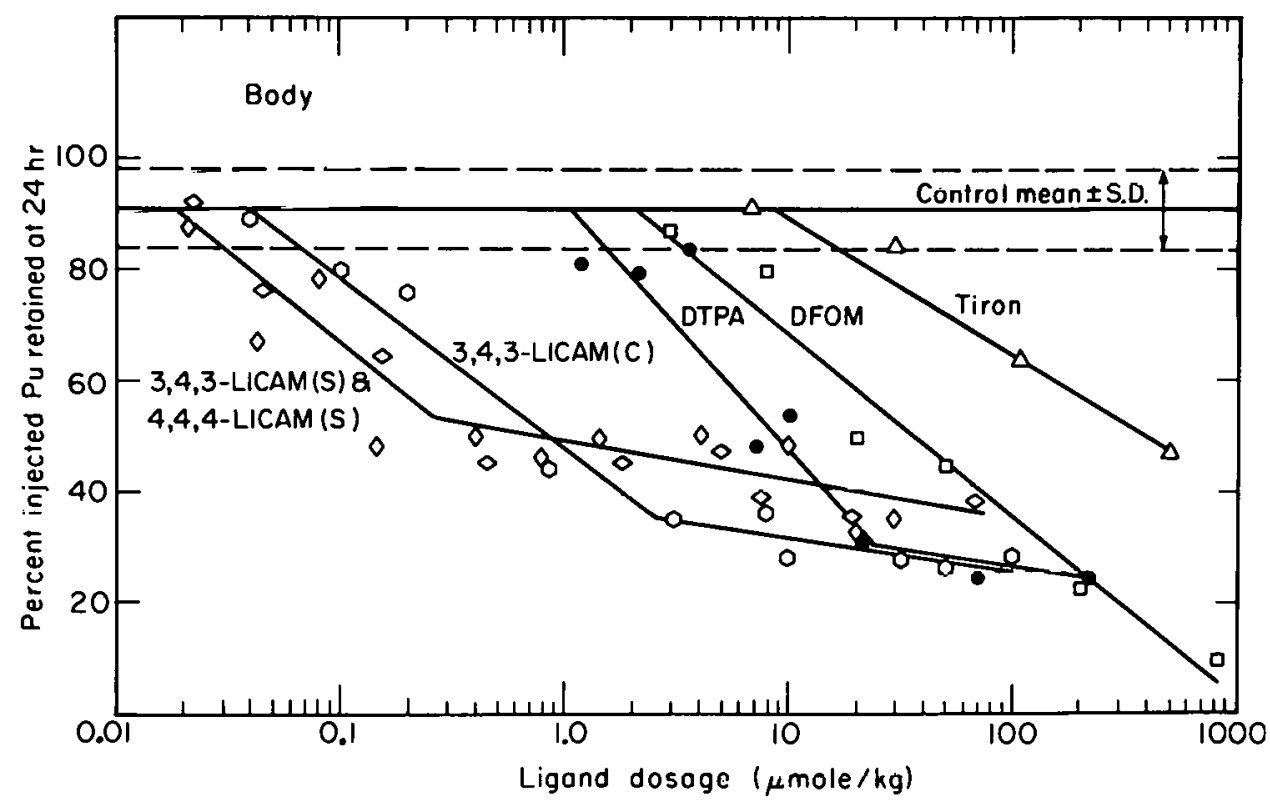

Fig. 3. Effect of ligand dosage on retention of $P u$ in the body of a mouse. 


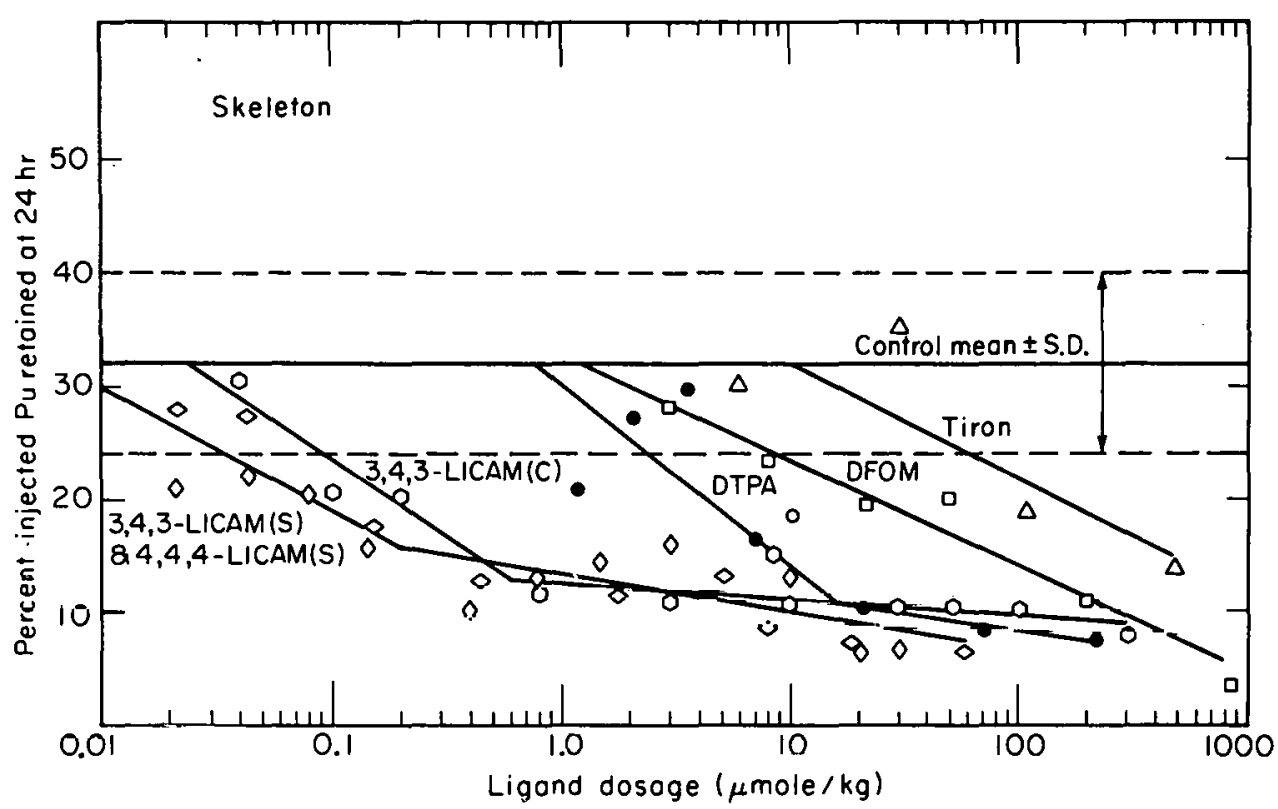

Fig. 4. Effect of ligand dosage on retention of Pu in the skeleton of the mouse. (XBL 8312-4149)
(1)

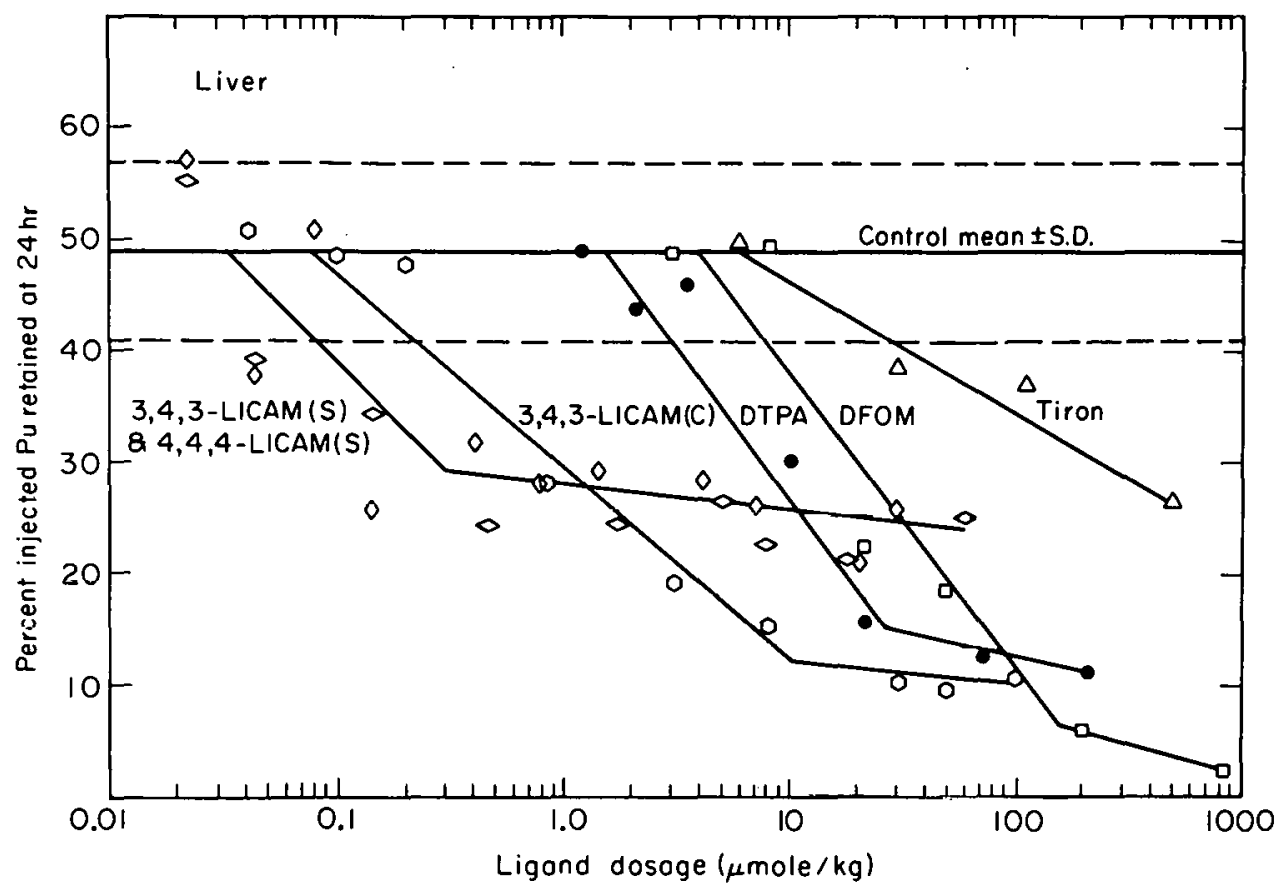

Fig. 5. Effect of ligand dosage on relention of Pu in the liver of the mouse.

(XBL 8312-4148) . 
he $\mathrm{Pu}$ in the whole body to $63 \%$ of the injected dctivity [24-hour control body content $(93 \%)$ minus the difference between the $\mathrm{Pu}$ in soft tissue remainder at 1 hour and 24 hours (27.9\%)]. Ligand efficiency for removal of some Pu already deposited but not yet firmly bound in the target tissues was estimated as follows: Ligand dosages were read from the D-E curves that reduced the $\mathrm{Pu}$ in skeleton and liver to $40 \%$ of the control Pu content at 1 hour $(9.6$ and $12.4 \%$ of the injected activity respectively), or reduced the $\mathrm{Pu}$ content of the body to $50 \%$ of the 24 -hour control content $(46.5 \%$ of the injected activity). The ligand dosages required to obtain that array of equal effects are collected in Table 1.

If efficiency is defined as production of the same effect with a smaller dosage, the CAM ligands are 10 to 100 times more efficient than DTPA for promoting excretion of circulating $\mathrm{Pu}$ (except that the sulfonated CAM ligands are less efficient than DTPA in removing $\mathrm{Pu}$ already deposited in the liver). Even at high dosages $(10 \mu \mathrm{mole} / \mathrm{kg})$, the sulfonated CAM(S) were more efficient than DTPA for removing loosely bound $\mathrm{Pu}$ from the skeleton; and 3,4,3-LICAM(C) was more efficient than DTPA for promoting removal of $\mathrm{Pu}$ from the liver. When 3,4,3-LICAM(S) and DTPA were each given to dogs at a dosage of $30 \mu \mathrm{mole} / \mathrm{kg}$, the combination was not more effective than 3,4,3-LICAM(S) alone, ${ }^{4}$ because both ligands were acting on $\mathrm{Pu}$ in the same tissues to the same degree. However, 3,4,3LICAM $(C)$, with its more efficient action on $\mathrm{Pu}$ in the liver, should in combination with DTPA or with a sulfonated CAM ligand produce more Pu removal than an equimolar amount of either ligand alone.

The overall efficiencies of the six ligands for removing $\mathrm{Pu}$ are in the same order as the stabilities of their 1:1 complexes (or chelates) with Pu(IV) and Fe(III): CAM ligands $>$ DTPA $>$ DFOM $>>$ Tiron $(1,5,8)$, confirming the view that metal-chelate stability is a major determinant of in vivo ligand efficiency.

The effectiveness thresholds, intercepts of the initial limbs of the $D-E$ curves with the control means, appear to depend mainly on Pu-ligand chelate stabilities. However, the intercepts of the final portions of the D-E curves, except for the behavior of the sulfonated CAM ligands with respect to $\mathrm{Pu}$ in the liver, and the slopes of both initial and final limbs of the D-E curves were similar and in some cases, identical. The tendency toward common trends in the D-E curves for ligands with such a wide range of chemical properties and $\mathrm{Pu}$ chelate stabilities suggests that physiological and biochemical factors such as rates of ECF circulation and ligand excretion limit the ability of these ligands to remove the $\mathrm{Pu}$ already deposited in tissues.

\section{REFERENCES}

1. Kappel, M.J. Complexation of Pu and Am by Catecholate Ligands. Thesis, University of California, Berkeley (1983).

2. Durbin, P.W., Jones, E.S., Raymond, K.N., and Weitl, F.L. Specific sequestering agents for the actinides. 4. Removal of ${ }^{238} \mathrm{Pu}$ (IV) from mice by sulfonated tetrameric catechoylamides. Radiat. Res. 81, 170-187 (1980).

3. Durbin, P.W., Jeung, N., Joncs, E.S., Weitl, F.L., and Raymond, K.N. Specific sequestering agents for the actinides. 10. Enhanced elimination of ${ }^{238} \mathrm{Pu}$ from mice by poly(catechoylamide) ligands. Submitted to Radiation Research, June 15, 1983.

4. Lloyd, R.D., Bruenger, F.W., Atherton, D.R., Jones, C.W., Taylor, G.N., Stevens, W., Mays, C.W., Durbin, P.W., Jeung, N., Jones, E.S., Kappel, M.J., Raymond, K.N., and Weitl, F.L. Removal of $\mathrm{Pu}$ or Am from beagles and mice by 3,4,3-LICAM(C) or 3,4,3-LICAM(S). Submitted to Radiation Research, June 15, 1983.

5. Kappel, M.J., and Raymond, K.N. Ferric ion sequestering agents. 10 . Selectivity of sulfonated poly(catechoylamides) for ferric ion. Inorg. Chem. 21, 3437-3442 (1982).

6. Lloyd, R.D., McFarland, S.S. Yaylor, G.N., Williams, J.L., and Mays, C.W. Decorporation of ${ }^{241} \mathrm{Am}$ in beagles by DTPA. Radiat. Res. 62, 97-106 (1975).

7. Fisher, R.A. Statistical Methods for Research Workers, 12th ed., Hafner Publishing Co., New York (1954).

8. Harris, W.R., Raymond, K.N., and Weitl, F.L. Ferric ion sequestering agents. 6. The spectrophotometric and potentiometric evaluation of sulfonated tricatecholate ligands. J. Amer. Chem. Soc. 103, 2668-2675 (1981). 
Table 1. Benchmarks of ligand effectiveness for promoting excretion of ${ }^{238} \mathrm{Pu}$ from mice. ${ }^{\mathrm{a}}$

\begin{tabular}{|c|c|c|c|c|}
\hline \multirow[b]{2}{*}{ Ligand and Tissue } & \multicolumn{4}{|c|}{ Effect at ligand dosage ( $\mu$ mole $/ \mathrm{kg}$ ) } \\
\hline & $\begin{array}{l}\text { Pu reduction } \\
\text { threshold }^{\mathrm{b}}\end{array}$ & $\begin{array}{c}\mathrm{Pu}<24-\mathrm{hr} \\
\text { control }^{\mathrm{c}}\end{array}$ & $\begin{array}{l}\text { Prevent Pu } \\
\text { deposition }\end{array}$ & $\begin{array}{c}\text { Remove } 50 \% \\
\text { of } 1-\mathrm{hr} \mathrm{Pu} \\
\text { content }^{\mathrm{e}} \\
\end{array}$ \\
\hline \multicolumn{5}{|l|}{ 3,4,3-LICAM(C) } \\
\hline Body & 0.04 & 0.1 & 0.3 & 1 \\
\hline Liver & 0.08 & 0.8 & 2.0 & 10 \\
\hline Skeleton & 0.02 & 0.1 & 0.2 & 150 \\
\hline \multicolumn{5}{|l|}{$\begin{array}{l}\text { 3,4,3-LICAM(S) and } \\
4,4,4-L I C A M(S)\end{array}$} \\
\hline Body & 0.02 & 0.04 & 0.1 & 2.5 \\
\hline Liver & U.us & $U .14$ & 20 & $>1000$ \\
\hline Skeleton & 0.007 & 0.02 & 0.09 & 10 \\
\hline \multicolumn{5}{|l|}{$\mathrm{CaNa}_{3}$-DTPA } \\
\hline Body & 1 & 7 & 4.5 & 11 \\
\hline Liver & 1.4 & 7 & 12 & 100 \\
\hline Skeleton & 0.8 & 7 & 4.5 & .35 \\
\hline \multicolumn{5}{|l|}{ DFOM } \\
\hline Body & 2 & 8 & 15 & 50 \\
\hline Liver & 4 & 20 & 30 & 95 \\
\hline Skeleton & 1 & 20 & 30 & 320 \\
\hline \multicolumn{5}{|l|}{ Tiron } \\
\hline Body & 8 & 110 & 120 & 480 \\
\hline Liver & 6 & 30 & 700 & $>>1000$ \\
\hline Skeleton & 10 & 110 & 180 & $\sim 1800$ \\
\hline
\end{tabular}

a Graded amounts of ligand were administered i.p. at $1 \mathrm{hr}$ and mice were killed $24 \mathrm{hr}$ after i.v. injection of ${ }^{238} \mathrm{Pu}$ (IV) citrate; five mice per dosage point.

b Threshold is the ligand dosage at which the extrapolated D-E regression lines (Figs. 3,4,5) intercepts the 24-hr control value.

c Ligand dosage to reduce tissue Pu content significantly below the 24-hr control value $(p<0.01)$.

d Ligand dosage that reduces Pu content of bone or liver at $24 \mathrm{hr}$ to $80 \%$ of the Pu content of those tissues of 1 -hr controls (read from D-E regression lines of Figs. 3,4,5): $20 \%$ of the control tissue $\mathrm{Pu}$ at $1-\mathrm{hr}$ is assumed to be in contained plasma, and $80 \%$ to be "deposited." In the case of whole body the ligand dosage tabulated is that required to remove the Pu circulating in ECF at the time of ligand administration, i.e., Soft Tissue $\mathrm{Pu}$ at $1 \mathrm{hr}$ - Soft Tissue Pu at $24 \mathrm{hr}=37.6 \%-9.7 \%=27.9 \%$ of the injected Pu.

e Ligand dosage that reduced Pu content of liver or skeleton at $24 \mathrm{hr}$ to $40 \%$ of the Pu content of those tissues of $1-\mathrm{hr}$ controls (read from D-E regression lines of Figs. 3,4,5): $80 \%$ of the $1-\mathrm{hr}$ Pu content is assumed to have been deposited (see footnote d), so this degree of Pu reduction represents removal of onehalf of the Pu that was deposited in tissues at the time of ligand administration. In the case of whole body, the ligand dosage tabulated is that required to reduce the $\mathrm{Pu}$ content at $24 \mathrm{hr}$ to 50 of the $1 \mathrm{hr}$ value, i.e., $93 \% \times 0.5=$ 46.5\% of the injected Pu. 


\section{SECTION 4. RADIATION BIOPHYSICS}

\section{INTRODUCTION}

The common research goal of the Radiation Biophysics Group is to study cancer as a group of cellular diseases. We have established an interdisciplinary approach to this problem, and the members of our group have expertise in the fields of physics, chemistry, biology, and medicine.

Many of our studies are carried out with highenergy heavy ions accelerated at the Bevalac. With heavy-ion beams it is possible to deliver precisely localized radiation to any part of the body and to control the quality or the rate of energy transfer. Our ability to accelerate heavy ions to high energies is unique, and our program is part of a national effort supported jointly by the Department of Energy and the National Cancer Institute. The major questions being studied center around the basic cellular mechanisms whereby heavy ions exert their biological effects, and our primary concern is to assess the potential value of heavy ions to treat cancer and certain abnormalities in the nervous system. Because high-energy heavy ions occur naturally in space, our group is also studying the possible deleterious effects of space radiation and the mechanisms of carcinogenesis.

A good deal of evidence has accumulated to show that both light and heavy ions effectively destroy tumors that are located near sensitive structures, with little damage to the sensitive structure. Some of these locations are inaccessible both to surgery and to conventional radiation. One example of using highly localized radiation is the helium-ion treatment of a malignant melanoma located inside the choroid of the retina (Saunders et al.). In most cases, this type of cancer is treated by removing the entire eye. With helium-ion therapy, however, normal vision can be retained if the tumor is not located on or near critical structures of the eye. Of the 200 patients treated to date, over $90 \%$ have had their cancers arrcsted and have retained their vision.

Local particle therapy also seems effective for sarcomas that are adjacent to the spinal cord; other methods of treatment have not been successful with these tumors. The deleterious effects on the cord itself, which might occur from treatment with onventional radiation, can be minimized with eavy charged particles. Another local application is the treatment of arteriovenous malformations in the brain using Bragg peak particles. These congenital blood vessel malformations can hemorrhage at any time, and they present a continuous hazard to the patient (see Donner Pavilion Section, Fabrikant et al.). Currently, the Bragg peak of the helium-ion beam is used for focal radiation therapy. The radiation causes the defective blood vessels to occlude, resulting in the redirection of their blood flow to other vessels. More than 50 patients have been treated to date, and preliminary results show the danger of hemorrhage from the treated malformation to be considerably reduced.

Our group has gathered data on the radiobiological properties of several heavy-ion particles, including carbon, neon, silicon, and argon. For the purposes of highly localized beam therapy, carbon and neon beams appear to be the most useful; however, to take advantage of the special radiobiological properties of their beams, silicon or argon might be particularly useful. We have made an initial assessment of neon, silicon, and argon particles for their therapeutic efficacy in patients. Protocols are now being written for statistically controlled therapy trials, in which 1) conventional radiation will be compared with helium ions, and 2) helium ions will be compared with one of the heavier ions, probably silicon. Chen et al. have developed special therapy planning techniques, and Castro et al. report that about 200 cancer patients have received heavy-particle therapy at the Bevalac.

We have developed adequate techniques to deliver heavy-ion beams for and biological use by using lead to scatter heavy-ion beams and by using rotating spiral-ridge filters. Nevertheless, much needed research is still in progress to improve the quality of the biomedical beam delivery by accurate scanning of the beam. Schimmerling et al. are studying the fragmentation of beam particles when they collide with target nuclei.

Heavy accelerated ions have some very special properties that in future might be useful to biomedical research and therapy. Alpen et al. describe the use of heavy radioactive beams generated at the Bevalac for accurately measuring the depth of certain tissue structures. Radioactive beams might soon be routinely used for cancer therapy. Another special technique is just beginning to be developed. Phillips et al. describe heavy-ion 
microscopy, and we believe that in the near future it might prove to be a useful technique to study chromosome aberrations.

The structure of heavy-ion tracks in matter determines the nature of the molecular effects they cause. Chatterjee and Magee have recently analyzed the production of single- and doublestrand scissions produced in DNA by various heavy ions. Roots et al. have characterized the role hydroxyl radicals play in the cellular effects of these particles. The effects of heavy-ion beams on integrated tissues are particularly relevant and applicable to medicine. Alpen et al. have studied the effects on lungs; Ainsworth et al. present data on blood-forming organs; Rodriguez has used multicellular spheroid cultures to assess the effects of heavy-ion beams and has highlighted the role of repair of potentially lethal damage in radiation effects on organized tissues.

In 1982 it became possible for the first time to accelerate the heaviest nuclei in the periodic table at the Bevalac, and in 1983 we performed the first biological experiments on the cellular and chromosomal effects of uranium beams. We are interested in uranium particles because of their extremely high rate of energy transfer. Our studies are conducted in collaboration with Doctors Gerhard and Wilma Kraft from the GSI heavy-ion accelerator laboratory in Darmstadt, Germany, where low-energy beams of very heavy ions have been under study for some time. The Krafts have shown that a single uranium ion can shatter the chromosomes of mammalian cells.

Earlier we developed a model for the cellular effects of radiation, the repair-misrepair model, which suggests that the complex responses of living cells to particle radiation can be separated into two parts, the production of lesions in cellular DNA and the cellular repair responses to those lesions. In the past it has not been possible to separate experimentally these two types of responses, but, we have now made good progress on the problem by studying cells from patients with a genetic disea: Patients with the homozygous form of ataxia telaugiectasia have cells that are very sensitive to ionizing radiation and to accelerated heavy ions. Our analysis indicates that these cells are suitable for measuring the quantity of radiation injury in vivo because the cells cannot successfully repair radiation lesions. The probability of producing lethal effects in ataxia cells, therefore, gives a measure of the probability of inducing radiolesions.

We have used human cells to quantitate the effects of mixed heavy-ion beams, which are diluted by the particle fragments produced as the beams pass through matter (Blakely et al.). A new set of experiments has begun lu measure the effects of heavy particles combined with chemical radiosensitizers. We are using the compound SR2508, developed at the Stanford Research Institute, which is less toxic to humans than the chemical sensitizers used earlier in medicine. $M$. Austin-Seymour et al. demonstrated that SR2508 can reduce the radiobiological oxygen effect by a factor of two.

The biophysical approach also includes the building of quantitative models for cellular processes. S.B. Curtis has recently proposed a lethal, potentially lethal model to explain some radiobiological phenomena. H.C. Mel has been concerned for some years about the basic thermodynamical description of nonequilibrium systems, such as living cells. An account of the delicate rheological studies of cell membranes is also given.

Perhaps the most interesting studies in our group this year relate to the ability of heavy accelerated ions to enhance the degree of transformation from normal cells to tumor cells that can be produced by oncogenic viruses (Yang et al.). The modifying effects of heavy ions on this process can be substantial: under certain conditions a dose of neon or argon ions can increase the yield of transformed cells by a factor of 10 or more. 


\section{Radiation Therapy}

\section{RADIOTHERAPY PHYSICS}

\section{George T.Y. Chen, J. Michael Collier, Sandra R. Zink, Samuel Pitluck, " and Todd Richards}

The Radiotherapy Physics Group is involved in a broad spectrum of activities in technical support of the clinical heavy charged particle radiotherapy trials at the Lawrence Berkeley Laboratory. Activities include treatment planning code development, dosimetry to verify the validity of the computational algorithms used, techniques for comparing rival treatment plans, and clinical physics support for patient treatment. Highlights of research and development activities in the past year are reviewed. The projects described here are part of a presentation given at the annual meeting of the American Association of Physics in Medicine, held in New York in August, 1983.

\section{TREATMENT PLANNING STUDIES}

Charged particle treatment plans have been calculated for a case involving irradiation of pelvic and para-aortic nodes and compared with state of the art photon treatment plans. Such studies are intended to examine the dose localization advantages of charged particle beams at specific sites. The rationale for irradiation of pelvic and paraaortic nodes in the treatment of primary pelvic tumors is the high probability of spread to these regional lymph nodes. As noted by Chin et al., ${ }^{1}$ standard photon irradiation of this type can lead to a high complication rate. More effective methods of dose delivery to para-aortic and pelvic lymph nodes might result in increased cure. In this study, dose distributions for helium- and neon-ion beams were calculated for a three-dimensional target volume and compared with conventional and dynamic photon irradiation techniques. Dose volume histograms were used to evaluate irradiation of adjacent critical structures.

The target spanned 14 axial slices and included the para-aortic nodes and a highly irregular $U$ shaped target volume in the pelvis to cover the lymphatics. This three-dimensional target volume was then treatment planned with charged particle beams, and isoeffective dose distributions were

Engineering and Technical Services Division, Electronics ?esearch and Development Group, LBL. generated. Integral dose volume histograms were calculated for the kidneys, target, liver, small bowel, transit portion of the duodenum, and spinal cord.

The dose volume histograms from particle plans were compared with published values for optimized photon irradiation of the identical target volume. Three photon treatment plans developed by $\mathrm{Chin}^{1}$ were used for this comparison: 1) a four-field box and 360-degree rotation (CP1), 2) a four-field box, 360-degree rotation, and anterior-posterior opposed fields (CP2), and 3) computer controlled radiation therapy (CCRT), where five longitudinal scans with 4- $\mathrm{cm}$ wide $\mathrm{x}$-ray beams were used. In the last mode, conformation of the high-dose region to the target volume was achieved by matching collimator dimensions to the projected target dimensions.

Figures $1 \mathrm{a}$ and $1 \mathrm{~b}$ show representative isoeffective dose distributions for one slice using charged particle beams. Figure $1 \mathrm{a}$ is treatment planned with opposed anterior-posterior helium-ion beams, where compensation has been used to match the beam stopping region with the distal target contour. Figure $1 \mathrm{~b}$ is a similar plan using neon beams. Figures 2a-f show dose volume histograms comparing the irradiation techniques. These histograms show substantial reduction in normal tissue dose when charged particles are used. In particular, because of the finite range of charged particles, and the ability to produce biologically uniform dose from single fields, the target in this study may be irradiated with a pair of opposed fields. In this field arrangement, the kidneys, and to a great extent the liver, are geometrically excluded from the irradiated field. In contrast, to more evenly spread the high-dose transit region with photon techniques, multiple fields (four or more) are generally used, necessarily irradiating substantial portions of these critical structures.

As shown in Fig. 2a, substantially less small bowel is irradiated with particles, particularly in the dose range between $0 \%$ and $60 \%$ of tumor dose. No bowel is irradiated by particles to greater than $70 \%$ of the tumor dose. In Fig. $2 \mathrm{~b}$ relatively small differences exist between the best photon therapy (CCRT) and particles with respect to the duodenum. Irradiation with helium is slightly better than 

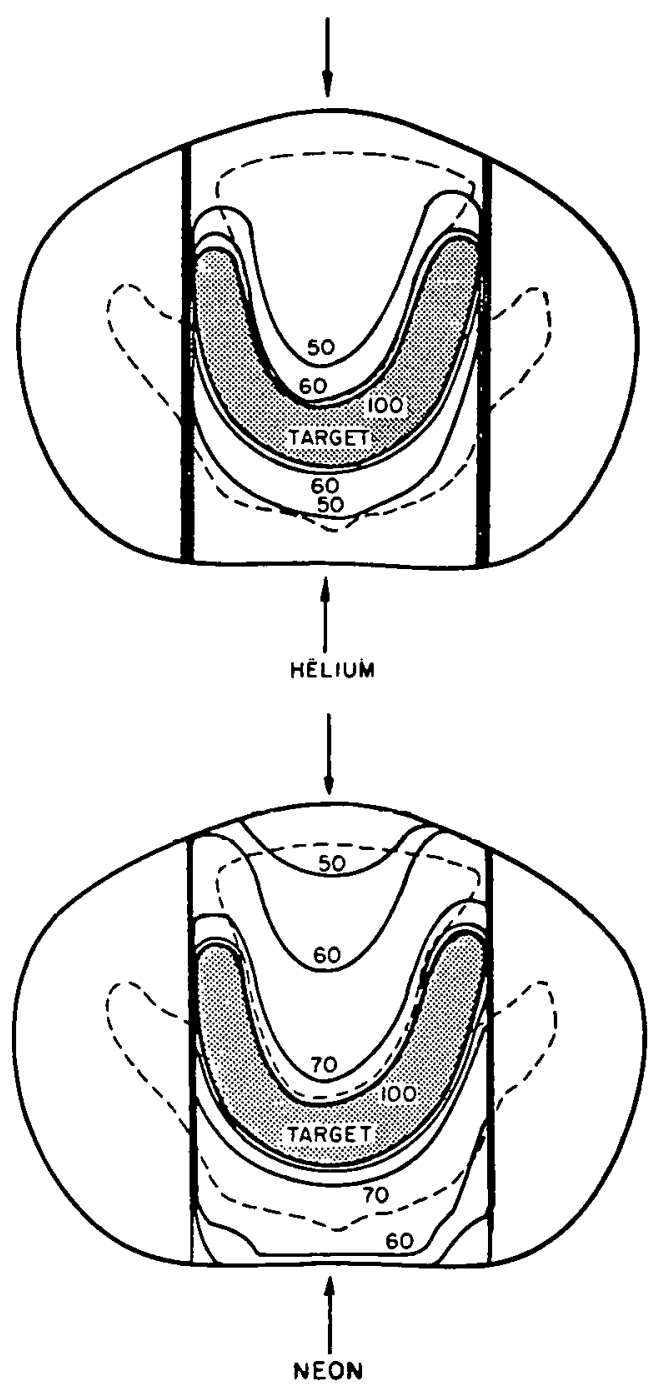

Fig. 1. Representative isoeffective dose distributions for one level, comparing helium and neon ion beams.

(a: $X B L 837-3869, b: X B L 837-3870$ )

CCRT. In Figs. $2 \mathrm{c}$ and $2 \mathrm{~d}$ no dose is given to either kidney by particles beams, as mentioned before. CCRT and standard photon therapy irradiate one half of the kidney mass to about $20 \%$ or greater tumor dose. In Fig. $2 \mathrm{e}$ much less liver is irradiated by particles; $70 \%$ of the liver receives no dose from particle plans. Approximately $70 \%$ of the liver receives $35 \%$ of the tumor dose or more from the three photon plans. In Fig. $2 f$ dose to spinal cord from particles is approximately the same as from CCRT. One factor to be considered is a possible differential RBE for high-LET particles for this structure.

High dose gradients as seen in particle plans require precision alignment and stability of target volume over extended periods of time. To ensure target irradiation with possible motions presen margins may have to be enlarged. Effects of this field enlargement on the dose volume histographs are under analysis.

\section{DOSIMETRY}

In the past year, CR-39 has been evaluated as a dosimeter for heavy-ion therapy beams. This work has been performed in collaboration with Doctors E.V. Benton, R. Henke, and R. Cassou of the Physics Department of the University of San Francisco, Doctors J. Llacer, W. Holley, and J.T. Lyman at LBL, and Dr. T. Kanai of the NIRS, Chiba, Japan.

CR-39 is a thermoset plastic that is very sensitive to heavy-ion damage. ${ }^{2-5}$ The principal advantage of this detector in heavy charged particle clinical dosimetry is that it records both radiation dose and quality. Particle fluence is measured over a sheet of the detector by scanning with a computer-controlled microscope and digitizer. LET is determined by sorting the etched holes according to size. Calibration of the LET determination is achieved by exposing the material to known radiations. The wide dynamic range of this material permits the recording of tracks in the entire radiation field, including both the plateau and fragmentation tail. Data demonstrate that tracks are recorded from low LETs of about $15 \mathrm{keV} / \mathrm{micron}$ to very high LETs. Integration of the LET spectra yields the dose. When thin sheets of this detector are interspersed within a phantom, information on radiation dose and quality may be obtained in three dimensions. These dosimetry data are essential in 1) characterization of heavy charged particle radiation fields used in therapy and 2) mapping dose and radiation quality in complex compensated fields used in individual patients.

Initial studies have emphasized uncompensated "open field" measurements. Sheets of CR-39 were placed in a polyethylene phantom both along the central axis of the beam and in various radial positions. These dosimeters were exposed to both accelerated monoenergetic and spread Bragg peak neon beams. Samples were placed in the plateau, proximal, mid and distal spread Bragg peak region of a $12-\mathrm{cm}$ spiral-ridge filtered beam. The sheets were developed (etched) and digitized with a Quantamet scanning microscope system. Shape factor analysis is used in track acceptance criteria. Individual track diameter is correlated to LET (infinity in water) through a calibration curve. The $C R$ 39 spectra were compared with those obtainer with BERKLET, a solid state detector. ${ }^{6}$ 


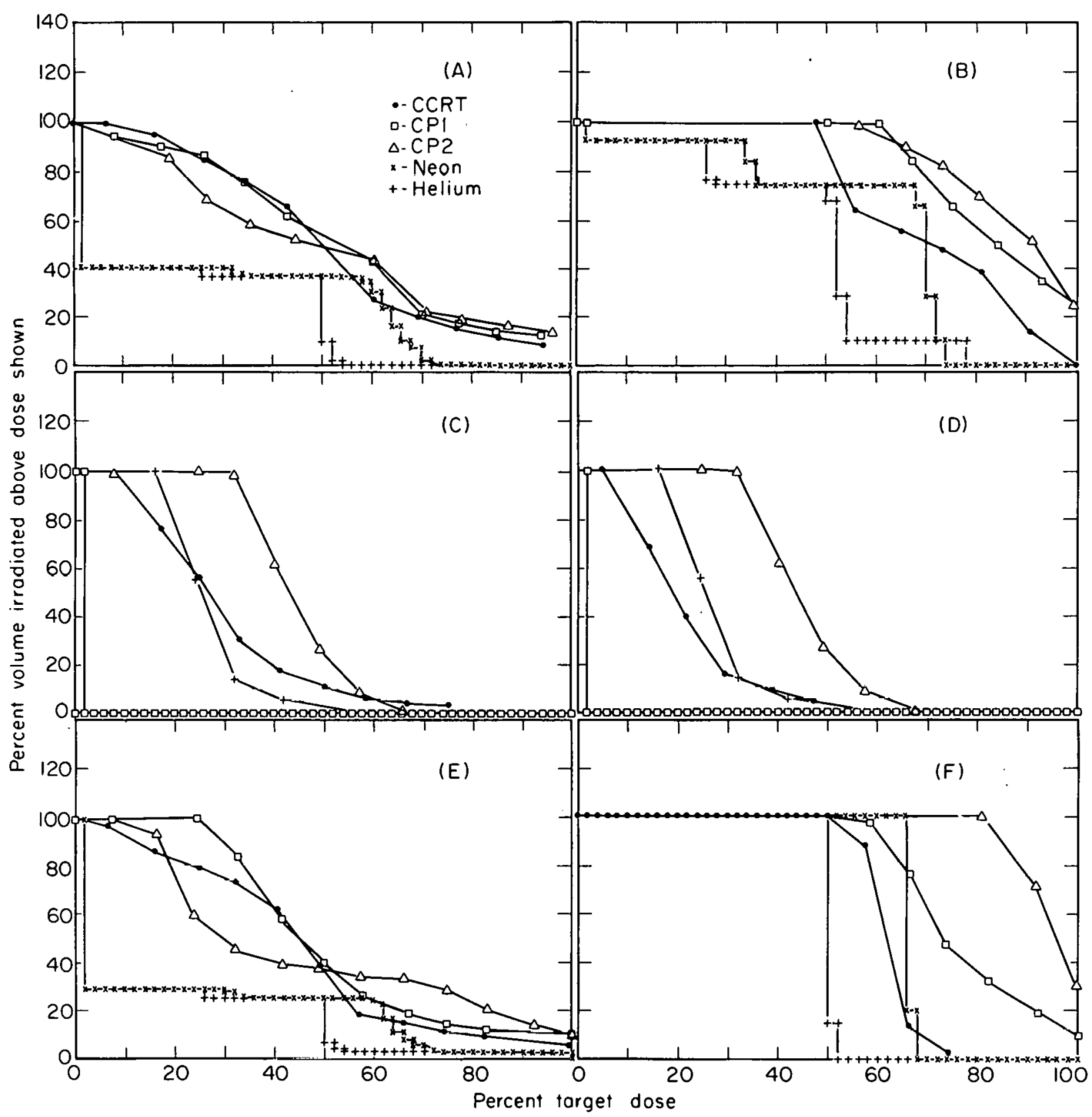

Fig. 2. Dose volume histograms comparing irradiation techniques for six critical structures. See text for symbol definition.

(XBL 8311-4112)

\section{UNSPREAD NEON BRAGG PEAK SPECTRA AND DOSE}

A comparison of spectra from CR-39 and Berklet are presented in Fig. 3, where smooth curves show Berklet data and curves with open boxes denote CR-39 measurements. Figure 3a includes ' $: T$ spectra for neon in the plateau region of the sam (residual range 30.42). The data were nor...alized at peak height. Agreement between the spectra is excellent, and both techniques show the LET spectra peak at approximately $2.7 \mathrm{keV} /$ micron.

Agreement between CR-39 and Berklet spectra at other residual ranges is good (see Figs. $3 b-f$ ). The neon spectra peaks for CR-39 and Berklet agree within a few $\mathrm{keV} / \mathrm{micron}$. The spectra from Berklet appear to be slightly narrower. The present optical digitizer used in CR-39 data analysis introduces a few percent spread into the measured track 


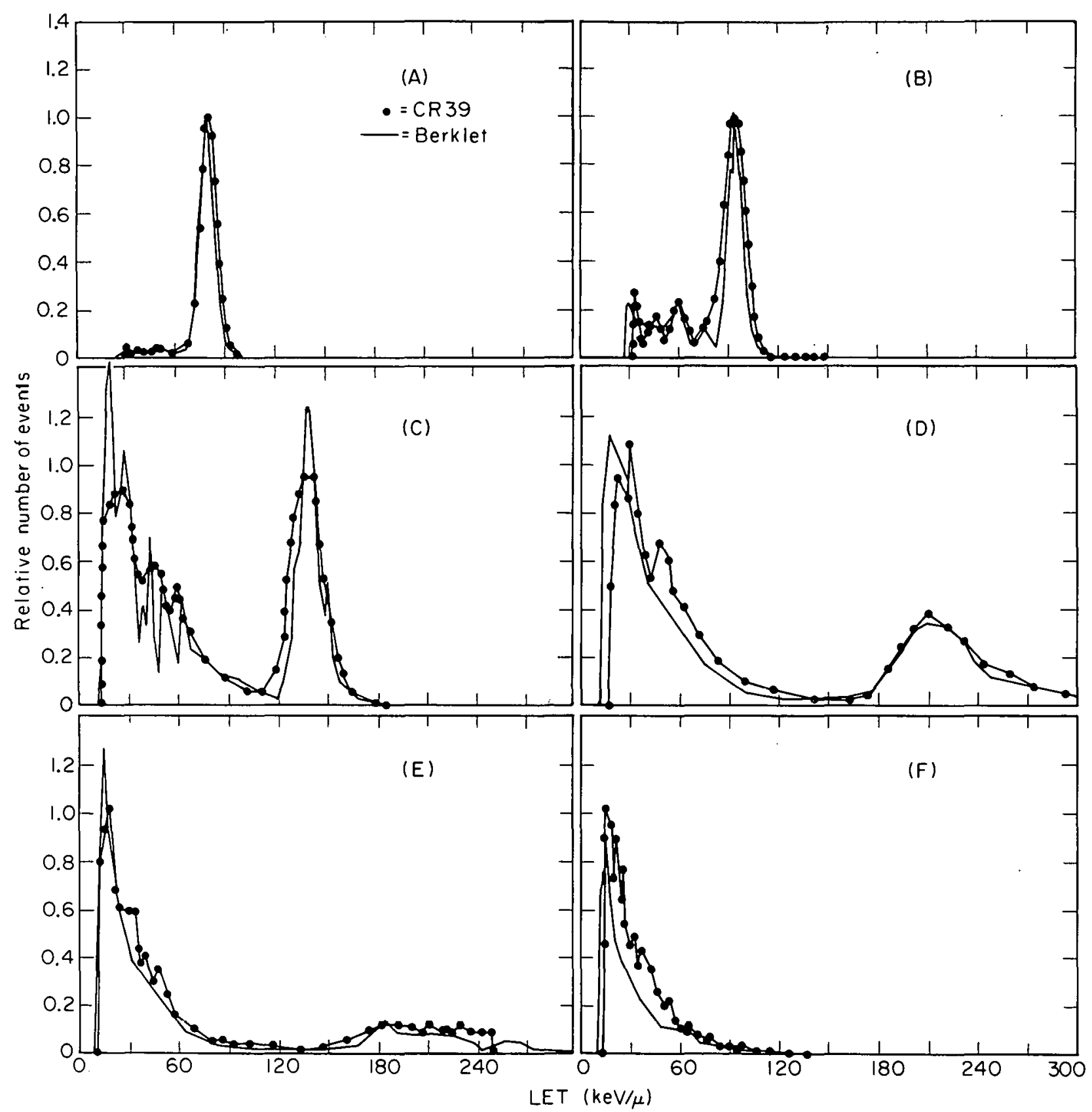

Fig. 3. Comparison of LET spectra from Berklet data (smooth curves) and CR-39 measurements (curves with solid circles) for radiations with various residual ranges.

(XB́L 8311-4110)

diameters. This will be calibrated out in future analyses. Approximately 6500 tracks were used in generating each CR-39 histogram. The number of events in the Berklet spectra are about $1 / 3$ this number. Some of the differences in the spectra are due in part to low statistics in the Berklet runs.

The integrals of these spectra are proportional to the relative dose in depth. Agreement between the depth dose integrated from CR-39 spectra and ion chamber measurements is generally within a few percent. No direct correlation between integrated CR-39 spectra and dose on the central axis is currently available. Rather, while awaiting further measurements, we note that CR-39 and Berklet spectra appear to be very similar, and Berklet data agree with ion chamber measurement: Therefore we expect CR-39 to have similar agree ment. Experiments using scintillation counters as 
seam monitors are planned in the near future in urder to directly establish the accuracy of CR-39 in the measurement of relative dose. We currently estimate this to be approximately $5 \%$.

\section{SPREAD BRAGG PEAK SPECTRA}

Preliminary data for the $12-\mathrm{cm}$ SOBP neon beam are shown in Fig. 4 for four points in the spread Bragg peak. Agreement between CR-39 and Berklet spectra in the spread out Bragg peak appears to be sumewhat worse than in the monoenergetic beam. In the plateau, the spectra peaks are distinctly separate by approximately 3 $\mathrm{keV} /$ micron. In the proximal peak (Fig. 4b), this spread increases to approximately $5 \mathrm{keV} /$ micron or about $12 \%$. At distal peak (Fig. 4c), although the magnitude of the difference in the primary peak position is approximately $2-3 \mathrm{keV} /$ micron, the relative sign is reversed. At this point, CR-39 data produce spectra with the primary beam peak position at a lower LET than the Berklet. Data in the fragmentation tail are inconclusive. The ambiguity in these data are complicated by the fact that they were taken on two different days separated by six weeks. Although identical setup and beam optics were strived for, there is no guarantee that they were achieved. These experiments are planned to be repeated.

We are encouraged by these preliminary results that suggest that CR-39 has a role to play in clinical dosimetry. Although this technique needs to be refined and understood in more detail before being routinely implemented, the current results suggest such developmental work is warranted. Factors that influence the applicability of CR-39 to clinical dosimetry include the presence of noise on the detector surface (imperfections that result in etched pits), leading to background events, even at high LET, and the low energy cutoff of the detector for charged particles with an energy loss of less than $15 \mathrm{keV} /$ micron. Although the percentage of lowLET particles (less than $15 \mathrm{keV} /$ micron) can be quite large $(20 \%$ or greater) relative to the fraction of primary particles, their contribution to the dose is small (on the order of a $6 \%$ of the primary beam at residual ranges of a monoenergetic neon beam of $2 \mathrm{~cm}$ or less).

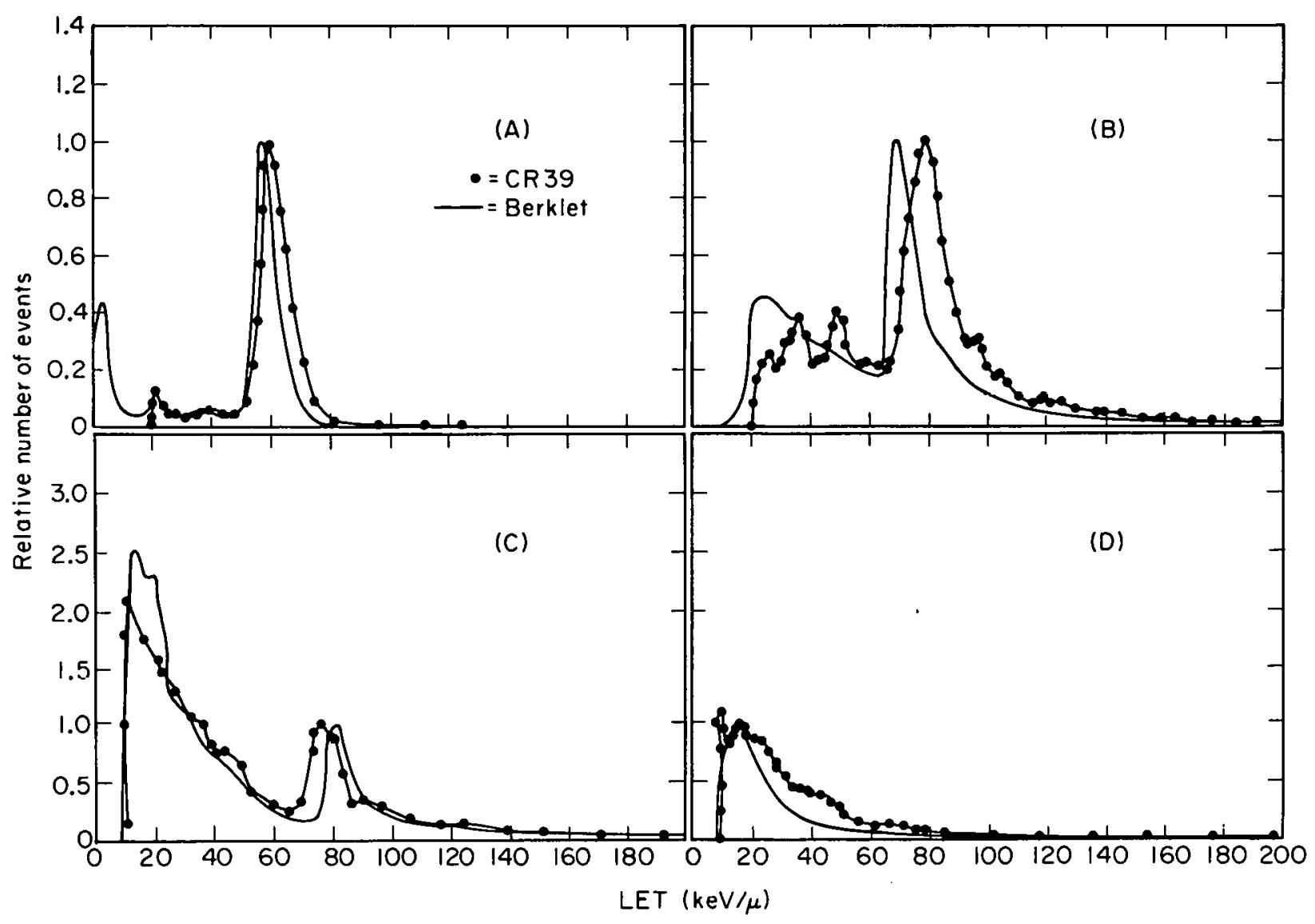

Fig. 4. Preliminary LET spectra for the 12-cm spread out Bragg peak neon beam. 


\section{PHANTOM DEVELOPMENT}

Multisection phantoms have been constructed and evaluated for treatment planning verification of heavy charged particle radiotherapy. This work has been done in collaboration with Dr. Cari Borras of the West Coast Cancer Foundation. The phantoms are based on tissue substitutes formulated by White and Constantinou and are cast to represent typical cross sections of the head or body. The first section of the phantom also contains conical cavities which are used to determine the effective energy of the scanner at points of interest. The third section allows direct dosimetric measurements. The accuracy of algorithms to convert CT number to relative stopping power will be retested, and measurements of dose at specific points within the phantom will be compared with calculated values. In particular, these phantoms will be used to follow the entire treatment planning process from $C T$ to dose delivery and to document the current accuracy of dose delivery and distribution of beam quality within anthropomorphic phantoms.

\section{REFERENCES}

1. Chin, L.M., et al. Int. J. Rad. Onc. Bio. Phys. 7, 61-70 (1981).

2. Cartwright, B.G., Shirt, E.K., and Price. P.B. A nuclear tract recording polymer of unique sensitivity and resolution. Nucl. Inst. Meth. 153, 457-460 (1978).

3. Cassou, R., and Benton, E.V. Properties and application of CR-39 polymeric nuclear track detector. Nuclear Track Detection 2, 173 (1978).

4. Francois, H., Kurtz, N., Massue, J., Monnin, M., Schmitt, R., and Durrant, S., eds. Solid State Nuclear Track Deteclors. Pergamon Press (1980).

5. Fowler, P.H., and Clapham, V.M., eds. Solid State Nuclear Track Detectors. Pergamon Press (1980).

6. Henshaw, D.L., Griffiths, N., Landen, O.A.L., and Benton, E.V. A method of producing thin CR-39 plastic nuclear track detectors and their application in nuclear science and technology. Nucl. Instrum. Meth. 180, 65 (1981).

\title{
TREATMENT OF CANCER WITH CHARGED PARTICLES HEAVIER THAN HELIUM
}

\author{
Joseph R. Castro, William M. Saunders, Mary Austin-Seymour, George T.Y. Chen, \\ J. Michael Collier, Sandra R. Zink, Samuel Pitluck,* Kay A. Woodruff, \\ Denise Capra-Young, Aude Cartigny, Todd Richards, Jacquelyn St. John, and \\ Robert E. Walton ${ }^{\dagger}$
}

This project, Treatment of Cancer with Heavy Charged Particles, is now in its eighth year of continuing $\mathrm{NCl}$ and DOE support for study of the role of heavy charged particles in clinical radiotherapy.

As in previous years, the majority of patients are referred from members of the Northern California Oncology Group and the Radiation Therapy Oncology Group who together provide the clinical trial support services for protocol design, patient accrual, statistical services, data collection, and analysis.

Through September 30, 1983, 594 patients have been irradiated with charged particles and 20 evaluable patients irradiated as controls, with accrual by year given in Table 1.

*Engineering and Technical Services Division, Electronics Research and Development Group, LBL.

${ }^{\dagger}$ Engineering and Technical Services Division, Mechanical Technology Group, LBL.

Current protocols are ongoing for the following tumor sites:

\section{Description}

1. Localized squamous cell carcinoma of the esophagus, nonrandomized (helium and heavy ions)

2. Localized ocular melanoma, nonrandomized (helium)

3. Phase 1-Phase II Study of miscellaneous locally advanced tumors, nonrandomized (helium and heavy ions)
Protocol No.

LBL-NCOG 3E81/RTOG 79.09

LBL-NCOG 7081/RTOG 79-08

LBL-NCOG OR81/RTOG 79-11 
Table 1. Patients irradiated with charged particles.

\begin{tabular}{|c|c|c|}
\hline Year & $\begin{array}{c}\text { All } \\
\text { patients }\end{array}$ & $\begin{array}{l}\text { Heavy-ion } \\
\text { patients }\end{array}$ \\
\hline $1975-1977$ & 46 & 2 \\
\hline 1978 & 65 & 7 \\
\hline 1979 & 78 & 16 \\
\hline 1980 & 90 & 25 \\
\hline 1981 & 102 & 30 \\
\hline 1982 & 120 & 60 \\
\hline $1983(9 / 30)$ & 93 & 39 \\
\hline Total & 594 & 179 \\
\hline \multicolumn{3}{|c|}{$\begin{array}{l}\text { Number of patients treated } \\
\text { with each charged-particle beam: }\end{array}$} \\
\hline Helium ions & & 415 \\
\hline \multicolumn{3}{|l|}{ Heavy ions } \\
\hline Carbon & 24 & \\
\hline Neon & 148 & \\
\hline Silicon & 5 & \\
\hline Argon & 2 & 179 \\
\hline Total & & 594 \\
\hline
\end{tabular}

\section{HEAVY-PARTICLE PHASE I-II STUDIES}

Currently, using neon and/or silicon ions, we are studying their effect on such tumors as 1) localized carcinoma of the pancreas, 2) selected, advanced tumors of the head and neck, 3) malignant gliomata of the brain (glioblastoma and anaplastic astrocytoma), 4) carcinoma of the esnphagus, biliary tract, and stomach, 5) metastatic skin and subcutaneous nodules, and 7) squamous carcinoma of the lung.

As these represent tumors not likely to be successfully treated by current modalities, they are appropriate for initial studies but may well be supplanted by other, more treatable tumors when the Phase I-II studies are completed, particularly if little or no improvement in results is apparent. We must decide whether results in these Phase I-II studies warrant continuing with prospective controlled Phase III studies or whether other tumor sites than those listed above should be studied first. The best -se of beam availability and patient resources must e made during the next 3-4 years in order to uptimize use of heavy particles in radiotherapy.
For the patients treated with heavy ions, the tumor site distribution is shown in Table 2.

The early results with heavy ions at several sites are summarized below but should be interpreted with the realization that these are patients with advanced disease, in whom, for reasons of patient safety, doses have intentionally been started at a low level and gradually raised, and in whom RBE values and treatment have been gradually refined.

Thus, it is too soon to make a definitive judgment about results of treatment with heavy ions. Refinement of neon and silicon RBE values for skin and mucosa is being continued and should be completed by the end of this year. We have gradually escalated total doses and daily fraction sizes in an attempt to deliver doses of 22-24 Gy of neon irradiation in 16 fractions in 4 weeks wherever possible.

\section{CARCINOMA OF THE PANCREAS}

We have now completed a pilot study followed by a randomized trial of helium-ion radiotherapy in 97 patients with carcinoma of the pancreas, of whom 77 were irradiated with helium ions and 20 with low-LET x-ray therapy. There is approximately a $10 \%$ incidence of control within the irradiated area using helium ions, but only about $6 \%$ of patients have a long term remission of $2-1 / 2$ years or longer. The median survival in all patients receiving at least 50 Gray-equivalents of helium-ion irradiation is 8 months from the first day of radiation.

Table 2. Tumor-site distribution of patients treated with heavy ions.

\begin{tabular}{lrc}
\hline \hline $\begin{array}{l}\text { Abdomen: } \\
\text { Pancreas }\end{array}$ & 59 & \\
$\quad$ Biliary & 6 & \\
$\quad$ Stomach & 4 & 72 \\
Other & 3 & 25 \\
Brain & & 12 \\
Other Intracranial & 23 \\
Thorax & & 32 \\
Head/neck & 5 \\
Pelvis & 5 \\
Skin, subcutaneous & 179 \\
Retroperitoneum & 5 \\
Total & & 5 \\
\hline \hline
\end{tabular}


The randomized prospective study (LBL-NCOG 3P81/RTOG 79-10) did not show a significant advantage for helium-ion therapy over standard low-LET irradiation to 6000 rads. Therefore we have started a Phase I trial utilizing neon heavyparticle irradiation together with multidrug chemotherapy (5 fluourouracil, adriamycin, mitomycin c) in hopes of improving overall results in this disease. Currently this study has accrued about 15 patients in Phase $\mathrm{I}$ in which we are evaluating toxicity of the regimen. We expect to complete this study within the next six months so as to be ready to begin Phase II-III trials shortly thereafter.

Our previous efforts with neon heavy-particle therapy alone or after photon or helium therapy were carried out in 35 patients with far advanced disease and were useful only to develop treatment techniques and acquire information concerning normal tissue toxicity of heavy-particle irradiation. Thus data concerning neon heavy-particle irradiation of carcinoma of the pancreas is just beginning to be accrued and is too recent for meaningful evaluation.

\section{CARCINOMA OF THE ESOPHAGUS}

Twenty-two evaluable patients were accrued in a Phase II nonrandomized prospective study for helium-ion irradiation of localized carcinoma of the esophagus (NCOG protocol 3E81/RTOG 79-09). Only $18 \%$ of patients had local control of their tumor, with a median survival of 9 months. This was not improved over historical results with standard irradiation techniques. We are now continuing this trial using neon heavy-particle irradiation. Ten patients have been irradiated to date, but the follow-up period is too short for conclusions. Unless some significant improvement is seen over historical results or the helium-ion results, this target site will be discontinued.

\section{GLIOMA OF THE BRAIN}

Our experience in glioblastoma and anaplastic astrocytoma of the brain has been limited, although we have irradiated a small group of 23 patients, 11 patients entirely with neon ions and 12 patients with only a portion of the radiotherapy given with carbon or neon. In the group of 12 "boost" patients, only one remains free of disease. The median survival is 12 months. The total doses ranged from 45 to 72 Gray-equivalents given in 25 to 30 fractions over 6 to 7 weeks.

More recently we have irradiated 11 patients entirely with neon particle therapy using partial brain target volumes selected by utilizing the $\mathrm{CT}$ scan to identify a target volume in which a 3margin around the contrast enhanced lesion .. drawn. In this group the tumor dose in 8 patients has been 48 Gray-equivalents given in 16 fractions in 4 weeks (TDF $=90$ ). Failure occurred in all but one patient with a median survival of 6 months. A second group of patients has been started on a higher neon dose of 54 Gray-equivalents in 16 fractions over 4 weeks (TDF $=110$ ), but only three patients have been treated to date, and the followup period is too short for analysis. We propose to continue this study until 8 to 10 patients are accrued at the current dose level, and consider an additional group of 8 to 10 patients to be treated to 60 Gray-equivalents.

While these results are not particularly worse than standard therapy in a small group of unselected patients, unless improved results are forthcoming in the higher dose group, new approaches such as combined modality therapy should be sought.

\section{HEAD AND NECK TUMORS}

We have treated a small group of 23 patients with miscellaneous, selected tumors of the head and neck area, including such sites as the upper aero-digestive tract, paranasal sinuses, salivary glands, and trachea. Many of the initial patients received boost therapy with heavy particles such as carbon or neon after partial irradiation with photons or helium ions. Since doses have been gradually escalated and these have been patients with advanced tumors, the results to date are fragmentary. In the total treated group, 11 of 23 appear to have control within the irradiated volume, although with relatively short follow up (median survival of 9 months). This short survival rate is due in part to the fact that many of the patients were treated recently and in part to the presence of advanced disease and a high metastatic rate. Of 15 patients receiving all or the preponderance of their therapy with neon and/or silicon ions, 8 have local control. Development of treatment techniques and compensation procedures has largely been completed, but more patients are required in this Phase I study before decisions can be made regarding Phase II or III trials.

Of the 179 patients who have received all or part of their therapy with heavy ions, the large majority have been treated with neon ions. In coming years we will endeavor to increase our experience with silicon ions since these appear $t$ have promising biological potential, althoug perhaps not as good dose localization properties as 
irbon or neon ions. In these studies we are - raluating acute and subacute responses of normal tissues and tumors as well as developing effective treatment techniques with heavy particles.

During the next year we will concentrate on completing Phase I-II heavy-particle studies in order to begin prospective Phase III trials by mid to late 1984. This will coincide with completion of the local injector upgrade, which will facilitate the clinical irradiation program at the Bevatron. Additionally, the magnetically scanned beam (wobbler) should be characterized physically and biologically so as to permit its use in patient treatment. This will allow us to use lower energy with less lead scattering material in the beam, thus providing beams with less fragmentation and improved biological effect.
We believe continued optimization of heavyion beam delivery is warranted together with further study of which target sites are optimal for heavy-ion therapy. Better tumor localization by CT and NMR scanning and identification of improved methods for predicting response to heavy ions should lead to better selection of tumors to be irradiated with heavy particles.

Thus, our present target sites for heavy ions may change in the next 1 to 3 years as more experience is gained. The success of the dose localization program with helium ions at the LBL 184-Inch Cyclotron and the proton beam at the Harvard Cyclotron suggest that the ultimate use of heavier ions should be strongly based on their ability to deliver precise, high-dose irradiation to which some biological advantage over lighter particles can be added.

\section{PRECISION HIGH-DOSE RADIOTHERAPY WITH HELIUM-ION BEAMS: TREATMENT OF MALIGNANT TUMORS IN HUMANS}

William M. Saunders, Joseph R. Castro, Mary Austin-Seymour, George T.Y. Chen, J. Michael Collier, Sandra R. Zink, Denise Capra-Young, Samuel Pitluck,* Robert E. Walton, ${ }^{\dagger}$ Charles R. Pascale, ${ }^{\dagger}$ Leal L. Kanstein, ${ }^{\ddagger}$ and Frederick $W$. Yeater ${ }^{\ddagger}$

Since the Lawrence Berkeley Laboratory/ University of California San Francisco cancer radiotherapy program began in 1975, 415 patients have been treated using the helium-ion beam at the LBL 184-Inch Synchrocyclotron. To date, we have obtained the best results in tumors that ordinarily could be satisfactorily treated with conventional radiation therapy beams (e.g., gamma rays or $x$ rays), but are located close to critical radiation sensitive organs such as the spinal cord. If the tumor requires a high radiation dose to give an acceptable cure rate, and it is near a critical structure that would be damaged at a much lower dose, it often is impossible to find a satisfactory treatment plan using conventional radio-therapy beams. By exploiting the Bragg peak and the sharp penumbra of the helium-ion beam, we have been able to plan and deliver satisfactory treatments in many such cases. This requires very careful tumor localization,

\footnotetext{
*Engineering and Technical Services Division, Electronics Research and Development Group, LBL.

${ }^{\dagger}$ Engineering and Technical Services Division, Mechanical Techlogy Group, LBL.

ccelerator and Fusion Division, Accelerator Operations Group, LBL.
}

treatment planning, patient immobilization, and verification of treatment parameters.

Perhaps the best example of this type of treatment is that for the treatment of malignant melanoma of the eye. We have treated 136 such patients, 48 in the last 12 months. We continue to have very encouraging results in this group. Only five patients have had a recurrence of their tumor, and in all five a second treatment, usually removal of the eye, has apparently cured the tumor. We have generally been able to preserve the pretreatment visual acuity as long as the edge of the tumor is at least 3 to $4 \mathrm{~mm}$ away from the optic disc or macula. The tumor dose selected for the initial patients was biologically equivalent to 70 Gray of cobalt-60, that is 70 Gray-equivalent (GyE). The next group of patients received $80 \mathrm{GyE}$. The only serious complication has been the development of glaucoma in the treated eye in 13 of 71 patients who received a total dose of $80 \mathrm{GyE}$ or more. Since this complication was not seen in the 19 patients who received $70 \mathrm{GyE}$, we decided to decrease the tumor dose. Forty-six patients have been treated since that time. Thirty-nine received a dose of $60 \mathrm{GyE}$, and seven patients with direct invasion of the optic disc or macula received a 
dose of $50 \mathrm{GyE}$. To date none of these patients has had a recurrence of their tumor, and none has developed glaucoma.

In summary, at tumor doses of $70 \mathrm{GyE}$ and less we are observing excellent tumor control rates and low complication rates. We are continuing the program, searching for a dose level that will minimize the complication rate while maintaining the high tumor control rate.

We have also had good results treating tumors in critical locations other than the eye. We are particularly optimistic about a group of patients with tumors adjacent to the base of the brain, brain stem, or spinal cord. We have treated 17 patients to date with chordomas, chondrosarcomas, or meningiomas in those locations. The location of these tumors very close to critical, radiation sensitive central nervous system structures severely limits the radiation dose which could be given safely with conventional radiotherapy beams. By using techniques similar to those described for treating uveal melanomas, we have been able to deliver doses ranging from 60 to $80 \mathrm{GyE}$ to the tumors, while keeping the dose to the nearby critical tissues at acceptably low levels. Figure 1 shows a helium-ion treatment plan for a " $U$ " shaped chordoma which enveloped the spinal cord in the upper neck. The tumor received a dose of 7000 CoRE ( $=70 \mathrm{GyE})$. The spinal cord came to within $1 \mathrm{~mm}$ of the apex of the " $U$ ". The cord received a dose of $49 \mathrm{GyE}$ or less except for the front $2 \mathrm{~mm}$, which received a somewhat higher dose. This patient is alive and well with no evidence of tumor two years following treatment. We believe that no other treatment technique would be potentially curative for this patient.

The 17 patients have been followed from 3 to 60 months after their treatment at LBL, with an average follow-up of 24 months. To date, only two have had a recurrence of their tumor. The only complications have been in one patient who has

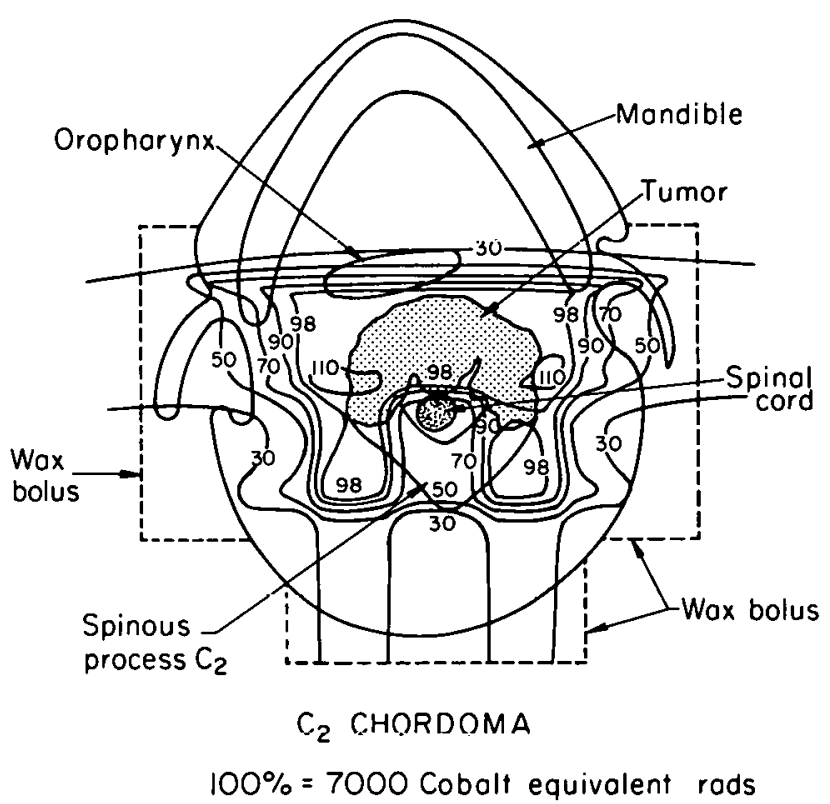

Fig. 1. Helium-ion treatment plan for a " $U$ " shaped chordoma which enveloped the spinal cord in the upper neck.

(XBL 818-4121)

evidence of damage to her optic tract, and another patient with evidence of damage to his spinal cord. These two cases have been assessed in great detail, and appropriate modifications have been made in our treatment techniques. We are continuing to treat this category of patient, since we know of no alternative treatment that offers a reasonable chance of curing these life-threatening tumors. We are confident that we will continue to see good tumor control rates with acceptable complication rates.

In summary, we have demonstrated a substantial clinical advantage for helium-ion radiotherapy over conventional radiotherapy for carefully selected patients with tumors near critical radiation sensitive structures. We are continuing to refine our techniques and anticipate treating increasing numbers of such patients in the future.

\section{Tissue Radiobiology}

\section{LATE EFFECTS OF RADIATION ON MOUSE LUNG}

\section{Edward L. Alpen, Linda D. Harrison, and Patricia Powers-Risius}

The late effects of x-ray, helium, and heavy-ion irradiation in mouse lung are presently being studied with single-dose and fractionated-dose experi- ments. The findings will have important applictions to the many treatment regimens (e.g., es phagus) in clinical therapy involving the lung fiel... 
/e are investigating these effects by measuring wieathing frequency, at 10 -week intervals after irradiation for as long as 56 to 70 weeks, with a version of the whole body plethysmograph developed by Travis. ${ }^{1}$ The rationale for this technique is that reduced lung elasticity from late fibrotic alterations will express itself as an increase in breathing rate. Preliminary data show an initial increase in breathing frequency at 16 weeks due to radiation pneumonitis. ${ }^{2,3}$ A continued elevated breathing rate 70 weeks post irradiation is due to fibrosis and is seen at higher doses. There is no recovery from this late developing lesion. Furthermore, in very preliminary studies we have shown that tissue hydroxyproline content is a useful indicator of connective tissue proliferation. Therefore we are using this assay as a terminal measurement of fibrotic development in the irradiated lung.

$L A F_{1}$ female mice, age 10-12 weeks, have been used for all experiments. The mice are housed seven per cage in a temperature and humidity controlled animal facility. Food and water are available ad libitum. The $250-k V p$-ray and helium-ion irradiated mice were anesthetized for irradiations. The $670-\mathrm{MeV}$ neon mice have specially designed restraining holders and were not anesthetized for irradiations. The thoracic area only was irradiated in all cases.

Table 1 shows the mean of the breathing rates and standard error of the mean for each dose level versus number of weeks after irradiation. All groups had no fewer than four animals, (usually 5-8), except where otherwise indicated. Ten weeks post-irradiation little increase in breathing rate above control levels is apparent. At 16-24 weeks breathing frequency increased in all dose and radiation groups exceeding threshold level (threshold level indicating any value above age control levels).

In Fig. 1 are the data from a single dose of $250-k \vee p \times$ rays, showing breaths per minute versus weeks after irradiation. The dose range was from 8-20 Gy. For doses from 16-20 Gy only one animal remained living in each group after 16 weeks: therefore, the graphic data were not considered reliable and were omitted. The same is true for $14 \mathrm{~Gy}$ after 24 weeks. As shown by Travis, ${ }^{4} 8 \mathrm{~Gy}$ produced no increase above control levels. At 16 weeks doses above $11 \mathrm{~Gy}$ showed a significant increase above control levels and remained elevated throughout the study.

Figure 2 shows the results after a single exposure to $910-\mathrm{MeV}$ helium ions with the animals placed in the plateau region of the Bragg peak ionization curve. Again 8 Gy produced results in the control range, but for higher doses there was a time and dose dependent response. All doses seem to produce peak response at about the same time.

With doses between 16-31 Gy, fractionated in 8 equal doses over an 11-day period (4 days on $/ 3$ days off/4 days on) (Fig. 3 ), it can be seen that only 31 Gy exceeded control levels. Therefore, we will have to repeat these experiments with doses between 26-31 Gy. The repair seen is consistent with that observed by Travis et al., 5,7 for $x$-ray fractionated exposures.

Figure 4 represents $670-\mathrm{MeV}$ neon single doses in the plateau region. Doses range from 6-10 Gy. Again, radiation pneumonitis is apparent in the increased breathing rate between 16 and 24 weeks. Dose effect curves were obtained above a threshold level of $8 \mathrm{~Gy}$ and remained elevated throughout the 70-week period.

Figure 5 is a $250-k V p$ x-ray 8 -fraction experiment, similar to the helium-ion experiment in Fig. 3, but with dose ranges of 16-31 Gy. We chose to use $x$ rays to clarify the proper dose range for this fractionated study due to the similar RBE of helium and $x$ rays and the ready availability of the $x$-ray source. Only early data are available at this time. From the 10-week and 20-week interval results, the choice of dose range appears correct, with 10 weeks showing little change from control level and 20 weeks showing a significant increase from 27-29 Gy.

The dose-response curves are steep between 16 and 24 weeks for all 5 experiments for doses above threshold levels. This agrees with the onset of radiation pneumonitis as seen by Travis ${ }^{2,3}$ histologically and with breathing frequency. The breathing frequency decreases slightly around 40 weeks but remains elevated through 70 weeks, never recovering to threshold levels. There seems to be a very narrow range of doses between threshold level and lethality which makes this noninvasive method of detecting early (radiation pneumonitis) and late (fibrosis) damage very useful as a late effects end point. 
Table 1. Breathing rates following irradiation.

\begin{tabular}{|c|c|c|c|c|c|c|c|c|}
\hline \multirow[b]{2}{*}{ Dose $(G y)$} & \multicolumn{8}{|c|}{ Weeks after irradiation } \\
\hline & 8 & 16 & 24 & 32 & 40 & 48 & 56 & 64 \\
\hline \multicolumn{9}{|c|}{$X$ ray (single dose), Exp 1: } \\
\hline 0 & $306 \pm 12.7^{a}$ & $252 \pm 18.5$ & $242 \pm 25.7$ & $290 \pm 13.3$ & $163 \pm 13.5$ & $289 \pm 7.8$ & $265 \pm 22.3$ & $243 \pm 23.7$ \\
\hline 8 & $213 \pm 20.8$ & $191 \pm 13.8$ & $247 \pm 23.5$ & $250 \pm 22.3$ & $251 \pm 22.5$ & $238 \pm 18.0$ & $288 \pm 11.2$ & $298 \pm 8.7$ \\
\hline 10 & $241 \pm 10.6$ & $273 \pm 12.2$ & $293 \pm 7.7$ & $322 \pm 7.3$ & $303 \pm 13.5$ & $324 \pm 4.1$ & $310 \pm 16.3$ & $295 \pm 18.4$ \\
\hline 11 & $246 \pm 17.3$ & $277 \pm 20.4$ & $349 \pm 13.8$ & $349 \pm 23.8$ & $371 \pm 24.1$ & $342^{\prime} \pm 13.1$ & $349 \pm 17.4$ & $337 \pm 12.2$ \\
\hline 12 & $250 \pm 25.3$ & $335 \pm 16.7$ & $336 \pm 26.0$ & $343 \pm 36.8$ & $322 \pm 16.5$ & $329 \pm 10.6$ & $361 \pm 6.3$ & $330 \pm 12.3$ \\
\hline 14 & $281 \pm 13.6$ & $421 \pm 26.9$ & $387 \pm 52.5$ & $369^{b}$ & b & $339^{b}$ & b & b \\
\hline 16 & $326 \pm 19.3$ & $435 \pm 11.0$ & $359^{b}$ & $151^{b}$ & b & $284^{b}$ & b & b \\
\hline 20 & $311 \pm 35.0$ & $225^{b}$ & $233^{6}$ & $461^{b}$ & b & $291^{b}$ & Dead & - \\
\hline & \multicolumn{8}{|c|}{ Weeks after irradiation } \\
\hline & 10 & 20 & & & & & & \\
\hline
\end{tabular}

(8 Fx/11d) $X$ ray, Exp. 5:

$\begin{array}{rlc}0 & 217 \pm 16.7^{\mathrm{a}} & 312 \pm 7.3 \\ 16 & 270 \pm 13.1 & 314 \pm 4.1 \\ 21 & 280 \pm 12.5 & 319 \pm 8.8 \\ 26 & 317 \pm 6.1 & 361 \pm 17.5 \\ 27 & 303 \pm 7.5 & 427 \pm 20.4 \\ 28 & 319 \pm 7.1 & 378 \pm 18.7 \\ 29 & 317 \pm 7.7 & 441 \pm 14.7 \\ 31 & 345 \pm 8.5 & \text { Dead }\end{array}$

Weeks after irradiation

\begin{tabular}{lllllll}
\hline 8 & \multicolumn{7}{c}{ Weeks after irradiation } \\
\hline 8 & 16 & 24 & 32 & 48 & 58 & 68 \\
\hline
\end{tabular}

Helium (8 Fx/11d), Exp. 2:

$\begin{array}{rlllllll}0 & 228 \pm 13.1^{\mathrm{a}} & 267 \pm 12.3 & 283 \pm 8.9 & 251 \pm 23.3 & 289 \pm 7.2 & 303 \pm 3.4 & 284 \pm 5.0 \\ 16 & 268 \pm 16.1 & 268 \pm 10.2 & 247 \pm 19.6 & 271 \pm 25.3 & 299 \pm 6.8 & 305 \pm 4.9 & 286 \pm 8.3 \\ 21 & 248 \pm 12.0 & 246 \pm 14.7 & 275 \pm 19.9 & 302 \pm 6.5 & 298 \pm 11.3 & 314 \pm 6.8 & 288 \pm 4.9 \\ 26 & 234 \pm 20.3 & 254 \pm 22.0 & 302 \pm 26.0 & 297 \pm 29.8 & 291 \pm 6.0 & 305 \pm 9.4 & 310 \pm 8.0 \\ 31 & 237 \pm 13.9 & 267 \pm 14.2 & 368 \pm 16.6 & 387 \pm 36.3 & 336 \pm 48.6 & 311 \pm 7.8 & 287 \pm 25.9 \\ & & & & & c & c\end{array}$

Weeks after irradiation

$\begin{array}{llllll}8 & 16 & 24 & 34 & 44 & 54\end{array}$

Helium (single dose), Exp. 4:

$\begin{array}{rccccc}0 & 251 \pm 14.7^{\mathrm{a}} & 277 \pm 10.1 & 292 \pm 8.7 & 285 \pm 3.7 & 284 \pm 6.2 \\ 8 & 275 \pm 26.9 & 300 \pm 10.6 & 290 \pm 24.6 & 305 \pm 6.6 & 291 \pm 5.6 \\ 10 & 240 \pm 15.1 & 323 \pm 15.1 & 328 \pm 12.6 & 333 \pm 10.7 & 324 \pm 5.0 \\ 11 & 242 \pm 19.6 & 344 \pm 20.0 & 366 \pm 27.6 & 372 \pm 20.2 & 333 \pm 18.5 \\ 12 & 246 \pm 16.8 & 383 \pm 27.0 & 403 \pm 23.2 & 387 \pm 16.6 & 379 \pm 40.8 \\ 13 & 245 \pm 18.9 & \text { All dead } & - & - & - \\ 14 & 278 \pm 28.4 & \text { b } & \text { b } & \text { b } & \text { b }\end{array}$


Table 1. Continued.

Weeks after irradiation

\begin{tabular}{lllllll}
\hline \multicolumn{8}{c}{ Weeks after irradiation } \\
\hline 8 & 16 & 24 & 40 & 50 & 60 & 70 \\
\hline
\end{tabular}

670-MeV neon (single dose), Exp. 3:

$\begin{array}{rllllllc}0 & 231 \pm 9.8^{\mathrm{a}} & 274 \pm 15.4 & 312 \pm 12.1 & 281 \pm 18.0 & 302 \pm 7.3 & 295 \pm 6.1 & 286 \pm 6.3 \\ 6 & 207 \pm 11.4 & 284 \pm 12.3 & 268 \pm 18.5 & 310 \pm 10.4 & 299 \pm 12.6 & 299 \pm 5.2 & 286 \pm 7.8 \\ 7 & 198 \pm 13.5 & 253 \pm 23.4 & 289 \pm 12.3 & 310 \pm 33.6 & 320 \pm 10.8 & 315 \pm 8.1 & 305 \pm 10.5 \\ 8 & 245 \pm 14.1 & 264 \pm 16.4 & 327 \pm 25.9 & 351 \pm 22.2 & 330 \pm 15.5 & 329 \pm 7.8 & 331 \pm 15.8 \\ 9 & 213 \pm 11.1 & 335 \pm 18.1 & 328 \pm 62.1 & 315 \pm 43.5 & 388 \pm 17.5 & 335 \pm 10.9 & \text { All dead } \\ 10 & 240 \pm 23.9 & 336 \pm 34.9 & 344 \pm 45.1 & 305 \pm 23.7 & 356 \pm 23.7 & 337 \pm 32.5 & \text { b }\end{array}$

a S.E. of mean

b 1 mouse

c 2 mouse

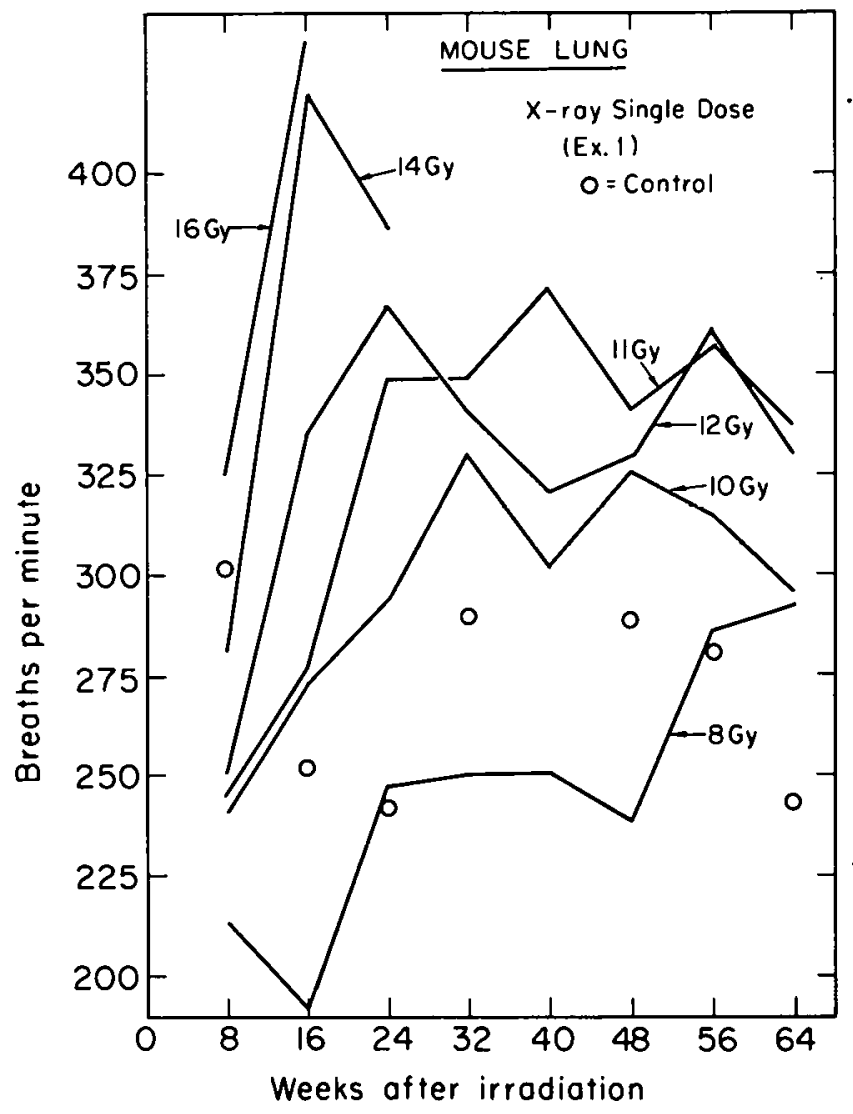

5ig. 1. Mouse lung irradiation: Breathing rates after a single dose of $250-k V p \times$ rays.

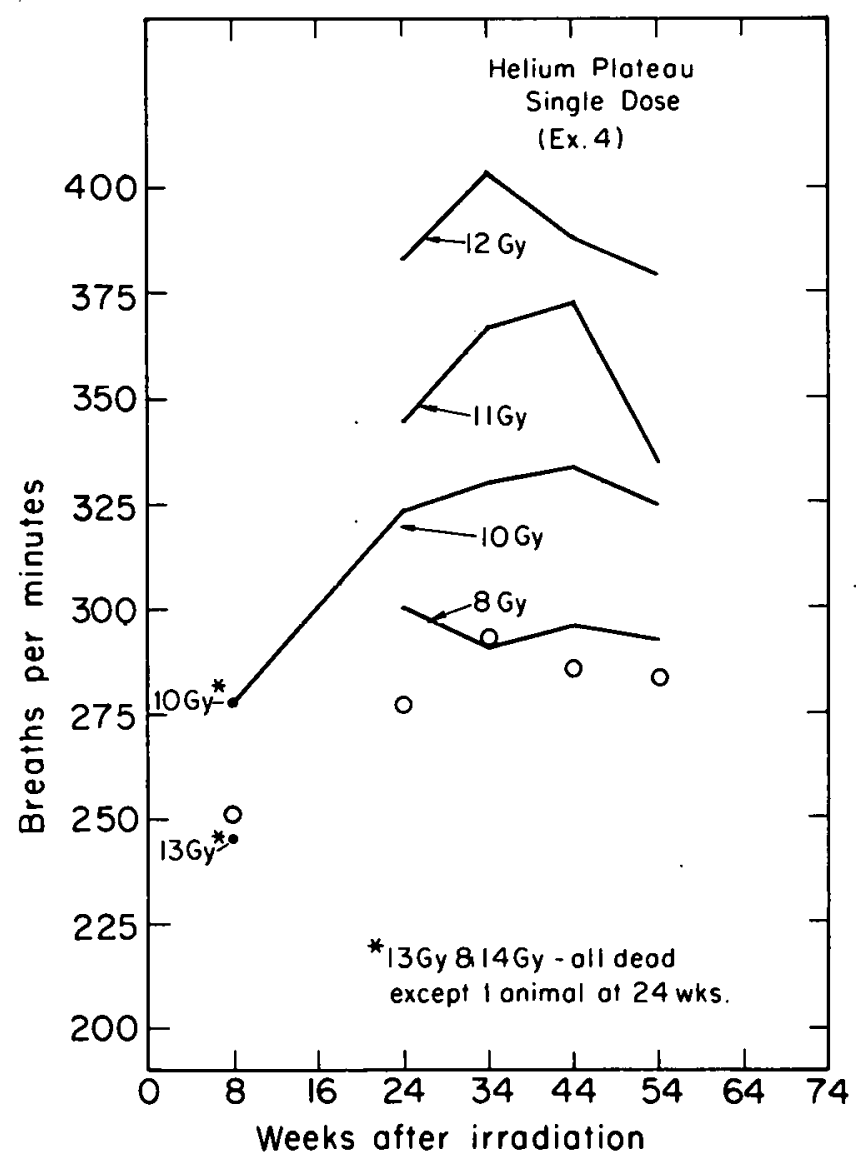

Fig. 2. Mouse lung irradiation: Breathing rates after a single exposure to 910-MeV helium ions (plateau region).

(XBL 8312-4142) 


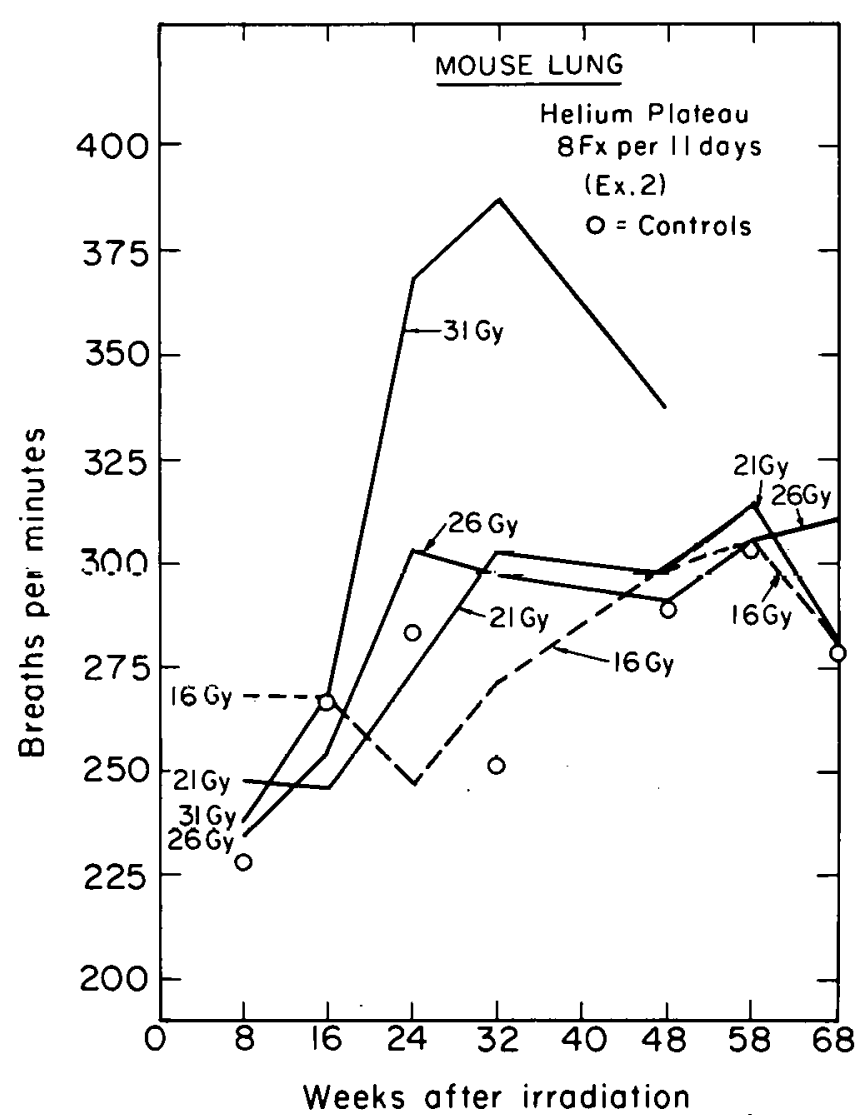

Fig. 3. Mouse lung irradiation: Breathing rates after 910-MeV helium-ion (plateau region) irradiation with total doses of 16 to $31 \mathrm{~Gy}$ administered in 8 equal fractions over an 11-day period.

(XBL 8312-4143)

\section{REFERENCES}

1. Travis, E.L., Vojnovic, B., Davies, E.E., and Hirst, D.G. A plethysmagraphic method for measuring function in locally irradiated mouse lung. Br. J. Radiol. 52, 67-74 (1979):

2. Travis, E.L., Down, J.D., Holmes, S.J., and Hobson, B. Radiation pneumonitis and fibrosis assayed in mouse lung by respiratory frequency and histology. Radiat. Res. 84, 133-143 (1980).

3. Travis, E.L. The sequence of histological changes in mouse lungs after single doses of $x$ rays. Int. J. Radiat. Oncol. Biol. Phys. 6, 345-347 (1980).

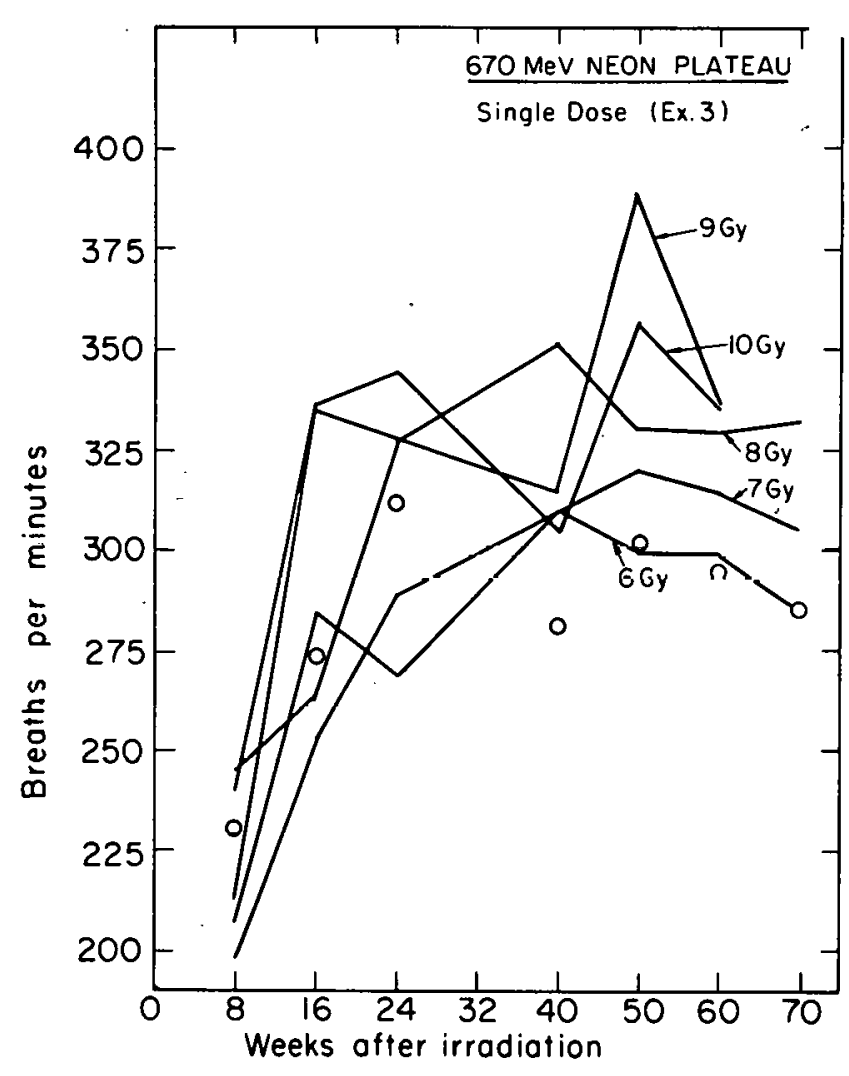

Fig. 4. Mouse lung irradiation: Breathing rates after a single exposure to 670-MeV neon ions (plateau region).

(XBL 8312-4144)

4. Travis, E.L., Voynovich, G., Hirst, D.G., and Hill, S.A. Quantitative changes in rodent lungs after irradiation. Proc. Brit. Inst. Radiat., 239 (abstract) (1978).

5. Travis, E.L., and Down, J.D. Repair in mouse lungs after split doses of $x$ rays. Radiat. Res. 87, 166-174 (1981).

6. Travis, E.L., Fowler, J.F., Curtis, S.B., DeLuca, A.M., Ross, G., and Howard, J. Early and late lung damage in mouse lung after fractionated doses of neon ions. A.S.T.R. 1981 Annual Meeting (Abstract).

7. Travis, E.L., Parkens, C.S., Down, J.D., Fowler, J.F., and Thomas, H.D., Jr. Repair in mouse lung between multiple small doses of $x$ rays. Rad. Research 94, 326-339 (1983). 


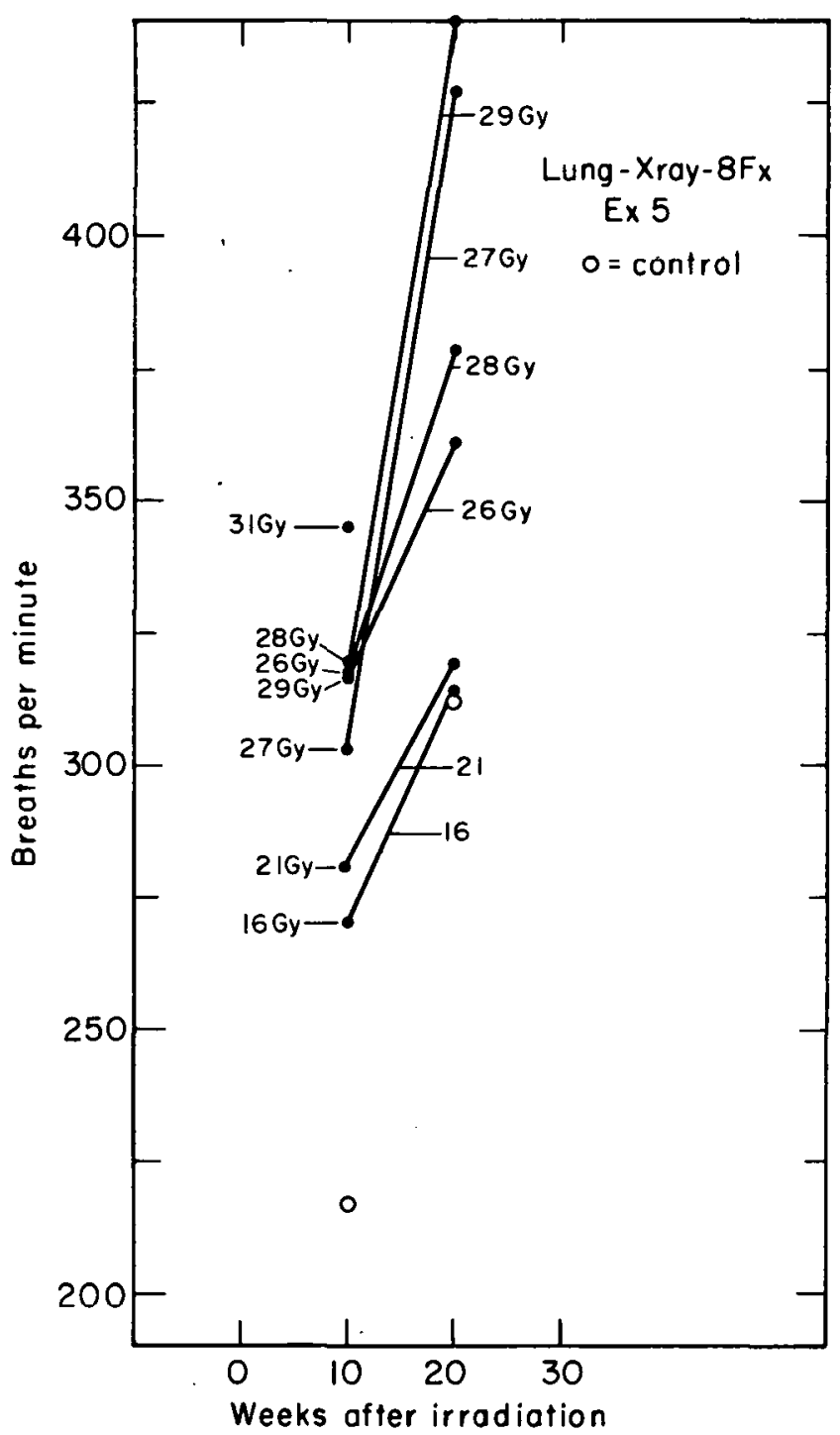

Fig. 5. Mouse lung irradiation: Breathing rates after 250-kVp $x$-ray irradiation with total doses of 16 to $31 \mathrm{~Gy}$ administered in 8 fractions.

(XBL 83/2-4/45)

\section{LATE EFFECTS OF RADIATION ON THE HEMATOPOIETIC SYSTEM}

\section{E. John Ainsworth, Lynn J. Mahlmann, and John C. Prioleau}

When doses of high-LET radiation are fractionated, early and late radiation responses are characteristically either not reduced or may be enhanced. In contrast, dose fractionation with low-LET radiation produces a sparing effect for most early and late radiation responses. The purpose of this project is to contribute new information to the nderstanding of how proliferative systems, particuiarly the hematopoietic system, respond to high- and low-LET dose fractionation. We have used primarily the CFU-S as a model system, and this report deals with late effects on the CFU-S compartment after partial body exposures to photons or charged particles and response of the CFU-S compartment to fractionated doses of photons or charged particles.

Our collaboration with Dr. Michael Hagen at the Armed Forces Radiobiology Research Institute, 
Bethesda, was continued, and a presentation of our results was made at the 7 th International Congress of Radiation Research held in Amsterdam in July, $1983 .^{7}$ We had shown previously that irradiation of the right femur of $\mathrm{Balb} / \mathrm{C}$ mice with photon doses ranging from about 2,000-7,000 cGy resulted in a sustained decrease of the CFU-S population in the irradiated femur and also resulted in a smaller reduction, usually, in the size of the CFU-S population in the unirradiated femur. Our earlier estimates of the CFU-S population size in the irradiated femur were conservative because it was impossible to irradiate the entire femur without producing intestinal damage sufficient to kill the animal. We have estimated that approximately one quarter of the femur was not irradiated; consequently, our estimates of radiation-reduced CFU-S reduction were conservative. Because the tibia is indeed uniformly irradiated in our animals, the studies have been extended using changes in the size of the tibial CFU-S population and alterations in cell population kinetics. The results generally confirm our early observations with the femur. For example, tibial CFU-S content at 16 months age is approximately 3,600 per leg, and at 20 months after a ${ }^{20} \mathrm{Ne}$ dose of $15 \mathrm{~Gy}$ given in 7-9 fractions, the CFU-S population size in both the irradiated and unirradiated leg was approximately 2,100. Crouse and Ainsworth have previously demonstrated an increased fraction of CFU-S population. ${ }^{2}$ That observation has been extended in collaboration with Dr. Hagen, and the BrdCyd/313-nm light technique was used to study the fraction of CFU-S in cycle in the tibias of aged-irradiated animals. Using this technique, killing of the proliferative fraction of CFU-S is integrated over a period of 4 days and represents a sensitive measure for determining change in CFU-S kinetics. While the results are considered preliminary and are not totally consistent, the trend is toward an increased proliferative fraction in the irradiated leg and a concomitant decrease in the proliferative fraction in the unirradiated leg. For example, the proliferative fraction, integrated over 4 days, in unirradiated control animals 16 months of age was 54\%; whereas, at 20 months after a total fractionated ${ }^{20} \mathrm{Ne}$ dose of 3,800 $\mathrm{Gy}$, the proliferative fraction in the irradiated leg was $67 \%$ and $39 \%$ in the unirradiated leg. While the general trend among groups exposed to various doses of $230-k V p \times$ rays, ${ }^{12} \mathrm{C}$, or ${ }^{20} \mathrm{Ne}$ ions was as described above, in some cases the proliferative fraction was actually reduced in both legs. The results described above are from pooled samples based on groups of two to five animals and must be repeated. The importance of work in this at relates to the mechanism whereby the CFL population is reduced and alterations in cell population kinetics are affected by irradiation of one hind limb. Clearly, the release of humoral factors from the irradiated leg is among the possibilities. Future studies will emphasize mechanisms of hematopoietic control and their disruption as a late consequence of either partial or total body radiation. To the extent that alterations in cell population kinetics may influence susceptibility or expression of the carcinogenic effects of radiation, studies in this area are related directly to our other projects on life shortening and carcinogenic effects of heavy charged particles.

Another project concerns the effect of dose fractionation on CFU-S repopulation after total body exposures to ${ }^{60} \mathrm{Co}$ gamma rays or heavy charged particles. The effect of dose fractionation on hematopoietic recovery, based on CFU-S or mature cellular elements in the peripheral blood, is poorly understood at this time. The hypothesis tested in these studies is that the rate of CFU-S repopulation will be similar following an eightfraction radiation course of photons or charged particles if the dose per fraction produces equal reduction in the CFU-S population size. Implicit in this hypothesis is the assumption that repair and proliferation processes for photons and charged particles are also similar. Using high-LET fission spectrum neutrons, we have previously demonstrated a delay in CFU-S repopulation during the first 4-7 days, in comparison with gamma radiation, when nine fractionated doses, expected to reduce fractional survival to approximately 0.4 , were given over 3 weeks. A similar delay in repopulation might be expected with other high-LET charged particles, but this is found not to be the case for ${ }^{20} \mathrm{Ne}$ ions under circumstances where the ${ }^{20} \mathrm{Ne}$ and ${ }^{60} \mathrm{Co}$ gamma doses per fraction were selected to reduce the surviving fraction to approximately 0.30 . In fact, the results indicated animals exposed to ${ }^{20} \mathrm{Ne}$ ions show significant CFU advantage at 3-5 days after completion of the eight-fraction sequence, but at 15 and 20 days the ${ }^{20} \mathrm{Ne}$ irradiated animals had femur CFU-S populations that were significantly reduced in comparison with gamma radiated animals. Recently we have extended these studies to animals exposed to ${ }^{28} \mathrm{Si}$ ions where the dose per fraction was also selected to produce fractional survival of 0.30 . Under these circumstances we have found CFU-S repopulation to be similar among ${ }^{28} \mathrm{Si}$ ions and ${ }^{60} \mathrm{Co}$ gamma radiated animals during $\mathrm{tl}$ first 10 days after radiation. During the phase 
epopulation between 15 and 20 days the trend -gain is toward reduced CFU-S content in the ${ }^{28} \mathrm{Si}$ ion groups. Between 25 and 30 days the CFU-S population size does not differ significantly among the various experimental groups. In another experiment for which the data are not presented here CFU-S repopulation was measured following a fractionated ${ }^{28} \mathrm{Si}$ dose selected to reduce the CFU population to 0.43 . Comparison of CFU-S repopulation as a function of ${ }^{28} \mathrm{Si}$ ion doses indicated early repopulation after the lower fractionated dose given at the first 10 days but no significant differences thereafter.

Complete interpretation of the CFU-S repopulation results is beyond the scope of this document. First, it is clear that the delay in CFU-S repopulation we reported earlier for fission spectrum neutrons does not occur when fractionated doses of ${ }^{20} \mathrm{Ne}$ or ${ }^{28} \mathrm{Si}$ ions are used. Also in contrast with previous neutron results, CFU population size in charged particle irradiated animals was lower than was the case for gamma radiation during the repopulation phase between approximately 15 and 20 days. The hypothesis that high-LET charged particles should produce a CFU-S repopulation pattern similar to fission neutrons must be rejected. However, our original hypothesis that the pattern of repopulation should be similar for charged particles and ${ }^{60} \mathrm{Co}$ gamma radiation providing the fractional survival were equal must also be rejected because of the significant differences in femur CFU population size during the third week after irradiation. The processes that contribute to these differences in CFU population size are currently not understood. A possible explanation for the CFU-S advantage among animals that received fractionated doses of ${ }^{20} \mathrm{Ne}$ ions is that the fractional survival was greater than predicted. The dose per fraction to reduce survival to approximately 0.3 was derived from the ${ }^{20} \mathrm{Ne}$ survival curve where the extrapolation number was 0.88 with $95 \%$ confidence limits that did not clearly preclude an extrapolation number of 1 . If in fact the $D_{0}$ were the same, namely, $65 \mathrm{cGy}$, and the extrapolation number were actually 1.0 , the fractional survival would have been 0.365 rather than 0.30 .

No further work on CFU-S repopulation is currently planned because of the large number of experimental animals required.

\section{REFERENCES}

1. Hagen, M., and Ainsworth, E.J. Response of bone marrow progenitor cells to heavy charged particles: Late effects upon cell kinetics. Presented at 7th International Congress of Radiation Research, Amsterdam, July 1983.

2. Crouse, D.A., Ainsworth, E.J., and Hulesch, J.S. Thymidine suicide studies on hematopoietic stem cells in aging irradiated mice. Anatomical Record 189, 539 (1977).

\section{RADIOSENSITIVITY OF MOUSE COLONY FORMING UNITS-SPLEEN (CFU-S) TO HEAVY CHARGED PARTICLES}

\section{E. John Ainsworth, Lynn J. Mahlmann, and John C. Prioleau}

The purpose of this research is to define the radiation response of mouse marrow CFU-S to heavy charged particles in relation to particle flux, charge, and LET. Results are pertinent to various medical applications of heavy charged particles as well as increasing understanding of relationships between track structure and the killing of cells in vivo. Our initial studies emphasize the use of Bragg peaks spread to $4-12 \mathrm{~cm}$, some of which have been used medically. ${ }^{1}$ More recent efforts have emphasized the use of the plateau portion of the Bragg curve where the range of LETs to which the cells at risk are exposed is small in comparison with the range experienced in the spread Bragg seak. Table 1 summarizes the survival curve parameters derived from replicate experiments with
${ }^{20} \mathrm{Ne},{ }^{40} \mathrm{Ar},{ }^{28} \mathrm{Si}$, and ${ }^{56} \mathrm{Fe}$ ions. The results are consistent with the interpretation that the RBE peak of about 1.7 occurs at a dose-averaged LET of approximately $100 \mathrm{keV} / \mu \mathrm{m}$, an interpretation totally consistent with results from previous experiments where marrow CFU-S was irradiated in vivo with spread Bragg peak and in vitro with the plateau portion of the Bragg curve. A composite summary of CFU-S results is shown in Fig. 1. The RBE estimate of 2.1 for CFU-S irradiated in vitro with plateau ${ }^{40} \mathrm{Ar}$ ions was from an unreplicated experiment, and an appreciably lower RBE estimate was obtained for CFU-S irradiated in vivo with plateau ${ }^{40} \mathrm{Ar}$ ions at substantially the same dose-averaged LET. While different responses in vivo and in vitro cannot be precluded, and could be related to frag- 
Table 1. CFU-S survival curve parameters.

\begin{tabular}{lccccccc}
\hline \hline lon & MeV/amu & Position & $\begin{array}{c}\text { Residual } \\
\text { range }(\mathrm{cm})\end{array}$ & $\mathrm{D}_{\mathrm{o}} \pm 95 \%$ C.L. & $\mathrm{N} \pm 95 \%$ C.L. & $\mathrm{RBE}_{10}$ & $\begin{array}{c}\mathrm{LET}_{\alpha}^{\alpha} \\
\mathrm{keV} / \mu \mathrm{m}^{\mathrm{b}}\end{array}$ \\
\hline $\mathrm{Ne}$ & 670 & Plateau & 30.7 & $61(58-65)$ & $1.0(0.89-1.13)$ & 1.5 & 26 \\
$\mathrm{Ar}$ & 330 & Plateau & 3.30 & $67(62-72)$ & $0.87(0.75-1.01)$ & 1.5 & 136 \\
$\mathrm{Ar}$ & 470 & Plateau & 8.92 & $52(50-55)$ & $0.99(0.89-1.11)$ & 1.7 & 103 \\
$\mathrm{Si}$ & 320 & Plateau & 3.80 & $52(49-55)$ & $1.0(0.89-1.17)$ & 1.8 & 85 \\
$\mathrm{Fe}$ & 600 & Plateau & 8.20 & $73(65-84)$ & $1.0(0.71-1.39)$ & 1.3 & 193 \\
$\mathrm{C.n}$ & - & - & - & $93(8.7-98)$ & $1.0(0.89-1.2)$ & - & $\cdots$ \\
\hline \hline
\end{tabular}

a C.L. = confidence limits

b CAT LET $\alpha$ estimates

$$
\mathrm{CB}_{6} \mathrm{~F}_{1} / \mathrm{IAX}
$$

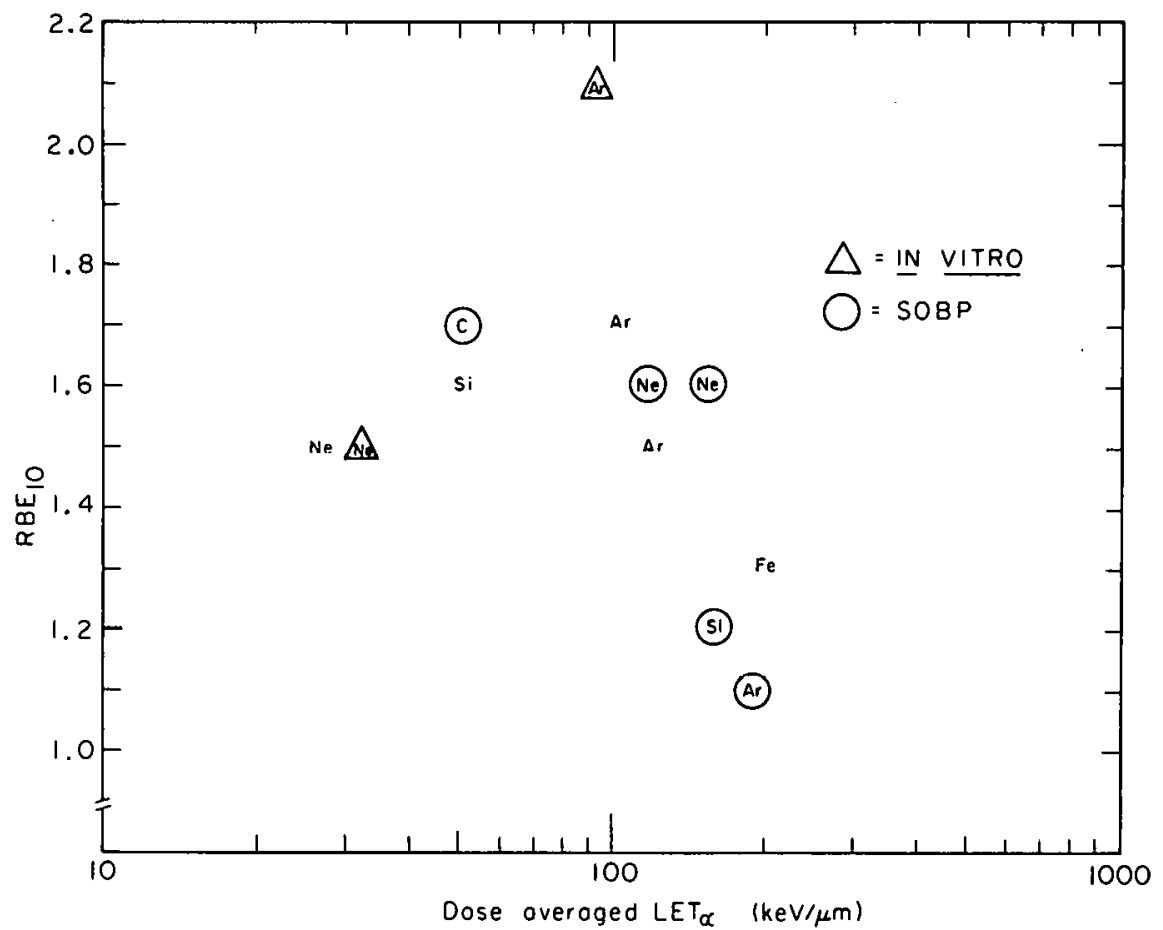

Fig. 1. Comparison of RBE ${ }_{10}$ vs. LET for Marrow CFU-S irradiated in vitro with the plateau portion of the Bragg curve $(\Delta)$ and in vivo with the spread out Bragg peak (O).

mentation characteristics of the beams used, it is noteworthy that quite similar estimates of RBE were obtained by the in vitro and in vivo methods for ${ }^{20} \mathrm{Ne}$ ions where the dose-averaged LET is about 30 $\mathrm{keV} / \mu \mathrm{m}$. The one unreplicated point for ${ }^{40} \mathrm{Ar}$ ions in vitro excluded, the results are consistent with the absence of a well defined peak. Over the LET range of 30 to $\sim 150 \mathrm{keV} / \mu \mathrm{m}$, the $\mathrm{RBE}_{10}$ for CFU-
$S$ ranges only from about 1.5-1.7. As the LET of about $200 \mathrm{keV} / \mu \mathrm{m}$ is approached, RBE for ${ }^{56} \mathrm{Fe}$, ${ }^{28} \mathrm{Si}$, and ${ }^{40} \mathrm{Ar}$ ions tends to decrease. In the near future we will collect data on the response of CFU-S irradiated in vivo with plateau ${ }^{12} \mathrm{C}$ ion where the LET is approximately $10 \mathrm{keV} / \mu \mathrm{m}$. Th ${ }^{12} \mathrm{C}$ data will permit clearer inferences about the shapes of the ascending portion of the curve that 
sscribes relationships between RBE and doseaveraged LET. In the future we also plan to perform a limited series of "track segment" experiments with bone marrow CFU-S irradiated in vitro in a very thin container so comparisons can be made between CFU response in vivo and in vitro and indirect inferences can be drawn concerning the potential role of beam fragmentation.

Because the CFU-S is an excellent model system to evaluate drug-induced changes in radiosensitivity, two collaborative projects have been initiated. In collaboration with Dr. W.R. Hanson, RUSH-Presbyterian Hospital, Chicago, the radioprotective effects of prostaglandin $P E_{2}$ has been evaluated. A subcutaneous dose of 5 micrograms of this drug was given $\mathrm{CB}_{6} \mathrm{~F}_{1}$ mice about 60 minutes before exposure to ${ }^{60^{\circ}} \mathrm{Co}$ gamma radiation, with the following result. The CFU-S $D_{0}$ was determined to be $114(110-119)$ cGy, in comparison with the value for uninjected controls of 92 (87-93) cGy. This drug significantly increased the extrapolation number $(\mathrm{N})$ from $1.0(0.89-1.20)$ to 1.4 $(1.27-1.54)$. In collaboration with $\mathrm{Dr}$. Javed Afzal we have initiated studies to evaluate the effects of WR-2721 on CFU-S in mice exposed to heavy charged particles. The objective is to determine the LET dependence of the radioprotective effects. Preliminary results indicate WR2721 increases the $D_{0}$ for $330 \mathrm{MeV} / \mathrm{amu}{ }^{40} \mathrm{Ar}$ ions by approximately $20 \%$.
Future plans include the initiation of split-dose studies, using a 48-hour interval, to evaluate the net effects of repair, proliferation, and alterations in CFU-S radiosensitivity. The CFU-S is an adequate model system to evaluate effects of dose fractionation in those physiological systems where the capacity for repair is small in comparison with other tissues such as the gut. These studies will compare ${ }^{60} \mathrm{Co}$ gamma radiation and a heavy charged particle such as ${ }^{28} \mathrm{Si}$ or ${ }^{40} \mathrm{Ar}$ where the RBE in the plateau portion of the Bragg curve is in the range of 1.6-1.7. In addition to determining how the CFU-S survival curves may be altered with dose fractionation, we plan to explore the use of various radioisotope incorporation techniques as an additional measure of radiation damage to cellular proliferation in the bone marrow. These dose fractionation studies are relevant to other previous and ongoing studies that utilize CFU-S response as a model to understand early and late effects of high-LET dose fractionation.

\section{REFERENCE}

1. Ainsworth, E.J., Kelly, L.S, Mahlmann, L.J., Schooley, J.C., Thomas, R.H., Howard, J., and Alpen, E.L. Response of colony forming units-spleen to heavy charged particles. Radiat. Res. 93, 180-197 (1983).

\section{LIFE SPAN STUDIES ON MICE EXPOSED TO HEAVY CHARGED PARTICLES: A STATUS REPORT}

\section{E. John Ainsworth, John C. Prioleau, and Lynn J. Mahlmann}

The purpose of this research is to evaluate lifeshortening/carcinogenic effects of heavy charged particles in mice. This project, designated SKYHOOK, complements other work ongoing at this Laboratory in which transformation of $10 \mathrm{~T} 1 / 2$ cells in vitro and induction of Harderian gland tumors in vivo are used to study relationships between linear energy transfer (LET) and carcinogenic response. The hope is that SKYHOOK and complementary experiments will contribute to the fundamental understanding of relationships between charged particle track structure DNA damage, cell population kinetics of tissues at risk, and the carcisgenic response. Additionally, information on e-shortening/carcinogenic effects of heavy ularged particles may ultimately assist with assign- ment of appropriate quality factors (Q) needed for purposes of radiation protection in either terrestrial or space radiation environments.

While for many years it was expected that carcinogenesis data from Hiroshima and Nagasaki would assist with selection of RBEs and Q's for high-LET neutron irradiation, recent reevaluations of dosimetry data indicate this will probably not be the case. The implication is that the importance of information derived from animal models for highLET radiation carcinogenesis will assume greater importance than in the past. The concept of LET does not consider the importance of microdosimetry in terms of charged particle track structure, and the concept of dose is of far less importance for charged particles than is the case for low-LET 
photon irradiation. For these reasons, high priority will be given to interpreting results from SKYHOOK and other carcinogenesis experiments in terms of particle fluence and the nature of energy deposition in the core and penumbra of charged particle tracks.

These NASA-supported studies were initiated in 1977, and results from the first experiments with single and fractionated doses of ${ }^{12} \mathrm{C}$ ions and ${ }^{60} \mathrm{Co}$ gamma radiation are now complete and ready for open literature publication. A preliminary report of those results is available (7th International Congress abstract). SKYHOOK is a long-term project, and in the ensuing five years experiments with particles other than ${ }^{12} \mathrm{C}$ have been initiated. The purpose of this brief report is to indicate the charged particles under investigation, describe the status of the study, and briefly summarize results available.
The radiation source for heavy charged partic was the Lawrence Berkeley Laboratory Bevalac, unique national facility that provides charged particles at preselected LETs of choice. Unanesthetized hybrid $\mathrm{C} 57 \mathrm{bl} / 6 \times \mathrm{Balb} / \mathrm{C}\left(\mathrm{CB}_{6} \mathrm{~F}_{7}\right)$ mice from the Roscoe $B$. Jackson Memorial Laboratory were given whole body exposures at rates that range from approximately 10 to several hundred $\mathrm{rad} / \mathrm{min}$. The radiation qualities under investigation are shown in Fig. 1, together with the approximate time each study began. Based on the hypothesis that doseaveraged LET was suitable for prediction of lifeshortening/carcinogenic effects of charged particles, ${ }^{12} \mathrm{C}$ ion doses were selected based on their expected similarity to fission-spectrum neutrons. The dose range explored initially was from $40 \mathrm{cGy}$ to $320 \mathrm{cGy}$. The same dose range was used for some other particles, but as early mortality data

SKYHOOK REPLICATES AND MAXIMUM DAYS AT RISK

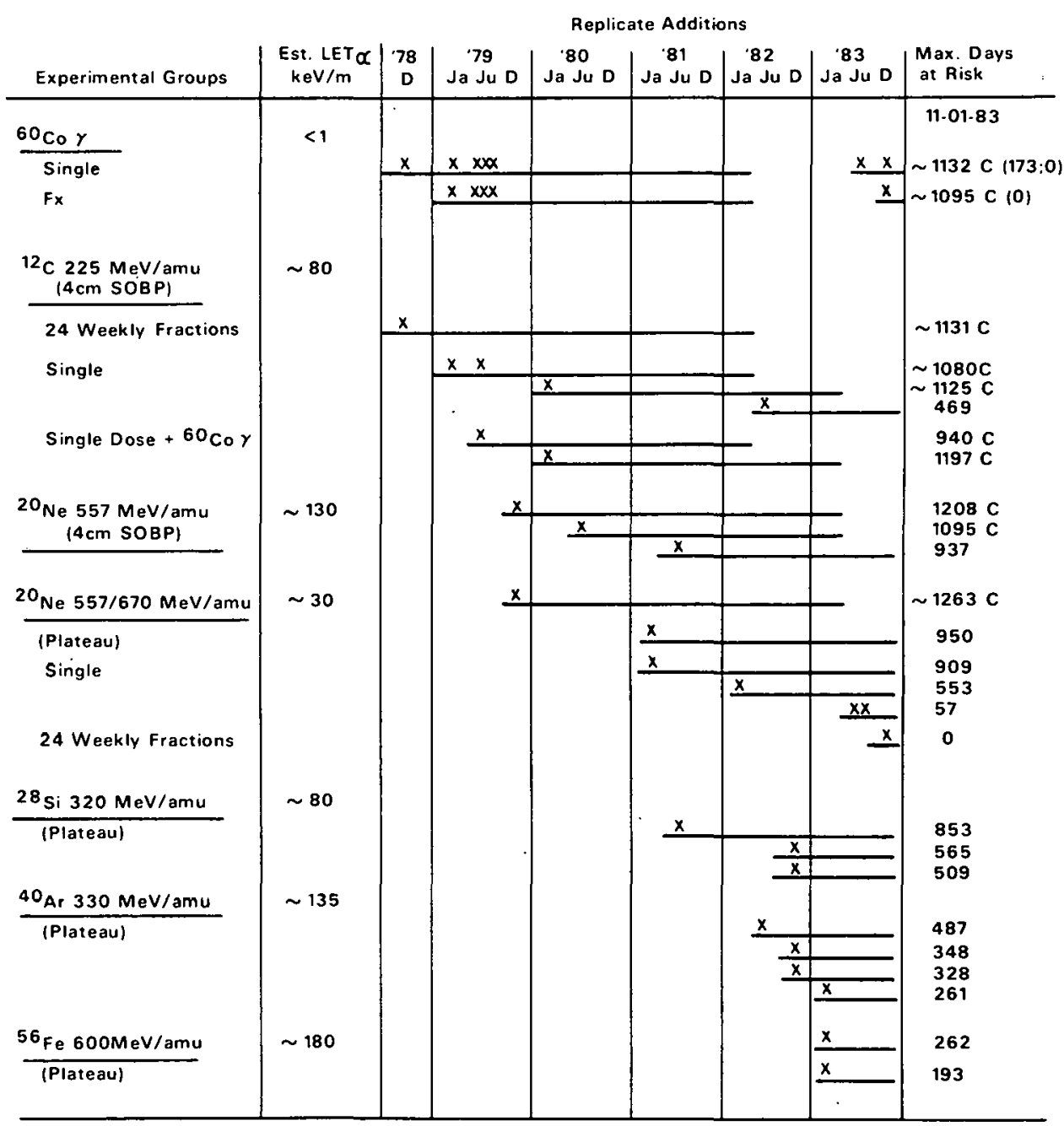

Fig. 1. Experimental groups in the SKYHOOK Project. Male $\mathrm{CB}_{6} F_{1}$ mice were irradiated at 90 to 140 days of age. Days at risk are from the time of the single dose or the first fractionated dose. 
merged, higher doses were added because lifeshortening effects were less than expected based on the LET hypothesis specified. Sample sizes generally ranged from 50-80 mice per group. After irradiation, animals are placed in a geriatric ward, under carefully controlled conditions, death checks are performed daily, including weekends, and decedents are prepared for histological evaluation. Doctors Lisbeth Kraft and Fernando D'Amelio of the NASA/Ames Laboratory in Mountain View, California, perform autopsies and histopathological analysis and maintain appropriate data files. Mortality data are entered in computer files retained in the University of California San Francisco Computer Center, San Francisco, and analysis of mortality data is performed using computer programs developed by Mr. Sylvannus Tyler, our biometrical consultant.

Mortalities are complete among animals from the first experimental series that compared the effects of single or fractionated doses of ${ }^{12} \mathrm{C}$ ions and ${ }^{60} \mathrm{Co}$ gamma radiation. Exposure to ${ }^{12} \mathrm{C}$ ions was accomplished by positioning animals in the approximate center of a Bragg peak spread to $4 \mathrm{~cm}$ using a brass spiral-ridge filter. Over the dimensions of the spread Bragg peak the estimated doseaveraged LET is approximately $80 \mathrm{keV} / \mu \mathrm{m}$, a value similar to the estimate for fission-spectrum neutrons from the JANUS reactor. Fractionated doses of ${ }^{12} \mathrm{C}$ ions or ${ }^{60} \mathrm{Co}$ gamma radiation were given weekly over a period of 24 weeks. Results from our single-dose studies with ${ }^{12} \mathrm{C}$ ions and ${ }^{60} \mathrm{Co}$ gamma radiation are shown in Fig. 2; also presented for comparison are results obtained with fissionspectrum neutrons from the JANUS reactor. The RBE is in the range of 2.1-2.4 over the range from approximately 2.5 to $12.5 \%$ life shortening. Note that the ${ }^{12} \mathrm{C}$ ion curve ignores the data point collected at $120 \mathrm{cGy}$ in order to provide an upper limit approximation for RBE over the range of life shortening specified. Comparison between the results for ${ }^{12} \mathrm{C}$ ions and fission neutrons indicate neutrons are appreciably more effective, but both the fission neutron and ${ }^{12} \mathrm{C}$ ion curves present a dimension of nonlinearity. The significance of this nonlinearity remains to be determined and may have inferences concerning the effects of fractionated doses. One clear conclusion on the results presented here is that dose-averaged LET does not predict life-shortening effects for ${ }^{12} \mathrm{C}$ ions.

When the space radiation environment or occupational exposures to high-LET radiation is the issue, results from fractionated exposures are of eatest importance. Results in Fig. 3 compare the umber of days of life span lost for single and frac-

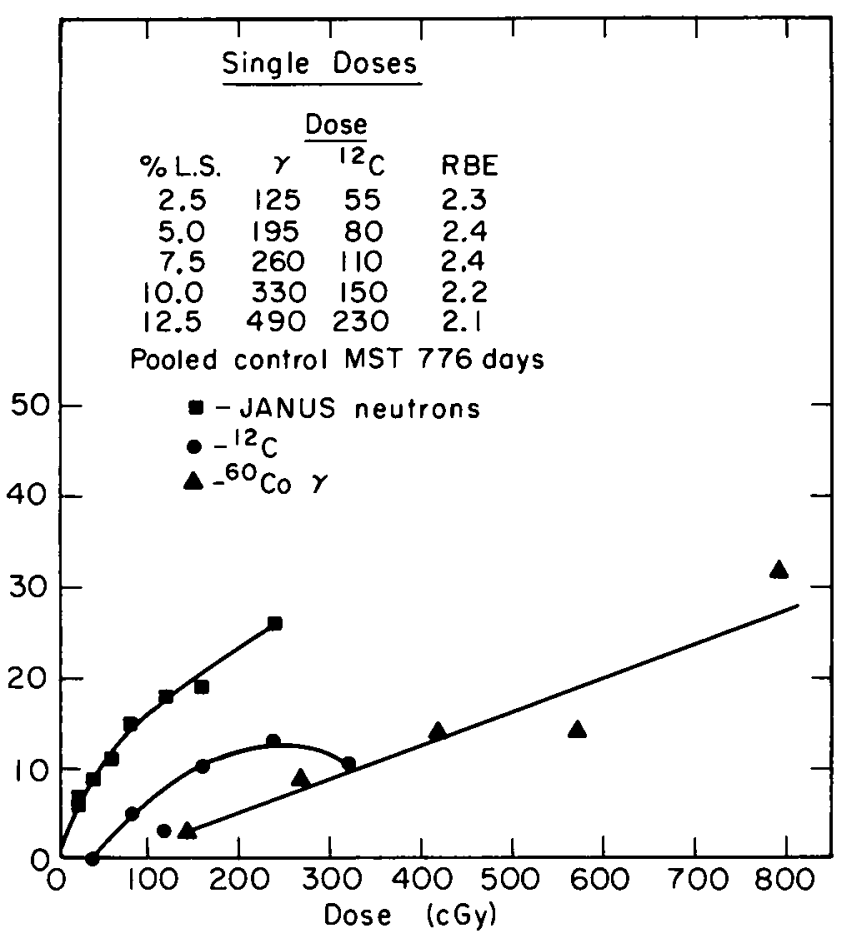

Fig. 2. Percent life shortening in $C B F$ male mice given single doses of carbon-12 ions (225 MeV/amu) or cobalt-60 gamma radiation. Results from earlier studies with fission spectrum neutrons from the JANUS reactor at Argonne National Laboratory are plotted for comparison. $B_{6} C F$, mice were used in the JANUS experiments.

(XBL 833-3668)

tionated exposures to ${ }^{12} \mathrm{C}$ ions based on control results from a pooled group and from results on control survival time for small individual groups. The traditional procedure for handling such comparisons is based upon results from pooled control groups. Statistically significant differences in survival time between irradiated and control animals occurred only at the two or three highest levels of dose, and in no case was the difference in survival between single and fractionated doses significant. Conspicuously absent is a consistent trend for a reduction in life shortening with ${ }^{12} \mathrm{C}$ ion dose fractionation. The results are not shown here, but a clear trend toward reduction of life-shortening effects was clear with gamma dose fractionation based on the response of groups with approximately the same sample size. Within the constraints of the sample sizes involved in these experiments, we conclude that little or no sparing effect on life shortening occurs when ${ }^{12} \mathrm{C}$ ion doses are fractionated, and the possibility of some degree of enhanced shortening, as occurs with fissionspectrum neutrons, cannot be precluded. Our preliminary estimates of RBE for life shortening under conditions of dose fractionation involves a 
range of 5-10 over the dose range where data are available.

Because of the importance of estimation of life shortening/carcinogenic hazards under conditions of dose fractionation, we have recently initiated a study that compares ${ }^{60} \mathrm{Co}$ gamma radiation and ${ }^{20} \mathrm{Ne}$ ions when animals are exposed in the plateau portion of the ${ }^{20} \mathrm{Ne}$ ion Bragg curve where the estimated LET is approximately $30 \mathrm{keV} / \mu \mathrm{m}$. The hypothesis tested is that at $32 \mathrm{keV} / \mu \mathrm{m}$ the sparing effect is as great for ${ }^{20} \mathrm{Ne}$ ions as for ${ }^{60} \mathrm{Co}$ gamma radiation. Mice are being given 24 radiation fractions over approximately 20 weeks, depending upon the Bevalac schedule. This dose fractionation study was delayed until mortality results were available from early replicates of animals exposed to single doses of ${ }^{20} \mathrm{Ne}$ ions. The preliminary mortality results indicate ${ }^{20} \mathrm{Ne}$ ions are probably less effective for production of life shortening than ${ }^{12} \mathrm{C}$ ions and maybe only marginally more effective than ${ }^{60} \mathrm{Co}$ gamma radiation. Dose selection for the ${ }^{20} \mathrm{Ne}$ ion fractionated dose experiment was based on the expectation of a very low RBE for life shortening for single doses of ${ }^{20} \mathrm{Ne}$ ions. The new experiment with ${ }^{20} \mathrm{Ne}$ ions is appropriately controlled and includes groups that received single as well as fractionated doses of ${ }^{20} \mathrm{Ne}$ ions and ${ }^{60} \mathrm{Co}$ gamma radia- tion, as well as an unirradiated group.

i

Depending upon the outcome of life-shorteni.'s experiments with spread peak ${ }^{20} \mathrm{Ne}$ ions (LET $140 \mathrm{keV} / \mu \mathrm{m}$ ) and single doses of ${ }^{56} \mathrm{Fe}$ ions (LET $190 \mathrm{keV} / \mu \mathrm{m})$, it may be appropriate to conduct future dose fractionation experiments at some LET in excess of $80 \mathrm{keV} / \mu \mathrm{m}$ where we have data for animals exposed to ${ }^{12} \mathrm{C}$ ions. Until results on relationships between RBE and LET are in hand for the single-dose studies described in Fig. 1, it is imprudent to contemplate new experiments at lower doses, namely, below 40 cGy, or an extensive series of dose fractionation experiments. Additionally, results obtained from in vitro transformation experiments as well as studies on Harderian gland carcinogenesis will be considered carefully when directing consideration to any future low dose studies with single or fractionated studies. If appropriate fiscal resources were available, information could be collected on early and late tissue responses to a range of charged particle speries in, for example, cataracts, and altered responsiveness of the immune, hematopoietic, and endocrine systems.

The contributions of Louise Chere, Andy Shih, and Linda Harrison to various aspects of this research are gratefully appreciated.

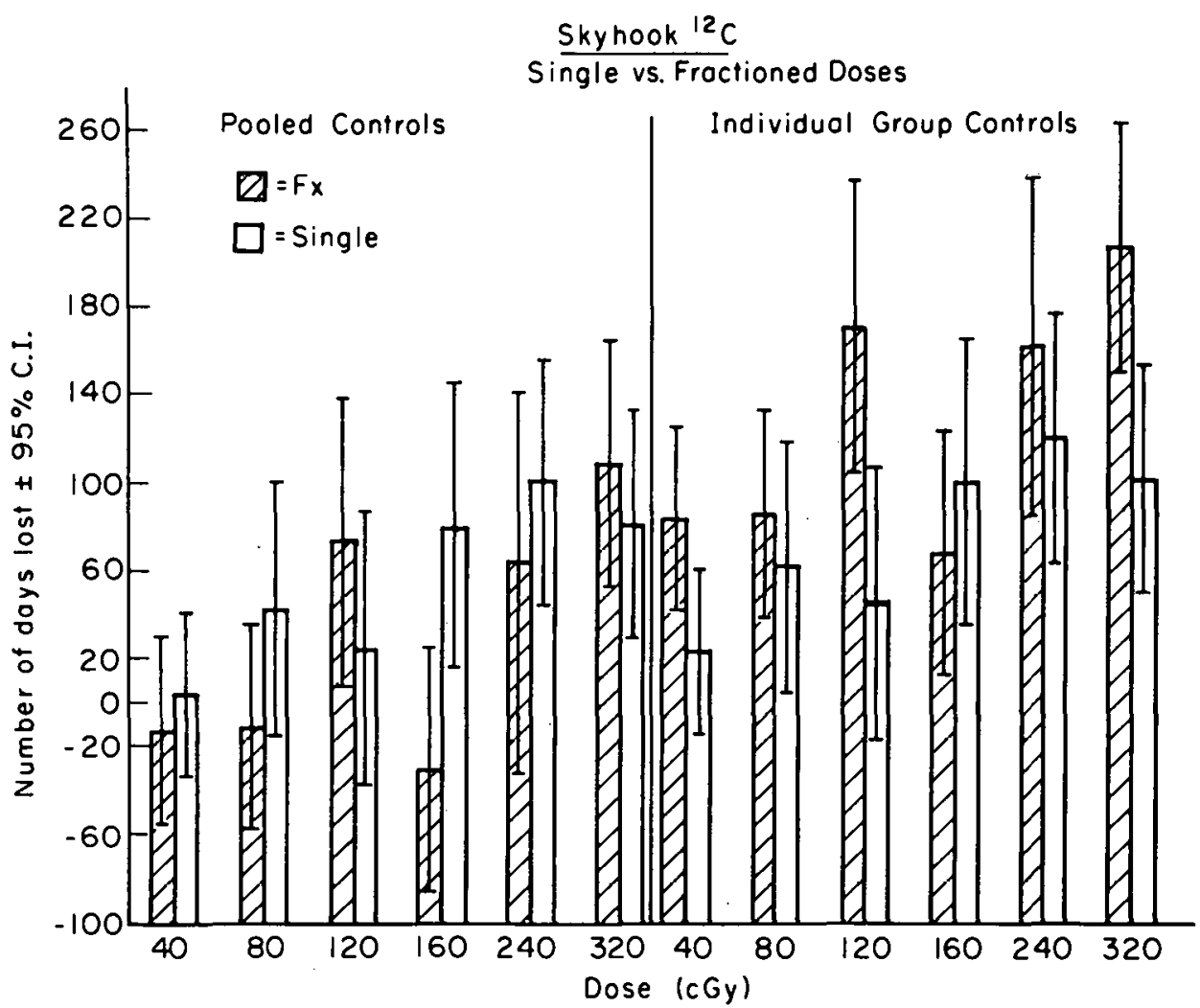

Fig. 3. Days of life span lost when carbon-12 ions (225 MeV/amu) were given as a single dose or in 24 weekly fractions. The estimates compare life shortening based on results from pooled unirradiated control groups and from small individual control groups.

(XBL 833-3676) 


\title{
HE RELATIVE BIOLOGICAL EFFECTIVENESS OF HEAVY-ION RADIATION FOR . .ORMAL TISSUE AND 9L MULTICELLULAR TUMOR SPHEROIDS
}

\author{
Adrian Rodriguez, Edward L. Alpen, Patricia Powers-Risius, Linda D. Harrison, and \\ Randy J. DeGuzman
}

We are studying the relationship between the relative biological effectiveness (RBE) in normal tissue and the linear energy transfer (LET) of heavyion beams accelerated at the LBL Bevalac, in support of the heavy-ion radiotherapy program. We use the mouse intestinal crypt cell survival and testes weight loss assays, and the multicellular tumor spheroid (MTS) to evaluate this relationship. We find that LET has a limited significance for the interpretation of radiobiological response.

We have shown that the response of normal tissues to high-LET radiations is not entirely predictable on the basis of the response of in vitro systems. $^{1-3}$ The peak RBE for gut, testes, and MTS occurs at an LET of $100 \mathrm{keV} / \mu \mathrm{m}$, and for T1 cells in monolayer culture the peak occurs at about 150 $\mathrm{keV} / \mu \mathrm{m} .{ }^{4}$ In the spread Bragg regions of ionization, at a constant LET, the higher mass particles appear to have a higher RBE. Since tumors are organized cellular systems, the choice of ions for radiotherapy is critically related to the radiobiological response of tissue as well as cells.

Figure 1(B) shows RBE as a function of LET for these tissues following irradiation with helium, carbon, neon, silicon, or argon beams modified with a spiral-ridge filter. The three LET pusitions for each ion correspond to the plateau, proximal, and distal portions of the spread Bragg peaks. For these beams, the peak effectiveness is seen with 570 $\mathrm{MeV} / \mathrm{amu}$ plateau argon ions. With 425-MeV/amu neon, the peak effectiveness is seen at the proximal peak region. These regions are associated with LET values of about $100 \mathrm{keV} / \mu \mathrm{m}$, which is well below the peak effectiveness of 150 to $200 \mathrm{keV} / \mu \mathrm{m}$, for $\mathrm{T} 1$ cells in vitro. ${ }^{4}$

The top panel (A) of Fig. 1 shows the plateau irradiation data as seen in panel $B$, plus an additional energy for neon and argon, and three energies for silicon ions. It appears that the RBE for plateau region irradiation of gut, testes, and spheroids increases monotonically for the range of LET values used, $1-200 \mathrm{keV} / \mu \mathrm{m}$. It is not clear if, at a constant LET in the plateau region, the higher mass ion has a higher RBE.

The recent modification of the Bevalac accelerator increases the number of particles and rergy levels available for biology experiments, and e can choose ions and energies that will test for
RBE differences at approximately equal values of LET. In the plateau region of the Bragg ionization curve there is quite a narrow spread of LET around the average value, a few percent at most. It is now possible to carry out irradiations with well-defined LET distributions in the ranges of 10-35, 50-85, 90-120, and more than $200 \mathrm{keV} / \mu \mathrm{m}$.

The highest priority is the LET range of 90-120 $\mathrm{keV} / \mu \mathrm{m}$; apparently this is the region of peak RBEs for the systems we are studying. As Fig. 1(A) illustrates, the majority of our experiments to date using the plateau portion of the Bragg curve, have been in the LET range that approaches $100 \mathrm{keV} / \mu \mathrm{m}$. This peak LET range can be obtained with argon
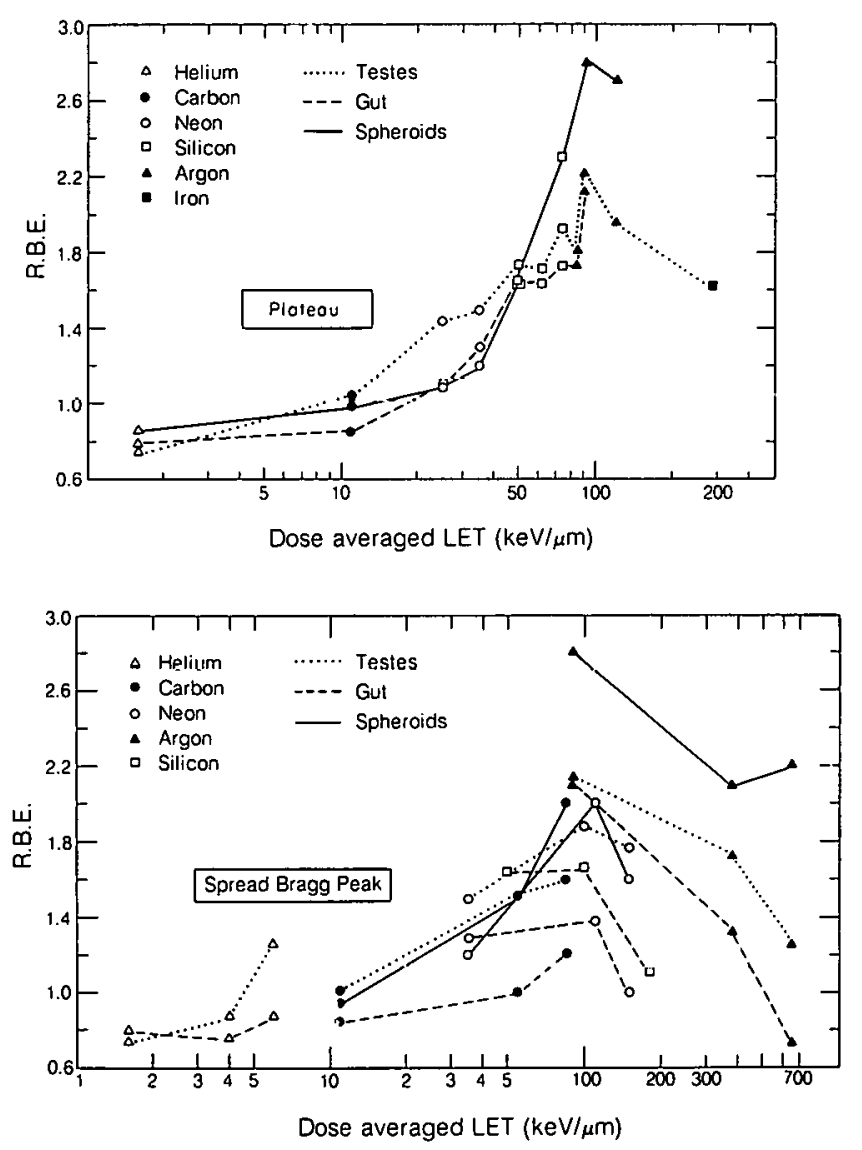

Fig. 1. RBE as a function of LET. The RBEs in the plateau region of ionization are shown in the upper figure. Each series of three points in the lower figure represents RBEs in the plateau, proximal, and distal regions in the spread Bragg peak.

(XBL 836-968A) 
and silicon plateau beams. It may be possible to use ions of greater mass, e.g., scandium, iron, and lanthanum, to compare RBE values in the LET range of 90 to $120 \mathrm{keV} / \mu \mathrm{m}$ and greater than 200 $\mathrm{keV} / \mu \mathrm{m}$. This would allow us to compare the significance of ion mass, charge, and fragmentation to LET, and their influence on RBE.

Our preliminary observations with extended Bragg peak irradiation may be due to physical energy deposition and fragmentation under various experimental conditions, or to different fundamental radiobiological responses in organized systems and in vitro monolayers. Our experiments will be conducted in the plateau region of ionization where fragmentation is minimal and the LET is narrowly defined; the results will be compared with in vitro mammalian cell survival data.

\section{REFERENCES}

1. Alpen, E.L., Powers-Risius, P., and McDonald, $M$. Survival of intestinal crypt cells after exposure to high $Z$, high energy charged particles. Radiat. Res. 83, 677-687 (1980).

2. Alpen, E.L., and Powers-Risius, P. The relative biological effect of high $Z$, high-LET charged particles for spermatogonial killing. Radiat. Res. 88, 132-143 (1981).

3. Rodriguez, A., and Alpen, E.L. Cell survival in spheroids irradiated with heavy-ion beams. Radiat Res. 85, 24-37 (1981).

4. Blakely, E.A., Tobias, C.A., Yang, T.C.H., Smith, K.C., and Lyman, J.l. Inactivation of human kidney cells by high-energy monoenergetic heavy-ion beams. Radiat. Res. 80, 122-160 (1979).

\title{
POTENTIALLY LETHAL DAMAGE REPAIR IN 9L MULTICELL TUMOR SPHEROIDS
}

\author{
Adrian Rodriguez, Edward L. Alpen, and Randy J. DeGuzman
}

Multicell tumor spheroids (MTS) have been shown to have a cellular radiation response similar to that of in vivo tumor cells. X-ray radiation studies with various cell lines grown as MTS have shown fundamental differences to the radiation response of monolayer cultured cells:

1. Three-dimensional contact enhances survival of cells similar to in vivo tumors compared to in vitro monolayer. ${ }^{1,2}$

2. Radioresistant hypoxic cells in MTS have been demonstrated by characteristic changes in the final slope of the cell survival curve. ${ }^{3,4}$

3. Cell radiation repair is enhanced in MTS. ${ }^{5,6}$

4. Studies with high-LET radiations (pion, neutron, and heavy ions) have shown that MTS cells are more radioresistant than monolayer cells up to an LET of 70 to $80 \mathrm{kcV} / \mu \mathrm{m}^{7-9}$

Questions remain as to the nature of the contact effect. The effect could be due to radioprotection from the low oxygen tension in the MTS or to repair of radiation damage mediated through cellcell contacts. Work is being directed to examine radiation repair in $9 \mathrm{~L}$ cell $\mathrm{MTS}$ compared to repair in monolayer cultures. Previous studies with the $9 \mathrm{~L}$ cell system have shown enhanced cellular radioresistance with both low- and high-LET radiation. Experiments to examine the repair of potentially lethal damage (PLD) have been initiated with 150-kVp $x$ rays and 320- and 670-MeV/amu silicon ions. Repair of PLD was evaluated in intact MTS and compared with confluent stationary phase monolayer cultures. PLD was determined after incubation at $37^{\circ} \mathrm{C}$ and delayed plating of 5 hours for MTS and confluent monolayers. The monolayers were incubated during this period with depleted media. The results for $x$ ray (Fig. 1) show that initial survival of MTS cells is enhanced compared to monolayer cells, as has been reported previously. ${ }^{1}$ With delayed plating the monolayer survival curve clearly indicates that PLD repair has occurred. Monolayer cell survival after repair does not appear to be significantly different from MTS survival. MTS cells do not show any PLD repair and may indicate that PLD repair is rapid and occurs during the time (30-45 minutes) that the MTS cells were dispersed and plated.

Figure 2 shows the results of PLD repair after silicon irradiation. In the $670-\mathrm{MeV} / \mathrm{amu}$ beam with an LET of $55 \mathrm{keV} / \mu \mathrm{m}$, PLD repair is exhibited by the monolayer (Fig. 2a) but not by MTS (Fig. 2b), as was the case with $x$ rays. The $R B E_{0.1}$ for repair of monolayers in this beam is 1.92 compared to the $R^{2} E_{0.1}$ for initial survival of 1.76. For MTS the $\mathrm{RBF}_{0.1}$ is 1.54 . In the $320-\mathrm{MeV} / \mathrm{amu}$ silicon beam

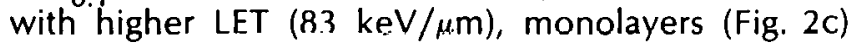
do not repair PLD; however, the MTS (Fig. 2d) do repair PLD. This result was unexpected on the basis of the $\mathrm{x}$-ray and $670-\mathrm{MeV} / \mathrm{amu}$ silicon da and may indicate the MTS cells have an add capacity to repair high-LET radiation damage. This 


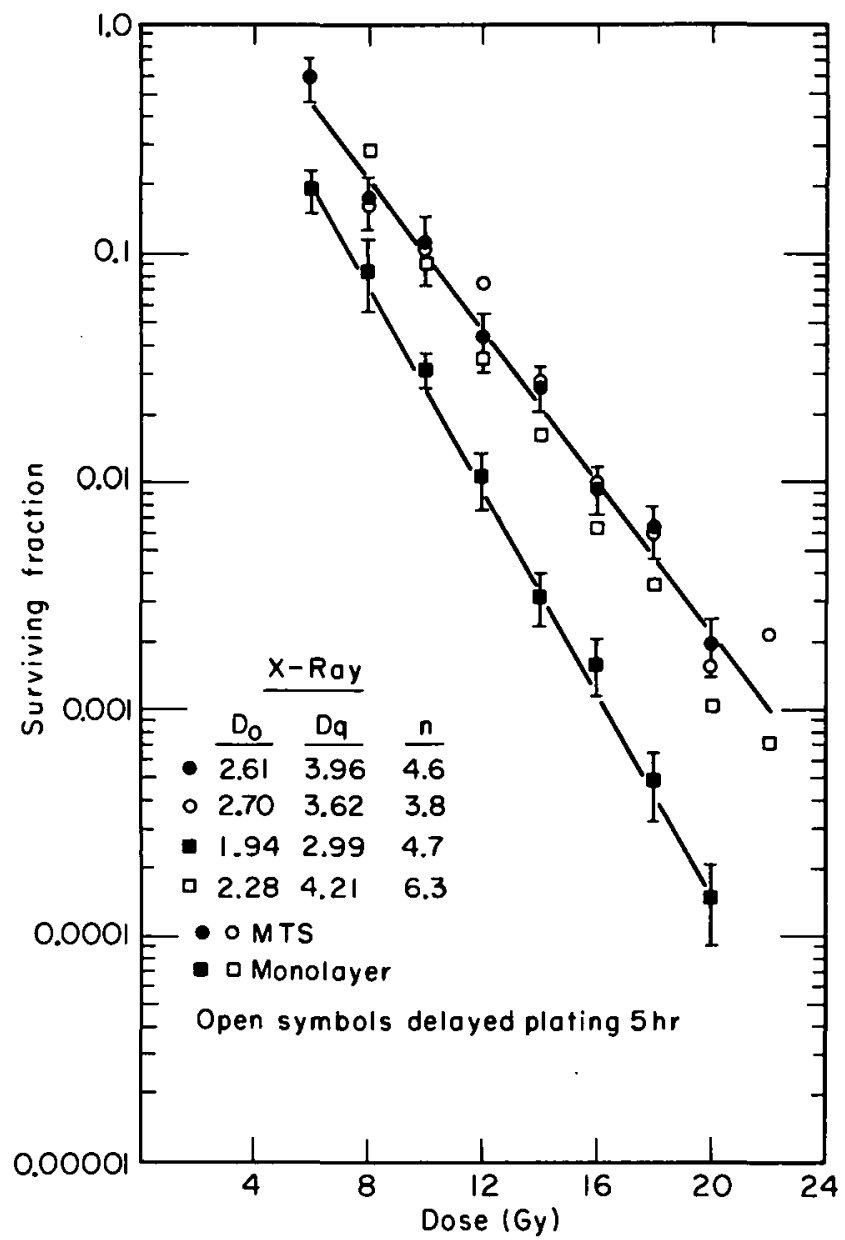

Fig. 1. Repair of potentially lethal damage in $9 L$ MTS and monolayers after $x$-ray irradiation. Survival curve parameters are given for initial survival curves (closed symbols) and after delayed plating (open symbols). Error bars are standard deviations.

(XBL 836-3839)

is an important result and bears further study in consideration of the mechanism of radiation repair in in vivo tumors and tissues for heavy ions. The $R_{B E}$, for repair of MTS cells is 2.1, and for initial survival it is 2.5. For monolayers the $R_{B E}$ for
PLD repair and initial survival are 2.86 and 2.1, respectively.

\section{REFERENCES}

1. Sutherland, R.M., Inch, W.R., McCredie, J.A., and Kneuw, J. A multicomponent radiation survival curve using an in vitro tumor model. Int. J. Radiat. Biol. 18, 491-495 (1970).

2. Durand, R.E., and Sutherland, R.M. Radiation-resistant tumor cells may be more sensitive in vitro. Cancer Research 32, 2587-2588 (1972).

3. Sutherland, R.M., and Durand, R.E. Hypoxic cells in an in vitro tumor model. Int. J. Radiat. Biol. 23, 235-246 (1973).

4. Song, C.W., Clement, J.J., and Twitt, S.H. Elimination of hypoxic protection by 5-thioD-glucose in multicell spheroids. Cancer Research 38, 4499-4503 (1978).

5. Dertinger, $H_{\text {., }}$ and Seiter, A, Split dose survival and cycle progression of proliferating and non-proliferating cells in V79 spheroids. Int. J. Radiat. Biol. 31, 401-403 (1977).

6. Durand, R.E., and Sutherland, R.M. Effects of intercellular contact on repair of radiation damage. Exp. Cell Res. 71, 75-80 (1972).

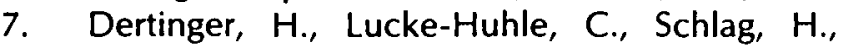
and Wiebezahn, K.F. Negative ion irradiation of mammalian cells. I. Survival characteristics of monolayers and spheroids of Chinese hamster lung cells. Int. J. Radiat. Biol. 29, 271-277 (1976).

8. Lucke-Huhle, C., Blakely, E.A., Ngo, F.Q., - Chang, P.Y., and Tobias, C.A. Survival and kinetic response of V79 spheroids after exposure to heavy-ion beams. Int. J. Radiat. Biol. 37, 483-492 (1980).

9. Rodriguez, A., and Alpen, E.L. Cell survival in spheroids irradiated with heavy-ion beams. Radiat. Res. 85, 24-37 (1981). 

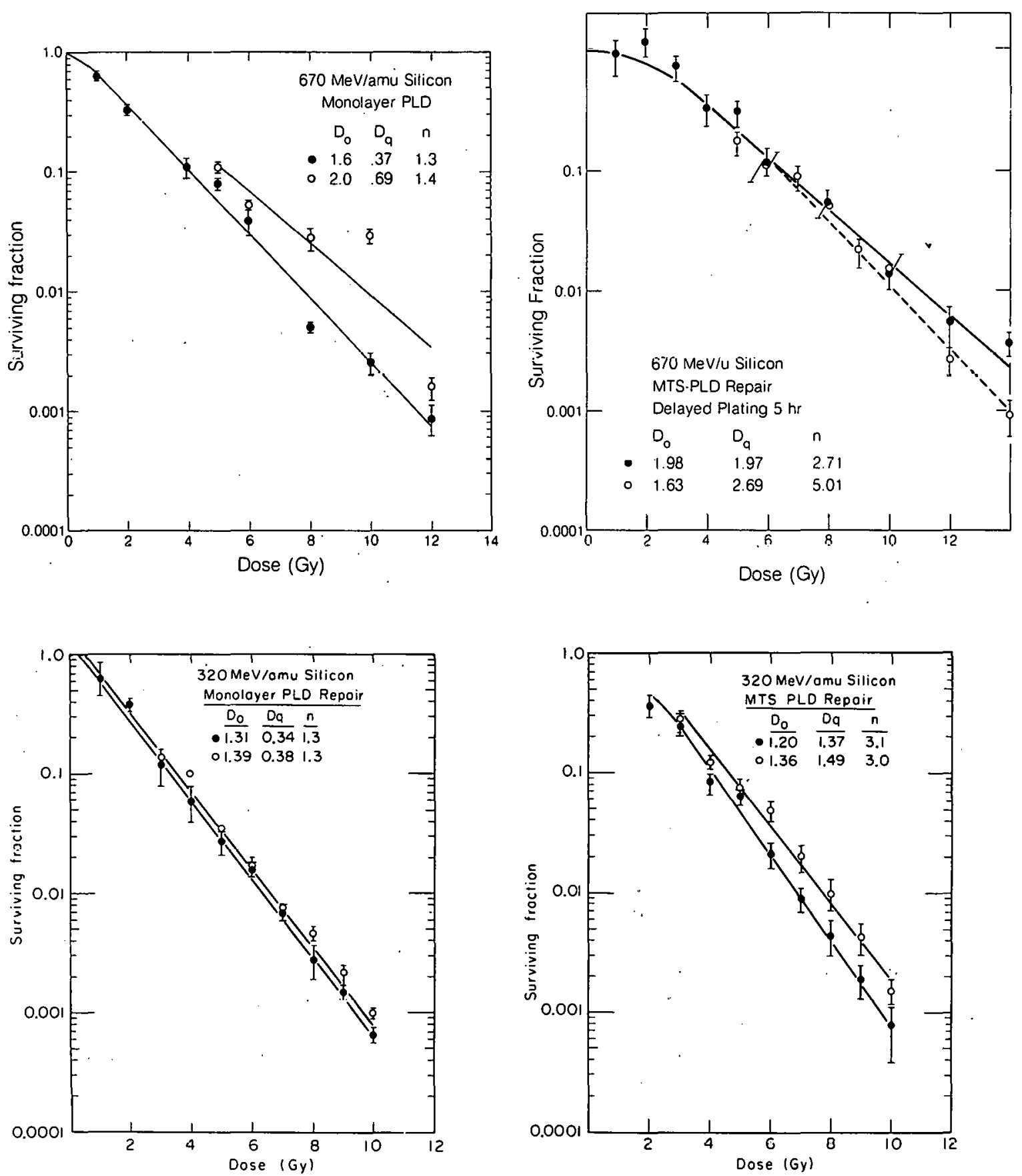

Fig. 2. Repair of potentially lethal damage in MTS and monolayers after 670-MeV/amu (a and b) and 320$\mathrm{MeV} / \mathrm{amu}(\mathrm{c}$ and d) silicon ion irradiation in the plateau. Initial survival is indicated by closed symbols, and delayed plating survival is indicated by open symbols. Error bars are standard deviations.

(XBL 8311-4093) 


\section{Radiological Physics}

\section{PHYSICAL CHARACTERIZATION OF HEAVY-ION BEAMS}

Walter Schimmerling, Marwin Rapkin, Mervyn Wong, Jerry Howard, Selig N. Kaplan, ${ }^{*}$ Helmuth G. Spieler, ${ }^{\dagger}$ Blair V. Jarrett, ${ }^{\dagger}$ and John T. Walton ${ }^{\dagger}$

The radiation field of relativistic heavy ions is significantly altered by the inevitable presence of matter in the path of the particles. For radiation therapy and radiobiological research these materials are mainly in the beam-flattening and rangemodification devices, as in the generally healthy tissue between the entrance portal and the tumor volume of a patient. In addition, an energetic heavy-ion beam must traverse vacuum windows, particle detectors, and air volumes. The radiation field at the exit of these materials consists of the residual primary particles as well as significant fluences of lighter particles produced by nuclear interactions in the matter traversed. The velocity and charge distribution of the emerging particles is also a function of emergence angle, so that the radiation field depends on the location (parallel or perpendicular to the beam axis) where it is measured. These distributions are being measured in order to evaluate and predict biological effects on cells and tissues, as well as for the design of beam-modification devices and shielding.

\section{PORTABLE TIME-OF-FLIGHT TELESCOPE}

The extent to which data in one beam area can be extrapolated to another "equivalent" beam is an important question that we have attempted to address by developing a portable particle identification instrument and providing an experimental setup in Cave II of the Biomedical Facility of the Bevalac that can easily be carried over into the Beam 40 experimental area.

Figure 1 illustrates the apparatus. It consists of dual time-of-flight (TOF) telescopes, $T_{1}-T_{2}$ and $T_{3}$ $\mathrm{T}_{4}$, between which are placed several finite energy loss $(\Delta E)$ detectors $D_{1}-D_{3}$. The detectors are mounted at the center of aluminum flanges that can be positioned independently. In the current arrangement shown in Fig. 1 the detectors are mounted inside a vacuum pipe maintained at 30 $\mu \mathrm{m}$ pressure in order to avoid corrections for energy loss at low velocities in an air path between

sclear Engineering Department, UCB; Physics, Computer Sci....e, and Mathematics Divison, LBL.

${ }^{\dagger}$ Engineering and Technical Services Division, Instrument Science and Engineering Group, LBL.
TOF detectors. Two detectors $\left(\mathrm{T}_{3}\right.$ and $\left.\mathrm{T}_{5}\right)$ are placed next to each other at the $\mathrm{T}_{3}$ position in order to provide an absolute calibration of zero TOF.

The incident beam is aligned on the bench using the multiwire proportional counter (MWPC), and the number of particles per pulse (ppp) is monitored by the J scintillator. The beam intensity information provided by $\mathrm{J}$ is also relayed to the Bevalac main control room for machine tuning at low intensity.

The beam traverses J, the MWPC, the first of two ionization chambers, $I C_{\mathrm{O}^{\prime}}$ a variable depth water column, and the second ionization chamber, $I_{1}$. The Bragg curve on the apparatus bench is measured for each setup as the ratio of $I C_{1} / I C_{0}$ ionization, normalized to zero water in the tank.

All the detectors are ion implanted silicon detectors. ${ }^{1}$ The TOF detectors, $\mathrm{T}_{1}-\mathrm{T}_{4}$, are $\sim 200$ $\mu \mathrm{m}$ thick and $1.9 \mathrm{~cm}$ diam. The $\Delta \mathrm{E}$ detectors, $\mathrm{D}_{1}$ $\mathrm{D}_{3}$, are $\sim 0.7 \mathrm{~g} / \mathrm{cm}^{2}$ thick. Their cumulative thickness results in an energy loss of $\sim 20 \mathrm{MeV} / \mathrm{A}$ for a typical $670-\mathrm{MeV} / \mathrm{A}$ neon beam and corresponds to the residual range (in $\mathrm{Si}$ ) of a $\sim 104-\mathrm{MeV} / \mathrm{A}$ neon beam.

Each TOF telescope consists of two fully depleted silicon detectors mounted $\sim 1 \mathrm{~m}$ apart. The detectors are biased beyond depletion to provide a field strength of $1-1.5 \times 10^{4} \mathrm{~V} / \mathrm{cm}$ throughout their sensitive volume. Figure 2 shows the mounting arrangement used to minimize the amount of extraneous material in and near the beam. A $25-\mathrm{cm}$ length of thin $50-\Omega$ tefloninsulated coax cable connects the detector to the fast preamplifier, which is mounted externally. The fast preamplifiers use bipolar transistor input stages especially designed to provide both low noise $(<0.5 \mathrm{nV} / \sqrt{\mathrm{Hz}})$ and low input reflection at high frequencies. The latter is achieved by feedback techniques that do not significantly degrade the input noise. ${ }^{2}$ Considerable care was taken to provide good shielding, and external pickup is insignificant, i.e., the noise floor of the system is determined by preamplifier noise $(<10 \mu \mathrm{v}$ rms over a $300-\mathrm{MHz}$ bandwidth). The fast preamplifiers have a voltage gain of 15 . Since the signal level at the detector may be as low as a few hundred micro- 


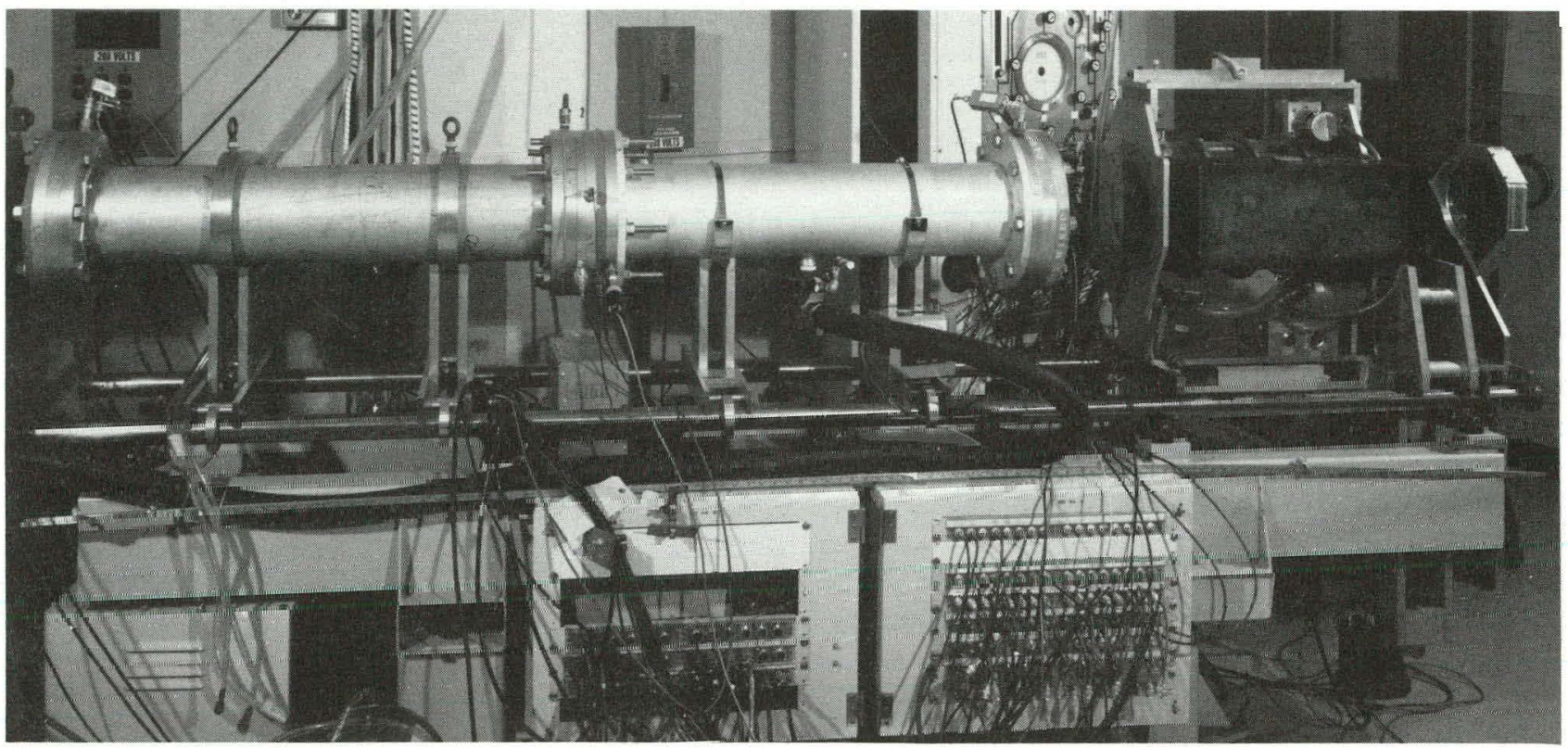

Fig. 1a. Photograph of portable particle identifier. Entire apparatus is contained inside vacuum pipe to avoid corrections due to energy loss in flight paths at lowest energies measured. Detectors are mounted on flanges and can be reconfigured quickly. From right to left are shown the multiwire proportional chamber (MWPC) used for beam monitoring, the variable thickness water column, and the dual time-of-flight spectrometer.

(CBB 835-4781)

DUAL T.O.F. CONFIGURATION

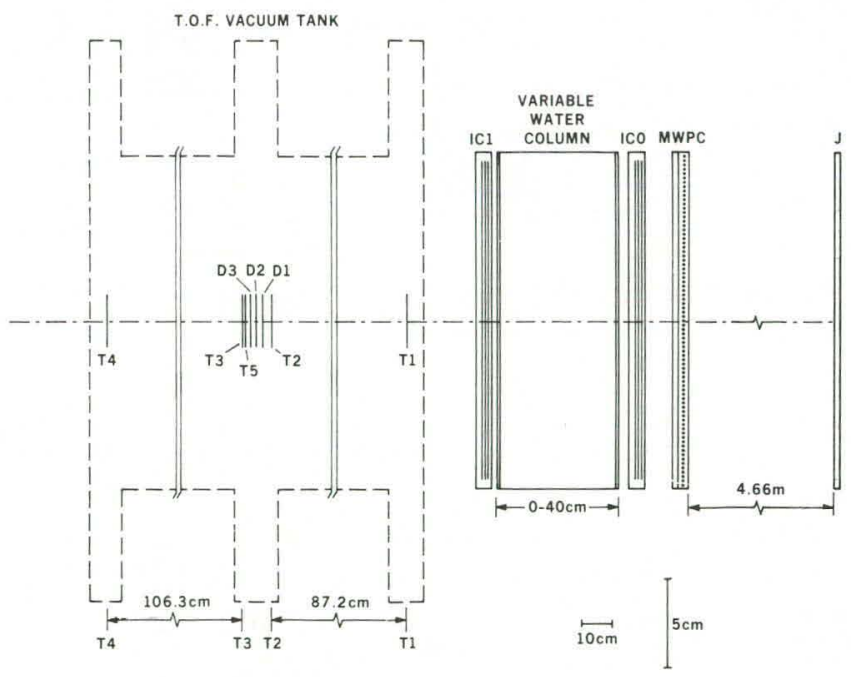

Fig. 1b. Schematic scale drawing of the dual time-of-flight spectrometer (note different horizontal and vertical scales). $J=$ beam monitoring scintillator (not shown in photograph), $M W P C=$ multiwire proportional counter used for beam profile monitoring, $I C$ and $I C$ (not shown in figure) = ionization chambers used for dosimetry and Bragg curve measurements. $T_{1}-T_{5}=$ time-of-flight detectors, $D_{1}-D_{3}=$ energy loss detectors.

(XBL 8310-11900)

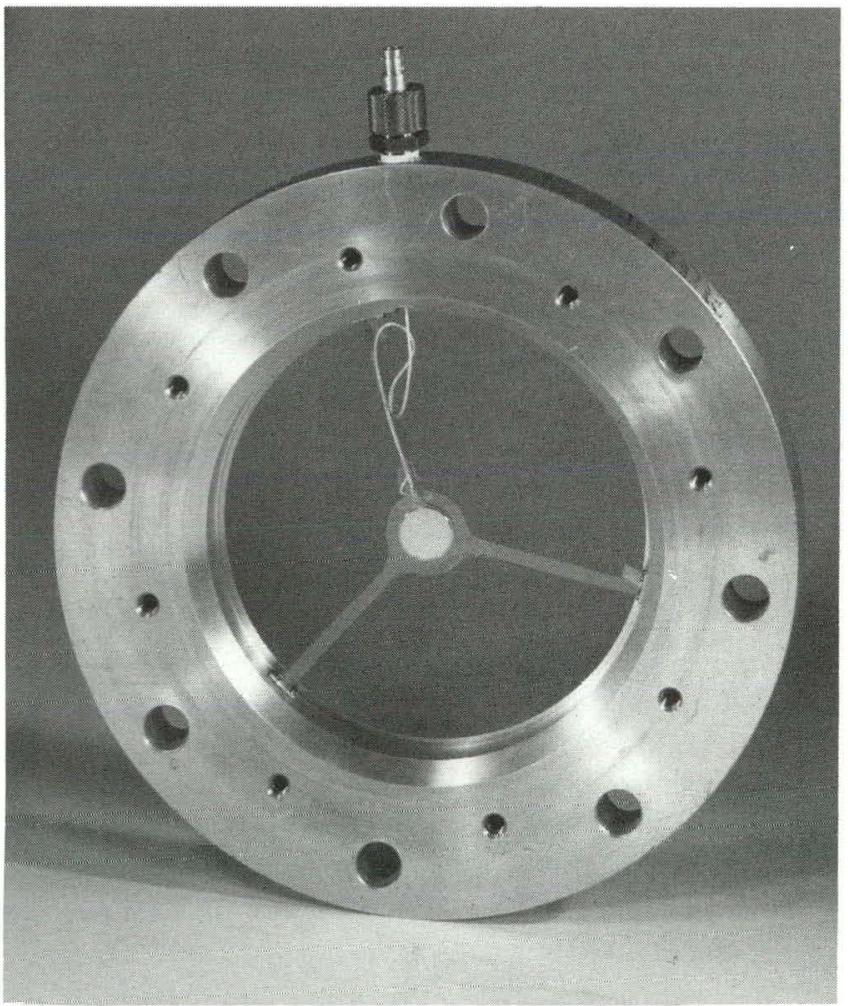

Fig. 2. One of the time-of flight deteclors inside the flar The detector is held in place at the center of the flange with Mylar support shown, to minimize material around the detec. Electronic signals are derived using the shielded cable and a vacuum-tight connector on the flange.

(CBB 830-9561) 
'olts, an additional insertion amplifier with a gain of 25 is used to provide adequate drive level for the constant fraction timing discriminator. ${ }^{3}$ The time difference between start and stop channels is measured conventionally with a TAC-ADC system.

The timing resolution of the TOF telescope depends on the signal-to-noise ratio, and has been measured to be $50-75$ psec for beams ranging from argon to neon (cf. Fig. 3).

The dual TOF detector corresponds in principle to the simplest means of identifying particle masses by means of the relation

$$
A=\Delta E / \Delta \epsilon,
$$

where $\Delta \epsilon$ is the change in energy per nucleon as measured by the TOF telescope. In practice, the mass resolution is dominated by the ratio of TOF resolution to $\triangle \mathrm{E}$. In the current setup, the mass resolution is only $\sim 20 \%$ for $150-\mathrm{MeV} / \mathrm{A}$ neon, but can easily be improved by increasing the flight path.

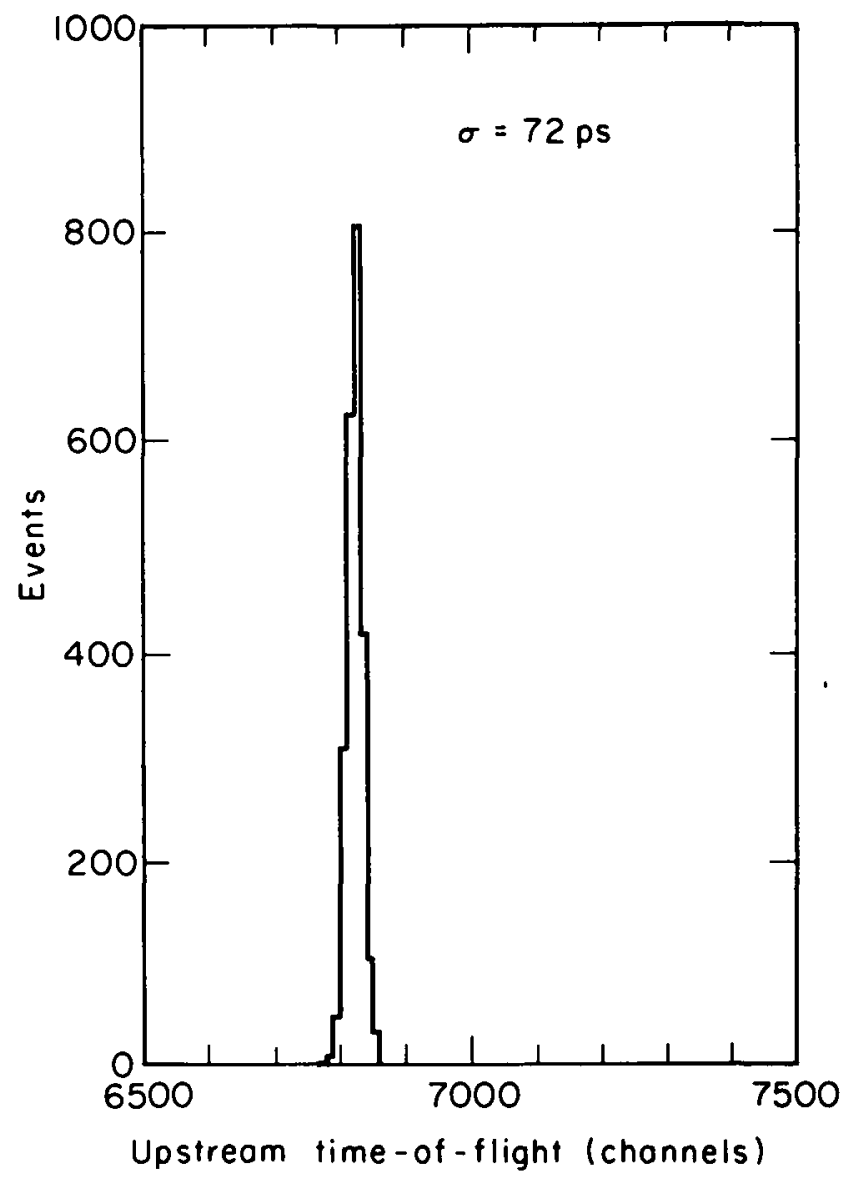

ig. 3. Typical $T_{1}-T_{2}$ time-of-flight spectrum.

(XBL 8311-4127)
The charge resolution of the system (element identification) is better than $5 \%$, as may be seen in Fig. 4, where the different charge groups due to argon fragmentation are clearly separated.

\section{BEAM FRAGMENTATION STUDIES}

The following studies have been performed in the past year, using the indicated beams:

Neon at $670 \mathrm{MeV} / \mathrm{A}$. This is the beam used for routine therapy. We have measured the velocity spectrum and fragmentation at several positions along the Bragg curve as modulated with a $10-\mathrm{cm}$ spiral-ridge filter.

Silicon at 670 and $330 \mathrm{MeV} / \mathrm{A}$. We have measured fragmentation at $1.87 \mathrm{~cm}$ upstream of the unmodulated Bragg peak, to provide data for comparison with other existing physics and biology measurements, including some obtained in Beam 40. These data are currently being analyzed.

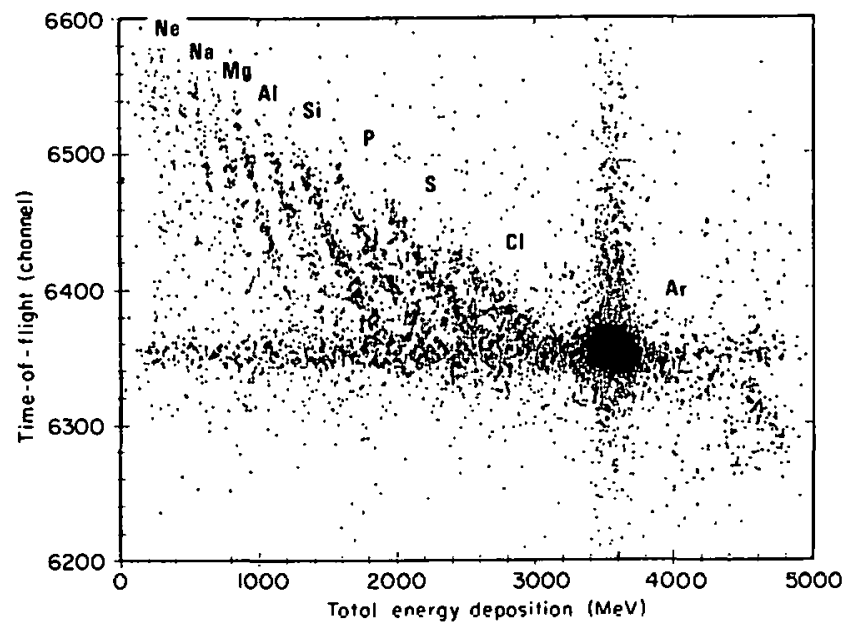

Fig. 4. A two-dimensional plot of time-of-flight channel vs. energy deposition in the finite energy loss detectors, for 570 $\mathrm{MeV} / \mathrm{A}$ argon and $11.35 \mathrm{~cm}$ of water. Increasing channel number in this plot corresponds to increasing velocity. The large contribution of the primary beam is clearly separated from the contributions of fragments. The velocity of the fragments is limited between the velocity of the primary beam at the entrance to the water column (neglecting contributions due to other material in the beam) and the velocity of the primany beam at the exit of the water column. At the primary beam velocity, a broad band extends along the energy deposition axis. These signals correspond to fragments made at the exit of the water column and to primary beam particles and beam-velocity fragments suffering nuclear interactions in the energy loss detector. Signals corresponding to pulse heights greater than that of the (stopping) primary beam are due to fragments of the primary beam that have the same charge but have been produced by neutron loss. 
Argon at 330 and $570 \mathrm{MeV} / \mathrm{A}$. We have measured the fragmentation of argon at several points along the Bragg curve, including a thickness of water calculated to yield a primary beam LET of 150 $\mathrm{keV} / \mu \mathrm{m}$ and a residual range corresponding to the standard $1.87 \mathrm{~cm}$ upstream of the Bragg peak. These data are also being analyzed.

The details of the ridge filter study, using neon extracted from the Bevalac at $670 \mathrm{MeV} / \mathrm{A}$, are presented to illustrate the results being obtained. Typical biology-therapy conditions were simulated on the Physics Bench in Cave II. Neon, fully stripped at $670 \mathrm{MeV} / \mathrm{A}$, was used (this is the usual therapy beam). The lead scattering foils were increased to $8 / 64$ inch. The $10-\mathrm{cm}$ spiral-ridge filter was used to spread out the Bragg peak.

The measured Bragg curve showing the spread-out peak is illustrated in Fig. 5a. The scale on the left-hand side of the figure shows relative average ionization. The filled circles represent the mean energy per nucleon of the emerging primaries, measured at selected points along the Bragg curve using the time-of-flight telescope (right-hand scale). The production of fragments is examined at three locations: (I) on the plateau, (II) at the distal peak, and (III) halfway along the spread-out peak.
These points correspond to water column settir of 15,20 and $25 \mathrm{~cm}$, respectively.

Figures $5 b, 5 c$, and $5 d$ are histograms of the summed pulse heights of the solid state detectors. The individual pulse height signals from the three detectors are digitized in the data acquisition system. The summation of the signals is accomplished using software techniques and is shown here in terms of channel number, equivalent to energy deposited. Figure $5 \mathrm{~b}$ is the fragment distribution at a point corresponding to $15 \mathrm{~cm}$ of water penetration distance, along the plateau region. As would be expected, the amount of fragmentation is minimal, the ratio of primary to fragment being almost 10 to 1 for the four fragments observed.

At the proximal peak (Fig. $5 \mathrm{c}$ ), the ratio of primary events to fragment events is of the order of 5 to 1 . The peaks after the main peak in Figs. $5 \mathrm{~b}$ and $5 c$ are believed to be caused by multiple events.

Half way along the spread-out Bragg peak (Fig. 5d), the fragment production ratio is almost 3 to 1. Also, fragments down to $Z=4$ (beryllium) are observed. Note that the multiple event peak is no longer seen. The beam is sufficiently reduced in intensity to prevent pulse pile-up, and the
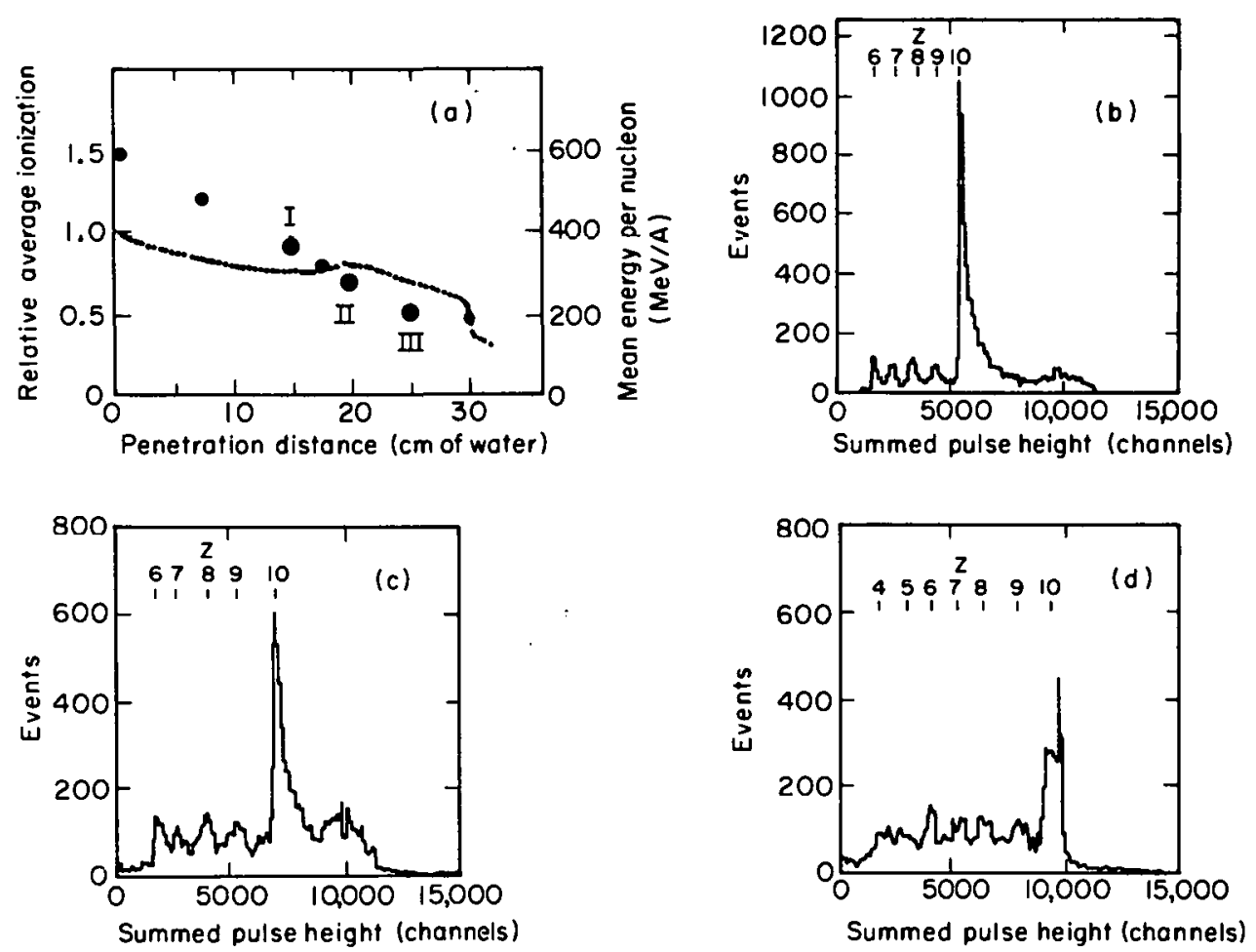

Fig. 5. (a) Range-modulated Bragg curve for $670-\mathrm{MeV}_{\mu} \mathrm{A}$ neon (left scale) and mean energy per nucleon (right scale) as a function of water absorber thickness. Filled circles show measured points, of which points labeled $I$, 11 , and III refer to the next three panels of the figure. (b) Energy deposition spectra at $15 \mathrm{~cm}$ of water; (c) Energy deposition spectra at $20 \mathrm{~cm}$ of water; (d) Energy deposition spectra at $25 \mathrm{~cm}$ of water.

(XBL 8311-4129) 
eavier fragment components of multiple-particle - vents are likely to have stopped (or have been scattered out) further upstream.

\section{REFERENCES}

1. Walton, J.T., and Haller, E.E. Silicon radiation detectors-materials and applications, Proc.
Material Res. Soc. 1982 Annual Meeting, Symposium F, Vol. 16, Elsevier Science Pub. Co., 1983. Lawrence Berkeley Laboratory Report LBL-14909.

2. Spieler, H. IEEE Trans. Nucl. Sci. NS-29, 1142 (1982).

3. Maier, M.R., IEEE Trans. Nucl. Sci. NS-30, 385 (1983).

\title{
MEASUREMENTS OF W FOR HIGH-ENERGY HEAVY IONS
}

\author{
Walter Schimmerling, Selig N. Kaplan, ${ }^{\star}$ T.S. Subramanian, ${ }^{\dagger}$ W. John McDonald, ${ }^{\ddagger}$ \\ George Gabor, ${ }^{\$}$ and Ahren J. Sadoff'
}

The linear relationship between energy deposition and ionization provides the basis for a large body of measurement results in radiation dosimetry. An accurate measurement of the constant of proportionality $\mathrm{W}(\mathrm{eV} / \mathrm{ion}$ pair) requires precise and independent measurements, or inferences, of energy deposition and free-charge production. High-energy heavy ions used in radiation therapy have a considerably different range of charge, mass, and velocity than the radiations, alphas, and electrons, for which there are extensive measurements of W. Because for high-energy heavy ions the energy transfer is small compared to the total energy, $W$ measurements could be made at a constant velocity. We have used beams of neon and silicon to measure $W$ at Bevalac energies.

- Figure 1 is a schematic diagram of the experimental arrangement. The beam particles incident on the apparatus were monitored by an array of scintillation counters to measure the beam intensity and to define the accepted beam spot area. Multiwire proportional chambers were used to trace the trajectory of the beam particles. The energy of the incident beam was degraded by an absorber of variable thickness consisting of remotely controllable inserts and a double wedge made of Lucite. The velocity of each particle incident on the ionization chamber was measured with a chevron channel plate time-of-flight (TOF) telescope. The charge of each particle traversing the ionization chamber was determined with an array of silicon

\footnotetext{
"Physics, Computer Science, and Mathematics Division, LBL.

†Swedish American Hospital, Rockford, Illinois.

¥University of Alberta, Edmonton, Alberta.

ggineering and Technical Services Division, Instrument Scices and Engineering Group, LBL.

- apartment of Physics, Ithaca College, Ithaca, New York.
}

detectors. For each particle traversing the system a measurement is made of particle velocity before entering the ion chamber and of differential and total energy loss after leaving the chamber. These measurements permit, in addition to determination of energy, identification of particle mass and charge.

The energy loss by each fast heavy ion in the ionization chamber was calculated using the Bethe formula. The chamber pressure and temperature were monitored, and the ideal gas law was used to derive the mass and the gas volume.

Over the range of ion velocities in the present measurement a significant fraction of the energy loss produces fast electrons (delta rays) with ranges greater than the thickness of the ion chamber. Under conditions of electronic equilibrium the high-energy electrons that are produced in but leave the chamber are compensated for by similar high-energy electrons entering the chamber following production upstream.

In the present experimental setup, however, the mass of absorbing material upstream of the chamber is less than the range of the highestenergy delta rays, and therefore a correction must be made for an uncompensated loss of electrons from the chamber volume. This absence of compensating absorber upstream of the chamber is due to the evacuated time-of-flight beam pipe. The total absorber immediately upstream of the sensitive volume of the ion chamber amounted to 50 $\mathrm{mg} / \mathrm{cm}^{2}$ of $\mathrm{N}_{2}$ equivalent, and consisted primarily of Mylar windows, on both the time-of-flight pipe and the ion chamber.

If the total thickness of chamber plus upstream absorber is $z_{o^{\prime}}$ then for all energy transfers that produce an electron with a range greater than $z_{o^{\prime}}$ the energy deposited in the chamber will on the aver- 


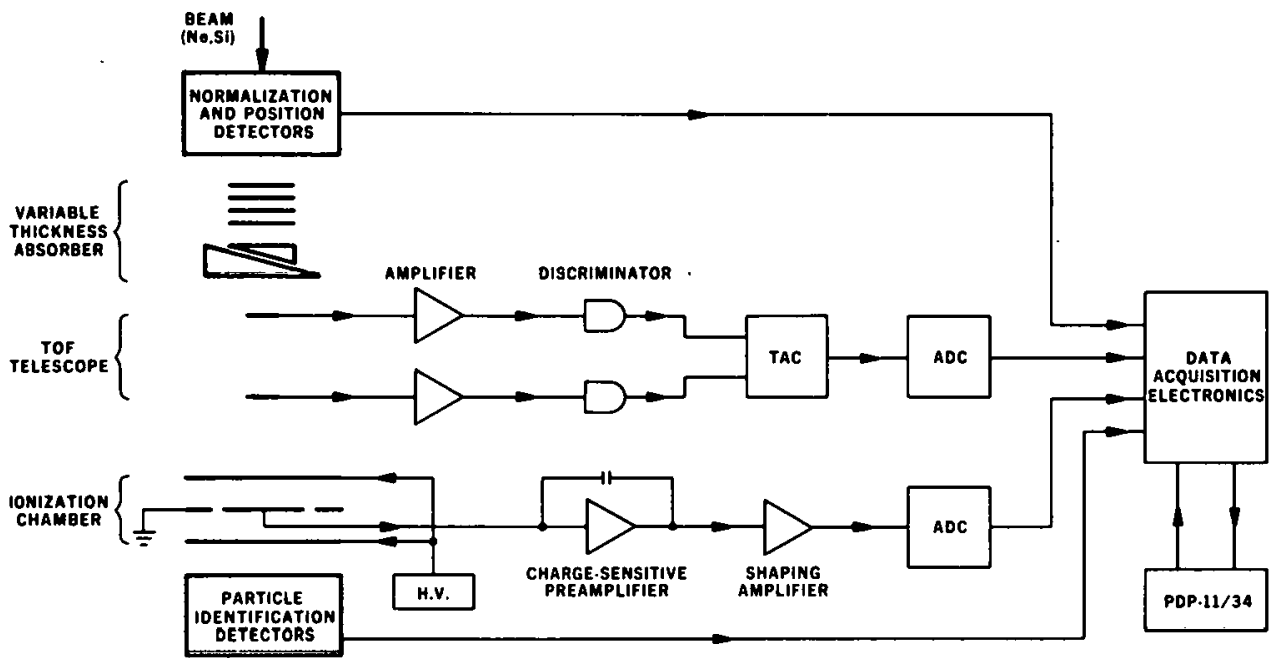

Fig. 1. Schematic layout of experiment.

(XBL 826-10328)

age be less than the ion energy loss. The average energy deposition is reduced by the average residual energy of the electron after it transverses a distance of $z_{0}$. That is, for a delta ray produced with kinetic energy $E_{o^{\prime}}$ corresponding to a mean range $R\left(E_{o}\right)$, the average reduction in energy deposition would be the average kinetic energy of an electron with residual range, $R\left(E_{0}\right)-z_{0}$.

To obtain a quantitative estimate of the total reduction in energy deposited we use the so-called hard collision expression for the differential energy-transfer cross section. ${ }^{1}$ For the electron range we use the empirical formula of Katz and Penfold ${ }^{2}$ for $\mathrm{Al}$, making a small linear correction for the difference in electron density of the upstream material compared to that of Al. The following expression was obtained for the ratio of "escaped energy" $\Delta \mathrm{E}_{\mathrm{T}}$ to total energy transferred $\mathrm{E}_{\mathrm{T}}$

$$
\frac{\Delta E_{T}}{E_{T}}=\frac{\int_{\max }^{E_{\max }}\left(1-\beta^{2} E_{o} / E_{\max }\right) E\left(R\left(E_{o}\right)-z_{o}\right) d E_{o} / E_{o}^{2}}{2\left(\ln \left(E_{\max } / I\right)-\beta^{2}\right.}
$$

where $E_{\min }$ is the energy corresponding to a mean electron range of $z_{o}, E_{\max }$ is the maximum energy that can be transferred in a single collision, $\beta$ is the heavy-ion velocity, and $I$ is the average ionization energy of the chamber gas. For the highest energy, $600 \mathrm{MeV} / \mathrm{A}$, the correction amounts to almost $6 \%$ of the energy loss. This result is relatively insensitive to small uncertainties in the upstream absorber thickness. An uncertainty of $\pm 10 \%$ in the effective stopping power of this upstream absorber changes the calculated value by only $\pm 0.3 \%$ of the total energy loss in the chamber.
$W$ values were obtained both for primary-beam ions and for some fragments produced by primarybeam nuclear interactions in the energy degrader. Figure 2 shows the measured $W$ as a function of energy for $\mathrm{Ne}, \mathrm{Al}$, and $\mathrm{Si}$ in $\mathrm{P}-7$ gas, where the most detailed measurements were made. The weighted mean and the standard deviation of the points about the mean are

$$
W(P-7)=26.3 \pm 0.8 \mathrm{eV} / \text { ion pair }
$$

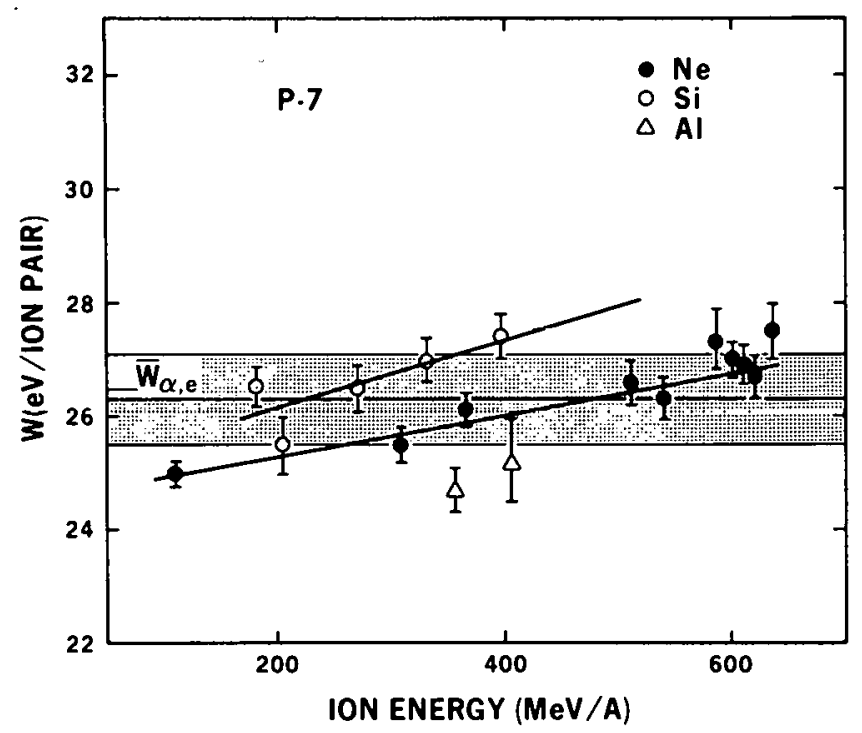

Fig. 2. Measured $W$ values in $P-7$, as a function of energy, for $\mathrm{Ne}, \mathrm{Al}$, and Si. Also shown are the linear fits to the Ne rnd Si data, a comparison of $W$ for alphas and electrons (see te and an average of the measured values (shaded areas).

(XBL 826-10363) 
This result is shown by the thick line and shaded drea in Fig. 2. For comparison, $W$ values for alphas and electrons in $\mathrm{P}-7$ were calculated using recommended $\mathrm{W}$ values for $\mathrm{Ar}$ and $\mathrm{CH}_{4}$, and the formula of Bortner and Hurst. ${ }^{3}$ For both calculations $W_{\alpha, e}$ $=26.5$, in very good agreement with our average.

To investigate whether a statistically significant residual dependence on heavy-ion energy $T$ exists, we have fitted the $\mathrm{Ne}$ and $\mathrm{Si}$ data independently to a straight line of the form $W=W_{0}+a T$. The results of these fits have also been plotted as the straight lines through the $\mathrm{Ne}$ and Si points in Fig. 2. A separation of the data by charge seems to accompany these results.

A residual energy and charge dependence seems to persist in our data, at a statistically significant level, despite the attempts to correct for known physical processes. It is not clear whether this represents a true physical dependence or is merely due to systematic effects of the order of $4 \%$ in the data analysis. Some effects, such as particle misidentification, can be excluded, since neon ions produced by silicon fragmentation fall on the same line as primary neon ions. Errors in TOF calibration, leading to erroneous $\mathrm{dE} / \mathrm{dx}$ used for calculation of energy deposition, are also an unlikely source, since $\mathrm{dE} / \mathrm{dx}$ does not change sufficiently to account for the systematic trend. A detailed analysis of the delta-ray correction is in progress.

\section{REFERENCES}

1. See, for example, Evans, R.T. The Atomic Nucleus, Chap. 18. McGraw-Hill Co., 1955.

2. Katz, L., and Penfold, A. Rev. Mod. Phys. 24, 28 (1951).

3. Bortner, T.E., and Hurst, G.S. Phys. Rev. 93, 1236 (1954).

\section{ENERGY DEPOSITION NEAR HEAVY-ION TRACKS}

\section{Les A. Braby, ${ }^{\star}$ Noel F. Metting," Harold H. Rossi, † Paul J. Kliauga, † Jerry Howard, Marwin Rapkin, Mervyn Wong, and Walter Schimmerling}

A Battelle-Columbia-LBL collaboration has completed preliminary experiments to measure microdosimctric energy-deposition spectra as a function of the distance from the center of high-energy heavy-ion single particle tracks.

It is generally agreed that most biological effects of exposure to ionizing radiation are a function of the spatial deposition of energy in tissue and the rate at which it is deposited. High-energy heavyion beams are used for radiobiology and radiotherapy because of their large LET and favorable ratio of dose at peak to dose at entrancc plateau. The associated delta-ray spectrum produces a significant low LET contribution to the lineal energy distribution. The range of these delta rays is such that in a uniformly irradiated medium, many events are produced by delta rays of primary particles passing outside the site. The number of such events depends on the charge of the primary, while the range of delta rays depends on the primary particle's velocity.

Early experiments attempting to measure these lineal energy distributions could not be performed under charged particle equilibrium, because the

Sattelle Pacific Northwest Laboratory, Richland, Washington.

Zolumbia University, New York, New York. range of the most energetic delta rays exceeded the size of the apparatus and materials available for such measurements. As a consequence, early experiments using proportional counters mounted in 8-inch-diameter tissue equivalent shells were hampered by wall effects. ${ }^{1}$ It was also realized that although it was possible to build a larger shell, or tank, to house and pressurize the detectors, it was not possible to expand the diameter of the Bevalac beam so that it completely filled the tank. Therefore, the most practical method of obtaining accurate microdosimetric spectra of these beams is by taking differential spectra, i.e., to record energy deposition events in the proportional counter that are in coincidence with primary ion tracks at known distances (impact parameters). The data will then be properly integrated to construct a complete spectrum.

The experimental apparatus consists of a large 2.44-m-long by $0.61-\mathrm{m}$-diameter aluminum tank with a forward window of Mylar and sailcloth (see Fig. 1). Two detectors are mounted inside: a solid-state position-sensitive detector to determine the position of each primary ion, and a wall-less proportional counter $0.64 \mathrm{~cm}$ in diameter, capable of detecting low- or high-energy events. The tank was pressurized with propane gas to 82 torr so that 

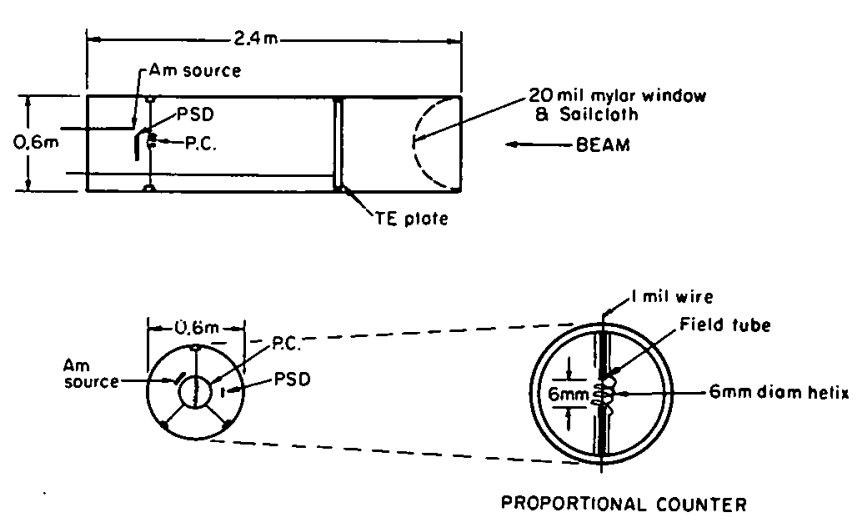

Fig. 1. Experimental apparatus. The interior of the vacuum tank shows the proportional counter (P.C.), the positionsensitive solid-state detector (PSD), and the tissue equivalent plastic plate (TE platc).

(XBL 8311-4125)

the proportional counter simulated a 1- $\mu \mathrm{m}$ diameter volume of tissue.

Measurements were made of ${ }^{20} \mathrm{Ne}(570$ $\mathrm{MeV} / \mathrm{amu}),{ }^{40} \mathrm{Ar}(570 \mathrm{MeV} / \mathrm{amu})$, and ${ }^{56} \mathrm{Fe}(600$ $\mathrm{MeV} / \mathrm{amu}$ ) beams. Figure 2 summarizes the data for argon for three different ranges of the wall-less proportional counter to primary beam particle distance ("impact parameter"). As is illustrated, both the probability of energy deposition events per primary ion ( $R$ ), and the average lineal energies $(y)$ of these events are essentially independent of the distance to the TE plate. Similar results were measured for neon.

The main thrust of the Battelle-Columbia effort has been to determine the energy deposition due to delta rays as a function of the radial distance from the primary beam path. In the next series of experiments, the time-of-flight particle identification spectrometer will be used to provide coincident signals for selection of microdosimetric spectra separated by incident particle species. Both experiments already share the same data acquisition electronics and software. In a preliminary series of tests, proper timing of all signals was achieved.

These experiments have delineated the ranges of impact parameter and wall distance over which measurements of this kind should be made. They

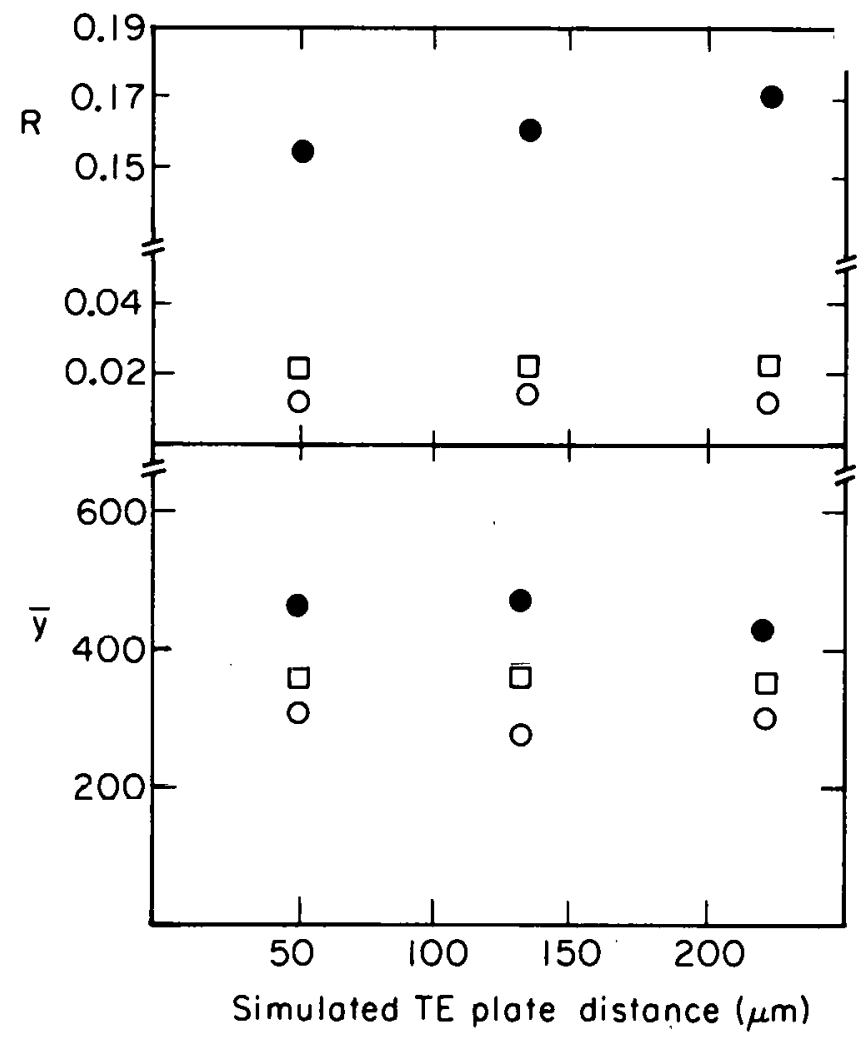

Fig. 2. Test for secondary particle equilibrium. The probability of energy deposition per primary ion $(R)$ and the average lineal energy $(\bar{y})$ are plotted vs. the simulated distance to the TE plate for three impact parameter ranges: 1-1.5 $\mu \mathrm{m}$ (filled circles), 1.5-2.5 $\mu \mathrm{m}$ (open squares), and 2.5-3.5 $\mu \mathrm{m}$ (open circles).

(XBL 8311-4126)

have also provided information necessary for improvement of the design of the detector positioning apparatus. Improvements in the signal-to-noise ratio of the position determining detector electronics should also be considered.

\section{REFERENCE}

1. Howard, J., Curtis, S.B., Rossi, H.H., and Kliauga, P.J. Microdosimetry Research with Accelerated Heavy Ions at the Bevalac, 1977-1980, Lawrence Berkeley Laboratory report LBL-11220. 


\section{ANSPORT OF HIGH-ENERGY HEAVY IONS THROUGH EXTENDED MATTER}

\section{Mervyn Wong, Walter Schimmerling, Joe Civello, Jerry Howard, John W. Wilson," Lawrence W. Townsend,* and Hari B. Bidasaria*}

Work on transport calculations has progressed in the past year. This is a collaborative effort with scientists from NASA.

The key approach has been to use a perturbative solution of the Boltzmann equation (see Fig. 1). The transport studied here is limited to one dimension. The transport problem is a steady state problem with boundary condition at entrance to the absorber. As indicated in Fig. 1, the boundary condition constrains the incident particle to have the identity of a beam particle with a Gaussian energy spread. Using perturbation theory, the analytic solution of the problem is given by $\phi(x, E)$, as shown in the figure. The various quantities are defined as:

$$
\begin{array}{ll}
\phi_{j}(x, E) & =\begin{array}{l}
\text { charged particle fluence of } \\
\mathrm{KE} / \text { nucleon } E \text { at depth } x
\end{array} \\
\mathrm{~S}_{\mathrm{j}}(\mathrm{E}) & =\text { particle stopping power } \\
P_{j}(E) & =\text { particle nuclear survival probability }
\end{array}
$$

$$
\begin{array}{lll}
A_{j} & \text { particle mass } \\
\sigma_{k}(E) & = & \text { nuclear absorption cross section } \\
m_{j k}(E) \sigma_{k}(E)= & \text { production cross section for } \\
& \text { type } \mathrm{j} \text { ions by collision of type } k \\
& \text { ion with a target nucleus }
\end{array}
$$

As can be seen, the primary term $\left[\phi_{j}\right.$ (primary) $]$ is obtained by following the attenuated and degraded beam incident. on the absorber boundary. The secondary term is obtained by substituting the primary term into the integral expression. Similarly, the tertiary term is obtained by substituting the secondary term into the integral expression. Higher order terms can be obtained by following this iterative procedure.

Results to date have been presented at a conference $^{1}$ and in a paper to be published in

\section{HIGH ENERGY HEAVY-ION TRANSPORT}

Transport Equation:

$$
\left\{\frac{\partial}{\partial x}-\frac{1}{A_{j}} \frac{\partial}{\partial E} S_{j}(E)+\sigma_{j}(E)\right\} \phi_{j}(x, E)=\sum_{k>1} m_{j k}(E) \sigma_{k}(E) \phi_{k}(x, E)
$$

Boundary Condition:

$$
\phi_{j}(0, E)=\delta_{j J} \frac{1}{\sqrt{2 \pi} \sigma} e^{-\frac{\left(E-E_{j}\right)^{2}}{2 \sigma^{2}}}
$$

Solution:

$$
\begin{aligned}
\phi_{j}(x, E)= & \frac{\left\{\left.S_{j}(E) P_{j}(E) \phi_{j}(x, E)\right|_{\text {bdry }}\right.}{S_{j}(E) P_{j}(E)}+\sum_{k} \int_{E}^{E_{\text {bdry }}} d E^{\prime} \frac{A_{j} P_{j}\left(E^{\prime}\right)}{S_{j}(E) P_{j}(E)} m_{j k}\left(E^{\prime}\right) \sigma_{k}\left(E^{\prime}\right) \cdot \phi_{k}\left\{x+R_{j}(E)-R_{j}\left(E^{\prime}\right), E^{\prime}\right\} \\
=\phi_{j}^{\text {(primary) }} & +\phi_{j}^{\text {(secondaries) }}+\phi_{j}^{\text {(tertiaries) }}+\ldots \ldots . .
\end{aligned}
$$

Fig. 1. Analytic approach to high-energy heavy-ion transport studies using the Boltzmann equation and perturbation theory, in one dimension. Shown are the transport equation, boundary condition, and perturbative

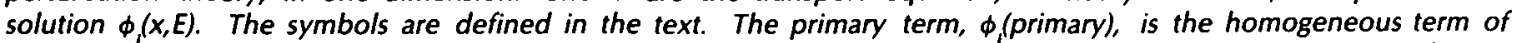
the integral equation solution; the secondary, tertiary, and higher order terms are obtained from the integral term as discussed in the text. 
Health Physics. ${ }^{2}$ The most recent results are shown in Figs. 2, 3, and 4 . Figure 2 is a depth-dose curve for a neon beam of $670 \mathrm{MeV} /$ nucleon. Shown are the separate doses from primaries, secondaries, and tertiaries and the dose from the sum of these three. The open circles are the results of an experimental run at the Bevalac. The agreement between theory and experiment is satisfactory.

Figure 3 shows the dose contributions from neon beam ions fragmenting into lighter constituents, down to the lightest fragments, protons. The figure is broken up into three parts, to indicate separately the fragment production in the plateau region of the Bragg curve, at the peak, and beyond the peak on the tail of the curve. The normalization of each plot is absolute, thus permitting quantitative comparison for production at different parts of the Bragg curve for specific elemental species. This is a key feature of the present work.

Figure 4 shows the energy dependence of fragment production at an absorber depth $(1.06 \times$ peak depth) beyond the Bragg peak, on the fragment tail portion of the Bragg curve. As can be seen, the fragment production rapidly increases with incident beam energy, contributing about $30 \%$ of the peak dose at the highest energies considered. This particular result has relevance for therapy situations where vital organs are located behind and in close proximity to the tumor volume to be treated. Work is in progress to quantitatively

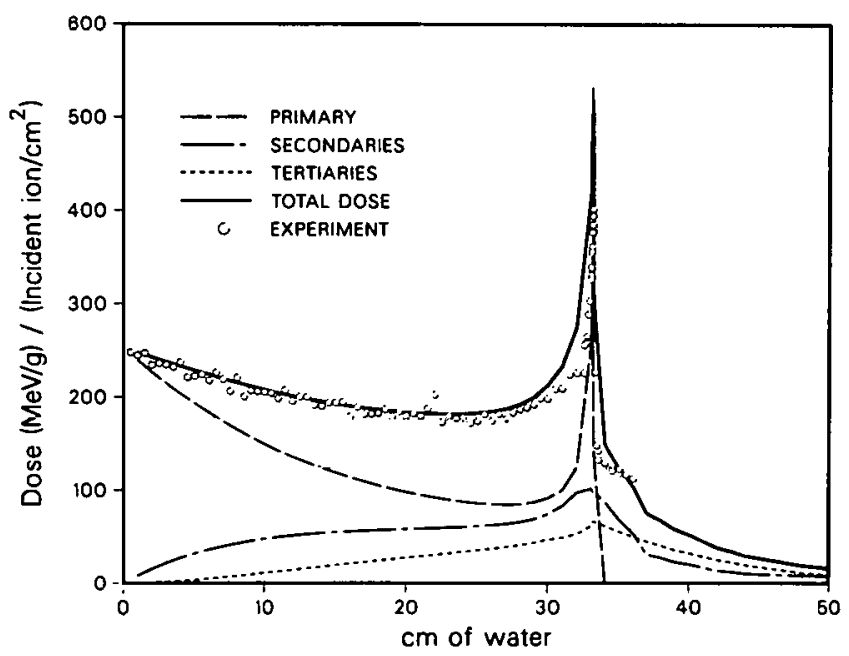

Fig. 2. Depth-dose curve for a $670 \mathrm{MeV} / \mathrm{A}$ neon beam incident on water. Absolute values for the dose from the primary beam and produced secondary and tertiary fragments are separately shown as a function of penetration depth. The open circles are the results of an experimental run at the Bevalac. The experimental points have been normalized to the calculated total dose at zero water column thickness.

(XBL 8311-4104)

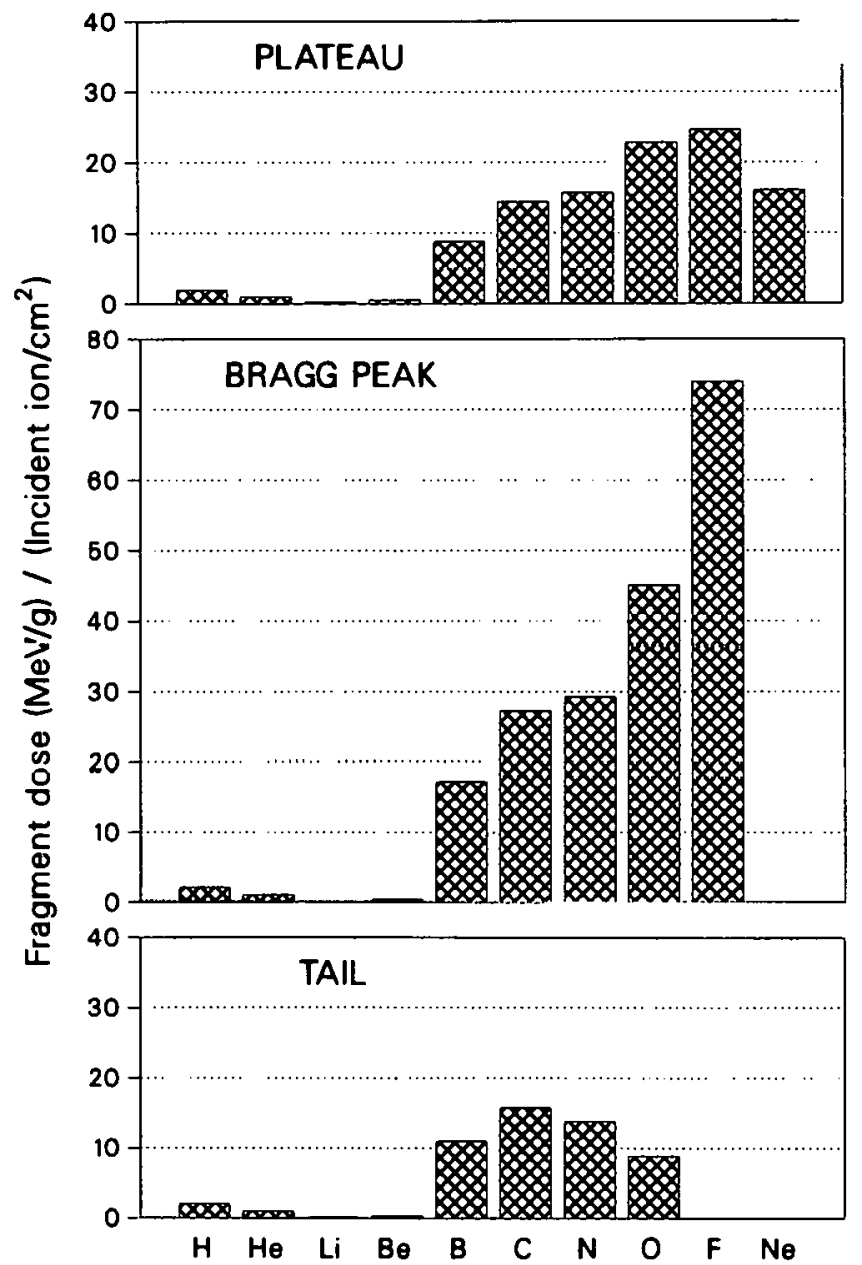

Fig. 3. Fragmentation-dose contributions from the traversal of neon beam ions through a water absorber. Shown separately is the fragment production from three different absorber thicknesses, corresponding to the plateau, peak, and tail regions of the Bragg curve.

(XCC 841-13011)

study the effect of beam modification devices (e.g., ridge filters) on the fragment tail contribution for various beam energies. These studies are also important for a future medical accelerator capable of delivering variable energy heavy-ion beams in rapid succession.

A major thrust in this effort is to improve the physics input for the fragmentation parameters. The present input makes use of fragmentation parameters from Silberberg and Tsao. In their work, ${ }^{3}$ motivated by cosmic ray studies, the fragmentation parameters are taken from semi-empirical formulae with parameters fitted to available cross sections. Our eventual goal is to replace the use of semi-empirical formulae by measured cross sectio augmented by accurate theoretical fragmentati models. ${ }^{4}$ A systematic series of measurements is 


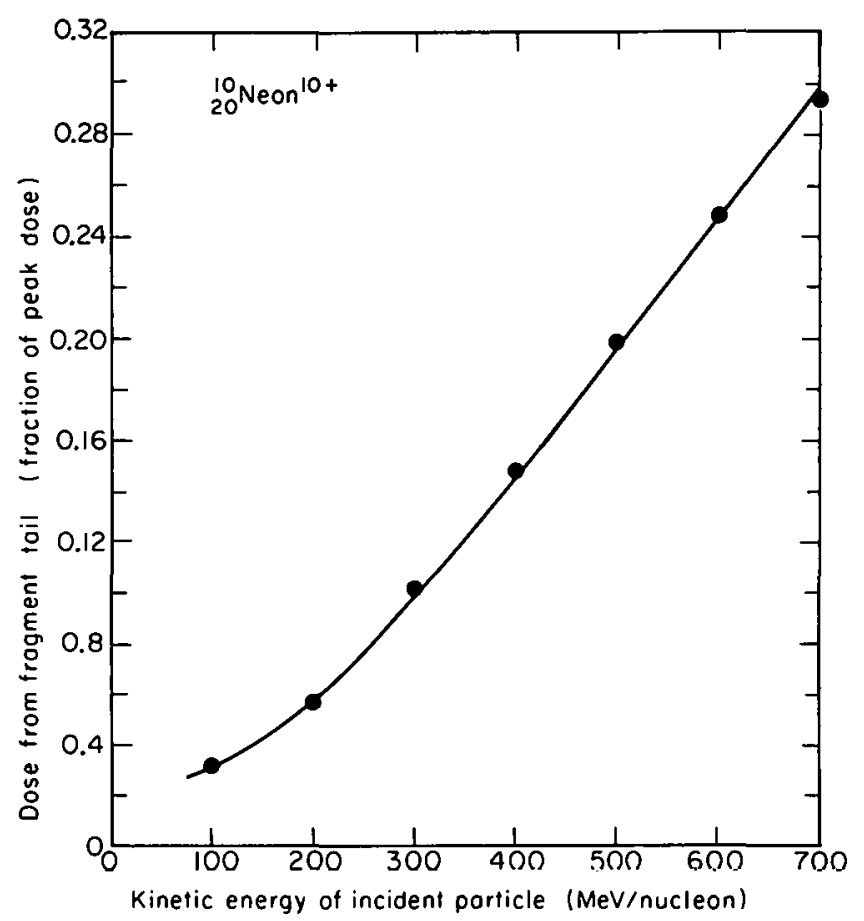

Fig. 4. Energy dependence of fragment production at a water thickness corresponding to the tail portion of the Bragg curve, expressed as a fraction of the peak dose. The fragment production rapidly increases with beam energy. This result has relevance for therapy situations where vital organs are located behind and in close proximity to the tumor volume to be treated.

(XBL 8311-4114)

now under way, ${ }^{5}$ utilizing beams at Beam 40 and at Cave II of the Bevalac.

The transport code will play an increasingly important role in the design of beam line configurations. It is therefore important for the code to be available in a form convenient for practical use. A general purpose computer program, PROPAGATE, has been developed that provides easily available calculations of the energy loss, range, and other related properties of a high-energy heavy-ion beam at any one of a set of beam line elements. This program makes certain approximations in order to trace a heavy ion through the elements, such as cylindrical symmetry, and the validity of polynomial approximations to the range-energy curve, that have been found to be adequate for beam energies above about $10 \mathrm{MeV} / \mathrm{A}$. PROPAGATE also calculates the loss of multiply-scattered particles to any finite-aperture detector and estimates the position of the Bragg peak as given by particles stopping in the second of the two ionization chambers used for such a measurement. Comparison of the calculations with experiment seems to be satisfactory. The editing features of the program allow the user to simulate the insertion of a large number of beam elements, and to vary their radius and their thickness at will. Calibration values may also be entered for beam elements flagged as "detectors." This would enable the user to predict actual pulse heights, ADC channels, and so forth, in the course of planning and setting up experimental runs.

\section{REFERENCES}

1. Wong, M., Schimmerling, W., and Wilson, J.W. Transport studies of the interaction of high-energy heavy ions with extended matter. Proceedings, Seventh International Congress of Radiation Research. Amsterdam, The Netherlands, July 1983.

2. Wilson, J.W., Townsend, L.W., Bidasaria, H.B., Schimmerling, W., Wong, M., and Howard, I. $\mathrm{Ne}$ depth-dose relations in water. Health Physics, in press (1983).

3. Silberberg, R., Tsao, C.H., and Shapiro, M.M. Semiempirical cross-sections, and applications to nuclear interactions of cosmic physics. In Spallation Nuclear Reactions and Their Applications, Edited by B.S.P. Shen and M. Mecker. Reidel Publications, Boston, 1977, pp. 49-82.

4. Townsend, E.L., and Wilson, W.J. Space radiation protection methods. Proceedings, Space Radiation Effects Workshop. Houston, Texas, November 1983.

5. Schimmerling, W., Rapkin, M., Wong, J., Howard, J., Kaplan, S.N., Spieler, H., Jarrett, B., and Walton, J. Physical characterization of heavy-ion beams. In this annual report (1983). 


\title{
A COMPARISON OF WATER EQUIVALENT THICKNESS MEASUREMENTS: CT METHOD VERSUS HEAVY-ION BEAM TECHNIQUE
}

\author{
Edward L. Alpen, William M. Saunders, Aloke Chatterjee, Jorge Llacer,* \\ George T.Y. Chen, and Janis S. Scherer
}

The usefulness of accelerated heavy charged particles for the treatment of malignant tumors is currently being investigated by groups in Europe, Russia, and North America. Various heavy ions, such as protons, helium ions, negative pi mesons, and neon and silicon ions are being tested. At the Lawrence Berkeley Laboratory, clinical trials are under way with beams of helium, neon, and silicon. ${ }^{1,2}$ Very encouraging results have been obtained with helium ions for treatment of ocular melanomas and for tumors adjacent to critical radiosensitive organs such as the spinal cord. ${ }^{3}$

The rationale for using this type of radiation therapy is based on the possible therapeutic gain to be achieved as a result of precise localization, an improved depth-dose distribution (Bragg ionization curve), and an enhanced biological response. ${ }^{4}$

In theory, once the location of the tumor volume is determined, the initial energy of the beam can be selected so that the beam stops precisely at the distal edge of the tumor volume. In practice, however, problems arise because of the difficulty of obtaining a good estimate of the electron density of the tissues in the beam path. Often a small error in the stopping point of the beam in the patient is not clinically important. However, in some patients an error of 2 or $3 \mathrm{~mm}$ in the stopping point of the beam could lead to a severe overdose to a critical organ, or an underdosing of part of the tumor.

Several practical methods have been proposed to overcome this problem, and other efforts are continuing. One commonly used technique is based on the utilization of quantitative data from computerized tomographic (CT) scans. In most clinical situations, this empirical method is thought to be capable of predicting the range with an error of about $3 \%$.

The purpose of the study discussed in this report was to measure directly the water equivalent thickness required for a beam of heavy ions to stop at a specific target, to compare this with the predictions of the CT method, and to explore the clinical applicability of radioactive beams for localizing the stopping region for charged particles.

*Engineering and Technical Services Division, Instrument Science and Engineering Group, LBL.

\section{METHODS AND MATERIALS}

In this study, solid state detectors (silicon diodes) were implanted in the brain, the soft tissue between the scapulae, the thorax, the upper abdomen, and the lower abdomen of a frozen dog cadaver. The diodes served not only as detection devices for ionization due to heavy charged particles, but also as targets for the stopping beams. Beam entry points were marked on the surface of the animal with radio-opaque markers. The cadaver was scanned by a computerized axial tomography scanner (CAT), and the water equivalent thickness (WET) required to penetrate from the surface markers to the front edge of the diode targets was calculated. The same water equivalent thicknesses were directly measured using ion chambers and beams of helium and neon ions, except in the thorax, where measurements were made only with helium ions.

The helium-ion beam was obtained from the Lawrence Berkeley Laboratory 184-Inch Synchrocyclotron. The beam was extracted from the accelerator with an energy of $234 \mathrm{MeV} / \mathrm{amu}$, and with a range of $27.5 \mathrm{~cm}$ in water. The neon beam was obtained from the Bevalac, a compound heavy-ion accelerator at the Lawrence Berkeley Laboratory. This beam was extracted from the accelerator with an energy of $500 \mathrm{MeV} / \mathrm{amu}$, and the corresponding range was $23 \mathrm{~cm}$ in water.

The experimental arrangement for measuring the water equivalent thickness from the surface to an implanted diode is shown schematically in Fig. 1. The Bragg ionization curve was obtained, and the depth of water in the water column corresponding to the $50 \%$ level on the distal Bragg peak was noted. From the ionization curve and standard Bragg curve, water equivalent thickness for the location under study can be measured.

Using the CT method, calculation of the water equivalent thickness was performed by one of us (who had no prior knowledge of the results of the direct measurements by heavy ions as described below).

\section{RESULTS}

In Fig. 2, the various Bragg curves are presented as an example for a neon beam only. In 


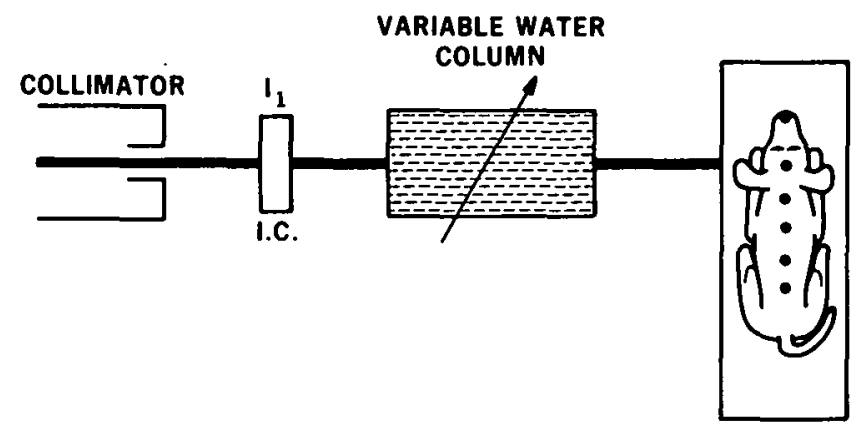

Fig. 1. Sketch of an experimental set-up for measuring water equivalent thicknesses between the beam entry point on the beagle and the location of the diode. The ionization due to the full beam energy is measured by the ion chamber I. The Bragg peak ionization is measured by the diode.

(XBL 8211-3498)
Table 1, the data have been summarized in terms of the location of measurements. Results of experiments with helium and neon beams are tabulated along with the values obtained from $\mathrm{CT}$ calculations.

It is seen from Table 1 that there is a fairly good agreement between the data obtained with helium and neon beams. The thickness measurements should be independent of the particle charge or mass, and the results bear this out quite accurately. Also since the two results agree so well, it gives us confidence in the beam alignment technique we have followed.

For most of the clinical situations, one would conclude that agreement between the $C T$ results

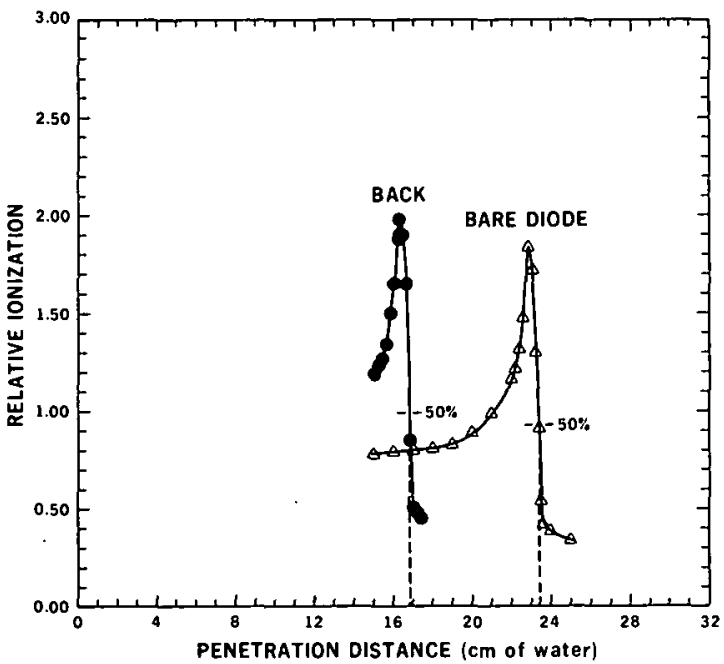

b)

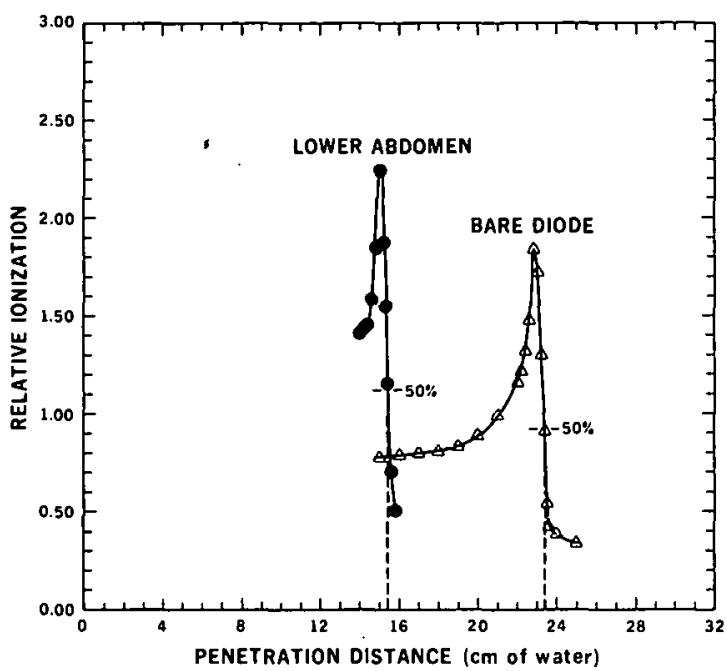

d)

Fig. 2. Neon Bragg curves for bare diodes, and (arrangements of Fig. 1) back, upper abdomen, and lower abdomen. The dashed lines are drawn at the $50 \%$ point of the peak ionization, and the intercepts on the $x$ axis represent the mean ranges. 
Table 1. Water equivalent thickness $(\mathrm{cm})$ using a frozen beagle.

\begin{tabular}{lccc}
\hline Location & Neon & Helium & $\begin{array}{c}C T \\
\text { scanner }\end{array}$ \\
\hline Brain & $4.90 \pm 0.10$ & $4.85 \pm 0.10$ & $5.25 \pm 0.10$ \\
Back & $6.60 \pm 0.10$ & $6.68 \pm 0.10$ & $6.7 \pm 0.15$ \\
$\begin{array}{l}\text { Thorax (beam from } \\
\text { left side) }\end{array}$ & No data yet & $6.80 \pm 0.10$ & $7.0 \pm 0.2$ \\
$\begin{array}{l}\text { Thorax (beam from } \\
\text { right side) }\end{array}$ & No data yet & $4.60 \pm 0.10$ & $5.0 \pm 0.2$ \\
$\begin{array}{l}\text { Upper abdomen } \\
\begin{array}{l}\text { Lower abdomen } \\
\hline\end{array}\end{array}$ & $7.65 \pm 0.10 \pm 0.10$ & $7.65 \pm 0.10$ & $7.8 \pm 0.2$ \\
\hline
\end{tabular}

and those obtained by beam measurements is fairly close, except in the region of brain and in the region of thorax (when beam came from the right). It is well known that CT tends to undercorrect for bone (skull) and overcorrect for air (lung). Our measurements with heavy-ion beams tend to indicate such differences. It is our belief that in most clinical situations measurements with $C T$ scan are reliable enough to make clinical trials with confi-

\section{RADIOLOGICAL PHYSICS AND CHEMISTRY}

\section{Aloke Chatterjee and John L. Magee}

For several years the authors have conducted studies on the fundamental nature of the chemical effects of high-energy radiations for the purpose of understanding radiation effects on biological systems, particularly mammalian cells. Because of the special interest of LBL in accelerated heavy particles, we have emphasized heavy-particle track effects and their relationships to low-LET radiations. Applications have been made to the radiolysis of water, ${ }^{1-4}$ and we have now turned our attention to radiation effects in biological molecules. It is generally accepted that single- and double-strand breaks (particularly the latter) are significant types of damage in DNA, and we have initiated a program of experimental and theoretical studies of these effects. Our first objective is to understand the chemical mechanisms that produce strand breaks in DNA solutions, and we expect to be able to relate these mechanisms to the initial action of radiation in cells.

Experimental investigations of strand breaks are best conducted in DNA solutions under carefully dence. But there may be a small number of cases where more accuracy is desired than can be obtained with CT.

\section{REFERENCES}

1. Castro, J.R., Quivey, J.M., Lyman, J.T., Chen, G.T.Y., Tobias, C.A., and Phillips, T.L. Radiotherapy with heavy charged particles at Lawrence Berkeley Laboratory. J. Can. Assoc. of Radiology 31, 30-34 (1980).

2. Castro, J.R., Quivey, J.M., Lyman, J.T., Chen, G.T.Y., Tobias, C.A., and Phillips, T.L. Current status of heavy charged particle radiotherapy at Lawrence Berkeley Laboratory. Cancer 46, 633-461 (1980).

3. Chen, G.T.Y, and Gaddemann, G. Utility of $C T$ in charged particle treatment planning for ocular melanomas. Medical Physics 8, 568 (1981).

4. Phillips, T.L., Fu, K.K., and Curtis, S.B. Tumor biology of helium and heavy ions. Int. /. Radiation Oncology, Biology and Physics 3, 103-113 (1971).

controlled conditions. The $\phi \mathrm{X}-174$ molecule is convenient for this purpose, particularly because it has been studied extensively with low-LET radiations. Electrophoretic analysis of irradiated solutions provides a convenient method for determining the fraction of molecules as a function of dose that have acquired single- and double-strand breaks, and the G-values of the breaks are easily obtained from the $D_{37}$ values. The $\phi X-174$ molecule weighs $6 \times 10^{-18^{37}}$ grams; elementary considerations show that

$$
\mathrm{gj}_{\mathrm{j}}=\frac{278}{\mathrm{D}_{37}^{i}}
$$

where the yield is measured in terms of energy absorbed in the molecule, $\mathrm{j}$ refers to the type of break $(j=1,2)$, and $D_{37}$ is in kilorads.

There are several hierarchies of problems arriving at explicit theoretical expressions for values based on track models. Geometrical con'siderations involve both the track and the target. 
רere is, however, a simple general expression for the average number of breaks in a molecule, and $\mathrm{g}$ follows directly. Consider a DNA solution irradiated by a beam with $n$ particles per unit area. We can say that the average number of breaks of type $j$ in some particular molecule is

$$
y_{j}=n \int p_{j} d A
$$

where $p_{j}$ is the probability that a particle penetrating the differential area $\mathrm{dA}$ causes a j-type strand break $(j=1,2)$ in the molecule and the integration is over the entire beam. All particles that come within a distance $r_{p}$ (the penumbra radius) can contribute. The g-value is

$$
g_{j}=\frac{1.67 \times 10^{-5}}{X} \int p_{j} d A
$$

where $X$ is the LET in $e V / A$ and the area $d A$ is measured in $A^{2}$.

We expect to find both direct and indirect mechanisms for DNA strand breaks. Our own experimental program is aimed at obtaining quantitative information on the indirect mechanism. However, Christensen et al. ${ }^{5}$ have studied strand breaks under conditions where only the direct effect is observed. They used radical scavengers and sulfhydryl concentrations to minimize radical reactions and to provide chemical restitution to the few. molecules undergoing radical attack before strand breaks could be completed. The only strand breaks observed, presumably, were by a mechanism not involving radical intermediates. A direct dissociation is indicated. Such dissociation could involve a positive ion created with excess energy, or a neutral molecule with excess energy from an ionic recombination.

Use of Eq. (3) requires the probabilities for various strand breaks for every possible position of a particle penetration; of course an average over molecular orientation is also required. The excitation can come from track core or penumbra. Consider first the core penetration and say that $\nu$ ionizations result (i.e., $\nu / 2$ ions in each strand); $\nu$ must be proportional to $X$. All ions will not dissociate; say there is a probability $\rho$ that a strand break results. A double-strand break requires that pairs of single-strand breaks, formed independently in each of the strands, are close enough so that the double helix unravels. In our particular case the ionizaons are created essentially at the same base pair id the unravelling is ensured. We can assign the tollowing probabilities for strand breaks:
Probability for:

No break $(1-\rho)^{\prime} \quad=e^{-2 q x}$

Breaks in

one strand $\quad 2(1-\rho)^{p / 2}\left[1-(1-\rho)^{p / 2}\right]=2 e^{-q x}\left(1-e^{-q x}\right)$

Breaks in

both strands $\left[1-(1 \dot{-} \rho)^{p / 2}\right]^{2} \quad=\left(1-e^{-q x}\right)^{2}$

where $q X=-\nu / 21 n(1-\rho)$.

If the core does not penetrate the molecule but comes within a distance $r_{p^{\prime}}$ the penumbra can deposit energy. The penumbra is made up of electron tracks, and there are probabilities for both single- and double-strand breaks arising from energy deposits by these tracks. The probabilities appearing in Eq. (3) will be proportional to the energy deposit (and thus to $X$ ). G-values can be assigned directly to the total penumbra effect, i.e., the integral over track positions that do not penetrate the molecule.

These considerations have been used along with data presented by Christensen et al. ${ }^{5}$ to produce the following equations for $g_{1}(X)$ and $g_{2}(X)$.

$$
\begin{aligned}
& g_{1}(X)=\frac{9.56}{X} e^{-q x}\left(1-e^{-q x}\right)^{2}+0.11 \\
& g_{2}(X)=\frac{4.78}{X}\left(1-e^{-q x}\right)^{2}+0.01
\end{aligned}
$$

where the first terms give core effects and the second terms give penumbra effects. The constants were chosen so that the low-LET limit for $g_{1}$ and $g_{2}$ would be 0.33 and 0.01 , respectively, and the maximum in $g_{2}(X)$ would occur at $X=55$. We get from this fitting $q=0.023$ and $\rho=0.11$. Equations (5) are shown in Fig. 1; the points give experimental results of Christensen, et al. ${ }^{5}$

Although the treatment sketched here is rough, we believe that the direct effect is correctly presented. Of course many refinements are possible within the established framework. We believe that this mechanism is operative in the irradiation of cells. Although the G-values are rather small, many strand breaks are expected by the direct effect because the DNA is very concentrated in a cell.

The mechanism (i.e., indirect effect) for creation of strand breaks in DNA by the action of radicals is also of concern. Actually it is widely held that the most important mechanism for strand breaks is through extraction of $\mathrm{H}$ atoms from the sugar moiety by $\mathrm{OH}$ radicals. The $\mathrm{G}$-values for strand 


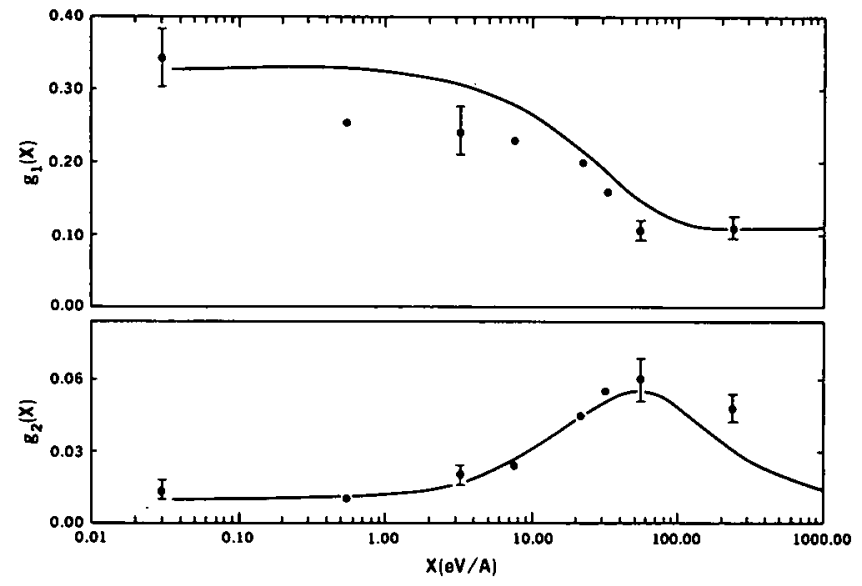

Fig. 1. $g_{1}(X)$ and $g_{2}(X)$ for single- and double-strand breaks in $\phi X-174$ DNA arising from direct absorption of energy. The experimental points are taken from Christensen et al. ${ }^{5}$

(XBL 836-10310) breaks measured under conditions in which wa radicals can participate are many times larger tha" those found for the direct effect. Our experimental program involves dilute solutions of DNA, and we are using an appropriately varied composition of scavengers in order to get reliable G-values for radical strand break mechanisms.

\section{REFERENCES}

1. Magee, J.L., and Chatterjee, A. J. Phys. Chem. 82, 2219 (1978).

2. Magee, J.L., and Chatterjee, A. J. Phys. Chem. 84, 3529 (1980).

3. Chatterjee, A. and Magee, J.L. J. Phys. Chem. 84, 3537 (1980).

4. Turner, J.E., Magee, J.L., Wright, H.A., Chatterjee, A., Hamm, R.N., and Ritchie, R.H. Radiat. Res., forthcoming.

5. Christensen, R.C., Tobias, C.A., Taylor, W.D. Int. J. Radiat. Biol. 22, 457 (1972).

\section{Cellular and Molecular Radiobiology}

\section{ATAXIA TELANGIECTASIA: MODELING EXTREME RADIOSENSITIVITY}

\section{Eleanor A. Blakely, Cornelius A. Tobias, Polly Y. Chang, and Leora Lommel}

Ataxia telangiectasia (hereafter ataxia) is a human genetic disease characterized by progressive neurovascular degeneration and immunological deficiencies that frequently culminates in the appearance of malignancies. ${ }^{1}$ Approximately 50 million people carry this recessive disease. People with homozygous genes die early, and their cells have been shown in vitro to be hypersensitive to radiation damage. The study of the radiobiological responses of cultured ataxia cell lines and cells derived from individuals assumed to be ataxia heterozygotes has led to the discernment of several "complementation groups." The correlation between the inability to repair lesions produced by radiation and the abnormal development of the nervous system in this disease is not established. Since the exact mechanism of this radiosensitivity is still not known, many laboratories are currently investigating multiple characteristics of the cell lines, including the notable absence of repair of potentially lethal damage.

We have been interested in the fact that all ataxia $x$-ray survival curves are exponential functions of the dose (see Fig. 1). Established human cell lines that have been stable in their radiation response for more than two decades are more radioresistant, as evidenced by a survival curve with a shoulder (also shown in Fig. 1) that decreases in size with increasing energy density of the radiation. We have completed a study to compare the radiation responses of these genetically sensitive and resistant cell lines to high-LET radiations. Results from track-segment exposures to neon, silicon, argon, or iron ion beams accelerated to initial energies of from 225 to $670 \mathrm{MeV} / \mathrm{u}$ provided a LET range between 30 and $1000 \mathrm{keV} / \mu \mathrm{m}$. The data indicate that 1 ) the sensitivity of ataxia cells increases with increasing LET, similar to resistant human lines (e.g., T-1 cells), however, due to efficient repair, T-1 cells are more resistant than ataxia cells at LET values below $200 \mathrm{keV} / \mu \mathrm{m}$ (see Fig. 2); 2) maximum cell kill occurs for both lines at $100-200 \mathrm{keV} / \mu \mathrm{m}$; at higher LET the sensitivity of the two lines approach each other; 3 ) there is only small variation in the sensitivity of ataxia cells to particles of various atomic numbers at the sar LET-differences are more pronounced in the $L$ domain between 50 and $200 \mathrm{keV} / \mu \mathrm{m}$; and 4) ataxıa 


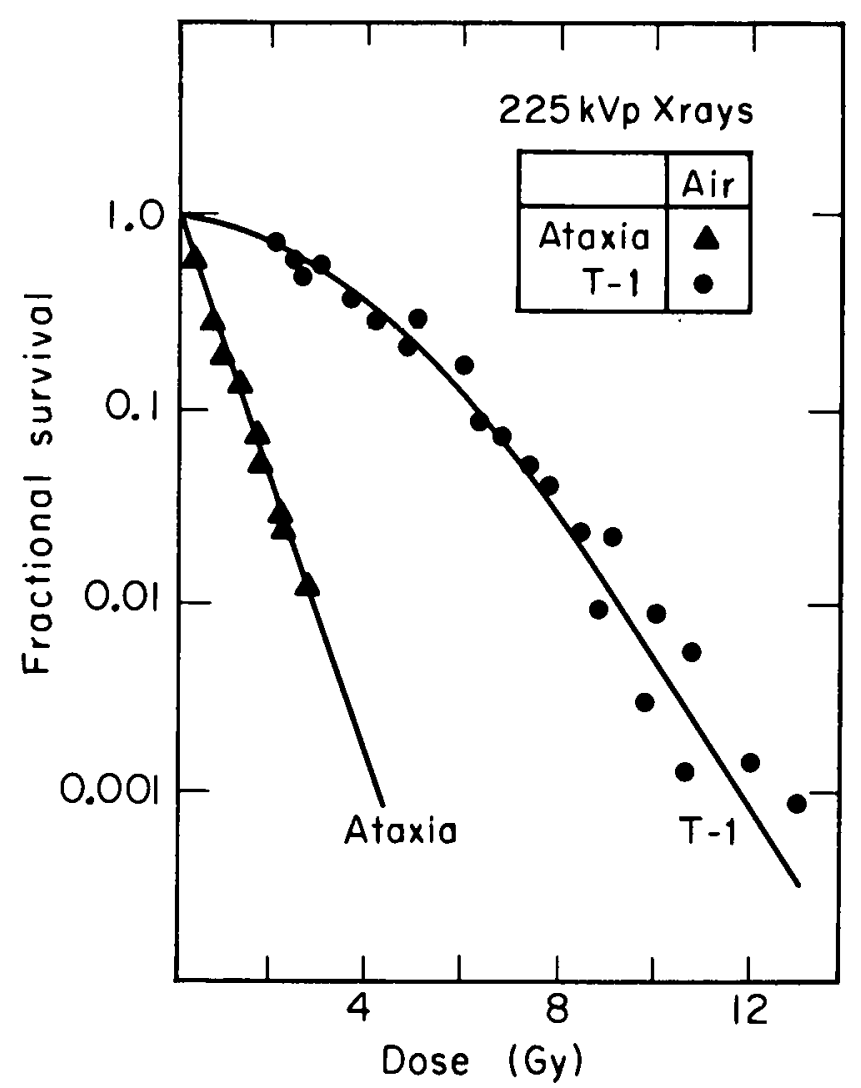

Fig. 1. X-ray survival curves of ataxia telangiectasia (AT-2SF) cells and $T-1$ cells irradiated in air on plastic petri dishes.

(XBL 8312-4156)

cells have slightly lower OER values than T-1 cells in the range of LET studied below $200 \mathrm{keV} / \mu \mathrm{m}$.

The repair-misrepair model ${ }^{2}$ has been used to interpret these results. According to this model, the molecular repair processes culminate either in eurepair or in misrepair. We have obtained mathematical expressions that describe the cross sections and inactivation coefficients for both human cell lines as a function of the LET and the type of particle used (see plot in Fig. 3). The results suggest either that high-LET particles induce a greater number of radiolesions per track or that heavy ions at high LET induce lesions that kill cells more effectively and that are different from those produced at low LET. We assume that the lesions induced in T-1 and ataxia cells are qualitatively similar and that each cell line attempts to repair these lesions. The result in most irradiated ataxia cells, however, is either lethal misrepair or incomplete repair leading to cell death. T-1 cells have efficient repair mechanisms at low LET, and the pair-misrepair model suggests that at high LET the

1 cells can still efficiently repair individual lesions, out that as the lesions become closely spaced along

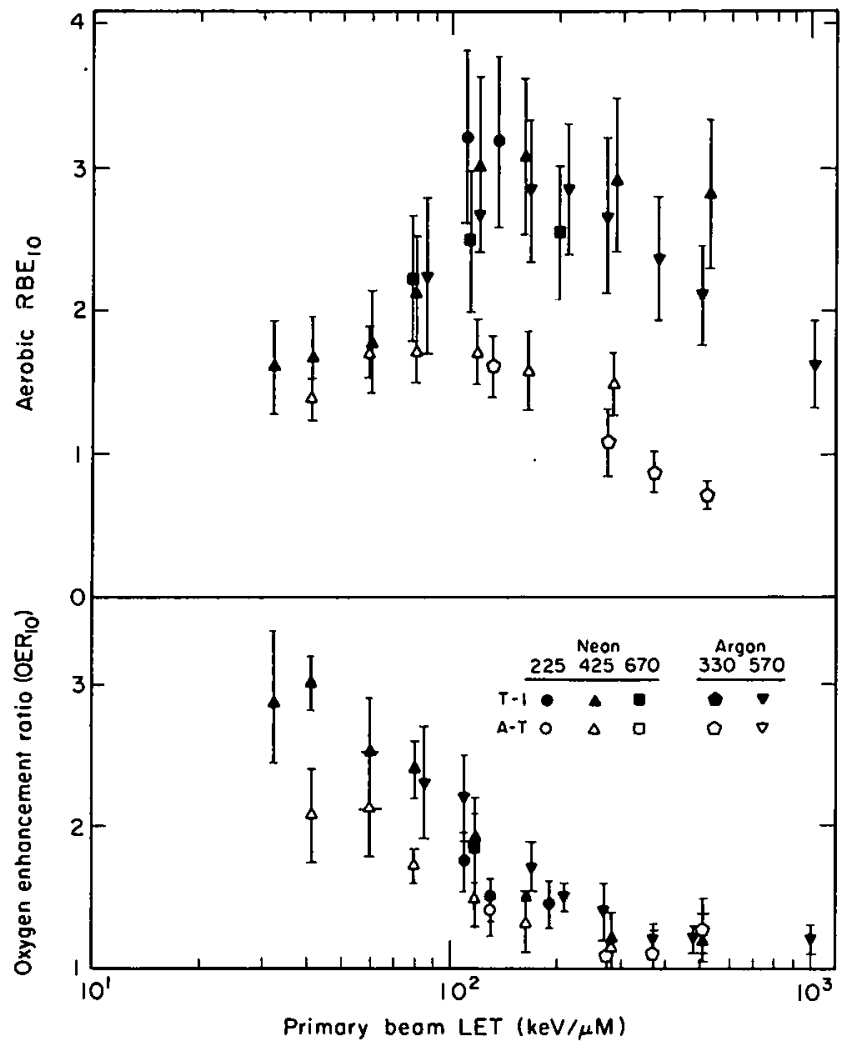

Fig. 2. $R B E_{10}$ relative to $x$ rays (top panel) and OER ${ }_{10}$ (lower panel) for human $T-1$ and ataxia cells exposed to heavy-ion beams (neon and argon) at various values of initial energy and LET. The OER of ataxia cells is consistently but not significantly lower than the OER ${ }_{10}$ of $T-1$ cells.

(XBL 838-3976)

the tracks, the probability of misrepair increases. The ataxia cell line appears to misrepair damage produced by radiation of any LET.

\section{REFERENCES}

1. Patterson, M.C., Smith, P.J., Bech-Hansen, N.T., Smith, B.P., and Middlestadt, M.V. Anomalous repair of radiogenic DNA damage in skin fibroblasts from ataxia telangiectasia patients, Ataxia Telangiectasia, Eds. D.G. Harnden and B.A. Bridges. John Wiley and Sons, New York (1982).

2. Tobias, C.A., Blakely, E.A., Ngo, F.Q.H., and Yang, T.C. The repair-misrepair model, Radiation Biology and Cancer Research, R.E. Meyn and H.R. Withers, Eds. Raven Press, New York (1980), pp. 195-230.

3. Tobias, C.A., Blakely, E.A., Chang, P.Y., Lommel, L., and Roots, R. Response of sensitive human ataxia and resistant $\mathrm{T}-1$ cell lines to accelerated heavy ions. Br. J. Cancer, in press. 


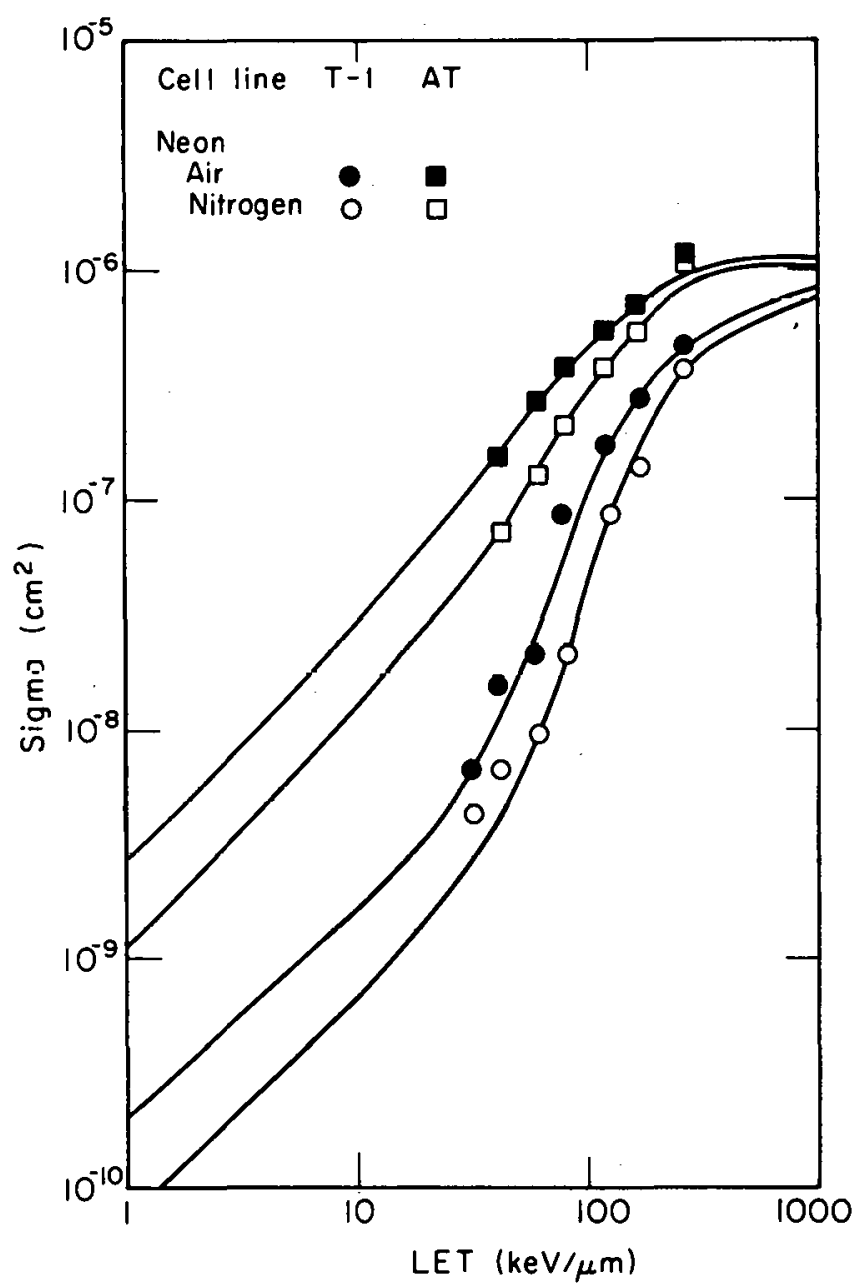

Fig. 3. Plots of the theoretically calculated cross sections for producing lesions responsible for inactivation of ataxia and T-1 cells by neon ions (upper two curves). ${ }^{3}$ The lower curves correspond to the cross sections for $T-1$ cells after repair has occurred. The actually measured inactivation cross sections are also shown.

(XBL 838-3971)

\section{VERY HEAVY IONS: CHROMOSOMAL ABERRATIONS AND INACTIVATION OF MAMMALIAN CELLS}

\section{Gerhard Kraft, Wilma Kraft-Weyrather, and Eleanor A. Blakely}

Low-energy heavy ions up to uranium are available at GSI in Darmstadt, West Germany, and a group of scientists there has developed a biomedical research program similar to that at LBL. There is a collaborative program between our respective laboratories manifested by an exchange of scientists who are interested in the biological effects of the heaviest ions, about which new biological information is being obtained.
Ion beams of uranium, the heaviest natural element on earth, will probably never be used for clinical medicine applications, but the ionization density created by the passage of a uranium ion through a biological object is about 100 times higher than from the lighter ions like alpha particles. In extrapolation from cellular experime with lighter ions, it has been suggested that $i$ high ionization density would be wasted by an 
verproduction of biological damage (overkill - ffect) and there would be no variation in the biological response to the different ion beams as long as the linear energy transfer to the cell is above a certain threshold (LET $100 \mathrm{keV} / \mu \mathrm{m})$. In experiments with low-energy heavy ions it has been shown that even for the heaviest ions the biological efficiency does not exhibit an overkill effect, and the cellular sensitivity, which is plotted in Fig. 1 in terms of a cross section, exhibits a strong variation depending on the structure of the particle track. For the heavier particles only the declining branches of the $\sigma$ curves have been measured. There are no data available for high-energy heavy charged particles that would connect the high-LET values of the inactivation curve with the common curve for all low-LET particles. These data are essential for the development of any basic theory of the mechanisms of cell injury caused by ions. In the recent uranium experiments at the Bevalac, the inactivation of different cell lines, the induction of chromosomal aberrations (see Fig. 2) and transformation, and the strand break efficiency of DNA in solution are being studied because the high-energy uranium beams available only at the Bevalac permit us to examine the missing intermediate-LET range. The first (and preliminary) result shows that the efficiency of uranium ions is usually underestimated by the Katz model calculations.

\section{REFERENCES}

1. Kraft, G., Reisbe, H., Slubet, M., KraftWeyrathe, W., and Miltenberger, H.G. Gesellschaft für Schwerionenforschung, Darmstadt, Germany, Scientific Report 83-1, p. 199 (1983).

2. Muller, W., Miltenberger, H.G., and Kraft, G. Gesellschaft für Schwerionenforschung, Darmstadt, Germany, Scientific Report 83-1, p. 197 (1983).

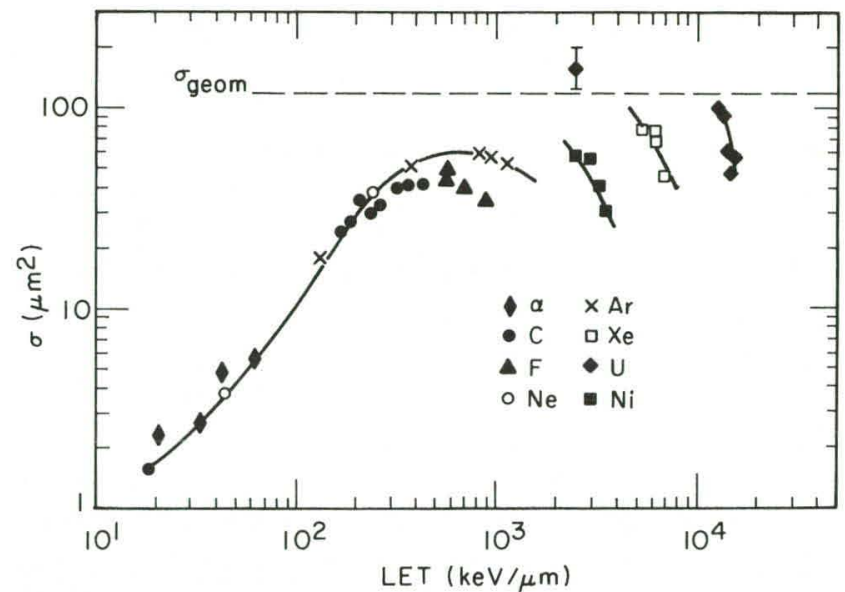

Fig. 1. Inactivation cross section of V79 Chinese hamster cells as a function of linear energy transfer. For the low-LET values the different ions show a common curve, while for the high-LET value each ion separates from this curve.

(XBL 8312-4155)

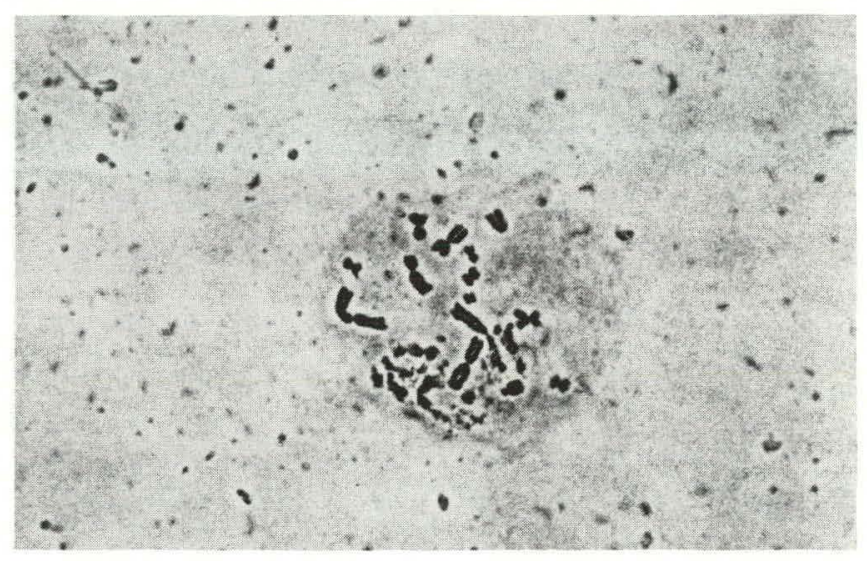

Fig. 2. Chromosomal aberrations of V79 Chinese hamster cells irradiated with $10-\mathrm{MeV} / \mathrm{u}$ uranium ions during mitosis. ${ }^{2}$ If condensed chromosomes are hit by a high-energy particle, the chromatin is chopped into many pieces.

(XBB 8312-10793)

\section{ATTEMPTS TO REDUCE THE RADIOBIOLOGICAL OXYGEN EFFECT WITH NEW HYPOXIC RADIOSENSITIZERS}

\section{Mary Austin-Seymour, Eleanor A. Blakely, Polly Y. Chang, and Leora Lommel}

A major part of our effort over the past year has been an attempt to reduce the differences between radioresistance of hypoxic cells and normal cells. We did find that silicon and argon conderably reduced the resistance of hypoxic cells, w these beams did not completely eliminate the oxygen enhancement ratio (OER). There is a national effort to augment radiation therapy with hypoxic sensitizers. Actual therapeutic trials with metronidazole and misonidazole to date have been disappointing because the drugs used so far have side effects, notably neurotoxicity. 
Quite recently researchers at Stanford University have developed new pharmacological agents that have been shown in cell and animal studies to have fewer toxic effects. As part of a potential collaboration between the Stanford Medical School and our laboratory, we decided to explore the radiobiology of one such substance, a 2nitroimidazole amide called SR-2508.

Our first step has been to use the 934-MeV helium-ion beam produced at the Lawrence Berkeley Laboratory 184-Inch Cyclotron, which has excellent physical dose localization characteristics but, unlike heavier ions, has an OER that even in the Bragg ionization peak is only slightly less than that of $x$ rays. We have, therefore, been interested in the reports of hypoxic cell radiosensitization by SR-2508 at concentrations that in animal studies in vitro and in vivo ${ }^{1}$ and in preliminary clinical trials ${ }^{2}$ have been shown to be less toxic than misonidazole. We have demonstrated that SR-2508 is not cytotoxic to human $\mathrm{T}-1$ cells in vitro at concentrations from $0.5 \mathrm{mM}$ to $5 \mathrm{mM}$. We investigated the effects of a reasonably achievable plasma level of SR-2508 $(0.5 \mathrm{mM})$ on aerobic and hypoxic survival in vitro of asynchronous human T-1 cells irradiated in the 4-cm extended Bragg peak of a helium-ion beam. The cells were grown in monolayers on glass petri dishes that were inserted into chambers that permitted irradiation under conditions of either $95 \%$ air plus $5 \% \mathrm{CO}_{2}$ or $95 \%$ nitrogen plus $5 \%$ $\mathrm{CO}_{2}$. The x-ray OER for this system is $2.9 \pm 0.3$.
Track-segment exposures were completed the Bragg plateau (dose average LET of $6 \mathrm{keV} / \mu$, ) and in the proximal peak of the $4-\mathrm{cm}$ extended Bragg peak (dose average LET of $11 \mathrm{keV} / \mu \mathrm{m}$ ). Preliminary results indicate that the OER at $10 \%$ survival is reduced from 2.7 to 1.8 in the entrance plateau of the Bragg ionization curve, and from 2.4 to 1.6 in the proximal Bragg peak of the helium beam. The measured SR-2508 sensitization enhancement ratio (SER) of approximately 1.5 indicates that this radiosensitizer used in combination with helium-ion radiotherapy may augment the excellent physical characteristics with additional biological effectiveness against hypoxic tumor cells. These results are preliminary to our evaluation of the use of hypoxic cell sensitizers in the hedvier ions accelerated at the Bevalac for the heavy-ion radiotherapy program.

\section{REFERENCES}

1. Brown, J.M., Yu, N.Y., Brown, D.M., and Lee, W.W. SR-2508: A 2-nitroimidazole amide which should be superior to misonidazole as a radiosensitizer for clinical use. Int. J. Radiat. Oncol. Biol. Phys. 70, 695-703 (1981).

2. Coleman, C.N., Wasserman, T.H., Urtasun, R.C., Harris, J.W., Hancock, S., Halsey, J., and Hirst, K.V. Preliminary results of the phase 1 trial of the hypoxic cell radiosensitizer, SR2508. Int. J. Radiat. Oncol. Biol. Phys. 91 (supplement), 96 (1983) (Abstract).

\title{
CHARACTERIZATION OF CELLULAR AND MOLECULAR DAMAGE AFTER IRRADIATION WITH DENSELY IONIZING PARTICLE BEAMS
}

\author{
Ruth J. Roots, Gerhard Kraft, Aloke Chatterjee, Polly Y. Chang, Leora Lommel, and \\ Eleanor A. Blakely
}

The extent of hydroxyl radical mediated cell inactivation was measured for a variety of particle beams ranging from $8.5-\mathrm{MeV} / \mathrm{u}$ neon ions to 570 $\mathrm{MeV} / \mathrm{u}$ argon ions. In general, the fraction of the total radiosensitivity caused by $\mathrm{OH}$. radicals decreases from close to $60 \%$ at low ionization density or low linear energy transfer (low LET) to close to $25 \%$ at high LET for aerobically irradiated mammalian cells. ${ }^{1}$ The extent of $\mathrm{OH}$. radical-induced lethality can be explained in terms of LET only for low-energy or low-atomic-number particles. For the high-energy particles, fragmentation introduces a significant component of low-LET radiation. Figure 1 illustrates the differences, in terms of biological effects, between low- and high-energy charged particles. For example, at a calculated LET of 100 $\mathrm{keV} / \mu \mathrm{m}$, the $\mathrm{OH} \cdot$ mediated fraction of the total radiation damage is about $25 \%$ for $15.6-\mathrm{MeV} / \mathrm{u}$ carbon but close to $40 \%$ for $308-\mathrm{MeV} / \mathrm{u}$ carbon ions. The biological effect, therefore, cannot be predicted accurately from calculated LET values for high-energy particle irradiation. As more is learned about the energy deposition for energized charged particles in terms of track structure (core and penumbra), it may be possible to characterize the radiobiological data with a better physical parameter than LET.

A different set of experiments addresses $t$ nature of high-LET-induced damage at the molec lar level. After irradiation with heavy ions, 


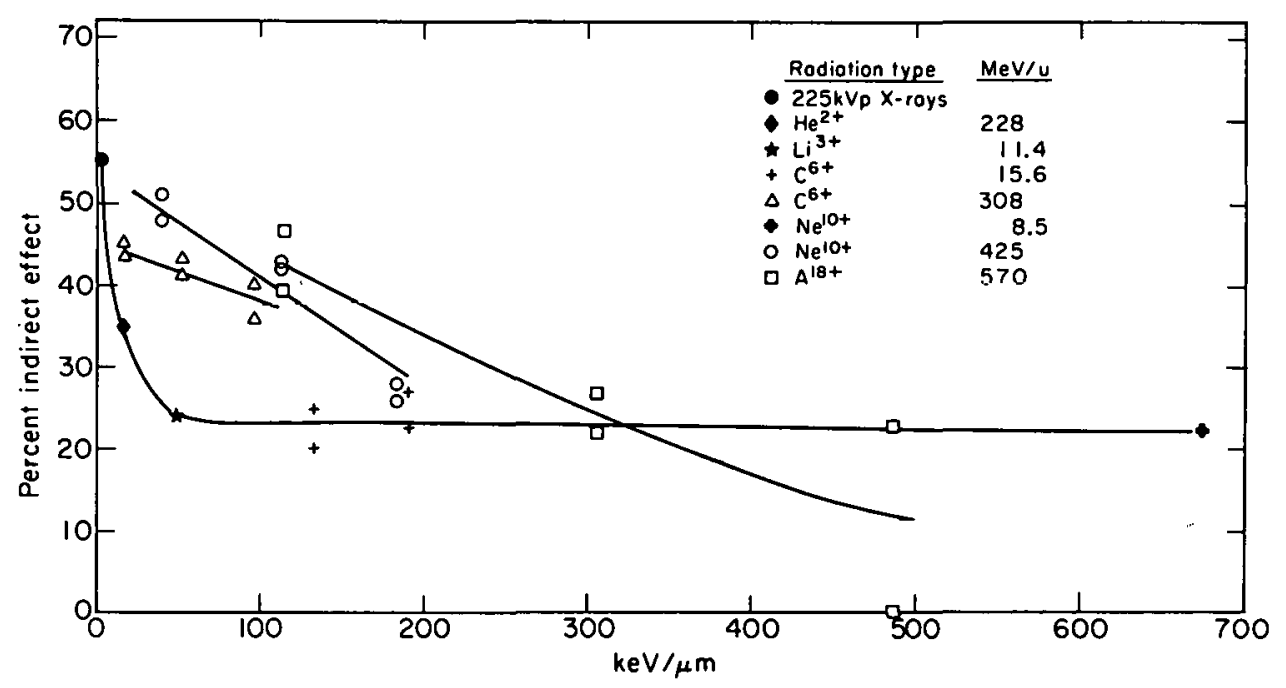

Fig. 1. The fraction of the total cell lethality that is mediated by the hydroxyl radical (indirect effect) has been graphed against the $0.05-\mathrm{cm}$ track segment mean $L E T(\mathrm{keV} / \mu \mathrm{m})$. The radiosensitivies of Chinese hamster ovary cells protected maximally against $\mathrm{OH}$. induccd lethality was determined after irradiations with a variety of accelerated charged particles from $\mathrm{He}^{2+}$ to $\mathrm{Ar}^{18+}$ covering an LET range of about 16 to $700 \mathrm{keV} / \mathrm{\mu m}$.

(XBL 832-3583)

unrepairable DNA lesions (probably some type of a double-strand break) accumulate in the cell. ${ }^{2}$ in order to better understand high-LET-induced lesions in DNA, we are presently measuring the yields of DNA single-strand as well as double-stand breaks in DNA molecules in solution. The ratio of DNA double-strand breaks (DSB) to single-strand breaks (SSB) is an important parameter. This ratio has been shown to increase with increasing LET. ${ }^{3}$ Recent experiments have yielded somewhat surprising results. As the ionization density increases, the number of DNA breaks per rad decreases, but only up to a certain LET value. This decline in the DNA breakage efficiency (increase in $D_{37}$ values) and subsequent reversal at an LET value of approximately $10,000 \mathrm{keV} / \mu \mathrm{m}$ is shown in Fig. 2. When the DSB/SSB ratio is calculated as a function of LET, a similar rise and fall is seen.

These types of data are presently under study and can be used in confirmations of theoretical calculations of high-LET energy deposition.

\section{REFERENCES}

1. Roots, R., Chatterjee, A., Blakely, E.A., Chang, P., Smith, K., and Tobias, C.A. Radiation in air, nitrous oxide and nitrogen saturated mammalian cells. Radiat. Res. 92, 245-254 (1982).

2. Roots, R., Yang, T., Craise, L., Blakely, E.A., and Tobias, C.A. Impaired repair capacity of DNA breaks induced in mammalian cellular DNA by accelerated heavy ions. Radiat. Res. 78, 38-49 (1979).
3. Roots, R., and Kraft, G. Characterization of lesions in viral DNA induced by radiation or chemicals. Radiat. Res. 91, 107 (abstract) (1982).

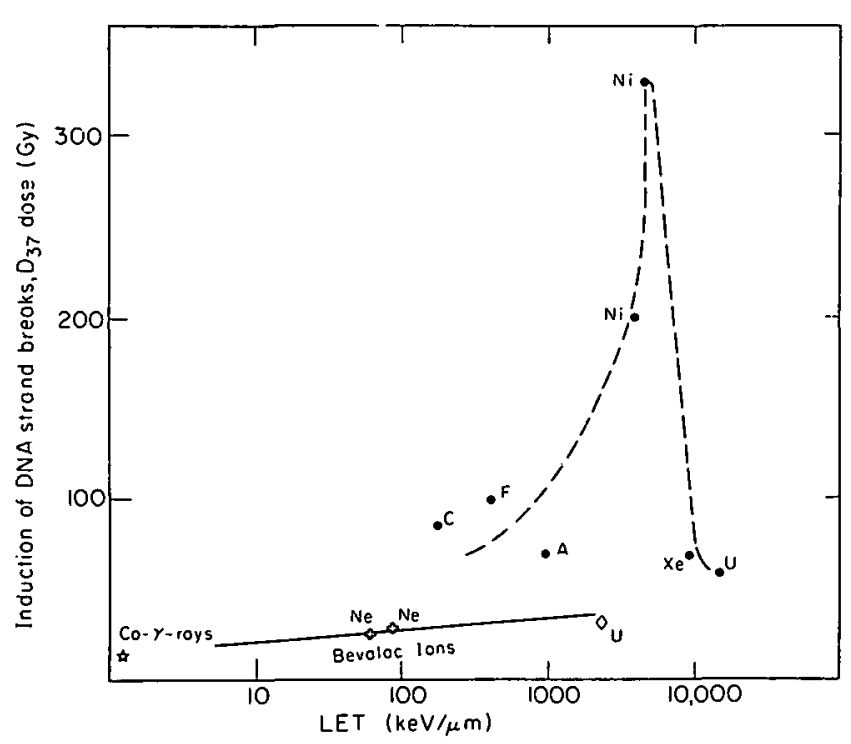

Fig. 2. The radiation dose necessary to cause a break in a DNA molecule (the $D_{37}$ dose) has been plotted as a function of particle energy' deposition (LET) for a number of different heavy-ion beams. The $D_{37}$ dose for ${ }^{60} \mathrm{Co}-\gamma$ rays is $16 \mathrm{~Gy}$ and increases to a maximum of $335 \mathrm{~Gy}$ for $\mathrm{N}^{28+}$. The range in particle energy at the target stretches from $2 \mathrm{MeV} / \mathrm{u}$ to about $385 \mathrm{MeV} / \mathrm{u}$. Results from the high-energy particle beams ( $\mathrm{Ne}^{10+}$ and $\left(^{92+}\right)$ are shown with the solid line labeled Bevalac ions. Results from low-energy particle beams from the Darmstadt accelerator in Germany are shown with the broken line. These ions are $\mathrm{C}^{+t}, \mathrm{~F}^{2+}, \mathrm{Ar}^{18+}, \mathrm{Nr}^{28+}, \mathrm{Xe}^{5+t}$, and $\mathrm{U}^{92+}$. (XBL 8312-4153) 


\section{CELL PROGRESSION CELL EFFECTS}

Eleanor A. Blakely, Ruth J. Roots, Polly Y. Chang, Leora Lommel, and Michael J. Yezzi

X-ray radiosensitivity of cells varies as the cell progresses through its growth cycle from one mitosis to the next. The explanation for this variability is unknown and is probably quite complex. One of the phases most resistant to acute doses of $x$ rays is late in the DNA synthetic (S) phase. Irradiation of synchronized S-phase cells results in an immediate depression of the rate of DNA synthesis and a prolnngation of the duration of the $S$ phase. In normal human cells, lie iinhibition of DNIA syn. thesis arises mainly from a blockage of the initiation process, while DNA chain elongation is only slightly inhibited.

Both high- and low-LET radiation depress the DNA synthetic rate. However, while this causes an S-phase delay after low-LET irradiation, such a delay may not occur after high-LET irradiation. ${ }^{1}$ We have measured the rate of DNA synthesis as a function of heavy-ion radiation dose, and (confirming the results of Schlag and Lucke-Huhle) have found that the inhibitory effect is greater for low-LET radiation than for high-LET radiation (Fig. 1).

Cells irradiated in $G 1$ phase with $x$ rays show only very slight prolongation of the immediate $S$ phase, ${ }^{2}$ and we have evidence from early G1-phase human T-1 cells that this is also true for irradiation with neon Bragg peak ions at an LET of 183 $\mathrm{keV} / \mu \mathrm{m}$ (see Fig. 2).

As we reported last year, mitotic cells are approximately equally sensitive to radiations of low

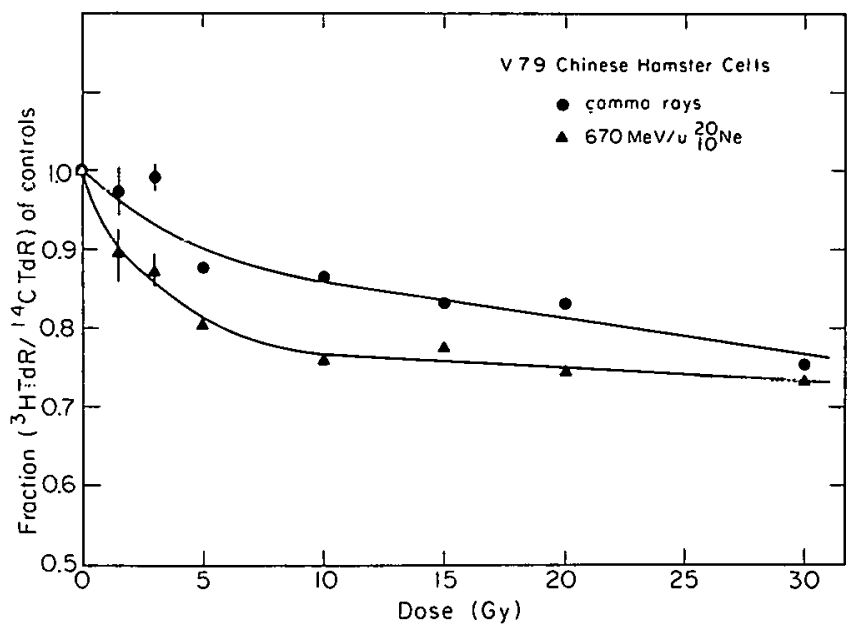

Fig. 1. Reduction in DNA synthesis as a function of 670 $\mathrm{MeV} / \mathrm{u}$ neon Bragg peak ( $\Delta$ ) or gamma ray (0) dose in asynchronous Chinese hamster V79 cells.

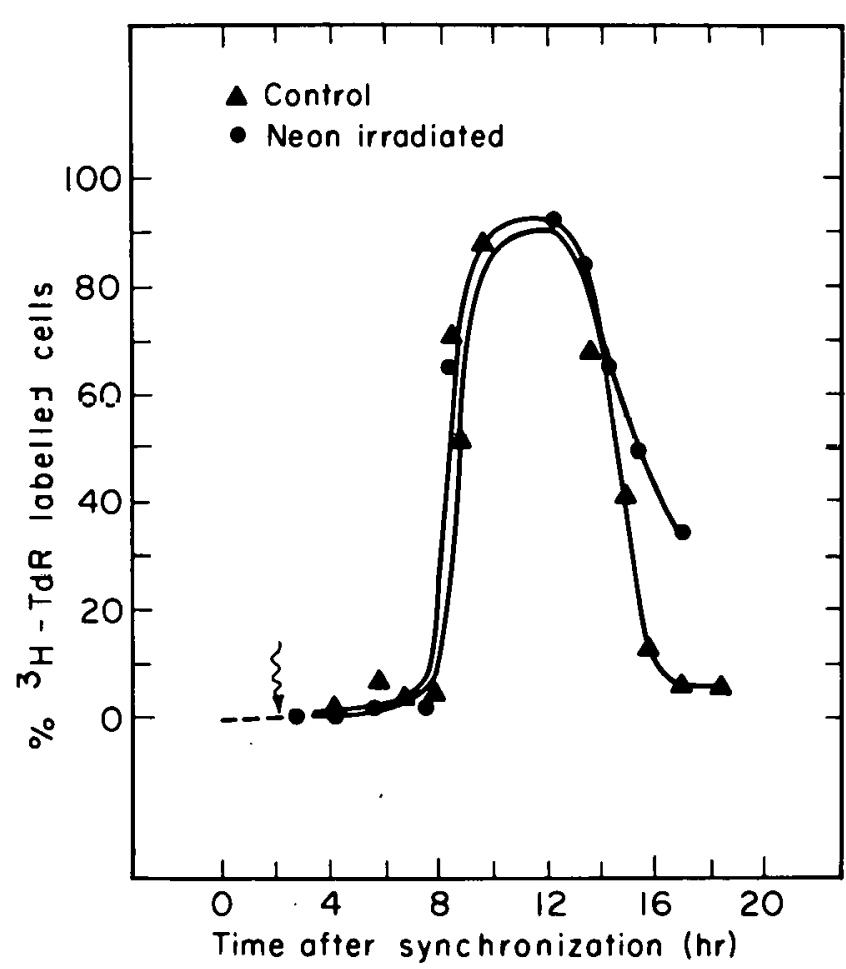

Fig. 2. Percent labeled cells as a function of cell age from autoradiographic analyses of ${ }^{3} \mathrm{H}-T d R$ pulse-labeled control and neon ion irradiated human $T-1$ cells irradiated 2 hours after mitotic selection.

(XBL 8312-4154)

or high LET. As the cell progresses in age from mitosis through $\mathrm{C} 1 \mathrm{1}$ phase and into $\mathrm{S}$ phase, qualitative and quantitative differences develop in the response to both radiations, with the greatest change happening between 2 and 4 hours after mitotic selection in human $\mathrm{T}-1$ cells.

We are investigating the detailed radioresponses and repair capabilities of resistant and sensitive cells. These include the human ataxia telangiec.tasia cell line, whose resistance to the radioinhibition of replicon initiation may somehow be related to its extreme radiosensitivity. We are also studying protein synthesis in a mutant of the Chinese hamster ovary cell line that rapidly shuts down protein synthesis when it is transferred from its normal growth temperature of $35^{\circ} \mathrm{C}$ to $40^{\circ} \mathrm{C}$. ${ }^{3}$

We have previously reported that the split dose survival response to $x$ rays of the exponentially growing mutant cells is reduced if the cells are hi at $40^{\circ} \mathrm{C}$ for 2 hours before the first dose and duri a 2-hour interval between doses. ${ }^{4}$ In conjunction 
vith the survival experiments on asynchronous cells, we also examined the DNA rejoining ability in split dose studies, both with and without inhibition of protein synthesis. ${ }^{5}$ The results of these experiments suggest that inhibition of protein synthesis affects a pool of proteins that are necessary for the correct expression of the DNA, although they do not appear to be involved in rejoining DNA breaks. We have extended this work to the study of cells synchronized in $G 1$ phase (2-hour post-mitosis) and $S$ phase (10-hour post-mitosis). Autoradiographic analyses, using $3 \mathrm{H}-\mathrm{TdR}$ pulse labeling, demonstrated that a delay in the progression of each synchronized cell population occurs after inhibition of protein synthesis (see for example $G 1$ cell data in Fig. 3). Studies of the effects of inhibition of protein synthesis on the ability of G1- and S-phase cells to repair sublethal damage are in progress.

\section{RFFERENCES}

1. Schlag, $H_{\text {., }}$ and Lucke-Huhle, $C$. The influence of ionization density on the DNA synthetic phase and survival of irradiated mammalian cells. Int. J. Radiat. Biol. 40, 75-85 (1981).

2. Terasima, T., and Tolmach, L.J. Biophys. J. 3, 11 (1963).

3. Thompson, L.H., Harkins, J.L., and Stanners,

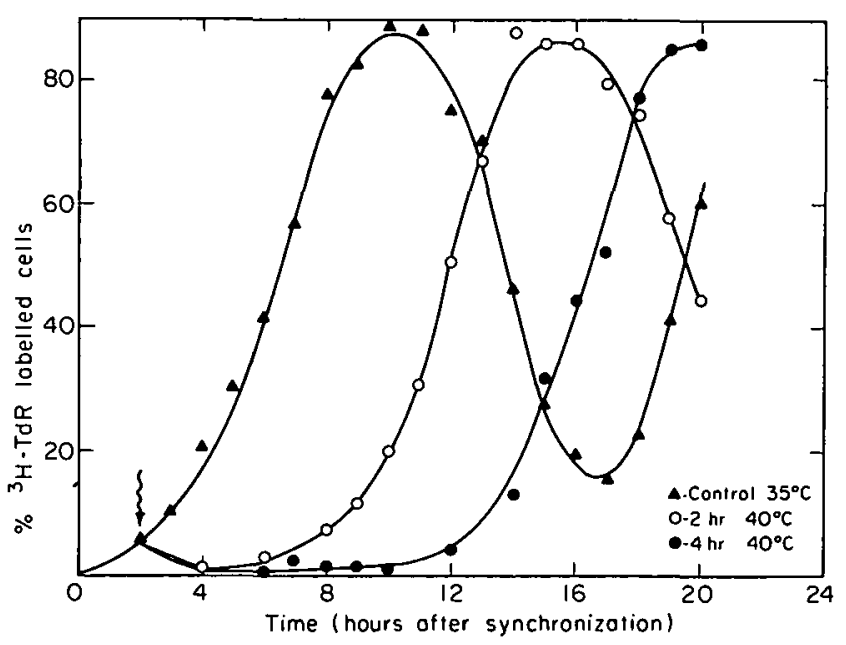

Fig. 3. Delay and resumption in the DNA synthetic phase of synchronized Chinese hamster TSH1 cells transferred from $35^{\circ} \mathrm{C}$ to $40^{\circ} \mathrm{C}$ at 2 hours after mitotic selection. $(\Delta)$ control $35^{\circ} \mathrm{C}$, (O) held for 2 hours at $40^{\circ} \mathrm{C}$ and then returned to $35^{\circ} \mathrm{C}$; (6) held for 4 hours at $40^{\circ} \mathrm{C}$ and then returned to $35^{\circ} \mathrm{C}$.

(XBL 8312-4159)

C.P. Proceedings of the National Academy of Science 70(11), 3094-98 (1973).

4. Yezzi, M.J., Tobias, C.A., and Blakely, E.A. Radiat. Res. 83, 406 (1980) (Abstract).

5. Yezzi, M.J., Okada, S., Roots, R.J., and Tobias, C.A. Radiat. Res. 91, 391 (1982) (Abstract).

\section{HEAVY-ION FRAGMENTATION: PHYSICS AND BIOLOGY}

\section{Eleanor A. Blakely, Jorge Llacer, and Cornelius A. Tobias}

The interactions of heavy-ion beams accelerated in the Bevalac deposit more energy to an absorber at depth than near the surface. The interactions are described by the Bragg ionization curve, which consists of two major components: energy transfer from primary beam particles and from particle fragments. The trajectories of particles formed in various types of collisions are shown in Fig. 1. In central collisions the primary beam particles and the target nuclei disintegrate, and a multiplicity of atomic particles is emitted with large angular divergence. Though locally important, doses from central collisions are usually only a few percent of the total dose. In peripheral collisions, fragments with varying atomic number are produced and travel along the primary beam trajectories. The angular divergence of light fragments is reater than that of heavy fragments. Together the agments often produce a significant portion of the total dose.
Heavy-ion beams have so many biological and medical applications that it became important to be able to characterize the mixture of particle species in various beam configurations and to relate these mixtures to certain biological effects the beams can produce. We have constructed a special instrument, the Berklet, which is able to classify the presence of a variety of particle fragments in the beam and quantitate their physical parameters. ${ }^{1}$ The cellular effects of these beams were then assessed on the same day in collaborative experiments between physicists and radiobiologists.

A schematic of the Berklet is shown in Fig. 2. This instrument can measure simultaneously 1) the LET of each particle as it passes through a thin silicon crystal detector and 2) the residual range of the same particle in a special germanium detector that was built in our laboratory. We also use passive particle track detectors to independently measure the LET spectra. Examples of the LET distributions 


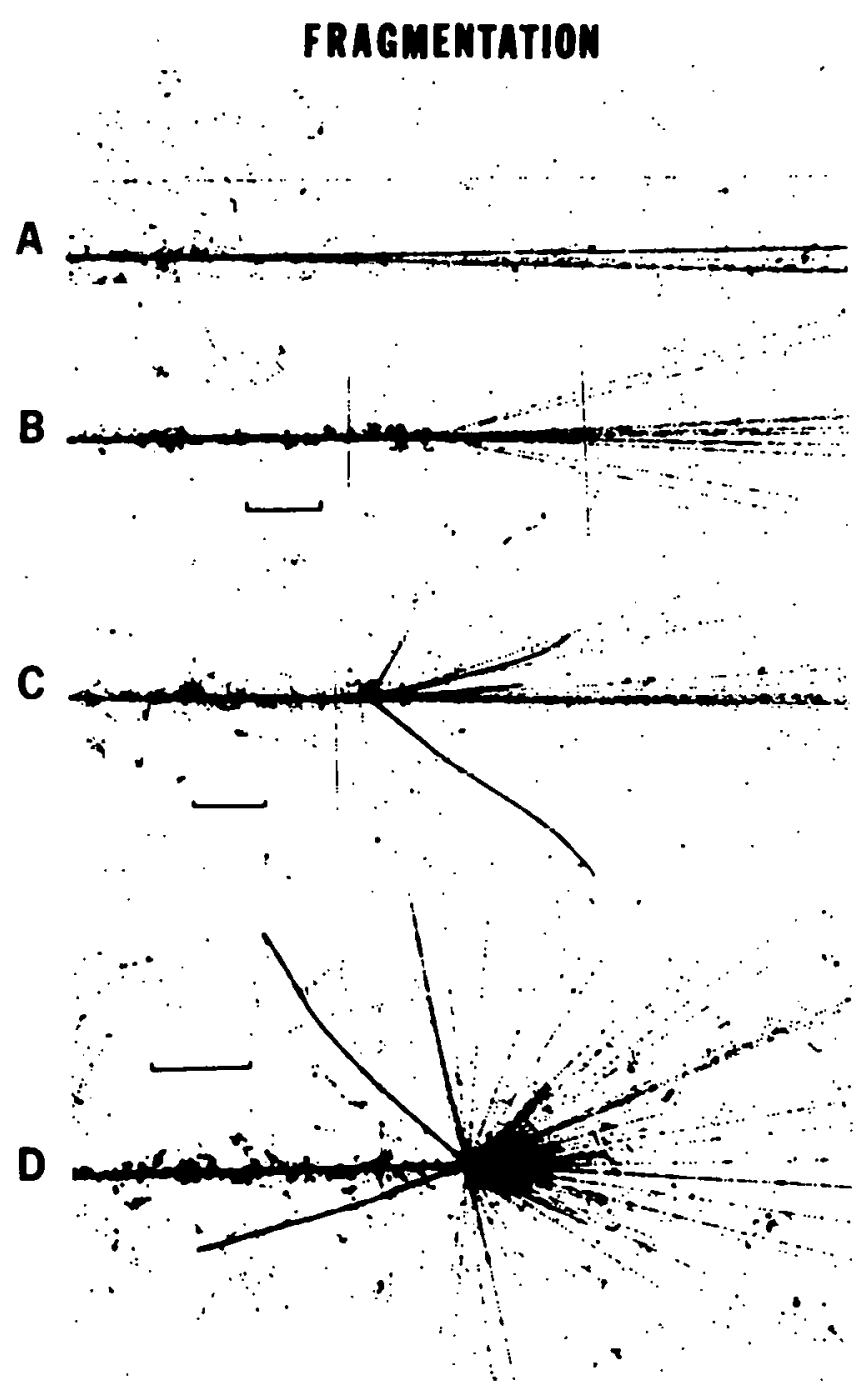

Fig. 1. Heavy-ion fragmentation effects. Four kinds of projectile and target fragmentation events: (a) and (b) are pure projectile fragmentation cases in which the beam particle breaks up into higher particles; cases (c) and (d) show events in which a target nucleus also breaks up. of a $670-\mathrm{MeV} / \mathrm{u}$ neon beam after the particles hi crossed various thicknesses of water absorber are shown in Fig. 3. These data were obtained with a sensitive plastic callèd CR-39 in collaboration with E.V. Benton of the University of San Francisco. The relative ionization doses of the various atomic fragments (from boron to fluorine) found in neon ion beams of two initial energies are clearly separated. Figure 4 shows similar data from the Berklet where the LET is displayed against the residual energy on a CRT screen, and one obtains characteristic distributions with dots representing each particle and with particles of the same atomic number distributed on hyperbolic trajectories. In Fig. 4, the parent neon species produces the highest LET values, and the contaminating fragments each lie on lower curves. The Berklet cannot measure precisely all of the hundreds of types of events that occur when beam particles collide with resting nuclei of matter, but the distributions are suitable for calculating parameters of biological significance.

The cultured human fibroblast cells are more sensitive to particles of high LET (e.g., low-velucity neon) than to particles of low LET (e.g., fast protons to carbons). Exposure to high-LET radiation yields exponential survival curves, whereas the cells respond to low-LET radiation with a shoulder type survival curve. Many of the lesions are repaired at low LET. The domain of very high LET is from about $100 \mathrm{keV} / \mu \mathrm{m}$ to several thousand $\mathrm{keV} / \mu \mathrm{m}$.

We have performed survival experiments on cultured human cells irradiated in aerobic and hypoxic environments. Neon and silicon ion beams were studied at three energies. Acceleration at low initial energies provided pure primary particle beams, and higher initial energies provided mixed beams with particle fragments.

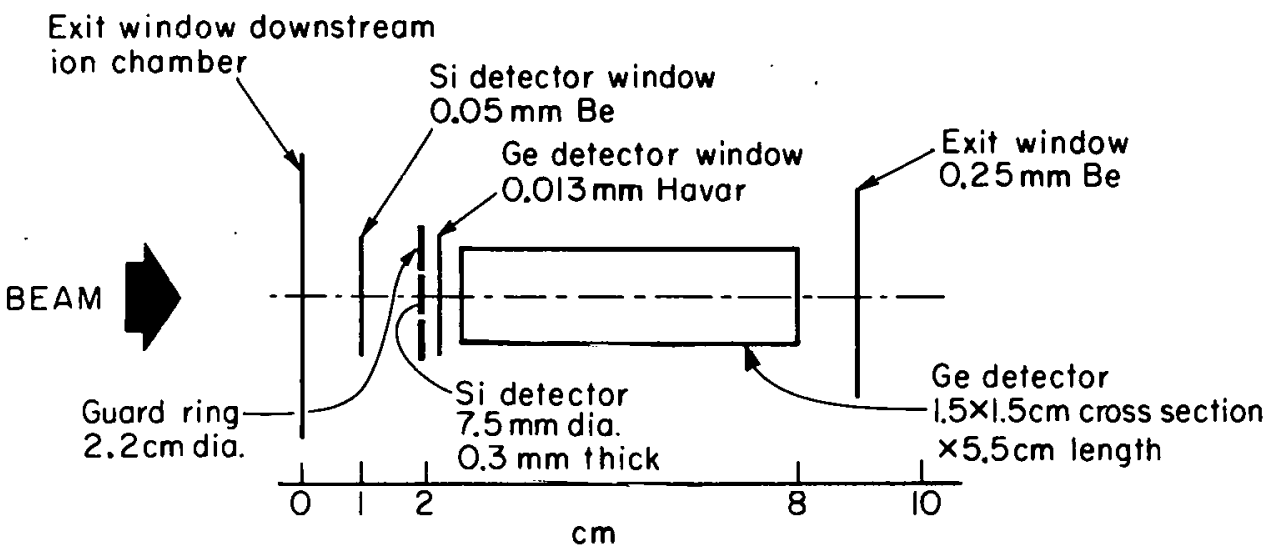

Fig. 2. Schematic drawing of the experimental setup used in Berklet measurements showing the detector system, with the windows for light and vacuum tightness. The germanium detector is kept in a cryostat at liquid nitrogen temperature ( $77 \mathrm{~K})$. 

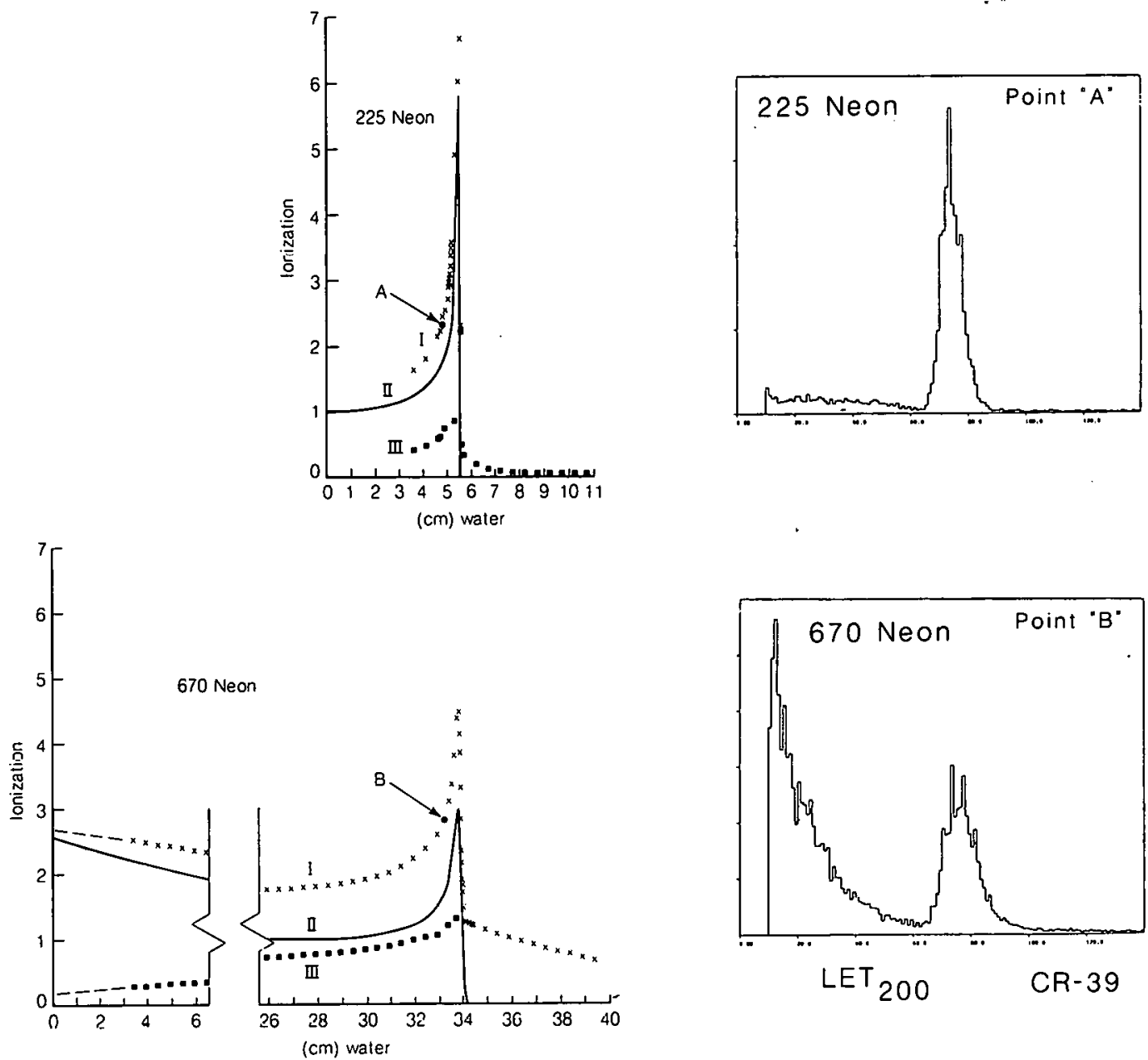

Fig. 3. Neon fragmentation spectra from 225- and $670-\mathrm{MeV} / \mathrm{u}$ beams. The same residual range al an LET of $1 / 18$ $\mathrm{keV} / \mu \mathrm{m}$ was examined in each case. The data are from $C R-39$ studies by Professor Eugene $V$. Benton at the University of San Francisco.

Several conclusions have come from analyzing the results of this study:

1. Below $118 \mathrm{keV} / \mu \mathrm{m}$, mixed beam effects can be well described with two beam parameters: dose and dose-average LET. The atomic number of the particles is not important.

2. Above $118 \mathrm{keV} / \mu \mathrm{m}$, track structure effects become identifiable.

3. At $118 \mathrm{keV} / \mu \mathrm{m}$ an increased quantity of fragments increase survival (decrease the RBE) for either neon or silicon (for example, see the neon results in Fig. 5).
4. At $180 \mathrm{keV} / \mu \mathrm{m}$ and higher, track structure effects are apparent; neon is biologically more effective than silicon.

5. At $118 \mathrm{keV} / \mu \mathrm{m}$, higher beam fragmentation lowers the RBE for both neon and silicon ions (see upper panel, Fig. 6), and has relatively little effect on the oxygen enhancement ratio in this LET range (see lower panel, Fig. 6), perhaps reflecting the importance of even a small high-LET dose component in reducing the OER.

6. The RMR model appears to be suitable for quantitating the complex phenomena in heavyparticle radiobiology. 


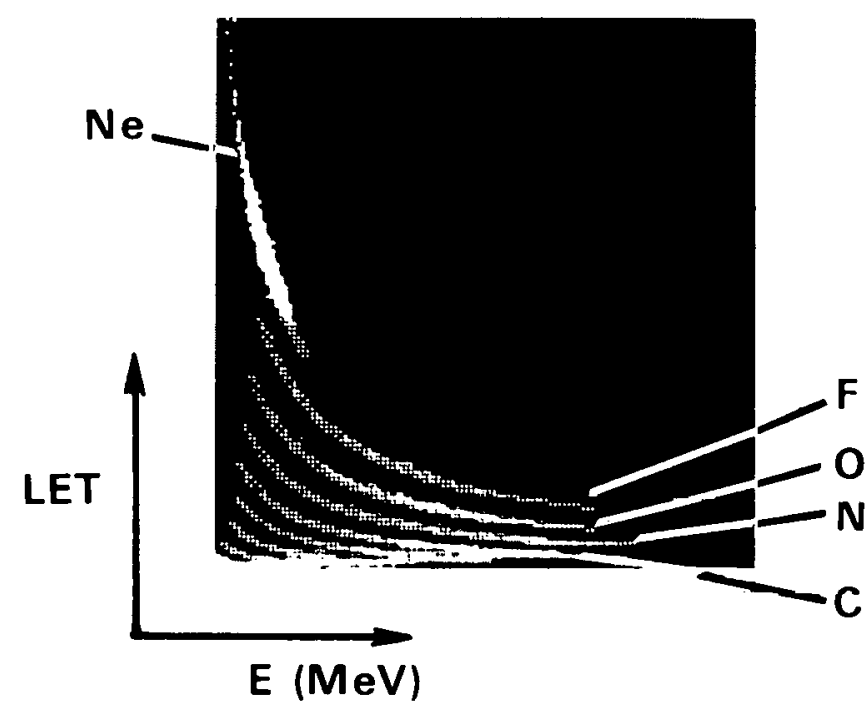

Fig. 4. Theoretical loci corresponding to the various values of $Z$ calculated from first principles and the detector calibration parameters superimposed on experimental results. Only minor adjustments (a few percent) are needed to secure the fit between theory and experiment. The theoretical loci are used in assigning pixels in the histogram to specific values of $Z$ for analysis.

(XBB 8312-6241)

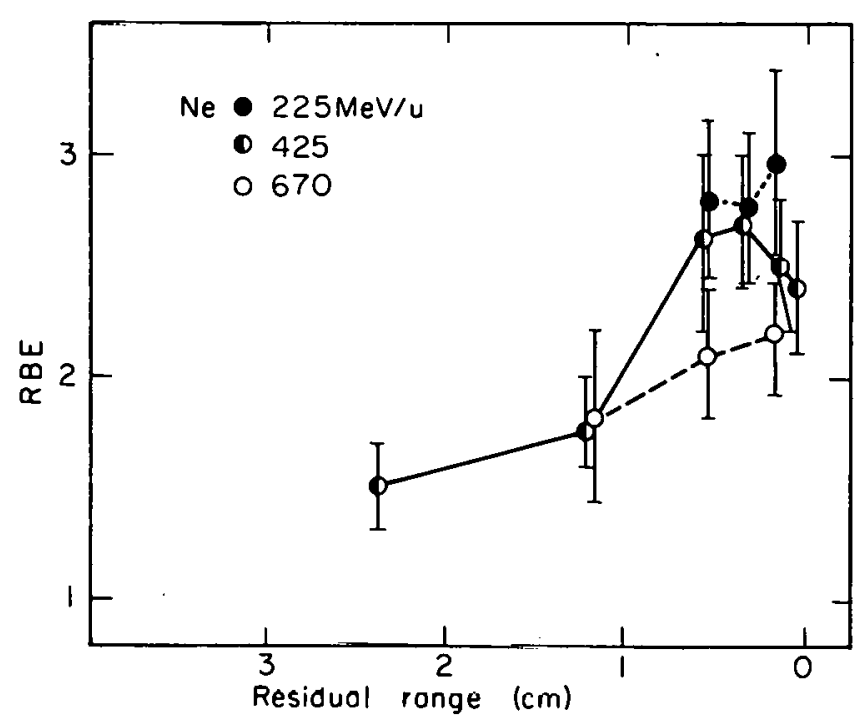

Fig. 5. Relative biological effectiveness at $10 \%$ survival for various residual range positions of neon ion beams of three different initial energies. The lighter fragments in the highenergy beams depress the RBE in the last centimeter of range.

(XBL 8312-4160)

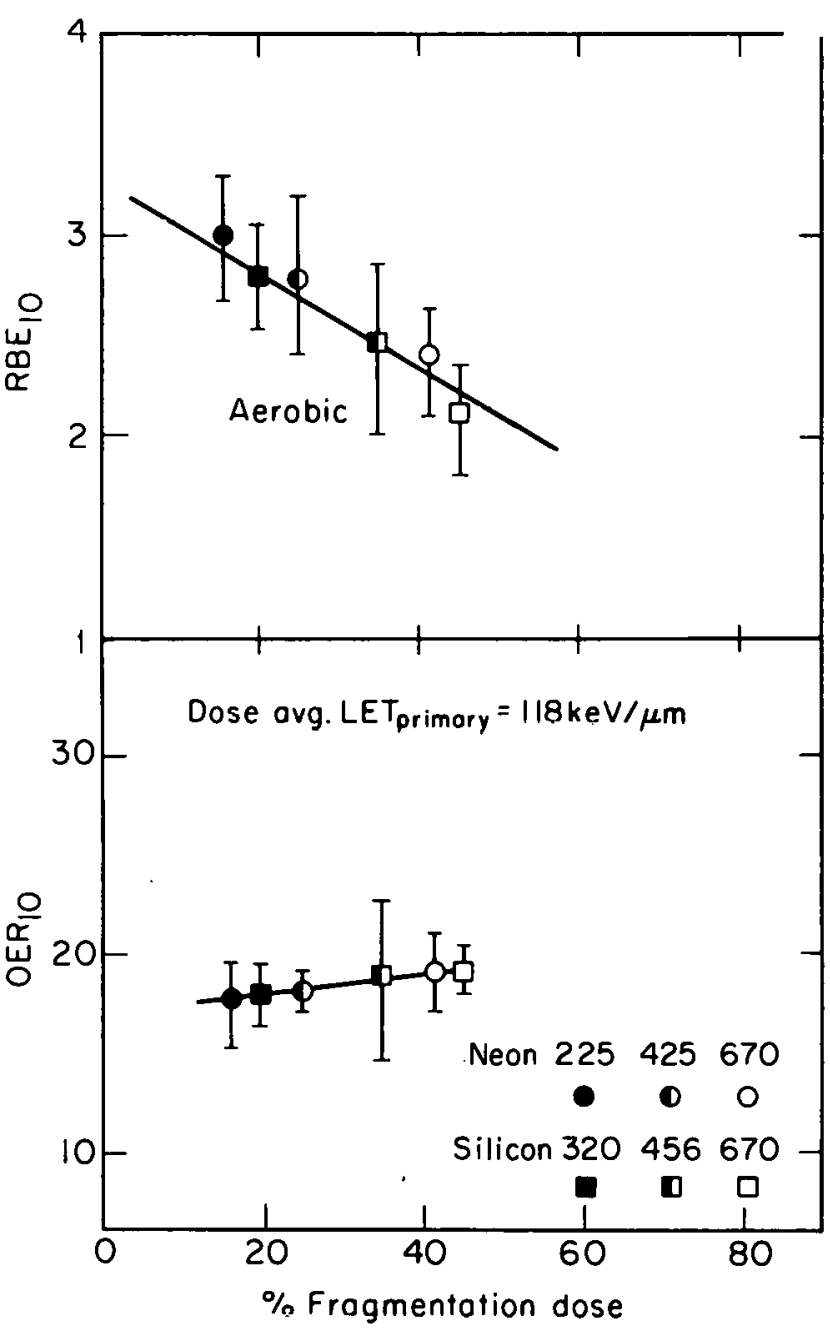

Fig. 6. The RBE and OER values at $10 \%$ survival for neon and silicon beams of various initial energies at residual ranges yielding a primary ion LET of $118 \mathrm{keV} / \mu \mathrm{m}$. The beams of higher initial energies have a greater fragmentation dose and show a decreased RBE (top panel) and relatively little change in the OER (bottom panel).

(XBL 8312-4163)

\section{REFERENCE}

1. Llacer, J., Tobias, C.A., and Holley, W.R. On line characterization of heavy ion beams with semiconductor detectors. Med. Phys., in press (1984). 


\section{EAVY-ION MICROSCOPY}

\section{Mark H. Phillips, Joseph M. Jaklevic, James B. Schmidt, Ann C. Birge, and Cornelius A. Tobias}

During this year our research on heavy-ion microscopy has had two aims: 1) achieving a fuller understanding of the physical mechanisms of image formation, and 2) developing reliable, accurate methods for obtaining the images. Earlier impressive results have demonstrated the unique capabilities of this technique., With a higher resolution than possible with optical microscopy, heavy-ion microscopy images biological specimens that are too thick for transmission electron microscopy (TEM) and still provides information about the sample's interior structure that is unobtainable by scanning electron microscopy (SEM). In addition, the processing procedures that are necessary to visualize the important cellular structures with SEM and TEM alter the structures. We hope to exploit the properties of heavy-ion microscopy to study aberrations in chromosomes caused by radiation damage. These aberrations have been implicated in carcinogenesis and have resisted study by other methods.

The basic technique of heavy-ion microscopy can be described briefly. The sample to be imaged is placed on a substrate that is sensitive to damage by heavy ions, CR-39 plastic for example. The sample and substrate together are exposed to a monoenergetic parallel beam of a particular species of heavy ion. The energy of the beam is chosen so that the ion range just exceeds the thickest part of the sample. In passing through the sample, the ions lose varying amounts of energy, depending on the thickness and electron density of the sample along the path of each ion. As a result, after the ions pass through the sample, they will have different residual ranges in the plastic, depending on which part of the sample they penetrated. After the exposure, the sample is removed from the substrate, and the substrate is etched chemically to remove all material from the surface to the end of the individual ion ranges. The resulting contour (topography) is then examined using a scanning electron microscope.

To fully realize the potential of heavy-ion microscopy, we have begun to develop several aspects of the technique. We have investigated the physical mechanisms involved in contrast and resolution. The contrast of the image depends on the sensitivity of particle range to differences in ectron density within the sample; the depth solution is determined by range straggling. These two imaging parameters are thus intimately related.
In addition, the dose delivered to the sample must be considered. At the ion energies we use $(\sim 1 \mathrm{MeV} / \mathrm{u})$, theoretical calculations of range and range straggling are not very accurate. In general, when considering ion-electron scattering, there is less range straggling with the heavier ions, but this is not the case when charge exchange and nuclear scattering are considered. Measurements of such short ranges and range straggling is difficult. We are currently trying to achieve some quantitative measure by looking at the images of known samples, such as electron microscopy grids.

Lateral resolution is determined by multiple Coulomb scattering of the ions. Using the Moliere theory, we have done calculations that indicate the heavier the incident ion, the less the multiple scattering. Here too, however, the results of the theory are less accurate at the small ranges and low energies of interest in heavy-ion microscopy. Presently, we are using ${ }^{4} \mathrm{He}$ and protons in an effort to strike a balance between high image resolution and high sample doses.

The second focus of our work has been to explore different substrates, the effect of dose and dose rates on them, and the etching conditions. Currently we are using two substrates, polymethylmethacrylate (PMMA) and CR-39. PMMA is used in the semiconductor industry as a resist in $x$-ray and proton lithography. CR-39 has been well characterized for nuclear track detection, but as yet little is known about it for our applications. Both plastics have produced good images, but we have not determined which one is preferable for microscopy. Figure 1 shows a recent PMMA lithograph that we produced with $1-\mathrm{MeV}{ }^{4} \mathrm{He}$ ions.

Work on the dose, dose rate, and etching conditions is proceeding in parallel with studies to establish heavy-ion microscopy as an accurate and reliable technique. Clearly, these parameters must be optimized in order to obtain conclusive results for the resolution, contrast, and substrate studies.

Our recent work on heavy-ion microscopy has paralleled and been stimulated by several related developments. Semiconductor devices have been steadily decreasing in size, and work has started on utilizing the high resolution of heavy-ion lithography to make circuits smaller than those made with lithography using visible light. ${ }^{3}$ The development of bright synchrotron sources of soft $x$ rays and associated $x$-ray optics has spurred interest in $x$-ray microscopy. ${ }^{4}$ The applications and methods of $x$ - 


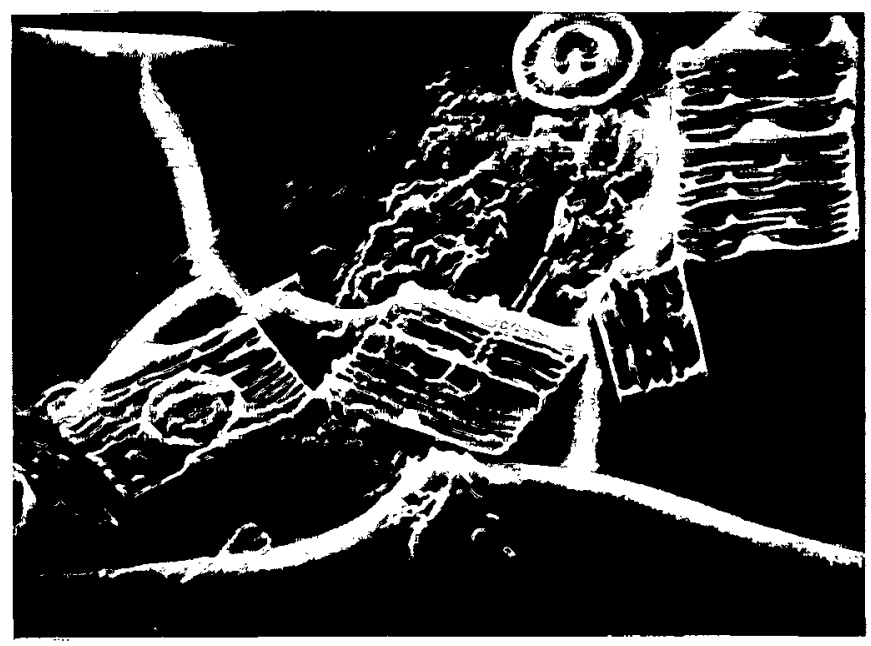

Fig. 1. Scanning electron micrograph of a PMMA replicate of several diatom species produced after exposure to $1-\mathrm{MeV} / \mathrm{u}^{4} \mathrm{He}$ particles.

(XBB 839-7942)

ray microscopy are similar to those of heavy-ion microscopy, although $x$-ray microscopy images the photoelectric absorption by the sample. Prugr (e.g., characterization of substrates) in each of these rclated techniques often applies to all of them. We liupe liad tuture work will result in the completc development of these complementary techniques.

\section{RFFERENCES}

1. Kraft, G., Yang, T.C., Richards, T., Tobias, C.A., and Hayes, T.L. Biology and Medicine Division Arrilual Report 1979.. 1980, Lawrence Berkeley Laboratory report LBL-11700 (1981), p. 56.

2. Blakely, E.A., Hayes, T.L., Schmidt, J., and Lommel, L. Biology and Medicine Division Annual Report 1980-1981, Lawrence Berkeley Laboratory report LBL-13501 (1982), p. 65.

3. Slayman, C.W., Bartelt, J.L., McKenna, C.M., and Chen, J.Y. Opt. Eng. 22, 208 (1983).

4. Attwood, D.T. Current developments in high resolution x-ray measurements. A.I.P. Conference Proc. 90, 254 (1982).

\title{
$\beta$-araA ENHANCED CELL TRANSFORMATION BY RADIATION
}

\author{
Tracy C. Yang, Cornelius A. Tobias, and Laurie M. Craise
}

lonizing radiation can directly induce neoplastic cell transformation in vitro, and there are experimental results indicating that cellular DNA may be the primary target. It is unknown, however, how the transformation lesion is formed in the cell following irradiation. One of the possible mechanisms for the formation of transformation lesions may be related to radiation-produced DNA breaks that can be repaired properly or misrepaired. The transformation lesion may therefore result from a misrepair of DNA damage. To test this hypothesis, we conducted experiments with $\beta$-araA, a known DNA polymerase inhibitor. Our results suggest that when the activity of DNA polymerase was inhibited, some radiation-induced damage was modified to form transformation lesions, through an as yet unknown process.
When well-confluent mouse embryonic cells ( $\mathrm{C} 3 \mathrm{H} 10 \mathrm{~T} 1 / 2)$ were treated with $100-\mu \mathrm{M} \beta$-araA for 7 hours immediately following $x$-irradiation and incubated at $37^{\circ} \mathrm{C}$ for 16 hours after $\beta$-araA medium was removed from the cell culture, there was a great increase of cell killing and transformation frequency. The survival curve changed from one with a significant shoulder to one close to exponential, as shown in Fig. 1. An enhancement of transformation by $\beta$-araA is evident in $x$-rayed cells (Fig. 2). Because no repair of potential transformation lesions could be detected in the cells treated with $\beta$-araA, some radiation-induced DNA damage was probably misrepaired to form irrepairable transformation lesions. Further studies are needed to identify the cellular enzymes and the mechanisms involved in the misrepair process. 


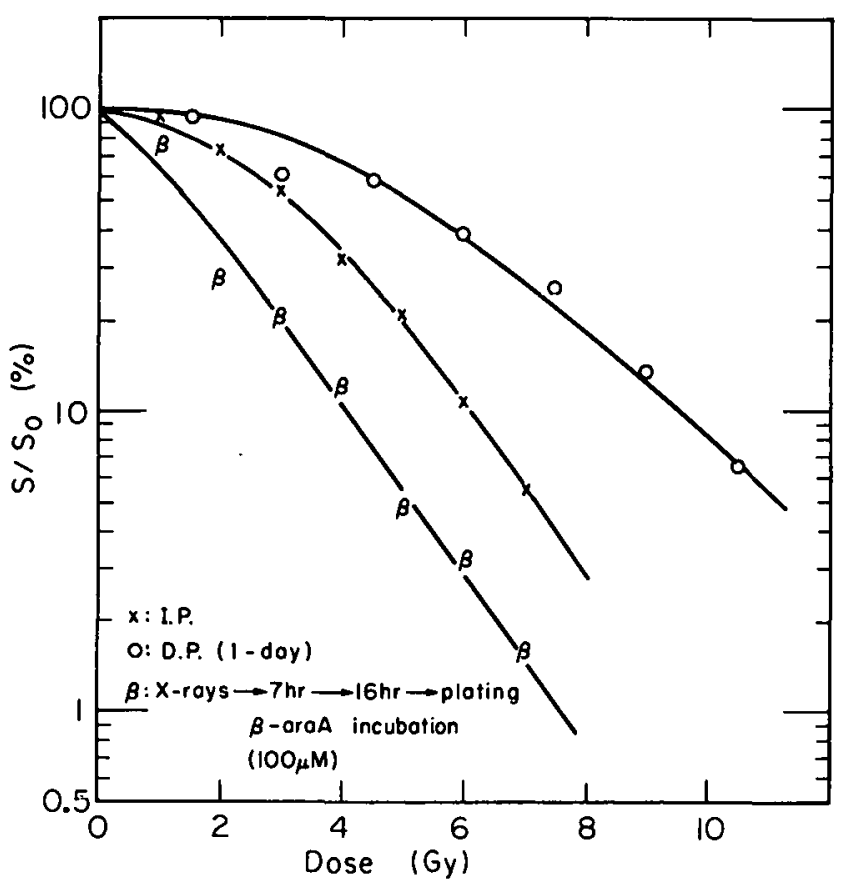

Fig. 1. Effect of $\beta$-araA on the radiosensitivity of confluent mouse embryonic fibroblasts. A short treatment of $\beta$-araA inhibits the repair of potential lethal damage. (XBL 8312-4161)

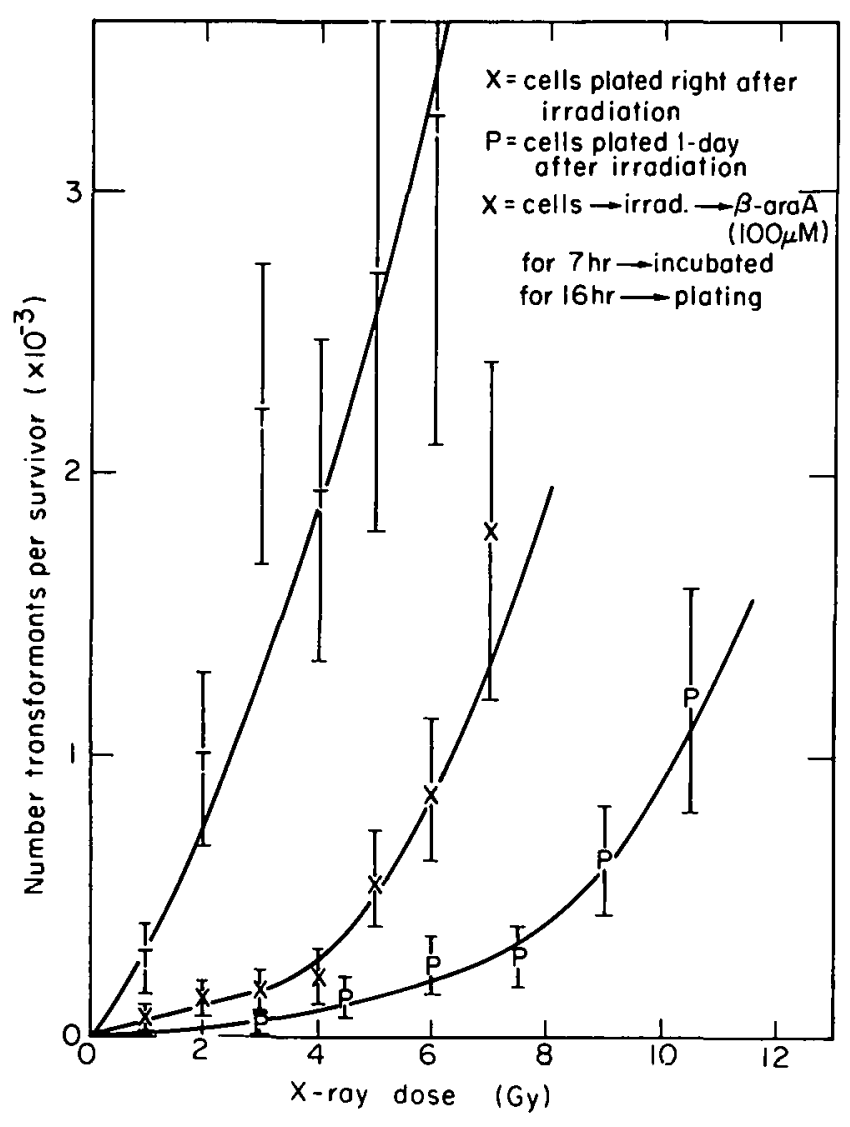

Fig. 2. An enhancement of $\beta$-araA on the radiation-induced cell transformation. No repair of potential transformation lesions could be observed in cells treated with $\beta$-araA for 7 hours.

(XBL 8312-4162)

\section{IONIZING RADIATION ENHANCES DNA TRANSFECTION}

\section{Carl F. Perez, Cornelius A. Tobias, and Tracy C. Yang}

Our laboratory is engaged in a systematic study of the effects of radiation on the processes responsible for transforming normal cells to cancer cells. It has been clearly demonstrated that a dose of ionizing radiation enhances the transforming ability of certain viruses (e.g., Simian virus SV40) by a large factor. It is possible to harvest 25 to 50 times more transformed cells under conditions of combined exposurc to virus and radiation compared to conditions in which either of these agents is acting alone. The enhancement of radiogenic transformation by chemical modifiers is also a part of our cellular heavy-ion studies (see previous section).

We are also investigating the role of oncogenic ..-uses in transformation. It has been shown that a virus SV40 has a well-defined oncogene, a gene ....at is responsible for transforming normal mouse cells (3T3) to tumor cells. It is also known that in the course of viral infection this oncogene is transferred, perhaps in several copies, to the genome of the host cells. We do not understand, however, the detailed processes wherehy the oncogene is integrated into the host cell genome. According to an hypothesis we formulated, ionizing radiation enhances viral carcinogenesis because the radiation produces sites in the host DNA that become sites of integration for viral DNA. Furthermore, partial evidence is available to show that the enzyme system involved in the repair of radiation damage may be used by the cell to integrate the foreign DNA into its own fabric. To study these processes, we needed an abundant source of viral oncogenes and methods to introduce the foreign DNA into mammalian cells. In collaboration with 
Professor Michael Botchan of the Molecular Biology Department, U.C. Berkeley, we constructed recombinant DNA bacterial plasmids.

Rat- 2 cells are thymidine kinase deficient ( $\mathrm{tk}^{-}$) and nonpermissive for SV40 viral transformation. These cells can only survive in HAT selective media if stable integration and expression of a transfected thymidine kinase (tk) gene occurs. Recombinant DNA bacterial plasmids were constructed that contained the herpes simplex virus thymidine kinase (HSV-tk) gene. Confluent Rat-2 cells were irradiated with $x$ rays or argon particles $(330 \mathrm{MeV} / \mathrm{u})$ immediately after transfection with a tk-gene containing the plasmid pOT-TK5. Irradiated cells were then selected in HAT to screen for tk-transformants. Figure 1 shows the effect of ionizing radiation on the enhancement ratio for tk-transformation of pOT-TK5 transferted cell. The enhancement ratio is calculated by dividing the number of transformants per irradiated survivor by the number of transformants per survivor for an unirradiated population. For both radiation modalities, the enhancement curves are dose dependent and more than additive. Compared to $x$ rays, argon particles were more efficient in enhancing the tk-transformation. Subclones of these transformants are being studied by blot-hybridization techniques to establish the integration profiles of pOT-TK5 DNA in the cellular DNA. The enhancement of DNA-mediated gene transfer by ionizing radiation opens a new approach to studying DNA repair in mammalian cells, particularly DNA repair mutants.

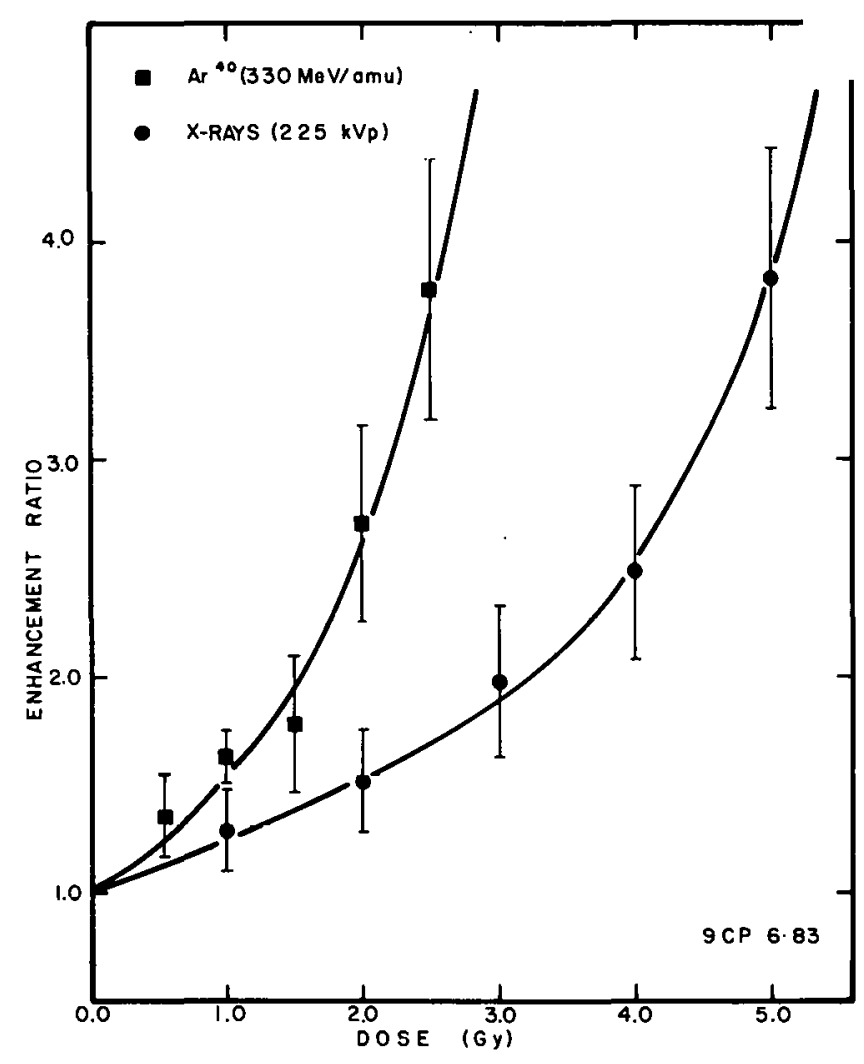

Fig. 1. Dose-response curves for tk-transformation of pOTTK5 transfected Rat-2 cells. Enhancement ratio $=[(H A T+$ colonies/survivor) $\left.{ }_{\text {imadized }}\right]$ divided by [(HAT+ colonies/survivor) innimadiated .

(XBL 836-10416)

\section{PROTECTION EFFECT OF DIMETHYL SULFOXIDE ON THE INITIATION AND EXPRESSION OF RADIOGENIC NEOPLASTIC CELL TRANSFORMATION}

\section{Tracy Chui-hsu Yang, Laurie M. Craise, and C.A. Tobias}

Dimethyl sulfoxide (DMSO) is a well known chemical radioprotector for cell killing and is widely used for studying physico-chemical mechanisms of biological effects of ionizing radiation. The potential of DMSO for reducing the radiation effect on neoplastic cell transformation, however, has not been investigated before. For understanding the fundamental mechanisms of radiation cell transformation, we initiated studies on the effects of DMSO on the initiation and expression of cell transformation. Our data show that DMSO, when present during irradiation, gives a dose reduction factor (DRF) about 2.6 for cell killing and about 3.0 for neoplastic cell transformation. The frequency of cell transformation also decreased rapidly with an increase of concentration of DMSO when DMSO was added to cells 10 days after x-irradiation and plating. The inhibition of expression of cell transformation by DMSO is irreversible based on current data. Our recent experimental results showed that cells treated with 1\% DMSO for only one week, started 10 days after $x$-irradiation and plating, yielded no transformation. DMSO at a concentration of $1 \%$ or less has very little effect on the cell growth and the colony-forming ability. These experimental results suggest that DMSO may be a useful chemical agent for reducing the effect of radiation on neoplastic cell transformation.

Experimental observations on the modulatior radiation cell transformation indicate that the pro- 
zSs of neoplastic cell transformation is a compli-ated one and includes at least two different stages: induction and expression. The induction stage is a relatively short one and may be completed after one cell division. The expression stage, however, will usually take several weeks and can be modulated by various physical and chemical agents. In our laboratory we have been interested in radiation protection and recently initiated studies on the effect of DMSO on radiogenic cell transformation. Mouse embryonic fibroblasts (C3H10T1/2) was the model system for our cell transformation studies. When confluent $G_{1}$ cells were treated with $2 \mathrm{M}$ DMSO during $x$-irradiation, there was a significant increase of cell survival and a decrease of transformation frequency, and the dose modifying factor for survival was about 2.6 and for cell transformation about 3.0, as shown in Figs. 1 and 2. The radioprotection of cell killing by DMSO has been commonly suggested as a result of scavenging of $\mathrm{OH}$ free radicals induced by ionizing radiation. Because DMSO can protect cells from being transformed by radiation, it is very likely that some transformation lesions are produced through indirect action, i.e., by $\mathrm{OH}$ radicals. Our present results indicate that for a given $x$-ray dose $\mathrm{OH}$ radi-

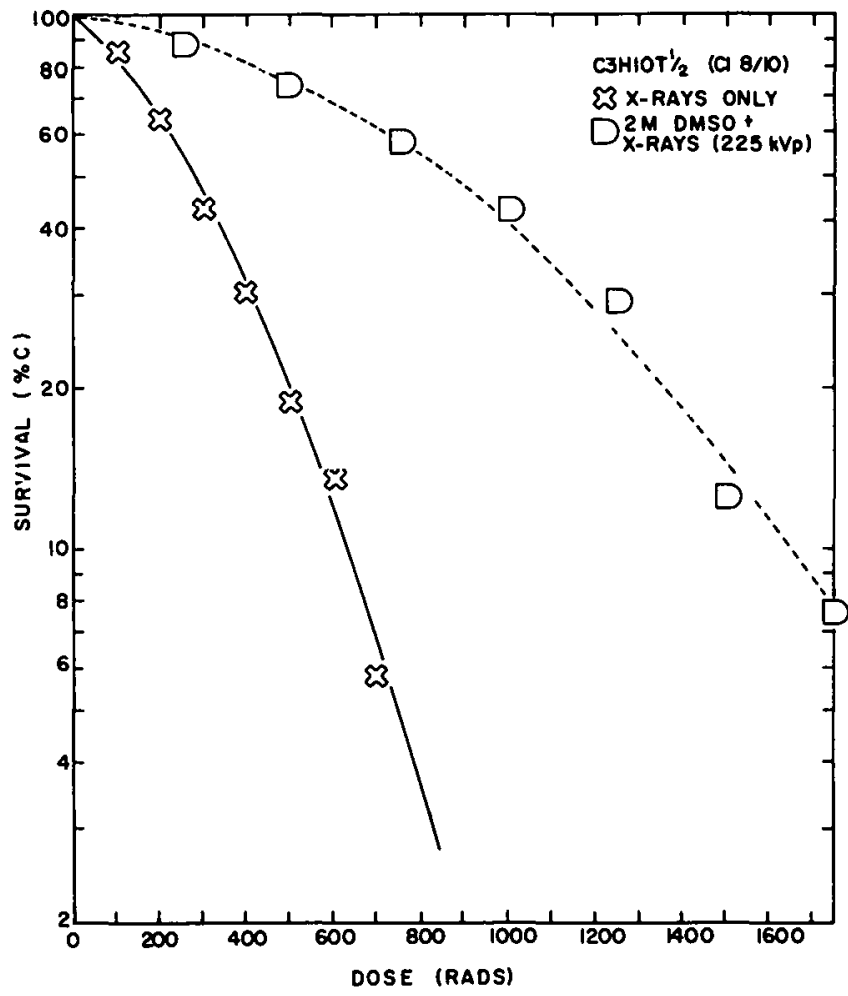

g. 1. Radioprotection of DMSO on cell killing. 2M DMSO present during irradiation.

(XBL 835-9900)

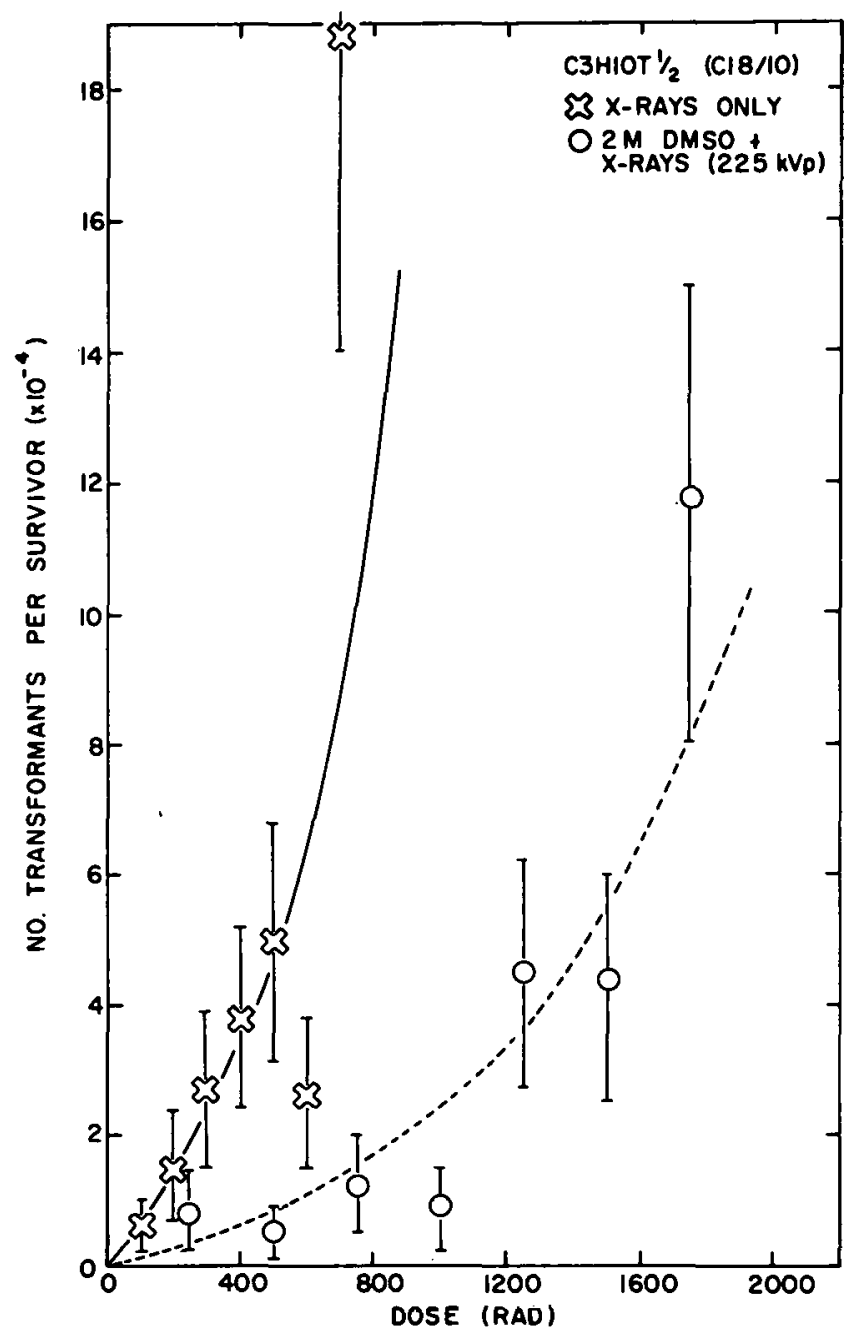

Fig. 2. Protection effect of DMSO on $x$-ray induced cell transformation. Cells were in $2 \mathrm{M}$ DMSO during $x$-irradiation only.

(XBL 835-9901)

cals may induce as much as $80 \%$ of transformation lesions in the mammalian cells.

We also observed a protection effect of DMSO on radiogenic cell transformation when DMSO was added to cells 10 days after irradiation and plating. After 10 days incubation, cells usually formed a confluent monolayer in the dish and had about 10 cell divisions. The presence of DMSO in the medium through the rest of the incubation period, about 4 weeks, can suppress the expression of morphological transformation by radiation. With an increase of concentration of DMSO $(0.025-1.0 \%)$, the frequency of cell transformation decreased rapidly, and no transformant was observed in cells exposed to $1 \%$ DMSO for 4 weeks (Fig. 3). This suppression of radiogenic cell transformation by DMSO is not due to an inhibition of cell growth, because the cells treated with DMSO give about 


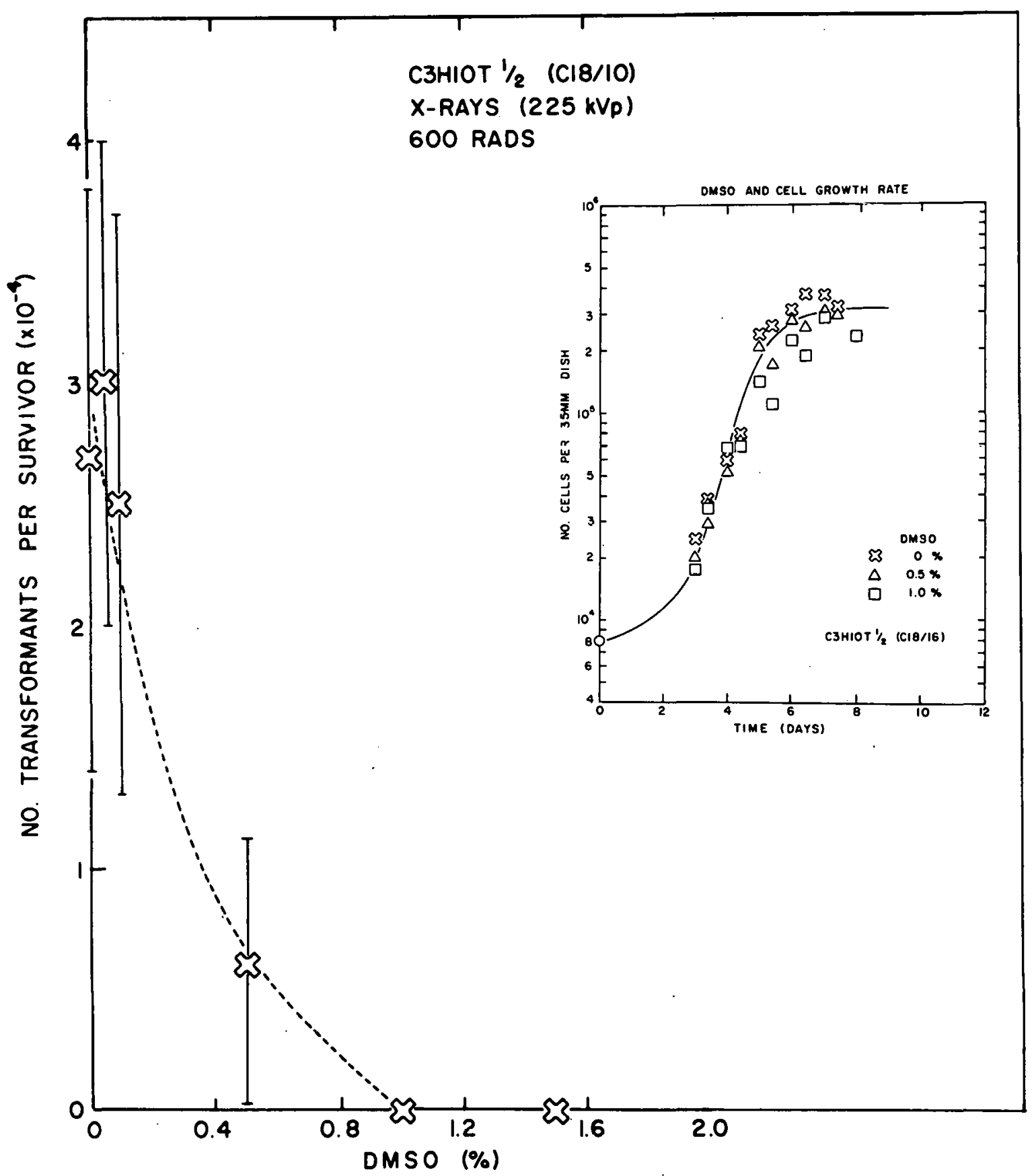

Fig. 3. Suppression of cell transformation by various concentrations of DMSO. Cells were treated with DMSO 10 days following $x$-irradiation and plating. Insert: Growth of cells in various concentrations of DMSO medium.

(XBL 835-9899A)

the same number of survivors as nontreated ones and show no significant change of growth rate, as shown in the insert of Fig. 3.

In general, for a significant reduction of cell killing, radioprotectors have to be present during irradiation and at a cytotoxic concentration. Our DMSO studies, however, suggest that for radiogenic cell transformation a complete protection can, be achieved with DMSO some time after irradiation and at a concentration with very little cytotoxic effect. Although there are no data on the effects of DMSO on the cell transformation by high-LET radiation, it is very likely that a similar protection effect will be found with some heavy ions. There is, therefore, a possibility that through further studies on the mechanisms of DMSO effect on the expression of cell transformation one may find some chemical protectors which can significantly redu the carcinogenic effect of radiation, includi . cosmic rays. 


\title{
FECTS OF SEQUENTIAL EXPOSURE OF MIXED RADIATION MODALITIES ON . .EOPLASTIC CELL TRANSFORMATION
}

\author{
Tracy C. Yang, Laurie M. Craise, Jerry Howard, and Cornelius A. Tobias
}

The objective of this project is to obtain quantitative data on the carcinogenic effect of mixed radiation modalities by using the in vitro cell transformation technique. The specific aims are: 1) to test the hypothesis that high-LET heavy particles can act synergistically with low-LET radiation in inducing neoplastic cell transformation; 2) to obtain doseresponse curves for sequential exposure of high-LET silicon, neon, or argon ions and $x$ rays; and 3 ) to determine whether the sublesions induced by high-LET heavy particles are repairable in mammalian cells. Our recent experimental results suggest that lesions induced by $x$ rays and heavy particles can interact for both cell killing and neoplastic cell transformation.

The potential biological effects of sequential exposure to ionizing radiation of different qualities have been studied more extensively in recent years. The motivation for such experiments is threefold: first, to address the fundamental radiobiology question of the interaction of sublesions in cellular systems, second, to explore the possibility of mixed radiation modalities in clinical cancer radiotherapy, and third, to assess the potential biological hazards of cosmic rays in space. Several investigators have demonstrated that fast neutrons delivered within a few minutes before or after $x$-ray irradiation killed cells more effectively than would be expected based on the assumption of the independent action of each radiation. ${ }^{1-4}$ Some of the neutron-induced lesions that interact with $x$-ray induced damage appear to be repairable in mammalian cells. Similar results were observed with high-LET neon particles, which yielded an exponential survival curve for asynchronous Chinese hamster V79 cells. ${ }^{5}$ Although there was no evidence of split-dose repair, as observed earlier by $\operatorname{Todd}^{6}{ }^{6}$ the survival curve for cells irradiated with graded doses of $x$ rays shortly after a priming dose of neon ions had a reduced shoulder relative to the $x$-ray-only survival curve. Using synchronized V79 cells, Bird et al. ${ }^{7}$ found that the synergistic effect of mixed lowand high-LET radiation increases with the LET of the primary dose.

Because there is no information available in the literature concerning the effect of mixed radiation modalities on the neoplastic cell transformation, we

tiated some studies on the interaction between

and $x$ rays on the cell transformation and observed a synergistic effect. Figure 1 shows the transformation frequency per survivor as a function of x-ray dose. There is clearly a synergistic effect, especially at high doses. Recently we have extended these studies to high-LET heavy ions. For all experiments we used cultured stationary phase cells $(\mathrm{C} 3 \mathrm{H} 10 \mathrm{~T} 1 / 2)$ as a model system. Wellconfluent cells between passage 8 and 15 were irradiated sequentially with $x$ rays and a monoenergetic heavy-ion beam at the plateau of the Bragg curve. After irradiation, cells were seeded into tissue culture dishes at a density that yields an optimal frequency of transformation and incubated at $37^{\circ} \mathrm{C}$ for $5-6$ weeks. At the end of the incubation period, cells were fixed and stained, and the transformed foci were scored under a low-power

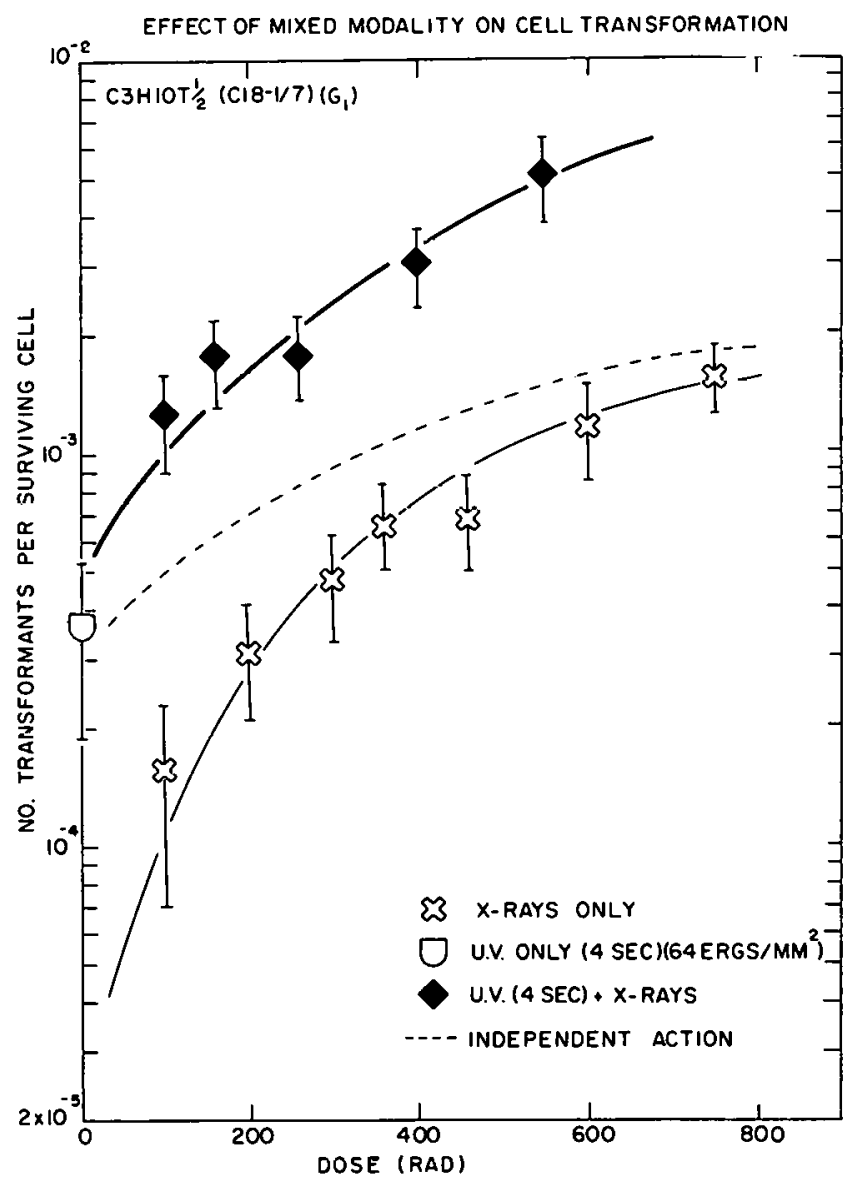

Fig. 1. Synergistic effect between uv and $x$ rays on neoplastic cell transformation. The transformation frequency per survivor for cells irradiated by a single dose of uv $\left(64 \mathrm{ergs} / \mathrm{mm}^{2}\right)$ and followed by $x$ rays is higher than for cells irradiated by $x$ rays only. Dotted curve is the dose-response curve for cells if uv and $x$ rays act independently. 
dissecting microscope. Figures 2 to 5 show the results of studies on the interaction between $x$ rays and silicon ions $(320 \mathrm{MeV} / \mathrm{u} ; \mathrm{LET}=86 \mathrm{keV} / \mu \mathrm{m})$ on the cell killing and on the neoplastic cell transformation. These data suggest that the $x$ rays and silicon ions do not act independently. When cells were irradiated first with $x$ rays and followed immediately by silicon ions, for example, the survival curve showed no shoulder (Fig. 2). If the action of each radiation modality were independent, there should be no reduction of the shoulder and the survival curve should be like the dotted line. A change in the survival curve shoulder is also evident for cells irradiated by silicon ions and followed by $x$ rays, as shown in Fig. 3 . The neoplastic cell transformation results are presented in Figs. 4 and 5. On a semi-log plot, the transformation frequency per survivor for cells exposed to mixed radiation is parallel to and consistently higher

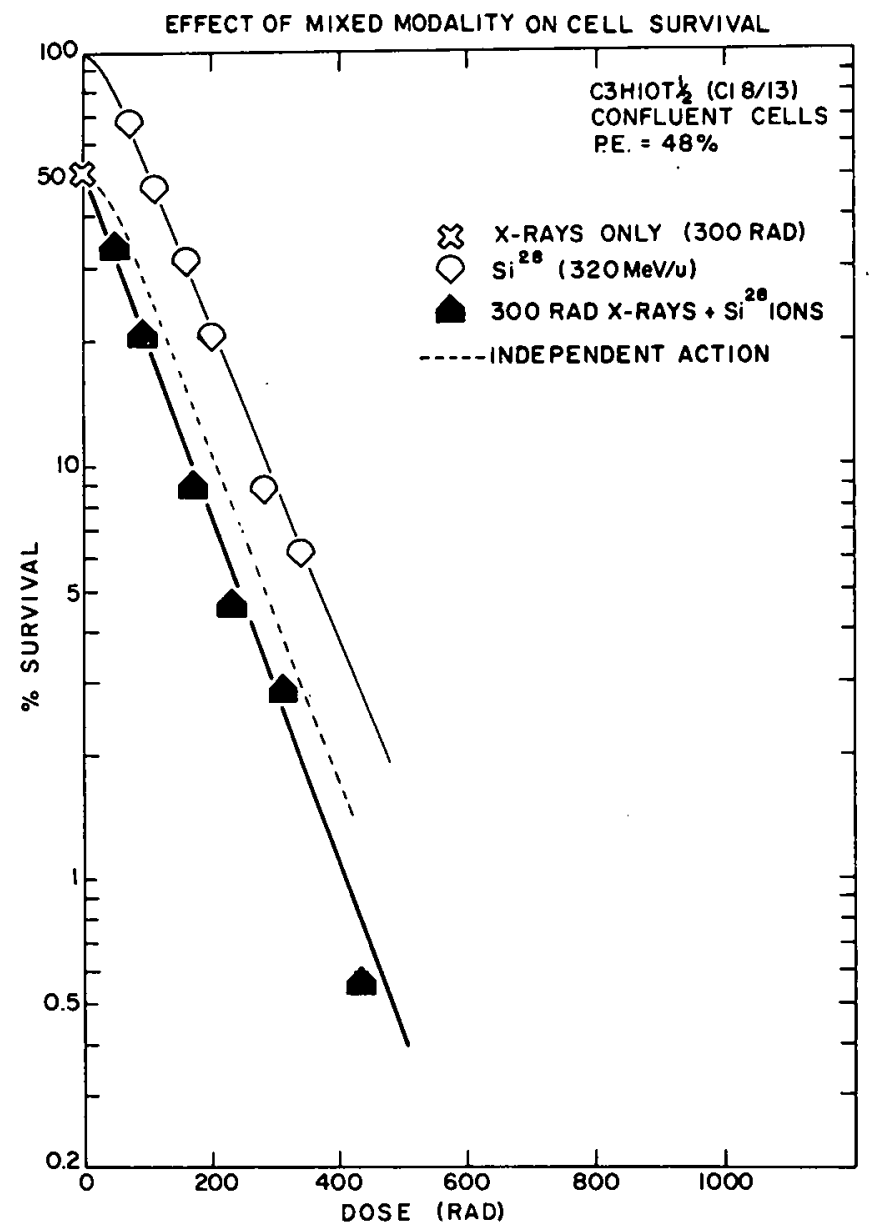

Fig. 2. Survival curves for cells irradiated by silicon ions $(320$ $\mathrm{MeV} / \mathrm{u})$ only or by $x$ rays $(300 \mathrm{rad})$ and followed by silicon particles.

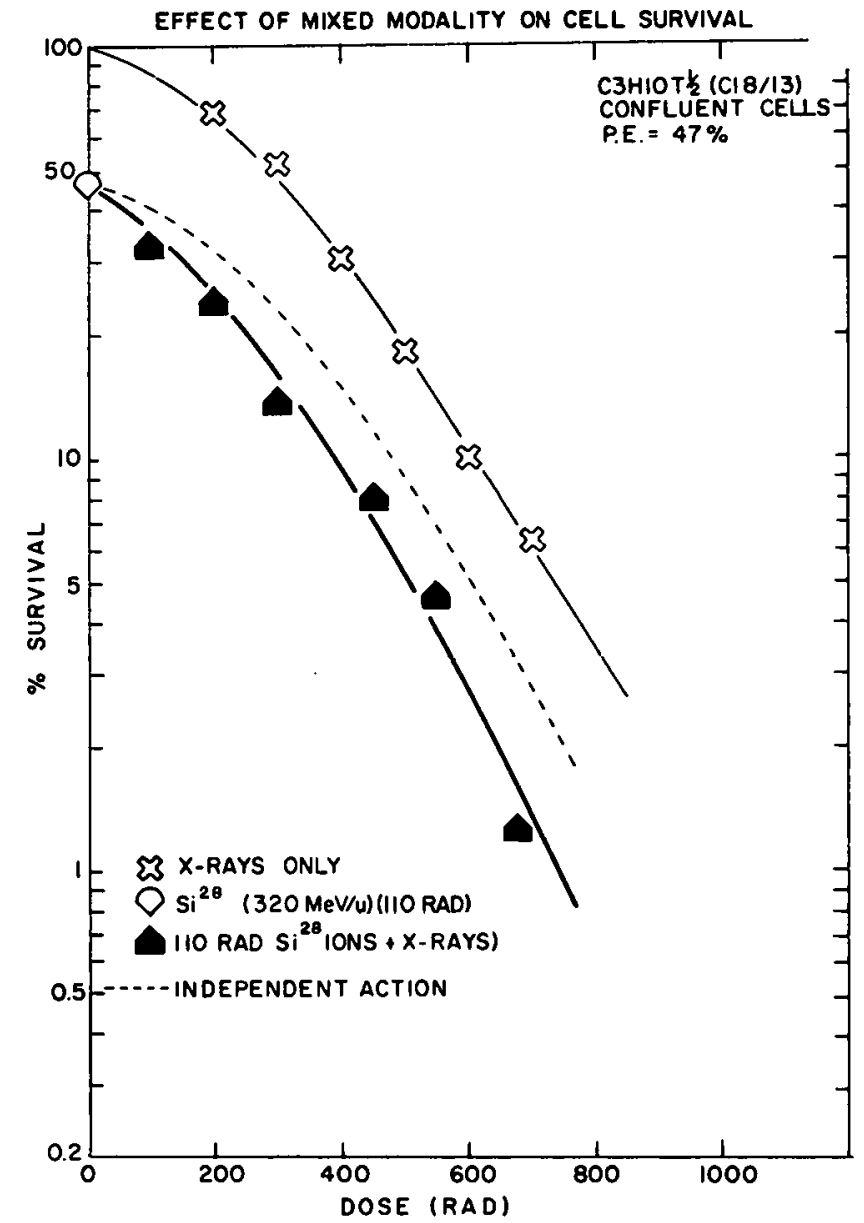

Fig. 3. Survival curves for cells exposed to $x$ rays only or to silicon ions and $x$ rays.

(XBL 8311-4553)

than that irradiated with $x$ rays or silicon ions only. The dotted curve shows the result if $x$ rays and silicon ions act independently.

At present we do not know whether a similar mechanism is involved in the synergistic effect between nonionizing $\mathrm{uv}$ and ionizing radiation ( $x$ rays) and in that between low- and high-LET radiation, and further investigations are needed to elucidate the fundamental mechanisms involved. Results obtained from these studies will also provide a clearer understanding of fundmental aspects of the biological response to heavy-ion beams and useful information for assessing the carcinogenic effects of cosmic rays in space, for evaluating the potential use of mixed modalities in cancer therapy, and for development of theoretical descriptions of radiation carcinogenesis. 


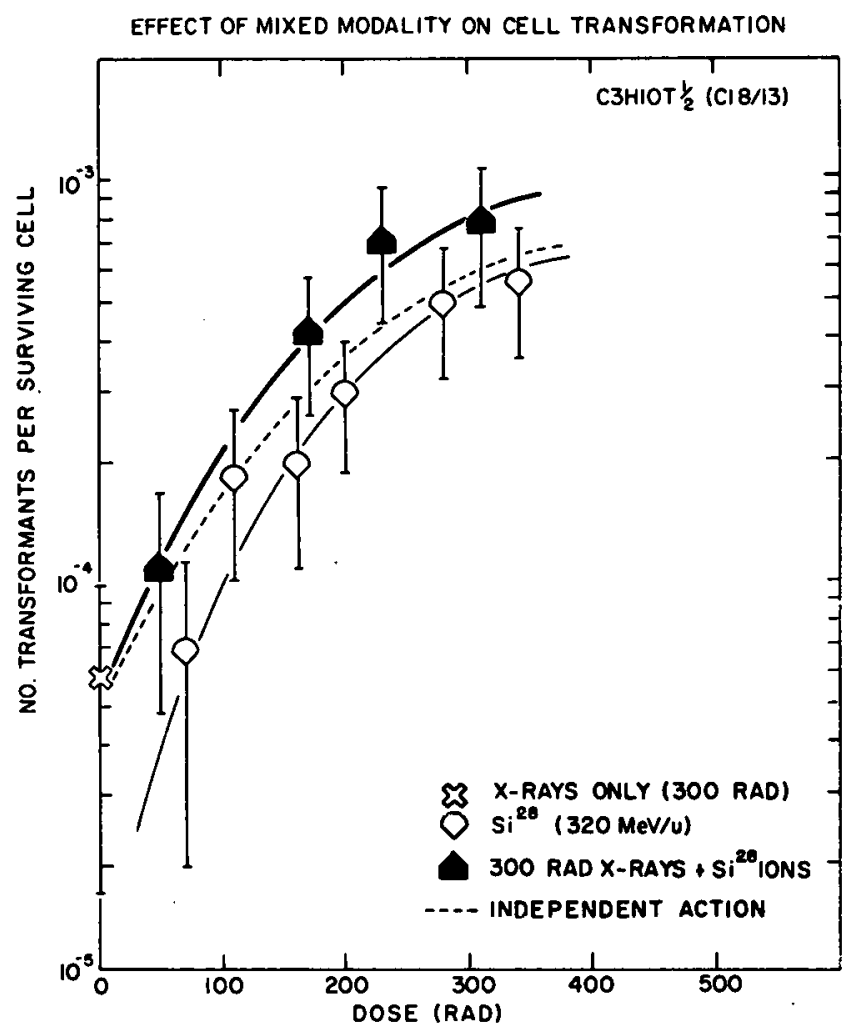

Fig. 4. Dose-response curves for neoplastic cell transformation. The number of transformants per survivor for cells receiving a sequential exposure to $x$ rays and silicon ions is higher than that for cells irradiated by silicon particles only.

(XBL 8317-4552)

\section{REFERENCES}

1. Masuda, K.J. Radiat. Res. 11, 107-112 (1970).

2. Railton, R., Lawson, R.C. and Porter, D. Int. J. Radiat. Biol. 27, 75-82 (1975).

3. Durand, R.E., and Olive, P.L. Int. J. Radiat. Biol. 30, 589-592 (1976).

4. Ngo, F.Q.H., Han, A., and Elkind, M.M. Int. J. Radiat. Biol. 32, 507-511 (1977).

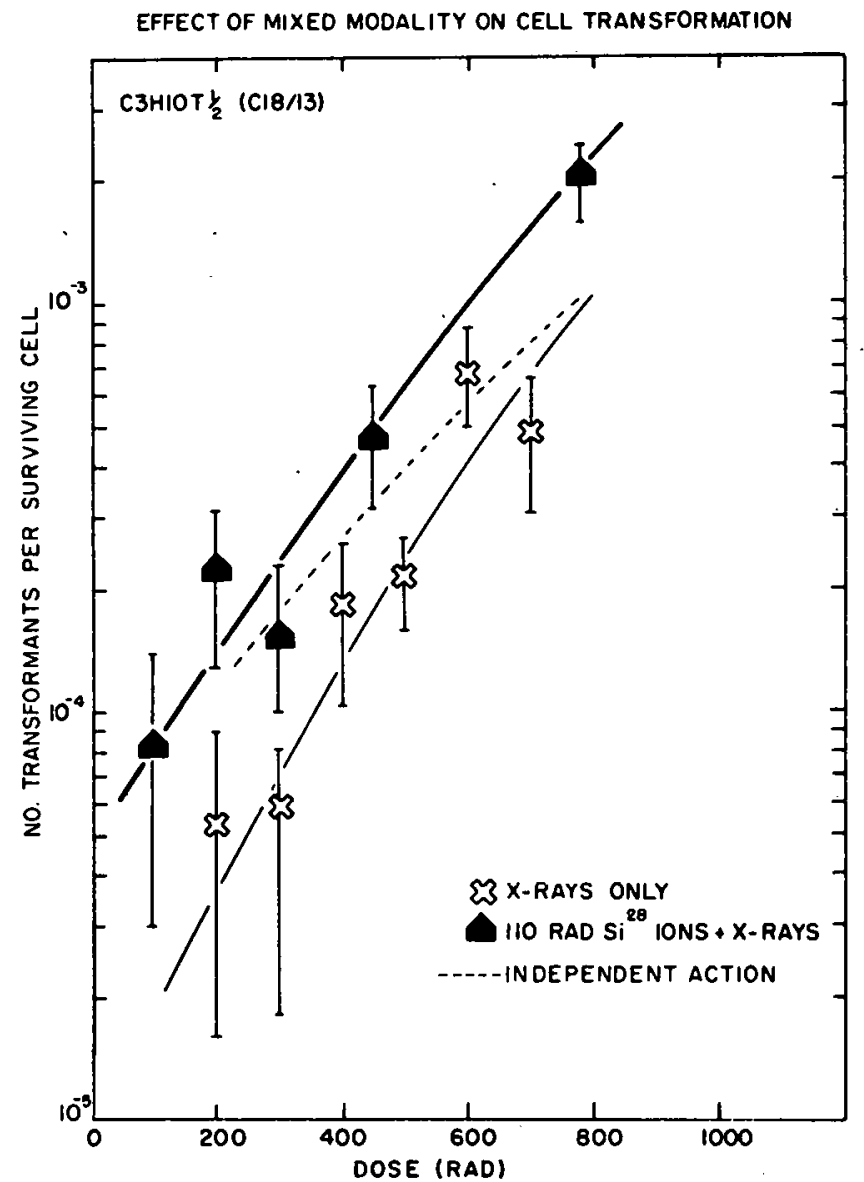

Fig. 5. Induction of neoplastic cell transformation by $x$ rays only or by a mixed radiation of $x$ rays and silicon ions.

(XBL 8311-4551)

5. Ngo, F.Q.H., Blakely, E.A., and Tobias, C.A. Radiat. Res. 87, 59-78 (1981).

6. Todd, P.W. Radiat. Res. 34, 378-389 (1968).

7. Bird, R.P., Zaider, M., Rossi, H.H., Hall, E.J., Marino, S.A., and Rohrig, N. Radiat. Res. 93, 444-452 (1983).

\section{NEW DEVELOPMENTS IN THE LETHAL, POTENTIALLY LETHAL MODEL}

\section{Stanley B. Curtis}

Two new aspects in the continuing development of the lethal, potentially lethal (LPL) model ${ }^{1,2}$ are described.

\section{LOW DOSE RATE}

At low dose rates, the assumption of "instanleous" production of initial lesions cannot be made. Lesions are being created, repaired, and misrepaired during the irradiation time itself. In this case, the differential equations describing the time rate of change for the potentially lethal and lethal lesions, respectively, are

$\mathrm{dn}_{B}(\mathrm{t}) / \mathrm{dt}=\eta_{\mathrm{AB}} \dot{\mathrm{D}}-\epsilon_{\mathrm{BA}} n_{B}(\mathrm{t})-\epsilon_{\mathrm{BC}} \mathrm{n}_{B}^{2}(\mathrm{t})$ 
$\mathrm{dn} C(\mathrm{t}) / \mathrm{dt}=\eta_{\mathrm{AC}} \dot{\mathrm{D}}+\epsilon_{\mathrm{BC}} \mathrm{n}_{\mathrm{B}}^{2}(\mathrm{t})$

Here, $\dot{D}$ is equal to the dose rate, $\eta_{A B}$ and $\eta_{A C}$ are equal to the rate of production with absorbed dose of potentially lethal and lethal lesions, respectively, and $\epsilon_{B A}$ and $\epsilon_{B C}$ are the repair and misrepair rates, respectively, for the potentially lethal lesions. The solutions of these equations, with initial conditions $n_{B}(0)=n_{C}(0)=0$, are

$n_{B}(t)=2 \eta_{A B} D(1-x) /(a+b x)$

$$
\begin{aligned}
n_{C}(t) & =\eta_{A C} \dot{D} t+\frac{\epsilon_{B A}}{\epsilon_{B C}} \log \frac{2 \epsilon_{o}}{a-1 b x} \\
& +\frac{\left(\epsilon_{0}-\epsilon_{B A}\right)^{2} t}{4 \epsilon_{B C}}-\frac{2 \eta_{A B} D(1-x)}{a+b x}
\end{aligned}
$$

where

$$
\begin{aligned}
& a=\epsilon_{0}+\epsilon_{B A} \\
& b=\epsilon_{0}-\epsilon_{B A} \\
& x=e^{-\epsilon_{0} t} \\
& \epsilon_{0}=\left[\epsilon_{B A}^{2}+4 \eta_{A B} \dot{D} \epsilon_{B C}\right]^{1 / 2}
\end{aligned}
$$

For short irradiation times, i.e., $t \ll 1 / \epsilon_{0}$, we see that $1-x$ approaches $\epsilon_{0} t$ and $a+b x$ approaches $a+b=2 \epsilon_{0}$, so that

$\mathrm{n}_{\mathrm{B}}(\mathrm{t})=\eta_{\mathrm{AB}} \dot{\mathrm{D}} \mathrm{t}=\eta_{\mathrm{AB}} \mathrm{D}$

and

$n_{C}(t)=\eta_{A C} D+\frac{\left(\epsilon_{0}-\epsilon_{B A}\right)^{2} t}{4 \epsilon_{B C}}-\eta_{A B} D$

At high dose rates, which can now be defined as the situation when $\left[4 \eta_{A B} \dot{D} \epsilon_{B C}+\epsilon_{B A}{ }^{2}\right]^{1 / 2} \gg 2 \epsilon_{B A}$, we find $n_{C}(t)=\eta_{A C} D$ and the initial assumptions of the previous treatment ${ }^{1}$ are satisfied.

For low dose rates, on the other hand, defined when $\dot{D} \ll \epsilon_{B A}{ }^{2} / 4 \eta_{A B} \epsilon_{B C}, \epsilon_{0}=\epsilon_{B A}$ and $a+b x=$ $2 t_{B A}$, we obtain

$\mathrm{n}_{\mathrm{B}}(\mathrm{t})=\frac{\eta_{\mathrm{AB}} \mathrm{D}\left[1-\mathrm{e}^{-\epsilon_{\mathrm{BA}} \mathrm{t}}\right]}{\epsilon_{\mathrm{BA}}}$

and

$\mathrm{n}_{\mathrm{C}}(\mathrm{t})=\eta_{\mathrm{AC}} \dot{\mathrm{D}} \mathrm{t}-\frac{\eta_{\mathrm{AB}} \dot{\mathrm{D}}\left(1-\mathrm{e}^{-\epsilon_{\mathrm{BA}} \mathrm{t}}\right)}{\epsilon_{\mathrm{BA}}}$
The total initial number of lesions, $n_{B}(t)+n_{C}($ is always $\eta_{A C} \dot{D} t=\eta_{A C} D$. Therefore, the survival is exponential with slope $D_{0}=1 / \eta_{A C}$.

\section{Comparison with Experimental Data}

The recent data of Wells and Bedford ${ }^{4}$ have been analyzed using the above formalism. They used $\mathrm{C} 3 \mathrm{H} 10 \mathrm{~T} 1 / 2$ cells in stationary (plateau) phase to study the variation in survival curve shape using dose rates of cesium-137 gamma rays ranging from $55.6 \mathrm{~Gy} / \mathrm{hr}$ to $0.06 \mathrm{~Gy} / \mathrm{hr}$. Using the following values of the model parameters, $\eta_{A B}=0.6 \mathrm{~Gy}^{-1}$, $\eta_{\mathrm{AC}}=0.1366 \mathrm{~Gy}^{-1}, \epsilon_{\mathrm{BA}}=0.5 \mathrm{hr}^{-1}, \epsilon_{\mathrm{BA}} / \epsilon_{\mathrm{BC}}=9$, a comparison of the calculated curves with the experimental data is shown in Fig. 1 . The agreement between the experimental dald and the model calculations appears reasonable.

With the above values of the parameters, the following regions of dose rates can be defined for the $\mathrm{C} 3 \mathrm{H}$ 10T1/2 cell line: The high dose rate region includes dose rates $\dot{D} \gg 1 \mathrm{~Gy} / \mathrm{hr}$, and the low dose rate region includes dose rates $\dot{D} \ll 1 \mathrm{~Gy} / \mathrm{hr}$.

\section{SUBLETHAL AND POTENTIALLY LETHAL} DAMAGE IN THE LPL MODEL

The survival equation in the LPL model can be written

$S=\exp \left[-n_{B}\left(n_{O B}, t\right)-n_{C}\left(n_{O C}, t\right)\right]$

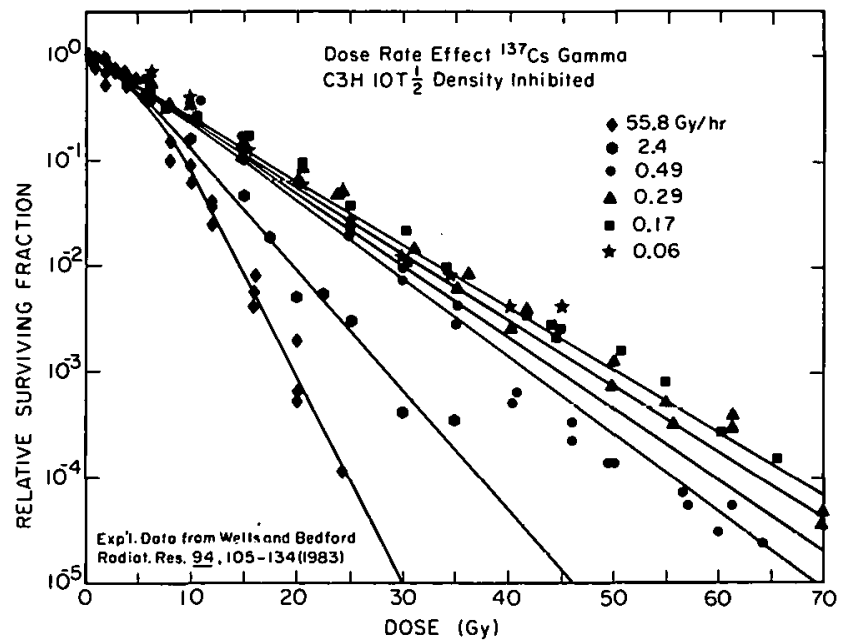

Fig. 1. Comparison of survival curves calculated from the $L P L$ model (solid curves) and the experimental data from $\mathrm{C} 3 \mathrm{H}$ $10 T 1 / 2$ density inhibited cells irradiated with ${ }^{137} \mathrm{Cs}$ gamma rave obtained by Wells and Bedford." Parameters in the model we $\eta_{A C}=0.1366 \mathrm{~Gy}^{-1}, \eta_{A B}=0.6 \mathrm{~Gy}^{-1}, \epsilon=9$, and $\epsilon_{B A}=0.5 \mathrm{hr}^{-1}$. 
th:

$\mathrm{n}_{\mathrm{B}}\left(\mathrm{n}_{\mathrm{OB}}, \mathrm{t}\right)$

$=n_{O B} \exp \left(-\epsilon_{B A} t\right) /\left\{1+\frac{n_{O B}}{\epsilon}\left[1-\exp \left(-\epsilon_{B A} t\right)\right]\right\}$

where $\mathrm{n}_{\mathrm{OB}}=$ the initial number of potentially lethal lesions produced by a dose, $D$, and

$n_{C}\left(n_{O C}, t\right)=n_{O C}+n_{O B}-n_{B}\left(n_{O B}, t\right)$

$$
-\epsilon \ln \left\{1+\frac{n_{O B}}{\epsilon}\left[1-\exp \left(-\epsilon_{B A} t\right)\right]\right\}
$$

where $\mathrm{n}_{\mathrm{OC}}=$ the initial number of lethal lesions produced by an absorbed dose, $D$, and $\epsilon=\epsilon_{B A} / \epsilon_{B C}$.

For simplicity, we will consider only stationary (plateau) phase cells. There is experimental evidence that in an immediate plating experiment, a considerable time period, $t_{o}$ (on the order of 3 hours), can be available for repair after plating. After this period, the remaining potentially lethal lesions are assumed in the model to be "fixed," perhaps by their passing through a "fixation" point in the cell cycle. Thus, the survival equation for an immediate plating experiment is

$S=\exp \left[-n_{B}\left(n_{O B}, t_{0}\right)-n_{C}\left(n_{O C}, t_{O}\right)\right]$

This reduces to

$S=\exp \left(-n_{O B}-n_{O C}\right)$

$$
\times\left\{1+\frac{n_{O B}}{\epsilon}\left[1-\exp \left(-\epsilon_{B A} t_{o}\right)\right]\right\}^{t}
$$

Similarly, for a delayed plating experiment when the cells remain in "conditioned" medium, an "infinite" time for repair is allowed and the survival expression reduces to

$S=\exp \left(-n_{O B}-n_{O C}\left[+\frac{n_{O B}}{\epsilon}\right]^{\epsilon}\right.$

For an experiment in which it is assumed that at some time after the experiment all repair is stopped and damage is fixed (e.g., with the use of IraA), we can write the survival as a funclion of lair time, $t_{\text {rep }}$
$S\left(D, t_{\text {rep }}\right)=\exp \left[-n_{B}\left(\eta_{A B} D, t_{\text {rep }}\right)-n_{C}\left(\eta_{A C} D, t_{\text {rep }}\right)\right]$

where we have assumed that the initial number of each kind of lesion is proportional to the absorbed dose, $\mathrm{D}, \mathrm{n}_{\mathrm{OB}}=\eta_{A B} \mathrm{D}$, and $\mathrm{n}_{O C}=\eta_{A C} \mathrm{D}$. This is the high dose rate approximation in Section I.

A calculation for Ehrlich ascites tumor (EAT) cells in vitro is made at $7 \mathrm{~Gy}$ for fresh and conditioned media and compared in Figs. 2 and 3. Figure 2 shows the time course of the lesions in each medium, and Fig. 3 shows the calculated survival compared with experimental data obtained by lliakis using $\beta$-araA as the repair inhibiting drug. ${ }^{3}$

For a split-dose experiment with interval $\Delta t$ between doses $D_{1}$ and $D_{2}$, we assume that the new lesions produced by the second dose add to the remaining lesions not yet repaired from the first dose and produce a new total number of lesions per cell. If the cells are plated immediately, the survival equation becomes

$$
\begin{aligned}
S\left(D_{1}, D_{2}, \Delta t\right) & =\exp \left\{-n_{B}\left[n_{B}\left(\eta_{A B} D_{1}, \Delta t\right)+\eta_{A B} D_{2}, t_{0}\right]\right. \\
& \left.-n_{C}\left[n_{C}\left(\eta_{A C} D_{1}, \Delta t\right)+\eta_{A C} D_{2}, t_{0}\right]\right\}
\end{aligned}
$$

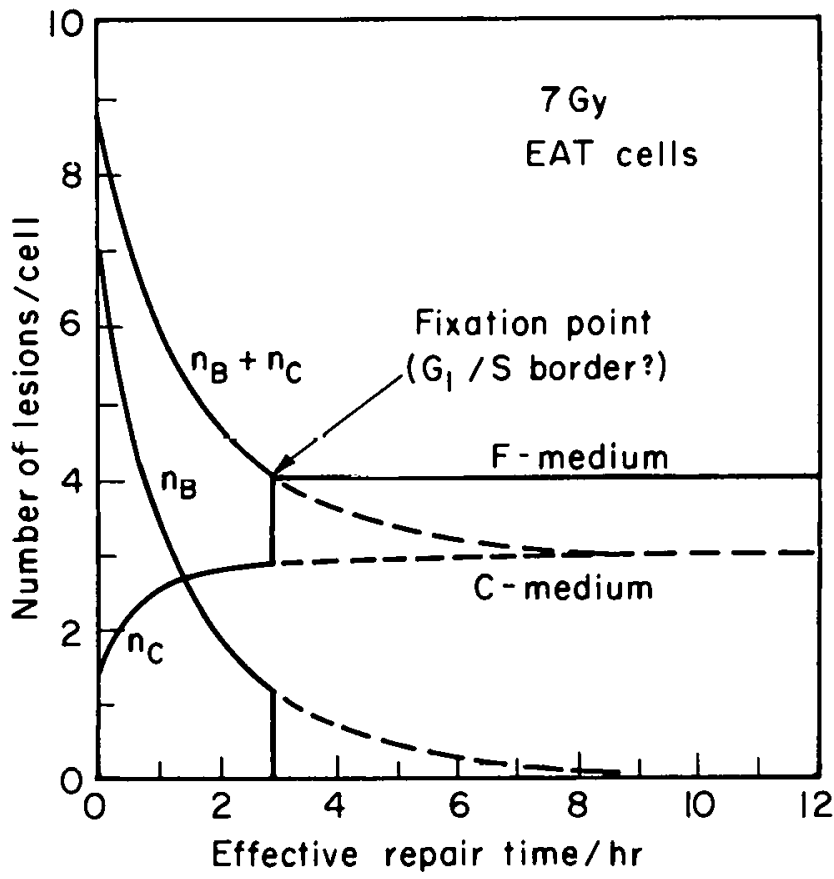

Fig. 2. A comparison of the time course of the mean numbers of lethal $(n)$ and potentially lethal $\left(n_{\theta}\right)$ lesions in $C$, "conditioned, (dashed line) and $F$, fresh, or growth medium (solid line) after an absorbed dose of $7 \mathrm{~Gy}$. A fixation point is assumed after three hours in fresh medium, i.e., all remaining potentially lethal lesions are fixed and become lethal at that point.

(XBL 837-10638) 


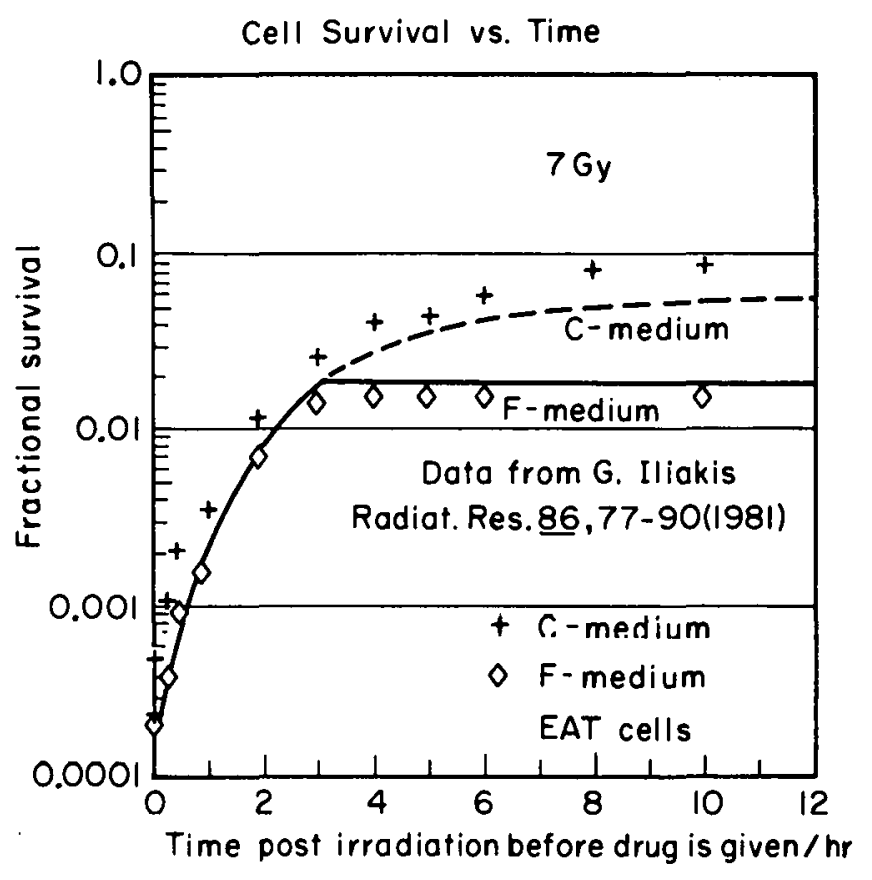

Fig. 3. Cell survival as a function of time in "conditioned" (dashed curve) or fresh (solid curve) medium after an absorbed dose of $7 \mathrm{~Gy}$. Comparison is made with experimental data from Ehrlich ascites tumor cells. ${ }^{3}$

(XBL 837-10639)

Here, repair is occurring both within the repair interval, $\Delta t$, and after plating occurs, during a time $t_{0}$.

Figure 4 gives the time course of lesions in conditioned medium (top) and fresh medium (bottom) for a split-dose experiment with a five-hour interval between doses. It is clear that after three hours in fresh medium, the time interval does not affect the final survival.

The lesions that are repaired (and misrepaired) in each type of experiment described above (delayed plating and split dose) are assumed to be the same. Thus, in this model the same (potentially lethal) lesions cause both "sublethal" and "potentially lethal" damage. A crucial consideration in the expression of the damage is the kind of medium in which the cells are placed during the repair period. Fresh or growth medium (F-medium) is assumed to cause fixation of damage after about three hours, while no fixation (only misrepair) occurs in conditioned medium ( $\mathrm{C}$-medium).

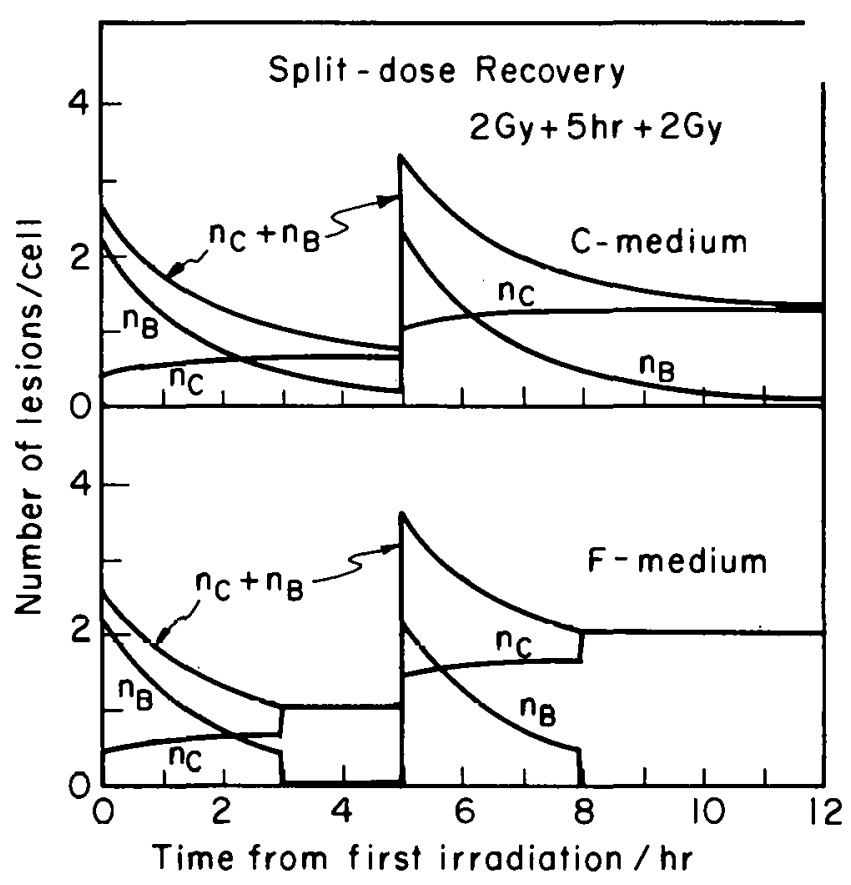

Fig. 4. Time course of the mean number of lethal ( $n$ ) and potentially lethal $\left(n_{B}\right)$ lesions for a split-dose recovery experiment in "conditioned" medium (top) and in fresh medium (bottom). The experiment assumes an absorbed dose of $2 \mathrm{~Gy}$ is followed by a repair period of five hours followed by another absorbed dose of $2 \mathrm{Cy}$.

(XBL 836-3802)

\section{REFERENCES}

1. Curtis, S.B. Ideas on the unification of radiobiological theories. Proceedings, 8th Microdosimetry Conference, October 1982, Julich, Germany. Lawrence Berkeley Laboratory report LBL-15193 (1983).

2. Curtis, S.B. The lethal, potentially lethal lesion model. Lawrence Berkeley Laboratory report LBL-16549 (1983).

3. Iliakis, G. Characterization and properties of repair of potentially lethal damage as measured with the help of $\beta$ arabinofuranosyladenine in plateau phase EAT cells. Radiat. Res. 86, 77-90 (1981).

4. Wells, R.L., and Bedford, J.S. Dose-effects in mammalian cells. IV. Repairable and nonrepairable damage in noncycling $\mathrm{C} 3 \mathrm{H} 10 \mathrm{~T} 1 / 2$ cells. Radiat. Res. 94, 105-134 (1983). 


\section{Biophysical Studies}

\section{BIOPHYSICAL STUDIES ON WHOLE RED BLOOD CELL. AND MEMBRANE SYSTEMS}

\section{Howard C. Mel, Gary V. Richieri, Frank Kooi, Steven P. Akeson, and James P. Yee*}

Studies focusing on whole red blood cells and their membranes are significant over the gamut of levels of biological organization from the ionic and molecular levels to the health status in complex human organisms. This is because biophysical and rheological properties, such as cell volume, form, deformability and fragility, are strongly influenced by the molecular structure of the membrane and the dynamics of the ionic and molecular traffic across the membrane (e.g., sodium and potassium transport) and by the cellular interactions with molecules, such as lipids, in the fluid bathing the membrane. These whole-cell properties, in turn, exert their own strong influence on higher-level physiology and human health. For example, vital blood flow is modified and regulated both by limiting cellular passage through restricted spaces of the microcirculation and by influencing bulk blood viscosity and flow.

This year we have further advanced the capabilities of the experimental techniques of resistive pulse spectroscopy (RPS) ${ }^{1,2}$ by developing useful new protocols for specific measurements, and by coordinating procedures for obtaining a matrix of independent yet interrelated properties. Table 1 presents such a matrix of cellular properties that

Table 1. How to measure properties by RPS.

\begin{tabular}{|c|c|c|c|c|c|c|c|c|}
\hline \multirow[t]{3}{*}{ Properties to be measured } & \multicolumn{8}{|c|}{ Essential independent control-variables ${ }^{\mathrm{a}}$} \\
\hline & \multicolumn{2}{|c|}{ Flow rate } & \multicolumn{3}{|c|}{$\begin{array}{c}\text { Electric } \\
\text { field strength }\end{array}$} & \multirow{2}{*}{$\begin{array}{c}\text { Osmotic } \\
\text { pressure } \\
\text { variat. }\end{array}$} & \multirow{2}{*}{$\begin{array}{c}\text { lonic } \\
\text { variat. }\end{array}$} & \multirow{2}{*}{$\begin{array}{l}\text { Temp. } \\
\text { variat. }\end{array}$} \\
\hline & Slow & Fast & Low & Med & $\mathrm{Hi}$ & & & \\
\hline \multicolumn{9}{|l|}{ Whole Cell: } \\
\hline $\begin{array}{l}\text { Size } \\
\text { Form }\end{array}$ & $\begin{array}{l}x \\
x\end{array}$ & & $\begin{array}{l}x \\
x\end{array}$ & & & & & \\
\hline \multicolumn{9}{|l|}{ Membrane: } \\
\hline $\begin{array}{l}\text { Deformability: } \\
\text { bimodality index }\end{array}$ & & $x$ & $x$ & & & & & \\
\hline $\begin{array}{l}\text { Osmotic } \\
\text { fragility } \\
\text { (kinetics) }\end{array}$ & & $x$ & & & $x$ & $x$ & & \\
\hline $\begin{array}{l}\text { Recovery } \\
\text { (kinetics) }\end{array}$ & $x$ & $x$ & & $x$ & & $x$ & & \\
\hline $\begin{array}{l}\text { Membrane } \\
\text { breakdown }\end{array}$ & $x$ & & $x$ & $x$ & & & & \\
\hline $\begin{array}{l}\text { Membrane } \\
\text { leakage }\end{array}$ & $x$ & $x$ & $x$ & & & $x$ & $x$ & \\
\hline \multicolumn{9}{|l|}{ Cytoplasmic: } \\
\hline $\begin{array}{l}\text { Deformability: } \\
\text { "form-shift" }\end{array}$ & $x$ & $x$ & $x$ & & & & & \\
\hline Conductance & $x$ & & $x$ & & $x$ & & & \\
\hline $\begin{array}{l}\text { Hb conc. and } \\
\text { state }\end{array}$ & $x$ & & $x$ & & $x$ & $x$ & & $x$ \\
\hline $\begin{array}{l}\text { Internal visc. } \\
\text { responses }\end{array}$ & $x$ & $x$ & $x$ & & & & $x$ & $x$ \\
\hline
\end{tabular}

a We display here only the minimum set needed for each property measurement.

-wount Zion Hospital, San Francisco, California. 
can now be determined from only a drop-sized blood sample, by taking advantage of the various different modes of the single technique of RPS.

The larger research goal is to organize this kind of information so we can use it to achieve a new and more detailed understanding of normal cell structure and function, which subsequently can lead to a better understanding of cell-membrane responses characteristic of specific disease states. Such information would be significant to identification (e.g., early diagnosis) as well as to management (e.g., following natural disease progression and responses to drugs) of blood-related diseases. Figure 1 illustrates how this approach is applicable to the investigation of a particular blood disease, sickle cell anemia. This figure presents a number of known or likely interrelationships between fundamental cellular properties and aspects of the disease. The full RPS characterization of the detailed differences between normal and sickle cells would be directly in line with this larger goal.

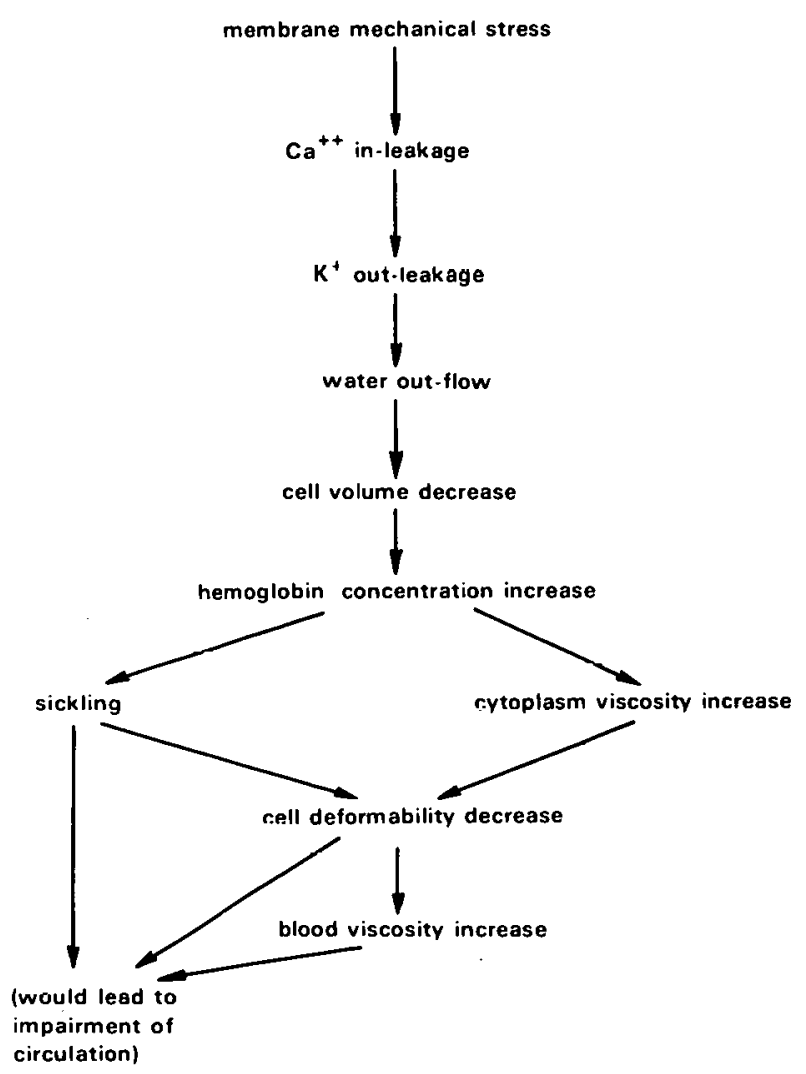

Fig. 1. Known or hypothesized interrelationships between various physical, chemical, and biomedical aspects of whole cells and membranes in sickle cell anemia.

(XBL 8310-4080)
VOLUME, SHAPE, DEFORMABILITY, AND ELECTRONIC CELL COUNTERS

The primary purpose of electronic cell "counters" is to obtain numbers (concentrations) of cells in suspensions. However, following calibration with standard particles (e.g., latex or polystyrene spheres), mean or modal cell volumes can also be obtained. For many applications cell shape is ignored in cell sizing. In more sophisticated usage, measured apparent size is corrected with a theoretical shape factor, calculated from an assumed model shape. ${ }^{3,4}$ Difficulties in evaluating cell shape have led to the frequent use of red blood cells themselves as standards for sizing red cells. ${ }^{5}$

The mathematical determination of volume and shape from an RPS-produced spectrum starls willi the assumption that the surface area of a cell is fixed and that the cell shape is restricted to a particular form class. For the present purposes we use the oblate ellipsoidal shape, which means that any change in volume results in a specific change in the so-called shape factor. The well-known relationship between the measured volume, true volume, and shape factor $\left(f_{E}\right)$ is:

$\operatorname{VOL}($ meas $)=\operatorname{VOL}($ true $) \times f_{E}$,

where $f_{E}$ for a sphere equals 1.5 .

We have derived several unifying theoretical relationships between these three factors; they depend on the independent variables: a (major semiaxis) and $b$ (minor semiaxis) and on the $a / b$ ratio.

By dividing Eq. (1) with a similar equation for spheres we obtain:

$\frac{V O L(\text { meas })}{\operatorname{VOL}(\text { meas }- \text { max })}=\frac{V O L(\text { true })}{V O L(\text { true }- \text { max })} \times \frac{f_{E}}{1.5}$

From this equation two particularly useful additional relationships can be derived by proceeding as follows: a) tabulate the magnitudes of the factors in Fq. (2) for many different $a / b$ ratios; b) plot the two relationships: $f_{E}$ versus VOL(true)/VOL(true-max) (Fig. 2), and $\mathrm{VOL}$ (meas)/VOL(meas-max) versus VOL(true)/VOL(true-max) (Fig. 3); and c) obtain by computer the best fourth-order polynomial equations fitting the curves. Proceeding in this way, we arrive at the equations:

$$
\begin{aligned}
\frac{\text { VOL(true) }}{\text { VOL(true-max) }} & =-2.979\left(f_{E}\right)+15.206\left(f_{E}^{2}\right) \\
& -10.576\left(f_{E}^{3}\right)+2.210\left(f_{E}^{4}\right)
\end{aligned}
$$




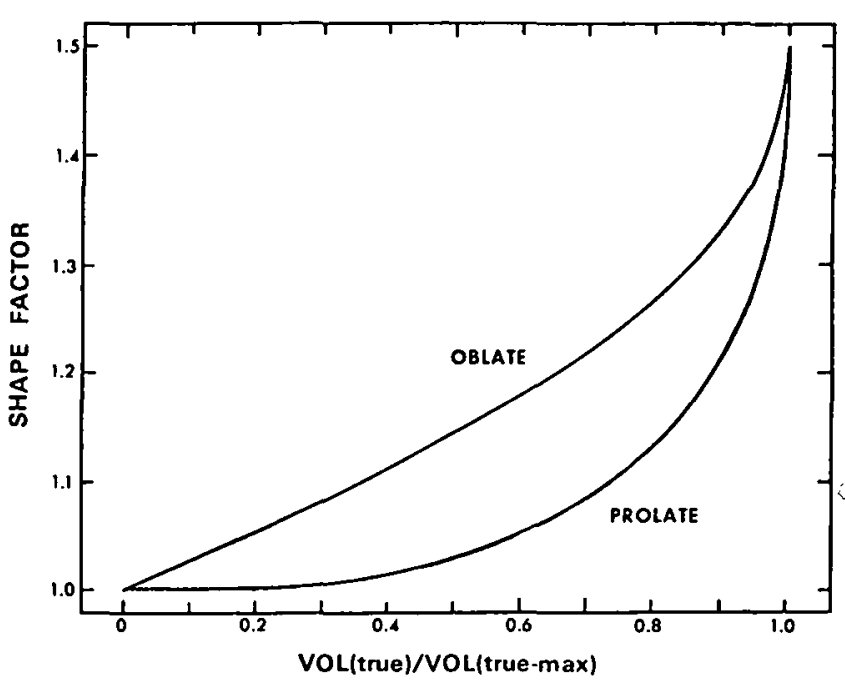

Fig. 2. The theoretical shape factor vs. relative true volume for oblate and prolate ellipsoids of revolution having constant surface area.

(XBL 8310-4081)

$$
-3.787
$$

(correlation coefficient for fit of data: $r=0.9988$ ), and:

$$
\begin{aligned}
\frac{\mathrm{VOL}(\text { true })}{\operatorname{VOL}(\text { true }-\max )} & =1.544(X)-0.854\left(X^{2}\right) \\
& +0.846\left(X^{3}\right)-0.531\left(X^{4}\right) \\
& -0.0014
\end{aligned}
$$

where $X$ is $\operatorname{VOL}(m e a s) / V O L(m e a s-m a x)$, (and $r=$ 0.9999).

By applying these equations and Figs. 2 and 3 to normal red blood cells in isotonic medium, we obtain the following values:

$\operatorname{VOL}($ true $)=88.2 \pm 1.0 \mu^{3} ;$

shape factor $=1.19 ; a / b=3.61 ; a=4.24 \mu$;

$\mathrm{b}=1.17 \mu ;$ surface area $=130 \mu^{2}$

This calculated isotonic "true volume" is essentially identical with the generally accepted value of $87 \mu^{3}$ with a normal range of from 82 to $94 \mu^{3} \cdot 6,7$ -ie calculated shape factor of 1.19 is also very ose to that reported by others for native red viood cells. ${ }^{8-10}$

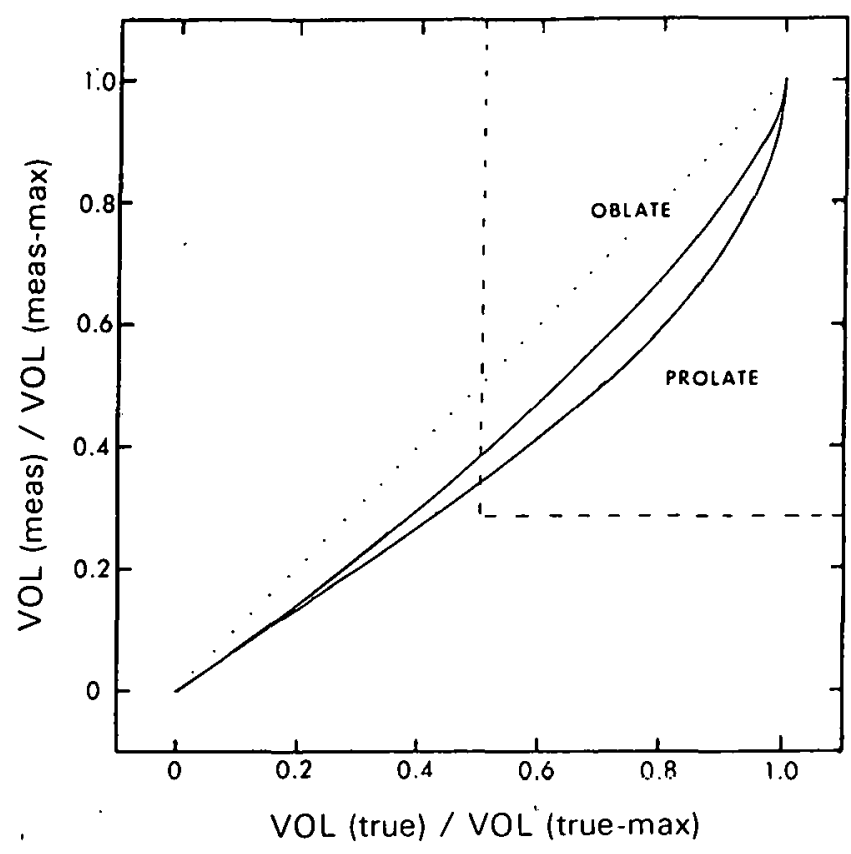

Fig. 3. The theoretical relationships between relative true volume and relative measured volume for oblate and prolate ellipsoids of revolution having constant surface area.

(XBL 8310-4082)

RPS-type cell sizers are typically operated in a "fast-fluid-flow" mode, which leads to elongation of the red cells. This is demonstrated by sizing cells at slow and fast flow, then calculating the change in shape between these two flows. In Fig. 4 this shift in form is demonstrated experimentally for cells suspended in many different

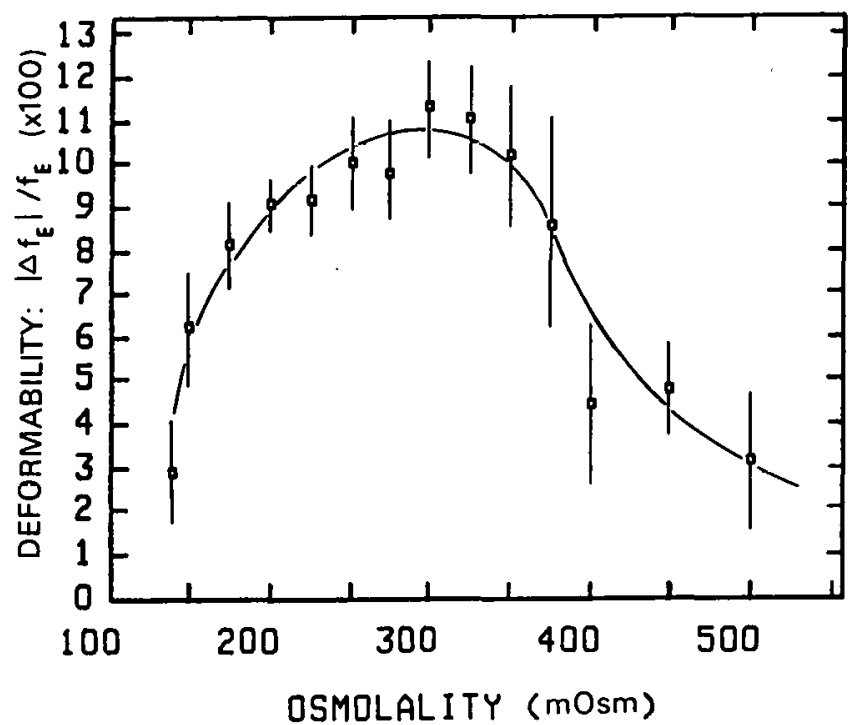

Fig. 4. Flow-rate-induced or "form-shift" deformability (i.e., change in relative form factor), as a function of osmolality, measured for red blood cells in PBS at $40^{\circ} \mathrm{C}$.

(XBL 8310-4083) 
osmolalities. The greatest ability to change form is seen to occur near isotonicity $(300 \mathrm{mOsm})$. This result is very similar to that obtained for another kind of RPS deformability measure ${ }^{11}$ (the so-called "bimodality index"), which also indicates that at isotonicity the red cells are "naturally" more deformable.

\section{TEMPERATURE}

It has long been known that temperature is a major factor in red cell fragility, resulting in resistance to hemolysis that increases with increasing temperature (Fig. 5). Two of the most commonly invoked explanations are 1) that the surface area of the cell increases with temperature (thereby increasing the relative surface-to-volume ratio, making the cells more resistant to hemolysis), or 2) that temperature influences the volume of the cell (a colder temperature increases the volume, thereby reducing the relative surface-to-volume ratio and consequently increasing the fragility).

By using the improved RPS volume=determination technique, we have found that the surface area remains constant with a change in temperature, but that the volume of the cell increases as the temperature is lowered (Fig. 6). Although such a change in volume will affect fragility as just indicated, the amount of volume change found is not nearly sufficient to explain the large fragility differences measured. Therefore, some other mechanism must be at work. Our goal in

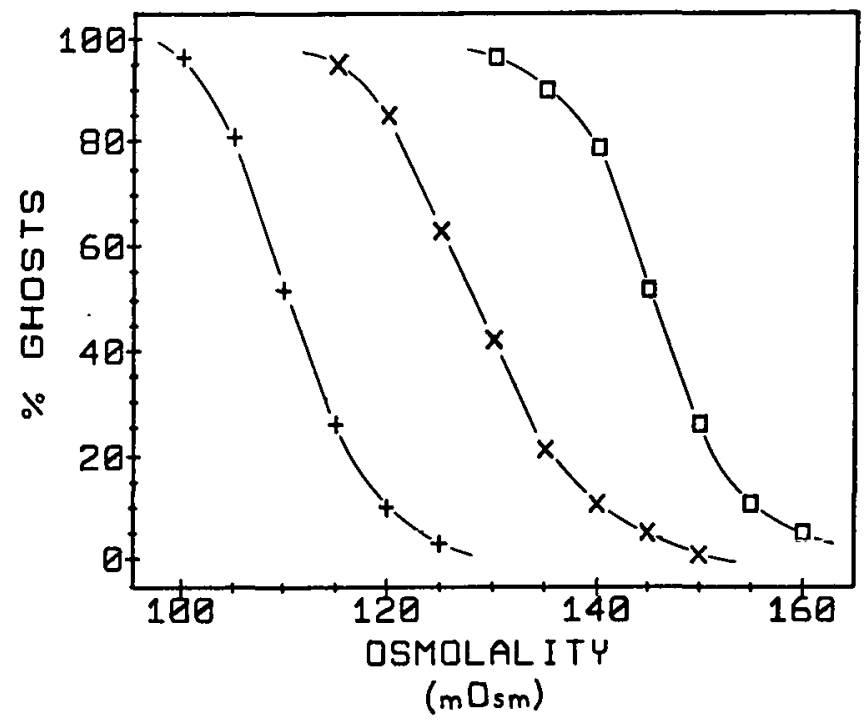

Fig. 5. Temperature dependence of osmotic fragility in diluted solutions of phosphate buffered saline. The red cell concentration is approximately $2 \times 10^{5} \mathrm{RBC} / \mathrm{ml}$. (+ at $40^{\circ} \mathrm{C} ; \mathrm{X}$ at $20^{\circ} \mathrm{C} ; \square$ at $0^{\circ} \mathrm{C}$.

(XBL 8310-4084)

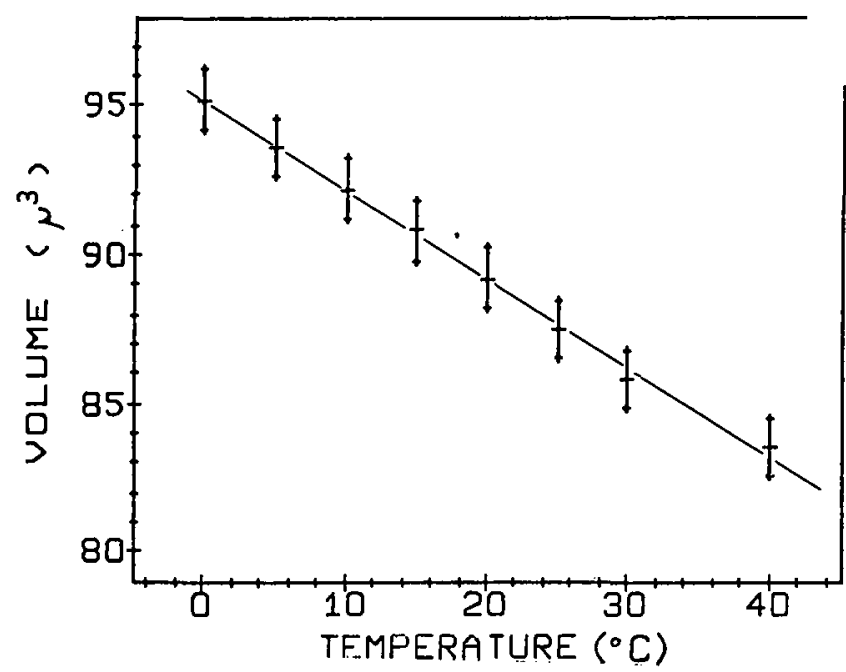

Fig. 6. Calculated "true" volume (slow flow and oblate approximation) as a function of temperature for $R B C$ at 300 mOsm PBS, assuming constancy of surface area.

(XBL 8310-4085)

this work for the coming year is to understand this mechanism.

\section{BIOMEDICAL APPLICATION: DETERMINATION OF FETAL MATURITY}

The leading cause of neonatal mortality in advanced nations of the world is the condition called "respiratory distress syndrome." This condition is a function of the degree of immaturity of the fetus and is a direct result of deficiency at birth of surface active material (surfactant) produced by the fetal lung. For premature births the levels of surfactant materials in the amniotic fluid are taken as an indicator of readiness for birth, but tests to determine these levels suffer variously from imprecision, inconvenience, and other problems. We wished to ascertain the feasibility of developing a rapid, sensitive, quantitative test of fetal maturity, based on measurable RPS responses of normal RBC (used as test probes) to the lipid/surfactant present in amniotic fluid. (Biochemically, the bulk of this surfactant consists of lecithin, the major surfaceactive component of which is saturated phosphatidylcholine.)

The specific RPS test we selected for a pilot study was dynamic osmotic hemolysis $(\mathrm{DOH})$, to determine changes in red blood cell osmotic fragility induced by various levels of amniotic fluid (AF). Initial results of this study are given in Fig. 7. They can be summarized as follows: 1) Incubation with AF for 40 to 70 minutes does affect the osmc " fragility of normal RBC, reducing the fragility all 1 more as the concentration of AF increases. 2) Tilus 


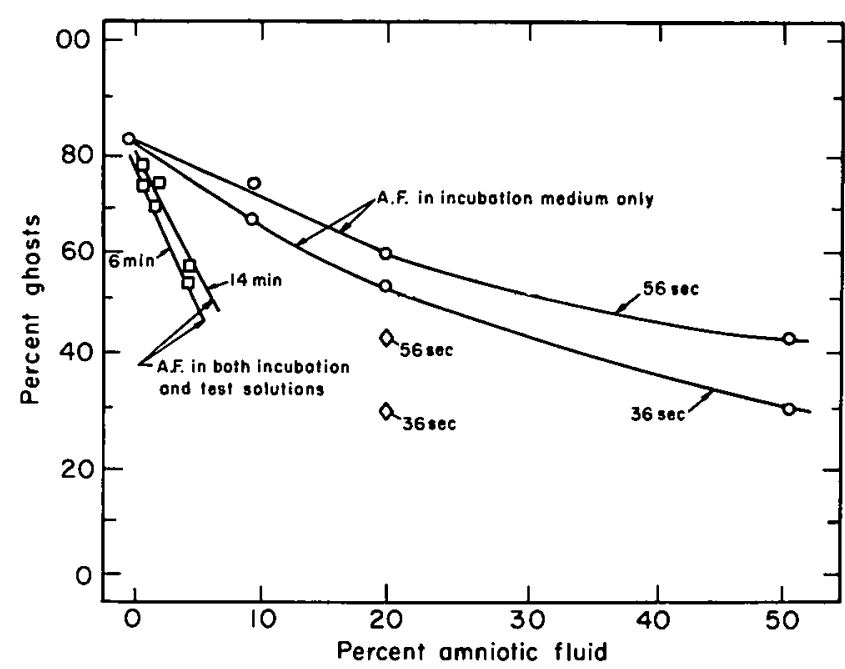

Fig. 7. Osmotic hemolysis of normal red blood cells and extent of protection induced by graded concentrations of amniotic fluid. $O$ and $\diamond$ represent amniotic fluid from two different individuals. The larger protection associated with the $\square$ points results from having the A.F. present in both the incubation and test medium.

(XBL 8310-4079)

effect reverses itself quite rapidly; if the AF is not also present during the measurement process, only about one quarter of the protection remains 60 seconds after start of the measuring process. 3) The extent of osmotic protection varies considerably among specimens from different individuals.

These results indicate that it is feasible to proceed with this approach to develop a method for determining fetal maturity.

\section{REFERENCES}

1. Mel, H.C., Akeson, S.P., Richieri, G., Rabinovici, S., Peros, S., and Lininger, D. Fundamental and applied studies on red hlood cellmembrane systems. pp. 120-125, in Biology and Medicine Division Annual Report 1980-81, LBL-13501, April 1982.
2. Mel, H.C., Akeson, S.P., Richieri, G., and Kooi, F. Fundamental and applied studies on cell-membrane systems. pp. 92-95, in Biology and Medicine Division Annual Report 1981-82, LBL-14986, April 1983.

3. Kachel, V. Electrical resistance pulse sizing (Coulter sizing). In Flow Cytometry and Sorting, eds. Melamed, Mullaney, and Mendelsohn. J. Wiley and Sons N.Y., pp. 61-104 (1979).

4. Velick, S. and Gorin, M. The electrical conductance of suspensions of ellipsoids and its relationship to the study of avian erythrocytes. J. Gen. Physiol. 23, 753-771 (1940).

5. Williams, W.J., and Schneider, A.S. Hematology, Chapter 2: Examination of the Peripheral Blood. Ed. Williams, Beutler, Erslev, and Rundles, McGraw-Hill, N.Y., second edition (1972).

6. Wintrobe, M.M., Lee, G.R., Boggs, D.R., Bithell, T.C., Athens, J.W., and Foerster, J. Clinical Hematology. Lea and Febiger, Philadelphia, seventh edition (1974).

7. Ponder, E. Hemolysis and Related Phenomena, Grune and Stratton, N.Y., second edition (1971).

8. Gregg, E.C., and Steidley, K.D. Electrical counting and sizing of mammalian cells in suspension. Biophys. J. 5, 393-405 (1965).

9. Golibersuch, D.C. Observation of aspherical particle rotation in poiseuille flow via the resistive pulse technique. I. Application to human erythrocytes. Biophys. J. 13, 265-280 (1973).

10. Grover, N.B., Naaman, J., Ben-Sasson, S., and Doljanski, F. Electrical sizing of particles in suspensions. III. Rigid spherodic and red blood cells. Biophys. J. 12, 1099-1116 (1972).

11. Mel, H.C., and Jung, D.G. Isotonicity and red cell-membrane deformability. Biophys. J. 21, 119a (1978).

\section{NEW THERMODYNAMICS RESEARCH: GLOBAL THERMODYNAMIC POTENTIAL FUNCTIONS FOR NONEQUILIBRIUM, OPEN SYSTEMS}

\section{Howard C. Mel and Peter S. Geissler}

During the year's work on global thermodynamic potential functions, a new such function is unexpectedly discovered, a function valid for eversible thermodynamic analysis of complex wemical reaction systems operating far from equili- brium, including enzymatic and other biochemical reaction networks.

Previous work by Mel and Geissler enabled thermodynamic analysis of far-from-equilibrium, open systems involving unstable and multistationary 
states based on the first such function discovered, the $\Phi$ function. The proven properties of $\Phi$ empowered it to serve as a global indicator of stability and to identify the location of the dividing line or "separatrix" in a mixed stable-unstable domain (not previously possible by thermodynamic means). These properties of $\Phi$ follow from basic thermodynamic and chemical kinetic considerations of series of the one- and two-body interactions that form complex reaction systems.

All aqueous biochemical reaction systems involve a series of such individual reactions; that is, if written in their most elementary form, there should be, at most, two reacting species for any individual reaction. An exact computer analysis of such a reaction system requires a detailed knowledge of the rates of each elementary step. This level of description is often not available for enzymatic reactions, for example, a series of rapid two-body interactions may appear experimentally as one "simultaneous" three-body interaction.

The new potential function, which is conceptually closely linked to (but distinctly different from) Prigogine's "entropy production per unit time," $P$, serves two purposes: 1) it permits relaxing the requirement that the individual reactions be strictly "elementary" (i.e., two-body interactions), in favor of a more general "flow-through" requirement of network topology; 2) in taking its place beside $\Phi$, it adds insight into the actual and permitted interrelationships between the various global thermodynamic potential functions: entropy and the "affinity squared minimum function," 1 as well as $P$ and $\Phi$.

The new function, called $\Phi$, has several important properties, one of which is that it serves as a global indicator of stability and instability. It also has a simple physical interpretation, based upon the differential form of the defining relation in terms of the reaction velocities, $v_{i}$, and affinities, $A_{i}$ :

$$
d \mathbb{Q} / d t=\sum_{i=1}^{n} v_{i} d A_{i} / d t
$$

$\mathrm{d} / \mathrm{dt}$ is evidently a measure of the time rate change of $\$$ resulting from kinetically weightcu changes occurring to the affinities during any irreversible process. Its integral, $\boldsymbol{\Phi}$, is interpreted as that portion of the entropy production due to changes in the affinities, alone.

The discovery of the state function, $\Phi$, with its exact differential, has been useful in affording a physical interpretation to Prigogine's inexact differential for the entropy production:

$$
d_{x} \mathscr{P}=\sum_{i=1}^{n} v_{i} d A_{i}
$$

This well-known inexact differential can be viewed as the local change per unit time of $\Phi$ along a particular trajectory connecting the state of the system in phase space with the final end point of the system's irreversible evolution.

The $\Phi$ function is significant because it permits thermodynamic analysis of less-precisely-defined far-from-equilibrium biochemical processes, based upon the properties of exact, rather than of inexact, differentials. Thus, these irreversible processes can be analyzed by methods analogous to those of the thermodynamics of quasi-static and linear processes. The new function joins with $\Phi$ in enabling the modeling of such unstable/multistable stationary state biological systems as the differentiation of pluripotential stem cells or the "switching" between oxidative and glycolytic metabolism.

\section{REFERENCE}

1. Mel, H.C., and Ewald, D.A. Thermodynamic potentials and evolution towards the stationary state in open systems of far-from-equilibrium chemical reactions: The affinity squared minimum function. J. Mathematical Biology 1, 133-151 (1974). 


\section{SECTION 5. STRUCTURAL BIOPHYSICS}

\section{INTRODUCTION}

The research projects in this group are eclectic and reflect the multiplicity of research interests in the areas of macromolecular structure, cell biology, cell ultrastructure, control of genetic information, and lipid metabolism. A common trend in many of the research approaches is the use of biophysical techniques to resolve biological problems. At least five major research areas are grouped under the general heading of structural biophysics:

- Ultrastructure research

- Studies on lipoproteins and other macromolecules

- DNA and genetic studies

- Cell culture studies

- Carcinogenesis

Ultrastructure research continues a very fertile tradition of advancing the methodology of electron microscopy and of applying electron microscopy to biological problems. Robert Glaeser and his associates have made substantial contributions to the field of transmission electron microscopy and the application of computerized three-dimensional reconstruction of EM images. Ken Downing carried out experiments that showed that lowering the temperature of an EM sample protects the sample from radiation damage. A very important observation from these investigations indicated that maximum beneficial cooling properties were achieved at liquid nitrogen temperatures. Additional cooling to liquid helium temperature did not significantly protect the test samples. These studies establish the usefulness of reduced temperatures in preserving EM structure in biological samples and set limits on the range of sample cooling. Bing Jap used a dual approach of biochemistry and transmission electron microscopy to unravel the ultrastructure of the bacteriophage lambda receptor protein. The membrane receptor protein was isolated and reconstituted with phospholipid. EM images were used to reconstruct the structure of the protein by computer processing techniques. The latter approach was also used by Wennie $\mathrm{Wu}$, who has just completed her graduate studies with Robert Glaeser. Using frozen hydrated samples of the highly ordered surface protein of the bacterium $\Delta$ ruaspirillum serpens, she was able to obtain ,h resolution EM images which provided unusual ....ee-dimensional images. Three-dimensional con- tours of the crystalline protein arrays revealed that they had a mushroom-like shape. Significant studies have been made in scanning election microscopy (EM) methodology and its application by Thomas Hayes and his associates. Jacob Bastacky is developing techniques to allow direct quantitation of 3-dimensional structures in SEM. In order to develop this methodology it is first necessary to assess tissue shrinkage during various SEM tissue preparation steps. Preliminary work by Bastacky with lung tissue indicates that during the criticalpoint drying step very significant shrinkage occurs with up to $51 \%$ volume-loss of lung tissue. This finding demonstrates the obvious need for critically examining tissue changes before morphometric analysis can be undertaken. In the area of applications of SEM to biological problems, Gregory Finch, who is completing his studies with Thomas Hayes, has developed an in vitro model for evaluating particulate airway injury. The model consists of guinea pig tracheal explants which are easy to maintain in organ culture and lend themselves well to SEM and $x$-ray microanalysis. The latter approaches are also being employed by Susan Kline, a graduate student of Thomas Hayes, who is tracking the migration of embryonic mesenchymal cells of sea urchins.

The application of biophysical techniques to the study of structure and function of biological macromolecules continues to be a strong area of research for several staff members. Marcos Maestre and his colleagues have developed a method of analyzing differential scattering of circularly polarized light. This methodology will be important in determining the circular dichroism pattern of complex macromolecules such as membranes and DNA aggregates. John Owicki has developed a model system in which to study physical and chemical alterations occurring during antibody-antigen interaction. Artificial phospholipid vesicles were formed and fluorescein was incorporated as a probe that acts as an antigen. A monoclonal antibody was produced against fluorescein. The kinetics of interaction between the model antigen and antibody were studied and provided interesting insights into the nature of the membrane and the immune response. Clearly the lipid composition of the membrane can dramatically affect antigen-antibody interactions. An artificial membrane system consisting of phos- 
pholipid and bacteriorhodopsin (bR) was developed by Jap and Glaeser to test the sensitivity of the $b R$ protein pump to the ATPase inhibitor, dicyclohexylcarbodiimide. Unlike the native membranes, the artificial system displays great sensitivity to this inhibitor, which can be used as a biochemical probe for the proton pump. In vitro model systems have also been extensively used by Alex Nichols and his colleagues to study lipoprotein structure and function. In the present summary he describes an apolipoprotein-phospholipid model that mimics "nascent" or discoidal high density lipoproteins (HDL) that are believed to be secreted by the human liver. The model "nascent" HDL incubated in the presence and absence of plasma enzymes provide new insights into the formation of mature or spherical HDL.

In addition to studies with macromolecular models of lipoproteins, investigations were also carried out on the physical properties of lipoproteins and on metabolism of lipoproteins. Talwinder Kahlon and Frank Lindgren carried out a very careful series of studies on the effects of ionic strength on the physical properties of low density lipoproteins (LDL). They were able to show that high salt adversely affects the hydration state of these macromolecules. Such information will be useful in guiding other investigators in their approach for isolating LDL. Trudy Forte and colleagues continue to explore the unique properties of cord blood lipoproteins. They have shown that the cord blood LDL possess an unusual distribution of the major LDL apoproteins called, B-100. This protein in cord blood forms several variants of smaller molecular weight and the amount of this material increases with increasing density of the particles. The finding suggests that LDL-protein undergoes processing during metabolism in vivo. In another unusual approach to lipoprotein studies, Forte has been studying lipoproteins isolated from lung lymph of sheep. This lymph is a close approximation of interstitial fluid that bathes cells and tissue. The lipoproteins from lymph, particularly the HDL, are unlike those of plasma. The altered chemical and physical properties of lymph HDL suggest that the particles are remodeled following interaction with cells. Free cholesterol is increased in lymph $\mathrm{HDL}$ which may serve as a vehicle for reverse cholesterol transport.

Research into DNA structure and regulation continues to be a strong endeavor in the Structural Biophysics Group and significant new advances have been made in the current year. Robert Mortimer and his associates report on several new yeast
DNA repair genes that they have uncovered in 1 RAD50 to RAD57 region. Many of these nevv genes are now under intensive investigation and, where possible, they are being cloned. The studies add significant new contributions to the genetic maps previously constructed by Mortimer and his group. The RAD50 gene that is involved in DNA repair in yeast is also required for meiotic recombination. In order to understand the role of RAD50 gene product in the entire timing process of meiotic recombination, Game and Mortimer are studying a cold-sensitive RAD50 mutant. This mutant is extremely useful since one can change incubation temperatures during meiosis and thus obtain an estimate of time required to generate the gene product in question. David Schild has been investigating the photoreactivation PHR1 gene of yeast at the molecular level. He has succeeded in cloning the gene and has used the clone to locate this elusive gene on the chromosome XV. New insights into understanding some of the factors that control both mitotic and meiotic recombination in yeast have been made by Michael Esposito and colleagues. To carry out their sophisticated experiments they employed the spoll-1/spoll-1 diploid yeast mutant. Over the past several years, Junko Hosoda has been very successful in isolating and characterizing major DNA binding protein from bacleriophage T4. This protein is known as gene product 32 (gp32). She has demonstrated that the protein has two functional domains, a carboxy terminal one of 50 amino acid residues, and an amino terminal one of 20 amino acids. The protein has strong tendencies to self-aggregate, and this property was investigated by affinity chromatography techniques. The experiments clearly established that the self-association property resided in the carboxy terminal end of the gp32 protein.

New and interesting approaches on cell control of growth, differentiation, and metabolism are being carried out by several groups using primary cell cultures or cell line cultures. Martha Stampfer and lack Bartley have successfully developed a serumfree defined medium in which to continuously culture human mammary epithelial cells. Only small subpopulations of cells are, in fact, able to grow continuously. These subpopulations were examined in order to be certain that they are functional epithelial cells and not an abnormal cell type. The continuously growing cells are probably derived from an epithelial stem cell and thus have biological properties of mammary epithelial cells. These epithelial cell cultures will be very valuable future research to study cell function and carcil 
?nesis. At the present time the above investigaiurs are using the mammary epithelial cultures to develop a screening method for carcinogenic agents. Although still in preliminary stages these investigators found that the cells undergo partial transformation when subjected to benzo(a)pyrene. Some of the mutated cells have been very useful as potential test systems in which to assay for tumor promoters. A different source of mammary epithelial cell cultures is being used by Gordon Parry, Mina Bissell, and their associates. They are using mouse mammary cells to study synthesis of extracellular matrix material (basal lamina). The ultimate goal of their studies is to understand what influences the composition of the basal lamina and how the basal lamina in turn influences function of the cells. This approach is certainly one of the key issues in understanding the metastatic process. Important results have been obtained that show that the substrate on which the cells grow regulates the distribution of the major glycosaminoglycans in the basal lamina. A human hepatoma-derived cell line, HepG2, is now being successfully used by Richard Thrift and Trudy Forte to study cholesterol metabolism and control of lipoprotein synthesis. This research has direct application to the problem of hyperlipidemia and atherosclerosis. Studies with the HepG2 cells suggest that the cells will be useful models of human liver cells for studies related to secretion of high density lipoproteins. This lipoprotein is the major nascent lipoprotein secreted by $\mathrm{HepG} 2$ and is an important protective agent in atherosclerosis. The Madin canine kidney cell line was used as a model to study changes in plasma membrane lipids during transformation of cells induced by phorbol esters. To carry out the studies, Packard, Bissell, and Klein developed a new fluorescent phospholipid probe, Collarein. The fluorescent tag revealed that cells treated with tumor promoters exhibited a change in membrane mobility. Changes in extracellular matrix secreted by primary avian tendon cells in culture were investigated by Robinson and Bissell as a function of time in culture and presence of ascorbate. Both these parameters had profound effects on the composition of extracellular matrix. Initial studies with virus-transformed cells indicate that the pattern of extracellular matrix is also greatly altered following virus-induced changes in the cells. Dolberg, Bissell, and their associates also studied the relationship between RSV virus infection and tumor formation in embryonal chick tissue as a function of age. nbryonic cells infected at early developmental ages in ovo appear to have normal phenotypes and are refractory to tumors. If these same young cells are isolated, plated, and then infected, they become transformed. This very interesting observation suggests that there is some factor in the embryonic environment that suppresses tumorigenesis.

The toxic effects of monofunctional alkylating agents were tested on Chinese hamster ovary cells in culture by Regine Goth-Goldstein. N-methyl-Nnitro-N-nitroso-guanidine (MNNG) at low doses is extremely toxic and cell killing is $98 \%$. The surviving $2 \%$ of cells appear to be resistant. Experiments were carried out with cloned survivors in an attempt to understand why these cells are resistant. Resistance appears not to be due to a mutation but may be due to an inducible process that makes the cells permanently resistant. The effect of MNNG and other mutagens on $E$. coli cells is the subject discussed by Priscilla Cooper and her colleagues. They have found that the DNA of cells resistant to the alkylating agent has undergone excision repair, which makes the surviving cells more resistant. Such repair mechanisms may have been induced by the chemical's insult to the cell's metabolic process.

In a very elegant approach to understanding chemical carcinogenesis in human mammary epithelial cells, Bartley and Stampfer have used their human cell system to determine what factors contribute to the process. The well known carcinogen, benzo(a)pyrene ( $\mathrm{BaP}$ ) was used as a test system. This compound is metabolized by cells to epoxide forms, which are highly carcinogenic. A significant finding was that in the mammary cells prostaglandins play a critical role in enhancing peroxidation of $\mathrm{BaP}$ leading to the formation of $\mathrm{a}$ potent ultimate carcinogen. The precursors for prostaglandins are polyunsaturated fatty acids such as arachidonic acid that are highly susceptible to oxidation. This observation is very consistent with the known link between high levels of dietary polyunsaturated fatty acids and increased breast cancer risk.

Joyce McCann and her associates are continuing to develop methods for analyzing published data on mutagenic or carcinogenic potency of various chemicals as determined in short-term tests such as the Ames Salmonella test. The reason for such a need is obvious when one considers the increasing numbers of chemicals and food substances being assessed as possible mutagens. Their numbers become staggering and long-term animal tests, which are perhaps more reliable, are out of the question. How to order the glut of information 
on short-term studies and how to draw conclusions on the mutagenicity based on reported short-term studies are the subjects of the report by the above authors. Lois Gold and her colleagues have made great strides in establishing a data base on which to analyze carcinogenic potency of chemicals animal bioassays. Described in their report is tic $\mathrm{TD}_{50}$ numerical index for carcinogenic potency which they have developed as a means of assessing various types of published reports on bioassays.

\section{Ultrastructural Research}

\section{TEMPERATURE DEPENDENCE OF RADIATION DAMAGE IN ELECTRON MICROSCOPY}

\section{Kenneth H. Downing and Robert M. Glaeser}

Radiation damage is one of the main barriers to obtaining structural information on biological molecules. While techniques of electron crystallography have recently been used with great success in extending the amount of information available through electron microscopy, any technique that could reduce the effects of radiation damage would be extremely beneficial. We showed a number of years ago that, as expected, cooling the specimen in the electron microscope using liquid nitrogen reduces the rate of radiation damage. A number or more recent reports indicated that cooling to liquid helium temperature could produce a further very dramatic decrease in the rate of damage. These results, however, were inconsistent with a number of other radiation damage studies that indicated no sudden changes in the rate of damage with temperature. The conditions of exposure in the electron microscope, however, are quite different than those used in other types of experiments. For example, the total dose delivered to the specimen is several orders of magnitude larger than commonly used in $x$-ray damage studies. We thus felt that it was necessary both to test the effects of liquid helium cooling and to investigate the temperature dependence of radiation damage effects in the electron microscope.

A set of hydrocarbon specimens was chosen for these measurements that was both easy to prepare in a reproducible manner and yielded results that were easy to interpret. Crystalline monolayers of fatty acids and other amphiphilic molecules were prepared on a Langmuir-Blodgett trough and transferred directly to specimen support grids. Observation of the fading of the electron diffraction patterns from these specimens gave a measurement of the destruction of the molecular structure by the electron beam.
The specimens were examined in liquidnitrogen cooled stages designed and built at LBL for use in a JEOL 100B microscope. We also constructed a special stage for electron diffraction that could be cooled by either liquid nitrogen or liquid helium.

The results of our measurements are shown in Fig. 1. With decreasing temperature, the resistance of these specimens to radiation damage increases in an apparently smooth manner. The resistance to damage at a given temperature is strongly correlated to the melting point of the specimen. These - results are easily interpreted in terms of the radiation chemistry of hydrocarbons, which has been extensively studied using, for example, electron spin resonance. However, the effects of damage have been found to be so dependent on the type of specimen that we should not extrapolate these

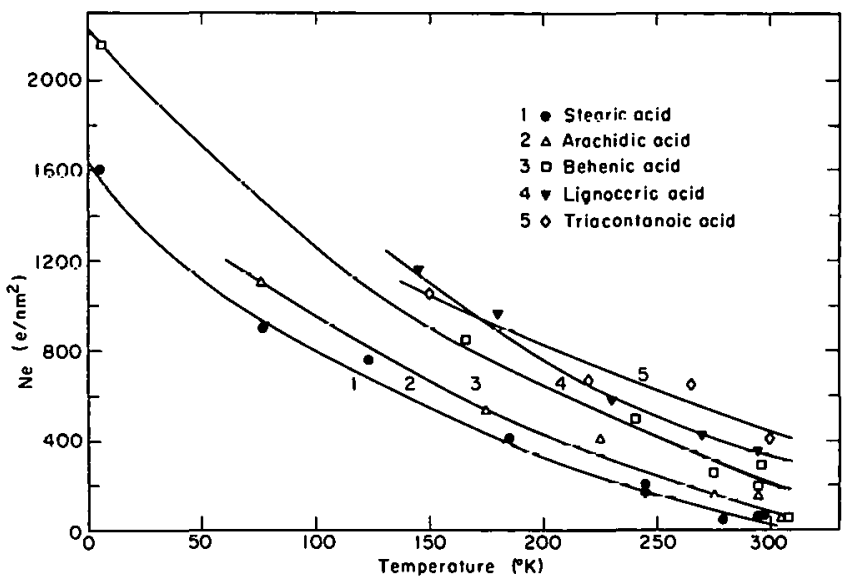

Fig. 1. The critical electron exposure, $N_{6}$, as a function of specimen temperature, for five saturated fatty acids. At the critical exposure, the intensity of spots in the electr diffraction pattern has been reduced by radiation damage $1 / e$ of the initial intensity. 
ults directly to other types of specimens such as r. Jteins.

Further work is continuing in a collaborative study involving laboratories at Duke University and in Berlin, Munich, and Heidelberg to test the effects of cooling to liquid helium temperature. The specimens in these studies, paraffin and purple membrane, represent small organics and proteins for which electron crystallography offers great opportunities for structural studies. Preliminary results are consistent with the understanding, which has developed during the last year to two, that most of the benefit of cooling a specimen is obtained at the temperatures at which our nitrogen-cooled stages operate (about $150 \mathrm{~K}$ ), while cooling to $4 \mathrm{~K}$ decreases the rate of damage by approximately another factor of two.

\section{STRUCTURAL ANALYSIS OF BACTERIOPHAGE LAMBDA RECEPTOR PROTEIN}

\section{Bing K. Jap}

Bacteriophage lambda receptor protein (LamB protein) is a major outer membrane protein in maltose-induced E. coli cells. LamB protein (mol wt 47400 ) acts as a receptor for bacteriophages, forms a nonspecific pore for small solutes, and facilitates the passage of maltose and maltoseoligosaccharides across the outer membrane. ${ }^{1-2}$ The presence of a recognition site for maltose compounds on the surface of the LamB protein has been established. ${ }^{1,3}$ The pore diameter has been estimated from conductivity studies to be about 11 Å. 3,4

The primary sequence of LamB protein has been derived from the nucleotide sequence of its encoding gene. ${ }^{5}$ The primary sequence shows a large number of charged residues almost uniformly distributed along the sequence. Hydropathic profiles of LamB protein, obtained using the method of Kyte and Doolittle, ${ }^{6}$ show no long stretch of hydrophobic residues, in marked contrast to a typical membrane protein such as bacteriorhodopsin. Our secondary structure prediction (Fig. 1) using the method of Chou and Fasman ${ }^{7,8}$ gives $22 \%$ alpha helix and 34\% beta sheet.

We have successfully reconstituted LamB protein with phosphatidylcholine from soybean. The reconstituted LamB membrane patches have diameters from 0.2 to $3 \mu \mathrm{m}$ with typical size about $1 \mu \mathrm{m}$. An electron micrograph of a typical LamB membrane sheet that has been negatively stained with phosphotungstic acid $(\mathrm{pH}=7.4)$ is shown in Fig. 2a together with its optical diffractogram. ${ }^{9}$ The optical diffraction pattern shows a hexagonal lattice, with lattice constant $72 \AA$. Computer processing of such images reveals two major image features: dark nearly circular stained domains (pores) having center-to-center spacing of $24 \AA$, and light "ellipti-

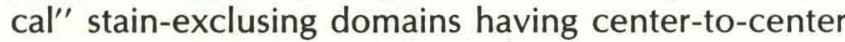
spacing of approximately $44 \AA$ (Fig. 2 b). Work is under way to obtain structural basis for understanding the functional mechanism of LamB protein, using both high resolution electron microscopy and biochemical techniques.

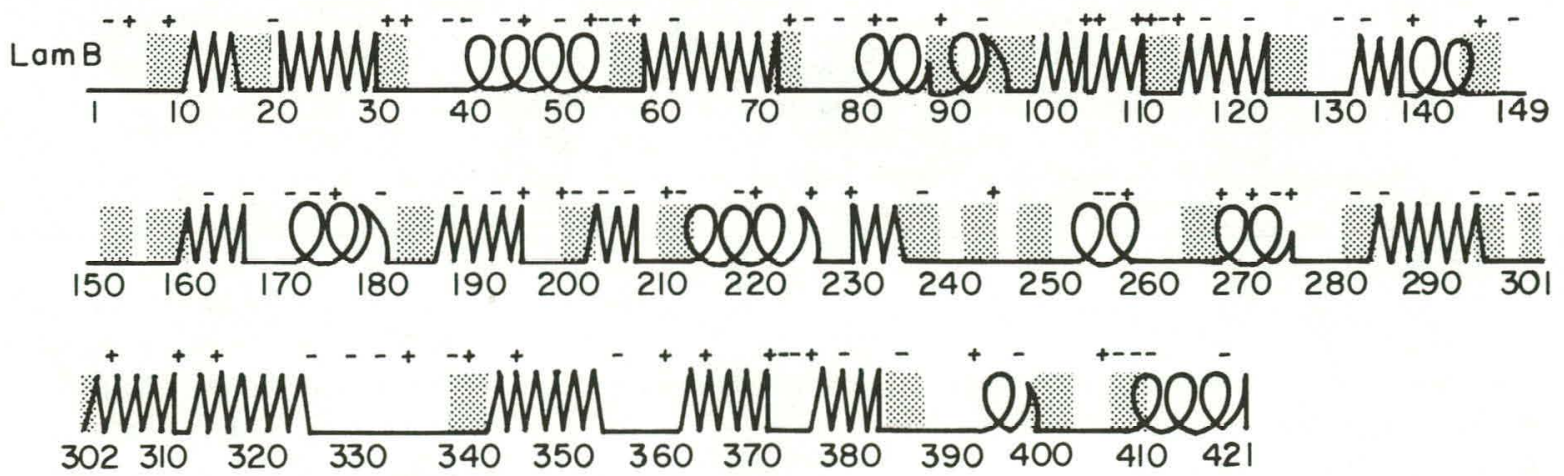

Fig. 1. Predicted secondary structure of LamB protein using the methods of Chou and Fasman., The sawteeth and loops represent respectively beta sheet and alpha helix regions. Shaded regions correspond to predicted beta turns. The distribution of charged residues is also shown. 

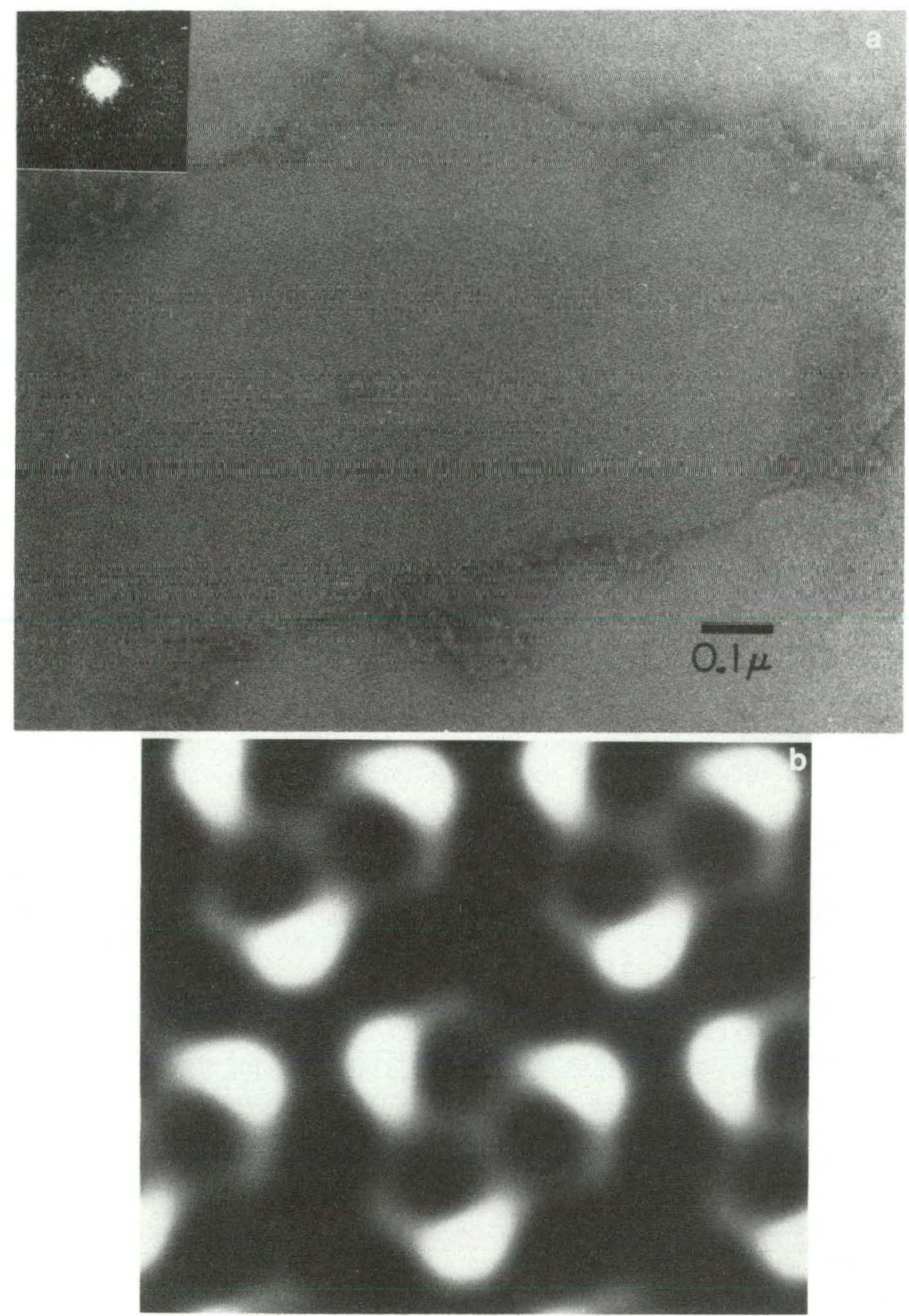

Fig. 2. (a) A typical image of a reconstituted LamB specimen negatively stained with phosphotungstic acid, and its optical diffraction pattern. (b) Greyscale map of a computer-filtered image of LamB specimen. Dark shade of grey corresponds to stain accumulation regions (pores) and light shade of grey indicates greater stain exclusion domains.

(XBB 830-8833)

\section{REFERENCES}

1. Luckey, M., and Nikaido, H. Diffusion of solutes through channels produced by phage lambda receptor protein of Escherichia coli: Inhibition by higher oligosaccharides of maltose series. Biochem. Biophys. Res. Com. 93, 166-171 (1980).
2. Szmelcman, S., and Hofnung, M. Maltose transport in Escherichia coli K12, involvement of the bacteriophage lambda receptor. J. Bacterial. 124, 112-118 (1975).

3. Ferenci, T., and Boos, W. The role of the Escherichia coli receptor in the transport maltose and maltodextrins. J. Supram Structure 13, 101-116 (1980). 
Boehler-Kohler, B.A., Boos, W., Dieterle, D., and Benz, R. Receptor for bacteriophage lambda of Escherichia coli forms larger pores in black lipid membranes than the matrix protein (porin). J. Bacterial. 138, 33-39 (1979).

5. Clement, J.M., and Hofnung, M. Gene sequence of the $\lambda$ receptor, an outer membrane protein of E. coli K12. Cell 27, 507-514 (1981).

6. Kyte, J., and Doolittle, R.F. A simple method for displaying the hydropathic character of a protein. J. Mol. Biol. 157, 105-132 (1982).

7. Chou, P.Y., and Fasman, D.G. Prediction of protein conformation. Biochemistry 13, 222-245 (1974).

8. Chou, P.Y., and Fasman, D.G. Prediction of the $\beta$-turns. Biophys. J. 26, 367-384 (1979).

9. Jap, B.K., and Glaeser, R.M. Structure of bacteriophage lambda receptor protein. Proc. of the 41st Annual Meeting of the Electron Microscopy Society of America, G.W. Bailey Ed., pp. 736-737 (1983).

\section{STRUCTURAL STUDIES OF THE SURFACE LAYER PROTEIN OF AQUASPIRILLUM SERPENS}

\section{Wennie H. Wu, Melvyn Dickson, Kenneth H. Downing, and Robert M. Glaeser}

For several years we have been interested in the protein that forms a surface layer on the outer membrane of the gram-negative bacterium Aquaspirillum serpens. The function of such protein arrays, which are found on a large number of bacteria, is not clear, although it appears that the main function may be different in different organisms. Structural and protective functions have been proposed for the arrays. Because the protein occurs in well ordered, two-dimensional crystalline arrays, it has been particularly amenable to structural study by electron crystallography. The use of the redundancy in such crystalline arrays allows a reduction in the electron exposure required to record an image of the protein. Structural alterations caused by radiation damage are thus not nearly as severe as encountered in "normal" microscopy of isolated molecules. Computer processing of electron micrographs is used to calculate the Fourier transforms of the image data, from which crystallographic structure factor amplitudes and phases can be obtained.

We have recently made major improvements in techniques for isolating the protein array from other components of the cell wall and for formation of very large arrays of the protein. These specimens were examined in both negatively stained and frozen hydrated preparations, using minimal exposure conditions in both cases to minimize radiation damage effects.

Negative stains are frequently used in microscopic examinations of proteins and protein arrays. w/hile such stains are probably the easiest way to eserve and visualize structures in the electron .....croscope, resolution beyond 15 to 20 angstroms is rarely obtained in the image, because of inherent limitations of the stain. In images of the negatively stained Aquaspirillum serpens protein array, the resolution regularly extended to slightly better than $14 \AA$. In addition, some information could be detected at higher resolution, up to $7 \AA$. It appears that in this case the information to around $15 \AA$ is provided by the stain distribution around the protein. The protein itself, however, is so well preserved under the conditions used that information is provided by the protein distribution in a resolution range beyond that provided by the stain.

In this laboratory we have developed techniques for preparing and examining specimens in the frozen hydrated state. The primary advantage of this approach is that it preserves the native, hydrated form of a protein. Frozen hydrated preparations of the protein array from Aquaspirillum serpens again showed regular resolution to around $14 \AA$, with some information present at resolutions up to about $7 \AA$. An image of the projection of the structure which was determined from these images is shown in Fig. 1.

To begin to investigate the relationship between the structure and function of the protein, a three-dimensional view of the structure is necessary. Information to compute the threedimensional structure can be obtained from images of the crystalline array tilted through various angles with respect to the electron beam. We recently installed the software required to implement the merging of data from different projections of the structure. A model of the three-dimensional structure of the protein which we have derived is shown in Fig. 2. Based on side views of the pro- 


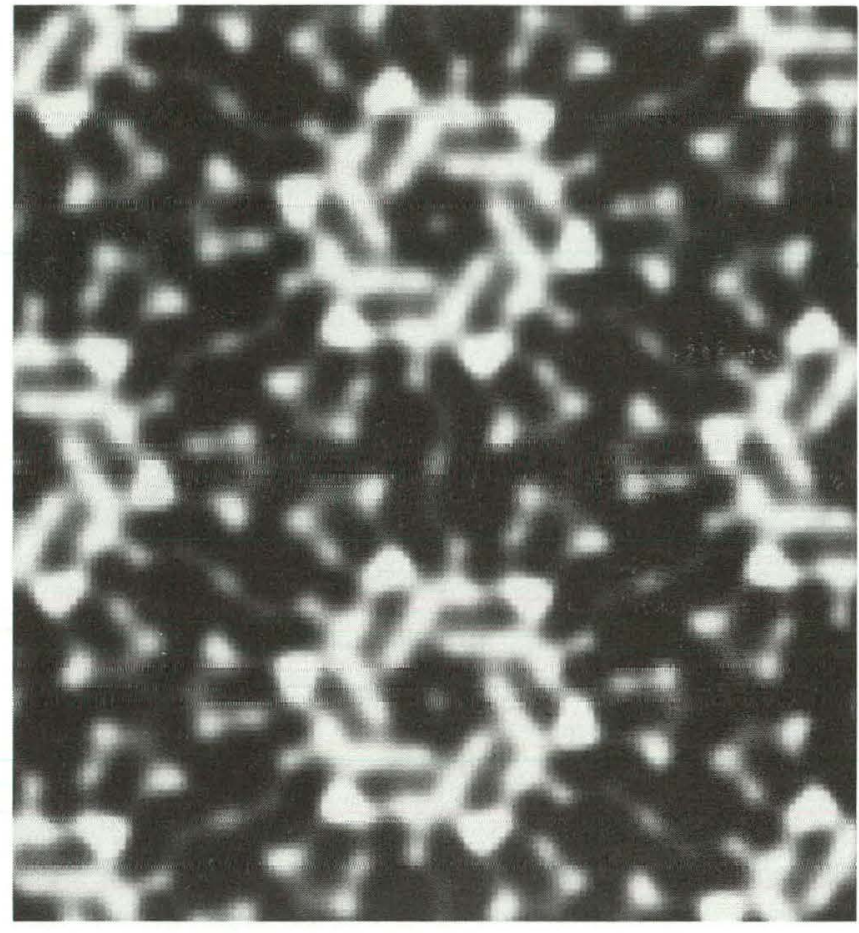

Fig. 1. Projection of Aquaspirillum serpens surface layer protein structure reconstructed from images of frozen hydrated samples. Information to $7 \&$ resolution has been used in this image. Protein appears white.

(XBB 836-5490)

tein, we had thought of the protein as having a mushroom shape. This three-dimensional structure

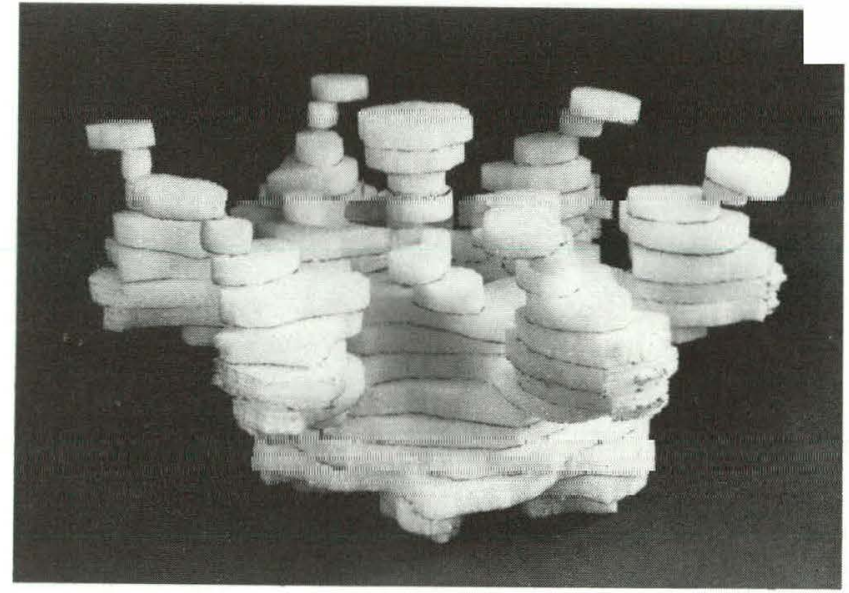

Fig. 2. Model of the three-dimensional structure of the protein obtained by rombining intormation trom images ot negatıvely stained arrays which have been tilted with respect to the electron beam.

(XBB 830-9844)

agrees well with our previous concept of the structure, although the "stalk" of the mushroom appears to have been flattened by effects of drying of the sample. The deep hole in the center of the stalk (which does not pass all the way through the structure) had not been identified previously. In addition, with the resolution in this model, we can see much more clearly the way in which adjacent proteins contact each other.

\title{
QUANTITATION OF HUMAN LUNG TISSUE SHRINKAGE DURING PREPARATION FOR ELECTRON MICROSCOPY
}

\author{
Jacob Bastacky, Thomas L. Hayes, Richard P. Gelinas, ${ }^{*}$ L. Michael Sprague, \\ May F. McKoon, Gregory L. Finch, Susan B. Klein, Barbara von Schmidt, ${ }^{\dagger}$ \\ Lee W. Paris, ${ }^{\dagger}$ and Mark E. Williams ${ }^{\dagger}$
}

Biological tissue undergoes a number of preparative steps for electron microscopic examination. Tissue is fixed so that structures do not change shape, water is removed or immobilized so as not to reduce the vacuum in the electron optical system of the microscope, and electron-opaque stains or coatings are added to increase contrast and reduce noise in the final image. Each of these steps alters the sample. In order to interpret images of the sample in a quantitative manner

*Saint Mary's College, Moraga, California.

'Children's Hospital Medical Center of Northern California, Oakland, California. these alterations must be known. The most common processes of stiffening, drying, and metalizing the tissue cause it to shrink, possibly to change shape, and to change color. Since these morphological changes reflect the denaturation and extraction of various chemical constituents of the tissue, one attempts to minimize them. Critical interpretation of microstructure requires an appreciation of the quality and degree of these structural changes. Accurate measurements of histological microstructures are important to human physiology and quantitative pathology. Quantitative morphometretin studies at the tissue and cellular levels are incre: ingly being directed towards an understanding . 
ucture and function in the normal and abnormal tes. These studies apply a set of mathematical stereological tools to LM or TEM sections to extrapolate two-dimensional images to three-dimensional structure. We are interested in developing techniques that allow direct quantitation of threedimensional structure in the scanning electron microscope. Because we are interested in the microdimensions of the human airways in the living state, and since we study this by making measurements of samples in the electron microscope, we must quantify the shrinkage of lung during each stage in the preparation for electron microscopy.

We have measured the degree of shrinkage of huninn lung tissue during osmium tetroxide postfixation, dehydration, and critical point drying and are preparing to extend the study to include the fixation step. This work will allow us to extrapolate accurately from measurements of structures made in our microscope to those in the living state in human beings. The measurements we are inlerested in are the lengths and diameters of the subdivisions of the airway, the diameters and configurations of alveoli, and the branch angles and branching patterns of the airway. These regional properties are preserved in our SEM samples and are available for measurement and interpretation with morphometric techniques adapted for SEM. In our experiments, lungs removed from patients at surgery are inflated with air within 15-30 minutes of excision. The inflation is achieved in a transparent, negative-pressure respirator designed and fabricated at LBL. We allow the lung to collapse, then inflate it with aqueous glutaraldehyde fixative to $20-\mathrm{cm}$ water pressure. We cut open the airway using microdissection techniques that we have developed, ${ }^{1,2}$ then cut 1 - to 6 - cm blocks of the exposed airway. We post-fix these blocks with osmium tetroxide then remove the water by dehydration through a series of increasing concentrations of acetone or ethanol. We then remove the solvent by critical-point drying from $\mathrm{CO}_{2}$. The tissue block sample is photographed after each step using a macrocamera. The outline of each tissue block is traced from the photographs onto transparent acetate and the linear dimensions parallel to and perpendicular to the pleura are measured and recorded after each step in processing.

Figure 1 shows the photographs of one sample of human lung tissue a) after fixation and dissection, b) after osmium tetroxide post-fixation, c) after dehydration, and d) after critical point drying. Fige 2 is the composite tracing of the tissue outlines. ne can see that there is little shrinkage with
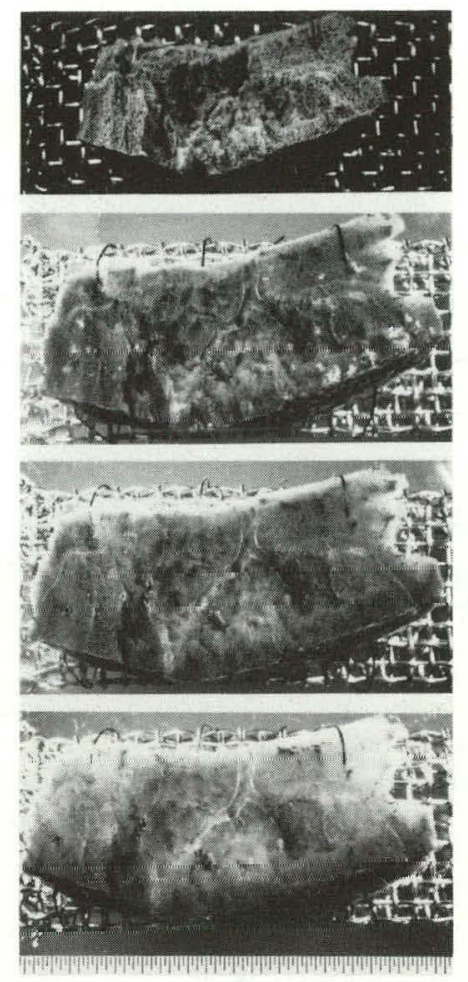

Fig. 1. Photographs of a single piece of human lung tissue after steps in the processing for electron microscopy. The bottom photograph is after fixation. Just above is a photograph after osmium tetroxide post-fixation. The next photograph above is after dehydration in ethanol. The top photograph is after critical point drying from $\mathrm{CO}_{2}$. This procedure is routinely used for scanning electron microscopy. Note that most shrinkage occurs during critical point drying. The tissue is sewn to a stainless steel screen for photography. Scale at the bottom applies to all photographs, each small division is $1 / 2 \mathrm{~mm}$. The top photograph is out of focus because the lung has shrunk in height as well as width and length while the focal length of the camera has remained unchanged.

(CBB 820-9793)

osmification and dehydration but considerable shrinkage with critical point drying. In our experiment, human lung tissue shrinks by an average value of $19 \%$ in each linear dimension to $81 \%$ of the width and length of the block of fixed tissue. This is equal to shrinking to $51 \%$ of its volume. We measured 51 samples of human lung with an average dimension of $25 \times 21 \times 10 \mathrm{~mm}$. Shrinkage values were rather consistent (Fig. 3a) and essentially equal in length and width. The means and standard deviations for the two values were $19.4 \%( \pm 2.7 \%$ SD) for length (L) and 19.0\% ( \pm $4.0 \% \mathrm{SD}$ ) for width (W). It is of interest that the lung shrank in length an amount equivalent to that which it shrank in width; length and width ( $L$ and W) being defined as dimensions perpendicular to 

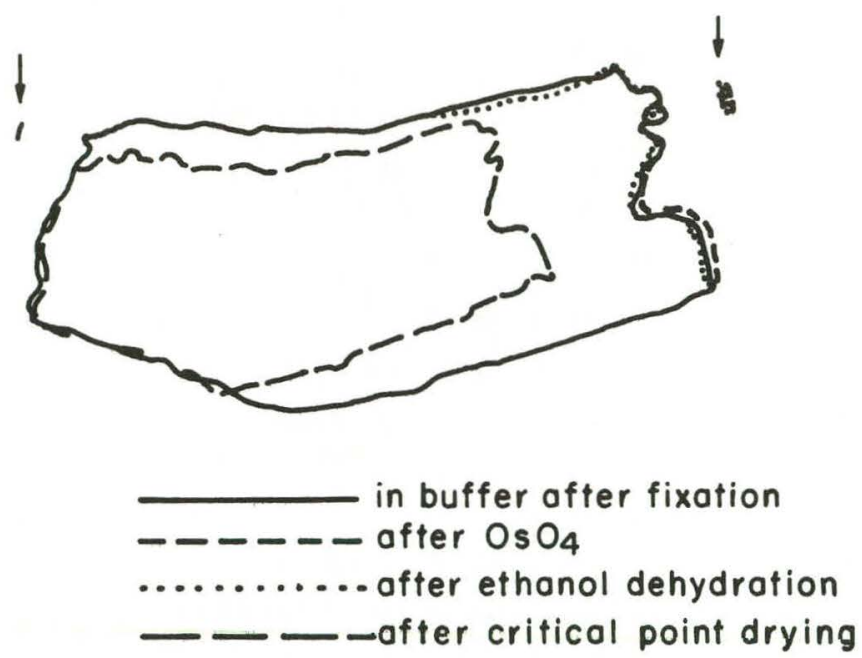

Fig. 2. Shrinkage of lung tissue is measured by tracing the outlines of the tissue in Fig. 1. These outlines are superimposed and the widths and lengths measured with a rule. Arrows point to screen reference points that measure photographic consistency.

(XBL 8211-4257)

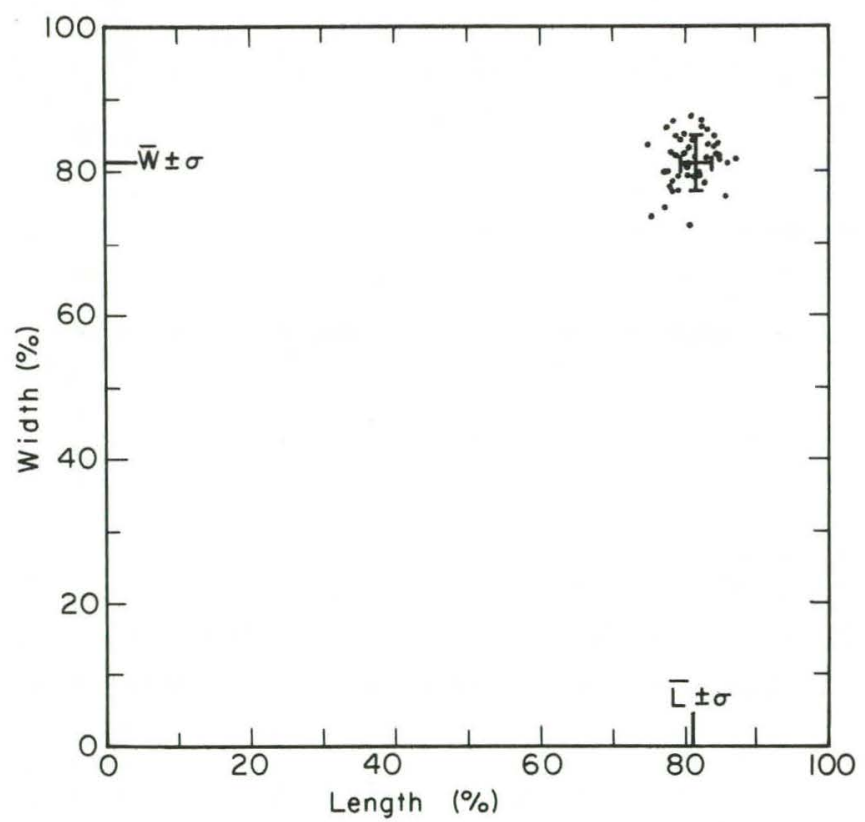

Fig. 3a. Size of human lung samples after preparation for electron microscopy expressed as a percentage of linear dimension of the width (W) and length (L) of the glutaraldehyde fixed sample. Shrinkage during the steps of post-fixation, rinsing, en bloc staining, dehydration, and critical point drying is included. Width is that linear dimension parallel to one pleural surface, length is the largest perpendicular dimension. All samples began at $100 \% / 100 \%$ at the upper right. Means $(L$, W) are shown with standard deviations. Note the tight clustering of values. $N=51$.

(XBL 8311-4101) and parallel to the pleura, respectively (Fig. This implies a structural isotropy that is fundamer.nu, to the interpretation of scanning electron micrographs. Figure $3 \mathrm{~b}$ shows the data points enlarged to show that the points are essentially random with no minor trends. The correlation coefficient (Pearson's r) is 0.15 . Twenty-one samples were dehydrated in ethanol (๑) and thirty samples dehydrated in acetone $(O)$. Both are routinely used in scanning electron microscopy. Shrinkage values for ethanol were not significantly different than those for acetone $\left(t_{s}=1.09, t_{0.05,100}=1.99\right)$. We are in the process of measuring the additional shrinkage attendant upon the fixation process itself. This is difficult because a whole lobe of lung is fixed by inflating it with liquid fixative in a negative pressure respirator. The curved and irregular lobe is difficult to measure; convenient rectilinear blocks of tissue are not cut out until after fixation. Quantitation is further complicated by the fact that lung dimension and shrinkage percentage vary with inflation pressure. One might expect approximately $11 \%$ linear dimension shrinkage during the fixation procedure from the work of Mazzone et al. in dogs. ${ }^{3}$

The other major preparative technique for scanning electron microscopy of biological tissue is freeze drying. Preliminary plans are under way to

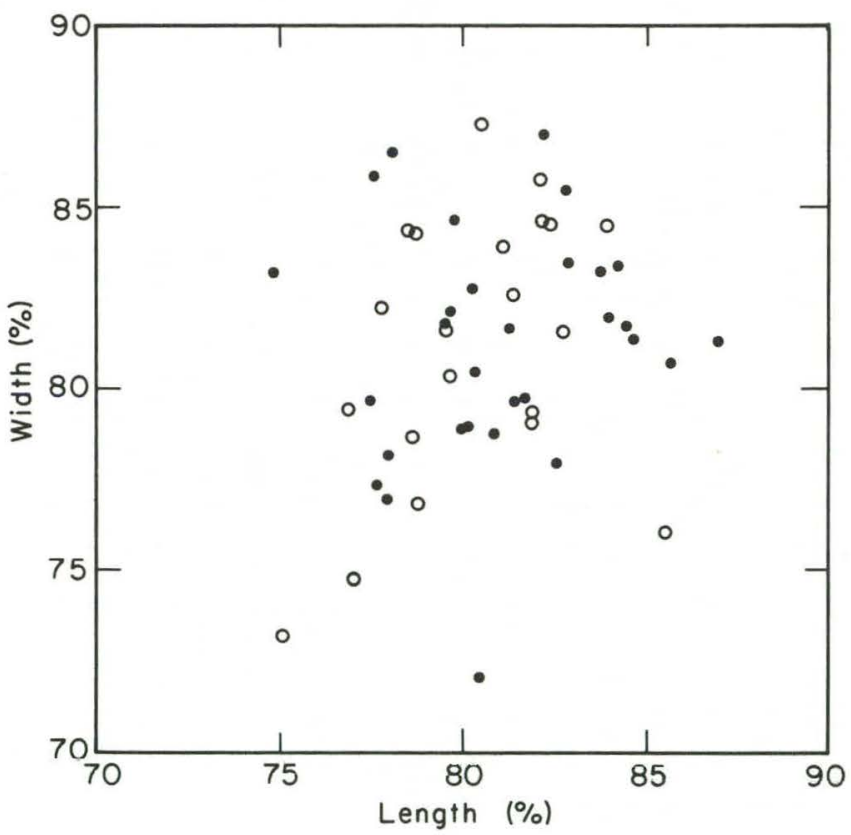

Fig. 3b. Shrinkage of human lung sample data from Fig. 3a enlarged to show random scatter: the correlation coefficient, $r$, is 0.15 . Values for dehydration through ethanol are plotted as $(\bullet)$, for dehydration through acetone as (O). The means for each are not significantly different indicating equal shrink. after critical point drying with either procedure.

$(X B L 8311-41 v<)$ 
ıdy the shrinkage with freeze drying in conjuncwun with the Electron Microscope Laboratory of the University of California Berkeley.

The shrinkage we measured in lung tissue is similar to that observed in the preparation of mouse liver (shrinkage to $76 \%$ of fixed tissue linear dimension) observed by Boyde and co-workers (Ref. 4 and personal communication). These studies demonstrate that tissue samples change in size considerably with preparation for electron microscopy. In order to reduce or eliminate these changes with new preparative techniques or to allow for their correction, it is necessary to have a quantitative measure of these changes. The studies described here provide objective data to aid in the interpretation of electron micrographs and are necessary for the extrapolation of microscopic measurements to living human beings.

\section{REFERENCES}

1. Bastacky, S.J., Hayes, T.L., Klein, S., Sprague, M., Baskin, L., and von Schmidt, B. Positional morphology of human lung. Am. Rev. Respir. Dis. 125, 213 (1982).

2. Bastacky, J., Hayes, T.L., and von Schmidt, B. Lung structure as revealed by microdissections: Positional morphology of human lung. Am. Rev. Respir. Dis. 128, S7-S13 (1983).

3. Mazzone, R.W., Kornblau, S., and Durand, C.M. Shrinkage of lung after chemical fixation for analysis of pulmonary structure-function relations. J. Appl. Physiol. 48(2), 382-385 (1981).

4. Boyde, A., Franc, F., and Maconnachie, E. Measurements of critical point shrinkage of glutaraldehyde-fixed mouse liver. Scanning 4, 69-82 (1981).

\title{
INTERACTIONS BETWEEN PARTICLES AND RESPIRATORY EPITHELIUM IN CULTURED TRACHEAL EXPLANTS AS REVEALED BY SCANNING ELECTRON MICROSCOPY
}

\author{
Gregory L. Finch, Thomas L. Hayes, Ming J.W. Chang, ${ }^{*}$ Gerald L. Fisher, ${ }^{*}$ and \\ Brooke T. Mossman ${ }^{\dagger}$
}

In recent years much research interest has been focused on the use of tracheal explants to model the interaction of particles with the upper respiratory tract mucosa. ${ }^{1}$ Hamster tracheas are easily excised, sectioned, and maintained in tissue culture, where exposures to a variety of agents can be carried out. This system can be thought of as a combination of in vivo and in vitro techniques in that a complex tissue consisting of many welldifferentiated cell types can be maintained with appropriate culture media. Advantages of using a system such as this include easy manipulation of the culture environment, ability to measure ciliary beat frequency and its alteration by external agents, and the ability to monitor cellular synthesis and biochemical alterations.

Our work reported here involves scanning electron microscopic (SEM) studies of explant airway surfaces, and changes in epithelium morphology induced by particle exposure. Syrian hamsters are sacrificed, each trachea removed and soaked in an

ttelle Laboratory, Columbus, Ohio.

epartment of Pathology, University of Vermont, Burlington, vermont. antibiotic-containing saline bath, then cut into 1 to $2 \mathrm{~mm}$ cartilage rings before being bisected and placed luminal (airway) side up in a petrie dish containing culture medium at $37^{\circ} \mathrm{C}$. All work is performed using sterile techniques. The composition of the culture medium is crucial to the maintenance of normal mucociliary differentiation; for example, vitamin A deficient medium causes a sloughing of the normal pseudostratified epithelium, with the resulting development of squamous cell metaplasia. We employ Eagle's minimal essential medium (Grand Island Biological Co., Grand Island, N.Y.), supplemented with HEPES buffer, gentamycin, and nystatin, to maintain normal differentiation. Sufficient medium is added to cultures to wet but not fully immerse the upwardly oriented mucosal surface.

To examine interactions between particles and the respiratory mucosal surface, we expose explants to nickel subsulfide $\left(\mathrm{Ni}_{3} \mathrm{~S}_{2}\right)$, a potent cytotoxic agent and inorganic carcinogen that has been shown to be cytotoxic to cultured alveolar macrophages. $^{2}$ Explants are first allowed to equilibrate in culture for three days before exposures are begun. $\mathrm{Ni}_{3} \mathrm{~S}_{2}$ particles are suspended in culture 
medium by sonication then vortexed immediately before being added to cultures at a dose of 20 $\mu \mathrm{g} / \mathrm{ml}$. Exposures are carried out for one hour, then the particle-laden medium is drawn off and fresh medium added. At appropriate times ranging from immediately after exposure up to 7 days $(0.0$, $0.25,1,4$, and 20 hours; 3 and 7 days), explants are fixed using $2.3 \%$ glutaraldehyde in $0.05 \mathrm{M}$ sodium cacodylate buffer $(\mathrm{pH}=7.4,360 \mathrm{mOsm})$. Samples are stored in fixative until processing is begun with three buffer rinses, dehydrated through a graded series of ethanol and water, then criticalpoint dried from $\mathrm{CO}_{2}$. Explants are mounted on carbon stubs, coated with $\mathrm{Pt}$ to prevent charging, then examined in a AMRay 1000A SEM with attached energy-dispersive $x$-ray microanalyzer.

Morphological evaluation of the explants is begun using a low magnification SEM micrograph for orientation and sample area selection (see Fig. 1). A grid is overlaid onto the micrograph then four grid points selected using a random number table for detailed examination. Areas selected are imaged at $2000 \times$ magnification after bringing the area roughly perpendicular to the electron beam. A conventional secondary electron (SE) micrograph of the area is used to assess morphology. For particle-exposed explants, a backscattered electron image (BSE) is obtained by turning off the electron collector cage voltage. This mode provides increased contrast between particles and tissues and aids in identifying particles. The beam is then placed onto each observed particle, and the presence of $\mathrm{Ni}$ and $\mathrm{S} x$-ray peaks confirms $\mathrm{Ni}_{3} \mathrm{~S}_{2}$ particle identity. Alternately, particles are located by

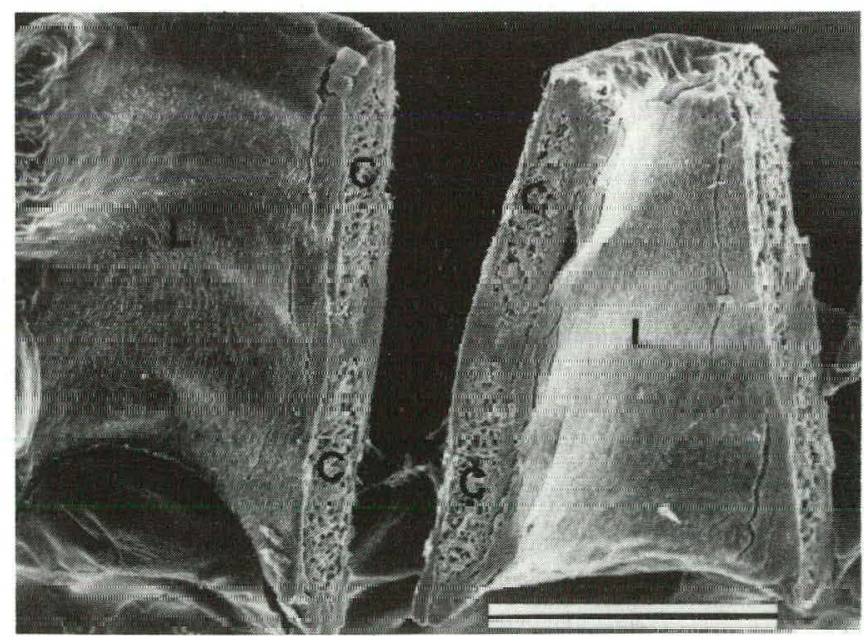

Fig. 1. Scanning electron micrograph (SEM) of hamster tracheal explants presenting their airway surfaces (L) for morphological analyses. Sections through rings of cartilage (C) are evident where explants have been cut. Bar $=0.5 \mathrm{~mm}$; original magnification $=80 \times$. making x-ray maps for the $\mathrm{Ni} \mathrm{K}_{\alpha}$ x-ray peak (s Fig. 2),

Control explants appear similar in surface architecture throughout the experimental timecourse. Figure 3 shows a selected area such as those used for morphological analysis. The luminal surface is comprised of ciliated and nonciliated cells occurring with variable incidences. Frequently, nonciliated cells greatly outnumber ciliated cells, and linear clusters of cilia are seen. This is particularly true near peripheral margins of the explants where the epithelium spreads to colonize explant edges. Cilia usually appear as numerous, free-standing cylindrical projections into the lumen, but occasionally are clumped due to incomplete rinsing of mucus from the surface. Nonciliated cells are present in two general types. The first, as seen in Fig. 3a, is characterized by indistinct cell borders and rounded luminal surfaces, with occasional short microvilli present. The other type, as shown in Fig. 3b, con-
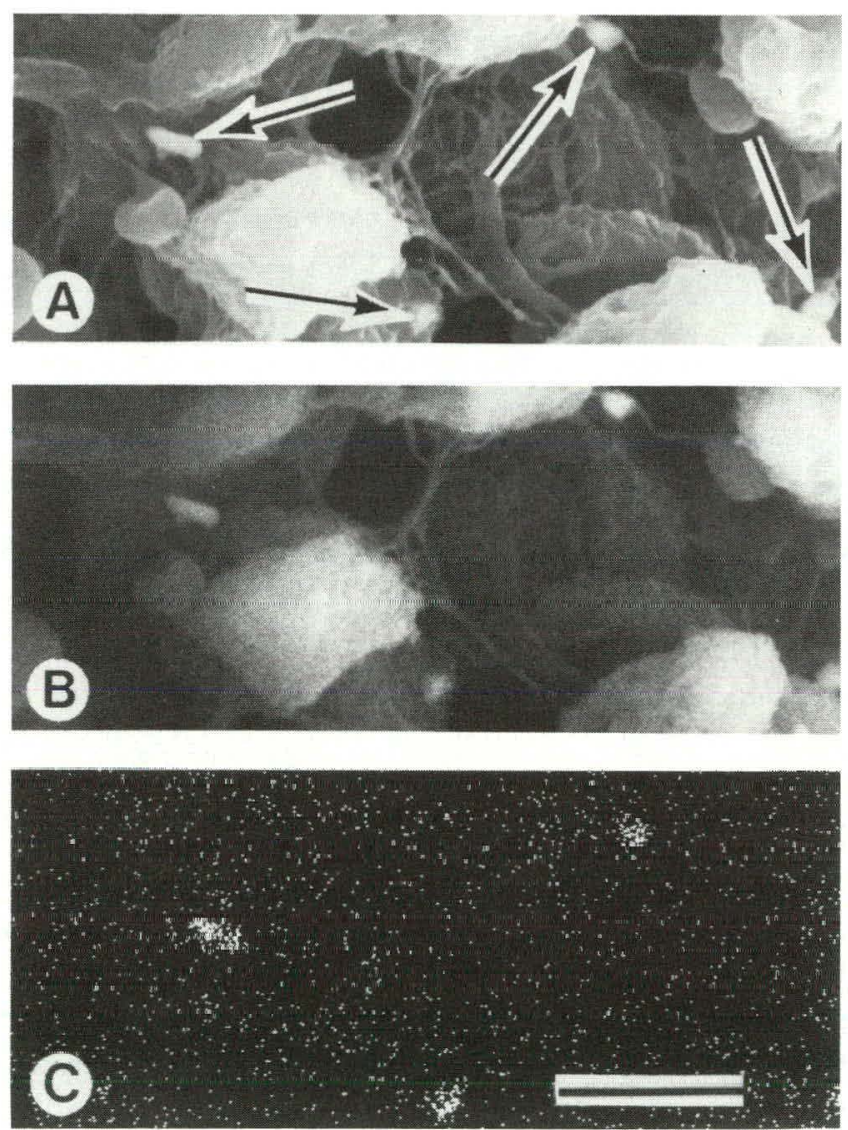

Fig. 2. Varinus SFM imaging modes used in examınıng cell/particle interactions. Top: Secondary electron image used to assess morphology. Arrows point to four $\mathrm{Ni}_{3} \mathrm{~S}_{2}$ particles present. Middle: Backscattered electron mode gives increased contrast in locating particles. Bottom: $X$-ray map for nich proving that four particles are present. $B a r=5 \mu \mathrm{m}$; origin magnification $=4000 \times$. 

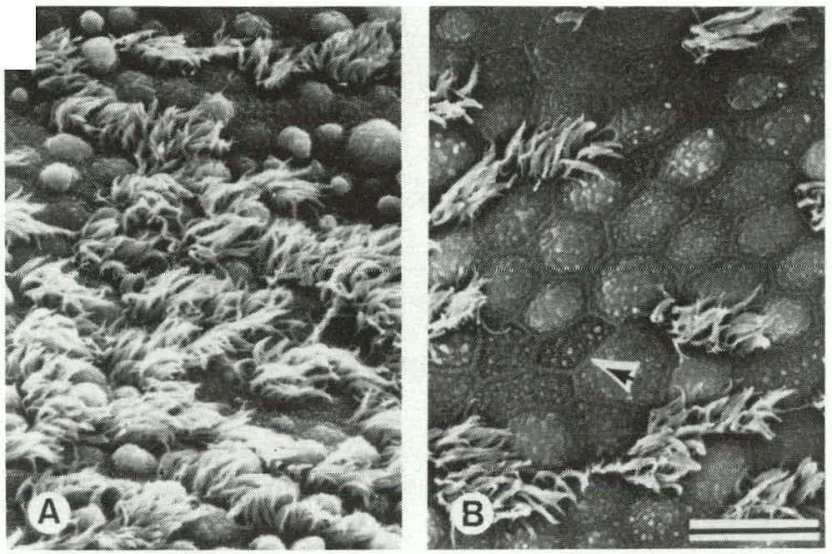

Fig. 3. Luminal surface of control explants displaying ciliated and nonciliated cells. (A) Many of the nonciliated cells are rounded into the lumen. (B) Occasionally ciliated cells are sparse and nonciliated cells have polygonal shapes with welldefined cell boundaries (arrowhead). Bar $=10 \mu \mathrm{m}$; original magnification $=2000 \times$.

(XBB 8311-10272)

sists of polygonally-shaped cells of irregular size, with microvilli clustered at cell edges forming distinct borders. These cells frequently possess short, stubby microvilli over the entire surface and are flatter than the first type, as determined from stereopair SEM micrographs.

In contrast to the control explants, $\mathrm{Ni}_{3} \mathrm{~S}_{2}$ exposed explants display a dramatic pattern of cell sloughing and regeneration of epithelium. The remaining micrographs (Figs. 4-7) depict stages in this process. In Fig. 4, from an explant fixed immediately after exposure, the normal differentiated epithelium is breaking up, and both ciliated

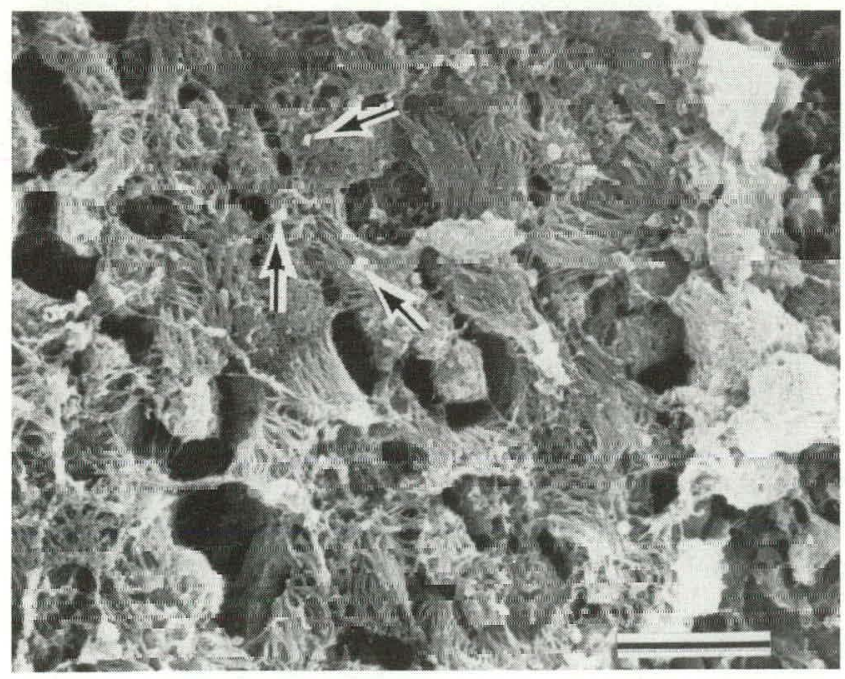

r:- 4. Tracheal explant after one hour exposure to $\mathrm{Ni}_{3} \mathrm{Si}_{3}$ ticles. Cell sloughing is occurring and several particles are sent (arrows). Bar $=10 \mu \mathrm{m}$; original magnification $=2000 \times$.

(XBB 8311-10273) and nonciliated cells are sloughing from the surface. Most particles appear adherent to the luminal surface yet external to the cells. Internalized particles are observed less frequently. In Fig. 5, one hour post-exposure, few columnar cells remain; those present appear rounded up, and an underlying network of basal cells is present. Over the next few hours, even fewer residual sloughed cells remain. More basal cells are present and the luminal surface is characterized by more complete cell coverage. This process is more advanced in Fig. 6, four hours post-exposure, in which the cellular coverage is complete and cell borders are beginning to appear. Note that neither ciliated or typical nonciliated cells are present; cell surfaces are characterized by a ragged appearance. Many particles are still observed to rest upon the epithelium. Figures $7 \mathrm{a}$ and $7 \mathrm{~b}$ are two areas from the same explant at seven days post-exposure. In Fig. 7a, cells are of irregular size and shape and are covered by numerous microvilli. A few areas are free of surface projections and are slightly lower than surrounding cells. These are probably spaces from which flattened squamous cells have been sloughed. Several cells are slightly rounded with many densely packed microvilli. These more closely reflect the typical morphology of nonciliated cells seen in control explants. An even more advanced regeneration is seen in Fig. 7b, which appears similar to control epithelium. Note that several cells project apparent short cilia into the lumen; these may be regenerating ciliated cells.

Examination of samples of exposed tracheal explants show that epithelial sloughing and regen-

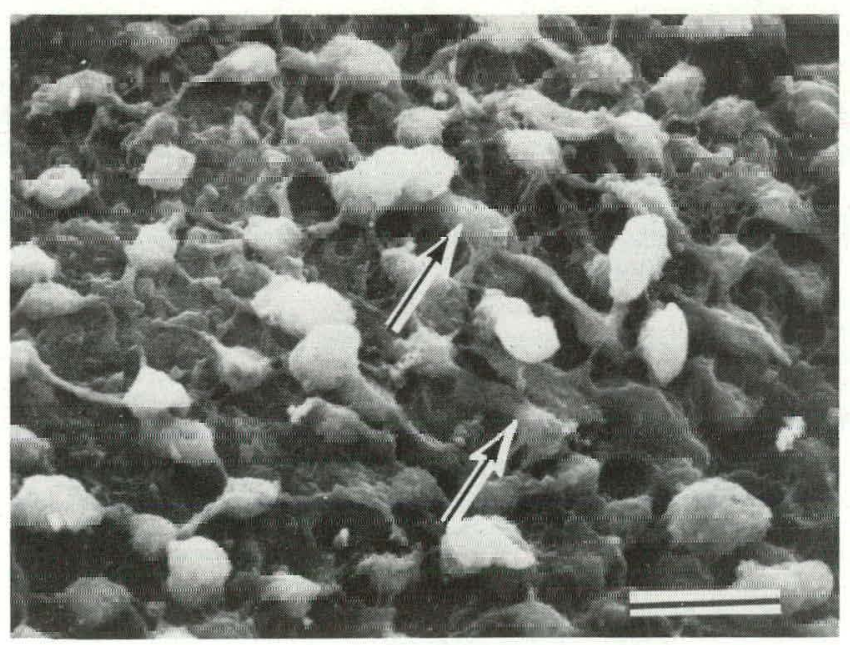

Fig. 5. Explant one hour after exposure to $\mathrm{Ni}_{3} \mathrm{~S}_{2}$. Most of the differentiated columnar cells are gone and underlying basal cells are visible (arrows). Bar $=10 \mu \mathrm{m}$; original magnification = $2000 \times$. 


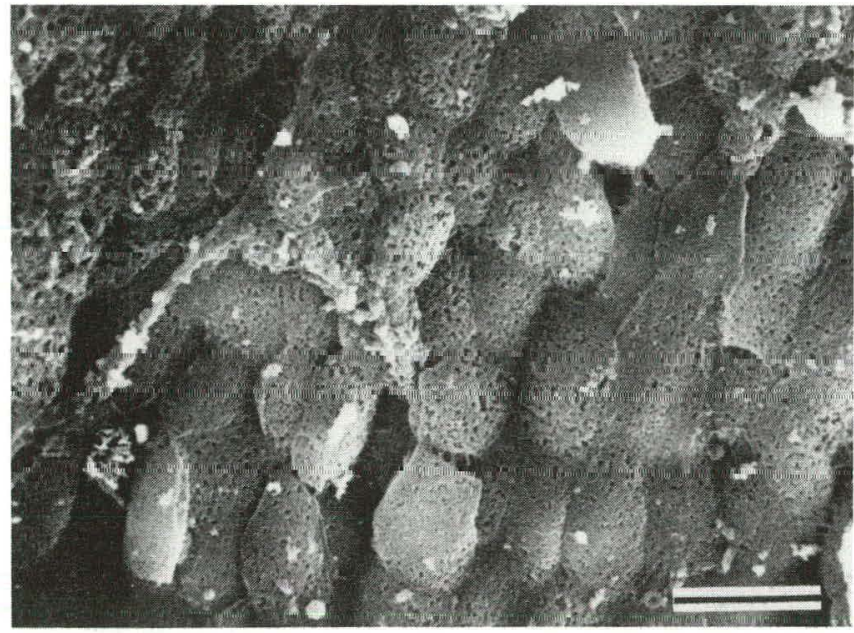

Fig. 6. Four hours after exposure, many particles are still present. Cell coverage is more complete. Cell borders are beginning to appear but no cilia are evident at this stage. Bar = $10 \mu \mathrm{m}$; original magnification $=2000 \times$.

(XBB 8311-10275)

eration is a typical reaction to even low doses of $\mathrm{Ni}_{3} \mathrm{~S}_{2}$ particles. Particles are present during the sloughing phase both internal and external to epithelial cells, and are still seen as the epithelium is recolonized. At longer timepoints, 3 and 7 days, few if any particles are present. Transmission electron microscopy of thin-sectioned explants would be of value to assess the extent to which particles are phagocytized by regenerating epithelium or existing basal cells, or transported to submucosal spaces. We are continuing efforts to characterize hamster tracheal explants as sensitive indicators of particulate material exposure, and to examine the
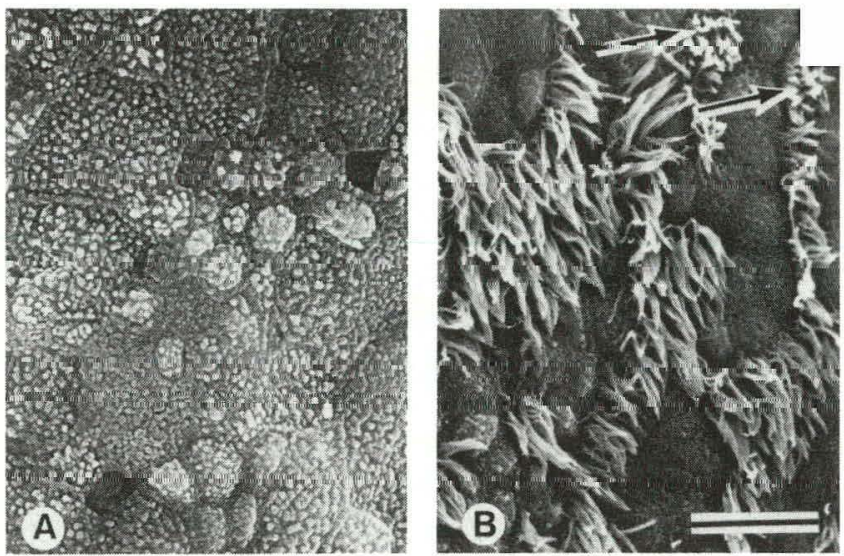

Fig. 7. Two areas from the same explant seven days after particle exposure. At this time, the luminal surface is free of particles. (A) Cells are of irregular size and shape, with no cilia present. (B) Both ciliated and nonciliated cells are present. Several patches of short cilia are evident (arrows). Bar $=10$ $\mu \mathrm{m}$; original magnification $=2000 \times$.

(XBB 8311-10271)

interactions between particles and cells using a variety of electron microscopic techniques.

\section{REFERENCES}

1. Mossman, B.T., Adler, K.B., and Craighead, J.E. Interaction of carbon particles with tracheal epithelium in organ culture. Env. Res. 16,110 (1978).

2. Fisher, G.L., Chrisp, C.E., McNeil, D.A., Democko, C., and Finch, G.L. "Mechanistic Evaluation of the Pulmonary Toxicology of Nickel Subsulfide," in The Toxicology of Petroleum Hydrocarbons, p. 87, American Petroleum Institute, Washington, D.C., 1982.

\section{X-RAY MICROANALYSIS OF DIFFERENTIATING PRIMARY MESENCHYME CELLS WITHIN THE SEA URCHIN EMBRYO, LYTECHINUS PICTUS}

Susan B. Klein, Thomas L. Hayes, and Fred H. Wilt*

In situ primary mesenchyme cells of sea urchin embryos provide an appropriate system for studying the biological mechanisms of migratory differentiation with little artificial interference. The first three mitotic divisions of the sea urchin embryo produce eight identical cells of equal volume and apparent chemical composition. The fourth division produces, by asymmetric cytokinesis, 16 cells: 12 with similar dimensions, and 4 miniature cells, called

*Zoology Department, University of California Berkeley. micromeres. The primary mesenchyme cells arise from the progeny of the micromeres. At about the 400 -cell stage, the primary mesenchyme cells are extruded into the blastocoel, where they migratc upon the inner surface of the single cell thick shell of the blastula. By the onset of gastrulation (invagination of the archenteron), this migration is limited to the vegetal hemisphere. Finally the primary mesenchyme cells arrest at predetermined locations around the archenteron, extrude long filopodia th entwine and form syncytia, and begin to lay dor the calcium carbonate skeleton of the larval sea 
shin (the pluteus). Thus the primary mesen...yme cells of the sea urchin embryo present us with four visually identifiable stages of differentiation: micromeres, freely migrating cells, restricted cells, and syncytia cells. The activity of these cells may be regulated by products within the primary mesenchyme cells, by surface products, by secreted products, or by the same set of possibilities involving the cells of the embryonic epithelial shell. Standard methods of chemical extraction do not have sufficient spatial localization, and autoradiographic techniques fail to prevent the movement of diffusible ions. Scanning electron microscopy (SEM) $\mathrm{x}$-ray microanalysis of frozen hydrated tissue circumvents both of these limitations.

In this technique sea urchin eggs of Lytechinus pictus are fertilized and cultured in millipore-filtered sea water, at $15^{\circ} \mathrm{C}$. They are collected at appropriate times, and allowed to settle into a loose pellet. Sea water is drawn off by pipette and filter paper until less than $25 \mu \mathrm{l}$ remain, and $25 \mu \mathrm{l}$ of $20 \%$ hydroxyethyl starch (HES) cryoprotectant and 50\% colloidal carbon in sea water is added (20/50 matrix). Two-mm diameter beads of embryos in matrix are formed on top of $1-\mathrm{mm}$ diameter cylindrical depressions drilled into carbon SEM stubs. These stubs are plunged into frozen nitrogen slush for rapid freezing, and are stored in liquid nitrogen until examination. Although we have observed embryos to develop normally for over an hour in the diluted 20/50 matrix, the process from dry pellet to frozen bead is performed in less than a minute, optimally 15 seconds, to reduce translocation of diffusible ions. Prior to examination, the stubs are transferred from liquid nitrogen into the AMRay Biochamber, which is maintained at a vacuum better than $10^{-4}$ torr and a temperature of less than $-170^{\circ} \mathrm{C}$ (for details of biochamber operation and specifications, see Ref. 1). During this transfer operation, the specimen is thermally isolated within a precooled transfer housing. The bead is fractured to expose interior surfaces of randomly oriented embryos. Fractures falling just short of the desired plane can be etched with a radiant heater to expose intact primary mesenchyme cclls within the blastocoel. Furthermore, processing in a continuous vacuum exposes relatively uncontaminated surfaces for $\mathrm{x}$-ray microanalysis. Although examination of bulk tissue provides superior thermal energy dissipation, bulk tissue reduces the spatial resolution of the $x$-ray data to cellular dimensions, due to teardrop shaped interaction volume. ${ }^{2}$

Fractured surfaces are examined in the AMRay OOA SEM by secondary electron imaging mode.
Stereo pair photographs are taken at $50 \times$ magnification and $20^{\circ}$ separation tilt, and are employed as guides to topography. This helps to maintain a constant average take-off angle and prevent soft $x$ rays from being absorbed by interposing tissue masses. An appropriate embryo is chosen, oriented for optimal x-ray collection, and photographed at $500 \times$ magnification. This photograph becomes a map for the microanalysis data collected; each cell analyzed yields information on the peak to background ratios of sodium, magnesium, phosphorous, potassium, sulfur, chlorine, calcium, and manganese. To standardize conditions and prevent translocations of diffusable ions, surfaces are neither etched nor coated prior to this initial data collection. Under these conditions cell boundaries are difficult to identify. In Fig. 1 small organelles can be seen, but cell-cell junctions lie beneath the ice surface. After initial elemental analysis, specimens are freeze dried in the biochamber overnight, for improved morphological examination. The freezedried sample is photographed at slightly greater than $500 \times$, to compensate for shrinkage (Fig. 2), and the images superimposed to verify $\mathrm{X}$-ray source location (Fig. 3).

Preliminary results from this investigation are presented here in the form of peak-to-background ratios since a matrix of known standards, collected under identical conditions, will be necessary to calculate weight percent concentrations by the method of Statham and Pawley. ${ }^{3}$ However, some trends have been observed in early primary mesenchyme extrusion into the blastocoel. Table 1 illustrates a higher concentration of $\mathrm{Cl}$ and reduced

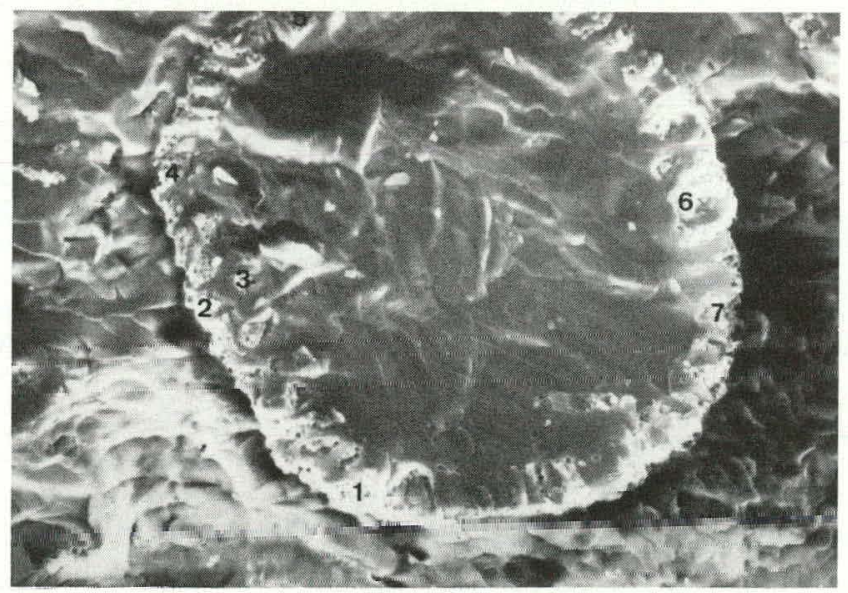

Fig. 1. Frozen hydrated blastula in $20 / 50$ matrix. The specimen is fully hydrated. Blastula is at about the 400-cell stage with no apparent primary mesenchyme cell extrusion. The numbers indicate cells from which data were collected. Magnification $500 \times$.
(XBB 830-9587A) 


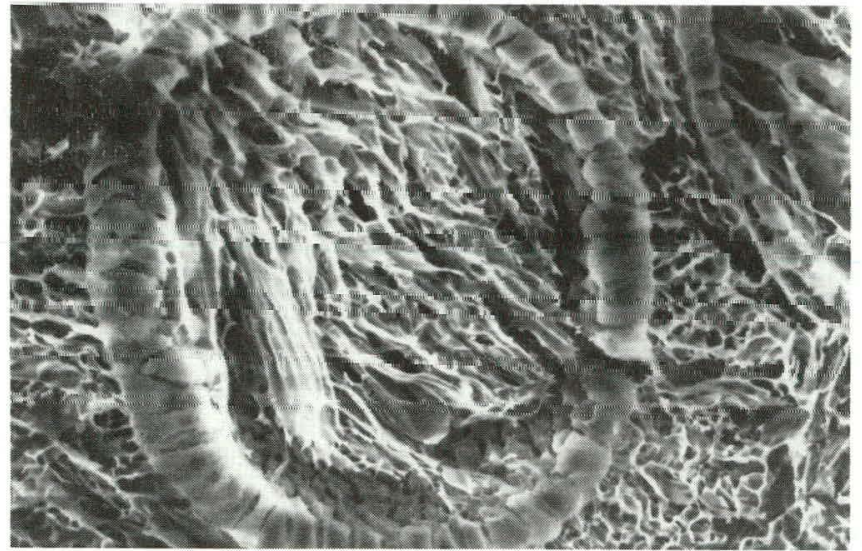

Fig. 2. The identical blastula as Fig. 1. free-dried. Magnification $520 \times$. (XBD 830-9588)

concentrations of $\mathrm{P}$ and $\mathrm{K}$ in primary mesenchyme cells. $\mathrm{S}$ and $\mathrm{Ca}$ exhibit considerable variation in the early mesenchyme blastula which may imply either rapid exchange of ions, or experimental errors, such as misidentification of the cells or slow freezing which allowed the ions to diffuse. Also, the high $\mathrm{Cl}$ peaks may be influenced by extraneous $x$ rays from the blastocoel.

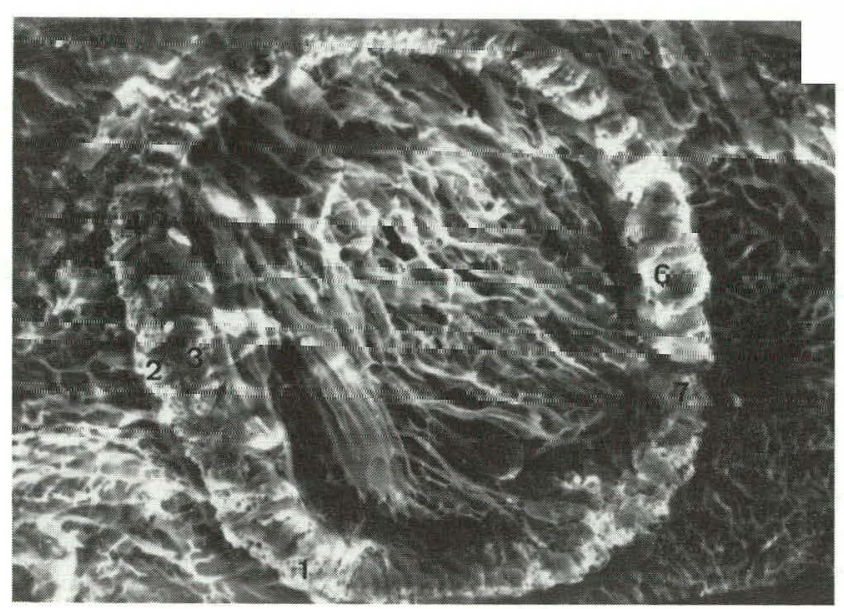

Fig. 3. Figures 1 and 2 superimpused fur identification of microvolumes analyzed. (XBB 830-9589A)

\section{REFERENCES}

1. Hayes, T.L., Bastacky, S.J., Sprague, L.M., Finch, G.L., Hook, G., and McKoon, M. Biology and Medicine Division Annual Report 1980-1981, Lawrence Berkeley Laboratory report LBL-13501.

2. Echlin, P., Lai, C., and Hayes, T.L. J. Micros. 126, 3, 285-306 (1982).

3. Statham, P.J., and Pawley, J.B. S.E.M. Inc. 1, 469-478 (1978).

Table 1. Peak-to-background ratios for elements exhibiting detected trends. Data were taken at about the 400-cell stage.

\begin{tabular}{lccccc}
\hline Cell type & $\mathrm{P}$ & $\mathrm{S}$ & $\mathrm{Cl}$ & $\mathrm{K}$ & $\mathrm{Ca}$ \\
\hline $\begin{array}{l}\text { Primary } \\
\text { mesenchyme }\end{array}$ & $0.29 \pm 0.04$ & $0.27 \pm 0.08$ & $1.97 \pm 0.33$ & $1.59 \pm 0.11$ & $0.10 \pm 0.04$ \\
Epidermal & $0.34 \pm 0.04$ & $0.23 \pm 0.01$ & $1.40 \pm 0.04$ & $1.67 \pm 0.10$ & $0.15 \pm 0.04$ \\
\hline \hline
\end{tabular}




\section{Studies of Lipoproteins and Other Macromolecules}

\section{CIRCULAR DIFFERENTIAL SCATTERING CAN BE AN IMPORTANT PART OF THE CIRCULAR DICHROISM OF MACROMOLECULES}

\section{Marcos F. Maestre, Carlos Bustamante," and Ignacio Tinoco, Ir.*}

Circular dichroism (CD) and optical rotatory dispersion (ORD) studies have been very helpful in providing useful knowledge about the structure of biological macromolecules. These methods were originally limited to homogeneous solutions of macromolecules. More recently, they have also been applied to increasingly complex systems such as viruses, erythrocytes, nucleohistones, DNApolylysine complexes, DNA aggregates, chloroplasts, etc. ${ }^{1}$ A remarkable common feature of many of these systems was the presence of anomalies in their CD and ORD spectra. The CD spectra presented: 1) Apparent differential absorption of circularly polarized light outside of the absorption bands. The $C D$ signal at long wavelengths was slowly varying, but nonzero; this long wavelength "tail" could be positive or negative. 2) Signals sensitive to the distance of the photomultiplier from the sample. 3) $C D$ values one or two orders of magnitude larger than normal. Figure 1 illustrates some of these anomalies (unpublished data).

Recently, a new quantitative understanding of differential scattering of circularly polarized light has been obtained. ${ }^{2-6}$ We were able to relate the difference in scattering efficiency for incident left and right circularly polarized light to the detailed structure of the scattering particle. ${ }^{2-5}$ We have measured the angular dependence of this circular intensity differential scattering for a helix of known structure, and obtained good agreement with theory. ${ }^{6}$ Thus, we can now explain the "anomalous" behavior of chiral macromolecules and aggregates. We find that the scattering "artifacts" can provide valuable information about the configuration (left- or right-handed) of the component particles.

Here we will show how the differential scattering of left and right circularly polarized light contributes to the differential extinction of circularly polarized light as routinely measured in a circular dichroism spectrometer. As the differential absorption of circularly polarized light can be measured by fluorescence-detected circular dichroism in a sedarate experiment, ${ }^{6}$ the circular differential

Lavoratory of Chemical Biodynamics, LBL. scattering can be obtained by difference. This circular differential scattering is directly related to the geometry (distances and orientations between the scattering elements); it can thus give information about the conformations of the macromolecules in the sample.

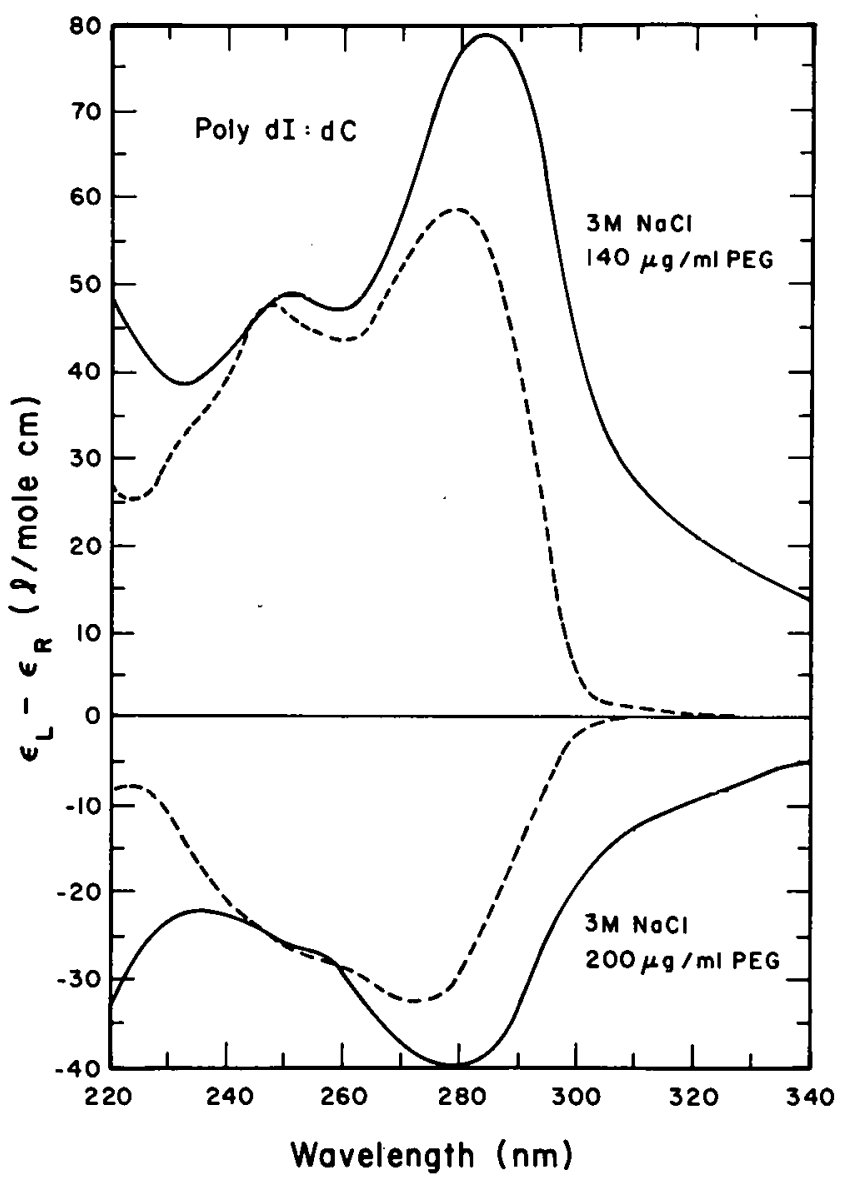

Fig. 1. An illustrative example of the effect of circular differential scattering on circular dichroism. The synthetic polynucleotide poly $D d l$ : poly $d C$ was placed in different concentrations of polyethylene glycol in $3 \mathrm{M} \mathrm{NaCl}$. The solid lines show the measured circular dichroism which is large at wavelengths above the absorption region of the polynucleotide, the dashed lines show the approximate removal of the differential scattering effect provided by a fluorscat cell.

(XBL 8210-3002) 


\section{THEORY}

\section{Phenomenological Equations}

We wish to derive the combined effect of circular differential absorption and circular differential scattering on circularly polarized light incident on a sample. The results will be obtained in terms of $\left(a_{L}\right.$ $\left.-a_{R}\right)$, the circular differential absorption $\left(s_{L}-s_{R}\right)$, the circular differential scattering, and $\sigma_{L^{\prime}}, \sigma_{R^{\prime}}$ the angular-dependent scattering cross-sections for circularly polarized light.

The scattering of a sample depends on the angle between the incident beam and the scattered beam; it can be characterized by a scattering cross-section per scattering solute molecule. The solvent scattering is usually subtracted from the sample scattering, therefore the scattering crosssection characterizes the scattering of the solute molecule compared to an equal volume of solvent. In dilute solutions the scattering cross-section per molecule is independent of concentration, i.e., multiple scattering effects can be neglected. For a chiral unoriented sample, the scattering crosssection will depend on the state of the circular polarization of the light.

The Beer-Lambert law defines an extinction coefficient, $\epsilon$.

$$
\mathrm{I}=\mathrm{I}_{\mathrm{o}} 10^{-\mathrm{\epsilon c \ell}}
$$

Here $I$ is the transmitted intensity when light of intensity $I_{0}$ is incident on a sample with concentration, $c$, in pathlength, $\ell$. The units of $\epsilon$ are $\ell$ mole $\mathrm{cm}^{-1}$. The extinction coefficient is the sum of an absorption coefficient, $a$, and a scattering coefficient, s. These coefficients are related molecular cross-sections for absorption and scattering. The molecular scattering cross-section is the integral over all angles of the angular-dependent cross-section for the scattering particle. The angular-dependent scattering cross-section has units of $\mathrm{cm}^{2}$ molecule ${ }^{-1}$ and characterizes the intensity scattered at any angle by a molecule. The scattered intensity depends on the light incident on the molecule, 1 , the distance, $r$, from the scattering molecule, and the angles measured relative to the incident beam. For an unoriented sample, in which the molecules have all orientations, the molecular scattering cross-section depends on only one angle, $\sigma_{\text {sca }}(\theta)$. The measured scattered intensity will depend on the experimental arrangement through $r$, the distance from the sample to detector, the angular acceptance of the detection optics, and the scattering volume as defined by the incident beam and the detection optics. The measured intensity will of course depend on the concentration of the sample. We will designate the angular-dependent scattering cross-section from the scattering volume (which depends on concentration and detection geometry) as $\sigma(\theta)$; it has units of $\mathrm{cm}^{2}$.

\section{The Scattered Beam}

At any angle except zero, only the scattered beam is detected. The derivation of the circular intensity differential scattering is straightforward; however one must realize that the scattered beam is not circularly polarized except at $0^{\circ}$ and $180^{\circ}$. Although we do not measure the polarization of the scattered beam, its attenuation in passing

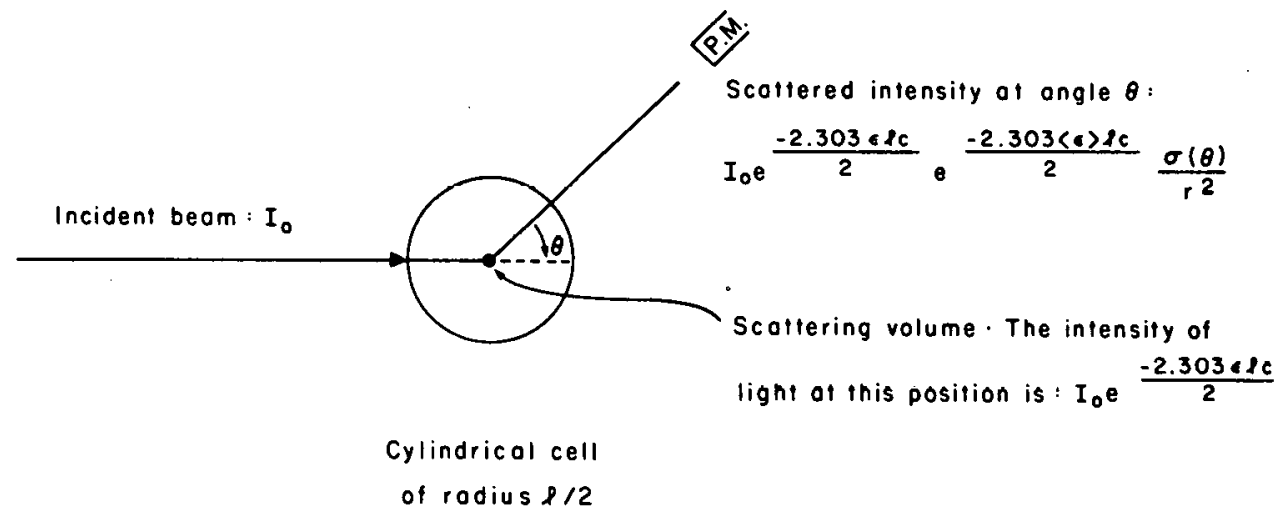

Fig. 2. The scattering geometry. The scattered intensity at angle theta depends on the scattering cross-section at that angle, $\sigma(\theta)$, divided by the square of the distance, $r$, from the scattering volume to the photomultiplier detector. The attenuation of the incident light before reaching the scattering volume, and of the scattered light before leaving the cell must be considered. As incident circularly polarized light changes its state of polarization depending on the scattering angle, the appropriate weighted extinction coefficient, $\langle\epsilon\rangle$, must be used for the scattered beam. 
rough the sample cuvette does depend on its ...te of polarization. When a left circularly polarized beam is incident on a point scatterer, the scattered light will be left circularly polarized at $0^{\circ}$, linearly polarized at right angles $\left(90^{\circ}\right)$, and right circularly polarized at $180^{\circ}$. At any angle in between the light is elliptically polarized, but its state of polarization depends only on the scattering angle. For larger scatterers the state of polarization also depends on the properties of the scattering molecule; however, for most samples the depolarization effect is much less than $5 \%$. We will assume that it is negligible, and obtain

$$
\begin{aligned}
\frac{I_{L}-I_{R}}{I_{L}+I_{R}} & =\frac{-2.303}{2}\left(\epsilon_{L}-\epsilon_{R}\right) c \ell\left[\frac{1+\cos \theta)^{2}}{2\left(1+\cos ^{2} \theta\right)}\right] \\
& +\frac{\sigma_{L}(\theta)+\sigma_{R}(\theta)}{\sigma_{L}(\theta)+\sigma_{R}(\theta)}
\end{aligned}
$$

This is an expression for the circular intensity differential scattering at any angle. Again there are two terms. The first term characterizes the differential attenuation of the scattered beam due to circular differential absorption and scattering in the cuvette. The second term characterizes the circular differential scattering cross-sections at any angle. The terms can be separated by varying the concentration; the first term is linear in the concentration, so extrapolation to zero concentration leaves only the second term, which is independent of concentration. In our earlier work ${ }^{1-4}$ we have only considered this second term. Outside all absorption bands $a_{L}-a_{R}$ is zero and only $s_{L}-s_{R}$ contributes to the first term. However, as mentioned before, the sign and magnitude of $s_{L}-s_{R}$ is not simply related to $\sigma_{L}(\theta)-\sigma_{R}(\theta)$.

Although we are primarily interested here in the effects of circular differential scattering, Eq. (1) can be applied to a nonchiral scatterer mixed with a chiral absorber (for example, polystyrene spheres in a camphor sulfonic acid solution). Then only the first term in Eq. (1) is nonzero. This method can be called scattering detected circular dichroism in analogy with fluorescence detected circular dichroism.

\section{CONCLUSION}

Circular differential scattering can be a significant contribution to circular dichroism whenever the dimension of the particles of interest is onetwentieth the wavelength of light, or larger. Whether the scattering effects are important or not will depend specifically on the shape of the particle and its polarizabilities. The sign and magnitude of the circular differential scattering depend directly on the distance and angles between the scattering units. It is not expected to be significant for unaggregated proteins or nucleic acids in solution. However, whenever an apparent circular dichroism is measured outside the absorption bands of the sample, the differential scattering must obviously be taken into account before a quantitative interpretation of the circular dichroism is attempted.

Circular differential scattering depends upon the phase difference of the light scattered from different points in the molecule, therefore to a first approximation the electronic interaction between the scattering units can be neglected. This circular differential scattering, which until now was treated as an unwanted artifact, is a measure of long-range organization (distances greater than $20 \mathrm{~nm}$ ). It can be interpreted simply and directly in terms of scattering from pairs of polarizable groups in the molecule.

\section{REFERENCES}

1. Tinoco, I., Jr., Bustamante, C., and Maestre, M.F. Ann. Rev. Biophys. Bioeng. 9, 107-141 (1980).

2. Bustamante, C., Maestre, M.F., and Tinoco, I., Jr. J. Chem. Phys. 73, 4273-4281 (1980).

3. Bustamante, C., Maestre, M.F., and Tinoco, I., Jr. J. Chem. Phys. 73, 6046-6055 (1980).

4. Bustamante, C., Tinoco, I., Jr., and Maestre, M.F. J. Chem. Phys. 74, 4839-4850 (1981).

5. Bustamante, C., Tinoco, I., Jr., and Maestre, M.F. J. Chem. Phys. 76, 3440-3446 (1982).

6. Maestre, M.F., Bustamante, C., Subirana, J., Hayes, T., and Tinoco, I., Jr. Nature 298, 773 (1982). 


\section{BIOPHYSICAL STUDIES OF IMMUNE RECOGNITION}

\author{
John C. Owicki
}

Much of the work in our laboratory during the past year has centered on the molecular mechanisms of interactions involving biological surfaces. We are especially interested in cases involving specific ligand-receptor interactions, as when antibodies bind to antigen-bearing membranes and thus mark them for destruction by other components of the immune system. More specifically, we are studying how the specificity and strength of such recognition phenomena depend on the physical and chemical states of the system of interacting molecules.

The complexity of native biological systems often hinders investigations, particularly at the molecular level. Such difficulties are severe in immunology. One solution is to study a simplified model system, thus allowing one to investigate many of the salient features in relative isolation. The remainder of this report is a description of the model system that we have devised, followed by a summary of some of our results from the past year.

Some basic questions about the recognition of biological membranes by antibodies include: What is the strength of the binding? What are the kinetic factors? Most antibodies are bivalent; how does this affect the interaction? Membranes act in many ways like two-dimensional fluids; what effects does this have on antibody binding, particularly under conditions that lead to a highly polymerized antibody-antigen complex?

The primary impediment is the complexity of the typical cell membrane. Therefore, we have substituted vesicles made from phospholipid bilayers. Such vesicles are not, however, particularly antigenic. So we had to develop an antibody-antigen system in which the antigen could be incorporated into the vesicles. An important criterion was that the antigen have properties that would make the antibody-antigen interaction easy to analyze.

The spectroscopic properties of many fluorescent molecules are sensitive to the molecular environment of the fluorophore. This is true for fluorescein. Its fluorescence spectra are shifted by solvents of varying polarity and structure, it selfquenches when clustered, and its fluorescence is usually quenched when it is bound by specific antifluorescein antibodies. The effects of antibody binding on the excitation spectrum of sodium fluorescein are shown more fully in Fig. 1. It

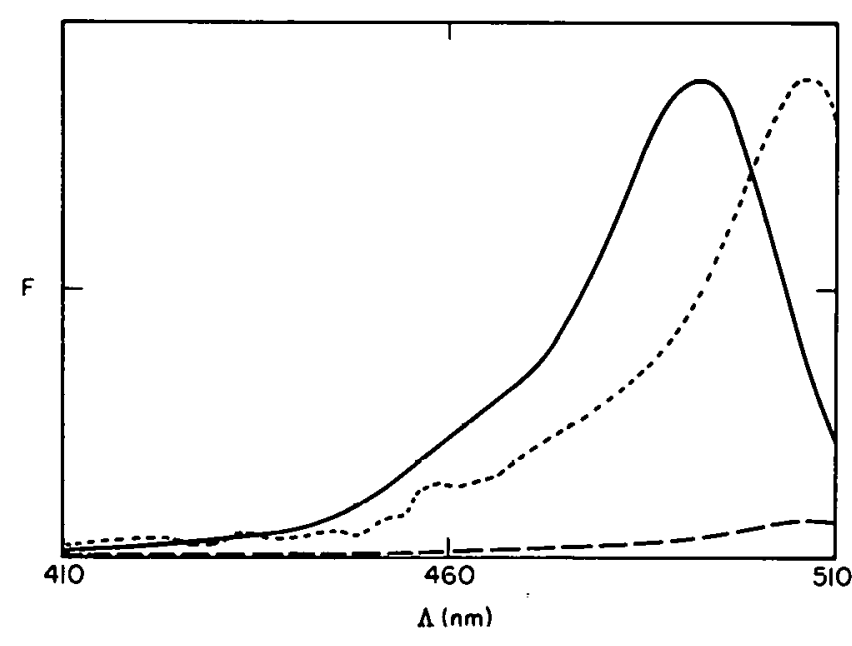

Fig. 1. Quenching of fluorescence of sodium fluorescein by monoclonal anti-fluorescein antibody. Fluorescence excitation spectra for unbound (solid line) and bound (dashed line) fluorescein. Dotted line represents bound spectrum expanded vertically to same height as unbound spectrum, for better display of spectral shape. Emission wavelength, $540 \mathrm{~nm}$. Fluorescence is in arbitrany units, excitation wavelength, $\Lambda$, is in $\mathrm{nm}$.

(XBL 8311-4116)

demonstrates the quenching of bound fluorescein and an associated red shift of its spectrum. We have tethered fluorescein covalently to the headgroup of a phospholipid and incorporated this into phospholipid vesicles as a minor component. Analysis of the fluorescence of these vesicles reveals a great deal about the behavior of the probe. More importantly, we have obtained monoclonal murine $\operatorname{lgC} 2 \mathrm{~b}$ antibodies against fluorescein. When these bond to the fluorescein hapten on the vesicles, they quench the fluorescence almost completely, allowing us to follow the antibodymembrane interaction in real time at nanomolar concentrations of the reacting components.

We reasoned that such vesicles would make an ideal model target system for studying the physical and chemical factors that are important in antibody-dependent immune recognition. Since we finished assembling the model system earlier this year, we have concentrated on two areas: characterizing the properties of the fluorescein hapten on the vesicles, and studying the equilibrium and kinetic aspects of the binding of the monoclonal antibodies. This has led to two principal result First, the accessibility of the hapten to antibod depends strongly on the lipid composition of th. 
icles. Second, we can clearly detect and study .... effects of bivalency in the antibody binding. These results are briefly discussed in turn below.

Vesicles were made from a variety of phosphatidyl-cholines ( $P C^{\prime}$ 's), with acyl chains that were saturated or unsaturated, and "fluid" or "solid" under experimental conditions. The kinetics of antibody binding to the haptenated vesicles showed an initial fast phase (time scale: tens of seconds) followed by a slow phase lasting many minutes. The rates and amplitudes of the two processes depend on the PC used. Further, they depend on the antibody concentrations employed. We made monovalent Fab fragments from the lgG, which showed binding behavior to sodium fluorescein identical to that of the parent lgG. Fab binding to the vesicles also showed the two processes.

Spectroscopic studies on the haptenated vesicles without antibody present suggested that some of the haptens are rather close to the PC head groups in spite of the oligopeptide spacer between the hapten and the lipid on our synthetic molecule. The evidence includes a red shift of the excitation spectrum, relative to that of sodium fluorescein, and an increase of the monoanion/di-anion protonation pKa for the probe of two units above the value for sodium fluorescein. Further, in some cases we have been able to detect the presence of two populations of haptens spectroscopically. Our conclusion is that in these systems the haptens exist in an equilibrium between at least two states: extended away from the vesicles where they are accessible to antibodies, and associated with the membrane surface, where they cannot be bound.
The fast binding phase involves those haptens initially extended, and the slow phase represents the binding on initially membrane-associated haptens as the hapten conformational equilibrium is shifted by the antibody binding.

When vesicles were made from binary mixtures of PC's and cholesterol, e.g., at a 2:1 molar ratio, antibody binding was enhanced and the slow phase substantially disappeared. Spectroscopically the hapten looked much more like sodium fluorescein than it did in pure PC vesicles. We believe that cholesterol largely eliminates the association of the hapten with the membrane surface. In other immunological systems involving haptenated vesicles, cholresterol has caused a similar increase in the target reactivity. We are in a good position to discover the molecular mechanism of this phenomenon.

DPPC:cholesterol vesicles were chosen for more extensive equilibrium binding studies, particularly comparing $\mathrm{Fab}$ and IgG. Computer analysis of fluorescence titrations of the haptenated vesicles by Fab demonstrated that the system obeyed the same mass-action binding law as did Fab or $\operatorname{lgG}$ with sodium fluorescein: $\mathrm{Fab}+\mathrm{H} \neq \mathrm{Fab} \cdot \mathrm{H}$, where $\mathrm{H}$ represents hapten. Moreover, the measured affinity constant was similar to that involving sodium fluorescein: 400/micromolar. IgG, however, bound to the membranes more avidly and did not obey a simple binding law. This is presumptive evidence for bivalent interactions between the IgG and the vesicle surface, which means that we will indeed be able to do proposed studies of the biological significance of such bivalent binding.

\section{INHIBITION OF PROTON TRANSPORT IN PURPLE MEMBRANE BY DICYCLOHEXYLCARBODIIMIDE}

\section{Bing K. Jap and Robert M. Glaeser}

Proton transport by bacteriorhodopsin (bR) might involve structural principles that are homologous to other cell membrane transport systems or, at least to other $\mathrm{H}^{+}$-transport systems. Several ion transport systems such as $\mathrm{Ca}^{2+}$-ATPase ${ }^{1}$ and the system that is involved in electrogenic $\mathrm{Cl}^{-}$transport in brown adipose tissue mitochondria ${ }^{2}$ are inhibited by a strongly hydrophubic small molecule, dicyclohexylcarbodiimide (DCCD). Many proton transport systems, such as $\mathrm{H}^{+}$-ATPase ${ }^{3}$ and cyto- ome oxidase ${ }^{4}$ are also inhibited by DCCD. The ibition of $\mathrm{H}^{+}$-ATPase involves a covalent reacun with a carboxyl group that is believed to be buried in the interior of the membrane. Previous efforts by other investigators to react $b R$ with DCCD have produced no evidence of DCCDinduced inhibition of proton transport. We report here that DCCD does inhibit proton transport by bR when $b R$ is reconstituted into soybean phospholipid vesicles using detergent. The reaction probably also involves covalent binding with a carboxyl group in the membrane, similar to the case for $\mathrm{H}^{+}$. ATPase.

Delipidated $b R$ reconstituted into phospholipid vesicles using deoxycholate/cholate technique ${ }^{5}$ consistently gives a large light-induced $\mathrm{pH}$ 
response. The $\mathrm{pH}$ response indicates a light-driven proton translocation from the outside medium to the interior of the vesicle. This translocation across the membrane has been shown using indicator dye. ${ }^{5}$

DCCD added at a small molar ratio gives small or no significant effect on proton transport by $b R$. At a large molar ratio, DCCD reacts with $b R$ giving a reduction in the maximum $\mathrm{pH}$ response and in the initial rate of $\mathrm{pH}$ change (Fig. 1). The initial rate of $\mathrm{pH}$ change is directly proportional to the efficiency with which $b R$ generates the lightinduced net transport of protons into the vesicles. The decrease in the initial rate of $\mathrm{pH}$ change indicates therefore that DCCD inhibits the proton transport by hR.

The reaction of DCCD with delipidated $b R$ reconstituted into vesicles also changes the visible absorption spectrum of the chromophore (Fig. 2). The absorption maximum is shifted from 555 to $500 \mathrm{~nm}$ after addition of DCCD. Purple membrane patches which have not been delipidated are not affected significantly by DCCD even when DCCD is added in a great excess. This suggests that DCCD reacts with a site or sites in the interior of the membrane that is or are made accessible by delipidation. Determination of the DCCD binding site(s) is an important next step as this information would provide additional constraints for the threedimensional modeling of $b R$ secondary and tertiary structure.

INHIBITION OF H \pm PUMPING BY IOO:I MOLE RATIO OF DCCD

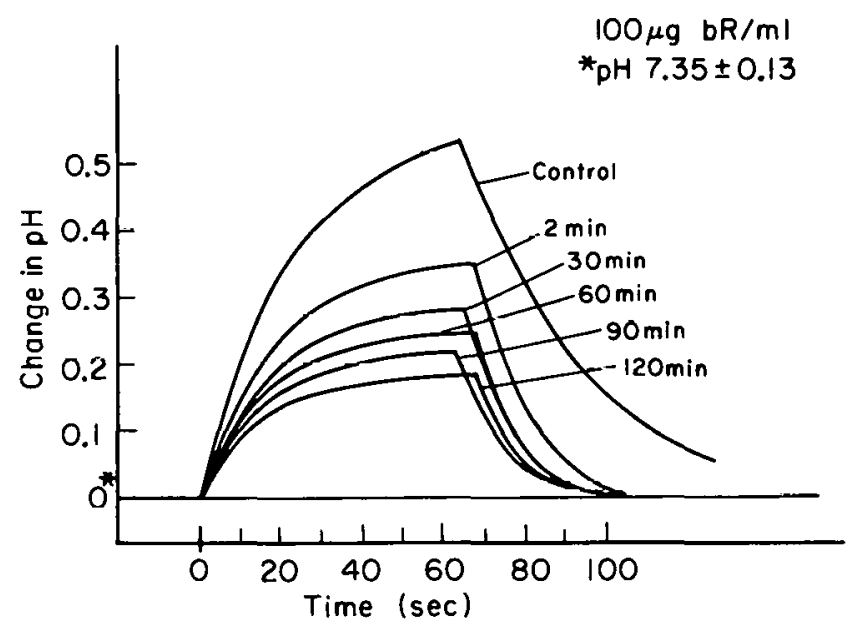

Fig. 1. Time dependent inhibition of the light-driven proton pumping by bacteriorhodopsin reconstituted in phospholipid vesicles after addition of excess of DCCD (100:1 molar ratio of $D C C D$ to $b R$ ) for various incubation times. The variation in the baselines of $\mathrm{pH}$ is within the range $7.35 \pm 0.13$. (XBL 831-3503)

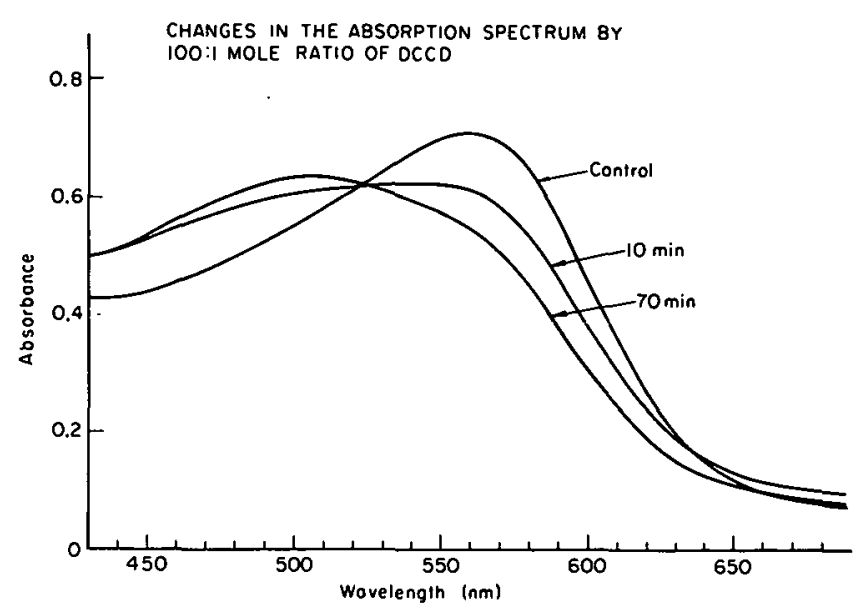

Fin. 2. The time dependent change in absorption spectrum of reconstituted hR vesirles after addition of excess DCCD (100:1 molar ratio of DCCD to $b R$ ).

(XBL 831-3556)

The observed reaclion of DCCD with $b R$ indicates that the proton transport "channel" of bR has properties analogous to that of other proton channels and other DCCD sensitive ion transport channels, in apparently unrelated membrane proteins. We can now expect that the mechanism of ion transport in $b R$ is similar to that of other ion pumps and that the determination of the high resolution structure of bR by electron crystallography may be of great significance in understanding general principles involved in ion translocation by other systems.

\section{REFERENCES}

1. Murphy, A.J. Kinetics of the inactivation of the ATPase of sacroplasmic reticulum by dicyclohexylcarbodiimide. J. Biol. Chem. 256, 12046-12050 (1981).

2. Warhurst, I.W., Dawson, A.P., and Selwyn, M.J. Inhibition of electrogenic anion entry into rat liver mitochondria by $\mathrm{N}, \mathrm{N}^{\prime}$-dicyclohexylcarbodiimide. FEBS Lett. 149, 249-252 (1982).

3. Sebald, W., and Hoppe, J. On the structure and genetics of the proteolipid subunit of the ATPsynthase complex. Current Topics in Bioenergetics, Vol. 12, pages 1-64 (1981).

4. Casey, R.P., Thelen, M., and Azzi, A. Dicyclohexylcarbodiimide inhibits proton translocation by cytochrome C-oxidase. Biochem. Biophys. Res. Comm. 87, 1044-1051 (1979).

5. Hwang, S.-B., and Stoeckenius, W. Purple membrane vesicles: Morphology and prof-translocation. J. Membrane Biol. 33, 325-: (1977). 


\title{
IGH DENSITY LIPOPROTEIN (HDL) ORIGINS: A MAJOR CONVERSION . .ITHWAY
}

\author{
Alex V. Nichols, Elaine L. Gong, Patricia J. Blanche, Trudy M. Forte, and \\ Virgie G. Shore
}

It is generally accepted that normal or mature plasma high density lipoproteins (HDL) consist of several subpopulations of spheroidal particles that exhibit a relatively wide range of particle size (7-12 $\mathrm{nm})$. In certain lipid abnormalities, such as lecithin:cholesterol acyltransferase deficiency, unique HDL particles, enriched in phosphatidylcholine and unesterified cholesterol and termed "discoidal" or "nascent" HDL, are present in plasma along with a subpopulation of low molecular weight spheroidal particles. We and others have shown that incubation of the discoidal HDL with active lecithin:cholesterol acyltransferase transforms them to spheroidal particles.

We have recently shown that it is possible to form relatively discrete classes of discoidal complexes composed of egg yolk phosphatidylcholine (egg yolk PC) and apolipoprotein A-I (the major structural protein of $\mathrm{HDL}$ ) with and without unesterified cholesterol. These complexes can serve as model precursors for detailed study of the time course and the products formed during lecithin:cholesterol acyltransferase-induced conversion.

In the present studies we have investigated the conversion of a major class of model discoidal complexes, designated complex class 3 , which has a mean long dimension of $10.5 \mathrm{~nm}$ by electron microscopy and a molar ratio of phosphatidylcholine:apolipoprotein A-I of 95:1. A gradient gel electrophoresis pattern of this complex class is shown in Fig. 1, together with an electromicrograph revealing discoidal particles aggregated together in stacks. Upon gradient gel electrophoresis, lipoprotein particles migrate to a position corresponding to their particle size; hence, particles with low migration numbers $\left(R_{f}\right.$ values) are larger than those with high values.

Our studies indicate significant reactivity of these model discoidal complexes with plasma components both in the absence and presence of lecithin:cholesterol acyltransferase activity. A major reaction pathway, in the absence of activity, includes conversion of the complexes to small par-

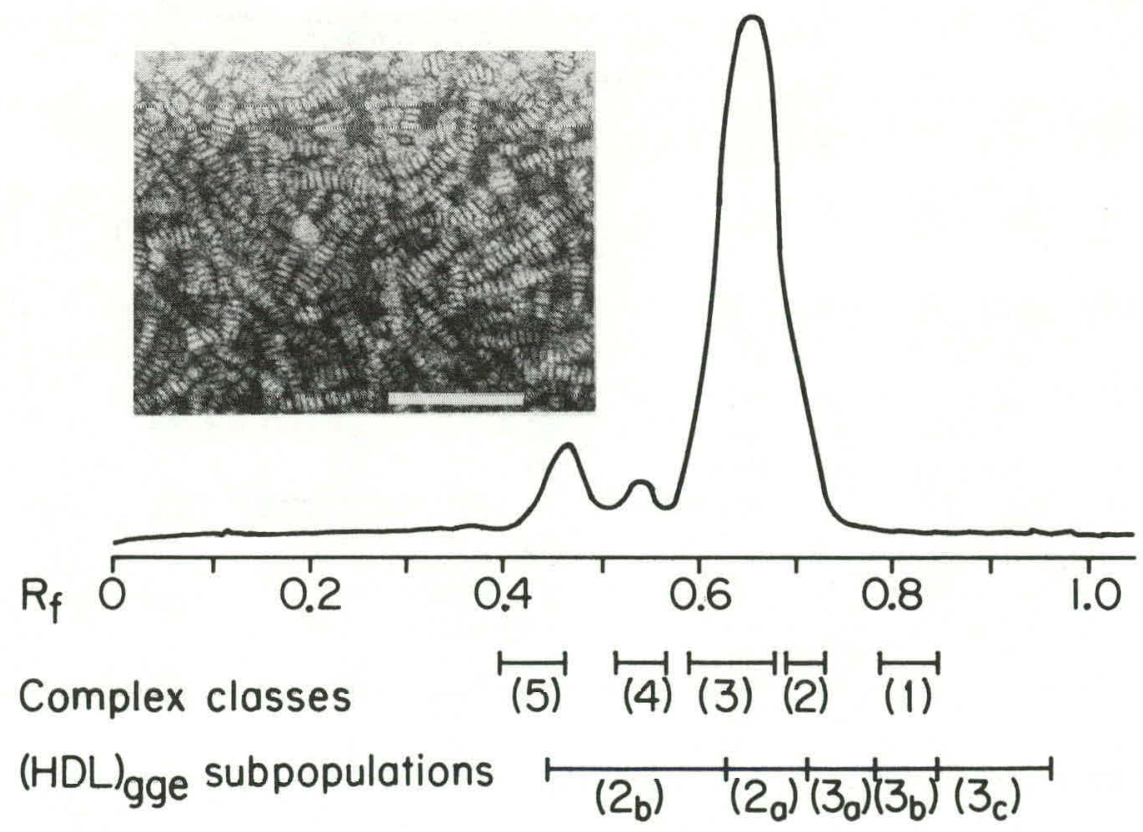

Fig. 1. Gradient gel electrophoresis pattern of an untreated discoidal complex preparation of egg yolk $P C$ and apolipoprotein A-I with molar ratio 95:1, respectively. $R_{f}$ intervals of the complex classes are: class 1 , 0.844-0.781; class 2, 0.72-0.682; class 3, 0.679-0.587., class 4, 0.564-0.512; and class 5, 0.459-0.391. $R_{f}$ intervals of the major subpopulations of $H D L$ are: $\left(H D L_{3}\right)_{\mathrm{gge}^{\prime}} 0.962-0.841 ;\left(H D L_{3 b}\right)_{\mathrm{gge}} 0.841-0.781 ;\left(H D L_{32}\right)_{\mathrm{gge}^{\prime}} 0.781-0.711$; $\left(H D L_{22}\right)_{g g e} 0.711-0.627$; and $\left(H D L_{2 b}\right)_{\text {gge' }} 0.627-0.445$. Electron micrograph of the discoidal complexes is shown in inset; bar marker represents $100 \mathrm{~nm}$. 
ticles, which by gradient gel electrophoresis (Fig. 2) show peak maxima in the migration intervals of the $\left(\mathrm{HDL}_{3 \mathrm{~b}}\right)_{\mathrm{gge}}$ and $\left(\mathrm{HDL}_{3 \mathrm{c}}\right)_{\mathrm{gge}}$ subpopulations of normal human plasma HDL. This conversion is accompanied by partial depletion of phospholipid from the complexes, apparently by transfer to components in the interaction medium. The small

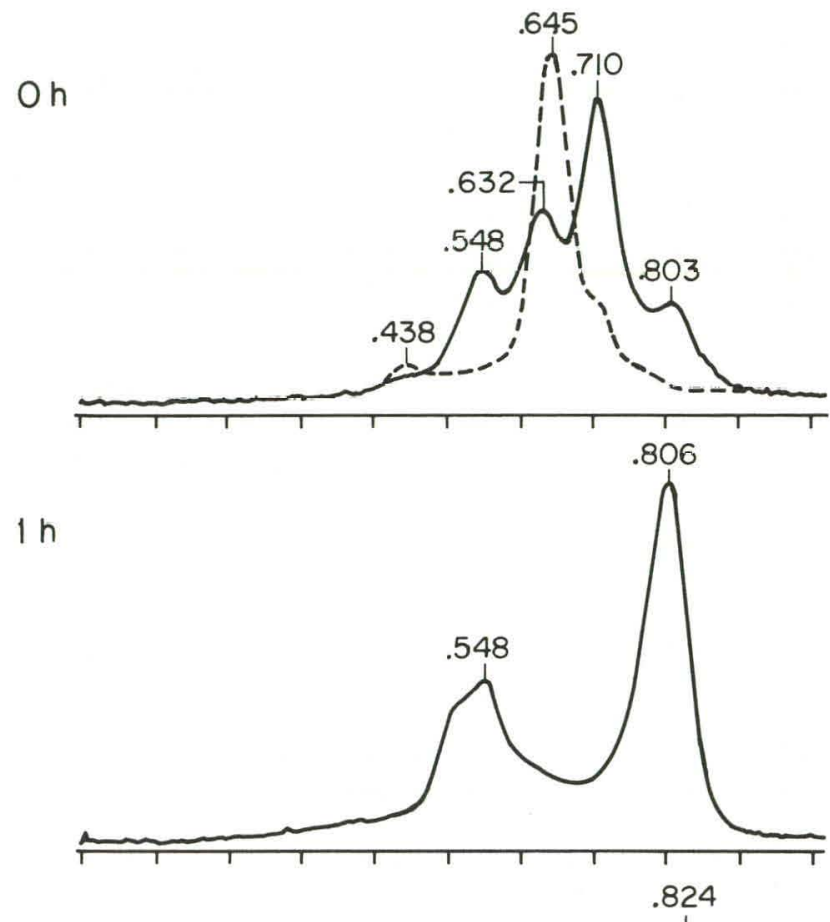

$24 h$

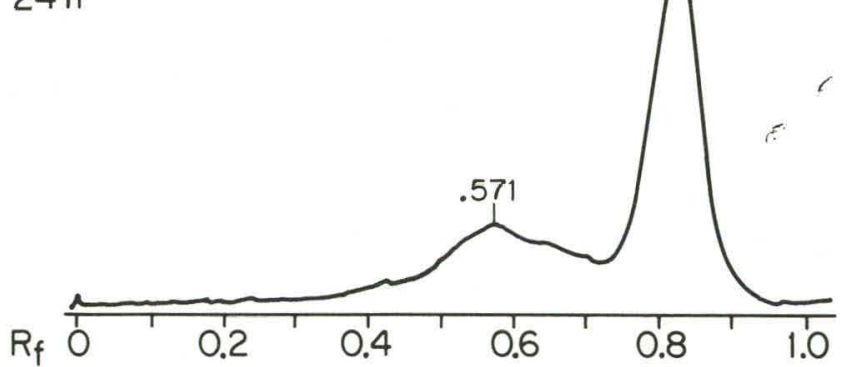

Complex classes

(5)

$(\mathrm{HDL})_{\text {gge }}$ subpopulations $\frac{}{\left(2_{b}\right)}\left(2_{a}^{\prime}\right)^{\prime}\left(3_{a}\right)\left(3_{b}\right)\left(3_{c}\right)$

Fig. 2. Time course of change in electrophoresis patterns of $d$ $1.063-1.20 \mathrm{~g} / \mathrm{ml}$ fractions isolated from incubation mixtures containing: discoidal complex preparations, $L D L$, and $d \geqslant 1.21$ $\mathrm{g} / \mathrm{ml}$ fraction containing lecithin:cholesterol acyltransferase. Lecithin:cholesterol acyltransferase activity was inhibited with paraoxon $(2 \mathrm{mM})$. Patterns of $d 1.063-1.20 \mathrm{~g} / \mathrm{ml}$ fraction from untreated complex preparation (----); complete incubation mixture (- ). $R$, values of major peaks (at maxima) are indicated. Similar results were obtained using $d \geqslant 1.21 \mathrm{~g} / \mathrm{ml}$ fractions isolated from plasma of four different normal subjects.

(XBL 839-3981)

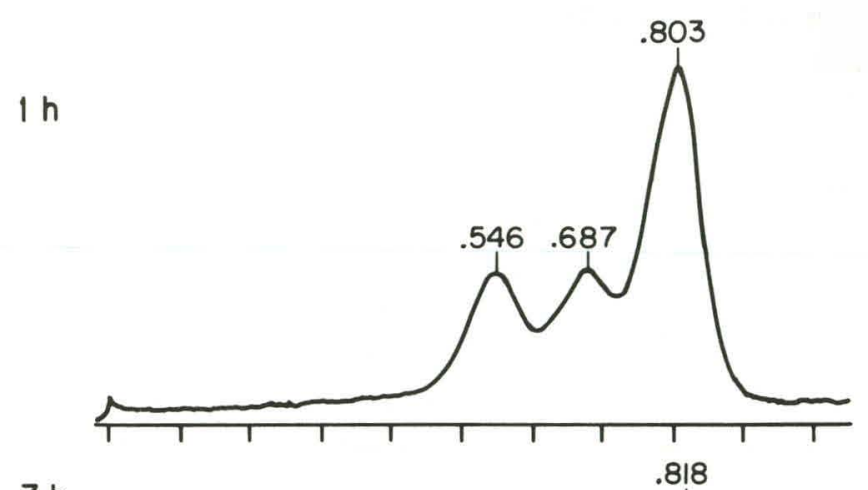

$3 \mathrm{~h}$

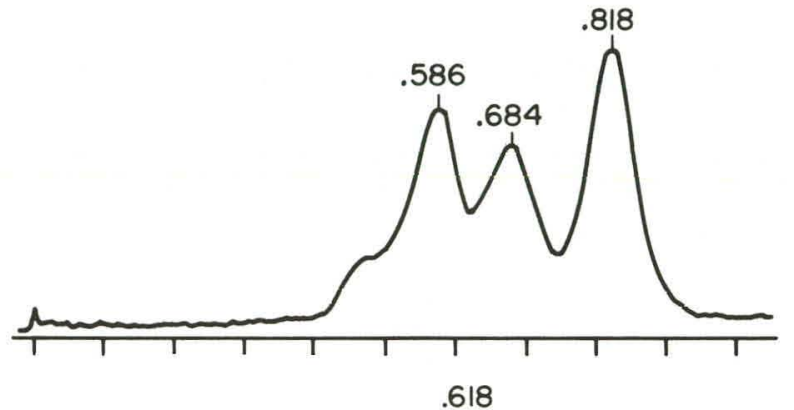

$6 \mathrm{~h}$

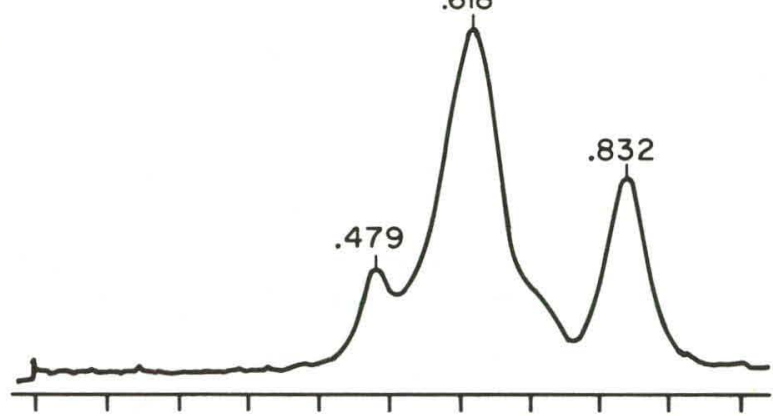

$24 \mathrm{~h}$

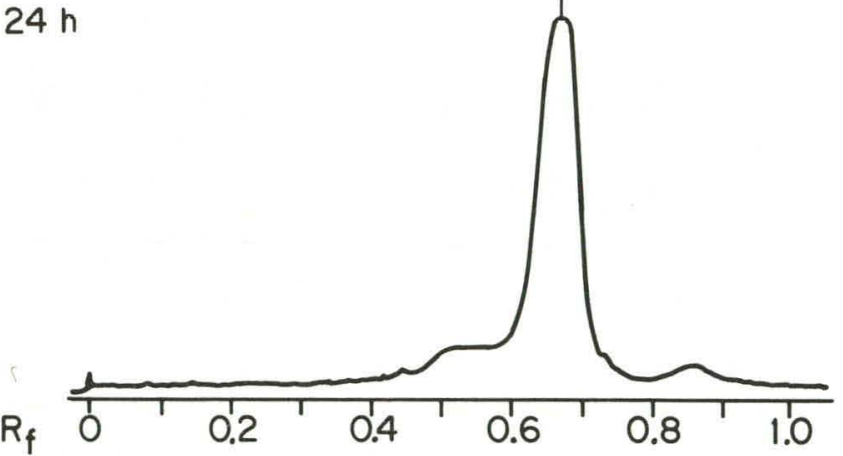

Complex classes

(5) (4) (3) (2)

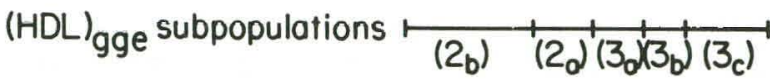

Fig. 3. Time course of change in electrophoretic patterns of $d=1.063-1.20 \mathrm{~g} / \mathrm{ml}$ fractions isolated from the same incubation mixtures as in Fig. 2, but with $14 \mathrm{mM}$ mercaptoethanol to activate lecithin:cholesterol acyltransferase. Similar results were obtained using $d \geqslant 1.21 \mathrm{~g} / \mathrm{ml}$ fractions isolated from plasma of four different normal subjects.

(XBL 839-398 
nversion product appears resistant to further - ospholipid depletion and serves as a precursor to core-containing products in our incubation media when the enzyme is active. In the presence of active enzyme and low density lipoproteins (LDL) as a source of unesterified cholesterol, the conversion, within 1 hour of incubation, of a major part of the initial complex mass to small species is similar to that observed when the enzyme is inhibited (Fig. 3). Following longer incubation periods, however, the small species are converted to larger round particles, whose $R_{f}$ values at peak maxima fall close to the $R_{f}$ value separating the plasma $\left(\mathrm{HDL}_{2 \mathrm{a}}\right)_{\mathrm{gge}}$ and $\left(\mathrm{HDL}_{3 \mathrm{a}}\right)_{\mathrm{gge}}$ subpopulations, and are enriched in apolar lipid.

The time course of conversion of the small product to larger species, at incubation times beyond 1 hour, does not appear as a progressive increase in particle size as might be expected from a gradual build-up of apolar core in precursor species. The conversion appears essentially as a single-step process proceeding from particles with electrophoretic peak maxima in the $\left(\mathrm{HDL}_{3 b}\right)_{\text {gge }}$ and $\left(\mathrm{HDL}_{3 \mathrm{c}}\right)_{\mathrm{gge}}$ intervals directly to products with peak maxima in the $\left(\mathrm{HDL}_{2 \mathrm{~b}}\right)_{\mathrm{gge}}$ and $\left(\mathrm{HDL}_{2 \mathrm{a}}\right)_{\text {gge }}$ intervals, with no discernible peak maxima appearing in the intervening $\left(\mathrm{HDL}_{3 \mathrm{a}}\right)_{\mathrm{gge}}$ interval. The latter interval is the location of one of the major HDL subpopulations observed in normal human plasma. If this conversion process is a major source of the $\left(\mathrm{HDL}_{3 \mathrm{a}}\right)_{\mathrm{gge}}$ subpopulation in vivo, then some remodeling of the $\left(\mathrm{HDL}_{2 \mathrm{a}}\right)_{\mathrm{gge}}$-like conversion product, in terms of its size and compositional properties, would be required.

Our studies indicate that both LDL and very low density lipoproteins (VLDL) can provide the unesterified cholesterol required for enzymeinduced conversion of the model complexes. In the presence of VLDL considerable transfer of triglyceride for cholesteryl ester appears to occur between the conversion products and the VLDL.

In more recent studies we have demonstrated that the discontinuous nature of this transformation pathway appears linked to the incorporation of one additional apolipoprotein A-I molecule into the small product in the course of conversion to the larger species. These findings provide detailed insight into a major conversion pathway whose transformation products correspond closely to $\mathrm{HDL}$ species encountered in normal human plasma. These results are of interest not only because they increase our understanding of the origins of plasma HDL, but also because they indicate how HDL production may control the accumulation of cholesterol in tissue sites and thereby reduce the risk of atherosclerosis.

\section{PARTIAL SPECIFIC VOLUME AND PREFERENTIAL HYDRATION OF LDL SUBFRACTIONS}

Talwinder S. Kahlon, Gerald L. Adamson, Laura A. Glines, Joseph R. Orr, and Frank T. Lindgren

We have determined the partial specific volume (v) for five human low density lipoprotein (LDL) subfractions $(n=5-7)$ and evaluated preferential hydration $(n=2)$ for LDL subfraction 3 in normolipoproteinemic subjects in order to characterize these highly atherogenic components of the human plasma lipoprotein spectra. Mean values for $\bar{v}$ were $0.9757 \pm 0.0019 ; 0.9701 \pm 0.0007 ; 0.9674 \pm$ 0.0016 , and $0.9550 \pm 0.0025 \mathrm{ml} / \mathrm{g}$ for subfractions $1,2,3,4$, and 5 , respectively. Thus, true densities ( $\rho$ ) obtained from $\rho=1 / \bar{v}$ for respective LDL subfractions were 1.0249, 1.0308, 1.0337, 1.0399, and $1.0471 \mathrm{~g} / \mathrm{ml}$, respectively. The preferential hydration values were determined in $\mathrm{D}_{2} \mathrm{O}-\mathrm{NaCl}$ and ) $\mathrm{NaCl}-\mathrm{NaBr}$ solutions. Preferential hydration of protein subfraction 3 in $\mathrm{NaCl}-\mathrm{H}_{2} \mathrm{O}$ solution was
3.2 to $5.0 \mathrm{wt} \%$, whereas values were much lower ( 0.3 to 0.6 wt\%) in a $\mathrm{NaCl}-\mathrm{NaBr}-\mathrm{H}_{2} \mathrm{O}$ solvent system. Unhydrated and hydrated densities of LDL subfraction 3 in one male subject are shown in Fig. 1. Unhydrated densities at $1 \mathrm{~g}$ and $200,000 \times$ $\mathrm{g}$ (used in flotation velocity determinations) for $\mathrm{LDL}$ subfraction $3(n=2)$ were 1.0274 and $1.0308 \mathrm{~g} / \mathrm{ml}$, respectively, indicating that these $\mathrm{LDL}$ fractions have $22 \%$ and $50 \%$ higher compressibility than the solvent at $200,000 \times \mathrm{g}$ force. It was observed that the linearity of $\eta \mathrm{F}_{\mathrm{o}}$ vs $\rho$ may not be valid for solvents $\mathrm{NaCl}-\mathrm{NaBr}-\mathrm{H}_{2} \mathrm{O}$ of density $1.4744 \mathrm{~g} / \mathrm{ml}$. Thus, flotation velocity data using extremely high salt concentrations $(1.4744 \mathrm{~g} / \mathrm{ml}$ and higher) may be viewed with caution. 


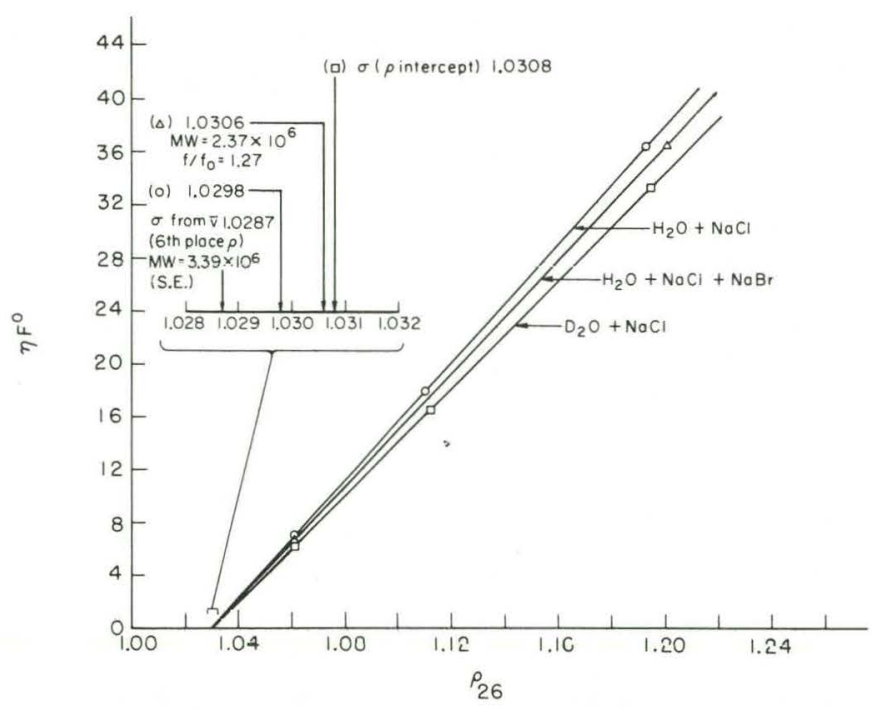

Fig. 1. Low density lipoprotein subfraction 3, male subject 7563. $\eta F_{o}$ vs $\rho$ plot. $\square-\square \quad \mathrm{D}_{2} \mathrm{O}-\mathrm{NaCl} ; \mathrm{O}-\mathrm{O} \mathrm{H}_{2} \mathrm{O}-\mathrm{NaCl}$ and $\Delta-\Delta \quad \mathrm{H}_{2} \mathrm{O}-\mathrm{NaCl}-\mathrm{NaBr}$. Inset: $\rho$ intercepts ( $\square$ ) 1.0308 ; (O) 1.0298 and $(\Delta) 1.0306 \mathrm{~g} / \mathrm{ml}$. True density $\sigma$ from $\bar{v}=1.0287$ $\mathrm{g} / \mathrm{ml}$ obtained from 6th place solvent and solution densities, and CHN elemental mass analysis. Molecular weights by flotation velocity $\left(2.37 \times 10^{6}\right)$ and by sedimentation equilibrium $(3.39 \times$ $10^{6}$ ) daltons. Shape factor $\mathrm{f} / \mathrm{f}$ (sedimentation equilibrium $\mathrm{mol}$ wt/flotation velocity $\mathrm{mol} \mathrm{wt}^{2 / 3^{\circ}}=1.27 . \quad(X B L \mathrm{B31}-3632)$

\section{EXTRAMURAL COLLABORATIONS BY THE ANALYTIC ULTRACENTRIFUGE CORE OF THE LIPOPROTEIN PROGRAM PROJECT}

\section{Frank T. Lindgren}

During the past year there have been several analytic ultracentrifuge collaborations related to a variety of research projects. Two have dealt with hepatic triglyceride lipase. A study with Dr. Alick Little and associates at the Toronto Lipid Research Clinic discovered a new familial abnormality in lipoprotein lipase. Both the male proband and his brother presented a normal extrahepatic lipase concentration, but a hepatic lipase that was reduced to $5 \%$ of normal. Apolipoproteins A-I, A-II, and D were normal, whereas apolipoproteins B, C-II, C-III, and $E$ were elevated 2-3 fold over normal concentrations and yet there was no deficiency in apolipoprotein E-III in very low density lipoproteins (VLDL). The latter is characteristic of primary Type-III hyperlipoproteinemia. Both low density (LDL) and high density (HDL) lipoproteins were enriched in triglyceride ( $30 \%$ by-weight for LDL).

In a related study with $W$. Virgil Brown and associates at Mount Sinai Hospital, New York, cynomolgus monkeys were studied. Antisera were produced against human postheparin hepatic lipase. Hepatic triglyceride lipase activities in liver biopsies were decreased by $65-90 \%$ after three hours continuous intravenous infusion of this antiserum into the cynomolgus monkeys. The ultracentrifugal and activity studies indicate hepatic triglyceride lipase participates in a parallel role with lipoprotein lipase in the hydrolysis of glycerides in the VLDL, intermediate density lipoproteins, and the larger LDL of $\mathrm{S}_{\mathrm{f}}$ 9-12.

A collaboration with Dr. Ernst Schaefer, Molecular Disease Branch, NHLBI, NIH, involved hormonal studies with premenopausal females. Subjects were five females given ethinyl estradiol, 0.1 mg orally, daily for study periods of 28 days. The estrogen administration resulted in significant $(p<$ 0.05) mean increases in plasma cholesterol, triglyceride, VLDL and HDL. Analytic ultracentrifugation demonstrated that the main $\mathrm{HDL}$ increase was in the $\mathrm{HDL}_{2 \mathrm{~b}}$ subfraction (+150\%). 


\title{
. UUSUAL COMPOSITION AND APOLIPOPROTEIN DISTRIBUTION OF CORD BLOOD LOW DENSITY LIPOPROTEIN SUBFRACTIONS
}

\author{
Trudy Forte, Paul Davis, Ronald Krauss, John Kane ${ }^{\star}$ and Conrad Blum ${ }^{\dagger}$
}

We have previously shown that umbilical cord blood from normal full term infants possessed low density lipoproteins (LDL) that had a single peak at $26 \mathrm{~nm}$ upon gradient gel electrophoresis. ${ }^{1}$ Unlike normal adults, there was little variation in the LDL peak among neonates. Although the particle diameter of the LDL peak was consistent with an equivalent particle found in adult plasma, the neonate LDL contained three apolipoproteins, apo B, apo $E$ and apo Al. In contrast, adults possess only apo B. Apo $\mathrm{E}$ and apo $\mathrm{Al}$ are usually associated with the high density lipoprotein (HDL) fraction.

In order to determine whether cord blood LDL were indeed heterogeneous with respect to density, size and apolipoprotein content, LDL of density $1.019-1.063 \mathrm{~g} / \mathrm{ml}$ were subfractionated by equilibrium density gradient centrifugation. The physical and chemical properties of the various subfractions were determined in order to ascertain whether there was a discrete subfraction associated with the apo $\mathrm{E}$ and apo $\mathrm{Al}$ proteins.

Seven cord blood LDL subfractions were generated by density gradient centrifugation with densities increasing from 1.024 to $1.062 \mathrm{~g} / \mathrm{ml}$. Electron microscopic examination (Fig. 1) revealed that at least three distinct size populations of particles were present: 1) large particles at $d=1.024 \mathrm{~g} / \mathrm{ml}$, $28.3 \mathrm{~nm}$ diameter, 2) medium size particles, $d=$ $1.036 \mathrm{~g} / \mathrm{ml}, 26.4 \mathrm{~nm}$ diameter, and 3) small particles, $\mathrm{d}=1.062 \mathrm{~g} / \mathrm{ml}, 15.6 \mathrm{~nm}$ diameter. According to protein distribution, the medium sized particles represent the major lipoprotein component in the LDL region.

SDS-polyacrylamide gel electrophoresis $(10 \%$ PAGE and $0.1 \%$ SDS) of the seven subfractions shown in Fig. 2 indicates that apo B is the major apoprotein in the top five fractions. Little or no apo $B$ is present in the most dense fraction. Apo $E$ appears throughout the fractions with increasing concentrations in the most dense fractions. Apo Al is predominant in fractions 6 and 7 which corresponds with the small particles seen in electron microscopy. The data suggest that the small dense components contain particles possessing both apo $\mathrm{Al}$ and apo $\mathrm{E}$ similar to $\mathrm{HDL}_{c}$ found in cholesterol-fed humans or dogs. They are in fact a less dense subset of the HDL region. Their appearance in cord blood plasma that is extremely low in total cholesterol is unique and unexpected.

The LDL subfractions were also examined by $3 \%$ polyacrylamide gel electrophoresis, which differentiates various forms of apo B. The largest molecular weight form of apo B is termed B 100 and is secreted by the liver. In some adult individuals, smaller forms of apo B, B 74 and B 26, believed to be complementary fragments of B 100, are also found in LDL. B 48, an intermediate molecular weight variant, is secreted by the intestine. The latter was not found in cord blood, which is consonant with the fact that nutrients are not being absorbed by the intestinal tract of the fetus. As shown in Fig. 3, apo B variants, B 74 and B 26, appear in intermediate density fractions and the amount of B 74 and B 26 increases with increasing density. This finding is the first demonstration that the concentration of apo $B$ variants is correlated with LDL density. It suggests that B 74 and B 26 are metabolic products generated during metabolism of LDL containing B 100.

\section{REFERENCES}

1. Davis, P.A., and Forte, T.M. Neonatal umbilical cord blood lipoproteins-Isolation and characterization of intermediate density and low density lipoproteins. Arteriosclerosis 2, 37-43 (1982).

2. Kane, J.P., Hardman, D.A., and Paulus, H.E. Heterogeneity of apolipoprotein B: Isolation of new species from human chylomicrons. Proc. Natl. Acad. Sci. USA 77, 2465-2469 (1980). 


\section{CORD BLOOD LDL SUBFRACTIONS}

Fr. 1

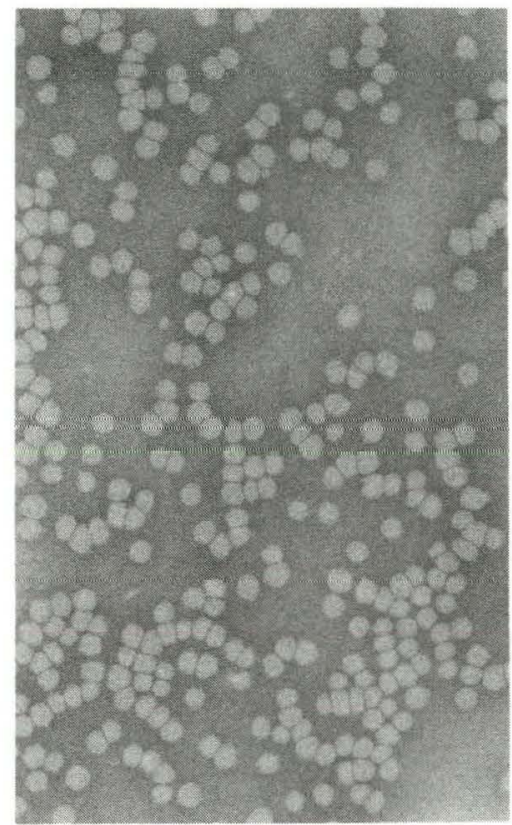

$28.3 \pm 3.2 \mathrm{~nm}$
Fr. 3

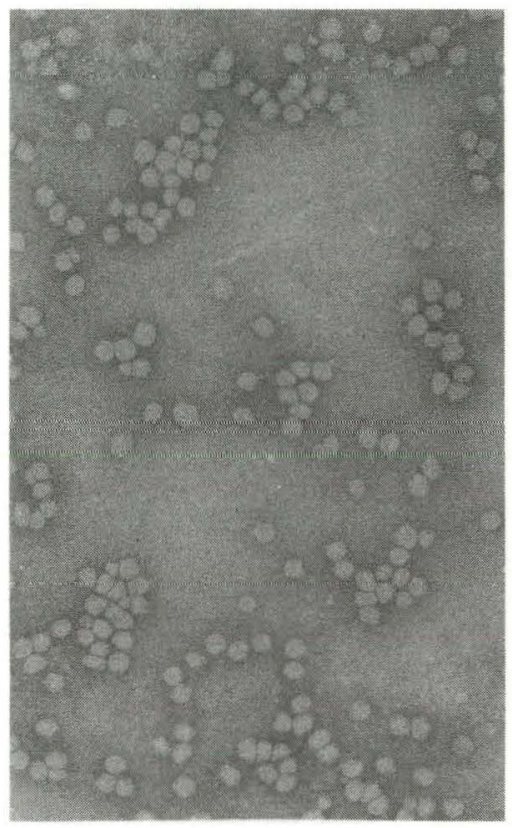

$26.4 \pm 3.0 \mathrm{~nm}$
Fr. 7

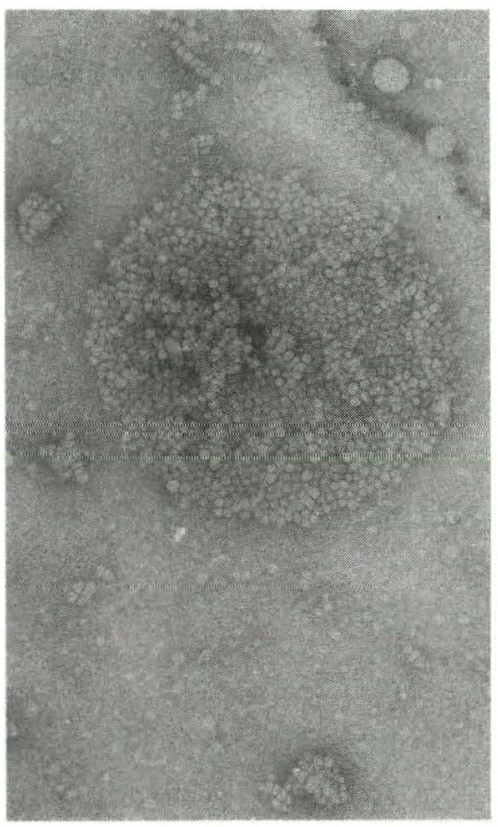

$15.6 \pm 3.5 \mathrm{~nm}$

Fig. 1. Electron micrographs of fractions 1 (A), 3 (B), and 7 (C) obtained by density gradient centrifugation. A progressive decrease in size with increasing density is apparent. The most dense fraction, 7 , seen in $C_{\text {, indicates }}$ that these particles are fairly homogeneous, small spheres which have a tendency to form hexagonal arrays. The numbers under the figures indicate mean particle diameters.

(XBB 825-4428)

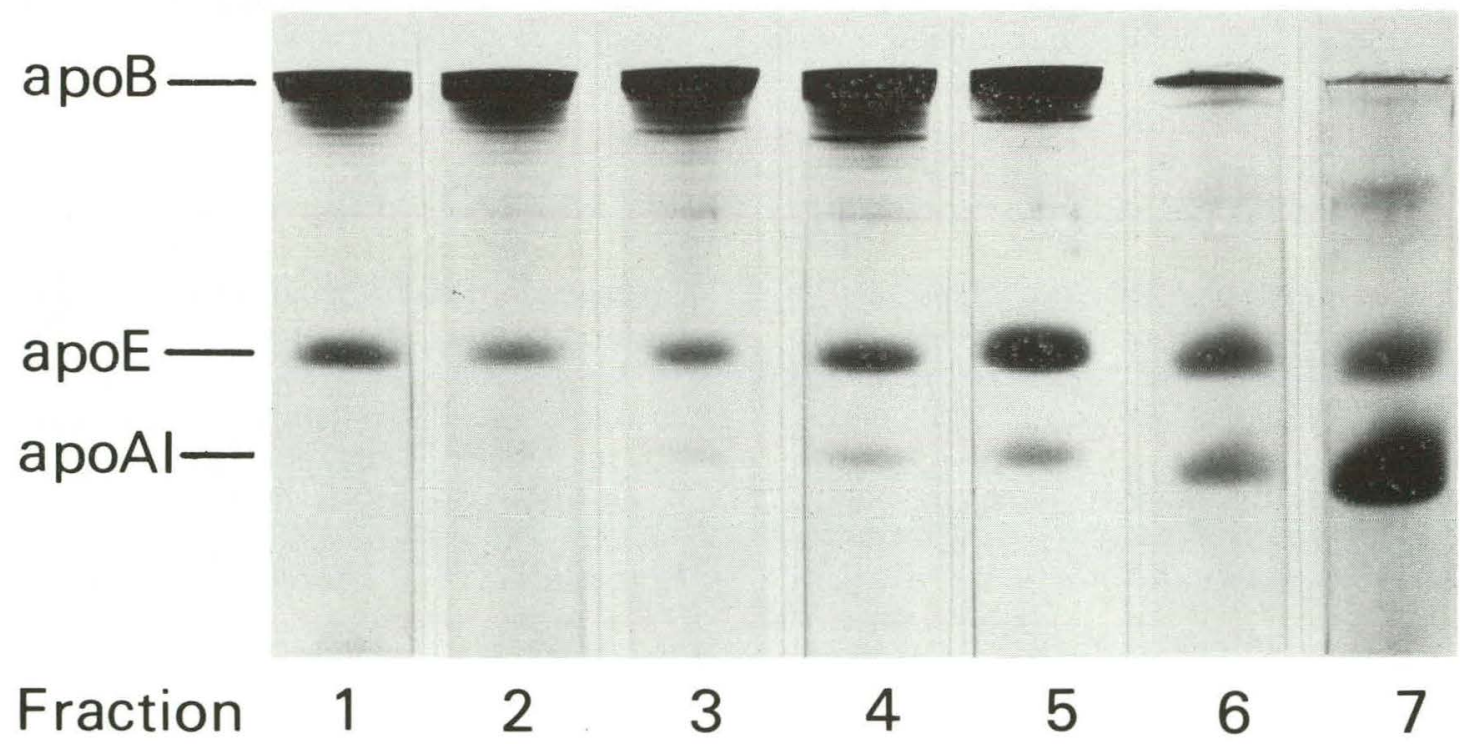

Fig. 2. SDS polyacrylamide (10\%) gel electrophoresis of LDL fractions. Each gel was loaded with approximately $60 \mu \mathrm{g}$ protein per gel. The gels were stained with Coomassie Brilliant Blue R-250. The apolipoproteins (apo) are indicated on the left side of figure. 


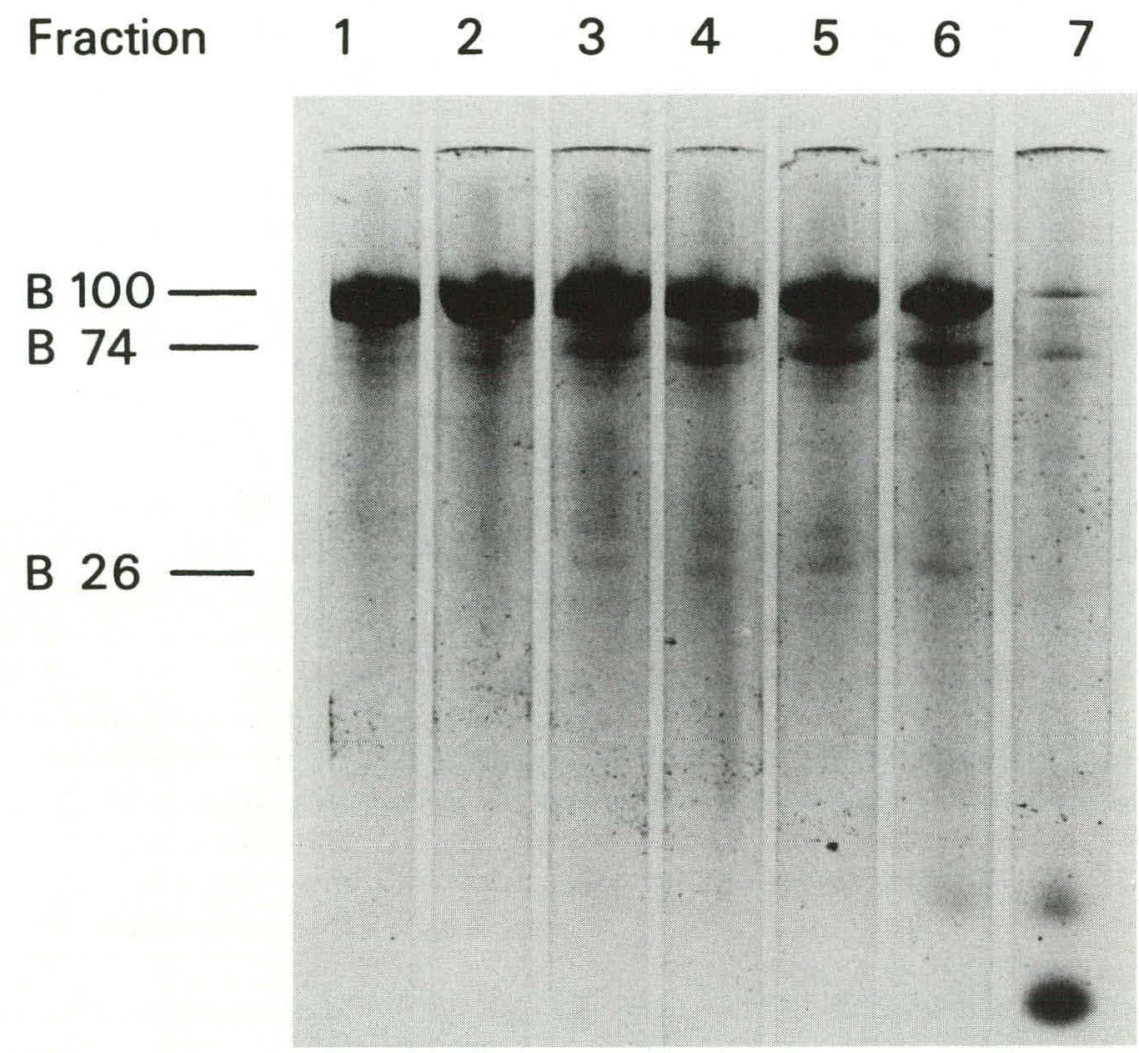

Fig. 3. SDS polyacrylamide (3\%) gel electrophoresis of LDL fractions. Each gel was loaded with approximately 40 $\mu \mathrm{g}$ protein per gel. The gels were stained with Coomassie Brilliant Blue R-250. The nomenclature of Kane et al. ${ }^{2}$ is used to identify apo $B$ species. The small molecular weight proteins appearing in fraction 7 probably correspond with apo $\mathrm{E}$ and apo Al.

(XBB 824-3228)

\section{WHAT HAPPENS TO LIPOPROTEINS IN THE INTERSTITIAL SPACE? A LOOK AT LUNG LYMPH}

\section{Trudy Forte, Carroll Cross," Rob Gunther," and George Kramer*}

In the past 25 years extensive studies have been carried out on plasma lipoproteins. This research was spurred by the link between certain lipoproteins and cardiovascular disease. What is generally not appreciated, however, is that at any given moment one-third of the plasma lipoproteins are in the interstitial space where they interact with cells and tissues. Little is known, however, about the properties of lipoproteins in the interstitium. Do all lipoproteins cross the capillaries into the interstitial space? If so, at what concentration in a given capillary bed? Also, does the transit time in interstitial space alter the lipoprotein particles

*Departments of Medicine, Surgery and Physiology University of California, Davis. chemically or physically? We had an opportunity to address these points by studying sheep lung lymph. It should be noted at the outset that the sheep is a ruminant with extremely low levels of plasma triglyceride and no detectable very low density lipoproteins (VLDL), which makes it different from the human, who has considerably more triglyceride and substantial amounts of VLDL.

Lung lymph was obtained from indwelling dorsal mediastinal lymph node catheters in unanesthetized sheep. For comparison, venous blood was also obtained from each sheep.

Table 1 shows the distribution of lymph versus plasma lipoproteins and lipids in sheep. HDL is the major plasma lipoprotein class in the sheep, and it remains the major class in the lung lymph. The 
Table 1. Lipid and lipoprotein concentration $(\mathrm{mg} / \mathrm{dl})$ in sheep lung lymph and plasma. ${ }^{a}$

\begin{tabular}{lccccc}
\hline \hline & Cholesterol & Triglyceride & Phospholipid & $\mathrm{HDL}^{\mathrm{b}}$ & LBL $^{\mathrm{b}}$ \\
\hline Plasma (P) & $42.1 \pm 10.5$ & $12.0 \pm 3.0$ & $43.2 \pm 7.6$ & $84 \pm 16$ & $52 \pm 17$ \\
Lymph (L) & $18.8 \pm 5.8$ & $6.1 \pm 1.3$ & $21.8 \pm 4.9$ & $37 \pm 8$ & $26 \pm 8$ \\
L/P Ratio & 0.45 & 0.50 & 0.50 & 0.44 & 0.50 \\
\hline \hline
\end{tabular}

lymph-to-plasma ratio for lipids and lipoproteins is close to 0.5 , which indicates that lipoproteins in the lymph represent approximately $50 \%$ of the level found in plasma. Moreover, the HDL and LDL in lymph are present in the same proportions as in plasma.

Lung lymph and plasma lipoproteins were separated into two fractions by preparative ultracentrifugal techniques. One fraction consisted of low density lipoproteins (LDL) isolated at density < $1.063 \mathrm{~g} / \mathrm{ml}$ and the other of high density lipoproteins isolated at $\mathrm{d}=1.063-1.21 \mathrm{~g} / \mathrm{ml}$. Size distribution of these lipoproteins was examined by gradient gel electrophoresis (GGE). As shown in representative scans in Fig. 1, LDL from plasma revealed great particle size heterogeneity with 3-5 peaks present in the $23-30 \mathrm{~nm}$ particle size range. Lung lymph possessed particles similar in size to plasma LDL, but it also had an additional broad

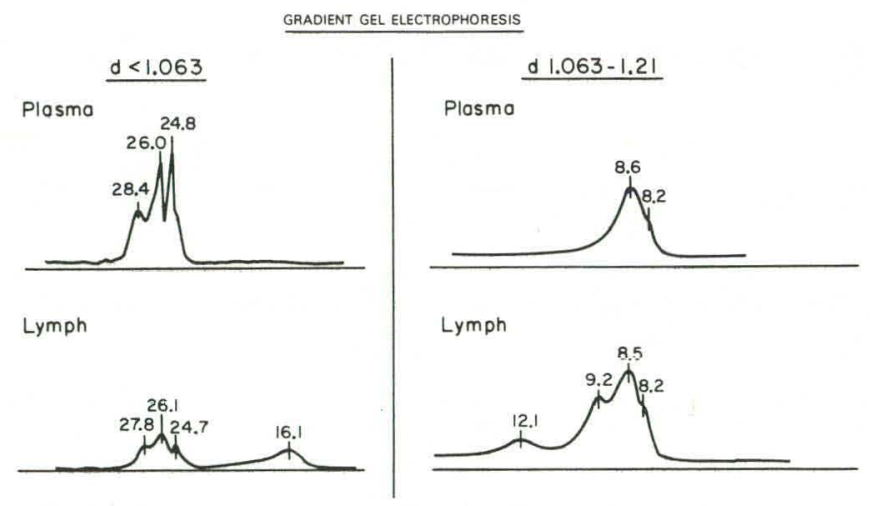

Fig. 1. Gradient gel electrophoresis scan from a representative sheep plasma and lymph $H D L(d=1.063-1.21 \mathrm{~g} / \mathrm{ml})$ and $L D L(d$ $<1.063 \mathrm{~g} / \mathrm{ml}$ ) fraction. Numbers above peaks and shoulders denote particle diameter in $\mathrm{nm}$. HDL was electrophoresed in precast $4-30 \%$ gels. Plasma HDL typically has a sharp, single peak that may possess a shoulder of smaller-size particles. Lymph HDL is more complex and shows several new larger components. LDL was electrophoresed on $2-16 \%$ gels. Plasma $L D L$ possess a great particle heterogeneity; even greater heterogeneity is seen in lymph $L D L$ where a broad peak is apparent at $16 \mathrm{~nm}$. peak of smaller particles in the size range of 15-16 $\mathrm{nm}$. Plasma HDL were less heterogeneous than $\mathrm{LDL}$ and had one major peak around 8.6-8.9 nm size. In contrast, lymph consistently contained two additional larger HDL components: one with a peak around $9.0 \mathrm{~nm}$ and the other at $12.0 \mathrm{~nm}$. The GGE results definitely show that both the LDL and HDL density regions have undergone alterations. This alteration in particle size probably ensues from the interaction of interstitial lipoproteins with their surrounding cells and tissues. This became more apparent when the chemistry of the lymph lipoproteins was examined.

Lymph HDL show a slight increase in total cholesterol; however, the most dramatic change in their composition is in the free-to-esterified cholesterol ratio, which increases from 0.15 in plasma to 0.36 in lung lymph. The composition of lymph LDL shows significant differences in phospholipid content, where lymph has a $34 \%$ increase relative to plasma and a twofold increase in the free-to-esterified cholesterol ratio. In addition, triglyceride in lymph LDL decreased $41 \%$. The compositional changes in lymph lipoproteins, particularly the noticeable elevation of free cholesterol, suggest that these lipoproteins may play a role in reverse cholesterol transport.

The electron microscopic structure of lymph lipoproteins is also altered. The difference between plasma and lymph fractions is seen in Fig. 2. The $\mathrm{HDL}$ are heterogeneous in structure, and both round particles and elongated or discoidal particles (2B, arrows) are present. We know from previous studies with lecithin:cholesterol-acyltransferasedeficient patients that discoidal HDL particles contain phospholipid and free cholesterol. ${ }^{1}$ Although further studies with lung lymph are required, it is likely that some of the elevation in lymph HDL-free cholesterol can be accounted for by these unusual particles. The LDL fraction from lung lymph is $a^{1 m}$ morphologically unusual. These particles in plası tend to be round, but in lymph they often fo.... extensive square-packing arrays. It is likely that the 
....usual geometry of these particles is also related to their altered chemical composition.

The present studies indicate that lipoproteins undergo chemical and physical changes during transit through the interstitial space of the lung. Modification may, in part, be related to the metabolic function of lipoproteins in the lung since it appears that there is a relationship between lipoproteins and surfactant synthesis. ${ }^{2}$
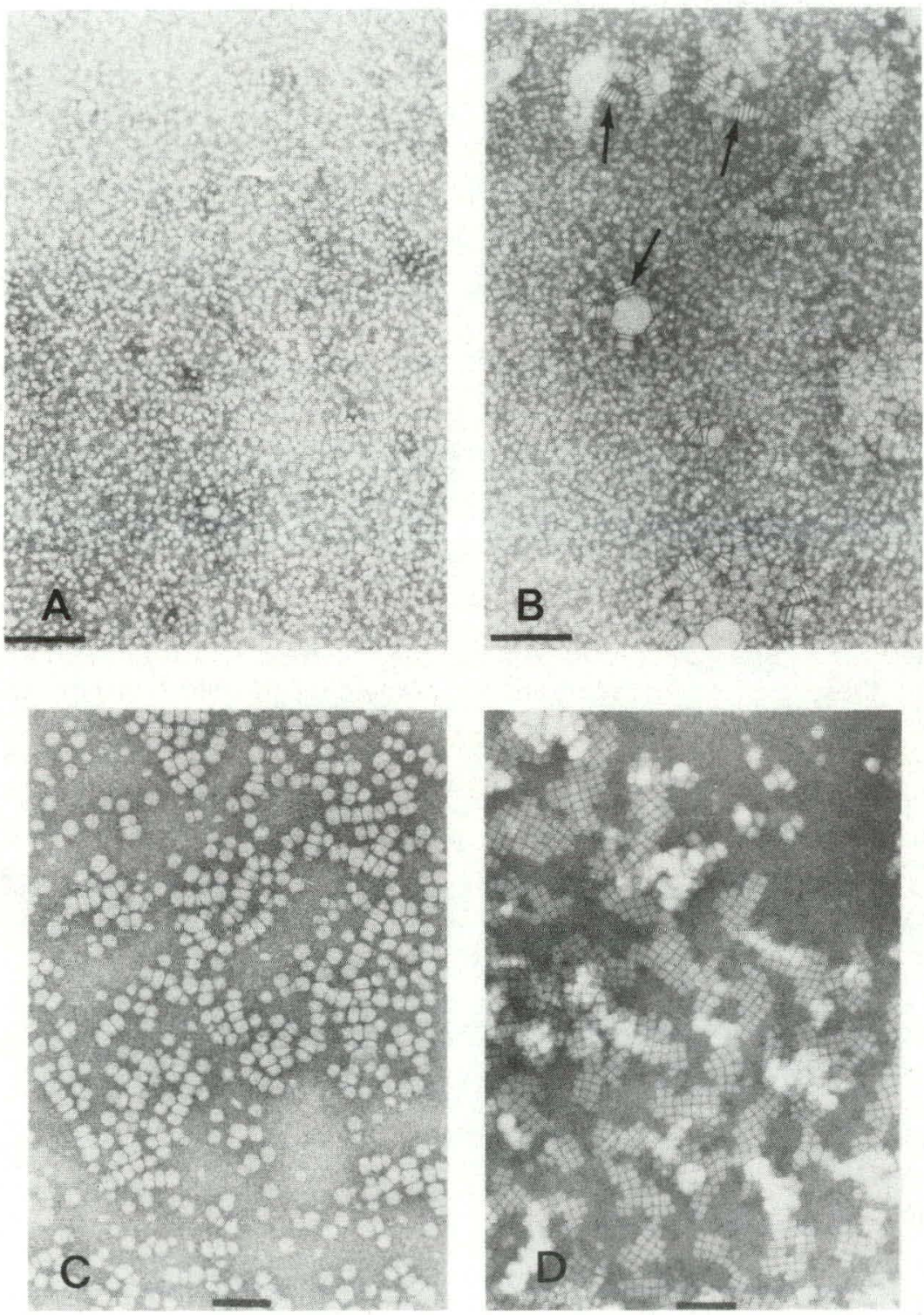

Fig. 2. Electron micrographs of negatively stained lymph and plasma lipoproteins. (A) Plasma HDL: rather uniform, round particles. (B) Lung lymph HDL: particles are heterogeneous in size and morphology. Note discoidal particles (arrows). (C) Plasma LDL: round particles, rather heterogeneous in size. (D) Lung lymph LDL: many particles have an unusual square-packing geometry. Bar markers represent $100 \mathrm{~nm}$. 


\title{
DNA and Genetic Studies
}

\section{CHARACTERIZATION OF ISOLATED YEAST DNA REPAIR GENES}

\author{
Robert K. Mortimer, Isabel L. Calderon, Rebecca Contopoulou, Herschell S. Emery, \\ Susan T. Lovett, David Schild, Karen C. Sitney, and John N. Takakuwa
}

In the yeast Saccharomyces cerevisiae several different DNA repair pathways have been identified. ${ }^{1}$ These include recombinational repair, errorprone associated repair, excision repair and photoreactivation (see following paper). Our research includes an examination of the RAD50 to RAD57 genes, a subset of the genes involved in DNA repair. The genes in the RAD50 to RAD57 epistasis group are thought to be involved in recombinational repair, since mutations in some of these genes decrease both repair and recombination. Although many phenotypes have been associated with mutations in the genes of this pathway, no enzyme or structural protein (such as a DNA binding protein) has been determined to be the product of any of these genes. In order to study these genes at the molecular level and to isolate and characterize their primary gene products, we have cloned several of them. The cloning of these genes was presented in last year's Annual Report and has recently been published. ${ }^{2-4}$ Here we report on work being done using these genes. In addition, while trying to obtain clones that would complement the $R A D 50$ gene, an amber suppressor was isolated that suppressed the amber rad50-1 mutation. Work leading to the further characterization of the suppressor gene is also reported here.

\section{RAD50}

Nine mutant alleles of RAD50 have been studied genetically. Crosses of strains each carrying one of these mutations were made against strains containing either amber or ochre suppressors. This revealed that two of these mutations are nonsense, one ochre (rad50-3) and one amber (rad50-1). A temperature sensitive modifier of rad50-7 was also isolated in this study. This modifier confers an $\mathrm{x}-$ ray resistant phenotype to rad50-7 at the permissive temperature, but has no detectable phenotype at the restrictive temperature. The modifier has not yet been mapped, but it is unlinked to rad50-7.

In addition to the cloning of the suppressor gene (discussed below), a second plasmid was isolated which also complemented the rad50-1 muta- tion. This plasmid [YEp13-RAD50-210B] has since been shown to complement one of the other mutant alleles of RAD50, rad50-3. However, genetic analyses on the plasmid showed that it integrated near the centromere of chromosome XV, tightly linked to pet17, and not at the chromosomal site of RAD50, which has been shown to be on chromosome XIV proximal to met2. We have concluded that the [YEp13-RAD50-210B] clone has no homology to RAD5O sequences and thus renamed the plasmid [YEp13-210B]. The possibility that this plasmid may be a nonsense suppressor was ruled out by genetic studies.

A second possibility that we are currently investigating is that the cloned gene codes for a protein that interacts in some way with RAD50, either structurally or in a regulatory capacity. In order to study this, an attempt was made to disrupt the genomic copy of 210B. An internal fragment of [YEp13-210B] has been deleted and replaced by the HIS3 gene. A 2.6-kb Hindlll restriction fragment containing the HIS3 insert flanked on each side by about $0.5 \mathrm{~kb}$ of homology to the $210 B$ sequences was integrated into a $R A D 5 O^{+}$his $3^{-}$strain using the method of Rothstein. ${ }^{5}$ The integrant carrying this disruption has now become, as expected, $\mathrm{His}^{+}$, and it is $\mathrm{Rad}^{-}$; it has not yet been demonstrated that this phenotype is due to an integration at the $210 B$ locus of chromosome $\mathrm{XV}$. This is currently under investigation.

A 4.7-kb Hindlll fragment of the [YEp13-210B] plasmid containing the complementing activity has also been subcloned into the integrating plasmid Ylp5 in order to determine whether this gene will still complement rad50 mutations when present in only one copy per cell.

\section{RAD51}

We originally isolated six plasmids that complemented rad51 and by restriction analyses these were all shown to be different. One of these six, [YEp13-RAD51-23], was shown to integrate at the site of rad51 on chromosome $\mathrm{V}$. The remaini। plasmids have been analyzed further and ha' 
?n shown to not overlap [YEp13-RAD51-23] and usu to not complement rad51. We deduce that the original yeast transformants contained at least two plasmids, only one of which complemented rad51. When plasmid DNA was isolated from these transformants and used to transform $E$. coli the plasmids recovered were the ones not containing RAD51. We are developing a more detailed restriction map of [YEp13-RAD51-23] and plan to make subclones from this plasmid in order to localize the RAD51 gene in the insert. The subcloned gene will be used for studies of regulation, DNA sequence and gene product.

\section{RAD52}

The rad52-1 mutation has been studied in many laboratories because of its pleotropic effects on both recombination and repair. Since it is possible that rad52-1 is a leaky mutation, we have isolated disruptions of this gene which should totally inactivate it. These disruptions were first constructed using the cloned RAD52 gene and then substituted into the genome in a way similar to that used for the disruption of $210 B$ (discussed above). Instead of using the HIS3 gene for the disruption of the RAD52 gene, as was done with gene $210 B$, the LEU2 and TRP1 genes were used. The disruptions of $R A D 52$ are viable, demonstrating that this gene codes for a protein that is nonessential for vegetative growth. ${ }^{3}$ We are currently testing various phenotypes of these disruptions to compare them with the phenotypes of the rad52-1 mutation. It has already been shown that these disruptions do not revert at a detectable level, whereas rad52-1 does revert. Strains carrying the disrupted copy of the RAD52 gene will be used as control strains in experiments to identify the RAD52 gene product (see section on RAD54). Since rad52-1 is prulably a missense allele, it is likely to produce a normal sized RAD52 protein. Since the disruptions should produce no such protein, they will be useful as controls lacking any RAD52 gene product.

\section{RAD54}

We have initiated gene structure and regulation studies of RAD54. To determine if this gene is regulated at the transcript level, we have prepared RNA from yeast cultures grown various lengths of time following $\mathrm{x}$-irradiation. The level of RAD54 mRNA in each RNA sample is now being determ: ed by hybridization to internal fragments of the ie previously cloned in our laboratory. Similar ...periments are also in progress to study RAD52 gene regulation. In order to utilize expression vectors for the isolation of gene product of the RAD54 gene, the structure of the gene is being studied. Using $\mathrm{S}$ 1 nuclease mapping, we have determined the direction of RAD54 transcription and the approximate point of transcription initiation. We have further determined 600 base pairs (b.p.) of continuous DNA sequence through this region. Sequence features include a potential "TATA box" at about -30 (b.p.), and a single open reading frame beginning with an AUG at about +150 (b.p.).

Sequence information has also revealed that an $X b a l$ site lies just downstream from the presumptive transcription initiation site. Using this site we are cloning the coding region of the gene downstream from a GAL1 promoter. This will allow us to amplify transcription of the gene 2-3 orders of magnitude, enough to isolate and identify the gene product. A similar method is also being applied to the other $R A D$ genes.

\section{RAD55}

The isolation of plasmids carrying the RAD55 gene has been reported by this lab previously. ${ }^{4}$ Analysis of these plasmids has been continued. Restriction mapping data have shown that the plasmids share a region of $2.6 \mathrm{~kb}$. A $1.7-\mathrm{kb}$ Hindll restriction fragment from this conserved region was subcloned into the yeast vector plasmid YCp50 and shown to retain $R A D 55$ complementing activity. Deletions of restriction fragments from these plasmids have defined two restriction sites internal to RAD55. Because all known RAD55 alleles are conditional, complete loss of RAD55 function may be lethal to the cell. To test this possibility, a restriction fragment carrying the LEU2 gene was inserted into one of the restriction sites within the $R A D 55$ gene. This disrupted form of RAD55 will be substituted for one copy of the chromosomal $R A D 55$ in a diploid strain to see if, upon sporulation, it segregates as a lethal mutation.

In order to continue the genetic analysis of $R A D 55$, revertants of a rad55-3 strain (having a cold-sensitive mutant phenotype) were selected on MMS-containing medium. In addition to true revertants, we hoped to obtain pseudo-revertants; strains which maintain the original rad55-3 mutation but which have suffered changes in other genes which compensate for the rad55-3 defect. Such pseudoreversions can occur by four different mechanisms: informational suppression (by changing tRNA interpretation of the mutant codon), regulatory suppression (by overproducing weakly-functional 
RAD55 gene product), bypass suppression (by providing a substitute pathway for $R A D 55$ function), or interactive suppression (by making compensating mutations in gene products which interact with RAD55 gene product). These modes of suppression can be distinguished genetically by dominance/recessiveness and allele specificity of suppression, and by the phenotypic effects of the suppressor mutation itself.

Out of 120 rad55-3 "revertants," approximately 40 were found to be candidates for interactive suppressor strains; these had lost the cold-sensitive Rad phenotype and assumed a heat-sensitive Rad phenotype. This ts-radiation sensitivity was recessive. Genetic crosses with 20 of these strains have shown that their new phenotype occurs by alterations within RAD55; these strains carry either improper reversions of rad55-3 or mutations at other sites within RAD55 which compensate for rad55-3." The remaining strains are presently being screened for the presence of extragenic suppressors that define gene products that may interact with RAD55.

One extragenic suppressor mutation was isolated which has the characteristics of a regulatory suppressor; it suppresses rad55-3 somewhat at tem.peratures where rad55-3 appears to have residual function. Its ability to suppress is recessive, indicating that if its action is regulatory, then the wild-type gene exerts negative effects on RAD55. Experiments are underway to test if this mutation suppresses other alleles of RAD55 and alleles of other RAD genes.

\section{INCIDENTAL CLONING OF A GENE FOR AN AMBER SUPPRESSOR IN YEAST}

In our attempt to clone the RAD50 gene of yeast we have incidentally isolated a plasmid which suppresses the rad50-1 mutation but fails to show homology to $R A D 50$ sequences. We have shown that $\operatorname{rad50-1}$ and $\operatorname{trp} 1-289$, both present in the recipient strain, are amber mutations, and that the cloned gene codes for an amber suppressor that suppresses both of these mutations as well as other known amber mutations in yeast. The suppressor gene is located on the $2.5-\mathrm{kb}$ yeast insert of the plasmid [YEp13-SUP] (Fig. 1).

When a $1.5-\mathrm{kb}$ restriction fragment from the insert was subcloned into the YRp7 replicating plasmid and yeast transformation carried out, all the transformants showed suppression of rad50-1 and other amber mutations, indicating that the suppressor gene is present in that fragment; when, however, the same $1.5-\mathrm{kb}$ fragment was subcloned into the integrating plasmid Ylp5 and yeast integra isolated, none of the 12 studied showed suppresion of rad50-1 or of any other amber mutations (Fig. 1). Since replicating plasmids, such as YRp7 and YEp13, are present in many copies in the cell $(\sim 25-100)$ and the integrating plasmids, such as Ylp5, generally integrate into the genome only once per cell, we concluded that we have cloned a weak suppressor that is expressed only, when present in high copy number.
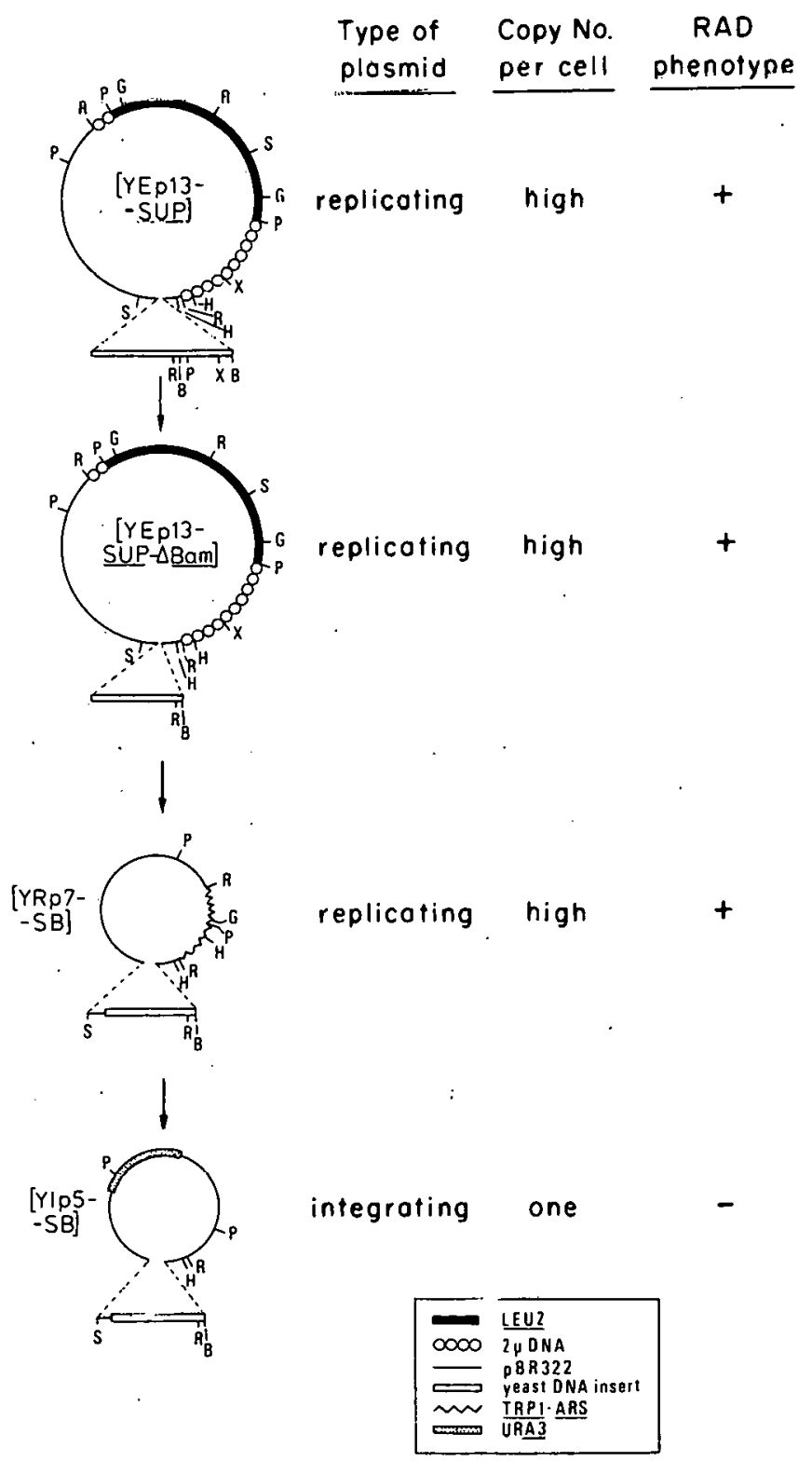

Fig. 1. Restriction maps of the plasmid |YEp13-SUP] and all the subclunes derived from it. Restriction enzymes used: $B$, Ban G, BgllI; H, HindIII; P, Pstl; R, EcoRI; S, Sall; X, Xbal.

(XBL 8310-40, כ) 
Genetic studies using standard genetic methods ....d the rad52 chromosome loss method ${ }^{6}$ showed that the plasmid bearing the $1.5-\mathrm{kb}$ fragment of the suppressor insert had integrated very close to the $M A L 4$. gene located on the right arm of chromosome XI. MAL4 is one of a set of polymeric genes conferring ability to ferment maltose, and there is evidence for considerable homology between different genes in this set. ${ }^{7,8}$ It is conceivable that the sequence containing the suppressor would show homology to other MAL regions or that this suppressor would integrate at other MAL loci.

\section{REFERENCES}

1. Game, I.C. Radiation-sensitive mutants and repair in yeast. In: Spencer, J.F.T., Spencer, D.M., and Smith, A.R.W. Yeast Genetics: Fundamental and Applied Aspects. Springer Verlag, N.Y., New York (1983).

2. Schild, D., Konforti, B., Perez, C., Gish, W., and Mortimer, R.K. Isolation and characterization of yeast DNA repair genes 1 . Cloning of the RAD52 gene. Current Genetics 7, 85-92 (1983).

3. Schild, D., Calderon I.L., Contopoulou, C.R., and Mortimer, R.K. Cloning of yeast recombination-repair genes and evidence that several are nonessential genes. In: Friedberg, E.C., and Bridges, B.A. Cellular Responses to DNA Damage. Alan R. Liss, Inc., New York (1983).

4. Calderon, I.L., Contopoulou, C.R., and Mortimer, R.K. Isolation and characterization of yeast DNA repair genes II. Isolation of plasmids that complement the mutations rad50-1, rad51-1, rad54-3, and rad55-3. Current Genetics 7, 93-100 (1983).

5. Rothstein, R.J. One-step gene disruption in yeast. Methods Enzym. 101, 202-211 (1983).

6. Mortimer, R.K., Contopoulou, R., and Schild, D. Mitotic chromosome loss in a radiationsensitive strain of the yeast saccharomyces cerevisiae. Proc. Natl. Acad. Sci. USA 78, 5778-5782 (1981).

7. Chow, T., Goldenthal, M.J., Cohen, J.D., Hedge, M., and Marmur, J. Identification and physical characterization of yeast maltase structural genes. Mol. Gen. Genet. 191, 366-371 (1983).

8. Needleman, R.B., and Michels, C. Family of genes controlling maltose fermentation in $S$. carlsbergensis. Mol. Cell. Biol. 3, 796-802 (1983).

\section{CLONING AND MAPPING OF THE YEAST PHOTOREACTIVATION GENE PHR 1}

\section{David Schild, John Johnston," Caren Chang ${ }^{\dagger}$ and Robert K. Mortimer}

The yeast Saccharomyces cerevisiae has several different repair mechanisms to deal with pyrimidine dimers caused by exposure to ultraviolet light. Although most dimers are removed by excision repair, they can also be repaired by directly splitting the dimers by photoreactivation. Photoreactivation involves a photolyase (or photoreactivating enzyme), a cofactor, and the absorption of visible light of low wavelength. A yeast mutation ( $p h r 1$ ) that is unable to photoreactivate dimers was isolated by $M$. Resnick in 1969.' Although the PHR1 gene is clearly linvulved in photoreactivation, it is not known for which product the gene codes since: 1) there appear to be two different photoreactivating enzymes in commercial batches of bakers yeast, one a monomeric enzyme and the other a heterodi-

epartment of Bioscience and Biotechnology, University of athclyde, Glasgow, GI 1XW, Scotland.

uepartment of Biology, Caltech, Pasadena, CA 91125. mer, ${ }^{2}$ 2) each enzyme seems to require a cofactor, ${ }^{2}$ and 3) a second photoreactivation-deficient mutation (phr2) has recently been isolated and shown to be loosely linked to phrl. ${ }^{3}$ In order to study the PHR1 gene at a molecular level and eventually to determine its primary gene product, we have cloned this gene. The cloned gene has also been used to determine the chromosomal location of PHR1, which would have been extremely difficult to do by other methods.

A plasmid containing a $6.4-\mathrm{kb}$ yeast DNA insert has been isolated and shown to restore photoreactivation in a phrl stralı. Tlie plasmid was targeted to integrate into chromosomal DNA at a site homologous to the insert by cutting within the insert. Two of these integrants have been studied and shown to map on the right arm of chromosome XV; the integrants have been further mapped at approximately $13 \mathrm{cM}$ from prt1. It has also been independently determined that phr1 maps at this 
location (Fig. 1). Thus, we have determined the map position of PHR1 and also have shown that the plasmid contains $P H R 1$, rather than a suppressor of the phr1 mutation.

Incidental to mapping the site of PHR1 we have also located a possible site of a TY1 sequence, one of the transposable elements of yeast. A spontaneous integration event of the plasmid was mapped at about $7 \mathrm{cM}$ from $A D E 3$ on chromosome VII (Fig. 1). Since phrl has been shown not to map at this location, this site may represent a chromosomal copy of a Ty1 sequence. The YEp13 vector and the PHR1 derivative of it contain part of a TY1 sequence and should therefore sometimes integrate at the site of TY1 sequences.

\section{REFFRFNCES}

1. MacQuillan, A.M., Herman, A., Coberlky, J.S., and Green, G. A second photoreactivationdeficient mutation in Saccharomyces cerevisiae. Photochem. Photobiol. 34, 673-677 (1981).

2. Madden, J.J., and Werbin, $H$. Purification of two DNA photolyases from Saccharomyces cerevisiae. Photochem. Photobiol., in press (1983).

3. Resnick, M.A. A photoreactivationless mutant of Saccharomyces cerevisiae. Photochem. Photobiol. 9, 307-312 (1983).

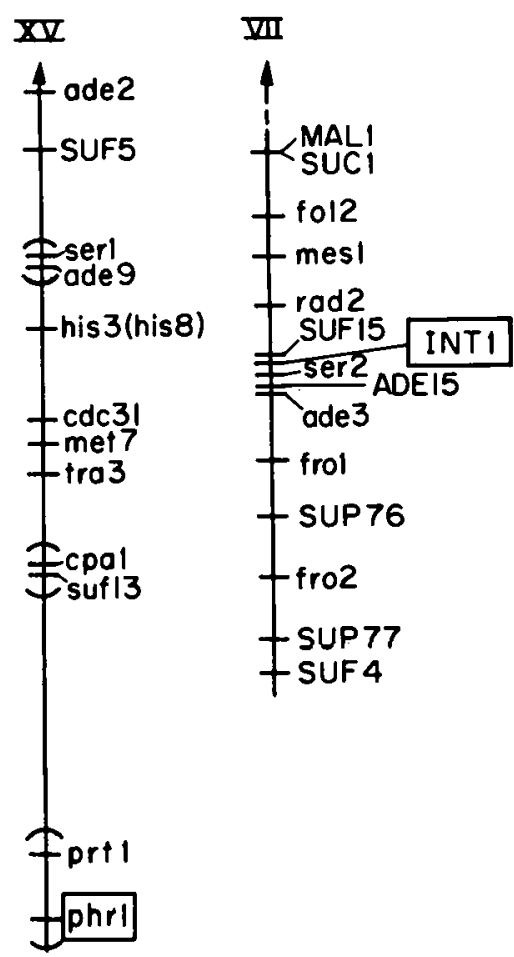

Fig. 1. Genetic map location of the yeast photoreactivation gene PHR1 and the probable site of a yeast TY1 transposon. Only part of each chromosome is shown and the arrows point towards the centromeres. (XBL 831-14035)

\section{THE USE OF A COLD-SENSITIVE DNA REPAIR MUTANT TO STUDY MEIOTIC RECOMBINATION IN YEAST}

\section{John C. Game and Robert K. Mortimer}

We have known for some time $e^{1,2}$ that the yeast RAD50 gene, originally identified as being involved in DNA repair, is also required for meiotic recombination. In rad50 mutants, no meiotic recombinants are formed, and the meiosis I division cannot be completed successfully to form viable products (see Ref. 3 for a review). In 1977. Ananthaswamy and Mortimer isolated a cold-sensitive rad50 mutant (unpublished observation). We are using it to study the role of the RAD50 gene product in meiotic recombination and the timing of meiotic recombination and its relationship to other meiotic processes.

Diploid yeast cells can readily be induced to undergo meiosis in liquid or solid culture media by specific changes in the nutrient conditions in which they are grown. The meiotic process consists of several separate but related stages that occur sequentially in each cell. These include DNA synthesis, meiotic recombination, first and second meiotic divisions, and spore formation. If the process is interrupted at an appropriate stage by plating cells back to medium that supports vegetative growth but does not induce meiosis, cells that have already undergone pre-meiotic DNA synthesis and are committed to recombination will undergo a mitotic rather than meiotic division. Thus, in yeast meiotic recombination can be separated from meiotic division, and the effects of meiosis-blocking mutations on each of these processes can be separately monitored.

It is particularly useful to study the behavior of temperature conditional mutations in this syste since by changing the incubation temperature do 
; the course of meiosis one can in principle c.termine the time at which the product of the gene in question is required. We have used the cold-sensitive rad50 mutation in this way and have confirmed earlier reports using other techniques ${ }^{1,2}$ that the RAD5O gene product is required early in yeast meiosis.

We have also constructed double mutant strains that carry the cold-sensitive rad50 mutation and a heat-sensitive allele of another gene required for meiosis, $c d c 21$. Such double mutant strains are more useful than the rad50 strain alone, since we can use them to determine if there is a required sequence in which the products of the two genes must function, and if so, what this sequence is. This can be achieved using an adaptation of the technique used by Jarvik and Botstein ${ }^{4}$ for studying phage maturation. Results from experimental regimes in which cells entering meiosis are incubated first at a high temperature (permissive for rad50) followed by a low temperature (permissive for $c d c 21$ ) are compared with those from the reverse treatment (low temperature incubation followed by high temperature incubation). If the $R A D 5 O$ gene product is required to function before the $C D C 21$ gene product can function, then only the first type of regime should yield viable meiotic progeny, whereas if there is a sequential requirement in the reverse order, only the second regime should allow cells to complete meiosis.

In practice, these experiments require the use of strains and conditions that optimize the degree of cell synchrony in meiotic populations, and provide very sensitive indicators of meiotic recombination. Using such methods, we have been able to show that the $C D C 21$ gene product functions prior to the $R A D 50$ product, in a dependent sequence. Live meiotic recombinants are formed in regimes where the low temperature precedes the high temperature, but not in reverse regimes.

The gene product of the CDC21 gene is known $n^{5,6}$ to be thymidylate synthetase, which is required for mitotic and pre-meiotic DNA synthesis. Thus, cdc21 mutants are unable to carry out premeiotic DNA synthesis at the restrictive temperature, and our results therefore suggest that premeiotic DNA synthesis must occur in yeast prior to the RAD50-mediated step in meiotic recombination. We are currently investigating the rad50 coldsensitive mutation in combination with another heat-sensitive mutation, $c d c 9$, which codes for DNA ligase. $^{7}$

\section{REFERENCES}

1. Game, J.C., Zamb, T.J., Braun, R.J., Resnick, M., and Roth, R.M. The role of radiation ( $\mathrm{rad}$ ) genes in meiotic recombination in yeast. Genetics 94, 51-68 (1980).

2. Malone, R.E., and Esposito, R. Recombinationless meiosis in yeast. Mol. Cell Biol. 1, 891-901 (1981).

3. Game, J.C. Radiation-sensitive mutants and repair in yeast. In: Yeast Genetics, Fundamental and Applied Aspects, J.F.T. Spencer, D.M. Spencer, and A.R.W. Smith, eds., SpringerVerlag, New York (1983).

4. Jarvik, J., and Botstein D. A genetic method for determining the order of events in a biological pathway. Proc. Natl. Acad. Sci. U.S.A., 70, 2046-2050 (1973).

5. Game, J.C. Yeast cell cycle mutant $c d c 21$ is a temperature-sensitive thymidylate auxotroph, Molec. Gen. Genet. 146, 313-315 (1976).

6. Bisson, L., and Thorner, J. Thymidine 5'monophosphate-requiring mutants of Saccharomyces cerevisiae are deficient in thymidylate synthetase. J. Bacteriol. 132, 44-50 (1977).

7. Johnston, L.H., and Nasmyth, K.A. Saccharomyces cerevisiae cell cycle mutant $c d c 9$ is defective in DNA ligase. Nature 276, 891-893 (1978).

\section{AN EMPIRICAL EQUATION THAT CAN BE USED TO DETERMINE GENETIC MAP DISTANCES FROM TETRAD DATA}

\section{Charles Ma* and Robert K. Mortimer}

In organisms amenable to tetrad analysis, genetic map distances between two genes on a

Idergraduate student at the University of California Berkeley, rked on this study as part of an honors section project in Biology 1A. chromosome are determined from the relative frequencies of parental ditype (PD), nonparental ditype (NPD), and tetratype (T) asci for those two genes (for review see Ref. 1). Perkins ${ }^{2}$ derived the standard equation used for determining map distances $\left(x_{p}\right)$ on the assumption that only 0,1 , or 2 
exchanges occur in the interval between the two genes and that there is no chromatid interference, i.e.,

$$
x_{p}=\frac{100(T+6 N P D)}{2(P D+N P D+T)}
$$

This equation gives a good estimate of map distances for short intervals (up to about $35 \mathrm{cM}$ ) but, because it ignores higher crossover ranks, underestimates lengths of longer intervals.

Snow $^{3}$ has used the maximum likelihood method to derive a set of equations for determining map distances $\left(x^{\prime}\right)$ that considers all crossover ranks. Solution of these equations for a given set of PD, NPD, and $T$ values yields, in addition to the $x^{\prime}$ value, a value for the interference parameter, $k$, and values for the standard deviations in $x^{\prime}$ and $k$. Values of $x^{\prime}$ and $x_{p}$ are very close for short intervals but differ greatly for longer invervals. Bccause values of $x^{\prime}$ more accurately reflect actual map distances they should be used in preference to $x_{p}$ values. However, solution of the equations derived by Snow involves iterative steps requiring a computer and, because of this, application of these equations has been limited. We have found empirically that the equation,

$$
x_{e}=\frac{80.7 x_{p}-.833 x_{p}^{2}}{83.3-x_{p}}
$$

gives a very good estimate of $x^{\prime}$ over the range $x_{p}=0$ to $x_{p}=75 \mathrm{cM}$ (see Fig. 1). The average deviation of $x_{e}$ from $x^{\prime}$ over the full range of values of $x_{p}$ is only $2.0 \%$, although the individual variations are greater than this for large $x_{p}$ values. This deviation is due, at least in part, to variations in interference over the yeast genome; the relationship between $x^{\prime}$ and $x_{p^{\prime}}$ in contrast to that between $x_{e}$ and $x_{p^{\prime}}$ depends on interference. For values of $x_{p}$ less than 35 to $40 \mathrm{cM}$, Eq. (1) yields sufficiently accurate values of map distances; Eq. (2) should be used for longer distances. The coefficients in Eq. (2) were chosen to give a best fit to data from Saccharomyces cerevisiae. In this organism the interference is positive and has an average value of 0.36. 3 We expect Eq. (2) would apply to other tetrad organisms such as Neurospora crassa with similar interference values. By use of Eqs. (1) and (2), long map distances in yeast and similar tetrad

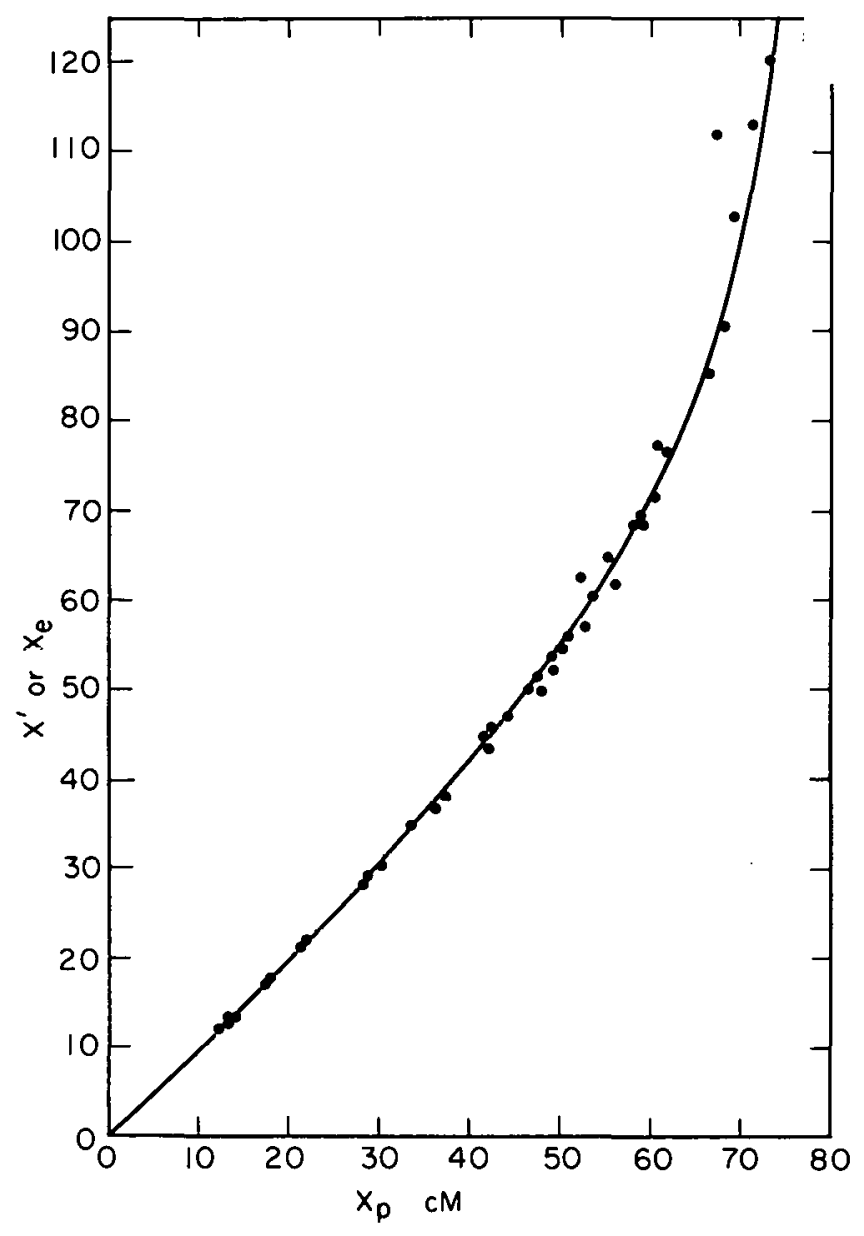

Fig. 1. Plot of $x^{\prime}$ (closed circles) and $x_{e}$ (line) vs. $x_{0}$

$(X B L$ 834-3688)

organisms can be determined relatively easily and with good accuracy.

\section{REFERENCES}

1. Fincham, J.R.S., and Day, P.R. Fungal Genetics. Blackwell Scientific Publ. Oxford, Fourth Edition (1979).

2. Perkins, D.D. Biochemical mutants of the smut fungus Ustilago maydis. Genetics 34, 607-626 (1949).

3. Snow, R. Maximum likelihood estimation of linkage and interference for tetrad data. Genetics 92, 231-245; 93, 285 (1979).

4. Mortimer, R.K., and Schild, D. Genetic map of Saccharomyces cerevisiae. Microbiol. Rev. 44, 519-571 (1980). 


\section{ITOTIC AND MEIOTIC RECOMBINATION IN SACCHAROMYCES CEREVISIAE: OPERTIES AND GENETIC CONTROL}

\section{Michael S. Esposito, Carlo V. Bruschi, Kathleen Bjornstad, and Dimitrios T. Maleas}

Spontaneous mitotic and meiotic recombination in yeast cells differ in several basic properties, including the timing of initiation of recombinational events relative to chromosomal replication, the distribution of recombinational events along chromosome arms and the effects of mutations of yeast REC genes on recombination. ${ }^{1,2}$ Previous studies provided preliminary evidence for gene conversion events in mitotic cells involving chromosomal DNA segments of considerably greater length than is observed in meiotic cell populations., ${ }^{3,4}$ Studies conducted during the past year demonstrate the occurrence of mitotic coincident conversion of widely separated genetic markers on the same chromosome involving both heterozygous and heteroallelic markers. ${ }^{5}$ Coincident mitotic gene conversion of chromosomal markers is stimulated by the spo11-1 mutation, which confers a mitotic hyper-recombination phenotype and a meiotic hypo-recombination phenotype. ${ }^{6}$ The mitotic and meiotic disturbances exhibited by spo11-1/spo 11-1 diploids are typical of classical meiotic mutants defective in chromosomal synapsis and exchange (asyndetic mutants). The properties of spo11-1 suggest that the different effects of such mutants in yeast mitosis and meiosis reflect underlying normal differences in the timing of recombination in mitosis and meiosis, the average length of chromosomal DNA regions that undergo gene conversion and the dependence of normal meiotic disjunction upon chiasmata formation.

Spontaneous Mitotic Recombination in Coisogenic spo11-1/spo11-1 and SPO11-1/SPO11-1 Hybrids

The spo11-1/spo11-1 hybrid CBX1 and the SPO11/SPO11 hybrids CBX2, JG44 and JG61 (Table 1) were employed to assess the effect of the

Table 1. Strains employed ${ }^{3}$

\begin{tabular}{|c|c|c|c|c|c|c|}
\hline Diploid & & & Relevant $\mathrm{g}$ & otypes & & \\
\hline \multirow[t]{3}{*}{ CBX1 } & $\frac{\text { spo11-1 }}{\text { spo11-1 }}$ & $\frac{\text { MAT } \alpha}{M A T \alpha}$ & $\frac{\operatorname{ade} 2-1}{\operatorname{ade} 2-1}$ & $\frac{\operatorname{can} 1^{r}}{C A N 1^{s}}$ & & \\
\hline & ADE5 & met13-c & cyh2 $2^{r}$ & $\operatorname{trp} 5-c$ & leu $1-c$ & ade 6 \\
\hline & ade5 & MET13 & $\mathrm{CYH2}^{5}$ & $\operatorname{trp5}-d$ & LEU1 & ADE6 \\
\hline \multirow[t]{3}{*}{$\mathrm{CBX} 2$} & $\frac{\text { SPO11 }}{\text { SPO11 }}$ & $\frac{\text { MAT } \alpha}{M A T \alpha}$ & $\frac{\operatorname{ade} 2-1}{\operatorname{ade} 2-1}$ & $\frac{\operatorname{can} 1^{r}}{C A N 1^{s}}$ & & \\
\hline & ADE5 & met13-c & cyh2 ${ }^{r}$ & $\operatorname{trp} 5-c$ & leu1-c & ADE6 \\
\hline & ade5 & MET13 & $\mathrm{CYH}^{\mathrm{s}}$ & $\operatorname{trp5-d}$ & LEU1 & $\overline{A D E 6}$ \\
\hline \multirow[t]{3}{*}{ JG44 } & $\frac{\text { SPO11 }}{\text { SPO11 }}$ & $\frac{\text { MAT } \alpha}{\text { MAT } \alpha}$ & $\frac{\operatorname{ade} 2-1}{\operatorname{ade} 2-1}$ & & & \\
\hline & ADE 5 & met13-d & $\mathrm{CYH}^{\mathrm{s}}$ & $\operatorname{trp} 5-d$ & leu $1-12$ & ADE6 \\
\hline & ade5 & met13-c & cyh2 $^{r}$ & $\operatorname{trp5}-\mathrm{c}$ & leu1-c & ADE6 \\
\hline \multirow[t]{3}{*}{ JG61 } & $\frac{\text { SPO11 }}{\text { SPO11 }}$ & $\frac{\text { MAT } \alpha}{\text { MAT } \alpha}$ & $\frac{\text { ade } 2-1}{\text { ade } 2-1}$ & & & \\
\hline & ADE5 & met13-d & $\mathrm{CYH} 2^{\mathrm{s}}$ & $\operatorname{trp} 5-d$ & leu $1-12$ & ADE6 \\
\hline & ade5 & met13-c & $\mathrm{cyh}^{\mathrm{r}}$ & $\operatorname{trp5-c}$ & leu1-c & ADE6 \\
\hline
\end{tabular}

a Meiotic linkage map of chromosome VII (centimorgans):

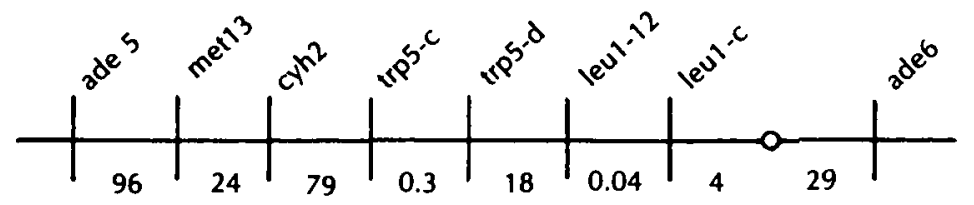


spo17-1 mutation on mitotic recombination. Intragenic recombination at the TRP5 locus, resulting in $\mathrm{Trp}^{+}$prototrophs, monitored intragenic events on chromosome VII. The genotypes of the hybrids also allow detection of intergenic recombination associated with conversional events at the TRP5 locus. The diploids are ade2-1/ade2-1 $A D E 5 / a d e 5$ hybrids and form red colonies due to the cell-limited pigment accumulated by ade2-1 mutants. Intergenic recombination, associated with intragenic recombination at TRP5, yields ade5/ade5 $\mathrm{Trp}^{+}$segregants. These cells form white colonies since the ade 5 mutation blocks accumulation of the red pigment precursor. Red-white sectored Trp ${ }^{+}$ colonies are also detected when conversion at the TRP5 locus yields a pair of prototrophic cells during the cell division preceding or immediately following plating on tryptophanless medium. The ensemble of mitotic events that results in red-white sectoring was monitored by the appearance of sectored colonies on synthetic complete medium. Mitotic segregation of the recessive drug resistance markers cyh2r, located on chromosomé VII, and can $1^{r}$, located on chromosome $V$, provided a further basis for comparison. The experimentally determined mitotic rates of recombinational events in spo111/spo11-1 and SPO11/SPO11 hybrids are summarized in Table 2. Mitotic events that result in total tryptophan prototrophic intragenic recombinants, cycloheximide resistant segregants and canavanine resistant segregants occur at similar rates in spo11- 1/spo11-1 and SPO11/SPO11 hybrids. Secto colonies resulting from segregation of the aucs mutation, and markers linked to it, recovered on synthetic complete medium, are four times more frequent in the spo11-1/spo11-1 hybrid. The enhancement is highly statistically significant (Table 2).

\section{Red-White Sectors Recovered on Synthetic Complete Medium}

We determined the genotypes of 51 red-white sectors recovered from platings of the spo11. 1/spo11-1 hybrid on synthetic complete medium to determine whether the enhanced sectoring is due to a stimulation of nonreciprocal and/or reciprocal recombination (Table 3). The spo11-1 mutation increases the frequency of both reciprocal and nonreciprocal events resulting in mitolic segregation. $43 / 51(84 \%)$ of the sectors exhibited only nonreciprocal sectoring for chromosome VII markers. $8 / 51(16 \%)$ ). sectors (Classes $4,5,8$ and 10 of Table 3) exhibited reciprocal segregation at the $A D E 5$ locus and three of these (Classes 5, 8 and 10) were accompanied by nonreciprocal events at the $\mathrm{CYH2}$ and MET13 loci. The presence of heterozygous markers at $L E U 1$ and $A D E 6$ on opposite sides of the centromere of chromosome VII provided an opportunity to determine whether nonreciprocal intergenic recombination events can cross a centromere. We observed no instances of

Table 2. Mitotic rates of spontaneous intragenic recombination at the TRP5 locus and segregation of heterozygous markers following growth of spo11-1/spo11-1 and SPO11/SPO11 hybrids.

\begin{tabular}{lll}
\hline \hline & \multicolumn{2}{c}{ Spontaneous mitotic rates } \\
\cline { 2 - 3 } Recombinant class & spo11-1/spo11-1 (CBX1) & SPO11/SPO11 (CBX2) \\
\hline Trp $^{+}$red & $1.63 \pm 0.17 \times 10^{-6}$ & $1.71 \pm 0.25 \times 10^{-6}$ \\
Trp $^{+}$white & $4.07 \pm 0.49 \times 10^{-7}$ & $2.72 \pm 0.47 \times 10^{-7}$ \\
Trp ${ }^{+}$red-white sectored & $1.90 \times 10^{-7}$ & $1.20 \times 10^{-7}$ \\
Trp ${ }^{+}$total & $3.20 \pm 0.32 \times 10^{-6}$ & $1.92 \pm 0.27 \times 10^{-6}$ \\
Can & $2.38 \pm 0.20 \times 10^{-5}$ & $3.39 \pm 0.38 \times 10^{-5}$ \\
Cyh & $1.83 \pm 0.36 \times 10^{-5}$ & $1.91 \pm 0.39 \times 10^{-5}$ \\
$\begin{array}{l}\text { Red-white sectored on } \\
\text { synthetic complete medium } \\
\text { due to segregation of ades }\end{array}$ & $5.2 \pm 1.2 \times 10^{-4}$ & $1.4 \pm 0.6 \times 10^{-4}$ \\
\hline \hline
\end{tabular}

a The frequency of red-white sectored colonies due to segregation of the ade5 mutation in $C B \times 1$ is statistically significantly different than that observed in CBX2 (Chi square $=6.9 ; N=1 ; P<0.01$ ) 
Table 3. Genotypes of red-white sectored colonies of the spo11-1/spo11-1 hybrid CBX1 recovered on synthetic complete medium.

\begin{tabular}{|c|c|c|c|c|c|c|c|c|c|c|c|c|c|}
\hline \multirow{3}{*}{ Class } & \multicolumn{12}{|c|}{ Genotypes observed $^{\mathbf{a}}$} & \multirow{3}{*}{$\begin{array}{c}\text { No. } \\
\text { observed }\end{array}$} \\
\hline & \multicolumn{6}{|c|}{ Red side } & \multicolumn{6}{|c|}{ White side } & \\
\hline & ADE6 & I.EU1 & TRP5 & $\mathrm{CYH} 2$ & MET13 & ADE5 & ADE6 & LEU1 & TRP5 & $\mathrm{CYH}_{2}$ & MET13 & ADE5 & \\
\hline 1 & \pm & \pm & $\frac{1+}{+2}$ & $\bar{t}$ & \pm & $\frac{-}{t}$ & $\overline{-}$ & \pm & $\frac{1+}{t 2}$ & $\frac{\bar{t}}{t}$ & \pm & $\bar{t}$ & 11 \\
\hline 2 & \pm & \pm & $\frac{1+}{+2}$ & $\overline{\bar{t}}$ & $\frac{t}{t}$ & $\bar{t}$ & $=$ & \pm & $\frac{1+}{t 2}$ & $\bar{t}$ & $\frac{t}{t}$ & $\frac{-}{t}$ & 1 \\
\hline 3 & \pm & $\frac{ \pm}{-}$ & $\frac{1+}{t 2}$ & $\bar{t}$ & \pm & $\frac{\bar{t}}{t}$ & \pm & \pm & $\frac{1+}{+2}$ & $\bar{T}$ & \pm & $=$ & 13 \\
\hline 4 & \pm & \pm & $\frac{1+}{+2}$ & $\bar{t}$ & \pm & $\frac{t}{t}$ & \pm & \pm & $\frac{1+}{t 2}$ & $\overline{7}$ & \pm & $\overline{-}$ & 5 \\
\hline 5 & \pm & $\frac{ \pm}{-}$ & $\frac{1+}{t 2}$ & $\frac{\bar{T}}{+}$ & $\frac{t}{t}$ & $\frac{t}{t}$ & \pm & \pm & $\frac{1+}{+2}$ & $\bar{t}$ & $\frac{t}{t}$ & $\overline{=}$ & 1 \\
\hline 6 & $\frac{t}{t}$ & \pm & $\frac{1+}{t 2}$ & $\bar{x}$ & $\frac{t}{t}$ & $\bar{t}$ & \pm & \pm & $\frac{1+}{+2}$ & $\bar{x}$ & $\frac{t}{t}$ & $\overline{-}$ & 1 \\
\hline 7 & \pm & \pm & $\frac{1+}{+2}$ & $\bar{t}$ & \pm & $\bar{t}$ & \pm & \pm & $\frac{1+}{t 2}$ & $\overline{-}$ & $\frac{t}{t}$ & $\overline{-}$ & 3 \\
\hline 8 & \pm & \pm & $\frac{1+}{t 2}$ & $\bar{t}$ & \pm & $\frac{t}{t}$ & \pm & \pm & $\frac{1+}{+2}$ & $\frac{\bar{t}}{+}$ & $\frac{t}{t}$ & $=$ & 1 \\
\hline 9 & \pm & \pm & $\frac{1+}{t 2}$ & $\bar{T}$ & \pm & $\overline{7}$ & \pm & \pm & $\frac{1+}{+2}$ & $\overline{-}$ & $\frac{t}{t}$ & $\overline{-}$ & 6 \\
\hline 10 & \pm & \pm & $\frac{1+}{+2}$ & $\frac{\bar{T}}{+}$ & $\frac{ \pm}{-}$ & $\frac{t}{t}$ & \pm & \pm & $\frac{1+}{+2}$ & $\overline{=}$ & $\frac{t}{t}$ & $\overline{-}$ & 1 \\
\hline 11 & \pm & \pm & $\frac{1+}{+2}$ & $\frac{-}{t}$ & $\frac{t}{t}$ & \pm & \pm & \pm & $\frac{1+}{t 2}$ & $\overline{-}$ & $\frac{t}{+}$ & $\overline{-}$ & 1 \\
\hline 12 & \pm & \pm & $\frac{1+}{t 2}$ & $\frac{-}{+}$ & $\frac{t}{t}$ & \pm & \pm & \pm & $\frac{1+}{+2}$ & $\overline{-}$ & $\frac{t}{t}$ & $\overline{=}$ & 1 \\
\hline 13 & \pm & \pm & $\frac{1+}{t 2}$ & $\bar{x}$ & $\frac{ \pm}{-}$ & \pm & \pm & \pm & $\frac{1+}{1+}$ & $\overline{-}$ & $\frac{t}{t}$ & $\overline{=}$ & 1 \\
\hline 14 & \pm & \pm & $\frac{1+}{t 2}$ & $\overline{7}$ & $\frac{ \pm}{-}$ & $\frac{\bar{t}}{+}$ & \pm & \pm & $\frac{+2}{+2}$ & $\overline{-}$ & $\frac{t}{t}$ & $\overline{-}$ & 2 \\
\hline 15 & \pm & \pm & $\frac{1+}{1+}$ & $\overline{7}$ & \pm & $\bar{\tau}$ & \pm & \pm & $\frac{1 t}{1+}$ & $\overline{=}$ & $\frac{t}{t}$ & \pm & 1 \\
\hline 16 & $\underline{ \pm}$ & \pm & $\frac{1+}{+2}$ & $\frac{\bar{t}}{t}$ & \pm & $\bar{t}$ & \pm & $\frac{t}{+}$ & $\frac{1+}{1+}$ & $\overline{-}$ & $\frac{t}{t}$ & $\overline{=}$ & 1 \\
\hline 17 & \pm & \pm & $\frac{1+}{t 2}$ & $\overline{\bar{t}}$ & $\frac{t}{t}$ & $\overline{\bar{t}}$ & \pm & $\frac{t}{t} \cdot$ & $\frac{1+}{1+}$ & $\overline{=}$ & $\frac{t}{t}$ & $=$ & 1 \\
\hline
\end{tabular}

at TRP5, $1+=\operatorname{trp5}-d$, and $+2=\operatorname{trp} 5-c$.

coincident conversion involving the ADE6 and LEU1 loci among a total of 14 sectors (Classes 1, 2, 16 $\checkmark 17$ of Table 3) in which nonreciprocal zregation occurred at either ADE6 or LEU1. The Ecnotypes of 6 red-white sectored colonies of the
SPO11/SPO11 hybrid JG61 were also determined (Table 4). 5/6 result from nonreciprocal events (Classes 1 and 2 of Table 4 ) and $1 / 6$ results from reciprocal recombination in the MET13-ADE5 interval (Class 3 of Table 4). 
Table 4. Genotypes of red-white sectored colonies of the SPO11/SPO11 hybrid JG61 recovered on synthetic complete medium.

\begin{tabular}{|c|c|c|c|c|c|c|c|c|c|c|c|}
\hline \multirow{3}{*}{ Class } & \multicolumn{11}{|c|}{ Genotypes observed $^{a}$} \\
\hline & \multicolumn{5}{|c|}{ Red side } & \multicolumn{5}{|c|}{ White side } & \multirow{2}{*}{$\begin{array}{c}\text { No. } \\
\text { observed }\end{array}$} \\
\hline & LEU1 & TRP5 & $\mathrm{CYH} 2$ & MET13 & ADE5 & LEUT & TRP5 & $\mathrm{CYH} 2$ & MET13 & ADE5 & \\
\hline 1 & $\frac{+2}{1+}$ & $\frac{1+}{+2}$ & $\bar{t}$ & $\frac{+2}{1+}$ & \pm & $\frac{+2}{1+}$ & $\frac{1+}{t 2}$ & $\frac{t}{t}$ & $\frac{1+}{1+}$ & $\frac{-}{-}$ & 4 \\
\hline 2 & $\frac{+2}{1+}$ & $\frac{1+}{t 2}$ & $\frac{-}{t}$ & $\frac{+2}{1+}$ & \pm & $\frac{+2}{1+}$ & $\frac{1+}{+2}$ & $\frac{-}{t}$ & $\frac{+2}{1+}$ & $\frac{-}{-}$ & 1 \\
\hline 3 & $\frac{+2}{1+}$ & $\frac{1+}{t 2}$ & $\frac{7}{t}$ & $\frac{+2}{1+}$ & $\frac{t}{t}$ & $\frac{+2}{1+}$ & $\frac{1+}{t 2}$ & $\frac{-}{t}$ & $\frac{+2}{1+}$ & $\overline{-}$ & 1 \\
\hline
\end{tabular}

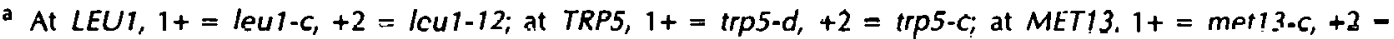
met13 d.

\section{Red-White Sectored Trp ${ }^{+}$Colonies}

We determined the genotypes of $17 \mathrm{Trp}^{+}$redwhite sectored colonies recovered from platings of the spo11-1/spo11-7 diploid on tryptophanless medium (Table 5) to inquire whether sectoring results from reciprocal intergenic recombination associated with intragenic recombination at the TRP5 locus. In the SPO11/SPO11 hybrids JG44 and JG61, 71 red-white sectored $\mathrm{Trp}^{+}$colonies were previously described. A total of $60 / 71$ (85\%) exhibited reciprocal intergenic recombination in the interval TRP5-CYH2 resulting in reciprocal segregation of markers at the $C Y H 2, M E T 13$ and $A D E 5$ loci. The spo11-1/spo11-1 red-white sectored Trp ${ }^{+}$ colonies exhibit a different pattern of segregation of markers at these loci. None of the spo11. 1/spo11-1 $\operatorname{Trp}^{+}$sectored colonies reflect simple reciprocal intergenic recombination in the interval $T R P 5-C Y H 2$ and concomitant reciprocal segregation of markers at the distal $\mathrm{CYH2}, \mathrm{MET13}$ and $A D E 5$ loci (Table 5). $12 / 17(71 \%)$ of the sectors (Classes $1,2,4,8,9$ and 10 of Table 5) result from conversional events involving the $C Y H 2, M E T 13$ and $A D E 5$ loci. 5/17 (29\%) (Classes 3, 5, 6 and 7 of Table 5) exhibit reciprocal segregation at the $A D E 5$ locus due to apparent reciprocal intergenic recombination in the most centromere distal interval, MET13ADE5.

\section{Coincident Nonreciprocal Segregation of Linked Recessive Markers Does Not Result by Chromosomal Deletion}

Spontaneous nonreciprocal segregation of recessive heterozygous markers of the same chromosome in SPO11/SPO11 hybrids does not result by deletion of the chromosomal segment bearing the corresponding dominant alleles. If the segregation of recessive heterozygous markers reflected hemizygosity following a deletion rather than homozygosity following gene conversion, this would have been detected during meiotic tetrad analysis of the white portions of sectored colonies. Asci from the white portions of sectored colonies would be expected to segregate $2+: 2$ - for a recessive lethal deletion. In order to determine whether the nonreciprocal sectoring observed in spo111/spo11-1 was due to hemizygosity following a deletion, we analyzed the genotypes of meiotic segregants from both the red and white portions of red-white sectored $\mathrm{Trp}^{+}$colonies. Hemizygosity would result in a strong bias in favor of the meiotic recovery of the intact chromosome from the white portions of $\mathrm{Trp}^{+}$red-white sectored colonies due to the meiotic hypo-rec phenotype of spo11-1. The putative deleted chromosome lacking the $\mathrm{CYH}$ $A D E 5$ segment must recombine with its homolog in order to, result in a haplo-viable segregant since there are known indispensable loci distal to the $\mathrm{CYH} 2$ locus. The results of this analysis are shown in Table 6. Markers in trans configuration at TRP5, LEU1 and ADE6 were employed to identify the nonrecombinant parental chromosomes. Parental chromosomes are recovered with equal frequency from both the red and white portions of sectured colonies and recombination in the relevant $L E U 1$. TRP5 interval is rare.

A Model to Explain the Mitotic and Meiotic Effects of the spo11-1 Mutation

The spo11-1 mutant alters the properties mitotic recombination in three respects: $1, \ldots$ 
Table 5. Genotypes of red-white sectored Trp ${ }^{+}$colonies of the spo11-1/spo11-1 hybrid $C B X 1$ recovered on tryptophanless medium.

\begin{tabular}{|c|c|c|c|c|c|c|c|c|c|c|c|c|c|}
\hline \multirow{3}{*}{ Class } & \multicolumn{12}{|c|}{ Genotypes observed $^{\mathrm{a}}$} & \multirow{3}{*}{$\begin{array}{c}\text { No. } \\
\text { observed }\end{array}$} \\
\hline & \multicolumn{6}{|c|}{ Red side } & \multicolumn{6}{|c|}{ White side } & \\
\hline & ADE6 & LEU1 & TRP5 & $\mathrm{CYH2}$ & MET13 & ADE5 & ADE6 & LEU1 & TRP5 & $\mathrm{CYH} 2$ & MET13 & ADE5 & \\
\hline 1 & \pm & \pm & $\frac{1+}{t+}$ & $\frac{\bar{t}}{+}$ & \pm & $\frac{\bar{t}}{+}$ & \pm & \pm & $\frac{1+}{t+t}$ & $\overline{-}$ & $\frac{t}{t}$ & $\overline{-}$ & 6 \\
\hline 2 & $\frac{\bar{t}}{t}$ & $\bar{x}$ & $\frac{t+}{1+}$ & $\bar{x}$ & \pm & $\bar{z}$ & \pm & \pm & $\frac{1+}{t+}$ & $\overline{-}$ & $\frac{t}{t}$ & $\overline{-}$ & 1 \\
\hline 3 & \pm & \pm & $\frac{t+}{t 2}$ & $\frac{-}{+}$ & \pm & $\frac{t}{t}$ & \pm & \pm & $\frac{t+}{+2}$ & $\bar{z}$ & $\frac{t}{t}$ & \pm & 2 \\
\hline 4 & \pm & \pm & $\frac{1+}{t+}$ & $\frac{t}{t}$ & \pm & $\bar{t}$ & \pm & \pm & $\frac{t+}{t+}$ & $\bar{z}$ & $\frac{t}{t}$ & $=$ & 1 \\
\hline 5 & \pm & \pm & $\frac{12}{t+}$ & $\overline{-}$ & \pm & $\frac{ \pm}{t}$ & \pm & \pm & $\frac{+2}{t+}$ & $\overline{-}$ & $\frac{t}{t}$ & $\bar{z}$ & 1 \\
\hline 6 & \pm & \pm & $\frac{1+}{t+}$ & $\overline{-}$ & \pm & $\frac{t}{t}$ & \pm & \pm & $\frac{12}{t+}$ & $\overline{-}$ & $\frac{t}{t}$ & $\bar{z}$ & 1 \\
\hline 7 & \pm & \pm & $\frac{1+}{t+}$ & $\frac{\bar{t}}{t}$ & \pm & $\frac{ \pm}{t}$ & \pm & \pm & $\frac{t+}{t 2}$ & $\overline{-}$ & $\frac{t}{t}$ & $\bar{z}$ & 1 \\
\hline 8 & \pm & \pm & $\frac{t+}{t 2}$ & $\overline{\bar{t}}$ & \pm & $\frac{7}{+}$ & \pm & \pm & $\frac{1+}{t+}$ & $\overline{=}$ & $\frac{t}{t}$ & $\overline{=}$ & 2 \\
\hline 9 & \pm & \pm & $\frac{t+}{t 2}$ & $\frac{7}{+}$ & $\frac{t}{t}$ & $\overline{\bar{t}}$ & \pm & \pm & $\frac{1+}{t+}$ & $\overline{\bar{z}}$ & $\frac{t}{t}$ & $\overline{=}$ & 1 \\
\hline 10 & $\bar{t}$ & $\overline{+}$ & $\frac{t+}{+2}$ & $\frac{\bar{t}}{+}$ & \pm & $\frac{\bar{T}}{+}$ & \pm & \pm & $\frac{1+}{+2}$ & 三 & $\frac{t}{t}$ & $\overline{=}$ & 1 \\
\hline
\end{tabular}

a At TRP5, $1+=\operatorname{trp5}-d$, and $+2=\operatorname{trp5}-c$.

results in a nonuniform enhancement of reciprocal and nonreciprocal recombination; 2) it enhances the relative proportion of intragenic conversional events at the TRP5 locus, associated with coincident conversion of widely separated markers distal to the TRP5 locus; and 3) it abolishes the occurrence of intragenic conversional events at the TRP5 locus, associated with simple intergenic recombination in the TRP5-CYH2 interval, unaccompanied by conversion at the $C Y H 2, M E T 13$, and $A D E 5$ loci. These effects of the spo11-1 mutation provide evidence that the SPO11 gene product

Table 6. Recovery of parental genotypes among meiotic segregants from the red and white sides of sectored Trp ${ }^{+}$colonies of the spo11-1/spo11-1 hybrid.

\begin{tabular}{lcccc}
\hline & \multicolumn{2}{c}{ Parental genotypes } & \multicolumn{2}{c}{ Crossovers } \\
\cline { 2 - 4 } Origin & ADE6 LEU1 trp5 & ade6 leu1 TRP5 & ade6 leu1 trp5 & Total $^{\text {a }}$ \\
\hline 7 Red sides & 59 & 42 & 1 & 152 \\
9 White sides & 49 & 41 & 0 & 133 \\
\hline \hline
\end{tabular}

a There were 31 putative disomics/152 tested from red sides and 34 putative disomics/133 from white sides. The disomics do not include the parental and recombinant classes listed and are typically heterozygous at ADE6, LEU1, and TRP5. 
controls the length of chromosomal regions that undergo simultaneous gene conversion and concomitantly modulates the distribution of reciprocal intergenic exchanges.

The length of DNA segments that can exhibit coincident conversion of linked genetic markers and the position of associated reciprocal exchange events are mutually dependent properties of recombination according to the Aviemore model of recombination and our prereplicational model of mitotic recombination in which recombination between homologous chromosomes is initiated before completion of the mitotic DNA synthesis phase. The relevant events envisaged on the prereplicational model are shown in Fig. 1. Strand transfer establishes a region of heteroduplex DNA in the recipient DNA molecule only, i.e., asymmetric heteroduplex DNA. Strand transfer is terminated by the isomerization postulated by Meselson and Radding resulting in formation of a Holliday structure. Resolution of the Holliday structure by DNA replication during the mitotic DNA synthesis phase results in reciprocal recombination of DNA sequences flanking the region of asymmetric heteroduplex DNA and the Holliday juncture (Fig. 1E). Coincident conversion of heterozygous markers in this region is not dependent upon mismatch repair of heteroduplex DNA. If mismatch

Fig. 1. Coincident gene conversion and reciprocal recombination on the prereplicational model of mitotic recombination. (A) Recombination is initiated before replication of the homologous chromosomes due to the presence of a single strand nick or gap in the DNA of one of the homologs. (B) Coordinated DNA synthesis (dashed line), strand displacement and strand uptake result in asymmetric transfer of single stranded DNA from the donor (black) to the recipient (white) homolog and transient $D$ loop formation. (C) The region of asymmetric heteroduplex DNA in the recipient duplex is extended by continued DNA synthesis, strand displacement and uptake into the recipient duplex. (D) Asymmetric strand transfer terminates as the Meselson-Radding isomerization and gap closure result in the formation of a Holliday structure in which the DNA double helices of the recombining homologs are joined by crossing single DNA chains. The length of the region of asymmetric heteroduplex DNA and the site of formation of the Holliday juncture are simultaneously determined. (E) Chromosomal DNA replication resolves the Holliday structure, and two pairs of sister chromatids $(1,2$ and 3,4) are formed. Genetic markers in the region of asymmetric heteroduplex DNA exhibit coincident gene conversion. Three chromatids (nos. 1, 3 and 4) contain only the donor (black) DNA sequence of this region; one chromatid (no. 2) contains the recipient (white) DNA sequence of this region. Genetic markers bracketing the region of coincident gene conversion and the site of formation of the Holliday juncture are reciprocally recombined, i.e., chromatids 1 and 4. Chromatids 2 and 3 retain the parental configuration of flanking sequences. repair does occur it can result in total elimination one of the input alleles at a heterozygous site. Ti.., results in sectors in which both portions are homozygous for the same allele of a locus previously in heterozygous condition (e.g., conversion at the MET13 locus, classes 2, 5, 6, 11 and 17 of Table 3).

The precise nature of the SPO11 gene product is not specified by the genetic results, but the data favor the hypothesis that it is the postulated Meselson-Radding isomerase or a protein whose activity affects this type of isomerization. Delayed termination of asymmetric heteroduplex DNA formation by isomerization would be expected to result in the mitotic phenotype exhibited by the spo11-1/spo11-1 diploid: diminished evidenre of Holliday structure formation in the immediate vicin-

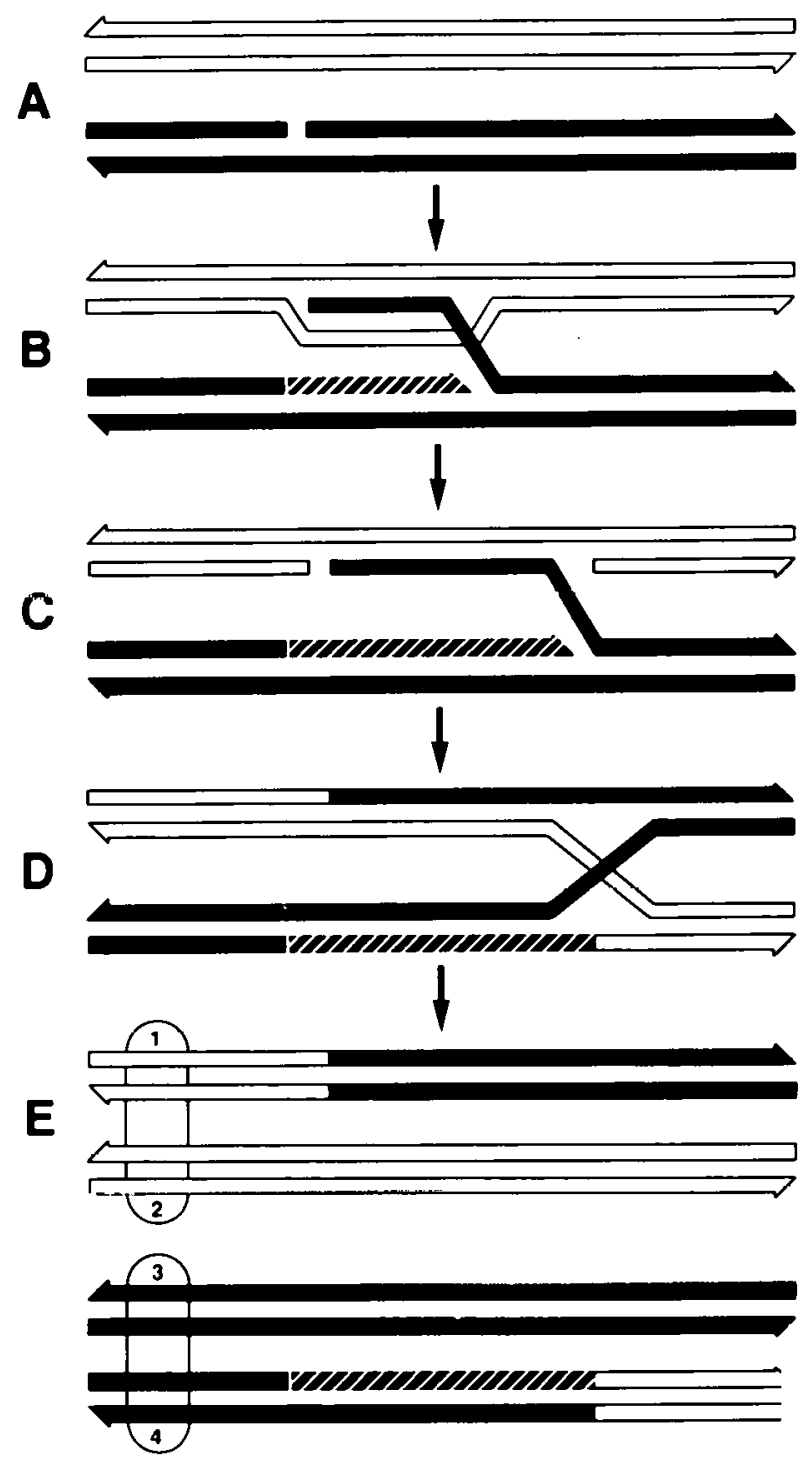


of selected conversional events (i.e., $\mathrm{Trp}^{+}$protouuphs) and perturbation of the usual frequency distribution of conversion and reciprocal recombination events along the length of a chromosome.

In meiosis spo11-1/spo11-1 cells exhibit a $\mathrm{Rec}^{-}$phenotype associated with high levels of chromosomal nondisjunction, and the SPO11 gene product is apparently required for stable associations of nonsister chromatids. The meiotic effects of the spo11-1 mutation are also consistent with the speculation that the SPO11 gene product is involved in the Meselson-Radding isomerization. In meiotic yeast cells recombination occurs postreplicationally, and asymmetric heteroduplex DNA is apparently limited to short regions that are on average less than 1000 base pairs in length, when events involving single copy genes are examined. This is a very small distance compared to the length of the TRP5 to ADE5 chromosomal segment, consisting of approximately $5 \times 10^{5}$ base pairs (bp), that exhibits mitotic coincident gene conversion in the spo11-1/spo11-1 diploid and to a lesser extent in SPO11/SPO11 diploids. Owing to constraints imposed by meiotic physiology, strand transfer may not be able to continue over long distances. Failure to isomerize and form Holliday structures, which are thought to be the molecular basis of meiotic chiasma formation, may result in disengagement of the interacting chromatids. This may occur both by eventual scission of the single DNA strand uniting the interacting chromatids and by reversal of strand transfer due to branch migration of the incomplete Holliday juncture to the site of single strand scissions in the transferred strand.

\section{2- $\mu \mathrm{m}$ DNA Plasmid Profiles of Mitotic and Meiotic Cells}

Most strains of Saccharomyces cerevisiae harbor a nuclear 2- $\mu \mathrm{m}$ circular double-stranded-DNA plasmid present at 60-100 copies/diploid cell. The $2-\mu \mathrm{m}$ DNA plasmid, consisting of $6300 \mathrm{bp}$, contains two regions of $599 \mathrm{bp}$ each that are inverted repeats of each other. The inverted repeats separate the plasmid into two domains of unique sequence, one of $2774 \mathrm{bp}$ and one of $2346 \mathrm{bp}$. Recombination occurs readily between the two inverted regions. Intermolecular as well as intramolecular recombination result in multimeric

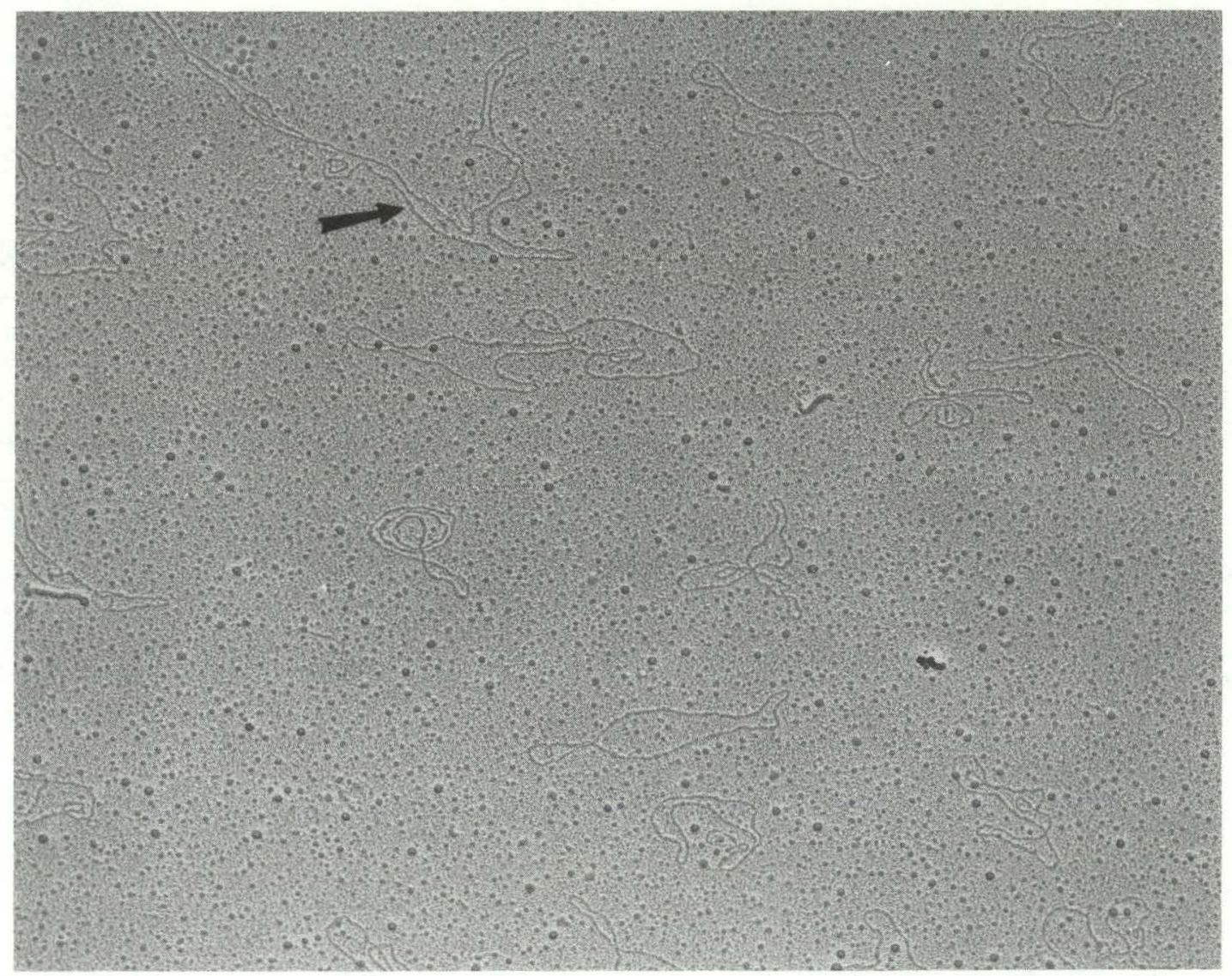

Fig. 2. 2- $\mu m$ DNA plasmid circles from mitotic cells of the SPO11/SPO11 hybrid CBX2. Arrow indicates a multimeric molecule. 
plasmids. In collaboration with Dr. Kenneth Downing, 2- $\mu \mathrm{m}$ plasmid DNA was prepared from mitotic and meiotic cell populations of spo11-1/spo11-1 (CBX1) and SPO11/SPO11 (CBX2) hybrids to determine whether the spo11-1 mutation affects maintenance of the 2- $\mu \mathrm{m}$ DNA plasmid and the frequency of multimeric molecules which may result from inter- or intramolecular recombination. DNA of meiotic populations in acetate sporulation medium was isolated two hours before onset of the first nuclear division, monitored by fluorescence microscopy of sporulating cells; $2-\mu \mathrm{m}$ DNA prepared by ethidium-bromide/cesium-chloride density gradient centrifugation was visualized by electron microscopy, and random fields were photographed for subsequent counting and contour length measurement of molecules. Typical monomeric and dimeric forms of $2-\mu \mathrm{m}$ circles are shown in Fig. 2. Mitotic plasmid populations isolated from the spo11-1/spo11-1 and SPO11/SPO11-1 hybrids exhibited nearly identical percentages of dimers, trimers and larger multimeric molecules (Fig. 3). Meiotic plasmid populations exhibited approximately the same level of dimeric and trimeric molecules (Fig. 3). The results demonstrate that the REC mutation spo11-1 does not affect the frequency of multimers.

\section{REFERENCES}

1. Esposito, M.S. Molecular mechanisms of recombination in Saccharomyces cerevisiae: Testing mitotic and meiotic models by analysis of hypo-rec and hyper-rec mutations. Symposia of the Society for Experimental Biology 38, in press (1983).

2. Esposito, M.S. Evidence that spontaneous mitotic recombination occurs at the twostrand stage. Proc. Natl. Acad. Sci. USA 75, 4436-4440 (1978).

3. Esposito, M.S., and Wagstaff, J.E. Mechanisms of mitotic recombination. pp. 341-370. In: Strathern, J.N., Jones, E.W. and Broach, J.R. (eds.) Molecular Biology of the Yeast Sac-

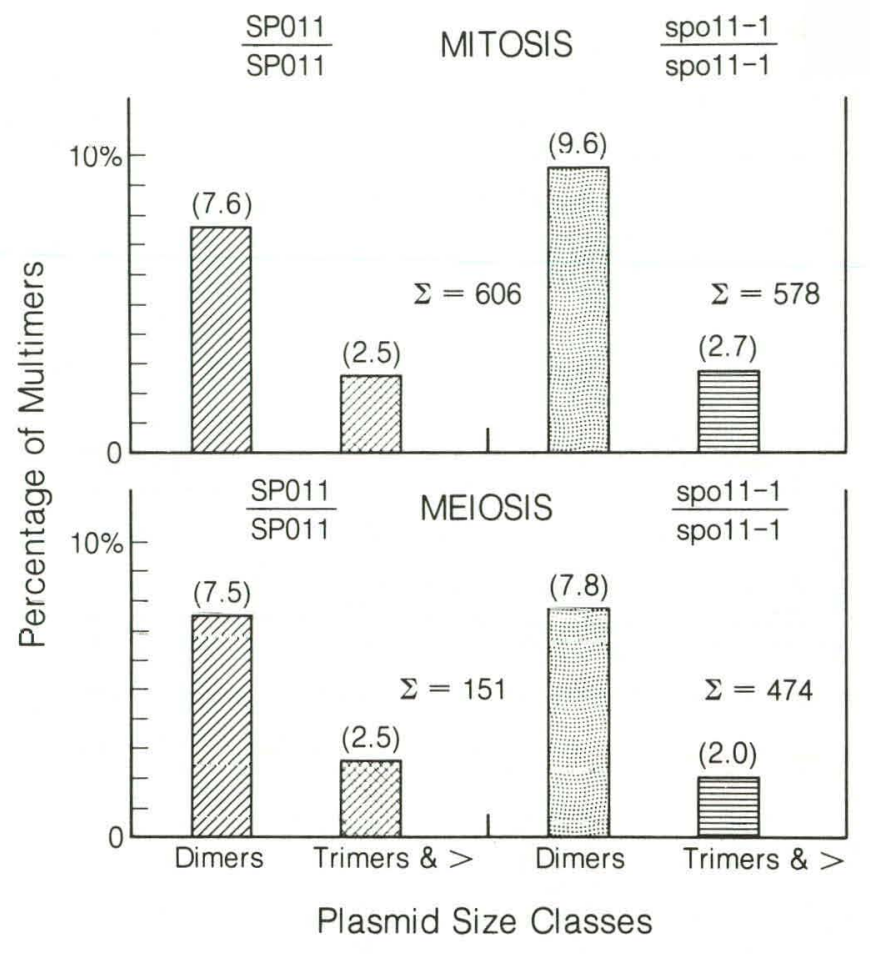

Fig. 3. 2- $\mu m$ DNA plasmid profiles of mitotic and meiotic cells.

(XBL 8310-4076)

charomyces: Life Cycle and Inheritance. Cold Spring Harbor Laboratory, Cold Spring Harbor, N.Y. (1981).

4. Golin, J., and Esposito, M.S. Mitotic recombination: Mismatch correction and replicational resolution of Holliday structures formed at the two-strand stage in Saccharomyces. Molec. Gen. Genet. 183, 252-263 (1981).

5. Bruschi, C.V., and Esposito, M.S. Enhancement of spontaneous mitotic recombination by the meiotic mutant spo11-1 in Saccharomyces cerevisiae. Proc. Natl. Acad. Sci. USA, in press (1983).

6. Golin, J.E., and Esposito, M.S. Coincident gene conversion during mitosis in Saccharomyces. Genetics, in press (1983).

\section{QUANTITATIVE gp32 AFFINITY CHROMATOGRAPHY OF THE INTACT AND MODIFIED gp32 MOLECULES TO EXAMINE gp32 SELF INTERACTIONS}

\section{Junko Hosoda and Herbert W. Moise}

Our previous research on bacteriophage T4 gene 32 product (gp32), a single-stranded DNA binding protein, led us to propose that both termi- nals of gp32 make discrete functional domai domain A, 50 amino acid residues at the carbc terminus, and domain $B, 20$ residues at the amino 
id terminus, which are involved in gp32 interacwuns with DNA and proteins. It has been shown that the intact amino acid terminus B domain is essential for cooperative binding to single-stranded DNA, while the intact carboxy terminus domain A is responsible for the kinetic block in the gp32induced melting of native DNA and is related to the gp32 interactions with other T4 proteins related to DNA metabolisms. ${ }^{1}$ A recently developed technique of affinity column chromatography allowed us further more precise examination of protein-protein interactions.

Self interactions of gp32 molecules is very important because the high cooperativity of their binding to single-stranded DNA is believed to be due to the interaction between the adjacently bound gp32 molecules. Such interactions will probably determine the conformation of the gp 32 DNA complex that serves as the template for the replication recombination complexes. Gp32 in solution shows very complicated self-association reactions; there are at least two types of (protein) concentration-dependent association that have different sensitivities to a variety of other environments. One such association produces indefinite oligomers, maximum at $0.1 \mathrm{M}$ salt, neutral $\mathrm{pH}$, and sensitive to high salt and high $\mathrm{pH}$, and another produces a dimer, resistant to high salt or high $\mathrm{pH}^{2}$ Our limited proteolysis experiments indicated that the proteolytic removal of nine amino acid residues from the amino terminus of gp32 reduced (or abolished) all three interactions, the oligomer formation, the salt resistant dimer formation, and cooperative DNA binding. ${ }^{1}$

De Haseth et al. ${ }^{3}$ measured binding constants of proteins for DNA using DNA-cellulose columns. The same technique was applied to measure binding constants for gene 32 protein self-association.

Small columns were made of agarose to which gp32 had been covalently attached. The columns were equilibrated with Tris- $\mathrm{HCl}$ buffer containing varying concentrations of $\mathrm{NaCl} .10 \mu \mathrm{g}$ of ${ }^{3} \mathrm{H}-\mathrm{gp} 32$ corresponding to $5 \%$ saturation of the binding sites in the column buffer was applied to a $0.5-\mathrm{ml}$ column and eluted with the same buffer. The concentration of the binding sites was measured by applying an excess amount of gp32 to the column in the buffer containing $50 \mathrm{mM} \mathrm{NaCl}$, and calculated from the amount of gp32 that saturated the column, assuming that one binding site retains one gp32. When data were plotted as log Pci vs. i (Pci $=$ percentage of ${ }^{3} \mathrm{H}$-gp32 remaining on the column id $\mathrm{i}=$ fraction number, as in Fig. 1), the major art of the profile can be characterized as single-

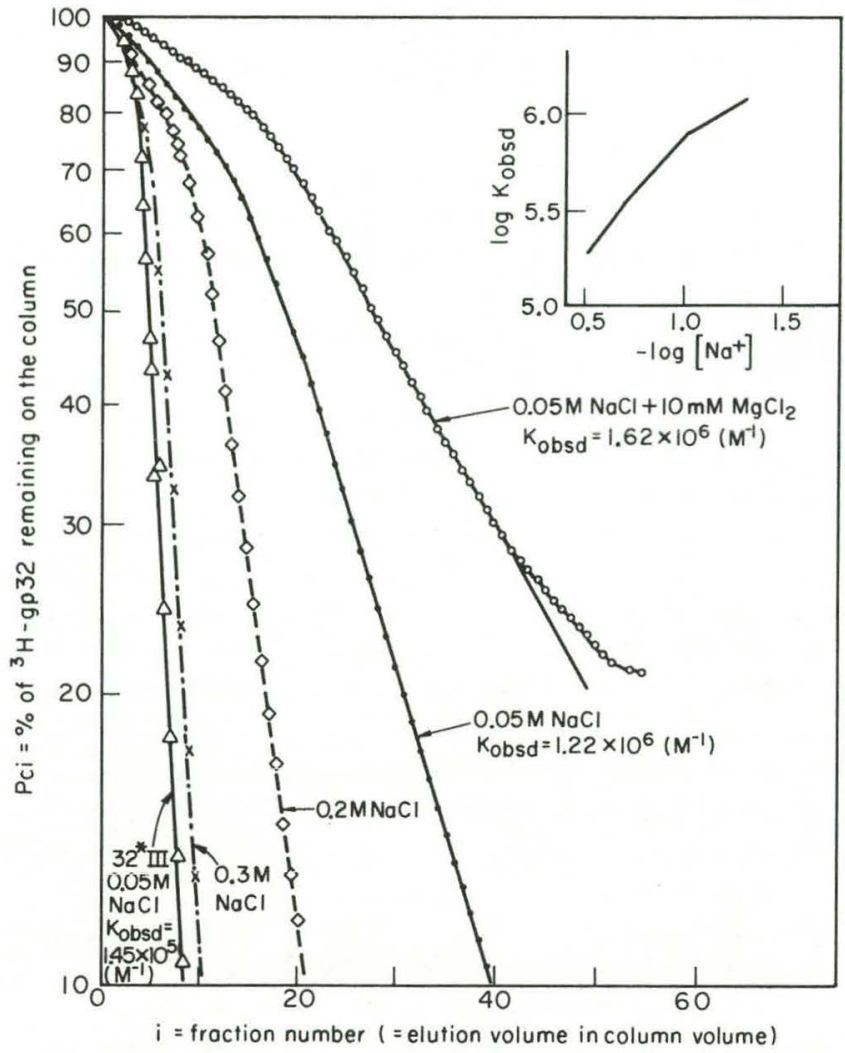

Fig. 1. Retention of $\left({ }^{3} \mathrm{H}\right)$-gp32 on a gp32-AffiGel column.

(XBL 831-3554)

exponential decay. The observed binding constants $\mathrm{K}_{\text {obsd }}$ were calculated from the lower part of the curves in Fig. 1 according to de Haseth et al. ${ }^{3}$ At $0.05 \mathrm{M} \mathrm{NaCl}, \mathrm{K}_{\text {obsd }}=1.2 \times 10^{6} \mathrm{M}^{-1}$. The slope of $\log \mathrm{K}_{\text {obsd }}$ vs. - $\log [\mathrm{Na}+]$ was approximately 1 , indicating that one pair of ionic bonds may be involved in the self-association. Addition of $10 \mathrm{mM}$ $\mathrm{MgCl}_{2}$ increased the binding constants, and $\mathrm{K}_{\text {obsd }}$ at $10 \mathrm{mM} \mathrm{MgCl}$ and $50 \mathrm{mM} \mathrm{NaCl}$ was $1.6 \times 10^{6}$ $M^{-1}$

$32 * \mathrm{II}$, a proteolytic product of gp32 lacking nine amino acid residues from the amino terminus, did not show any affinity for the 32-column (Fig. 2), while amE315 peptide lacking approximately one third of the molecule from the carboxy terminus seemed to have as strong an affinity as the intact protein (data not shown). 32* III, another proteolytic product lacking both the amino and carboxy terminus regions $A$ and $B$, had an affinity weaker than that of the intact 32 . It seemed that the presence of the intact carboxy terminus in region $A$ lessened the affinity, i.e., the longer the remaining carboxy terminus region, the less strong the affinity. The 32*III made by trypsin lacking 21 residues from 


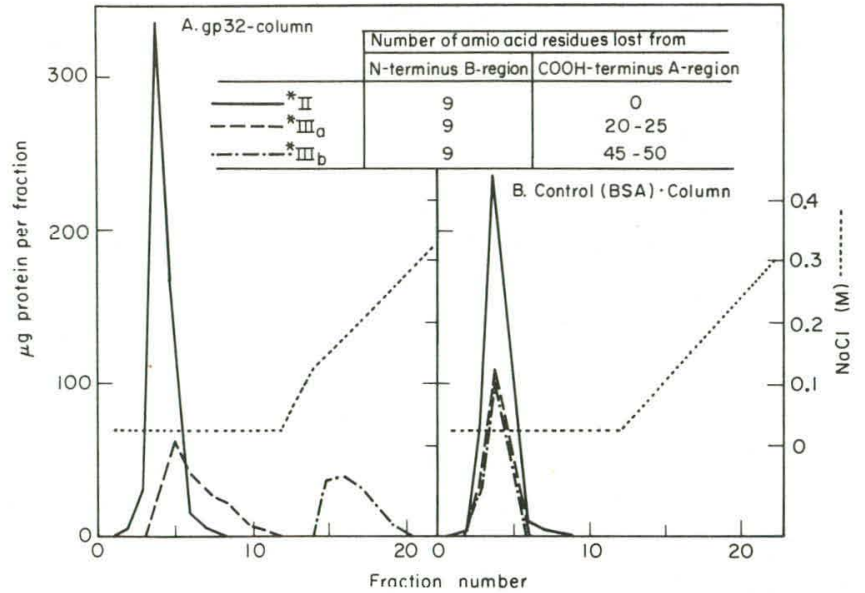

Fig. 2. Separation of Staph-protease cleavage products of gp32-affinity chromatography.
(XBL 831-3553) the amino terminus and 48 residues from the boxy terminus had $\mathrm{K}_{\text {obsd }}=1.5 \times 10^{5} \mathrm{M}^{-1}$ (Fig. 1).

\section{REFERENCES}

1. Hosoda, J., Burke, R.L., Moise, H., Kubota, I., and Tsugita, A. In: Mechanistic studies of DNA replication and genetic recombination. ICN-UCLA Symposia on Molecular Biology 19, 507-516, Academic Press, New York (1980).

2. Carroll, R., Neet, K., and Goldthwait, D. J. Mol. Biol. 91, 275-291 (1975).

3. de Haseth, P.L., Gross, C.A., Burgess, R.R., and Record, M.T. Jr. Biochemistry 16, 4777-4783 (1977).

\section{Cell Culture Studies}

\section{GROWTH OF HUMAN MAMMARY EPITHELIAL CELLS IN CULTURE}

\section{Martha R. Stampfer and Jack C. Bartley}

We have continued our collaboration with Dr. Richard Ham of the University of Colorado on development of improved media for growth of human mammary epithelial cells (HMEC) in culture. $^{1}$ Such improvements in the culture of these cells facilitate their general use in studies of human cellular physiology, differentiation, and carcinogenesis. The serum-free medium developed in this laboratory, designated MCDB170, with the addition of several growth factors, has now been tested on 12 different HMFC specimens derived from both normal and carcinomatous tissues. In all cases thus far tested, active growth in monolayer culture can be maintained for $12-20$ passages $^{2}$ with about 3 population doublings per passage. Thus a practically unlimited number of cells are available, and large standardized cell pools from individual specimen donors are being stored frozen for use in numerous and repeatable experiments. However, only a small subpopulation of the HMEC is capable of this extended growth; at passages 2-4 most cells appear to senesce while a minority population maintains the same growth rate and morphology. Addition of agents that elevate intracellular CAMP levels increases the number of these cells and stimulates the rate of cell growth. Possibly, those cells that continue to grow represent a stem cell population. We have now examined several indivi- duals at early and later passages in culture and find no alterations in expression of keratin and fibronectin distribution, human milk fat globule antigen, karyology, pattern of glucose metabolism, and sensitivity to $x$-irradiation. Thus it is unlikely that the continued growth in culture represents a selection of an abnormal cell population. However, the levels of some metabolites of benzo(a)pyrene metabolism do decrease with increased time in culture, a phenomenon often observed upon prolonged passage in culture with certain enzyme activities. It is possible that further improvements in the tissue culture conditions may prevent this loss of metabolic activity.

\section{REFERENCES}

1. Hammond, S.L., Ham, R.G., and Stampfer, M.R. Defined medium for normal human mammary epithelial cells. In Vitro 19, 252 (1983).

2. Stampfer, M.R., and Bartley, J.C. Development of human mammary epithelial cell culture systems and their use for studies of carcinogenesis and differentiation. In: In Vitro Models for Cancer Research, in press. Sekeley, M. Weber, eds., CRC Press, Bc Raton, Florida. 


\title{
VITRO TRANSFORMATION OF HUMAN MAMMARY EPITHELIAL CELLS.
}

\author{
Martha R. Stampfer and Jack C. Bartley
}

The ability to induce in vitro transformation of normal HMEC would greatly facilitate studies on the mechanisms involved in malignant transformation and the identification of agents responsible for such transformation. We have been using our HMEC culture system to investigate the potential transforming ability of the common environmental pollutant, benzo(a)pyrene $(\mathrm{BaP})$. A goal of these studies is to develop a simple assay of transformation that could be used to detect potential environmental carcinogenic agents. The use of HMEC is of particular value, since approximately $80-90 \%$ of human cancers derive from cells of epithelial origin, but most previous work on transformation in vitro has utilized fibroblastic or mesenchymal cells, generally derived from rodents.

We have now been able to repeatably demonstrate that addition of BaP to primary HMEC cultures exhibiting rapid growth in our originally derived mammary medium, MM, causes an increased growth potential in these cells. Growth is readily maintained for about 3-6 passages beyond where control cells senesce. Isolated foci of cells, often resembling the hyperplastic growth patterns seen in vivo, continue growth for several additional passages. Only rare cells maintain indefinite growth potential. We have developed one clonally isolated cell line actively growing at passage 71 , and 4 other cell strains, each with a distinctive morphology, currently at passages 9-11. It is hoped that careful characterization of these different cell lines will enable us to understand what changes occur in cells during the process of transformation, and the possible relationship between malignant transformation, immortal life in culture, and expression of normal cellular differentiated properties. These cells likely represent only partial (nonmalignant) transformants since our cell line does not display the tumor-associated property of anchorage independent growth, or form tumors in immunosuppressed nude mice. Such partial transformants may be valuable substrates for examining the effects of potential promoting agents.

\section{A POSSIBLE ROLE FOR BASAL LAMINA GLYCOSAMINOGLYCANS IN THE REGULATION OF MAMMARY EPITHELIAL CELL DIFFERENTIATION}

\section{Gordon Parry, Eva Lee, Debbie Farson, Mike Koval, and Mina Bissell}

It is becomingly increasingly clear that components of the cell surface and extracellular matrix play an important role in regulating the expression of a cell's differentiated characteristics. While several examples of this phenomenon have been described, there is very little information available on biochemical aspects such as what extracellular molecules are important, and what is the mechanism and route of information transfer from the cell's periphery to its biosynthetic and degradative apparatus. ${ }^{1}$ In attempting to answer these questions we have used cultures of epithelial cells from mammary glands of pregnant mice. These are ideal for study in that, in response to hormones, they produce and secrete many milk proteins. However, their ability to respond depends upon the nature and physical state of the substratum to which they

attached. Our previous studies have character-

ad this modulating effect in detail. ${ }^{2,3}$ In sumundry, we have found that cells cultured on col- lagen gels that have been made to float in the culture medium secrete many (though not all) milk proteins in significant quantities, while cells cultured on tissue culture plastic secrete only a few milk proteins in limited quantities. Cells cultured on attached collagen gels behave in a fashion intermediate between these two states.

Our recent studies have concentrated on the cell-substratum interface with particular concern for the nature and organization of basal lamina components deposited when cells are cultured on either tissue culture plastic, or attached on floating collagen gels. Our intent has been to determine whether a correlation exists between the deposition of a basal lamina with a specific composition and the cell's ability to secrete differentiated products.

Previous preliminary studies had demonstrated elevated levels of Type IV collagen in cultures maintained on released gels. ${ }^{2}$ During this last year we have focused on glycosaminoglycan com- 
ponents synthesized by the cells and have discovered some interesting correlations between casein secretion and the type and distribution of glycosaminoglycans (GAG's). Cultures produce hyaluronic acid (HA), heparan sulfate (HS), and chondroitin sulfates (CS) on all substrata, but significantly more ${ }^{3} \mathrm{H}$ glucosamine is incorporated into GAG's by cells on plastic than by cells on collagen substrata (Table 1). The location of the glycosaminoglycans differs considerably according to culture substratum in that cells on plastic secrete most of their GAG's into the medium while cells on floating collagen gels secrete very little material into the medium and incorporate most of their GAG's into the cell layer (Fig. 1). Although cells on plastic do incorporate considerable quantities of all classes of GAG's into the cell layer, only a small proportion is assembled into a detergent insoluble basal lamina. In contrast, over $70 \%$ of CAG's produced by cells on released collagen gels are assembled into an intact basal lamina.

The composition of the basal lamina itself also differs according to culture substratum, the most notable feature being the proportion of hyaluronic acid that is present. Nearly $19 \%$ of the basal lamina GAG's produced by cells on plastic are hyaluronic acid while they represent only $6 \%$ of the GAG's produced by cells on floating gels (Table 2 ). Interesting cells on attached collagen gels produce a hyaluronic acid-rich matrix just as do the cells on plastic. This correlates with the production of caseins, in that cells on attached gels produce little casein in the culture medium while cells on released gels secrete considerable quantities of caseins.

Currently we are attempting to modulate GAG synthesis and assess the consequences for the production of differentiated products. In addition we are testing the possibility that hyaluronic acid is a negative modulator of mammary differentiation by incorporating exogenous hyaluronic acid into the collagen substratum prior to cell attachment.

Table 1. Total glycosaminoglycans $(H A+C S+H S)$ synthesized. Cultures were labeled for 24 hours with ${ }^{3} \mathrm{H}$ glucosamine $(100 \mu \mathrm{Ci} / \mathrm{ml})$ and radiolabeled glycosaminoglycans isolated.

These were separated from glycopeptides derived from glycoproteins using DEAE cellulose chromatography and the total incorporation determined.

\begin{tabular}{lc}
\hline \hline Culture Substratum & ${ }^{3} \mathrm{H}$ glucosamine incorporated $/ \mu \mathrm{g}$ DNA \\
\hline Plastic & $13,802 \mp 1805$ \\
Attached Collagen Gel & $3,943 \mp 1947$ \\
Floating Collagen Gel & $3,858 \mp 616$ \\
\hline \hline
\end{tabular}

Our present data; then, are consistent with $t$ possibility that a cell-synthesized basal lamina required for maintenance of a differentiated phenotype and that glycosaminoglycans and proteoglycans are important components of this extracellular matrix. Our experimental system is ideal for inves-

(A) Extracellular Matrix

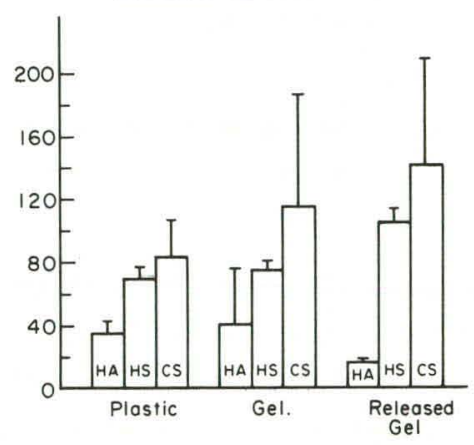

(B) Soluble Cellular Moterial

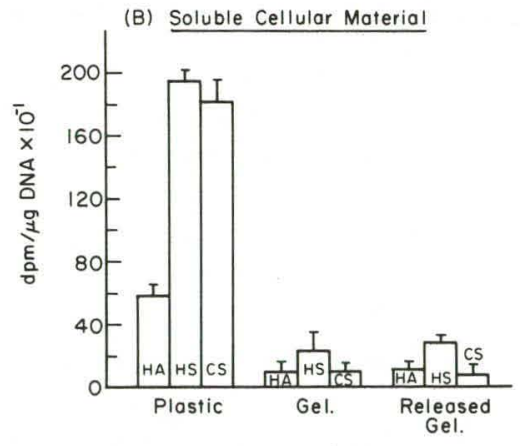

(C) Medium

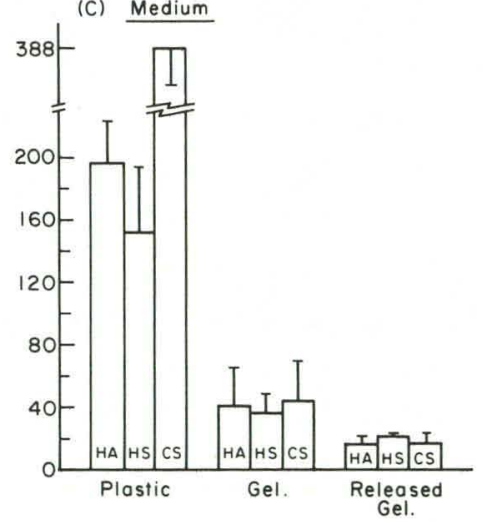

Fig. 1. Histograms demonstrating the distribution of glycosaminoglycans among cellular compartments. Cultures were radiolabeled as described in the legend to Table 1. After 24 hours, medium was separated from the cells, the monolayers washed with isotonic buffer, and the wash pooled with the medium. The cell layer was extracted with a detergent containing buffer $(10 \mathrm{mM}$ Tris $\mathrm{Cl} \mathrm{pH} 7.4,1 \%$ Triton $\mathrm{X}-100,1 \%$ deoxycholate) at $4^{\circ}$ for 30 minutes and the detergent-insoluble material removed by centrifuging in a microfuge at $12,000 \mathrm{~g}$ for 10 minutes at $4^{\circ}$. The insoluble material is referred to as the "extracellular matrix" or "basal lamina" fraction and the soluble material as the "soluble cellular fraction." Error bars den standard deviations. Values are the means of $f_{\mathrm{t}}$ determinations.

(XBL 8311-41, , 
able 2. Composition of the extracellular matrix produced by Ill cultured on different substrata. Values are expressed as a percentage of the total GAG's present in the isolated extracellular matrix.

\begin{tabular}{lccc}
\hline \hline & \multicolumn{3}{c}{ Total GAG's (\%) } \\
\cline { 2 - 4 } & Plastic & $\begin{array}{c}\text { Attached Collagen } \\
\text { Gel }\end{array}$ & $\begin{array}{c}\text { Released Collagen } \\
\text { Gel }\end{array}$ \\
\hline HA & 18.93 & 17.97 & 6.16 \\
HS & 36.98 & 32.36 & 40.06 \\
CS & 44.08 & 49.67 & 53.77 \\
\hline \hline
\end{tabular}

tigating this possibility further and should enable us to eventually discover how information is transferred from the extracellular basal lamina to the cell's biosynthetic apparatus.

\section{REFERENCES}

1. Bissell, M.J., Hall, H.G., and Parry, G. J. Theoret. Biol. 99, 31-68 (1982).

2. Parry, G., Lee, E. Y-H., and Bissell, M.J. In Extracellular Matrix (Hawkes, S.P., and Wang, J. eds.) Academic Press (1982) pp. 303-308.

3. Lee, E.Y-H., Parry, G., and Bissell, M.J. J. Cell Biol. (1984) (in press).

\section{CULTURED HUMAN HEP G2 CELLS AS A MODEL FOR INVESTIGATING LIPOPROTEIN SYNTHESIS AND METABOLISM}

\section{Richard Thrift and Trudy Forte}

We are studying lipoprotein secretion by a human hepatoma-derived cell line, Hep G2. This line has been used extensively to study the secretion of serum proteins and, in particular, apolipoproteins. Earlier work from our laboratory dealt with lipoprotein secretion by primary cultures of rat hepatocytes (i.e., cells isolated directly from rat liver). Since efforts to grow primary cultures of human hepatocytes have been unsuccessful, we hoped that the Hep G2 cell line could be used as a model to investigate the differences in lipoprotein metabolism between rats and humans. Humans are, of course, quite susceptible to atherosclerosis while the rat is resistant, yet far more is known about lipoprotein metabolism in the rat.

In our current experiments Hep G2 cells were cultured in serum-free medium supplemented with insulin and glucose. Medium was harvested daily and concentrated. The newly secreted proteins were then isolated by standard ultracentrifugal procedures into low density lipoprotein (LDL), high density lipoprotein (HDL), and nonlipoprotein fractions. Although daily secretion rates (per gram cell protein) of $\mathrm{LDL}$ protein and $\mathrm{HDL}$ protein were comparable to those obtained with the rat primary cultures after the first few hours of culture in the rat system, we found no very low density lipoproteins (VLDL) in the Hep G2 medium. VLDL secretion is a normal liver function, and electron micrographs of human liver biopsies as well as rat hepa- cytes show VLDL-sized lipid particles in smooth

doplasmic reticulum (SER), Golgi apparatus, and secretory vesicles. Electron micrographs of our cul- tured Hep G2 cells showed numerous Golgi, but SER was clearly diminished, and VLDL were absent (Fig. 1). Although the VLDL secretion rate of primary rat hepatocytes drops precipitously within hours after the cells are cultured, the rates in that system can be increased ten-fold by the addition of albumin-bound oleate. Fructose is expected to have a similar effect. Neither supplement added to the Hep G2 medium caused Hep G2 cells to produce VLDL, although both induced intracytoplasmic lipid droplets. In future studies we are planning to test the effects of anabolic hormones and other factors on VLDL secretion.

The compositions of secreted LDL and HDL, as well as their normal plasma counterparts, are listed in Table 1. The major core lipid (hydrophobic lipid, as opposed to the amphipathic "surface" components) of plasma LDL is cholesteryl ester, while for the Hep G2 LDL the major core lipid is triglyceride. If, as presumed, the microsomal enzyme acyl coenzyme A:cholesterol acyltransferase (ACAT) is the major source of VLDL and LDL cholesteryl ester, then our composition data suggest the enzyme may not be functioning in this cell line.

The composition of Hep G2 HDL is even more unusual. It is enriched in surface lipids (phospholipid and unesterified cholesterol) and deficient in core lipids (esterified cholesterol and triglyceride). Electron microscopy of negatively stained $\mathrm{HDL}$ shows it to contain discs of thickness $4.5 \mathrm{~nm}$ (the thickness of a phospholipid bilayer) and small spheres (Fig. 2). 


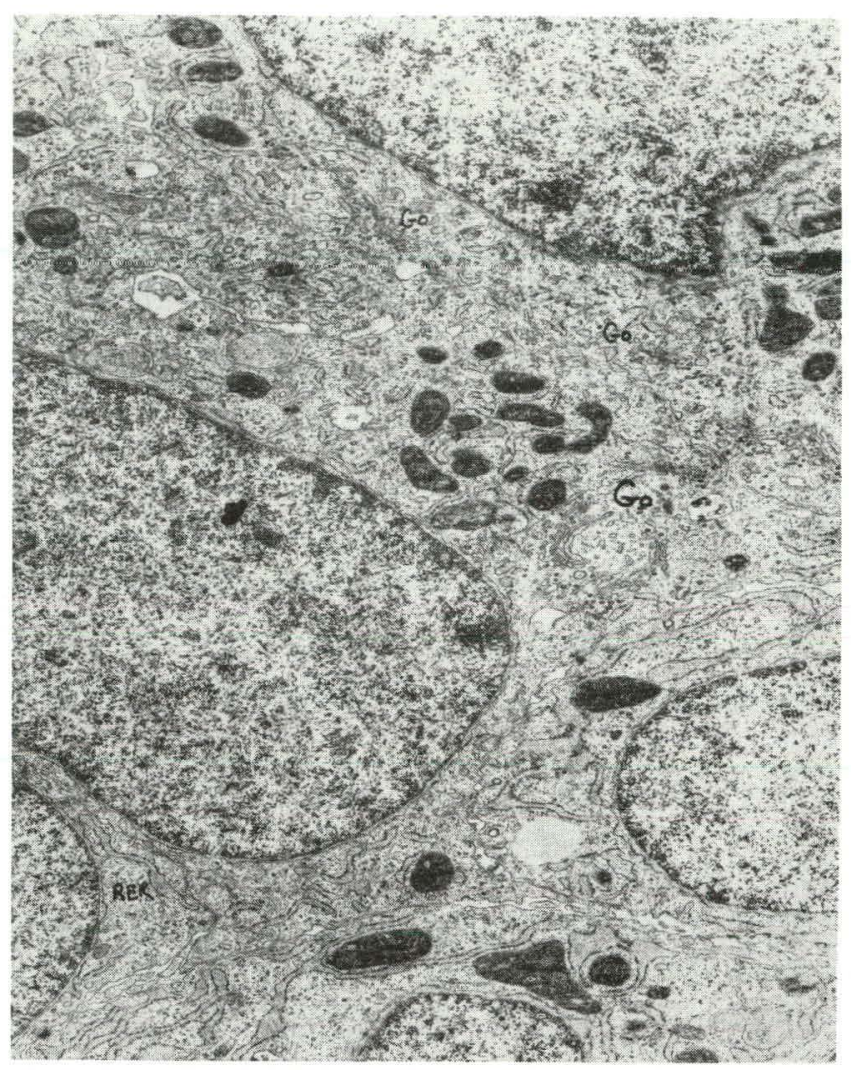

Fig. 1. Electron micrograph of Hep G2 cell culture sectioned parallel to the culture flask. The cells are closely packed and have large nuclei. The major intracellular organelles include mitochondria, extensive Golgi (Go), and rough endoplasmic reticulum (RER). Smooth endoplasmic reticulum is inconspicuous. VLDL which are usually seen within the Golgi cisternae of liver biopsies are not seen in the Hep G2 cells.

(XBB 8310-8904)

In their EM morphology and lipid composition, Hep G2 HDL resemble the HDL of patients with a genetic deficiency of the enzyme, lecithin:cholesterol acyltransferase (LCAT), which is normally secreted by the liver. In the presence of a required cofactor (apo A-I, the major apoprotein

Table 1. Composition of lipoproteins.

\begin{tabular}{lccccc}
\hline \hline & Protein & PL & UC & CE & TG \\
\cline { 2 - 6 } Lipoprotein & \multicolumn{5}{c}{ (\% total weight) } \\
\hline Hep G2 LBL & 32 & 28 & 13 & 5 & 22 \\
Human Plasma LDL & 22 & 22 & 8 & 42 & 6 \\
Hep G2 HDL & 39 & 40 & 16 & 3 & 2 \\
Human plasma HDL & 48 & 27 & 4 & 16 & 3 \\
\hline \hline
\end{tabular}

PL, phospholipid; UC, unesterified cholesterol; CE, cholesteryl ester; TG, triglyceride.

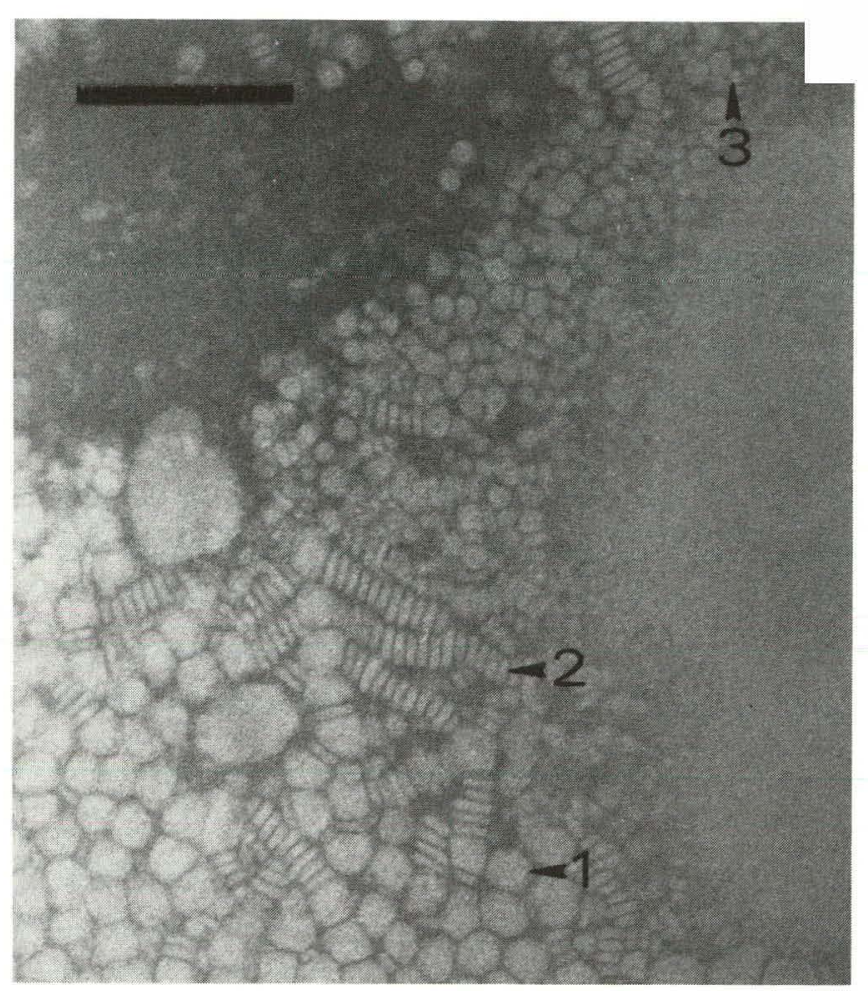

Fig. 2. Negatively stained lipoproteins of $d<1.21 \mathrm{~g} / \mathrm{ml}$ isolated from Hep G2 culture medium collected over 3 days. Arrow 1 indicates particles in the size range of $L D L(20-26 \mathrm{~nm})$, arrow 2 indicates discoidal or "nascent" $H D L$, and arrow 3 indicates small round $6-8 \mathrm{~nm} \mathrm{HDL}$ particles. Bar represents 100 $n m$.

(XBB 830-10799)

of $\mathrm{HDL}$ ), this enzyme normally catalyzes the formation of a core lipid, cholesteryl ester, from the two surface lipids, unesterified cholesterol and phosphatidylcholine. The net effect of this enzyme activity is the conversion of polar-lipid-rich discoidal particles into core-lipid-rich spherical particles. In collaboration with Dr. C.H. Chen of the University of Washington, we have determined that Hep G2 cells secrete catalytically active LCAT; therefore, there must be some other explanation for the persistence of discoidal HDL particles in Hep G2 culture medium.

Great interest has been generated by the recent demonstration, first with Hep G2 cells and then by other means, that apo A-I is secreted (both in the human and in the rat) as a pro-protein. That is, it has an $\mathrm{N}$-terminal hexapeptide segment not present on plasma apo A-I. (Only one other plasma protein, the $\alpha$ chain of complement $\mathrm{C} 4$, is known to be secreted in a form different from the major circulating form. Albumin and insulin, for instance, are synthesized as pro-proteins but cleaved in ' $\mathrm{A}^{\prime}$ Golgi.) It is not known whether pro apo A-I ha: specific function, but it has been suggested by a 
mber of groups that the pro segment may rievent the binding of pro apo A-I to HDL. Preliminary immunoblotting studies (immunoperoxidase staining of protein blots from gradient gel electrophoresis) carried out with Dr. Virgie Shore of Lawrence Livermore National Laboratory indicate, however, that Hep G2 apo A-I is present across the whole spectrum of newly secreted HDL. The possibility remains that the other known function of apo A-I, that of activating LCAT, may be inhibited by the pro segment.

Very little is known about the secretion and extracellular processing of $\mathrm{HDL}$. Based on results from rat livers perfused with an LCAT inhibitor, it has been proposed that HDL is secreted in a discoidal form and becomes spherical when it enters the circulation. Work from our laboratory with rat primary hepatocytes indicated, however, that the inhibitor is toxic, and that in its absence rat hepatocyte HDL is spherical. It is not known whether the differences in morphology between Hep G2 and rat hepatocyte HDL are due to metabolic alterations in our cell line or to species differences (such as the known difference in the structures of the apo A-I pro segments). However, the discoidal $\mathrm{HDL}$ and premature atherosclerosis of LCAT-deficient patients are evidence of the importance of post-secretory processing of HDL. The Hep G2 cell line will be extremely useful in the study of steps in HDL metabolism which were inaccessible with the rat hepatocyte model.

\section{PLASMA MEMBRANE REORGANIZATION INDUCED BY CHEMICAL TRANSFORMATION IN CULTURE}

\section{Beverly S. Packard, Mina J. Bissell, and Melvin P. Klein*}

The idea of transformation to a malignant phenotype inducing a reorganization of the intraand perimembranous macromolecular scaffolding of the plasma membrane is supported by a broad range of biophysical, biochemical, and morphologic studies. We are using the induction of a cell line (Madin-Darby Canine Kidney (MDCK) to a transformed phenotype by exposure to phorbol ester tumor promoters as a model in which to study the plasma membrane perturbations brought about by the transformation process in general.

As the initial intent was to probe the lipid environment of the plasma membrane, a number of commercially available fluorescent dyes were examined for their staining patterns. All wore fourld to internalize at rates unacceptable for the planned experiments. Therefore, a new probe Collarein, a fluorescent phospholipid analog, which has the property of exclusive localization in the plasma membrane, was synthesized. Collarein's apparent exclusive staining of the plasma membrane in cells viewed under the fluorescence microscope, combined with the single component exponential decay of its fluorescent lifetime when measured in stained cells, strongly supported its singular localization.
This was in sharp contrast to the heterogeneous fluorescence patterns and multiexponential decays observed for the commercial dyes (Fig. 1).

The effects of phorbol ester tumor promoters on the lateral diffusion in plasma membrane lipid environments were examined using the technique of fluorescence recovery after photobleaching (FRAP) (Fig. 2). Measured decreases for Collarein of the three parameters characteristic of this class of measurement, i.e., percent bleach $(30 \%)$, percent recovery $(52 \%)$, and halftime for recovery $(52 \%)$, connoted the induction of an immobile fraction upon treatment with biologically active tumor promoters. The idea of induced reorganization is supported by experiments in which cell-shape change, brought about by exposure to cytochalasin B, an inhibitor of cytoskeletal structure, or to growth on matrices of collagen, fibronectin, or to laminin, resulted in FRAP values similar to those with active phorbol esters.

Protein reorganization appears to be of high order in the hierarchy of biophysical perturbations to plasma membranes brought about by transformation to a malignant phenotype. 

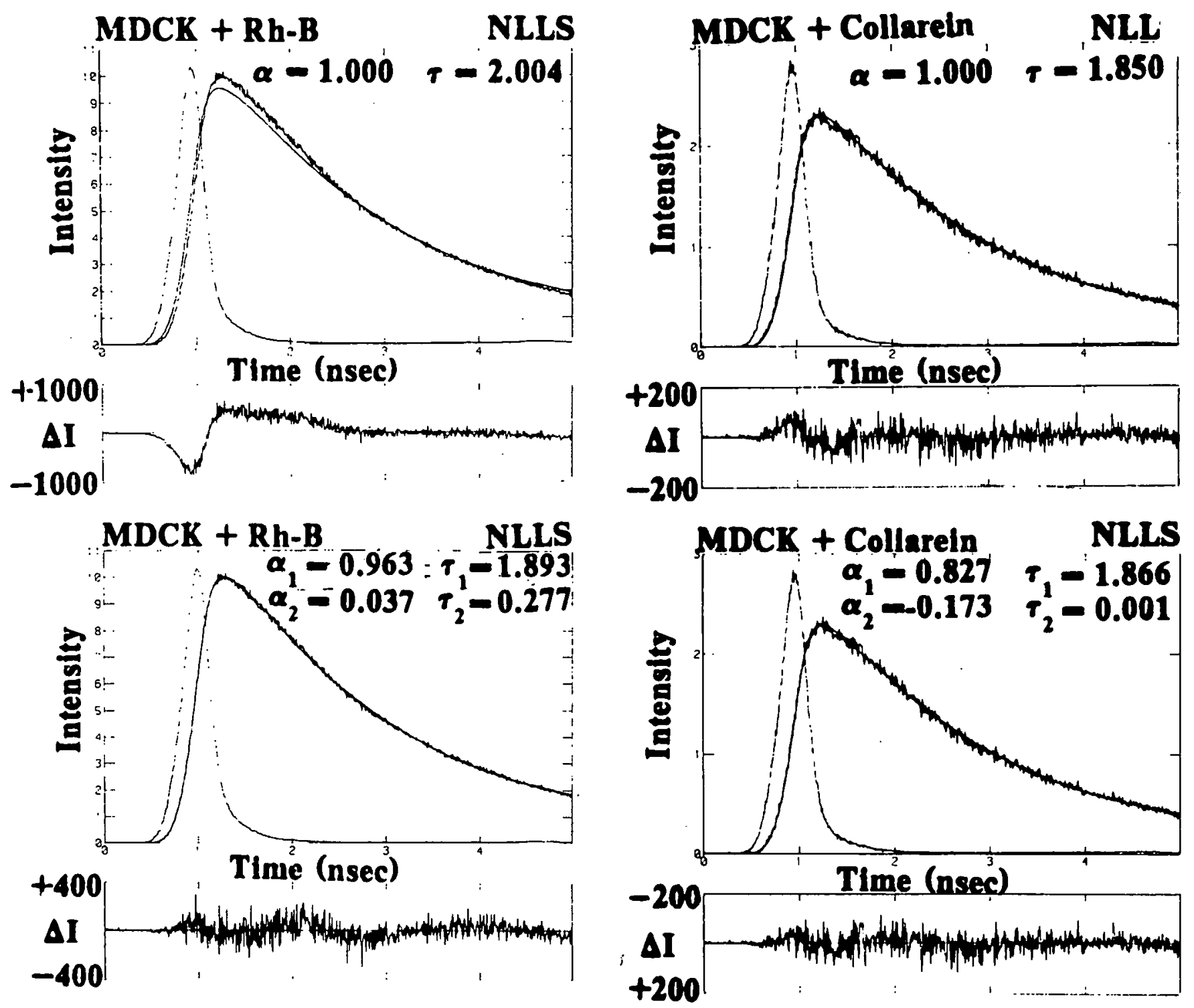

(a)

(b)

Fig. 1. Fluorescence decay curves of MDCK cells subsequent to incubations with (a) Rhodamine-B and (b) Collarein. Curves labeled $E$ are the excitation profiles induced by the laser pulse and the response of the system. Curves labled $F$ are the experimental fluorescence decay (noisy) and the calculated fit (smooth) essentially superimposed. Deviation plots are below. Data were fit with an assumed decay law approximated by a sum of exponentials:

$$
l(t)=\alpha_{i} \exp \left(-t / \tau_{i}\right)
$$

where $\alpha_{i}$ is the fraction, normalized to one, of the molecules with lifetimes $r_{i}$ Deviations from attempted fits are indicated by the pattern and the magnitude of $\Delta l$.

(a. $X B L$ 829-11814B, b. XBL 829-11814A) 


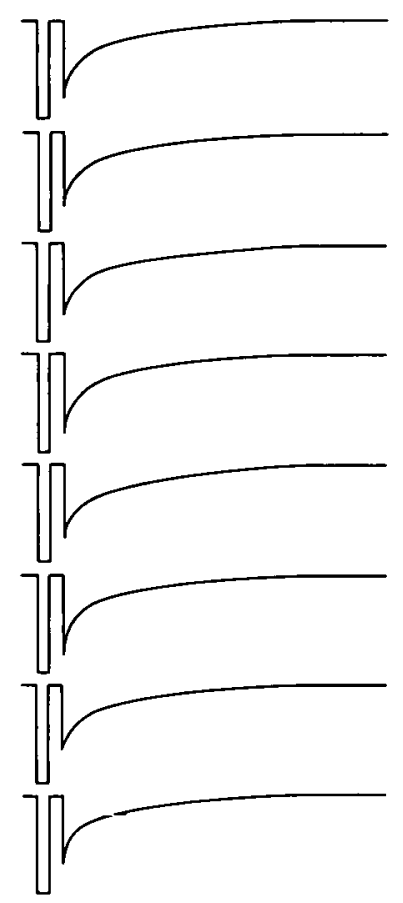

(a)

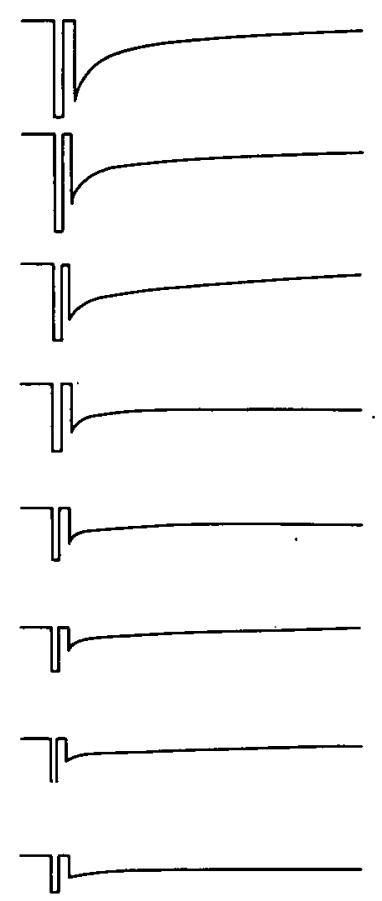

(b)

Fig. 2. Fluorescence recovery after photobleaching (FRAP) traces. Eight successive hits and recoveries on the same spot of (a) a control cell and (b) a cell after treatment with a biologically active tumor promotor.

(XBL 836-2641)

\section{REGULATION OF EXTRACELLULAR MATRIX FORMATION BY AVIAN TENDON CELLS IN CULTURE}

\section{Julie A. Robinson and Mina J. Bissell}

Previous workers in this laboratory ${ }^{1}$ have shown that primary avian tendon (PAT) cells cultured at a high density in medium with a low serum content $(0.2 \%$. FCS $)$ and ascorbate $(50 \mu \mathrm{g} / \mathrm{ml})$ maintain their embryonic slate of differentiation with respect to collagen synthesis (approximately $20 \%$ of their total protein synthesis is collagen). The PAT cells deposit onto the tissue culture dish an extensive network of extracellular matrix (ECM) fibrils that can be isolated free of cells by briefly treating the cell layer with $0.25-\mathrm{M} \mathrm{NH}_{4} \mathrm{OH}^{2}$ We have investigated the proteoglycan (PG) component of the ECM. After one week in culture, subconfluent PAT cells secrete into the ECM, proteoglycans containing heparan sulfate and dermatan sulfate as their main GAG components (see Table 1). After two weeks in culture, the composition of the proteoglycans - ing secreted into the ECM changes. The proporins of heparan sulfate and dermatan sulfate are reduced, and chondroitin sulfate constitutes the major proportion of the GAG's. This change in the composition of the proteoglycans being secreted into the ECM may reflect a trend towards restoration of the differentiated phenotype of the tendon cells in vivo, since it was found that whole tendons from 16-day-old chick embryos labeled in vitro with ${ }^{35}$ S-sulfate synthesized proteoglycans contain predominantly chondroitin sulfate and a smaller amount of dermatan sulfate. The PG's synthesized by embryonic tendon cells in vivo are currently being investigated.

Since both ascorbate and the ECM have been found to be important regulators of collagen synthesis by cultured PAT cells, the effect of these factors on PG synthesis was investigated. PAT cells were grown for four days in the absence of ascorbate, and then the cells were replated on plastic or $E C M$-coated dishes in the presence or absence of ascorbate and/or $\beta$-aminopropionitrite fumerate $(\beta a p n)$, an inhibitor of collagen cross-linking and 
Table 1. GAG composition of proteoglycans synthesized by PAT cells in culture. ${ }^{a}$

\begin{tabular}{lccccccc}
\hline & \multicolumn{4}{c}{$\%$ total ${ }^{35}$ S-GAC } \\
\cline { 2 - 4 } \cline { 5 - 7 } \\
$\begin{array}{l}\text { Age of } \\
\text { Culture }\end{array}$ & HS & CS & DS & HS & CS & DS \\
\hline 7 days & 50 & 17 & 33 & 8 & 19 & 73 \\
13 days & 26 & 67 & 7 & 20 & 23 & 57 \\
\hline \hline
\end{tabular}

a PAT cell cultures were radiolabeled with ${ }^{35} \mathrm{~S}$-sulfate $(50 \mu \mathrm{Ci} / \mathrm{ml}$ of medium) for $24 \mathrm{hr}$. The medium was then collected and the ECM was isolated by treatment of the cell layer with $0.25-\mathrm{M} \mathrm{NH}_{4} \mathrm{OH}$ for 5-10 minutes at room temperature. Radiolabeled PG's were extracted from the ECM in buffer containing 4-M GuHCl and $0.1 \%$ Triton $X-100$. I'he PG's in the medium and ECM extracts were partially purified by ionexchange chromatography on a column of DEAE-Sephacel equilibrated with $0.15 \mathrm{M} \mathrm{NaCl}$ in $0.05 \mathrm{M} \mathrm{NaOAc}$ buffer, $\mathrm{pH} 6.0$, containing $8 \mathrm{M}$ urea and $0.5 \%$ CHAPS and eluted with a $0.15-1.5 \mathrm{M}$ gradient of $\mathrm{NaCl}$. The radiolabeled GAG's were isolated following papain digestion of the PG's, and their composition was determined by selective degradation with chondroitinases $A B C$ and $A C$ and nitrous acid reagent.

HS = heparan sulfate; $C S=$ chondroitin sulfate; $D S=$ dermatan sulfate.

hence of collagen matrix formation. The results are given in Table 2. Replating the cells on ECMcoated dishes caused a rapid and marked increase in the rate of ${ }^{35} \mathrm{~S}-\mathrm{CAG}$ synthesis compared to control cells replated onto plastic. In contrast, addition of ascorbate to the culture medium was found to increase total ${ }^{35} \mathrm{~S}-\mathrm{GAG}$ synthesis only slightly during the 8-hour incubation period. However, further experiments in which PAT cells were cultured for longer periods in the presence or absence of ascorbate indicate that addition of ascorbate to the culture medium has a profound effect on the compartmentalization of newly synthesized GAG's into the medium or ECM (see Fig. 1). A higher proportion of the newly synthesized GAG's are secreted into the ECM when PAT cells are cultured in the presence of ascorbate, and this proportion increases with increasingly longer periods of incubation with ascorbate. The composition of the ECM GAG's was also found to be affected by ascorbate. PAT cells were maintained in culture for one or two weeks with or without ascorbate, and the compositions of the GAG's in the ECM's were determined. It was found that PAT cells cultured in the absence of ascorbate fail to undergo the change in matrix GAC composition (i.e., a decrease in HS synthesis
Table 2. Comparison of the effects of ascorbic acid and ECM on GAC synthesis by PAT cells in culture. ${ }^{a}$

\begin{tabular}{lccc}
\hline \hline & \multicolumn{3}{c}{$\begin{array}{c}35 \text { S-sulfate incorpn. into GAG } \\
\left(\mathrm{dpm} / 8 \mathrm{~h} / 10^{5} \text { cells }\right)\end{array}$} \\
\cline { 2 - 4 } & Medium & Cell layer & Total \\
\hline$-\mathrm{c}$ & 2775 & 1266 & 4041 \\
$-\mathrm{c}+\mathrm{ECM}$ & 8789 & 2334 & 11123 \\
$-\mathrm{c}+\beta$ APN & 2600 & 1721 & 4321 \\
$+\mathrm{c}$ & & & 4727 \\
++ ECM & 8568 & 1672 & 11153 \\
$+\mathrm{c}+\beta$ APN & 5784 & 2585 & 7496 \\
\hline \hline
\end{tabular}

a PAT cells were grown for 4 days in $F_{12}$ medium containing $0.2 \%$ FCS. The cells were then removed from the dishes by treatment with collagenase and replated on plastic or ECMcoated dishes in the absence $(-c)$ or presence $(+c)$ of ascorbate or $\beta$-amino propionitrile fumerate $(+\beta A P N)$. The $2^{\circ}$ cultures were immediately radiolabeled for 8 hours with ${ }^{35} \mathrm{~S}$ sulfate $(20 \mu \mathrm{Ci} / \mathrm{ml})$. Radiolabeled $G A G$ 's were isolated from papain digests of the medium and cell layers by precipitation with cetylpyridinium chloride.

in favor of CS synthesis) seen in cultures maintained in the presence of ascorbate. Further studies will be undertaken to determine the role of the substratum upon which the tendon cells are grown (e.g., matrices synthesized by PAT cells, rat tail collagen, or fibronectin) in the regulation of $P G$ synthesis and/or degradation by tendon cells in culture.

Previous studies in this laboratory have shown that the collagen matrix synthesized by tendon cells in culture is absent in cultures of tendon cells that have been transformed with Rous sarcoma virus (RSC, Prague A strain). It was found that whereas collagen synthesis was considerably reduced upon transformation, synthesis of fibronectin was not significantly affected. ${ }^{3}$ We are now investigating the effect of RSV-transformation on PG synthesis by PAT cells. We have found that RSV-transformed tendon cells seeded onto either plastic or ECMcoated dishes exhibit an increased rate of ${ }^{35} \mathrm{~S}$-GAG synthesis compared to- the untransformed cells (expressed as $\mathrm{dpm} / \mathrm{hr} / \mathrm{no}$. of cells). However, all of the GAG's synthesized by the transformed cells are secreted into the culture medium. Immunofluorescent staining experiments using mor clonal antibodies against chick fibronectin a heparan sulfate indicate that the fibrillar matrix con- 


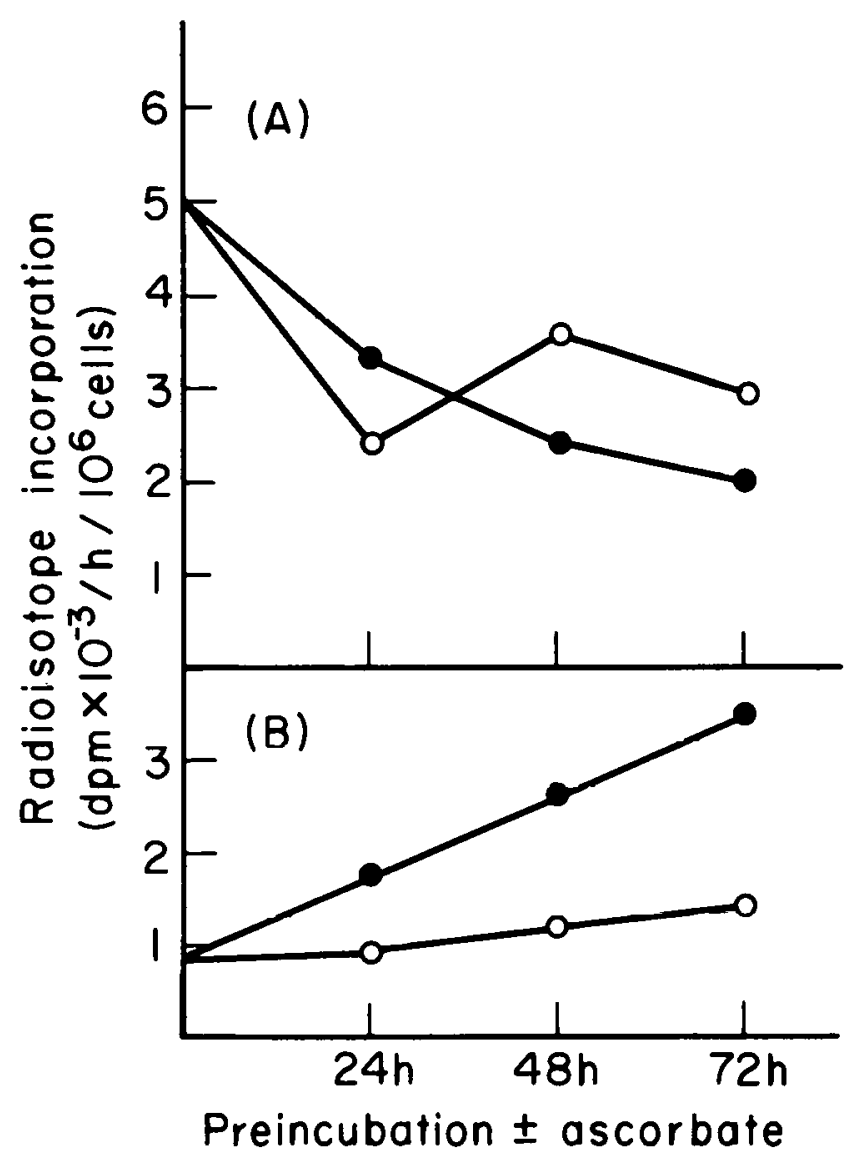

Fig. 1. Influence of ascorbate on the compartmentalization of newly synthesized GAG's into medium or ECM. PAT cells were seeded onto plastic tissue culture dishes (initial density $=1 \times$ $10^{6}$ cells $(6-\mathrm{ml}$ dish) and grown for 4 days in the absence of ascorbate. On day 5 , ascorbate $(50 \mu \mathrm{g} / \mathrm{ml})$ was added to half of the cultures. After various periods $(0-72 \mathrm{hr})$ of preincubation in the absence $\left(0_{-0}-0\right)$ or presence (-) of ascorbate, the cultures were pulse-labeled for $1 \mathrm{hr}$ with ${ }^{35} \mathrm{~S}$-sulfate. The amounts of ${ }^{35} \mathrm{~S}$-labeled GAG's in the medium (A) and the ECM (B) were then determined.

(XBL 8311-4115) taining fibronectin and heparan sulfate seen in cultures of untransformed cells is absent in cultures of RSV-transformed tendon cells. Thus there appears to be a concomitant loss of collagen, fibronectin, and proteoglycan from the matrix upon transformation.

It has been observed that when RSVtransformed PAT cells are replated onto ECMcoated dishes, their morphology changes to one that more closely resembles that of the untransformed cells. While the lowered rate of collagen synthesis by transformed cells is not changed when these cells are grown on matrices, the level of cell-associated fibronectin is increased. ${ }^{4}$ It has been suggested, therefore, that fibronectin is lost from the cell periphery of transformed tendon cells as a consequence of decreased levels of anchoring collagen molecules. ${ }^{3} \mathrm{We}$ intend to investigate further the relationship between RSV-transformation and matrix deposition by PAT cells in culture. Preliminary experiments indicate that RSV-transformed PAT cells seeded onto matrix-coated dishes secrete into the ECM PG's which have a very different GAG composition from that of the untransformed cells.

\section{REFERENCES}

1. Schwarz, R.I., Farson, D.A., and Bissell, M.J. In Vitro 15, 941-948 (1979).

2. Bissell, M.J., Orme, A. and Schwarz, R. J. Cell Biol. 87, 125a (1980).

3. Parry, G., Soo, W-J., and Bissell, M.J. J. Biol. Chem. 254, 11763-11766 (1979).

4. Bissell, M.)., Hatie, C., Laszlo, A., and Parry, G. J. Cell Biol. 91, 163a (1981).

\section{RSV ASSOCIATED MALIGNANCIES MAY REQUIRE ADDITIONAL FACTORS FOR TUMOR FORMATION}

David Dolberg, Missie-Joe Gates, and Mina J. Bissell

Although the initiating impulse (of tumorigenesis) may be related to viral genetic constitution, it is unlikely that the continuity of subsequent events can be ascribed entirely to specific viral influences. . (We must also consider) all the phenomena of the influences and the mechanisms governing the sequence and characteristics of cell differentiation resulting in the orderly development of the normal embryo. Although applications of tissue culture techniques have satisfied many demands on ques- tions of virus-cell relationships, an understanding of the processes of tumor formation must finally be dependent on the animal in which events transpire that are unseen in the absence of a host influence. ${ }^{1}$

As J.W. Beard noted, to study tumorigenesis one ultimately must return to the animal. In doing so, we have found that host factors in chicken embryos determine whether or not the tumorigenic potential of Rous sarcoma virus (RSV) is even 
expressed. We have now inoculated over 1500 embryos in the limb bud on day 4 of development with up to $10^{5}$ f.f.u. of SRD-RSV. The limb as well as peripheral tissue was evaluated 10 days later. As reported last year, in contrast to its effect in newborn chicks (palpable tumors within a week), the virus was remarkably nonpathogenic in young embryos. Based on morphologic and histologic examinations we have found 1) no evidence of teratogenesis, 2) no evidence of tumorigenesis, and 3) occasional presence of hemorrhagic lesions (endothelial blood blisters). These results confirm observations made over forty years ago. In addition, we have found that 1) the virus was integrated and expressed; 2) the embryos were viremic and all tissues contained virus, 3) the recovered virus was competent and could form foci in culture and tumors in newborns, 4) all tissues contained an elevated level of viral $p p 60^{\mathrm{src}}$ associated tyrosine specific phosphokinase activity, 5) this activity was detectable as early as two days after inoculation, and 6) the amount of kinase activity per microgram DNA in the limb bud was comparable to levels found in 10-day-old tumor tissue; this suggests that, in early embryos, kinase activity may be necessary but not sufficient for tumorigenesis.

Additionally we addressed the following questions: How do the cells from the limbs of infected 14-day-old embryos behave after being disrupted and placed in culture? And are the cultured cells from the limb buds of 4-day old embryos as susceptible to infection and virus production as cells from older embryos?

Using morphology and rate of sugar uptake as two commonly measured criteria of transformation, we compared cultures prepared from the wing of inoculated embryos to that of cultures derived from the wing of control embryos which were infected at the time of plating or to cultures derived from tumors generated in newly hatched chicks. Cells were cultured in $25-\mathrm{mm}$ multiwell plates at high density $\left(4-5 \times 10^{5}\right.$ cells per $\left.\mathrm{cm}^{2}\right)$ in order to discourage the horizontal spread of infectious virus. Cells infected in ovo appeared quite normal initially, and demonstrated no appreciable increase in the rate of sugar uptake. However, within 24 hours the morphology of these cultures began to appear transformed (in mass rather than as foci), and the rate of sugar transport increased. Kinase activity was elevated in the intact tissue and remained high after culturing. This effect does not seem to be due to the process of tissue disruption associated with the preparation of cultures, as transformed cul- tures retained all the characteristics of transforr tion (qualitative and quantitative) immediately a.... trypsinization and replating. On the other hand, cultures derived from normal embryos and infected after plating $(\mathrm{MOI}=0.2$, approximately the same virus to cell ratio found in the infected limb tissue at the time of culturing) began to show foci of transformation and a stimulation of the rate of sugar transport only after 72 hours, while cultures derived from tumor tissue behaved transformed as soon as cells attached.

Thus, embryonic cells infected in ovo retain their normal phenotype in ovo, as well as initially after plating. Furthermore, it appears that the capacity to display a transformed phenotype is rapidly acquired after the cells are placed in culture. Either the culture conditions are permissive for the expression of the transformed phenotype, or alternatively, these cells may experience an acceleration of the developmental program which would normally lead to the tumor permissiveness observable in newly hatched chicks. The notion that the developmental program accelerates in culture has been suggested, by our laboratory, to occur at high densities using other criteria. ${ }^{2}$

To find out whether cells from the limb bud of day-4 embryos are as susceptible to transformation, and whether they produce progeny virus at the same rate as cells derived from the limbs of day-14 embryos, limb bud tissues from the respective embryos were dissociated, plated at low density and infected with RSV at a high multiplicity of infection ( $\mathrm{MOI}=2)$. Cultures were subsequently screened for reverse transcriptase activity, sugar uptake and morphology. The growth rates and subsequent morphologies of infected and uninfected cultures derived from day- 4 embryos differed from their day-14 counterparts, as would be expected. However, the increase in sugar uptake and the production of viral particles (per cell) were similar in both infected cultures. Thus, the refractoriness of embryonic tissues to tumor formation is the result of the embryonic environment, and isolated cells lose this property in culture.

We are currently considering three general hypotheses that might explain the apparent inability of RSV to cause tumors in chick embryos. First, the intracellular concentration of viral kinase activity may be suboptimal. Alternatively, it is possible that only nontarget tissues are infectable in young embryos; the infection and replication of RSV in certain avian cell types in the absence of transformation has recently been reported. These explai tions seem unlikely because of the high levels 
tectable kinase activity in infected embryonic tissue and the presence of viral antigens in more that $90 \%$ of isolated limb cells prior to culturing. ${ }^{3}$ Second, a cellular component, required for tumorigenic expression, may be absent in the early embryo. This component might be a target for the viral kinase, for an additional "src" gene mediated activity, or a hormone, growth factor or endogenous promoter. Third, the early embryo may contain inhibitors for any of these necessary interactions.

We have not yet been able to determine whether or not embryos infected on day 4 of development will ultimately develop tumors. Due to the lethality of the virus, which becomes apparent around day 14-15, we have hatched only 4 of these embryos. None contained tumors, although all four died within 4 days of halching of as yet undetermined causes. Several examples exist both for sustained suppression of the neoplastic potential, and for temporary suppression related to the developmental stage of the animal, but obvi- ously more embryos must be hatched to draw any conclusions.

It appears that while the kinase activity of pp60 src may be necessary for RSV-mediated transformation and tumorigenesis, there are one or several other developmentally related criteria which must be met before expression of the malignant phenotype is possible. The temporal sequence of the expression of viral and cellular factors may also be an important determinant. In addition, infected cells, once placed in culture, overcome the in ovo restrictions and become transformed rapidly. The mechanisms of both the restriction in ovo and transformation in culture are under investigation.

\section{REFERENCES}

1. Beard, J.W. Viral Oncology. G. Klein, Ed., Raven Press, 1980, pp. 55-87.

2. Schwarz, R.I., tarson, D., and Bissell, M.J. In Vitro 15, 941 (1979).

3. Dolberg, D.S., Gates, M.J., and Bissell, M.J. Unpublished.

\section{Carcinogenesis}

\section{EFFECTS OF ALKYLATING CARCINOGENS ON MAMMALIAN CELLS IN CULTURE}

\section{Regine Goth-Goldstein and Mildred Hughes}

\section{CELL KILLING BY ALKYLATING AGENTS}

Our work in the last year has concentrated on analyzing the response of Chinese hamster ovary (CHO) cells, a well established cell line, to various monofunctional alkylating agents. By comparing the toxic effects of these agents we hope to undcrstand which alkylating agent-induced lesions are responsible for cell killing.

Cell survival of $\mathrm{CHO}$ cells after treatment with $\mathrm{N}$-methyl-N'-nitro- $\mathrm{N}$-nitrosoguanidine (MNNG) shows an unusual dose response consisting of two components, an initial steep drop to about $2 \%$ survival followed by a much flatter part (Fig. 1, circles). In trying to determine the reason for this unusual curve, we investigated the possibility that the biphasic response could be due to a reduced MNNG-uptake with higher dose. This does not seem to be the case. Binding of ${ }^{14} \mathrm{C}-\mathrm{MNNG}$ to acid --? cipitable cellular material and also mutation

luction to 6-thioguanine resistance are linear with uuse. Another possibility was that the flat com- ponent is due to a resistant subpopulation. When survival after MNNG treatment was measured in clones derived from single cells from our $\mathrm{CHO}$ line and tested as soon as enough cells were available for the experiment ( $\sim 26$ generations), each of the 6 clones tessled dydin gave a blphasic response, indicating that the flat component is inherent to the mechanism of cell killing by MNNG.

$\mathrm{N}$-methyl- $\mathrm{N}$-nitrosourea (MNU) reduces cell survival in a similar manner as MNNG, whereas survival after methyl methane sulfonate (MMS) and $\mathrm{N}$-ethyl-N-nitrosourea (ENU) shows a shouldered response followed by an exponential drop (Fig. 2, open circles). These two different shapes of survival curves indicate different mechanisms of killing by these agents. The grouping of the four agents according to their cell killing (MNNG and MNU versus MMS and ENU) does not correlate in any obvious way with their chemical reactivity, that is with the spectrum of alkylated bases they produce in DNA. Of course, MNU and MNNG yield the same pattern of alkylation, but MMS and ENU have 


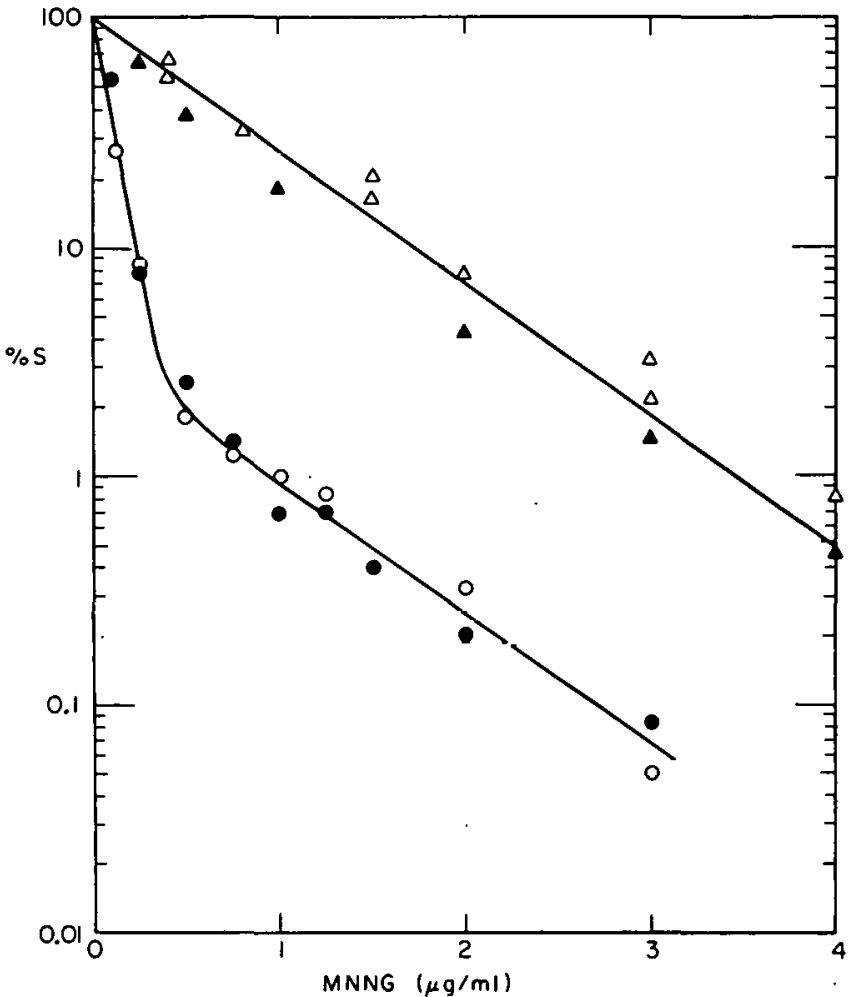

Fig. 1. Cell survival after MNNG treatment in our parent CHO-9 line (OO) and in a clone $(\mathrm{Cl} 3)$ isolated after treatment with $3-\mu g / m / ~ M N N G(\Delta \Delta)$.

(XBL 8310-4045)

a very different one. MMS methylates DNA bases almost exclusively at nitrogens, whereas ENU reacts predominantly with oxygens. More alkylating agents will have to be tested to find out how the structural characteristics and the chemical reactivity of alkylating agents relate to their cell killing.

\section{ACQUIRED RESISTANCE TO SOME ALKYLATING AGENTS}

During the study of the biphasic MNNG survival curve we investigated if clones derived from cells in the resistant part of the survival curve had a biphasic sensitivity to MNNG. Of four clones isolated after treatment with $3-\mu \mathrm{g} / \mathrm{ml}$ MNNG and tested for their MNNG sensitivity, all clones were much more resistant to the toxic effects of MNNG. One of these resistant clones, $\mathrm{Cl} 3$, has been characterized in more detail. It has been stable in culture for 10 months without a change in its response to MNNG. It has the same growth rate as the parent line. It is much more resistant to MNNG, and the dose response is monophasic with the same slope as the flat component in the survival curve of the parent cell line (Fig. 1, triangles). The increased resistance to MNNG is not due to

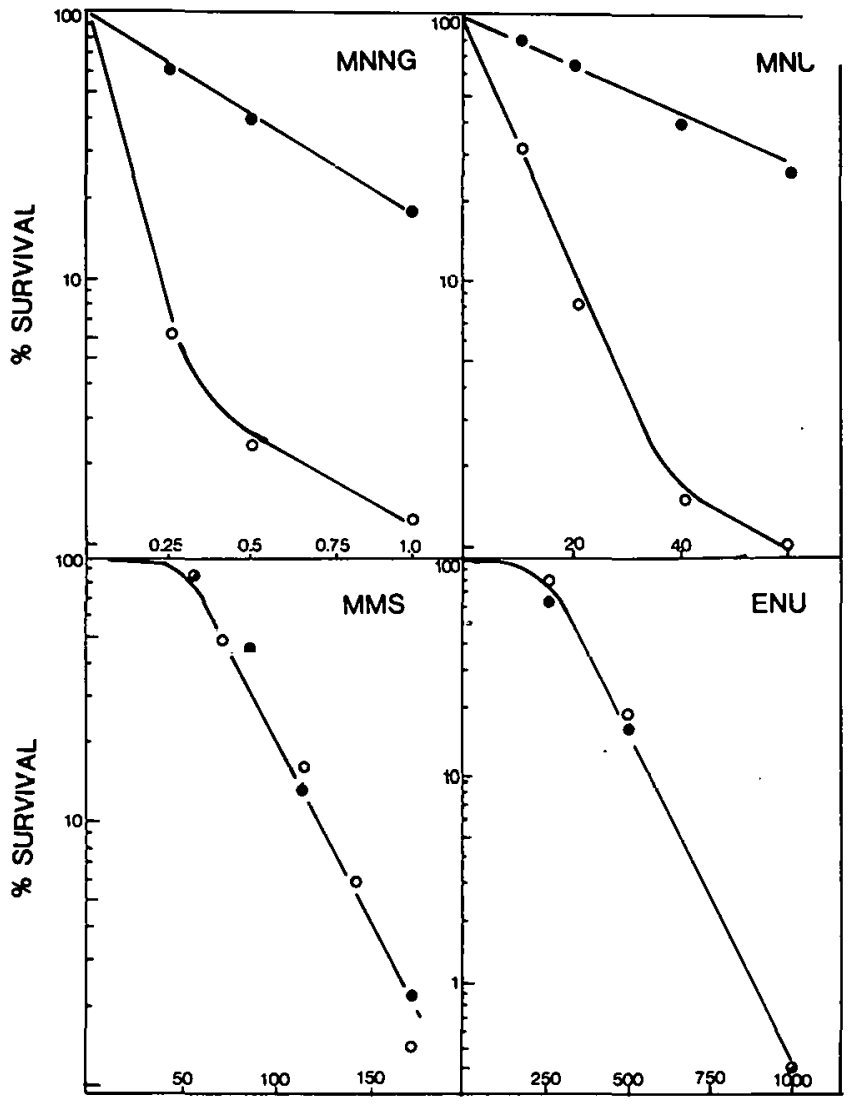

DOSE,ug/ml

Fig. 2. Cell survival after treatment with MNNG, MNU, MMS, ENU with (-) or without (-O-) pretreatment with the respective drug 14 days before. Pretreatment doses: $2-\mu \mathrm{g} / \mathrm{ml}$ MNNG, $50-\mu \mathrm{g} / \mathrm{ml} \mathrm{MNU}, 230-\mu \mathrm{g} / \mathrm{ml} \mathrm{MMS}$, and $1-\mathrm{mg} / \mathrm{ml}$ ENU.

(XBL 8311-4455)

decreased drug uptake, because the same amount of ${ }^{14} \mathrm{C}-\mathrm{MNNG}$ is bound to acid precipitable material in $\mathrm{Cl} 3$ and parent line. $\mathrm{Cl} 3$ is also more resistant to $M N U$, slightly more resistant to MMS and has the same sensitivity to ENU as the parent line.

To see if increased resistance occurs with alkylating agents in general, $\mathrm{CHO}$ cells were treated with a high dose of MNNG, MNU, MMS or ENU (a dose that reduces survival to between 1 and $0.1 \%$ ), and the surviving population was exposed to a second dose of the drug. Increased resistance was observed only after pretreatment with MNNG and MNU, the two agents that result in a biphasic survival curve. The MMS- and ENU-pretreated cells had the same sensitivity to a second dose of the agent as the unpretreated cells (Fig. 2). In the case of MNNG and MNU, resistance of the proge population increased as a function of pretreatm dose. 
The resistant clones isolated after MNNG treatent could arise by three mechanisms: selection of a resistant subpopulation, gene mutation, or some other inducible permanent change. Because the resistant clones appear at such a high frequency, a gene mutation seems very unlikely. A resistant subpopulation cannot be excluded yet. Even though the flat part of the MNNG survival curve does not seem to be due to a resistant sub- population, our $\mathrm{CHO}$ cell line might contain a very small resistant population for which we selected by MNNG treatment. In preliminary experiments, we were unable to find any evidence for a resistant subpopulation. We therefore think that we might be observing an inducible process that makes cells permanently more resistant to these methylating agents, and that the biphasic survival curve is somehow an indication of this process.

\section{INDUCIBLE REPAIR OF DNA DAMAGE BY CHEMICAL CARCINOGENS}

\section{Priscilla K. Cooper, Mark F. Henteleff, Peter Origenes, and Vincent Ling}

The effects of DNA damaging agents, most of which are mutagens and carcinogens, are extremely complex in both procaryotic and eucaryotic cells, and a growing body of evidence suggests that many of these effects are mediated by cellular processes induced in response to the damage itself. Two classes of such inducible responses have thus far been recognized in Escherichia coli: 1) SOS responses that are induced by a variety of DNA damaging agents and which comprise a diverse set of functions that are coordinately controlled by the recA-lexA regulatory circuit; and 2) the adaptive responses that are induced by alkylating agents and that are independent of recA and lexA and instead are controlled by the ada gene. Phenomenological evidence for similar responses has been obtained in mammalian cells. In both the SOS and adaptive responses there appears to be a dichotomy between processes affecting survival after damage and those affecting mutation resulting from damage. We are currently extending our previous studies ${ }^{1}$ on one SOS process, long patch excision repair of uv damage, in order to better understand the mechanism by which this induced process produces survival enhancement. ${ }^{2}$ We are also expanding our investigation to include repair of alkylation damage in order to understand the relationship between the SOS and adaptive responses and the interaction of their effects on survival and mutagenesis. Most of our effort during the past year has been directed to launching studies of repair in $E$. coli following treatment with the potent carcinogen $\mathrm{N}$-methyl- $\mathrm{N}$ '-nitro- $\mathrm{N}$-nitrosoguanidine (MNNG). Quantitative measurements of repair DNA synthesis by combined radioisotopic and density labeling ${ }^{3}$ in normal cells and in mutants defi$\therefore$ ?nt in one or more known repair functions are oployed together with analysis of cellular survival uıider various conditions.
The DNA adducts produced by alkylating agents are relatively well characterized: three major purine derivatives, 7-alkylguanine, 3alkyladenine, and $\mathrm{O}^{6}$-alkylguanine, are formed, together with a number of other relatively infrequent products. The most frequent of the purine adducts formed by MNNG treatment, 7-meG, seems to be relatively innocuous and is tolerated with no obvious deleterious effects. In contrast, methyl addition at the $\mathrm{O}^{6}$ position of $G$ produces an aberrant tautomeric form of the base which pairs with $T$ in addition to $C$, thus causing transition mutations. The third major product, $3-\mathrm{meA}$, is apparently responsible for much of the lethality associated with alkylation damage, since mutants that are unable to remove it are very sensitive to such damage. Indirect evidence suggests that the less-frequent 3-meG adduct may also have lethal consequences. $E$. coli contains several different repair enzymes that act on alkylated DNA. These include a constitutive 3-meA glycosylase (Tag I, the product of the $\operatorname{Tag} A$ gene), an inducible $3-\mathrm{meA}$ glycosylase that also has activity against 7-meG and 3-meG (Tag II, the product of the alkA gene), and a novel methyl transferase which specifically removes the methyl group from $\mathrm{O}^{6}-\mathrm{meG}$, apparently without disturbing the DNA structure. The Tag $\|$ and methyl transferase activities are induced via the adaptive response, in which $E$. coli cells grown in low levels of alkylating agents achieve greater resistance to killing and decreased mutagenesis in response to higher doses of an alkylating agent. Action of either the constitutive or inducible glycosylases would be expected to initiate an excision repair event following strand cleavage by an AP endonuclease activity, whereas removal of $\mathrm{O}^{6}$. methyl groups by the methyl transferase would not.

Repair synthesis in E. coli following uv damage results in patches that are heterogeneous in size. 
The majority of lesions are repaired by a constitutive process with patches 20-30 nucleotides in length, while a few (approximately $1 \%$ ) are repaired by an induced, rec-lex dependent process with very long patches of at least 1500 nucleotides. ${ }^{1}$ Both pathways require incision by the uvr $A, B, C$ complex to initiate the process. Treatment of cells with the protein synthesis inhibitor chloramphenicol immediately following irradiation prevents induction of SOS processes and substantially reduces repair synthesis by blocking the long patch pathway. SOS functions can be induced prior to damage by incubation of a tif (recA441) mutant at $42^{\circ} \mathrm{C}$; such prior induction results in a large increase in uv resistance in $u v r^{+}$but not in $\mathrm{uvr}^{-}$cells. We have found that this $u v r^{+}$-dependent survival enhancement correlates with the induction of long patch repair and also with induction of a similarly $\mathrm{uvr}^{+}$-dependent increase in ability to sustain DNA replication after irradiation. The following model has emerged from these and other results. Inducible enhancement of uv resistance and of post-uv DNA replication are primarily attributable to a $u v r^{+}$-dependent process, probably long patch repair, which is required for repair of lesions that are potent blocks to replication and are, perhaps for structural reasons, refractory to repair by the constitutive short patch process. Our investigation of repair in $E$. coli treated with MNNG seeks to determine whether SOS induction similarly affects events following alkylation damage.

We first investigated the effect on survival of induction of SOS responses by growth of the tif (recA441) mutant at $42^{\circ} \mathrm{C}$ prior to treatment with MNNG. As shown in Fig. 1, the induced cells were considerably more resistant to the alkylating agent than control cells grown at $32^{\circ} \mathrm{C}$ prior to treatment. Indeed, the tif-induced cells were found to be even more resistant to methylmethane sulfonate (MMS) treatment than were the MNNG-adapted cells (data not shown). This is an unexpected finding, since studies by others have shown that the adaptive response is apparently independent of SOS functions by the criterion that adaptation can occur in recA- and lexA-noninducible mutants.

The next question to be answered was whether $u v r^{-}$mutants display similar tif-induced resistance to alkylating agents. This question is significant because we and others have found that SOS induction of enhanced resistance to uv damage is largely dependent on the $u v r^{+}$genotype. We had presumed that this $u v r^{+}$dependence reflected a requirement for specific incisions in the induced process, but since the levels of the uvrA and uvrB

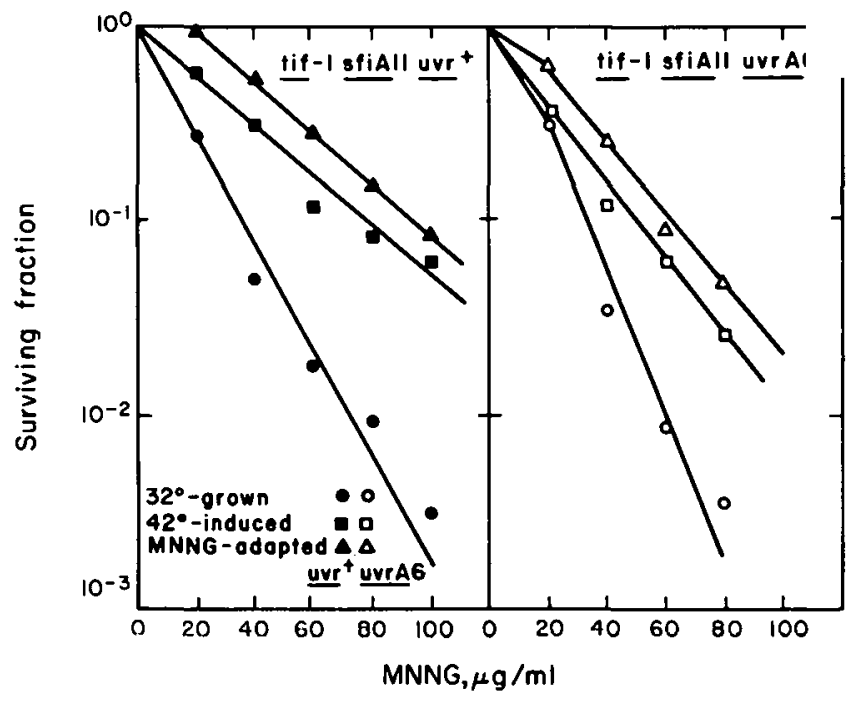

Fig. 1. Survival of uvr $^{+}$(left panel) and uvrA (right panel) E. coli cells following treatment with various concentrations of MNNG. Prior to treatment cells were grown cither continuously at $32^{\circ} \mathrm{C}$ (constitutive control conditions), for 90 minutes at $42^{\circ} \mathrm{C}$ in the presence of adenine (induction of SOS functions via the tif mutation), or for 90 minutes at $32^{\circ} \mathrm{C}$ in the presence of 0.5 $\mu \mathrm{g} / \mathrm{m} / \mathrm{MNNG}$ (adaptation).

(XBL 8311-4096)

proteins are known to be increased following induction, it was conceivable that some other role of the induced levels of the uvr gene products could be involved. However, our current experiments have shown that tif induction of resistance to both MNNG (Fig. 1) and MMS (not shown) occurs independently of the uvr genotype. Hence there is no evidence for a role other than incision for the uvr gene products in SOS enhancement of cellular resistance to DNA damage. In the case of methylation damage, the excision repair process is presumed to be initiated by action of either the constitutive (Tag I) or inducible (Tag II) 3-methyl adenine DNA glycosylase. Thus, if SOS induction produces enhanced resistance to MNNG or MMS via the inducible long patch repair pathway as we suggest for uv resistance, then it would be expected that mutants missing both of the glycosylase activities would be deficient in this induced resistance, analogous to the deficiency in enhanced uv resistance of uvrA mutants. Construction of appropriate strains containing the tif mutation in addition to tag and alk will be required to test this expectation.

During the current year we have also begun to characterize repair synthesis after alkylation treatment. Experiments have been performed with a $d n a B$ mutant at the restrictive temperature, with $t$ tif mutant in both $u v r^{+}$and $u v r A^{-}$backgroun 
d with a strain carrying both tag and alk muta... ns and thus having no 3-meA glycosylase activity. Patch size has been examined in the $d n a B^{-}$strain for repair of either MNNG or MMS damage. While these studies are far from complete, the following observations have been made to date. 1) As is the case for repair of uv damage, a large proportion of repair synthesis after treatment with either methylating agent is inhibited by chloramphenicol, suggesting that an inducible excision repair pathway operates as in the uv case. 2) Much of the repair is in long patches with either agent. Whether it is these long patches that require new protein synthesis remains to be conclusively established. Preliminary indications are that a greater proportion of the total repair sites are long patch than for uv repair. 3) Repair synthesis after MNNG treatment is not significantly reduced by a uvrA mutation. This result corroborates the above conclusion that the involvement of the uvr genes in long patch repair is confined to their role in incision. 4) There is no dose-dependent repair synthesis detectable in the tag-alk-double mutant, thus establishing that excision repair of methylation damage is initiated by action of either the Tag I or Tag II activities, presumably followed by strand cleavage by an apurinic endonuclease.

The enhanced resistance to alkylating agents produced by adaptation is thought to be attributable to the incrcased levels of the inducible Tag II enzyme found in adapted cells. ${ }^{4,5}$ In order to definitively establish that the tif-mediated resistance was indeed separate from the adaptive response, we assayed Tag II activity in collaboration with the laboratory of Dr. Erling Seeberg in the Division of Toxicology of the Norwegian Defense Research Establishment. As illustrated in Fig. 2, we conclusively showed that there was no induction of glycusylase activity by $4 L^{\circ} \mathrm{C}$ incubation of the $t i t$ mutant. $O^{6}$-methyl guanine transferase activity was also determined and likewise found not to be induced (not shown). We conclude that SOS induction confers enhanced resistance by affecting a later step in the excision repair process and hypothesize that the relevant event is induced repair synthesis. Further characterization of the effecl of prior SOS Induction and adaptation on repair synthesis will test this hypothesis. A preliminary account of this work has been presented. ${ }^{6}$

\section{REFERENCES}

1. Cooper, P.K. Characterization of long patch excision repair of DNA in ultraviolet-irradiated Escherichia coli: An inducible function under

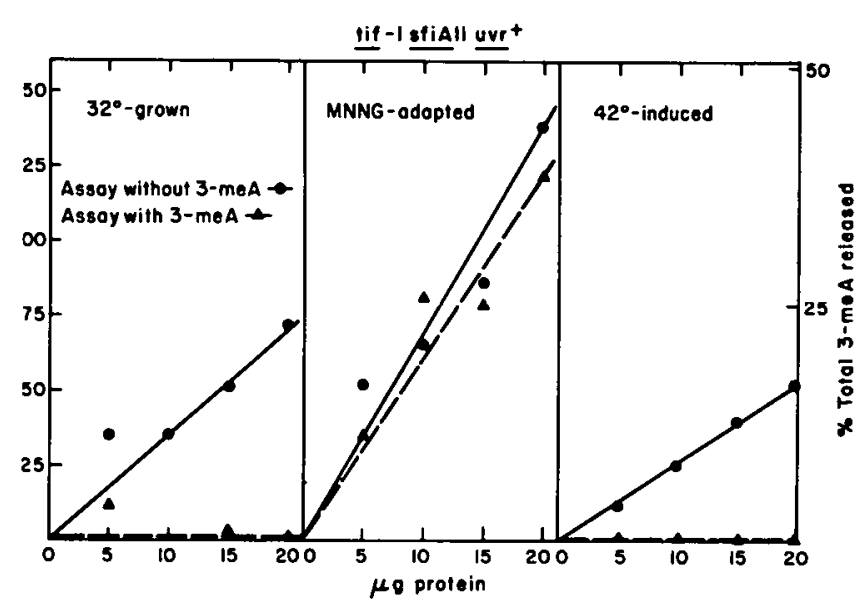

Fig. 2. Assay for 3-methyl adenine DNA glycosylase activity with or without SOS induction or adaptation as in Fig. 1. Assay is for release by cell extracts of ${ }^{3} \mathrm{H}$-cpm from DNA alkylated with ${ }^{3} \mathrm{H}$-dimethyl sulfate. Constitutive 3-meA activity (Tag I) is inhibited by free 3-meA in the assay mix, unlike the inducible 3-meA activily (Tag II). Hence, assay with 3-meA gives Tag II activity, while assay without 3-meA gives the sum of Tag $I$ and Tag II activities.

(XBL 8311-4098)

rec-lex control. Mol. Gen. Genet. 185, 189-197 (1982).

2. Cooper, P.K. Inducible excision repair in Escherichia coli. In: Chromosome Damage and Repair (E. Seeberg, K. Kleppe, eds). Plenum Press, New York (1981), pp. 139-147.

3. Smith, C.A., Cooper, P.K., and Hanawalt, P.C. Measurement of repair replication by equilibrium sedimentation, In: DNA Repair: A Laboratory Manual of Research Procedures (E.C. Friedberg and P.C. Hanawalt, eds), Marcel Dekker, Inc., New York (1981), pp. 289-305.

4. Evensen, G., and Seeberg, E. Adaptation to resistance involves the induction of a DNA glycosylase. Nature 296, 773-775 (1982).

5. Karran, P., Hjelmgren, T., and Lindahl, T. Induction of a DNA glycosylase for $\mathrm{N}$ methylated purines is part of the adaptive response to alkylating agents. Nature 296, 770-773 (1982).

6. Henteleff, M., and Cooper, P. SOS induction of long patch repair and resistance to alkylation damage. J. Cell. Biochem. Suppl. 7B, 210 (1983). 


\title{
HUMAN MAMMARY EPITHELIAL CELLS IN CULTURE: METABOLISM OF CHEMICAL CARCINOGENS
}

\author{
Jack C. Bartley and Martha R. Stampfer
}

Our overall objective is to investigate, in a human mammary epithelial (HMEC) culture system, the normal regulation of breast epithelial cell development and functional differentiation and the process of chemical carcinogenesis. All the investigations described have been made possible for the first time by the development of a system for growing HMEC in long term cell culture.

\section{CHEMICAL CARCINOGENESIS}

The major emphasis in our program studying HMEC in culture has been on the aspect of chemical carcinogenesis for several reasons: the high incidence of breast cancer in the U.S., and the clear relationship between polycyclic aromatic hydrocarbons (PAH) and initiation of mammary adenocarcinomas in experimental animals. We chose benzo(a)pyrene (BaP) as the PAH for our studies because $\mathrm{BaP}$ is the most abundant environmental carcinogenic by-product from the incomplete combustion of fossil fuel and because the metabolic pathway to the ultimate carcinogen is relatively well understood. The conversion of $\mathrm{BaP}$ to the ultimate carcinogen involves two epoxidation steps. Epoxidation of $\mathrm{BaP}$ at carbons 7 and 8 yields, after hydration, the 7,8-dihydrodiol. Epoxidation of the 7,8-dihydrodiol yields the 7,8dihydrodiol-9, 10-epoxide (BPDE), which is highly reactive, resulting in covalently bonded addition products with cellular DNA, RNA, and protein. One enantiomer of BPDE has been shown to possess particularly potent carcinogenic activity in several experiment models, both in vivo and in cell culture.

With this system, we have demonstrated previously that the mammary epithelial cells readily convert $\mathrm{BaP}$ to a spectrum of products characteristic of high yields of the ultimate carcinogen, and the extent of DNA addition products formed is similar to that in cells transformable by BaP.

These results indicate that chemical carcinogens could be a factor in the initiation of human breast cancer, if the breast epithelial cells are exposed to these agents under natural conditions.

We currently have several pieces of evidence that might provide an explanation for the extraordinary ability of HMEC to form the ultimate carcinogen. The basis of this explanation is the presence of prostaglandins synthetase in HMEC. This enzyme system could supplement the BaP oxidation by the usual pathway. The results from short exposure periods indicates that tetraols, the hydration product of BPDE, rather than dihydrodiols, were the predominant products even at the early time intervals. In contrast, fibroblastic cells, in which DNA adduct formation was difficult to demonstrate, metabolized BaP more slowly and released mainly dihydrodiols and phenols in the medium. This oxidative activity in human epithelial cells is compatible with the presence of prostaglandin (PG) endoperoxide synthetase, which is capable of oxidizing 7,8-dihydrodiol-BaP to the ultimate carcinogen.

The concept that the prostaglandin pathway is contributing to BaP metabolism is borne out by the results of our studies with fatty acids. Epoxidation of $\mathrm{PAH}$ and their metabolic derivatives by the PG pathway requires arachidonic acid as a co-oxidant. We have shown that linoleic acid, the precursor of arachidonic acid in the cell, specifically stimulates BaP metabolism in HMEC. The stimulating effect of polyunsaturated fatty acid on BaP oxidation is specific for epithelial cells in the human mammary gland; the extent of $\mathrm{BaP}$ metabolism and $\mathrm{BaP}$ metabolite pattern of breast fibroblasts was unchanged by the addition of polyunsaturated fatty acids.

Although the stimulation affects all metabolites, a specific increase is noted in the most carcinogenic enantiomer of BaP diolepoxide. Furthermore, addition of an analogue of arachidonic acid, a competitive inhibitor of several PG enzyme systems, inhibits BaP metabolism and specifically decreases production of this form of the diolepoxide of BaP.

These results support the contention that PGrelated $\mathrm{PAH}$ epoxidation contributes both to the initial oxidation resulting in formation of the dihydrodiol and, to an even greater extent, to the conversion of the dihydrodiol to the most potent carcinogenic product of BaP metabolism.

The results of the studies with fatty acids may have direct medical significance as well as portraying the pathway of conversion of $\mathrm{BaP}$ to the ultimate carcinogen in HMEC. First of all, the presence of the PG enzyme complex may help explain the particular risk of certain human epithelial $\mathrm{Cr}^{\text {" }}$ to initiation of cancer (breast, colon, prostal Secondly, the role of PG enzymes in BaP oxidatiu.. 
ay provide a partial explanation for the relation...ip, verified epidemiologically, between diets rich in polyunsaturated fatty acids and the incidence of breast cancer.

With respect to individual risk of breast cancer, it is interesting to note that HMEC grown out under precisely the same conditions from specimens from four individuals have been surveyed for the influence of polyunsaturated fatty acids on BaP epoxidation. Of these, one showed no response, even after attempts on four different cell preparations, one consistently exhibits a 3- to 4-fold stimulation by fatty acid, and the other two fall between these extremes. We plan to determine if a relationship exists between these differences and specific aspects of the donor's medical history, e.g., familial risk of breast cancer, nationality, age, hormonal history, use of tobacco, etc.

\section{HUMAN MAMMARY EPITHELIAL CELLS IN CULTURE: DEVELOPMENT AND FUNCTIONAL DIFFERENTIATION}

Because of the exquisite control exerted on the gland, the mammary epithelial cell is particularly appropriate for studies on control of functional differentiation. The mammary epithelial culture system provides a unique opportunity to study this regulation in a human system, and collaborations with Drs. Mina Bissell and Gordon Parry of this Division will allow us to conduct comparative studies between the human and murine systems.

We can monitor the modulation of functional differentiation in mammary epithelial cells in culture by the following markers: 1) overall glucose metabolite pattern, 2) synthesis of glycogen and lactose, 3) the spectrum of protein synthesized and secreted (casein, lactalbumin), 4) synthesis and secretion of medium chain triglycerides, 5) growth rate, and 6) miorptiolugy. We have shown previously that the pattern of labeled intermediates and synthesized products are characterized for the various stages of functional differentiation of the murine mammary epithelial cell.

Results of glucose metabolite patterns, including glycogen synthesis, for HMEC demonstrate that 1) the metabolic activity of cells grown in the serumfree medium is similar to that of the freshly isolated organoids, and 2) metabolic activity of HMEC is modulated by the medium in which they are grown. Indeed, the pattern by cells in secondary passage in $\mathrm{MM}$, the serum supplemented medium, resembled that for mammary cells from pregnant mice. The proteins secreted by the HMEC in the two media were very similar. The majority of the proteins synthesized within the cells remained the same in the two media, but cells in MM synthesized several proteins with acidic isoelectric points. Further investigations are required to determine if these proteins are related to milk components as might be expected from the glucose metabolite patterns.

The indicalion that the HMEC in MM may have characteristics of cells in the prelactating state is surprising in that the HMEC are derived, in all specimens used here, from nonpregnant, nonlactating women. The likely explanation is that the rich medium in which these preparations were grown produces a state of functional differentiation comparable metabolically to that in cells from pregnant mice. The rapid growth of these cells in culture is compatible with the latter explanation. In contrast, the serum-free medium more likely mimics the state in vivo in the donurs whose specimens were utilized in this study.

The availability of a serum-free medium will clarify studies of specific hormonal modulations to an extent not possible in other mammary cell culture systems, including mice. Therefore, many questions remain for further investigations in this human mammary epithelial cell system.

\section{COMPARATIVE ANALYSIS OF DATA FROM SHORT-TERM TESTS FOR CARCINOGENS AND MUTAGENS}

\section{Joyce McCann, Laura Horn, John Kaldor, and Bob Siegel}

The use of short-term tests, such as the Salmonella (Ames) test, ${ }^{1,2}$ for predicting the carcinogenic potential of chemicals has expanded so pidly that development of a systematic, quantita-

re approach for analyzing and interpreting results nas become essential.
The potential of short-term tests to provide quantitative information about carcinogenicity is much less certain than their potential to provide qualitative information. There is, however, suggestive evidence that some quantitative correlation in potency between short-term tests and animal 
cancer tests may exist, and it is important to thoroughly explore this possibility for practical as well as scientific reasons. Short-term tests of thousands of synthetic and natural chemicals have identified far more potential carcinogens than can be confirmed by conventional animal cancer tests. The carcinogenic potency of different chemicals can vary by more than a millionfold. Clearly, if potency in short-term tests could be used to make rough predictions of potency in animal cancer tests, risk evaluation could be more easily focused on chemicals with the greatest potential hazard.

In order to approach these problems, measures of mutagenic potency must be defined and then estimated from experimental data. While a number of studies have utilized such measures, important issues concerning their variability and reproducibility have not been thoroughly considered. The variability of potency estimates is not only important from the point of view of measuring the relationship between mutagenic and carcinogenic potency, but is also essential as a baseline against which to compare differences in the mutagenic potency of various chemicals and test conditions. Without utilizing such information, no general inferences can be drawn from between-experiment comparisons.

We have constructed ${ }^{3}$ a data base of short-term test results that will provide a powerful resource for resolving issues of comparability, both between various short-term tests and between short-term and animal cancer tests, by allowing quantitative comparisons to be made. Recently, we have suggested statistical procedures for analyzing individual Salmonella dose-response curves ${ }^{4}$ and results of mammalian cell mutagenesis assays. ${ }^{5}$ We have also discussed some alternative measures of mutagenic potency. ${ }^{6}$ In the past year we have completed a study involving dose-response Salmonella test results from a large number of experiments reported in the published literature, in which we have applied statistical procedures to obtain potency estimates, as well as the corresponding standard errors. We have also applied tests for significance and linear goodness of fit of the dose response to these data. Using these estimates we examined 1) the judgement of the statistical test for significance as compared to authors' opinions as to the positivity of each result, 2) the reproducibility of the test across replicate experiments from different laboratories (according to the test for statistical significance, authors' opinions, and the potency of the result, and 3 ) reproducibility in the published literature as compared to a standardized multilaboratory testing program. We also examined some problems involved in making comparisons betwi the potencies of experiments carried out under w...ferent test protocols. Below, we briefly discuss some of these results.

We searched the published literature for Salmonella test data on 450 chemicals. Even after excluding all articles that did not report quantitative test results, we still found that many papers did not report basic information about the test protocol (Table 1). In all, we were able to apply the statistical analysis to 1751 experiments, comprising data on 152 chemicals from 137 published articles.

The test for linear goodness of fit indicated that the overwhelming majority of mutagens produce dose-response curves that contain an initial region that is approximately lineds. Furthermore, of the few nonlinear curves, less than half (a total of 26 , or about $7 \%$ of all experiments to which the goodness of fit test was applied) are curves of increasing slope. With a few possible exceptions, these curves are not obviously clustered for any particular mutagens, even those generally considered to produce nonlinear effects in the Salmonella assay, such as MNNG and EMS.

In the published literature there are few cases where authors indicate that statistical methods were used to determine the significance of the response. We compared the author's opinion as to whether each result was positive or negative, with results of

Table 1. Incompleteness of the published literature in specifying details of the experimental protocol.

\begin{tabular}{|c|c|c|}
\hline Information not reported & $\begin{array}{l}\text { Experiments } \\
(2129 \text { total) }\end{array}$ & $\begin{array}{l}\text { Journa } \\
\text { articles } \\
\text { (188 tot }\end{array}$ \\
\hline \multicolumn{3}{|l|}{ Metabolic activation } \\
\hline Animal strain & 239 & 51 \\
\hline Animal species & 12 & 6 \\
\hline Inducer & 40 & 9 \\
\hline Amount of S-9 added & 404 & 29 \\
\hline $\mathrm{mg} / \mathrm{ml}$ protein in $5-9$ & 1011 & 147 \\
\hline Tester strain used & 14 & 3 \\
\hline Spontaneous revertant number & 264 & 40 \\
\hline $\begin{array}{l}\text { Whether spontaneous was } \\
\text { subtracted from response }\end{array}$ & 62 & 8 \\
\hline $\begin{array}{l}\text { Data needed to convert dose unit } \\
\text { to } \mu \mathrm{g} / \text { plate }\end{array}$ & 86 & 13 \\
\hline $\begin{array}{l}\text { Date needed to convert response } \\
\text { units to revertants/plate }\end{array}$ & 168 & 11 \\
\hline
\end{tabular}


e statistical test for significance. In almost all -nses $(99 \%)$ results of the statistical test and the author's opinion were the same. In the examples of conflicting opinions, the reasons were 1) the statistical test places more weight than do most authors on the presence of a linear dose-response, 2) most authors tend to require at least a 2-fold increase over the spontaneous background for "significance," and 3) when the number of spontaneous revertants is small (say fewer than 20), authors tend to require a larger increase in induced revertants than when the spontaneous background is large, whereas the statistical procedure makes no such distinction. These factors result in the statistical test tending to identify more experiments as positive than do authors, provided there is a linear dose-response effect, and authors tending to judge more experiments as positive than the statistical test when the dose-response is not linear.

Among the 1751 experiments to which we applied the statistical analysis, there were 122 data-sets (a total of 333 experiments) in which the same chemical was tested by two or more different laboratories under identical conditions. We have analyzed variability between laboratories, first, according to whether there was agreement between experiments as to pusitivity or negativity, and second, according to whether the estimated potencies were in agreement. Twenty-one of the 122 data-sets had some disagreement between experiments as to whether results were positive or negative. In a few cases there may be biological reasons to explain the discrepancies, such as the presence of mutagenic impurities in chemicals from different sources. In other cases, the use of different dosing ranges (i.e., doses tested that were too low to detect an effect) may be the cause. In still other cases, the difference appears due either to extrcmely weak effects occurring at the limit of sensitivity of the assay that are detected as positive in some but not all tests, or to the random fluctuation of negative data.

To analyze agreement among potencies from replicated experiments we selected, among the 122 data-sets, those that contained 3 or more positive experiments, and we further restricted the analysis to data.sets containing no negative experinnents. The results of this analysis indicate that estimates of mutagenic potency from different experiments are roughly clustered. However, marked acrossexperiment variability is also apparent. Thus, the within-laboratory precision of the potency estimates ses not account for the variation observed across boratories. Almost all data-sets are heterogene- ous, using a chi squared test. We also applied a test for the presence of outliers in these data-sets, but in only a small number (3) were any outliers identified (Fig. 1).

We next compared results from the published literature to those obtained in a National Cancer Institute/National Toxicology Program testing program in which a large number of chemicals were tested in four different laboratories using a standardized testing protocol. Overall, we compared 44 pairs of data-sets, each of which contained results of experiments carried out under the same test conditions. These were all such pairs having more than one experiment from the published literature and more than one experiment from the standardized testing program. For each data-set, we first obtained summary measures of positivity, potency, and variability, using procedures we have described. ${ }^{7}$ In Table 2 , the estimated potencies and variances are compared. As shown, in most cases the average slopes are similar for the two groups of experiments. More than half are within a factor of 3 . Variance is compared using the coefficient of variation (CV), which is the standard deviation divided by the mean. It is striking that there does not appear to be a great difference in reproducibility between the two sources of data. In fact, reproducibility, as measured by the $C V$, may be slightly better overall in the literature than in the standardized testing program. This is most likely due primarily to two factors. First, authors tend to publish results that have been verified by replication, whereas, in the standardized testing program, chemicals were, in general, tested only once, using predetermined doses. Second, in contrast to the standardized testing program, most testing done for publication is not done blind, and authors are aware of previously published results. which could conceivably bias their choice of which experimental results to publish.

It should be possible to classify chemicals according to their different mutagenic potencies when they are tested under different Salmonella test protocols. We have made two observations that, if generally correct, will greatly facilitate such comparative studies. The first observation is that the $C V$ of potency estimates across replicate experiments is approximately equal for all data-sets (about $70 \%$ ), and the second is that withinexperiment variances are often negligible compared to between-experiment variances. To illustrate how one might construct such a classification incorporating these two observations, we compared the mutagenic potency of a number of chemicals in 


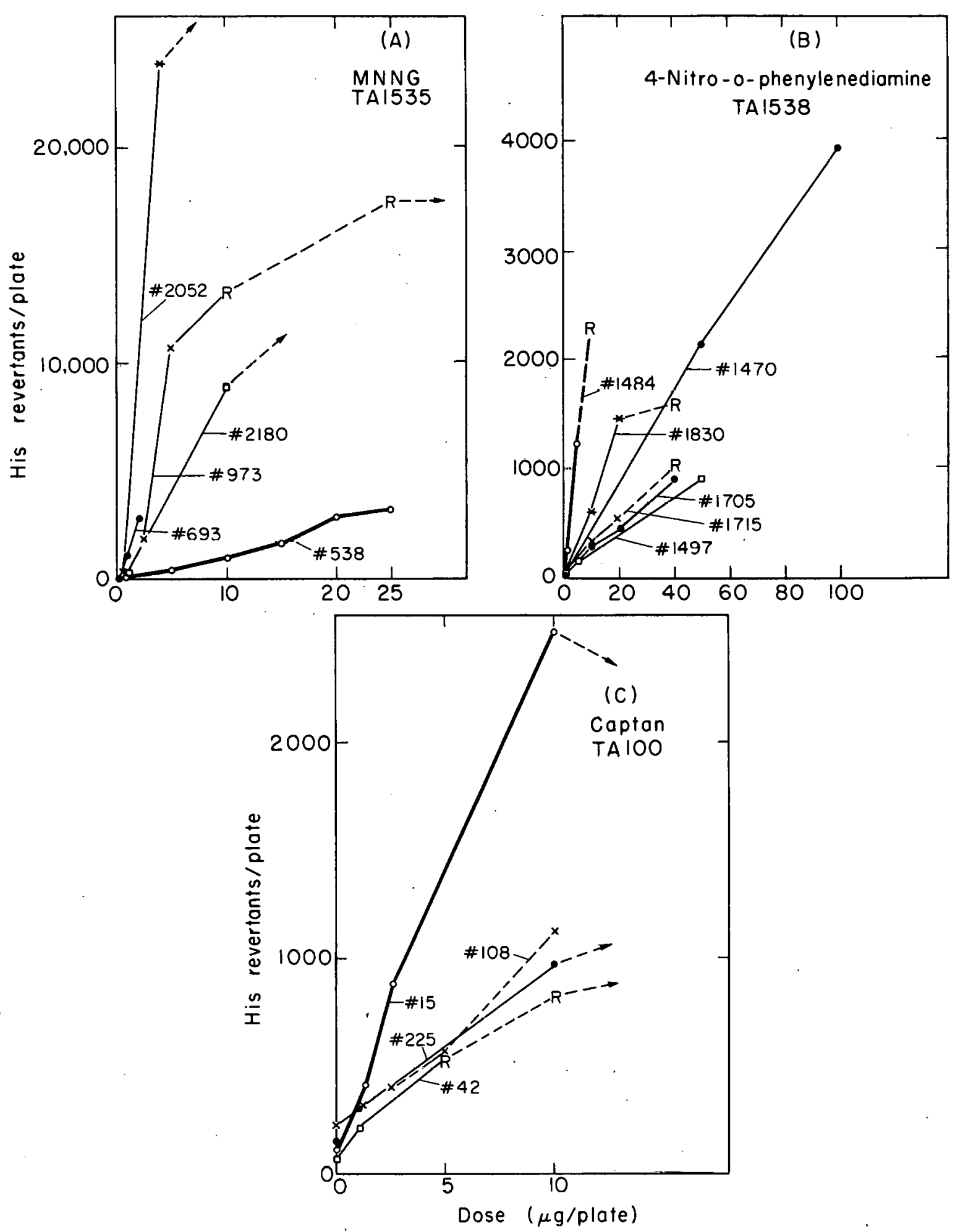

Fig. 1. Dose-response curves of experiments in data-sets that contain statistically significant outliers. References are in Ref. 7 . The dose-response curve of the outlier experiment is drawn in boldface. Numbers refer to experiment numbers defined in Ref. 7. (XBL 838-3943) 
Table 2. Comparison of results in the published literature and a standardized testing program: Mutagenic potency (average slope) and reproducibility (coefficient of variation).

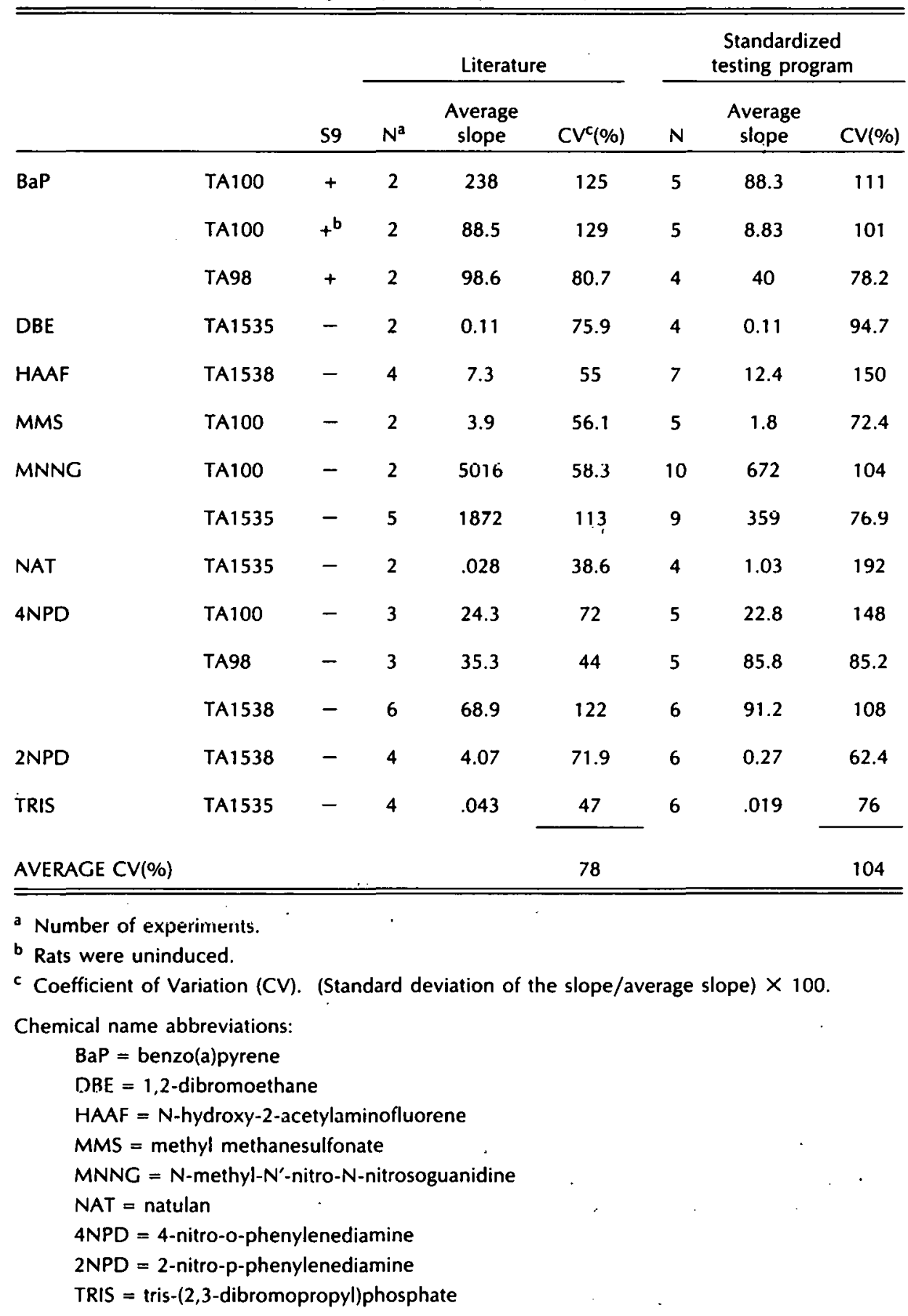

two pairs of tester strains, TA1535, which detects base-pair substitution mutations, and its isogenic pair, TA100, which contains the R-factor plasmid pKM101. In Fig. 2, the potencies of results in the two strains are plotted for 39 chemicals, tested der a variety of conditions. There are three vious classes of results, 1) those positive only in $1 A 100,2)$ those detected only in TA1535, and 3) the remainder, detected in both strains. If the two observations mentioned above are assumed to apply to these data, it can be shown that any two Salmonella test results are significantly different provided their ratio is at least about 8 (or according to a more conservative argument, about 30 ). Using this approach, the results in Fig. 2 that are positive in both tester strains can be subdivided into those 


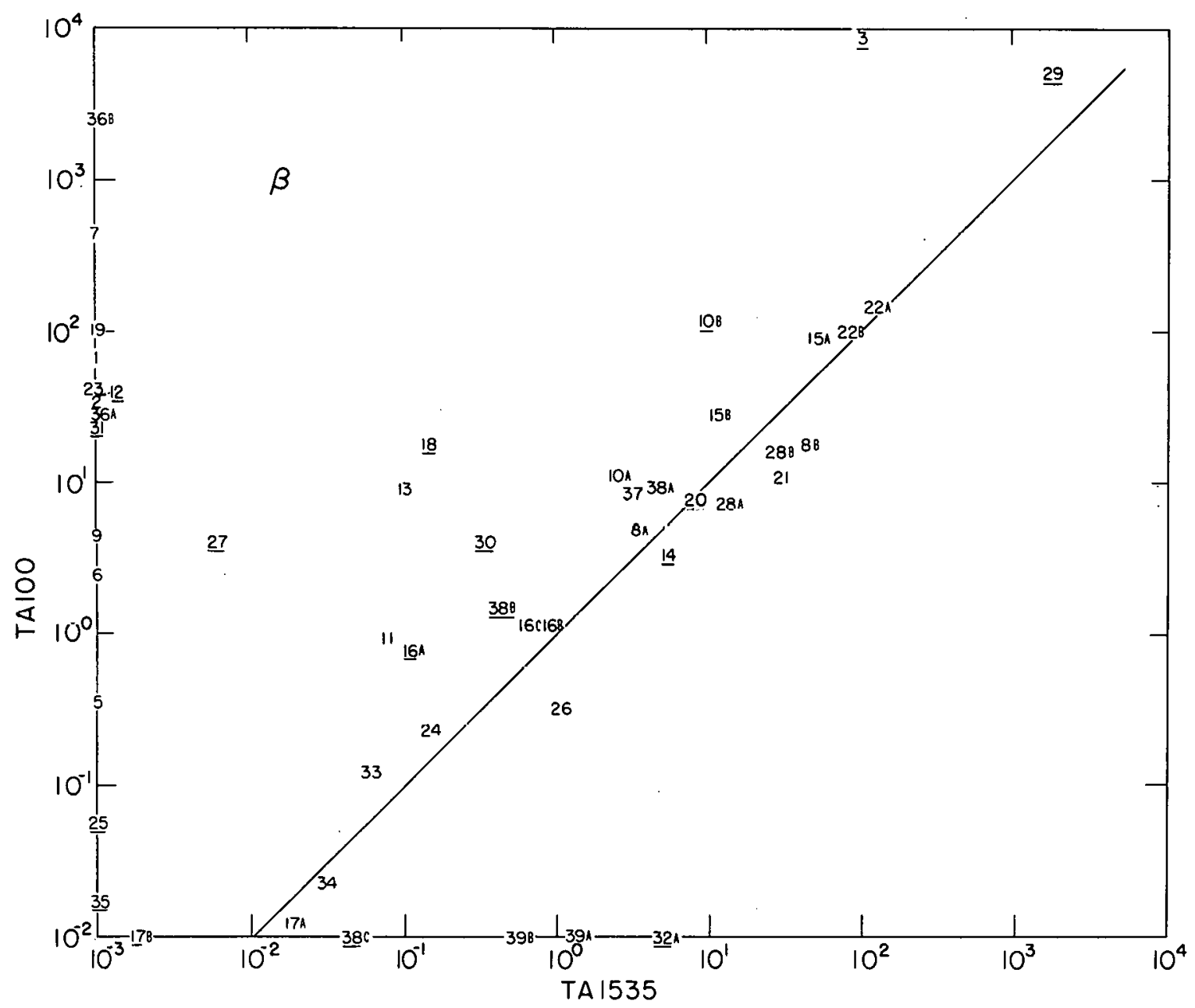

Fig. 2. Comparative potencies of 39 chemicals tested under various test conditions in TA100 and TA1535. The initial slope of each dose-response curve is plotted. Each number indicates a different chemical. Numbers and references are in Ref. 7. $(X B L 837-3887)$

more potent in TA100 and those of approximately equal potency in the two strains.

\section{REFERENCES}

1. Ames, B.N., McCann, J., and Yamasaki, E. Methods for detecting carcinogens and mutagens with the Salmonella/mammalianmicrosome mutagenicity test. Mut. Res. 31 , 347-364 (1975).

2. Hollstein, M., McCann, J., Angelosanto, F.A., and Nichols, W.W. Short-term tests for carcinogens and mutagens. Mut. Res. 65, 133-226 (1979).

3. McCann, J., Horn, L., Litton, G., Kaldor, J., Magaw, R., Bernstein, L., and Pike, M. Shortterm tests for carcinogens and mutagens: $A$ data-base designed for comparative, quantitative analysis. In: Structure Activity Correlation as a Predictive Tool in Toxicology. Fun- damental, Methods, and Applications. L. Golberg, ed., Hemisphere Press, pp. 229-240 (1983).

4. Bernstein, L., Kaldor, J., McCann, J., and Pike, M.C. An empirical approach to the statistical analysis of mutagenesis data from the Salmonella test. Mut. Res. 97, 267-281 (1982).

5. Kaldor, J. Statistical procedures for the design and analysis of in vitro mutagenesis assay. Ph.D. thesis. 1982, University of California Berkeley. Biometrika, in press.

6. Horn, L., Kaldor, J., and McCann, J. A comparison of alternative measures of mutagenic potency in the Salmonella (Ames) test. Mut. Res. 109, 131-141 (1983).

7. McCann, J., Horn, L., and Kaldor, J. An evaluation of Salmonella (Ames) test data in the published literature: Application of statis " cal procedures and analysis of mutager potency. Mut. Res., submitted. 


\section{ARCINOGENIC POTENCY}

Lois Swirsky Gold, Georganne Beckman, Margarita de Veciana, Robert H. Levinson, Renae I. Magaw, Mark Smith, and Bruce N. Ames

Efforts to use animal bioassays in the evaluation of the potential health risk of chemicals to humans have been hampered by the lack of a standardized method to compare experimental results. Experimental protocols as well as the type of information reported in the literature are quite diverse. Moreover, quantitative estimates of carcinogenic potency have not been applied to the results of tests on a broad range of chemicals. Our Carcinogenic Potency Database is an attempt to quantify and standardize the animal bioassay literature and to organize it systematically.

\section{TD $_{50}:$ A NUMERICAL INDEX OF CARCINOGENIC POTENCY}

As an index of carcinogenic potency, we have developed the $T D_{50}$, or Tumorigenic Dose-rate for $50 \%$ of the test animals. Briefly, the $\mathrm{TD}_{50}$ is defined as the chronic dose to induce tumors in half the test animals (in the absence of tumors in the control group). $\mathrm{TD}_{50}$ can be calculated for any single category of neoplasm or any combination of neoplasms. This numerical index permits comparisons of diverse test results and improves past efforts to estimate carcinogenic potency in two ways. First, our calculation takes into account whatever spontaneous tumor incidence occurs in control animals. Second, where data are available about the time of death and tumor incidence of each animal, we estimate a $T D_{50}$ using this information; because animals given high doses of chemicals frequently die early due to chemical toxicity, failure to account for this early mortality could lead to underestimates of the true potency. A full statislical description of $\mathrm{TD}_{50}$ is given in Sawyer et al. ${ }^{1}$

We have found that the range of $T D_{50}$ 's is more than a million-fold. The range of carcinogenic potency for female mice, for example, from the bioassays conducted by the National Cancer Institute and the National Toxicology Program (NCl/NTP) is from 526 nanograms for 2,3,7,8tetrachlorodibenzo-p-dioxin (TCDD) to 2.24 grams for 4-chloro-o-phenylenediamine. Both of these chemicals were evaluated as carcinogenic in the $\mathrm{NCl} / \mathrm{NTP}$ Technical Reports, and the statistical significance of $T_{50}$ is less than 0.01 .

\section{THE CARCINOGENIC POTENCY DATABASE}

Construction of the database of long-term animal tests has now been completed for the published literature through July 1981, and for the bioassays from the $\mathrm{NCl} / \mathrm{NTP}$ program through July 1980. There are approximately 800 experiments on 200 chemicals from the NCI/NTP program, and 1800 experiments on 550 chemicals from the published literature. During the past year we have added to the large literature on rats and mice, the results of many experiments with hamsters, dogs, and nonhuman primates.

The database is readily accessible for qualitative and quantitative analysis, and most results are presented graphically in a plot format. ${ }^{2,3}$ All positive and negative experiments that fit a set of standard criteria based on suitability for estimation of potency have been included in the database: tests in which exposure was chronic, the route of administration was likely to result in the whole body being exposed, a single compound was administered to the animals, and a control group was used. Some chemicals for which there is sufficient evidence of carcinogenicity are not included, if for example, the route of administration was skin painting or subcutaneous injection, or the dose level could not be measured in $\mathrm{mg} / \mathrm{kg} /$ day.

In order to determine how reasonable it is to use the results of animal experiments to predict carcinogenic potency in man we began by comparing potency in rats and mice. If there is little correlation between these two species, we cannot hope to exirapolate animal experimental results to man. We have found that the carcinogenic potencies of chemicals which are positive in both rats and mice are highly correlated. However, this relationship can be directly predicted statistically from the fact that there is a very high correlation between the experimental doses administered to the two species. This statistical artifact of potency estimation does not imply that there is no basis for extrapolating animal results to man, but it does suggest that the interpretation of correlation studies of potency is open to scientific question and further research. ${ }^{4}$ 


\section{REFERENCES}

1. Sawyer, C., Peto, R., Bernstein, L., and Pike, M.C. Calculation of carcinogenic potency from long-term animal carcinogenesis experiments. Biometrics, to appear 1984.

2. Peto, R., Pike, M.C., Bernstein, L., Gold, L.W., and Ames, B.N. The $T_{50}:$ A proposed general convention for the numerical description of the carcinogenic potency of chemicals in chronic-exposure animal experiments. Environmental Health Perspectives, to appear 1984.

3. Gold, L.S., Sawyer, C.B., Hooper, N.K., Havender, W.R., Bernstein, L., Backman,
G.M., Peto, R., Pike, M.C., and Ames, B (with assistance of D. Ang, L. Bertucelli, $M$. ue Veciana, A. Friedman, K. Gould, E. Higgins, P. Kato, R. Levinson, T. Liou, P.M. MacLeod, M. Needels, M. Nichols, M. Rosenfeld and W.E. Rouse). A carcinogenic potency database of the standardized results of animal bioassays. Environmental Health Perspectives, to appear 1984.

4. Bernstein, L., Gold, L.S., Ames, B.N., Pike, M.C., and Hoel, D.G. Some tautologous aspects of the comparison of carcinogenic potency in rats and mice. Submitted to Fundamental and Applied Toxicology, 1983. 


\section{APPENDICES}

\section{APPENDIX A: List of Contracts and Grants Supporting Portions of Work Presented in this Annual Report}

INVESTIGATOR

E.J. Ainsworth

E.L. Alpen

B.N. Ames

B.N. Ames

J.S. Bastacky

G. Brecher

T.F. Budinger

T.F. Budinger

J.R. Castro

A. Chatterjee

G.K. Clemons

P.K. Cooper

S.B. Curtis

D.S. Dolberg

K.H. Downing

\section{CONTRACT OR GRANT}

NASA P.O. \#T3516-G

Life-Shortening Effects of HzE Particles on

Mice/Heavy Ion Cell Transformation

PHS Grant \#CA 30236

Advanced Design Research Heavy Ion Medical Accelerator

PHS IAG\# 222-Y01-AS-10066

Quantitative Species Extrapolation in Carcinogenesis

PHS IAG\# N01-CP-15791-72

Comparative Carcinogenesis Data and Base Quantitative Species Comparison

American Lung Association

Positional Morphology of Human Lung

PHS Grant\# AM 27454

Kinetics of Transfused Stem Cells in Normal Mice

PHS Grant\# HL 25840

Cardiovascular Flow and Metabolism

PHS Grant\# HL 07367

Quantitative Cardiovascular Research, Training Grant

PHS Grant\# CA 19138

Treatment of Cancer w/Heavy Charged Particles

PHS Grant\# CA 27024

Bragg Peak Localization by Radioactive Beams

PHS Grant\# HL 22469

Radioassay of Erythropoietin

PHS Grant\# CA 32986

Inducible Responses to Carcinogenic DNA Damage

PHS Grant\# CA 17411

Response of Rat Tumor Cells to Heavy lons

PHS Grant\# CA 07068

Why does RSV Fail to Cause Tumors in the Avian Embryo?

PHS Grant\# GM 27291

DNA Structure by Electron Diffraction \& Microscopy 
K.H. Downing

P.W. Durbin

P.W. Durbin

S.N. Ebbe

S.N. Ebbe

M.S. Esposito

M.S. Esposito

T.M. Forte

R.M. Glaeser

R. Goth-Goldstein

J.W. Goodman

T.L. Hayes

J. Hosoda

R.M. Krauss

F.T. Lindgren/

A.V.Nichols

J.T. Lyman

J.T. Lyman

M.F. Maestre
PHS Grant\# RR 01925

Electron Diffraction Camera: Quantitative Structural Analysis

NRC IAG\# 60-83-153

Development of Metabolic Models for Alkaline Earth and Actinide Radionuclides

PHS Grant\# ES 02698

Biological Testing of New Actinide-Chelating Agents

PHS Grant\# AM 21355

Kinetics of Megakaryocyte and Platelet Turnover

PHS Grant\# AM 07349

Hemopoietic Cellular Proliferation/Regulation, training grant

PHS Grant\# GM 29002

Comparative Analysis of Mitotic and Meiotic

Recombination

PHS Grant\# ES 02756

Genetic Effects of Carcinogens in Mitosis and Meiosis

PHS Grant\# HL 07279

Lipoprotein Methodology, Structure and Function

Training Grant

PHS Grant\# GM 23325

Biological Structure Analysis by Electron Microscopy

PHS Grant\# ES 01916

Alkylating-Carcinogens Mutagenesis in Mammalian Cells

PHS Grant\# CA 28430

Factors Regulating Hemopoietic Progenitors in Marrow

EPRI Contract\# RP 1639

Trace Element Interactions In Metal Carcinogenesis

PHS Grant\# CM 23563

The Structure of Helix Destabilizing Protein

PHS Grant\# HL 24740

Dietary Effects on Serum High Density Lipoproteins

PHS Grant" HL 18574

Lipoprotein Methodology and Biomedical Applications

PHS IAG\# Y01-CM-20110

Evaluation of Treatment Planning for Particle Beam

Radiotherapy

PHS Grant\# CA 22286

AAPM B682-19

Charged Particle Beam Dosimetry Task Group: Dosimetry

Protocol

PHS Grant\# Al 08427 
J. McCann

R.K. Mortimer

T.A. Musliner

M.S. Raybourn

T.W. Sargent

T.W. Sargent

T.W. Sargent

T.W. Sargent

W. Schimmerling

W. Schimmerling

M.R. Stampfer

M.R. Stampfer

C.A. Tobias

C.A. Tobias/

J.I. Fabrikant

T.C. Yang
Physical Structure of Viruses, Chromosomes and Cell Nuclei

EPA 80-D-X0935

Plan for a Research and Information Center for the Analysis and Interpretation of Data from Short-Term Tests

PHS Grant\# GM 30990

Yeast RAD Genes in Repair, Recombination and Meiosis

American Heart Association

Metabolism of Plasma Lipoproteins by Human Lipolytic

Enzymes

U.S. Army IAG\# 0011

Radiation Damage to Vertebrate Photoreceptors

PHS Grant\# MH 36801

Transmethylation Kinetics in Schizophrenia

V.A. Medical Center, Martinez

Purch. Order V612P-1014

Cerebral Metabolic Indices of Dementia Pathophysiology

V.A. Medical Center, Palo Alto

Purch. Order \#640-D2-2229/WK

Automated Cyclotron Target and Synthesis System for Production of ${ }^{18} \mathrm{~F}$-FDG

V.A. Medical Center, Palo Alto

Purch. Order \#640-D3-0533/WK

Cerebral Metabolic Indices: Patient Runs

PHS Girant\# CA 23247

Physical Characteristics of Heavy Ion Beams

NASA P.O.\# L22395A

To Measure the Production of Neutrons by High Energy Heavy lons

PHS Grant\# CA 24844

Characterization of Human Mammary Cells

PHS Grant\# CA 30028 (R. Ham, Univ. of Colorado)

Purch. Order \#393952

Defined Medium for Human Mammary Epithelial Cells

PHS Grant\# CA 15184

Heavy Ion Radiobiology Related to Oncology

PHS Grant\# CA 27021

Heavy Ion Radiography and Cancer

Peralta Cancer Research Institute

Purchase Order \#0262

$\mathrm{X}$-ray Exposure and Dosimetry Analysis of Human

Mammary Epithelial Cells 


\section{Appendix B: 1983 Publications}

\section{CONTRIBUTIONS TO JOURNALS}

Ainsworth, E.J., Kelly, L.S., Mahlmann, L.J., Schooley, 1.C., Thomas, R.H., Howard, J., Alpen, E.L. Response of colony forming units-spleen to heavy charged particles. Radiation Research 93, 180-197 (1983).

Akeson, S.P., Mel, H.C. Osmotic hemolysis and fragility: A new model based on membrane disruption, and a potential clinical test. Biochim. Biophys. Acta 718, 201-211 (1982).

Akeson, S.P., Mel, H.C. Erythrocyte and ghost cytoplasmiç resistivity and voltage-dependent apparent size. Diophysical Journal 11, 397-103 (1983).

Bassel, J.B., Mortimer, R.K. Genetic and biochemical studies of $\mathrm{N}$-Alkane non-utilizing mutants of Saccharomycopsis lipolytica. Current Genetics 5, 77-79 (1982).

Bastacky, J., Hayes, T.L., Von Schmidt, B. Lung structure as revealed by microdissection: Positional morphology of human lung. Am. Rev. Resp. Diseases 128, S7-S13 (1983).

Bernstein, L., Kaldor, J., McCann, J., Pike, M.C. An empirical approach to the statistical analysis of mutagenesis data from the Salmonella test. Mutation Research 97, 267-281 (1982).

Bialek, W. Quantum noise and active feedback. Phys. Rev. D 28, 2096-2098 (1983).

Black, J.A., Forte, T.M., Forte, J.G. The effects of microfilament disrupting agents on $\mathrm{HCL}$ secretion and ultrastructure of piglet gastric oxyntic cells. Gastruenieru/ogy 83, 595-604 (1982).

Brecher, G. A further note on red cell discoveries. William B. Castle's contribution to the discovery of hemoglobin S. Blood Cells 8, 472-473 (1982).

Breckenridge, W.C., Little, J.A., Alaupovic, P., Wang, C.S., Kuksis, A., Kakis, G., Lindgren, F., Gardiner, G. Lipoprotein abnormalities associated with a familial deficiency of hepatic lipase. Atherosclerosis 45, 161-179 (1982).

Bruschi, C.V., Esposito, M.S. Recombination processes in a sporulation-defective mutant of $S$. Cerevisiae: role of Holliday structure resolution. Rec. Adv. Yeast Mol. Biol. 1, 254-268 (1982).

Budinger, T.F. Image analysis in critical care medicine. Critical Care Medicine 10, 835-845 (1982).
Bustamante, C., Tinoco, Jr., I., Maestre, M.F. Circular differential scattering can be an important part of the circular dichroism of macromolecules. Proc. Natl. Acad. Sci. (USA) 80, 3568-3572 (1983).

Calderon, I.L., Contopoulou, C.R., Mortimer, R.K. Isolation and characterization of yeast DNA repair genes. II. Isolation of plasmids that complement the mutations $\operatorname{rad} 50-1, \operatorname{rad} 51-1, \operatorname{rad} 54-3$, and $\operatorname{rad} 55-3$. Current Genetics 7, 93-100 (1983).

Castro, J.R., Saunders, W.M., Quivey, J.M., Chen, G.T., Collier, M., Woodruff, K.H., Lyman, J.T., Twomey, P., Frey, C., Phillips, T.L. Clinical problems in radiotherapy of sárcinoma of the palicieas. Aluter. J. Clin. Oncology (CCT) 5, 579-587 (1982).

Castro, J.R., Tobias, C.A., Saunders, W.M., Chen, G.T.Y., Collier, J.M., Phillips, T.L. Clinical experience with heavy ion radiotherapy at l,awrence Berkeley Laboratory. (In Japanese) Hoshasenka (Radiology) Vol. 1, 118-125 (1983).

Chandra, M., Garcia, J.F., Miller, M.E., Waldbaum, R.S., Bluestone, P.A., MacVicar, M. Normalization of hematocrit in a uremic patient receiving hemodialysis: Role of erythropoietin. J. Pediatrics 103, 80-83 (1983).

Chang, C.-F., Williams, R.C., Grano, D.A., Downing, K.H., Glaeser, R.M. Quantitative evaluation of highresolution features in images of negatively stained tobacco mosaic virus. Ultramicroscopy $11,3-12$ (1983).

Char, D.H., Castro, J.R. Helium ion therapy for choroidal melanoma. Arch. Ophthalmol. 100, 935-938 (1982).

Chatterjee, A., Magee, J.L., Dey, S.K. The role of homogeneous reactions in the radiolysis of water. Radiation Res. 96, 1-19 (1983).

Cohen, H., Chiu, W., Hosoda, J. Structural analysis of T4 DNA helix destabilizing protein (gp32*l) crystal by electron microscopy. J. Mol. Biol. 169, 235-248 (1983).

Cooper, P.K. Characterization of long patch excision repair of DNA in ultraviolet-irradiated Escherichia coli: An inducible function under Rec-Lex control. Mol. Gen. Genet. 185, 189-197 (1982).

Cross, C.E., Forte, T.M., Gunther, R.A., Kramer, G.C., Lindgren, F.T., Demling, R. Lipoprotein profiles in sheep plasma and lung lymph. Chest 83, 93S-94S (1983). 
-. Jss, C.E., Forte, T.M., Gunther, R.A., Kramer, G.C. Lipoprotein distribution in sheep lung lymph. J. Lab. Clin. Med. 101, 641-650 (1983).

Crowder, M.S., Bearden, A. Primary photochemistry of photosystem I in chloroplasts: Dynamics of reversible charge separation in open reaction centers at $25 \mathrm{~K}$. Biochimica et Biophysica Acta 722, 23-35 (1983).

Davis, P.A., Forte, T.M., Kane, J.P., Hardman, D.A., Krauss, R.M., Blum, C.B. Apolipoprotein and size heterogeneity in human umbilical cord blood low density lipoproteins. Biochim. Biophys. Acta 753, 186-194 (1983).

Davis, P.A., Forte, T.M., Nichols, A.V., Blum, C.B. Umbilical cord blood lipoproteins: Isolation and characterization of high density lipoproteins. Atherosclerosis 3, 357-365 (198.3).

Downing, K.H. Temperature dependence of the critical electron exposure for hydrocarbon monolayers. Ultramicroscopy 11, 229-238 (1983).

Fabrikant, J.I. Special Report. The effects of the accident at Three Mile Island on the mental health and behavioral responses of the general population and nuclear workers. Health Physics 45, 579-586 (1983).

Fisher, G.L., McNeill, K.L., Finch, G.L., Wilson, F.D., Golde, D.W. Functional evaluation of lung macrophages from cigarette smokers and nonsmokers. RES: J. Reticuloendothelial Society 32, 311-321 (1982).

Forte, T.M., Cross, R.A., Gunther, R.A., Kramer, G.C. Characterization of sheep lung lymph lipoproteins: chemical and physical properties. J. Lipid Research 24, 1358-1367 (1983).

Friedland, R.P., Budinger, T.F., Ganz, E., Yano, Y., Mathis, C.A., Koss, B., Ober, B.A., Huesman, R.H., Derenzo, S.E. Regional cerebral nitetabolic alterations in dementia of the Alzheimer type: positron emission tomography with $\left({ }^{18} \mathrm{~F}\right)$ Fluorodeoxyglucose. J. Comp. Assisted Tomography 7, 590-598 (1983).

Friedland, R.P., Mathis, C.A., Budinger, T.F., Moyer, B.R. Labeled choline and phosphorylcholine: Body distribution and brain autoradiography. J. Nucl. Med. 24, 812-815 (1983).

Fry, R.J.M., Powers-Risius, P., Alpen, E.L., Ainsworth, E.J., Ullrich, R.L. High-LET radiation carcinogenesis. Adv. Spac Res. 3, 241-248 (1983).

Gaffey, C.T., Tenforde, T.S. Bioelectric properties of frog sciatic nerves during exposure to stationary magnetic fields. Radiat. Environ. Biophys. 22, 61-73 (1983).
Ganesan, A.K., Cooper, P.K., Hanawalt, P., Smith, C.A. Biochemical mechanisms and genetic control of DNA repair. Prog. Mut. Res. 4, 313-323 (1982).

Goldberg, I.J., Le, N.-A., Paterniti, J.R., Jr., Ginsberg, H.N., Lindgren, F.T., Brown, W.V. Lipoprotein metabolism during acute inhibition of hepatic triglyceride lipase in the cynomolgus monkey. J. Clin. Invest. 70, 1184-1192 (1982).

Goldstein, R.F., Bialek, W. Vibronically coupled twolevel systems: Radiationless transitions in the slow regime. Phys. Rev. B 27, 7431-7439 (1983).

Hall, H.G., Farson, D.A., Chin, S., Bissell, M.J. Lumen formation by epithelial cell lines in culture. In Vitro 18,280 (1982).

Hammond, S.L., Ham, R.C., Stampfer, M.R. Defined medium for normal human mammary epithelial cells. In Vitro 19, 252 (1983).

Hanawalt, P.C., Cooper, P.K., Ganesan, A.K., Lloyd, R.S., Smith, C.A., Zolan, M.E. Repair responses to DNA damage; enzymatic pathways in $E$. coli and human cells. J. Cell. Biochem. 18, 271-283 (1982).

Hilger, F., Prevot, M., Mortimer, R. Genetic mapping of arg, cpa, car and tsm genes in Saccharomyces cerevisiae by trisomic analysis. Current Genetics 6, 93-98 (1982).

Horn, L., Kaldor, J., McCann, J. A comparison of alternative measures of mutagenic potency in the Salmonella (Ames) test. Mutagenic Research 109, 131-141 (1983).

Jap, B.K., Maestre, M.F., Hayward, S.B., Glaeser, R.M. Peptide-chain secondary structure of bacteriorhodopsin. Biophysical Journal 43, 81-89 (1983).

Johnston, L.H., Johnson, A.L., Game, J.C. The effect of the cdc9 mutation on premeiotic DNA synthesis in the yeast Saccharomyces cerevisiae. Exp. Cell Res. 141, 63-69 (1982).

Jones, A., Friedland, R.P., Koss, B., Ober, B.A., Stark, L. Saccadic intrusions in Alzheimer-type dementia. /. Neurology 229, 189-194 (1983).

Karczmar, G.S., Koretsky, A.P., Bissell, M.J., Klein, M.P., Weiner, M.W. A device for maintaining viable cells at high densities for NMR studies. I. Mag. Res. 53, 123-128 (1983).

Krauss, R.M., Roy, S., Mishell, Jr., D.R., Casagrande, J., Pike, M.C. Effects of two low-dose oral contraceptives on serum lipids and lipoproteins: Differential changes in high-density lipoprotein subclasses. Amer. J. Obstetrics and Gynecology 145, 446-452 (1983). 
Kübler, O., Downing, K.H., Ruchti, P., Koller, T. Statistical analysis of support films and the visibility of atoms. J. Microscopy 125, 249-264 (1982).

Laszlo, A., Bissell, M.J. TPA induces simultaneous alterations in the synthesis and organization of vimentin. Experimental Cell Research 148, 221-234 (1983).

Lim, T.H., Sargent III, T., Kusubov, N. Kinetics of trace element chromium (III) in the human body. American J. Physiology 244 (Regulatory Integrative Comp. Physiol. 13), R445-R454 (1983).

Ma, C., Mortimer, R.K. Empirical equation that can be used to determine genetic map distances from tetrad data. Molecular and Cellular Biology 3, 1886-1887 (1983).

Madey, R., Anderson, B.D., Cecil, R.A., Tandy, P.C., Schimmerling, $W$. Tutal inclusive neutron cross sections and multiplicities in nucleus-nucleus collisions at intermediate energies. Phys. Rev. C 28, 706-709 (1983).

Miller, M.E., Cronkite, E.P., Garcia, J.F. Plasma levels of immunoreactive erythropoietin after acute blood loss in man. Brit. J. Haematol. 52, 545-549 (1982).

Nichols, A.V., Gong, E.L., Blanche, P.J., Forte, T.M. Characterization of discoidal complexes of phosphatidylcholine, apolipoprotein A-I, and cholesterol by gradient gel electrophoresis. Biochim. Biophys. Acta 750, 353-364 (1983).

Ogrydziak, D., Bassel, I., Mortimer, R. Development of the genetic map of the yeast Saccharomycopsis lipolytica. Molec. Ceneral Genetics 188, 179-183 (1982).

Philipps, A.F., Widness, J.A., Garcia, J.F., Raye, J.R., Schwartz, R. Erythropoietin elevation in the chronically hyperglycemic fetal lamb. Proc. Soc. Exptl. Biol. Med. 170, 42-47 (1982).

Raju, M.R., Carpenter, S.G., Tokita, N., Howard, J., Lyman, J.T. Biological response across a ridge filter carbon ion Bragg peak. Int. J. Radiation Oncology, Biol., Phys. 9, 67-70 (1983).

Raybourn, M.S. The effects of direct-current magnetic fields on turtle retinas in vitro. Science 220, 715-717 (1983).

Resnick, M.A., Game, J.C., Stasiewicz, S. Cenetic effects of UV irradiation on excision-proficient and -deficient yeast during meiosis. Genetics 104, 603-618 (1983).

Resnick, M.A., Stasiewicz, S., Game, J.C. Meiotic DNA metabolism in wild-type and excision-deficient yeast following UV exposure. Genetics 104, 583-601 (1983).
Robertson, J.S., Price, R.R., Budinger, T.F., Fairbanks, '... ., Pollycove, M. (Task Group of the Medical Internal Radiation Dose Committee, Society of Nuclear

Medicine). MIRD Dose Estimate Report No. 11. Radiation absorbed doses from iron-52, iron-55, and iron59 used to study ferrokinetics. J. Nuclear Medicine $24,339-348$ (1983).

Schaefer, E.J., Foster, D.M., Zech, L.A., Lindgren, F.T., Brewer, H.B., Jr., Levy, R.I. The effects of estrogen administration on plasma lipoprotein metabolism in premenopausal females. J. Clin. Endocrinol. Metab. 57, 262-267 (1983).

Schaefer, E.J., Zech, L.A., Jenkins, L.L., Bronzert, T.J., Rubalcaba, E.A., Lindgren, F.T., Aamodt, R.L., Brewer, H.B., Jr. Human apolipoprotein A-I and A-II metabolism. J. Lipid Res. 23, 850-862 (1982).

Schild, D., Konforti, B.B., Perez, C.F., Gish, W., Mortimer, R.K. Isolation and characterization of yeast DNA repair genes. I. Cloning of the RAD52 gene. Current Genetics 7, 85-92 (1983).

Schimmerling, W., Subramanian, T.S., McDonald, W.J., Kapland, S.N., Sadoff, A., Gabor, G. Beam analyses spectrometer for relativistic heavy ions. Nuclear Instruments and Methods 205, 531-543 (1983).

Shu, H.P., Bymun, E.N. Systemic excretion of benzo(a)pyrene in the control and microsomally induced rat: the influence of plasma lipoproteins and albumin as carrier molecules. Cancer Research 43, 485-490 (1983).

Tenforde, T.S., Adesida, P.O., Kelly, L.S., Todd, P.W. Differing electrical surface charge and transplantation properties of genetically variant sublincs of the TA3 murine adenocarcinoma tumor. European /. Cancer \& Clin. Oncology 19, 277-282 (1983).

Tenforde, T.S., Gaffey, C.T., Moyer, B.R., Budinger, T.F. Cardiovascular altcrations in Macaca monkeys exposed to stationary magnetic fields: Experimental observations and theoretical analysis. Bioelectromagnetics 4, 1-9 (1983).

Tinoco Jr., I., Maestre, M.F., Bustamante, C. Circular dichroism in samples which scatter light. Trends in Biochem. Sciences 8, 41-44 (1983).

Vega, G.L., Illingsworth, D.R., Grundy, S.M., Lindgren, F.T., Conner, W.E. Normocholesterolemic tendon xanthomatosis with overproduction of apolipoprotein B. Metabolism 32, 118-125 (1983).

Wood, P.D., Haskell, W.L., Blair, S.N., Williams, P Krauss, R.M., Lindgren, F.T., Albers, J.J., Ho, P.O., I quhar, J.W. Increased exercise level and plasma 
lipoprotein concentrations: a one-year, randomized, controlled study in sedentary, middle-aged men. Metabolism 32, 31-39 (1983).

Yang, T.C., Stampfer, M.R., Smith, H.S. Response of cultured normal human mammary epithelial cells to $x$ rays. Radiation Research $96,476-485$ (1983).

\section{CONTRIBUTIONS TO BOOKS AND PROCEEDINGS}

Ainsworth, E.J. Radiation carcinogenesis - Perspectives. Pages 99-169 in Probability Models and Cancer. L. LeCam and J. Neyman, Eds. North-Holland Publishing Company, 1982.

Alpen, E.L., Powers-Risius, P., Fry, R.J.M., Ainsworth, E.J. "Harderian gland carcinogenesis from high LET, high $\mathrm{Z}$, charged particles." Pages 335-342 in Pion and Heavy Ion Radiotherapy: Pre-Clinical and Clinical Studies. (Proceedings of the International Workshop on Pion and Heavy Ion Radiotherapy: Pre-Clinical and Clinical Studies, Vancouver, B.C., Canada, July 29-31, 1981). L.D. Skarsgard, Ed. Elsevier Science Publishing Company, New York, 1983.

Bastacky, J., Hayes, T.L., Von Schmidt, B., Klein, S.B., Barr, J., Finch, G.L., McKoon, M., Baskin, L., Hook, G.R. "Correlative microscopy of native surfaces of human lung: Color macrophotography, SEM, LM, TEM, HVEM, and low-temperature scanning electron microscopy." Pages 500-503 in Proceedings, 41st Annual Meeting Electron Microscopy Society of America (Phoenix, Ariz., Aug. 6-12, 1983). G.W. Bailey, Ed. San Francisco Press, California, 1983.

Blakely, E.A. "Biology of Bevalac beams: Cellular studies." Pages 229-250 in Pion and Heavy lon Radiotherapy: Pre-Clinical and Clinical Studies (Proceedings of International Workshop on Pion and Heavy Ion Radiotherapy: Pre-Clinical and Clinical Studies, Vancouver, B.C., Canada, July 29-31, 1981). L.D. Skarsgard, Ed. Elsevier Science Publ. Co., New York, 1983.

Budinger, T.F. "Overview of imaging technologies: Present and future trends." Pages 7-12 in Atherosclerosis Reviews, Volume 10, R.J. Hegyeli, Ed. Raven Press, New York, 1983.

Budinger, T.F. Time-of-flight positron emission tomography: status relative to conventional PET. (Teaching editorial). J. Nucl. Med. 24, 73-78, 1983.

Budinger, T.F. "NMR in vivo studies: a comparison to other noninvasive imaging techniques." Pages 357-374 in Nuclear Magnetic Resonance (NMR) Imaging. C.L. Partain, A.E. James, F.D. Rollow, R.R. Price, Eds. W.B. Saunders Co., New York, 1983.
Budinger, T.F., Ganz, E., Price, D.C., Lipton, M., Moyer, B.R., Yano, Y. "Radionuclide and nuclear magnetic resonance methods of evaluating atherosclerosis." In Clinical Quantitation of Atherosclerosis (Proceedings of Workshop on Quantitative Evaluation of Atherosclerosis, Silver Spring, MD, Feb. 22-23, 1981). Springer-Verlag, New York, 1983.

Budinger, T.F., Yano, Y., Huesman, R.H., Derenzo, S.E., Moyer, B.R., Mathis, C.A., Ganz, E., Knittel, B. "Positron emission tomography of the heart." Pages 31-34 in The Physiologist, Vol. 26 (1). (Proceedings of 33rd Annual Fall Meeting of the American Physiological Society, San Diego, CA, Oct. 10-15, 1982), 1983.

Budinger, T.F., Yano, Y., Mathis, C.A., Moyer, B.R., Huesman, R.H., Derenzo, S.E. "Positron emission tomography of the heart." Pages 229-248 in Radioisotopes in Cardiology (Proceedings First Naples Cardiology Symposium, Naples, Italy, Sept. 21-23, 1981). M. Salvatore and E. Porta, Eds. Plenum Publ. Corporation, New York, 1983.

Burke, R.L., Formosa, T., Cook, K.S., Seasholtz, A.F., Hosoda, J., Moise, H. "The use of two-dimensional polyacrylamide gels for the identification of T4 prereplicative proteins." Pages 321-326 in Bacteriophage T4. C. Mathews, E. Kutter, G. Mosig, P.B. Berget, Eds. American Society Microbiology Press, 1983.

Carr, K.E., Hayes, T.L., Hume, S.P., Kamel, H.M.H. "Qualitative and quantitative SEM of gastrointestinal tract." Pages 496-499 in Proceedings, 41st Annual Meeting Electron Microscopy Society of America (Phoenix, Arizona, Aug. 6-12, 1983). G.W. Bailey, Ed. San Francisco Press, California, 1983.

Castro, J.R. "Heavy charged particle irradiation of human cancers." Radiation Medicine, Vol. 1-1: 70-75, 1983. Radiation Medicine Association, Univ. of Tokyo, Faculty of Medicine, Tokyo 113, lapan. ISSN 02882043.

Castro, J.R., Saunders, W.M., Tobias, C.A., Chen, G.T.Y., Collier, J.M., Pitluck, S., Lyman, J.T., Woodruff, K.H., Blakely, E.Z., Phillips, T.L., Alpen, E.L. "Clinical experience with heavy ion beams at Lawrence Berkeley Laboratory." Pages 385-394 in Pion and Heavy Ion Radiotherapy: Pre-Clinical and Clinical Studies (Proceedings of the International Workshop on Pion and Heavy Ion Radiotherapy: Pre-Clinical and Clinical Studies, Vancouver, B.C., Canada, July 29-31, 1981). L.D. Skarsgard, Ed. Elsevier Science Publ. Co., New York, 1983.

Castro, J.R., Saunders, W., Woodruff, K.H., Quivey, J.M., Phillips, T.L., Chen, G.T.Y., Lyman, J.T., Collier, M., Pitluck, S., Tobias, C.A. "Clinical radiotherapy with heavy charged particles at Lawrence Berkeley Labora- 
tory.". Page 81 in Progress in Radio-Oncology. "K. . ... Karcher et al., Ed. Raven Press, New York, 1982.

Castro, J.R., Tobias, C.A., Saunders, W.M., Chen, T.Y., Collier, J.M., Lyman, J.T., Woodruff, K.H., Phillips; T.L., Grewal-Bahl, R., Char, D., Carter, S.K. "Heavy particle experience in the treatment of human cancer." Pages 279-290 in 13th International Cancer Congress, Part $D$, Research and Treatment. Alan R. Liss, Inc, New York, 1983.

Chang, C.-F., Glaeser, R.M. "Structural investigation of frozen-hydrated ompC specimens prepared by fatty acid monolayer technique." Pages $734 \div-735$ in Proceedings of the 41st Annual Meeting Electron Microscopy Society of America, : Phoenix, Arizonia, August 6-12, 1983. G.W. Bailey, Ed. San Francisco Press, California, 1983.

Chen, G.T.Y., Castro, J.R., Collier, J.M., Saunders, W.M. "Heavy ion radiotherapy at the Lawrence Berkeley Laboratory." IEEE Trans. Nucl. Sci.. NS-30(2), 1813-1814, April 1983

Chen, G.T.Y., Pitluck, S. "Treatment planning for heavy charged particle radiotherapy." Pages $149-158$ in Pion and Heavy Ion Radiotherapy: Pre-Clinical and Clinical Studies (Proceedings of the International Workshop on Pion and Heavy Ion Radiotherapy: Pre-Clinical and Clinical Studies, Vancouver, B.C., Canada, July 29-31, 1981). L.D. Skarsgard, Ed. Elsevier Science Publ. Co., New York, 1983.

Cohen, H., Chiu, W., Hosoda, 1. "Crystalline structure of Gp32*I protein." Pages 23-24 in Proceedings, 10th International Congress on Electron Microscopy (Hamburg, W. Germany, Aug. 17-24, 1982). Vol. 3. Biology. . Editor, The Congress Organizing Committee. Published by Deutsche Gesellschaft f. Elektronenmikroscopie e.V., Frankfurt/Main, 1982.

Curtis, S.B. "Ideas on the unification of radiobiological theories." Pages 527-536 in Proceedings of Eighth Symposium on Microdosimetry (Julich, West Germany, Sept. 27-Oct. 1, 1982). J. Booz and H.G. Ebert, Eds. 1983.

Curtis, S.B., Goldstein, L.S. "In vivo radiobiology with heavy ions." Pages 315-323 in Pion and Heavy lon Radiotherapy: .Pre-Clinical and Clinical. Studies (Proceedings of the International Workshop un Pion and Heavy Ion Radiotherapy: Pre-Clinical and Clinical Studies, Vancouver, B.C., Canada, July 29-31, 1981). L.D. Skarsgard, Ed. Elsevier Science Publishing Co., New York, 1983.

Derenzo, S.E. "Comparison of detector matcrials for time-of-flight positron tomography." Pages 63-68 in Proceedings of the International Workshop on Timeof-Flight Positron Tomography (St. Louis, Missouri,
May 17-19, 1982). L.J. Thomas and M.M. Pogossian, . Eds. The Institute of Electrical and Electronics Engineers, Inc., 1982.

Derenzo, S.E., Budinger, T.F., Vuletich; T. "High resolution positron emission tomography using small bismuth germanate crystals and individual photosensors." IEEE Trans. Nucl. Sci. NS-30(1), 665-670, 1983.

Dolberg, D.A., Bissell, M.J. "Interaction of RSV with the developing chick: an in ovo reference for transformation studies in culture." (ICN-UCLA Symposia, March 1982). J. Cell. Biochem. 92 Suppt. 6, 255 (1982).

Downing, K.H. "Electron crystallographic studies of DNA structure." Pages 434-435 in Proceedings, 41st Annual Mletiing Clectron Alicroscopy Society of America. (Phoenix, Arizona, August 6-12, 1983). G.W. Bailey, Ed. San Francisco Press; California, 1983.

Downing, K.H., Glaeser, R.M. "Temperature dependence on the critical electron dose for fatty acid monolayers." Pages 78-79 in Proceedings, 40th Annual Meeting Electron Microscopy Society of America (August 9-13; 1982, Washington, D.C.). G.W. Bailey, Ed. Claitor's Publ. Division, Baton Rouge, LA, 1982.

Downing, K.H., Glaeser, R.M. "Temperature dependence on the critical dose for fatty acid films." Pages 459-460 in Proceedings of . 10th International Congress on Electron Microscopy (Hamburg, W. Germany, Aug. 17-24, 1982). Vol. 2. Material Sciences. Edited by The Congress Organizing Committee. Published by Deutsche Gesellschaft f. Elektronenmikroscopie e.V., Frankfurt/Main, 1982.

Durbin, P.W., Jeung, N., Schmidt, C.T. "Distribution and retention of ${ }^{238} \mathrm{Pu}$ in Macaque monkeys." Paper E5-03 in Proceedings of 7 th International Congress of Radiation Research, Section E. Dosimetry, Radionuclides and Technology. J.J. Broerse, et al., Eds. Martinus Nijhoff Publishers, Amsterdam, 1983.

Ebbe, S. "Characteristics of megakaryocytic stem cells as determined in vivo." Pages 365-375 in Haemopoietic Stem Cells, Alfred Benzon Symposium 18. Fditors: Sv.-Aa. Killman, E.P. Cronkite; C.N. Muller-Berat. Munksgaard, Copenhagen, 1983.

Echlin P., Lai, C., Hayes, T.L. "The uptake and distribution of potassium in roots of Duckweed (Lemna Minor) as measured using low temperature $x$-ray microanalysis." Pages 408-409 in Proceedings, 40th Annual Meeting Llectron Microscopy Society of America (Aug. 9-13, 1982, Washington, D.C.). G.W. Bailey, Ed. Claitor's Publ. Div., Baton Rouge, LA, 1982

Echlin, P., Lai, C., Hayes, T.L. "Uptake and distribut of rubidium into root tips of Lemna minor measured using low temperature $\mathrm{x}$-ray microanalysis." Pages 
401-402 in Proceedings, 10th International Congress on Electron Microscopy (Hamburg, W. Germany, Aug. 17-24, 1982): Vol. 3. Biology. Edited by The Congress Organizing Committee. Publ. Deutsche Gesellschaft f. Elektronenmikroscopie e.V., Frankfurt/Main, 1982.

Echlin, P., Hayes, T.L., McKoon, M. "Analytical procedures for bulk frozen-hydrated biological tissues." Pages 243-246 in Microbeam Analysis - 1983, Ron Gooley, Ed., San Francisco Press, California, 1983.

Fabrikant, J.I. "Radiation and health." (Editorial comment). Western J. Med. 138, 387-390, 1983.

Forte, T. "Origin and organization of high density lipoproteins." Pages 55-74 in USA - USSR First Lipoprotein Symposium, NIH Publication No. 83-1966, November 1982.

Friedland, R.P., Budinger, T.F., Yano, Y., Huesman, R., Knittel, B., Derenzo, S.E., Koss, B., Ober, B.A. "Regional cerebral metabolic alterations in Alzheimertype dementia: kinetic studies with 18fluorodeoxyglucose." J. Cerebral Blood Flow and Metab. 3 (Suppl. 1): S510-511, 1983.

Game, J.C. "Radiation-sensitive mutants and repair in yeast." Pages 109-137 in Yeast Genetics: Fundamental and Applied Aspects. J.F.T. Spencer, Dorothy M. Spencer, A.R.W. Smith, Eds. Springer Series in Molecular Biology. Springer-Verlag, New York, 1983.

Glaeser, R.M. "Electron microscopy." Pages 391-444 in Methods of Experimental Physics, Vol. 20, Biophysics. G. Ehrenstein, H. Lecar, Eds. Academic Press, New York, 1982.

Glaeser, R.M. "A critique of the theoretical basis for the use of HVEM in biology." Pages $2-3$ in Proceedings, 40th Annual Meeting Electron Microscopy Society of America (Aug. 9-13, 1982, Washington, D.C.). G.W. Bailey, Ed. Claitor's Publ. Division, Baton Rouge, LA, 1982.

Glaeser, R.M. "The fluorescence of electron crystallography." Pages 66-67 in Proceedings, 40th Annual Meeting Electron Microscopy Society of America (August 9-13, 1982, Washington, D.C.). G.W. Bailey, Fd. Claitor's Publ. Division, Baton Rouge, LA, 1982.

Goth-Goldstein, R. "4-Nitroquinoline oxide-induced cell killing and mutagenesis in synchronous Chinese hamster ovary cells." Paper B5-14 in Proceedings, 7th International Congress of Radiation Research. J.J. Broerse, G.W. Barendsen, H.B. Kal, and A.J. Van der Kogel, Eds. Martinus Nijhoff Publ., 1983.

Grano, D.A., Chang, C.F., Glaeser, R.M. "Structural investigations of the pore-forming ompC protein from
E. Coli." Pages 90-91 in Proceedings, 40th Annual Meeting Electron Microscopy Society of America (Aug. 9-13, 1982, Washington, D.C.). G.W. Bailey, Ed. Claitor's Publ. Division, Baton Rouge, LA, 1982.

Hackett, A.J., Stampfer, M.R., Bartley, J., Smith, H.S. "The cellular biology of mammary cancer: potential resource for biostatisticians." Pages 1-14 in Probability Models and Cancer (Proceedings of Conference on Statistics and Cancer), Dept. of Statistics, U.C. Berkeley, July 6-7, 1981. L. LeCam and J. Neyman, Eds. North-Holland Publ. Co., 1982.

Hall, H.G., Farson, D.A., Chin, S., Bissell, M.J. "Extracellular matrix and morphogenesis: collagen overlay induces lumen formation by epithelial cell lines." Pages 233-238 in The Extra-Cellular Matrix, S. Hawkes and J. Wang, Eds. Academic Press, 1982.

Hayes, T., Echlin, P., Lai, C., Bastacky, J. "New techniques for maintaining tissue context when performing cell analyses." Pages 467-468 in Proceedings, 10th International Congress on Electron Microscopy (Hamburg, W. Germany, Aug. 17-24, 1982). Vol. 3. Biology. Edited by The Congress Organizing Committee. Published by Deutsche Gesellschaft f. Elektronenmikroscopie e.V., Frankfurt/Main, 1982.

Hayward, S.B. "Techniques for obtaining high resolution information about periodic arrays of biological macromolecules in the electron microscope." Pages 68-71 in Proceedings, 40th Annual Meeting Electron Microscopy Society of America (Aug. 9-13, 1982, Washington, D.C.). G.W. Bailey, Ed. Claitor's Publ. Division, Baton Ruuge, LA, 1982.

Hook, G., Bastacky, J., Hayes, T., Conhaim, R., Staub, N. "Frozen-hydrated lung preparation for low temperature scanning electron microscopy." Pages 372-373 in Proceedings, 40th Annual Meeting Electron Microscopy Society of America (Aug. 9-13, 1982, Washington, D.C.). G.W. Bailey, Ed. Claitor's Publ. Division, Baton Rouge, LA, 1982.

Jaffee, J.S., Glaeser, R.M. "Preparation of frozen hydrated purple membrane for high resolution electron microscopy." Pages 72-73 in Proceedings, 40th Annual Meeting Electron Microscopy Society of America (Aug. 9-13, 1982, Washington, D.C.). G.W. Bailey, Ed. Claitor's Publ. Division, Baton Rouge, LA, 1982.

Jaffee, J.S., Glaeser, R.M. "Difference fourier analysis of glucose embedded and frozen hydrated purple membrane." Pages 74-75 in Proceedings, 40th Annual Meeting Electron Microscopy Society of America (August 9-13, 1982, Washington, D.C.). G.W. Bailey, Ed. Claitor's Publ. Division, Baton Rouge, LA, 1982. 
Jap, B.K., Glaeser, R.M. "Structure of bacteriophage lambda receptor protein." Pages 736-737 in Proceedings, 41st Annual Meeting Electron Microscopy Society of America (Phoenix, Arizona, Aug. 6-12, 1983). G.W. Bailey, Ed. San Francisco Press, California, 1983.

Kraft, T., Kramer, M., Meister, H., Miltenburger, H.G., Roots, R., Wulf, H. "The influence of radiation quality on biological effectiveness of heavy charged particles." Pages 743-753 in Proceedings of the Eighth Symposium on Microdosimetry, Julich, Federal Republic of Germany. J. Booz and H.G. Ebert, Eds. 1983.

Leith, J.T., Ainsworth, E.J., Alpen, E.L. "Heavy-ion radiobiology: Normal tissue studies." Pages 191-236 in Advances in Radiation Biology, Volume 10; J.T. Lett, U.K. Ehmann, A.B. Cox, tds. Acadenic Pitss, New York, 1983.

Lindyren, F.T., Shore, V., Hulley, S.B., Adamson, G.L., Kahlon, T.S. "Human serum lipoprotein fractionation, characterization, and analysis." Pages 564-573 in Dietary Fats and Health. Perkins, E.G. and Visek, W.J., Eds. American Oil Chemists' Society, Champaign, Illinois, 1983.

Llacer, J., Chatterjee, A., Batho, E.K., Poskanzer, J.A. "Design analysis and performance evaluation of a two-dimensional camera for accelerated positron emitter beam injection by computer simulation." IEEE Trans. Nucl. Sci. NS-30(1): 617-625, 1983.

Lyman, J.T. "Computer modeling of heavy chargedparticle beams." Pages 139-147 in Pion and Heavy Ion Radiotherapy: Pre-Clinical and Clinical Studies. (Proceedings of the International Workshop on Pion and Heavy Ion Radiotherapy: Pre-Clinical and Clinical Studies, Vancouver, B.C., Canada, July 29-31, 1981). L.D. Skarsgard, Ed. Elsevier Science Publ. Co., New York, 1983.

McCann, J. "Short-term tests and cancer policy." Pages 149-161 in Recent Advances in Occupational Health, Volume 1. J.C. McDonald, Ed. Churchill Livingstone, 1982.

McCann, J., Hurn, L., Litton, G., Kaldor, J., Magaw, R., Bernstein, L., Pike, M. "Short-term tests for carcinogens and mutagens: A database designed for comparative, quantitative analysis." Pages 229-240 in Structure Activity Correlation as a Predictive Tool in Toxicology. L. Goldberg, Ed. Hemisphere Press, 1983.

Magaw, R., McCann, J. "Short-term tests used to detect mutagens and their effect in body fluids." Pages 61-80 in Probability Models and Cancer (Proceedings of an Interdisciplinary Cancer-Study Conference). L. LeCam and J. Neyman, Eds. North-Holland, 1982.
Miller, M.E., Garcia, J.F., Shiue, G.G., Okula, R. Clemons, G.K. "Humoral regulation of erythropoiesis." Pages 217-233 in Haemopoietic Stem Cells, Killmann, S-A., Cronkite, E.P., Muller-Berat, C.N., Eds. Munksgaard, Copenhagen, 1983.

Ngo, F.Q.H. "Effects on mammalian cells of fractionated heavy-ion doses." Pages 251-268 in Pion and Heavy Ion Radiotherapy: Pre-Clinical and Clinical Studies (Proceedings of the International Workshop on Pion and Heavy Ion Radiotherapy: Pre-Clinical and Clinical Studies, Vancouver, B.C., Canada, July 29-31, 1981). L.D. Skarsgard, Ed. Elsevier Science Publ. Co., New York, 1983.

Nichols, A.V., Blanche, P.I., Strisower, E.M., Gong, E.L. "High density lipoprotein partirle distribution: Identification and determination." Pages 21-33 in USA USSR First Lipoprotein Symposium, NIH Publication No. 83.1966, November 1982.

Parry, G., Lee, E., Bissell, M.J. "Modulation of the differentiated phenotype of cultured mouse mammary epithelial cells by cullagen substrata." Pages 303-308 in The Extracellular Matrix, S. Hawkes and J. Wang, Eds. Academic Press, 1982.

Raymond, K.N., Kappel, M.J., Pecoraro, V.L., Harris, W.R., Carrano, C.J., Weitl, F.L., Durbin, P.W. "Specific sequestering agents for the actinides." Pages 491-507 in Actinides in Perspective, N.M. Edelstein, Ed. Pergamon Press, New York, 1982.

Richards, T., Budinger, T.F., Nunlist, R. "Proton NMR relaxation times of gray and white matter before and after tissue preservation." Pages 131-132 in Scientific Program, Society of Magnetic Resonance in Medicine. First Annual Meeting, 1982.

Richards, T., Budinger, T.F., Wesbey, G., Engelstad, B. "Evaluation of heavy ion radiation damage to the rat brain using proton NMR imaging." Pages 198-199 in Scientific Program, Society of Magnetic Resonance in Medicine. Second Annual Meeting, 1983.

Richards, T., Hasenfeld, A., Budinger, T.F. “'A computer simulation of surface coil selective region spectroscopy." Page 20 in Works in Progress, Society of Magnetic Resonance in Medicine. Second Annual Meeting, 1983.

Sakamoto, K., Okada, S., Lam, G.K.Y., Howard, J. "Comparison of the effects of pion and heavy ion beams in a mouse tumor system." Pages 325-334 in Pion and Heavy Ion Radiotherapy: Pre-Clinical and Clinical Studies (Proceedings of the International Workshop on Pion and Heavy Ion Radiotherapy: Pre-Clinical : Clinical Studies, Vancouver, B.C., Canada, July 29. 1981). L.D. Skarsgard, Ed. Elsevier Science Publ. Co., New York, 1983. 
-.. gent III, T., Shulgin, A.T., Mathis, C.A. "New iodinated amphetamines by rapid synthesis for use as brain blood flow indicators." J. Labelled Compounds Radiopharm. XIX(11-12), 1983.

Saunders, W.M., Castro, J.R., Quivey, J.M., Chen, G.T.Y., Lyman, J.T., Collier, J.M. "Clinical experience with helium ion radiotherapy at the Lawrence Berkeley Laboratory." Pages 373-384 in Pion and Heavy Ion Radiotherapy: Pre-Clinical and Clinical Studies (Proceedings of the International Workshop on Pion and Heavy Ion Radiotherapy: Pre-Clinical and Clinical Studies, Vancouver B.C., Canada, July 29-31, 1981). L.D. Skarsgard, Ed. Elsevier Science Publ. Co., New York, 1983.

Schild, D., Calderon, I.L., Contopoulou, C.R., Mortimer, R.K. "Cloning of yeast recombination-repair genes and evidence that several are nonessential genes." In UCLA Symposia on Molecular and Cellular Biology, New Series, Vol. 11, Cellular Responses to DNA Damage. Friedberg, E.C., Bridges, B.A., Eds. Alan R. Liss, Inc., New York, 1983.

Schimmerling, W., Kaplan, S., Subramanian, T.S., McDonald, W.J., Gabor, G., Sadoff, A., Alpen, E.L. "Measurements of W for high energy heavy ions." Pages 311-321, Proceedings Eighth Symposium on Microdosimetry, Julich, West Germany, Sept. 27-Oct. 1, 1982. J. Booz and H.G. Ebert, Eds. Commission of the European Communities, Luxembourg, 1982.

Schimmerling, W., Subramanian, T.S., Kaplan, S.N., McDonald, W.J., Sadoff, A., Blakely, E.A., Curtis, S.B. "Physical characterization of energetic heavy ion beams." Paper E2-33 in Proceedings 7th International Congress of Radiation Research, Amsterdam, The Netherlands, July 3-8, 1983. Martinus Nijhoff, Publisher, 1983.

Shu, H., Nichols, A.V. "The role of plasma lipoproteins in carcinogen transport: in vitro and in vivo studies." In Dietary Fats and Health. Perkins, E.C. and Visek, W.J., Eds. American Oil Chemists' Society, Champaign, Illinois, 1983.

Smith, A., Hilco, R., Dicello, J., Fessenden, P., Henkelman, M., Hogstrom, K., Lam, G., Lyman, J., Blattmann, H., Salzmann, M., Reading, D., Verhey, L. "Dosimetry intercomparisons between heavy charged particle radiotherapy facilities." Pages 49-62 in Pion and Heavy Ion Radiotherapy; Pre-Clinical and Clinical Studies (Proceedings of the International Workshop on Pion and Heavy Ion Radiotherapy: Pre-Clinical and Clinical Studies, Vancouver, B.C., Canada, July 29-31, 1981). L.D. Skarsgard, Ed. Elsevier Science Publ. Co., New York, 1983.

Smith, H.S., Stampfer, M.R., Hancock, M.C., Hackett, A.J. "Isolation, characterization and culture of human mammary epithelial cells." Pages 183-202 in Cell Separation, Methods and Selected Applications, Volume 2. T.G. Pretlow II, T.P. Pretlow, Eds. Academic Press, New York, 1983.

Sosinsky, G., Glaeser, R.M. "Isolation of the crystalline arrays from the yeast plasma membrane." Pages 100-101 in Proceedings, 40th Annual Meeting Electron Microscopy Society of America (Aug. 9-13, 1982, Washington, D.C.). G.W. Bailey, Ed. Claitor's Publ. Division, Baton Rouge, LA, 1982.

Tinoco, Ir., I., Maestre, M.F., Bustamante, C. "Circular dichroism in samples which scatter light." Pages 41-44 in Trends in Biochemical Sciences, I, Elsevier/North Holland Biomedical Press, Cambridge, England, 1983.

Tobias, C.A., Chu, W., Chatterjee, A., Benton, E.V., Fabrikant, J., Holley, W., Schmidt, J., Blakely, E., Hayes, T.H. "Special Topics in Heavy Ion Research." Pages 169-193 in Pion and Heavy Ion Radiotherapy: PreClinical and Clinical Studies (Proceedings of the International Workshop on Pion and Heavy Ion Radiotherapy: Pre-Clinical and Clinical Studies, Vancouver, B.C., Canada, July 29-31, 1981). L.D. Skarsgard, Ed. Elsevier Science Publ. Co., New York, 1983.

Wong, M., Schimmerling, W., Wilson, J.W. "Transport studies of the interaction of high-energy heavy ions with extended matter." Paper E2-38 in Proceedings, Seventh International Congress of Radiation Research, Amsterdam, The Netherlands, July 1983. Martinus Nijhoff, Publisher, 1983.

Wu, W., Glaeser, R.M. "Structural analysis of the surface layer protein of spirillum serpens by high resolution microscopy." Pages 738-739 in Proceedings, 41st Annual Meeting Electron Microscopy Society of America (Phoenix, Arizona, Aug. 6-12, 1983). G.W. Bailey, Ed. San Francisco Press, California, 1983.

Yang, T.C., Tobias, C.A. "Studies on the survival frequencies of irradiated mammalian cells with and without cancer cell morphology." Pages 189-210 in Probability Models and Cancer; Proceedings of Conference on Statistics and Cancer. Department of Statistics, U.C. Berkeley, July 6-7, 1981. L. LeCam and J. Neyman, Eds. North-Holland Publ. Co., New York, 1982.

\section{LBL REPORTS ISSUED}

Akeson, S.P. Rheological and Electrical Properties of Red Blood Cells and Their Ghosts. LBL-15041, Ph.D. Thesis, November 1982, 127 pp.

Bialek, W.S. Quantum Effects in the Dynamics of Biological Systems. LBL-16642, Ph.D. Thesis, September 1983, 259 pp. 
Blakely, E.A., Ngo, F.Q.H., Curtis, S.B., Tobias, C.A. Heavy Ion Radiobiology: Cellular Studies. LBL-11861, February 1983, 143 pp. (preprint).

Chang, C.-F. The Structure Analysis of OmpC, One of the Major Proteins in the Outer Membrane of E. coli, by High Resolution Electron Microscopy. LBL-16341, Ph.D. Thesis, July 1983, 114 pp.

Chu, W.T., Alonso, J.R., Criswell, T.L., Tobias, C.A. Shaping Heavy lon Beams for Biomedical Uses. LBL15798, March 1983, 1 p.

Curtis, S.B. Ideas on the Unification of Radiobiological Theories. LBL-15193, October 1982, $10 \mathrm{pp}$.

Curtis, S.B. The Lethal, Potentially Lethal Lesion Model. LBL-16549, July 1983, 22 pp. (Presented at the VIlth International Congress of Radiation Research, Amsterdam, The Netherlands, July 4-9, 1983, and the XIth L.H. Gray Conference, Clasgow, Scotland, July 18-22, 1983)

Derenzo, S.E. Gamma-Ray Spectroscopy Using Small, Cooled Bismuth Germanate Scintillators and Silicon Photodiodes. LBL-16628, August 1983, 12 pp.

Derenzo, S.E. Initial Characterization of a BGO-Silicon Photodiode Detector for High Resolution PET. LBL16952, November 1983, 7 pp.

Derenzo, S.E., Budinger, T.F., Huesman, R.H. Detectors for High Resolution Dynamic PET. LBL-17012, December 1983, 13 pp.

Derenzo, S.E., Budinger, T.F., Vuletich, T. High Resolution Positron Emission Tomography Using Small Bismuth Germanate Crystals and Individual Photosensors. LBL-15151, October 1982, $6 \mathrm{pp}$.

Dey, S., Chatteriee, A., Magee, J.L. Numerical Studies of a Mathematical Model for Radiolysis of Water. LBL16334, May 1983, 4 pp.

Dixon, M.L. A Yeast Screening System for the Detection of Mutation, Recombination, and Aneuploidy. LBL16686, Ph.D. Thesis, September 1983, 213 pp.

Fabrikant, J.I., Hosobuchi, Y., Lyman, J.T. Stereotactic Heavy-lon Bragg Peak Radiosurgery for Intracranial Vascular Disorders: Method for Treatment of Deep Arteriovenous Malformations. LBL-15341, 1982.

Fabrikant, J.I. Radiation and Health. LBL-15352, November 1982, $12 \mathrm{pp}$.

Forte, T.M., Wolosin, J.M., Okamoto, C., Forte, J.G. Role of Microfilaments in Membrane Transformation of the Gastric Oxyntic Cell. LBL-16834, August 1983, 10 pp.

Hall, K.B., Maestre, M.F. Temperature Dependent Reversible Transition of Poly $(\mathrm{dCdC}) \cdot \operatorname{poly}(\mathrm{dCdG})$ in Ethanolic and Methanolic Solutions. LBL-16623, Septem 1983, $17 \mathrm{pp}$.

Huesman, R.H. A New Fast Algorithm for the Evaluation of Regions of Interest and Statistical Uncertainty in Computed Tomography. LBL-16521, 1983 (to be published).

Jaffee, 1.S. A Difference Fourier Comparison between Frozen Hydrated and Glucose Embedded Purple Membrane. LBL-13873, Ph.D. Thesis, November 1982, $131 \mathrm{pp}$.

Kaldor, J. Statistical Procedures for the Design and Analysis of In Vitro Mutagenesis Assays. LBL-15735, Ph.D. Thesis, March 1983, 75 pp.

Lam, C-K.C. Cell Killing and Mutation Induction on Chinese Hamster Cells by Photoradiations. LBL-13078, Ph.D. Thesis, November 1982, 155 pp.

Lawrence, John H. Heavy Particle Irradiation of Intracranial Lesions. LBL-16011, April 1983, 76 pp.

Lyman, J.T., Kanstein, L., Yeater, F., Fabrikant, J.I., Hosobuchi, Y. Helium-Ion Beam for Stereotactic Radiosurgery of Central Nervous System Disorders. LBL-15342, 1982.

Ma, C., Mortimer, R.K. An Empirical Equation That Can Be Used to Determine Genetic Map Distances from Tetrad Data. LBL-16588, August 1983, 7 pp.

Magee, J.L. Radiation Chemistry and Biological Effects. LBL-16333, June 1983, 10 pp.

Raybourn, M., Twitchell, J., Steffensen, C., Clark, K., Wheeler, B. The Effects of Hypoxic Radiosensitizing Drugs on In Vitro Tissues of the Central Nervous System. LBL-15598, January 1983, 34 pp.

Sargent, T.W., III, Shulgin, A.T., Mathis, C.A. Radiohalogen Labeled Imaging Agents III: Compounds for Measurement of Brain Blood Flow by Emission Tomography. LBL-16582, August 1983, 14 pp.

Sosinsky, G.E. Structural and Physiological Studies on the Crystalline Membrane Particles in the Yeast Saccharomyces cerevisiae. LBL-16007, Ph.D. Thesis, April 1983, $159 \mathrm{pp}$.

Tincknell, B.P. Lethal and Mutagenic Effects of 4Nitroquinoline 1-Oxide in UV-Sensitive and Wild Type CHO Cell Lines. LBL-14730, M.S. Thesis, September 1982, $58 \mathrm{pp}$.

Wu, W.H. The Structural Analysis of the Surface La Protein of Aquaspirillum serpens by High Resolut Electron Microscopy. LBL-16626, Ph.D. Thesis, Jury 1983, 160 pp. 


\section{APPENDIX C: Biology and Medicine Division Staff September 30, 1983}

The accomplishments of the Biology and Medicine Division are due in large measure to the capability and dedication of its staff. Listed below are those who have participated in the Division's programs during fiscal year 1983 as full or part-time employees, consultants, and participating guests. The guest staff includes visiting scientists, postdoctoral trainees, resident physicians, graduate and undergraduate students, and summer research participants.

\section{DIVISION HEAD}

$\dagger$ Edward L. Alpen (on leave 'B2-'83)

t Thomas L. Hayes, Deputy (Acting Division Head ' $82-$ ' 83 )

Thomas S. Tenforde (Acting Deputy

Division Head '82-'83)

\section{DIVISION ADMINISTRATION STAFF}

Janice C. DeMoor

De A. Eggers

Michael B. Fizer

Wendell Hom

Allan W. Lung

Georgia A. Peterson

Robert W. Springsteen

Baird Whaley

Herbert Wiener

Mary L. Worth

\section{DIVISION SCIENTIFIC STAFF}

* Clara Adrados

S. Javed Afzal

E. John Ainsworth

Steve P. Akeson

+ Bruce N. Ames

Mary Austin-Seymour

- Mary E. Barker John C. Bartley John B. Bassel S. Jacob Bastacky

+ Alan J. Bearden Eugene V. Benton

* Seldon E. Bernstein

* Ann C. Birge Mina J. Bissell Eleanor A. Blakely Caridad Borras

$\ddagger$ George Brecher

* Carlo V. Bruschi

t Thomas F. Budinger Ralph Buncher

- David J. Burke

*f Gail E. Butterfield

*Left Biology \& Medicine Division prior to September 30, 1983.

tFaculty UCB

$\ddagger_{\text {Faculty UCSF }}$

${ }^{5}$ Faculty UC Davis

lly. lian D. Harrison died April 2, 1983.
Barbara E. Cahoon

Marco Capovilla

* Edward A. Carr Lewis Carroll

$\ddagger$ Joseph R. Castro

- Lai-Man Chan Chung-Fu Chang Aloke Chatterjee George T.Y. Chen Gisela K. Clemons Ruth A. Cohen J. Michael Collier Gerald M. Connell Priscilla K. Cooper

- Roger S. Cubirriotti Stanley B. Curtis Hunter O. Cutting

- Paul A. Davis Reginald A. Deering Stephen E. Derenzo Suhrit K. Dey

* Melvyn R. Dickson David S. Dolberg Kenneth $\mathrm{H}$. Downing Patricia W. Durbin

$\ddagger$ Shirley N. Ebbe Herschell S. Emery Michael S. Esposito

‡ Jacob I. Fabrikant Trudy M. Forte David L. Foster Kenneth A. Frankel

*t Michael Freeling

$\$$ Robert P. Friedland Jack $M$. Frumin

Cornelius T, Gaffey John C. Game

$\ddagger$ Grant E. Gauger Peter S. Geissler

t Robert M. Glacser Lois S. Gold Joseph D. Goldstein

- Robert F. Goldstein Joan W. Goodman Regine Goth-Coldstein

t Martin H. Graham

- David A. Grano H. Glenn Hall

1 Julian D. Harrison William R. Havender

- Stephen B. Hayward Lester Hollander 
William R. Holley

$\ddagger$ Yoshio Hosobuchi Junko Hosoda Jerry Howard Ronald $\mathrm{H}$. Huesman James $A$. Hunter

Jules $S$. Jaffe William J. Jagust

Bing K. Jap

Lin C. Jensen

* John R. Johnston

t* Jule G. Jose

Talwinder S. Kahlon John M. Kaldor

* Tatsuaki Kanai

* Robert L. Kong Betty Koss

$\ddagger$ Ronald M. Krauss

* Kenneth Krohn

$t$ Jühn $\%$. Lawrence Wen-Hwa Lee Robert $H$. Levinson Frank T. Lindgren

- Isabel Lopez-Calderon Susan T. Lovett Bruce A. Lulu John T. Lyman

Marcos F. Maestre John L. Magee Neela Manley Vera Martin Chester A. Mathis Joyce C. McCann

+ Howard C. Mel

- Carole R. Miller David H. Moore

$t$ Robert K. Mortimer

* John P. Murname Thomas A. Musliner

$t$ Alex V. Nichols

* Kunihide Nishizawa

* Oscar S. Nunez

- Yin Lie O

$t$ William G. Owen

$\dagger$ John C. Owicki

Gordon Parry Rukmani Pennathur-Das Mark H. Phillips

‡ Theodore L. Phillips

- Nancy A. Pope

* Rose M. Ray Michael S. Raybourn

* Mark F. Robb Julie A. Robinson Adrian Rodriguez Mark S. Roos Ruth J. Roots

- Bjorn Rydberg

Marc K. Samet

* Leona D. Samson Thornton W. Sargent, III $\ddagger$ William M. Saunders

- Charles B. Sawyer Peter Scherer David Schild Walter Schimmerling John C. Schooley Alexander T. Shulgin

$t$ Jerome R. Singer Stephen M. Stahl Martha R. Stampfer Susan G. Stanton Henry $H$. Stauffer

- Kenneth A. Taylor

t Cornelius A. Tobias Lucy Treagan Sylvanus A. Tyler David Warshawsky

- Ruberl J. Webber Philip R. Weinstein Margaret R. White

- Paul T. Williams Kay $\mathrm{H}$. Woodruff Mervyn Wong Wennie $\mathrm{H}$. Wu

Tracy C. Yang Yukio Yano

* Stephen D. Yee

* Chi-Kwan Yen

Sandra R. Zink

DIVISION SUPPORT STAFF

Linda D. Abe

Frederick E. Abrams

Gerald L. Adamson Hilda M. Alexander

* Christopher D. Alafi Cathryne C. Allan

* Lilia L. Ancheta Sharon Anderson

John Babiak Georganne Backman Violet Barghe-Sharghi

* William Baringer Josephine L. Barr Judy E. Barule

* Paul A. Bash

* David O. Been

* Ron Ben-Ari Sindy E. Berger

- Bruce I. Berkoff

- William S. Bialek

* William Bingham Patricia Biscay Kathleen A. Bjornstad Winona $M$. Blanchard Patricia J. Blanche Rubert Bordow Jochen Braun Kathleen Brennan S. Kay Bristol Gerald L. Brooks 
Michael Bruno

Mary Cabbage

- Michael Cahill

John L. Cahoon

- Kirk A. Campana

Denise Capra-Young

- Mark L. Carlson

Dorothy A. Carpenter

Betsy C. Carr

Aude Cartigny

- Eileen T. Castro

Polly Y. Chang

Tsu-Weng D. Chang

Louise Chere

Larry J. Chevez

Steven Chin

* David W. Chiu

- Mark L. Chiu

* Huey-Ling C. Chu

- Joe Civello

C. Rebecca Contopoulou

Vincent E. Cook

Maria R. Costin

Laurie M. Craise

- Steven C. Cramer

Freddie L. Crenshaw, Jr.

* Mark S. Crowder

Christopher Cullander

Mary P. Curtis

Wendy B. Curtis

- Maria M. DaCosta

* William R. Dedo Randy J. DeGuzman

- David Delaloza Marguerite DeVeciana

* Martha L. Dixon

* Odilon M. DoCanto

Dennis $P$. Duncan

- Frank J. Durante

Eva Edwards

Diana E. Fajardo

Dennis Fantin

Deborah A. Farson

Gregory I. Finch

Sherry L. Fitzsimmons

Brian L. Fletcher

Carol A. Fong-Lum

Myrtle L. Foster

Marilyn A. Fowler

Roscoe Frazier

* Jonathan Frisch

Charlie M. Fuller

- Missie J. Gates Patricia A. Garbutt

* Richard P. Gelinas Christine Giotas

Queen E. Gipson

- Bernard H. Glasauer

Laura A. Glines

Penelope Globus

Elaine L. Gong

Edwin H. Goodwin
Sara P. Goolsby

Eddy A. Gosschalk

Joan M. Graham

* Elizabeth G. Guy

Beth A. Hall

- Sheryl J. Hardesty

William A. Hare

Linda D. Harrison

Helen F. Hart

Andrew C. Hasenfeld

Carroll Hatier

Virginia C. Havens

Lilian E. Hawkins

Linda G. Hayashi

Britta Heise

Mark F. Henteleff

Irva Pertz-Picciotto

Sharon A. Hibdon

Lynn R. Hlatky

Minghisiu Ho

David S. Holder

* Roberl E. Hollingsworth, Jr. Laura J. Horn Mildred K. Hughes

- Holly K. Hurd

- Helen M. Isenberg

- Lee M. Jensen Marsha Jeung Nylan M. leung Patricia A. Johnson Reese Jones James W. Judnick

Karen A. Kalman

Aaron B. Kantor

- Elizabeth Kenney Susan B. Klein

* Donald G. Kneller Brian L. Knittell Frank Kooi

* Michael H. Koval Birgitta Kullgren Natalia Kusubov

Clifford E. Lai

- Wendy Lambert

* Cristoph Larson Blake A. Lasky Ann Lee Joanna $Y$. Lee Yue-Hwa Pan Lee

* Niles E. Lehman Robert R. Leist

* Cyril Y. Leung Johnny K.T. Leung Gerri A. Levine Lynette L. Levy

- David D. Light

- Shawn R. Lindsay

- Diana M. Lininger Leora Lommel Janet S. Lowe

- Linda J. Lutgens

- Lawrence ). McCabe 
Beverly G. McCalla

- Eric W. McFarland Tommy J. McKey

May F. McKoon

Velma B. MCNeal

Ian S. Madfes

Renae I. Magaw

Lynn ]. Mahlmann

Dimitrios T. Maleas

* Kenneth Mallach

- Peter M. Martin

Kenneth A. Mason

Marc S. Mendonca

Barbara Mercer

- John C. Mikesell

Herbert W. Moise, III

Victor Montoya

Maureen Morford

* Lenny Moss

- Jeanette Mowery Brian R. Moyer Kimberly Mulcahy

- Michael A. Munier

- Steve S. Neben

Rocky Nevin

- David Ng

- Carolyn Nishi

Robert W. Nordhausen

Rudi Nunlist

Virginia I. Obie

- Dennis H. Oh

Lucinda S. Olney

- Yohji Ono

Peter Origenes

Joseph R. Orr

Beverly S. Packard

Annie C.. Pang

Shannon S. Par

- Celeste A. Paz

Susan J. Pelkey

- Marc Y. Peltzer

- Steven I. Perakis

Carl F. Perez

Ashot Petrossian

Elizabeth A. Phalen

Garnet Piper-Iopez

James R. Potter

Patricia P. Powers-Risius

John C. Prioleau

* Raymond Ranken Marwin Rapkin

Louise Ray

- Ruthie Redic

Gary Reed

- Dahlia Remiler

* Clement L. Ren Todd Richards

Gary V. Richieri

- Brad K. Robison

Janis S. Scherer

James B. Schmidt

Annelie D. Schumann
Thea B. Scott-Garner

Peter R. Seipel

Janet F. Selmek

Victor Sevilla

Zahra Shahrokh

Katherine L. Shelton

Andy Shih

Sarah G. Shinpock

Robert D. Siegel

Mohindar Singh

Karen C. Sitney

- Charlotte P. Smith Mark Smith

- Gina E. Sosinsky

Dorothy L. Spencer Dorothy S. Sprague

Lore S. Stein

I inda I. Stimson

Jacquelyii St. John

- Aldean Stringfellow

Shirley C. Sutton

Susan F. Sweigert

John N: Takakuwa

Celeste C. Tang

Joseph R. Taylor

Richard Thrift

- Bonnie J. Tincknell

* Gayle Tom Julia A. Twitchell

Kristine Venstrom

- Maia N. Veres Margaret Vogt

- Sean R. Watson Davie D. Wei Nina Wong

- Vernon Wong

- Bradley T. Wrubel

- Gregory Yee Tamlyn K. Yee Michael J. Yezzi

* Yeganeh Zedarjadian 


\section{COMMITTEES}

\section{DIVISION ADVISORY COMMITTEE}

Edward L. Alpen

Eleanor A. Blakely

Thomas F. Budinger

Trudy M. Forte

Thomas L. Hayes

Robert K. Mortimer

Tom S. Tenforde

Cornelius A. Tobias

* Baird Whaley

\section{DIVISION STAFF COMMITTEE}

Shirley N. Ebbe, Chair

Aloke Chatterjee

Trudy M. Forte

John T. Lyman

Tony W. Sargent

\section{EQUIPMENT COMMITTEE}

Tony W. Sargent, Chair

Aloke Chatterjee

Shirley N. Ebbe

Cornelius T. Gaffey

John C. Bartley

Frank T. Upham

* Allan W. Long

* Herbert Wiener

\section{SPACE COMMITTEE}

Tom S. Tenforde, Chair E. John Ainsworth

Gisela K. Clemons

Michael S. Esposito

Tracy C. Yang

Yukio Yano

* Allan W. Long

\section{SALARY COMMITTEE}

Edward L. Alpen, Chair Thomas $F$. Budinger Trudy M. Forte

Thomas L. Hayes

Tom S. Tenforde

Cornelius A. Tobias

- Baird Whaley

\section{HUMAN USE COMMITTEE}

Henry H. Stauffer, Chair Thomas $\mathrm{F}$. Budinger Shirley N. Ebbe

\author{
Kathleen E. Handron \\ Walter Schimmerling \\ $t$ Janice C. DeMoor \\ - Baird Whaley
}

RADIOACTIVE DRUG RESEARCH COMMITTEE

\author{
Jacob I. Fabrikant, Chair \\ Edward L. Alpen \\ Aloke Chatterjee \\ Stephen B. Lewis \\ Henry H. Stauffer \\ Joseph D. Goldstein (Consultant) \\ + Janice C. DeMoor
}

ANIMAL WELFARE COMMITTEE

Gerald M. Connell, Chair

Herman Bonasch

John C. Bartley

Joan W. Goodman

John C. Schooley

* Robert W. Springsteen

\section{DONNER LIBRARY COMMITTEE}

Robert M. Glaeser, Chair

Edward L. Bennett

Thomas F, Budinger

Gerald M. Connell

Thomas L. Hayes

Frank T. Lindgren

* Dornthy F. Denney

* Gloria L. Haire

\section{DONNER SEMINAR COMMITTEE}

Mina J. Bissell, Chair

Michael S. Espnsitn

Stanley B. Curtis

"Ex-Officio, Nonvoting member

${ }^{\dagger}$ Executive Officer 


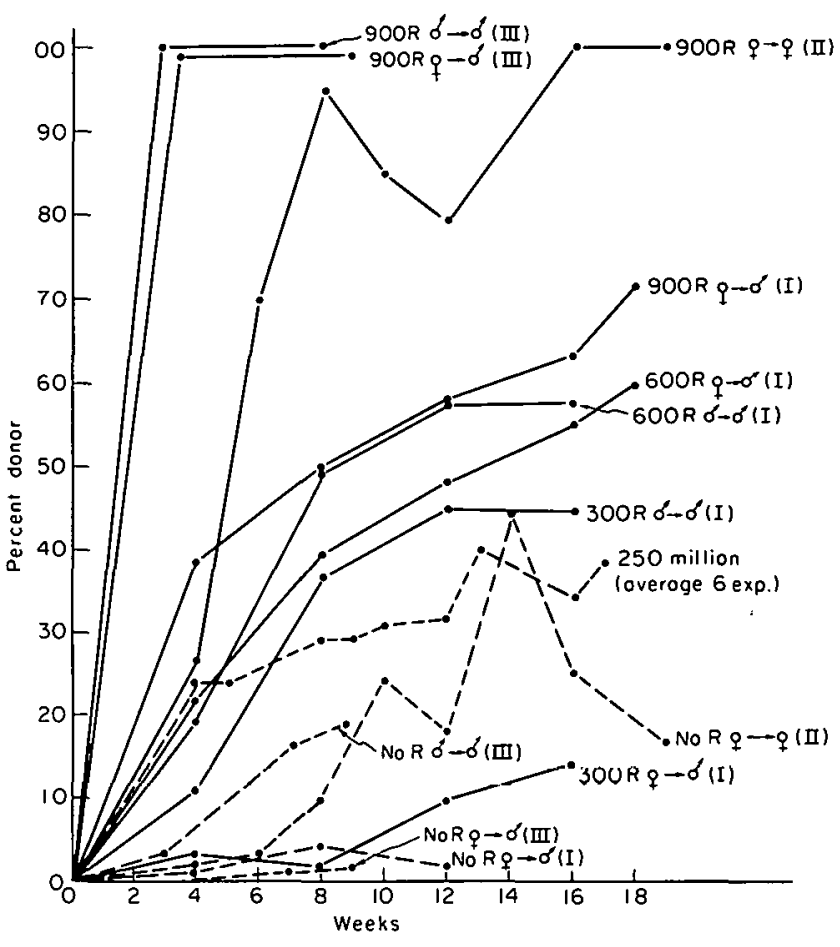

Fig. 1. The solid lines indicale the percentage of red blood cells of donor origin in the peripheral blood of mice exposed to 300,600 , and $900 R$ and transfused 2 months later. The broken lines represent unirradiated controls. All mice received 100 million marrow cells and the same suspensions of cells were used in irradiated and control animals of a given expcriment. The dose of irradiation, the sex of donor and recipient, and the number of the experiment (in Roman numerals) are indicated at the end of each line. Tor comparison the average values of six experiments, in which unirradiated animals received 250 million marrow cells from sex matched donors, are also shown.

(XBL 839-4002)

female cells in the male hosts was abolished by irradiation with 600 or $900 \mathrm{R}$ (Fig. 1).

The explanation given for the enhanced proliferation of transfused bone marrow cells in sublethally irradiated and recovered mice does not appear applicable to the previously reported increased proliferation of transfused cells following lethal irradiation. Survival of the lethally irradiated animals had been assured by an initial transfusion of bone marrow cells. These cells completely repopulated the host marrow. Subsequently, the cells of a second transfusion, given after hematologic recovery, proliferated more extensively in such hosts than in controls. This could not be ascribed to a reduced capacity of irradiated cells, since the host marrow was derived from cells of the first transfusion that had not been irradiated. It is conceivable, nevertheless, that these cells were damged by their sojourn in a recently irradiated nvironment, leading to their reduced self-renewal und extensive replacement by the normal cells of the second transfusion. If so, the mechanism of enhanced proliferation in the lethally and sublethally irradiated animals would be similar.

An alternative explanation for the enhanced proliferation of donor cells in irradiated recipients might be the well-known reduction of the number of pluripotential stem cells (CFU-S) following exposure to high doses of irradiation. The CFU-S have been shown to recover slowly, e.g., reaching only $80 \%$ of normal 12 months after $500 \mathrm{R}$. Consequently, we are now studying the duration of the enhanced post-radiation proliferation of donor cells at monthly intervals and, concomitantly, the level of CFU-S in subgroups of the irradiated animals. This experiment has been simplified by the development in our laboratory of a new CFU-S assay in the $\mathrm{CBA} / \mathrm{PGK}$ mice. Marrow from sublethally irradiated animals of a given enzyme type, for example $A$, in which the CFU-S are to be determined is mixed in equal proportion with normal marrow of the opposite enzyme type, in this case $B$, and the mixture transfused into lethally irradiated recipients. The proportion of $A: B$ enzyme determined in the recipients 3 or 4 weeks later reflects the fraction of normal CFU-S present in the experimental animal. Experience to date indicates that the new assay will enable us to follow the recovery of CFU-S after irradiation more easily and at much less cost than if the standard method of spleen nodule assay was used.

Recently we have started work on another facet of stem cell behavior, namely the cause of "serial exhaustion." This term refers to the repeatedly confirmed observation that only 4 or 5 sequential passages of marrow are possible through irradiated recipients before the marrow fails to rescue an irradiated animal on further transfer. A progressive loss of self-replicability of stem cells is involved, but at least three explanations have been offered for it: 1) The effect of transfusion itself is deleterious, 2) increased turnover of stem cells in the process of restoring the irradiated marrow leads to stem cell exhaustion, and 3) sojourn in a recently irradiated environment is deleterious. Since we can now obtain significant percentages of donor cells in normal animals, we can test the loss of self-replicability of stem cells after transfusion in animals not exposed to irradiation, using the principle of Micklem's "competitive regeneration assay." (The assay compares marrows with reduced selfreplicability to normal marrow.) From preliminary experiments it appears that a single transfusion does not affect self-replicability, but two consecutive transfusions do, implying a subclinical damage in the course of the first transfusion that manifests itself only on a second transfusion. 


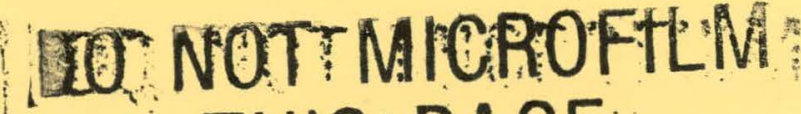 THIS PAGE:}

This report was done with support from the Department of Energy. Any conclusions or opinions expressed in this report represent solely those of the author(s) and not necessarily those of The Regents of the University of California, the Lawrence Berkeley Laboratory or the Department of Energy.

Reference to a company or product name does not imply approval or recommendation of the product by the University of California or the U.S. Department of Energy to the exclusion of others that may be suitable. 
TECHNICAL INFORMATION DEPARTMENT

LAWRENCE BERKELEY LABORATORY

UNIVERSITY OF CALIFORNIA

BERKELEY, CALIFORNIA 94720

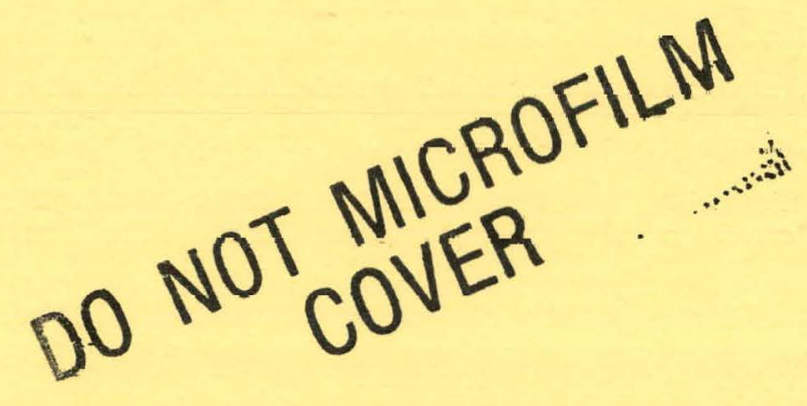

$\cdots$ 